NTP TECHNICAL REPORT ON

THE TOXICOLOGY AND

Carcinogenesis Studies OF

VINYLIDENE CHLORIDE

(CASRN 75-35-4)

IN F344/N RATS AND

B6C3Fl/N MICE

(INHALATION STUDIES)

NTP TR 582

AUGUST 2015 


\section{NTP Technical Report on the Toxicology and Carcinogenesis Studies of Vinylidene Chloride (CASRN 75-35-4) in F344/N Rats and B6C3F1/N Mice (Inhalation Studies)}

Technical Report 582

August 2015

National Toxicology Program

Public Health Service

U.S. Department of Health and Human Services

ISSN: $2378-8925$

Research Triangle Park, North Carolina, USA 


\section{Foreword}

The National Toxicology Program (NTP) is an interagency program within the Public Health Service (PHS) of the Department of Health and Human Services (HHS) and is headquartered at the National Institute of Environmental Health Sciences of the National Institutes of Health (NIEHS/NIH). Three agencies contribute resources to the program: NIEHS/NIH, the National Institute for Occupational Safety and Health of the Centers for Disease Control and Prevention (NIOSH/CDC), and the National Center for Toxicological Research of the Food and Drug Administration (NCTR/FDA). Established in 1978, NTP is charged with coordinating toxicological testing activities, strengthening the science base in toxicology, developing and validating improved testing methods, and providing information about potentially toxic substances to health regulatory and research agencies, scientific and medical communities, and the public.

The Technical Report series began in 1976 with carcinogenesis studies conducted by the National Cancer Institute. In 1981, this bioassay program was transferred to NTP. The studies described in the Technical Report series are designed and conducted to characterize and evaluate the toxicologic potential, including carcinogenic activity, of selected substances in laboratory animals (usually two species, rats and mice). Substances selected for NTP toxicity and carcinogenicity studies are chosen primarily on the basis of human exposure, level of production, and chemical structure. The interpretive conclusions presented in NTP Technical Reports are based only on the results of these NTP studies. Extrapolation of these results to other species, including characterization of hazards and risks to humans, requires analyses beyond the intent of these reports. Selection per se is not an indicator of a substance's carcinogenic potential.

NTP conducts its studies in compliance with its laboratory health and safety guidelines and FDA Good Laboratory Practice Regulations and must meet or exceed all applicable federal, state, and local health and safety regulations. Animal care and use are in accordance with the Public Health Service Policy on Humane Care and Use of Animals. Studies are subjected to retrospective quality assurance audits before being presented for public review.

The NTP Technical Reports are available free of charge on the NTP website and cataloged in PubMed, a free resource developed and maintained by the National Library of Medicine (part of the National Institutes of Health). Data for these studies are included in NTP's Chemical Effects in Biological Systems database.

For questions about the reports and studies, please email NTP or call 984-287-3211. 


\section{Table of Contents}

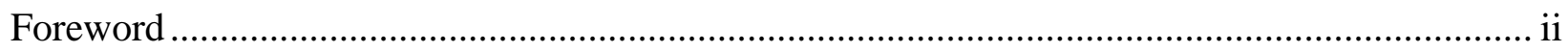

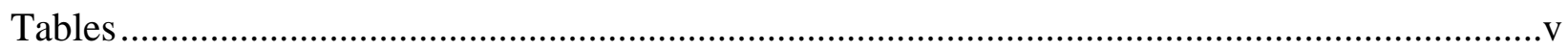

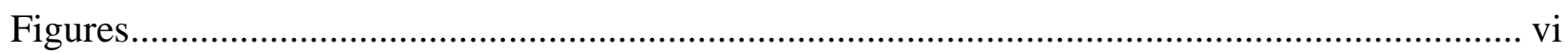

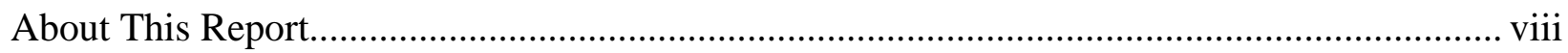

Explanation of Levels of Evidence of Carcinogenic Activity ................................................... xi

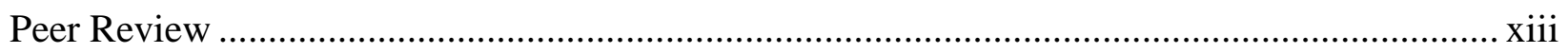

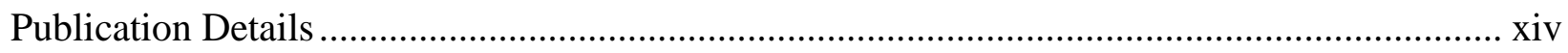

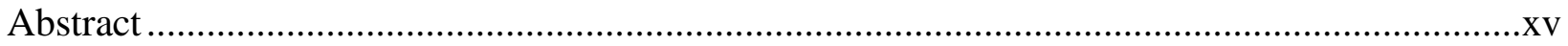

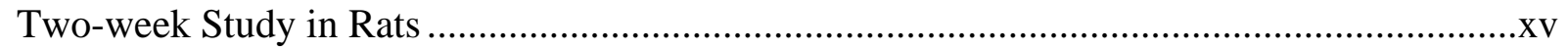

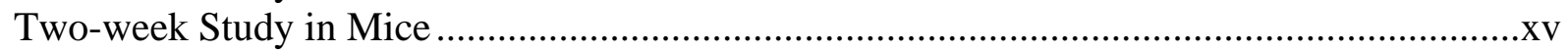

Three-month Study in Rats ........................................................................................... xvi

Three-month Study in Mice ......................................................................................... xvi

Two-year Study in Rats............................................................................................. Xvii

Two-year Study in Mice.................................................................................................. Xvii

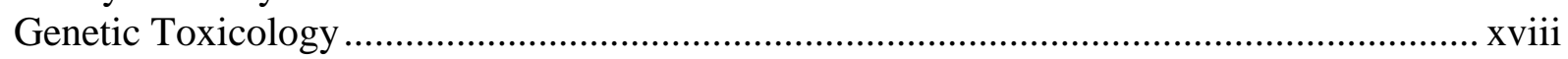

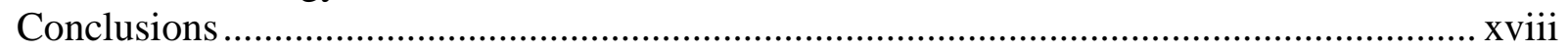

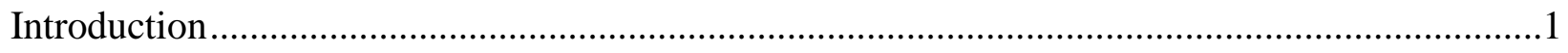

Chemical and Physical Properties ..................................................................................

Production, Use, and Human Exposure …………..............................................................

Absorption, Distribution, Metabolism, and Excretion .........................................................2

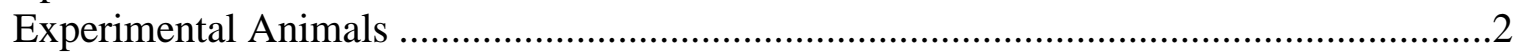

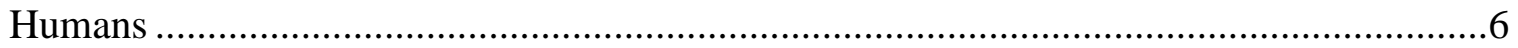

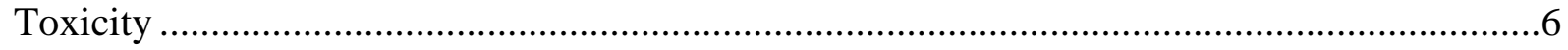

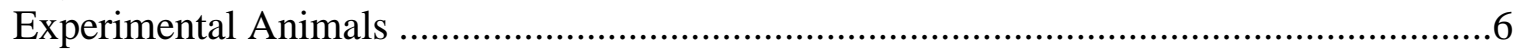

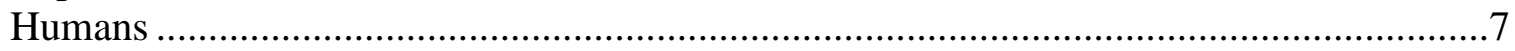

Reproductive and Developmental Toxicity …………….................................................

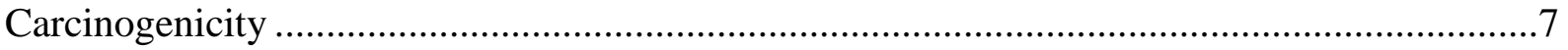

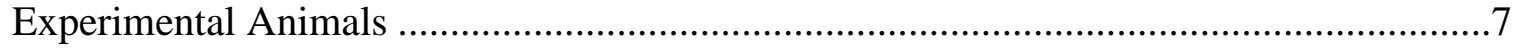

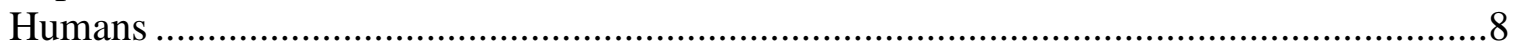

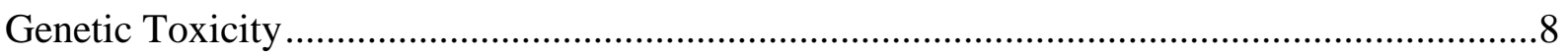

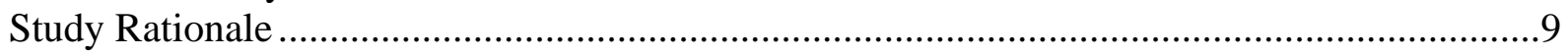

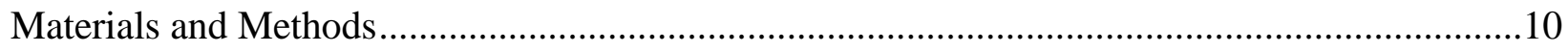

Procurement and Characterization ……………………................................................10

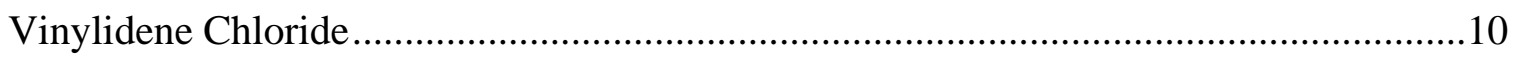

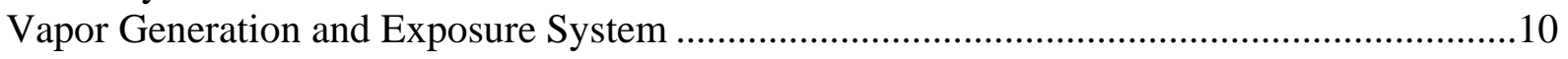

Vapor Concentration Monitoring ..................................................................................11

Chamber Atmosphere Characterization .............................................................................11

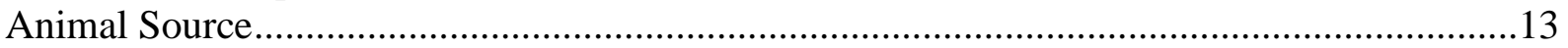

Animal Welfare

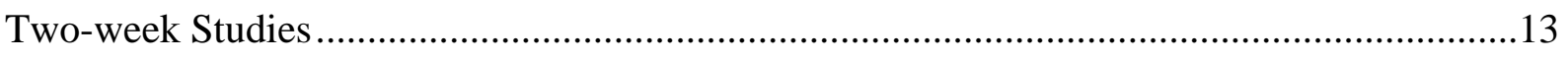




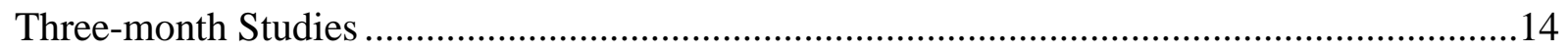

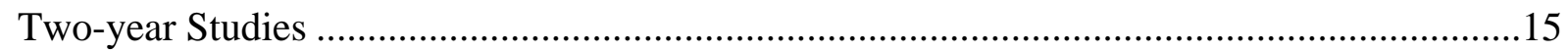

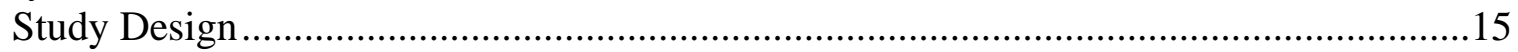

Clinical Examinations and Pathology ...........................................................................

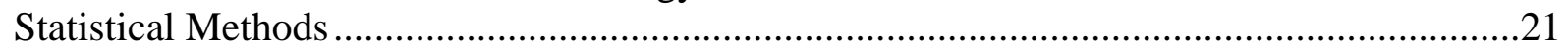

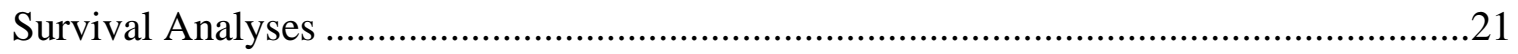

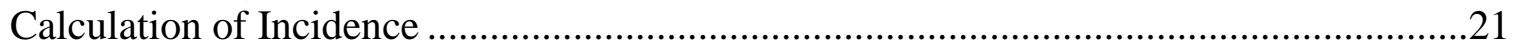

Analysis of Neoplasm and Nonneoplastic Lesion Incidences .........................................22

Analysis of Continuous Variables ...........................................................................22

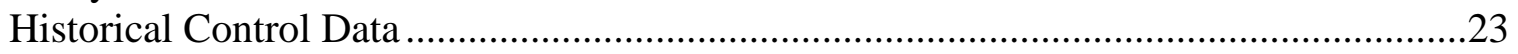

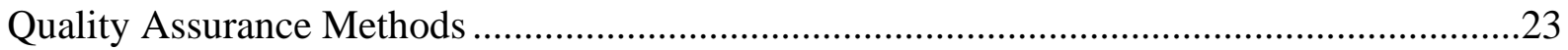

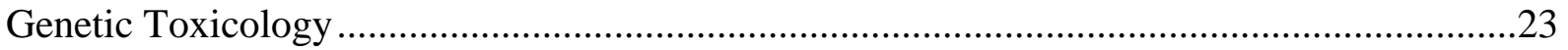

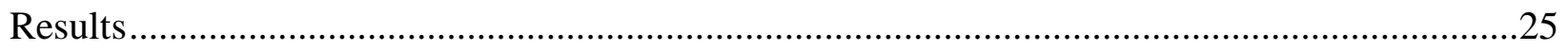

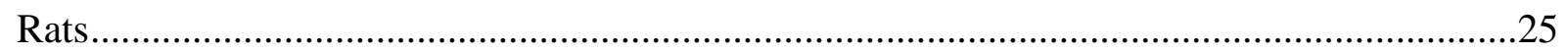

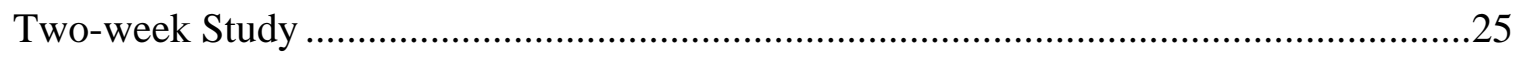

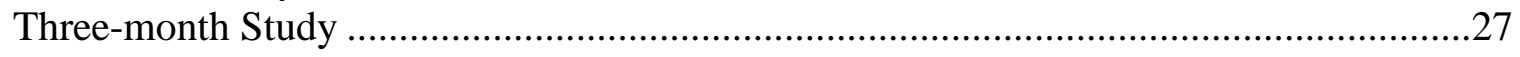

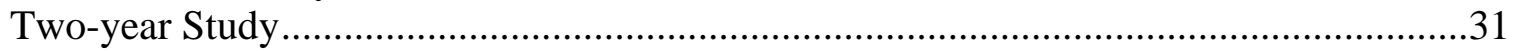

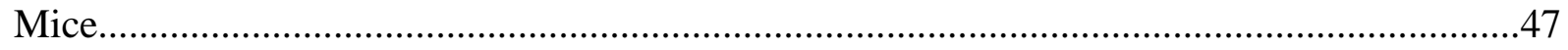

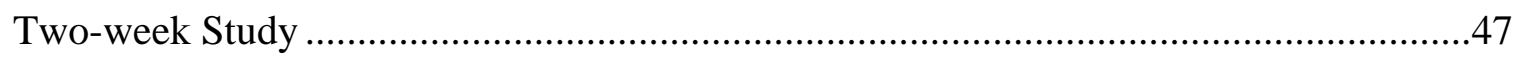

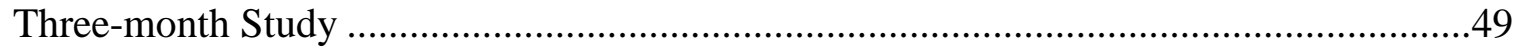

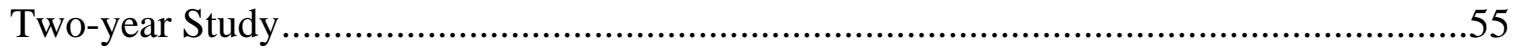

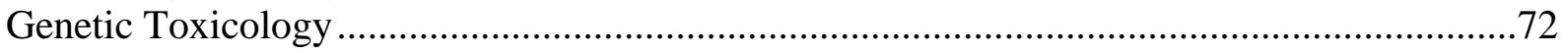

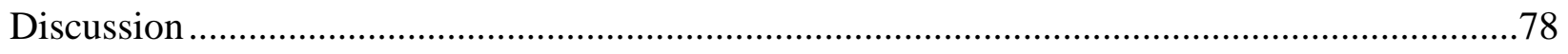

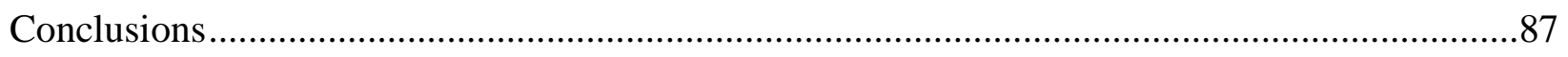

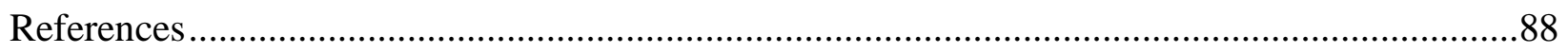

Appendix A. Summary of Lesions in Male Rats in the Two-year Inhalation Study of Vinylidene Chloride ......................................................................................... A-1

Appendix B. Summary of Lesions in Female Rats in the Two-year Inhalation Study of Vinylidene Chloride ....................................................................................

Appendix C. Summary of Lesions in Male Mice in the Two-year Inhalation Study of

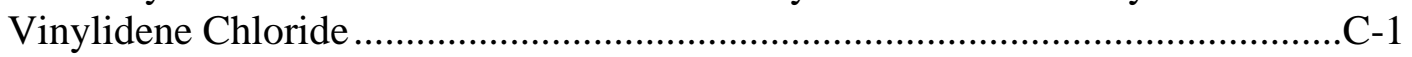

Appendix D. Summary of Lesions in Female Mice in the Two-year Inhalation Study of Vinylidene Chloride ...................................................................................... D-1

Appendix E. Genetic Toxicology ………………….........................................................

Appendix F. Clinical Pathology Results ………………....................................................

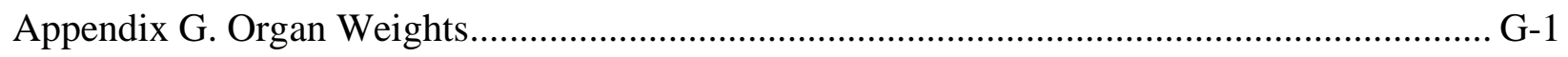

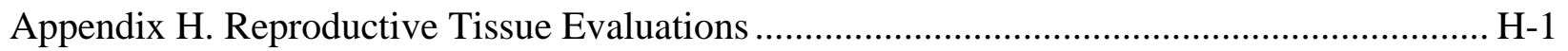

Appendix I. Chemical Characterization and Generation of Chamber Concentrations ................... I-1

Appendix J. Ingredients, Nutrient Composition, and Contaminant Levels In NTP-2000 Rat and Mouse Ration .......................................................................................... 
Appendix K. Sentinel Animal Program ......................................................................... K-1

Appendix L. Global Gene Profiling of Mesothelioma in Vinylidene Chloride-Exposed

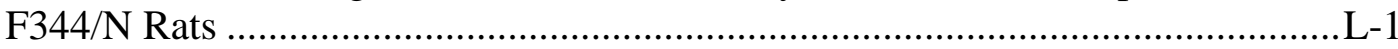

Appendix M. Summary of Peer Review Panel Comments ..........................................................

\section{Tables}

Summary of the Two-year Carcinogenesis and Genetic Toxicology Studies of Vinylidene Chloride...... . $\mathrm{xx}$

Table 1. Experimental Design and Materials and Methods in the Inhalation Studies of Vinylidene Chloride .....

Table 2. Survival and Body Weights of Rats in the Two-week Inhalation Study of Vinylidene Chloride .

Table 3. Incidences of Selected Nonneoplastic Lesions in Rats in the Two-week Inhalation Study of Vinylidene Chloride

Table 4. Survival and Body Weights of Rats in the Three-month Inhalation Study of Vinylidene Chloride .....

Table 5. Incidences of Selected Nonneoplastic Lesions in Rats in the Three-month Inhalation Study of Vinylidene Chloride

Table 6. Survival of Rats in the Two-year Inhalation Study of Vinylidene Chloride

Table 7. Mean Body Weights and Survival of Male Rats in the Two-year Inhalation Study of Vinylidene Chloride.

Table 8. Mean Body Weights and Survival of Female Rats in the Two-year Inhalation Study of Vinylidene Chloride

Table 9. Incidences of Malignant Mesothelioma in Rats in the Two-year Inhalation Study of Vinylidene Chloride

Table 10. Incidences of Neoplasms of the Thyroid Gland (C-Cell) in Female Rats in the Two-year Inhalation Study of Vinylidene Chloride

Table 11. Incidences of Mononuclear Cell Leukemia in Female Rats in the Two-year Inhalation Study of Vinylidene Chloride.

Table 12. Incidences of Neoplasms and Nonneoplastic Lesions of the Kidney in Rats in the Two-year Inhalation Study of Vinylidene Chloride .

Table 13. Incidences of Neoplasms and Nonneoplastic Lesions of the Nose and Lung in Rats in the Two-year Inhalation Study of Vinylidene Chloride

Table 14. Incidences of Nonneoplastic Lesions of the Liver in Rats in the Two-year Inhalation Study of Vinylidene Chloride.

Table 15. Survival and Body Weights of Mice in the Two-week Inhalation Study of Vinylidene Chloride

Table 16. Incidences of Selected Nonneoplastic Lesions in Mice in the Two-week Inhalation Study of Vinylidene Chloride.

Table 17. Survival and Body Weights of Mice in the Three-month Inhalation Study of Vinylidene Chloride

Table 18. Selected Hematology Data for Mice in the Three-month Inhalation Study of Vinylidene Chloride 
Table 19. Incidences of Selected Nonneoplastic Lesions in Mice in the Three-month Inhalation Study of Vinylidene Chloride.................................................................54

Table 20. Incidences of Selected Nonneoplastic Lesions in Mice in the Two-year Inhalation Study of Vinylidene Chloride.

Table 21. Mean Body Weights and Survival of Male Mice in the Two-year Inhalation Study of Vinylidene Chloride.

Table 22. Mean Body Weights and Survival Female Mice in the Two-year Inhalation Study of Vinylidene Chloride.

Table 23. Incidences of Neoplasms and Nonneoplastic Lesions of the Kidney in Male Mice in the Two-year Inhalation Study of Vinylidene Chloride.

Table 24. Incidences of Neoplasms and Nonneoplastic Lesions of the Liver in Mice in the Two-year Inhalation Study of Vinylidene Chloride.

Table 25. Incidences of Hemangioma and Hemangiosarcoma in Female Mice in the Twoyear Inhalation Study of Vinylidene Chloride.

Table 26. Incidences of Neoplasms and Nonneoplastic Lesions of the Lung in Mice in the Two-year Inhalation Study of Vinylidene Chloride

Table 27. Incidences of Neoplasms of the Small Intestine in Mice in the Two-year Inhalation Study of Vinylidene Chloride.

Table 28. Incidences of Nonneoplastic Lesions of the Nose in Mice in the Two-year Inhalation Study of Vinylidene Chloride.

\section{Figures}

Figure 1. Vinylidene Chloride (CASRN: 75-35-4; Chemical Formula: C2H2Cl2; Molecular Weight: 96.94) .............................................................................

Figure 2. The Proposed Metabolic Pathway of Vinylidene Chloride in Rodents..........................5

Figure 3. Growth Curves for Rats Exposed to Vinylidene Chloride by Inhalation for Three Months

Figure 4. Kaplan-Meier Survival Curves for Rats Exposed to Vinylidene Chloride by Inhalation for Two Years

Figure 5. Growth Curves for Rats Exposed to Vinylidene Chloride by Inhalation for Two Years

Figure 6. Growth Curves for Mice Exposed to Vinylidene Chloride by Inhalation for Three Months .51

Figure 7. Kaplan-Meier Survival Curves for Mice Exposed to Vinylidene Chloride by Inhalation for Two Years

Figure 8. Growth Curves for Mice Exposed to Vinylidene Chloride by Inhalation for Two Years

Figure 9. Malignant Mesothelioma in a Male F344/N Rat Exposed to 100 ppm

Vinylidene Chloride by Whole Body Inhalation for Two Years (H\&E).

Figure 10. Thyroid Gland C-Cell Adenoma in a Female F344/N Rat Exposed to 100 ppm Vinylidene Chloride by Whole Body Inhalation for Two Years (H\&E) 73

Figure 11. Thyroid Gland C-Cell Carcinoma in a Female F344/N Rat Exposed to 50 ppm Vinylidene Chloride by Whole Body Inhalation for Two Years (H\&E)

Figure 12. Renal Tubule Carcinoma in a Male F344/N Rat Exposed to 100 ppm Vinylidene Chloride by Whole Body Inhalation for Two Years (H\&E) .74 
Figure 13. Renal Tubule Adenoma in a Male F344/N Rat Exposed to $100 \mathrm{ppm}$ Vinylidene Chloride by Whole Body Inhalation for Two Years (H\&E) .......................75

Figure 14. Renal Tubule Hyperplasia in a Male F344/N Rat Exposed to 25 ppm Vinylidene Chloride by Whole Body Inhalation for Two Years (H\&E) .......................75

Figure 15. Nasal Adenoma in a Male F344/N Rat Exposed to 100 ppm Vinylidene Chloride by Whole Body Inhalation for Two Years (H\&E).

Figure 16. Renal Tubule Adenoma in a Male B6C3F1/N Mouse Exposed to $12.5 \mathrm{ppm}$ Vinylidene Chloride by Whole Body Inhalation for Two Years (H\&E) .76

Figure 17. Renal Tubule Carcinoma in a Male B6C3F1/N Mouse Exposed to $12.5 \mathrm{ppm}$ Vinylidene Chloride by Whole Body Inhalation for Two Years (H\&E) .77

Figure 18. Renal Tubule Hyperplasia in a Male B6C3F1 Mouse Exposed to $6.25 \mathrm{ppm}$ Vinylidene Chloride by Whole Body Inhalation for Two Years (H\&E) .77

This report has been reformatted to meet new NTP publishing requirements; its content has not changed. 


\section{About This Report}

National Toxicology Program ${ }^{1}$

${ }^{1}$ Division of the National Toxicology Program, National Institute of Environmental Health

Sciences, Research Triangle Park, North Carolina, USA

\section{Collaborators}

M.E. Wyde, M.J. Hoenerhoff, E.T. Adams, B. Atkinson, H. Batdorf, C.R. Blystone, M.C. Cora, J.A. Dill, P.M. Foster, S.L. Grumbein, S.J. Harbo, B.K. Hayden, R.A. Herbert, M.J. Hooth, A.P. King-Herbert, G.E. Kissling, H.M. Kolenda-Roberts, R.M. Kovatch, D.E. Malarkey, B.S.

McIntyre, R.A. Miller, B.J.T. Muir, A.K.R. Pandiri, B.A. Renne, S.L. Smith-Roe, M.D. Stout, G.S. Travlos, S. Waidyanatha, N.J. Walker, Y. Wang, K.L. Witt

Division of the National Toxicology Program, National Institute of Environmental Health Sciences, Research Triangle Park, North Carolina, USA

Evaluated and interpreted results and reported findings

M.E. Wyde, Ph.D., Study Scientist

M.J. Hoenerhoff, D.V.M., Ph.D., Study Pathologist

C.R. Blystone, Ph.D.

M.C. Cora, D.V.M.

P.M. Foster, Ph.D.

R.A. Herbert, D.V.M., Ph.D.

M.J. Hooth, Ph.D.

A.P. King-Herbert, D.V.M.

G.E. Kissling, Ph.D.

D.E. Malarkey, D.V.M., Ph.D.

B.S. McIntyre, Ph.D.

S.L. Smith-Roe, Ph.D.

M.D. Stout, Ph.D.

G.S. Travlos, D.V.M.

S. Waidyanatha, Ph.D.

N.J. Walker, Ph.D.

K.L. Witt, M.S.

Battelle Toxicology Northwest, Richland, Washington, USA

Conducted studies and evaluated pathology findings

J.A. Dill, Ph.D., Principal Investigator

S.L. Grumbein, D.V.M., Ph.D.

S.J. Harbo, D.V.M.

B.K. Hayden

B.A. Renne, D.V.M.

Experimental Pathology Laboratories, Inc., Research Triangle Park, North Carolina, USA

Conducted pathology review

E.T. Adams, D.V.M., Ph.D.

H.M. Kolenda-Roberts, D.V.M., Ph.D. 
R.A. Miller, D.V.M., Ph.D.

A.K.R. Pandiri, Ph.D.

Pathology Associates International, A Charles River Company, Research Triangle Park, North Carolina, USA

Coordinated NTP Pathology Working Groups for 2-year rats (December 14, 2010) and 2-year mice (August 19, 2010)

R.M. Kovatch, D.V.M.

Gene Logic Laboratories, Inc., Gaithersburg, Maryland, USA

Provided SMVCE analyses

B.J.T. Muir, Ph.D., Principal Investigator

B. Atkinson., M.S.

H. Batdorf, B.S.

Y. Wang, M.S.

\section{Contributors}

Experimental Pathology Laboratories, Inc., Research Triangle Park, North Carolina, USA Supervised pathology review

M.H. Hamlin, II, D.V.M., Principal Investigator

NTP Pathology Working Group, National Institute of Environmental Health Sciences, Research Triangle Park, North Carolina, USA

Participated in NTP Pathology Working Group on 2-year rats (December 14, 2010)

M.C. Boyle, D.V.M., Ph.D., National Toxicology Program

S.A. Elmore, D.V.M., National Toxicology Program

R.A. Herbert, D.V.M., Ph.D., National Toxicology Program

M.J. Hoenerhoff, D.V.M., Ph.D., National Toxicology Program

H.M. Kolenda-Roberts, D.V.M., Ph.D., Experimental Pathology Laboratories, Inc.

L.L. Lanning, D.V.M., National Institute of Allergy and Infectious Diseases

R.A. Miller, D.V.M., Ph.D., Experimental Pathology Laboratories, Inc.

J.P. Morrison, D.V.M., Ph.D., Pathology Associates International, A Charles River Company

A.B. Rogers, D.V.M., Ph.D., University of North Carolina

Participated in NTP Pathology Working Group on 2-year mice (August 19, 2010)

E.T. Adams, D.V.M., Ph.D., Experimental Pathology Laboratories, Inc.

G.C. Hard, Ph.D., D.Sc., Consultant

R.A. Herbert, D.V.M., Ph.D., National Toxicology Program

M.J. Hoenerhoff, D.V.M., Ph.D., National Toxicology Program

D.E. Malarkey, D.V.M., Ph.D., National Toxicology Program

R.A. Miller, D.V.M., Ph.D., Experimental Pathology Laboratories, Inc.

J.P. Morrison, D.V.M., Ph.D., Pathology Associates International, A Charles River Company

A.K.R. Pandiri, Ph.D., Experimental Pathology Laboratories, Inc.

A.B. Rogers, D.V.M., Ph.D., University of North Carolina 
SRA International, Inc., Research Triangle Park, North Carolina, USA

Provided statistical analyses

R.W. Morris, Ph.D., Principal Investigator

L.J. Betz, M.S.

S.F. Harris, B.S.

Dynamac Corporation, Research Triangle Park, North Carolina, USA

Prepared quality assessment audits

S. Brecher, Ph.D., Principal Investigator

S. Iyer, B.S.

V.S. Tharakan, D.V.M.

Biotechnical Services, Inc., Little Rock, Arkansas, USA

Prepared Technical Report

S.R. Gunnels, M.A., Principal Investigator

L.M. Harper, B.S.

T.S. Kumpe, M.A.

D.C. Serbus, Ph.D. 


\section{Explanation of Levels of Evidence of Carcinogenic Activity}

The National Toxicology Program describes the results of individual experiments on a chemical agent and notes the strength of the evidence for conclusions regarding each study. Negative results, in which the study animals do not have a greater incidence of neoplasia than control animals, do not necessarily mean that a chemical is not a carcinogen, inasmuch as the experiments are conducted under a limited set of conditions. Positive results demonstrate that a chemical is carcinogenic for laboratory animals under the conditions of the study and indicate that exposure to the chemical has the potential for hazard to humans. Other organizations, such as the International Agency for Research on Cancer, assign a strength of evidence for conclusions based on an examination of all available evidence, including animal studies such as those conducted by NTP, epidemiologic studies, and estimates of exposure. Thus, the actual determination of risk to humans from chemicals found to be carcinogenic in laboratory animals requires a wider analysis that extends beyond the purview of these studies.

Five categories of evidence of carcinogenic activity are used in the Technical Report series to summarize the strength of evidence observed in each experiment: two categories for positive results (clear evidence and some evidence); one category for uncertain findings (equivocal evidence); one category for no observable effects (no evidence); and one category for experiments that cannot be evaluated because of major flaws (inadequate study). These categories of interpretative conclusions were first adopted in June 1983 and then revised on March 1986 for use in the Technical Report series to incorporate more specifically the concept of actual weight of evidence of carcinogenic activity. For each separate experiment (male rats, female rats, male mice, female mice), one of the following five categories is selected to describe the findings. These categories refer to the strength of the experimental evidence and not to potency or mechanism.

- Clear evidence of carcinogenic activity is demonstrated by studies that are interpreted as showing a dose-related (i) increase of malignant neoplasms, (ii) increase of a combination of malignant and benign neoplasms, or (iii) marked increase of benign neoplasms if there is an indication from this or other studies of the ability of such tumors to progress to malignancy.

- Some evidence of carcinogenic activity is demonstrated by studies that are interpreted as showing a chemical-related increased incidence of neoplasms (malignant, benign, or combined) in which the strength of the response is less than that required for clear evidence.

- Equivocal evidence of carcinogenic activity is demonstrated by studies that are interpreted as showing a marginal increase of neoplasms that may be chemical related.

- No evidence of carcinogenic activity is demonstrated by studies that are interpreted as showing no chemical-related increases in malignant or benign neoplasms

- Inadequate study of carcinogenic activity is demonstrated by studies that, because of major qualitative or quantitative limitations, cannot be interpreted as valid for showing either the presence or absence of carcinogenic activity.

For studies showing multiple chemical-related neoplastic effects that if considered individually would be assigned to different levels-of-evidence categories, the following convention has been adopted to convey completely the study results. In a study with clear evidence of carcinogenic 
activity at some tissue sites, other responses that alone might be deemed some evidence are indicated as "were also related" to chemical exposure. In studies with clear or some evidence of carcinogenic activity, other responses that alone might be termed equivocal evidence are indicated as "may have been" related to chemical exposure.

When a conclusion statement for a particular experiment is selected, consideration must be given to key factors that would extend the actual boundary of an individual category of evidence. Such consideration should allow for incorporation of scientific experience and current understanding of long-term carcinogenesis studies in laboratory animals, especially for those evaluations that may be on the borderline between two adjacent levels. These considerations should include:

- adequacy of the experimental design and conduct;

- occurrence of common versus uncommon neoplasia;

- progression (or lack thereof) from benign to malignant neoplasia as well as from preneoplastic to neoplastic lesions;

- some benign neoplasms have the capacity to regress but others (of the same morphologic type) progress. At present, it is impossible to identify the difference. Therefore, where progression is known to be a possibility, the most prudent course is to assume that benign neoplasms of those types have the potential to become malignant;

- combining benign and malignant tumor incidence known or thought to represent stages of progression in the same organ or tissue;

- latency in tumor induction;

- multiplicity in site-specific neoplasia;

- metastases;

- supporting information from proliferative lesions (hyperplasia) in the same site of neoplasia or other experiments (same lesion in another sex or species);

- presence or absence of dose relationships;

- statistical significance of the observed tumor increase;

- concurrent control tumor incidence as well as the historical control rate and variability for a specific neoplasm;

- $\quad$ survival-adjusted analyses and false positive or false negative concerns;

- structure-activity correlations; and

- in some cases, genetic toxicology. 


\section{Peer Review}

The members of the Peer Review Panel who evaluated the draft NTP Report on the Toxicology and Carcinogenesis Studies of Vinylidene Chloride (CASRN 75-35-4) in F344/N Rats and B6C3F1/N Mice (Inhalation Studies) on October 29, 2013, are listed below. Panel members served as independent scientists, not as representatives of any institution, company, or governmental agency. In this capacity, panel members had five major responsibilities in reviewing the NTP studies:

- to ascertain that all relevant literature data have been adequately cited and interpreted,

- to determine if the design and conditions of the NTP studies were appropriate,

- to ensure that the Technical Report presents the experimental results and conclusions fully and clearly,

- to judge the significance of the experimental results by scientific criteria, and

- to assess the evaluation of the evidence of carcinogenic activity and other observed toxic responses.

\section{Peer Reviewers}

John Cullen, V.M.D., Ph.D., Chairperson

College of Veterinary Medicine

North Carolina State University

Raleigh, North Carolina, USA

Norman J. Barlow, D.V.M., Ph.D., MBA, MLD

Sanofi

Boston, Massachussetts, USA

Russell C. Cattley, V.M.D., Ph.D., Primary Reviewer

College of Veterinary Medicine

Auburn University

Auburn, Alabama, USA

Deborah Cory-Slechta, Ph.D.

University of Rochester School of Medicine and Dentistry

Rochester, New York, USA

\section{Terry Gordon, Ph.D., Primary Reviewer}

New York University Langone Medical Center

New York, New York, USA

Joel Parker, Ph.D., Primary Reviewer

University of North Carolina at Chapel Hill

Chapel Hill, North Carolina, USA

Karen Regan, D.V.M.

Regan Pathology/Toxicology Services, Inc.

Ashland, Ohio, USA

Timothy Zacharewski, Ph.D., Primary Reviewer

Michigan State University

East Lansing, Michigan, USA 


\section{Publication Details}

Publisher: National Toxicology Program

Publishing Location: Research Triangle Park, NC

ISSN: 2378-8925

DOI: https://doi.org/10.22427/NTP-TR-582

Report Series: NTP Toxicity Report Series

Report Series Number: 582

Official citation: National Toxicology Program (NTP). 2015. NTP technical report on the toxicology and carcinogenesis studies of vinylidene chloride (CASRN 75-35-4) in F344/N rats and B6C3F1/N mice (inhalation studies). Research Triangle Park, NC: National Toxicology Program. Technical Report 582. 


\section{Abstract}

Vinylidene chloride is used as an intermediate in organic synthesis reactions and is widely used in the production of a variety of polymers. Most of the vinylidene chloride in the plastics industry is used in the production of copolymers with polyvinylidene polymers that have a broad spectrum of application, including in films for household and industrial food packaging, as coatings on a variety of products, in flame-resistant fiber and carpet backing, as binders in paints, and to fabricate filaments, pipes, pipe liners, and gaskets. The highest potential for human exposure to vinylidene chloride is at its point of production and formulation, and occupational exposure may occur via inhalation or dermal contact. The general population is exposed via inhalation and ingestion of contaminated drinking water. Vinylidene chloride was nominated for study by the Agency for Toxic Substances and Disease Registry because of the potential for human exposure, and because there was insufficient critical information concerning its health effects and a need to fill critical data gaps. Male and female $\mathrm{F} 344 / \mathrm{N}$ rats and B6C3F1/N mice were exposed to vinylidene chloride (greater than $99.9 \%$ pure) by inhalation for 2 weeks, 3 months, or 2 years. Genetic toxicology studies were conducted in Salmonella typhimurium and Escherichia coli, L5178Y mouse lymphoma cells, Drosophila melanogaster, and mouse peripheral blood erythrocytes.

\section{Two-week Study in Rats}

Groups of five male and five female rats were exposed by whole body inhalation to vinylidene chloride vapor at concentrations of $0,25,50,100,200$, or 400 ppm, 6 hours plus T90 (12 minutes) per day, 5 days per week for 16 days. All male and nine of 10 female rats in the 200 and 400 ppm groups were found dead by day 2; one female in the 400 ppm group was found dead on day 4 . All other rats survived until the end of the study except one $25 \mathrm{ppm}$ male was removed from the study due to chylothorax (nonexposure-related condition). The mean body weight gain of $100 \mathrm{ppm}$ females was significantly less than that of the chamber controls. Prior to death, all females and nine of 10 males exposed to 200 or 400 ppm became lethargic, while all females and four of five males exposed to $400 \mathrm{ppm}$ developed ataxia. Kidney weights of all surviving groups of exposed males and females were significantly greater than those of the chamber controls. Centrilobular necrosis of the liver was associated with early deaths in male and female rats exposed to 200 or $400 \mathrm{ppm}$, and centrilobular cytoplasmic alteration of hepatocytes occurred in all exposed male and female rats that survived to terminal kill. The incidences of renal tubule casts in the renal papillae of 200 and 400 ppm rats were significantly increased.

\section{Two-week Study in Mice}

Groups of five male and five female mice were exposed by whole body inhalation to vinylidene chloride vapor at concentrations of $0,25,50,100,200$, or 400 ppm, 6 hours plus T90 (12 minutes) per day, 5 days per week for 17 days. All male mice exposed to $100 \mathrm{ppm}$ or greater died within the first 4 days of exposure. All females exposed to 200 or $400 \mathrm{ppm}$ were found dead following exposure on day 1 . One $50 \mathrm{ppm}$ male and one $100 \mathrm{ppm}$ female were removed dead before exposure on day 5 . Mean body weights of 25 and $50 \mathrm{ppm}$ male mice were less than those of the chamber control group. Lethargy and abnormal breathing occurred in 50 and $100 \mathrm{ppm}$ males. In all surviving groups of exposed females, lung weights were significantly greater than those of the chamber controls, and the liver weights of 50 and 100 ppm females were significantly greater than those of the chamber controls. Necrosis of the respiratory epithelium of 
the nose occurred in all mice exposed to 200 or $400 \mathrm{ppm}$ and in all $100 \mathrm{ppm}$ males. Centrilobular necrosis of the liver occurred in all males and females exposed to $100 \mathrm{ppm}$ or greater; in addition, regeneration occurred in the four $100 \mathrm{ppm}$ females that survived to the end of study. Proximal renal tubule necrosis and granular casts occurred in the kidney in all exposed males.

\section{Three-month Study in Rats}

Groups of 10 male and 10 female rats were exposed by whole body inhalation to vinylidene chloride vapor at concentrations of $0,6.25,12.5,25,50$, or $100 \mathrm{ppm}, 6$ hours plus $\mathrm{T}_{90}$ (10 minutes) per day, 5 days per week for 14 weeks. Additional clinical pathology groups of 10 male and 10 female rats were exposed to the same concentrations for 23 days. All rats survived until the end of the study. Mean body weights of exposed groups were similar to those of the chamber control groups. Sorbitol dehydrogenase activities were increased in $100 \mathrm{ppm}$ females on day 3 and in 100 ppm males and 50 and 100 ppm females on day 23. Alanine aminotransferase activities were increased on day 3 in 50 and 100 ppm male rats and on day 23 in 100 ppm male rats. Kidney weights of $12.5 \mathrm{ppm}$ or greater females were significantly greater than those of the chamber controls. In males, sperm motility was decreased and spermatid/g testis and total spermatid/testis were lower at $100 \mathrm{ppm}$ than those of the chamber control groups. No treatmentrelated effects were observed in females. These data suggest that vinylidene chloride may be a reproductive toxicant in male, but not female rats.

A combination of lesions in the nasal epithelium of male and female rats including olfactory epithelium atrophy, mineralization, and necrosis and turbinate atrophy occurred with generally increasing severity with increasing exposure concentration. In the liver, the incidences of centrilobular cytoplasmic alteration were significantly increased in males exposed to $12.5 \mathrm{ppm}$ or greater, and cytoplasmic vacuolization occurred in all 50 and 100 ppm females.

\section{Three-month Study in Mice}

Groups of 10 male and 10 female mice were exposed by whole body inhalation to vinylidene chloride vapor at concentrations of $0,6.25,12.5,25,50$, or 100 ppm (females only), 6 hours plus $\mathrm{T}_{90}(10$ minutes) per day, 5 days per week for 14 weeks. Two $50 \mathrm{ppm}$ males and four $100 \mathrm{ppm}$ females died during the first week of the study. The mean body weights of all exposed groups of females and of males exposed to $12.5 \mathrm{ppm}$ or greater were significantly less than those of the chamber control groups. Exposure concentration-related decreases in the erythrocyte counts, hemoglobin concentrations, and hematocrit values occurred at the end of the study in 12.5, 25, and $50 \mathrm{ppm}$ male mice. Female mice had decreased erythrocyte counts in the 50 and $100 \mathrm{ppm}$ groups. In addition, hemoglobin concentration and the hematocrit value were decreased in $50 \mathrm{ppm}$ female mice. Absolute kidney weights of all exposed groups of males were significantly less than that of the chamber control group. Absolute and relative liver weights of $12.5 \mathrm{ppm}$ or greater females and absolute and relative kidney and lung weights of $100 \mathrm{ppm}$ females were significantly greater than those of the chamber controls. In males, decreased cauda epididymis weights at 25 and $50 \mathrm{ppm}$ and total sperm/cauda epididymis in all vinylidene chloride-exposed groups were observed. No treatment-related effects were observed in females. These data suggest that vinylidene chloride may be a reproductive toxicant in male, but not female mice.

In male mice, the incidences and severities of nephropathy were significantly increased in the $12.5,25$, and $50 \mathrm{ppm}$ groups, and two $50 \mathrm{ppm}$ males had renal tubule necrosis and protein casts. The incidence of respiratory epithelium squamous metaplasia of the larynx was significantly increased in the $50 \mathrm{ppm}$ males. In female mice, laryngeal lesions consisted of necrosis and 
respiratory epithelium hyperplasia and squamous metaplasia and occurred primarily in the $100 \mathrm{ppm}$ group. Exposure-related lung lesions were limited to $100 \mathrm{ppm}$ female mice and consisted of bronchial epithelium necrosis and histiocytic inflammation. The incidences of nasal necrosis of the respiratory epithelium and atrophy of the turbinate were significantly increased in $100 \mathrm{ppm}$ females. The incidences of necrosis and hypertrophy of the liver were significantly increased in 100 ppm females, and necrosis occurred in two 50 ppm males.

\section{Two-year Study in Rats}

Groups of 50 male and 50 female rats were exposed by whole body inhalation to vinylidene chloride vapor at concentrations of $0,25,50$, or $100 \mathrm{ppm}, 6$ hours plus $\mathrm{T}_{90}$ (10 minutes) per day, 5 days per week for 105 weeks. Survival of exposed groups of males was similar to that of the chamber control group. Survival of 100 ppm females was significantly less than that of the chamber controls. Mean body weights of exposed groups of male and female rats were similar to those of the chamber control groups throughout the study.

In male rats, the incidences of malignant mesothelioma occurred with a positive trend and were significantly increased in all exposed groups compared to the chamber control group. Malignant mesothelioma occurred in one $25 \mathrm{ppm}$ female and one $50 \mathrm{ppm}$ female. Global gene expression analysis was performed to identify overrepresented pathways involved in mesotheliomas from vinylidene chloride-exposed $\mathrm{F} 344 / \mathrm{N}$ rats compared to spontaneous mesotheliomas in control F344/N rats.

The incidence of C-cell adenoma of the thyroid gland was significantly increased in $100 \mathrm{ppm}$ females, and the incidence of C-cell carcinoma was significantly increased in $25 \mathrm{ppm}$ females. The incidences of adenoma or carcinoma (combined) were significantly increased in 25 and 100 ppm females.

The incidence of mononuclear cell leukemia was significantly increased in $100 \mathrm{ppm}$ females.

Renal tubule carcinomas were observed in several vinylidene chloride-exposed males; these neoplasms are rare in male $\mathrm{F} 344 / \mathrm{N}$ rats.

The only exposure-related primary nasal neoplasm observed in rats was adenoma in the respiratory epithelium. Exposure concentration-related increased incidences of turbinate atrophy and hypertosis, olfactory epithelium respiratory metaplasia, respiratory epithelium hyperplasia, and chronic active inflammation occurred in all exposed groups of male and female rats, and the severities of the lesions generally increased with increasing exposure concentration.

The incidences of alveolar epithelium hyperplasia in the lung were significantly increased in all exposed groups of male rats; the severities increased with increasing exposure concentration. In the liver of rats, increased incidences of chronic inflammation, diffuse fatty change, and cystic degeneration in males and females and necrosis in females occurred.

\section{Two-year Study in Mice}

Groups of 50 male and 50 female mice were exposed by whole body inhalation to vinylidene chloride vapor at concentrations of $0,6.25,12.5$, or 25 ppm, 6 hours plus $\mathrm{T}_{90}$ (10 minutes) per day, 5 days per week for 105 weeks. Survival of 6.25 ppm males was significantly greater than that of the chamber controls. Survival of $25 \mathrm{ppm}$ males and 6.25 and $25 \mathrm{ppm}$ females was significantly less than that of the chamber control groups. Mean body weights of 12.5 and 25 ppm males were at least $10 \%$ less than those of the chamber control group after weeks 17 and 13 , respectively, and those of 25 ppm females were at least $10 \%$ less after week 21 . Exposure- 
related clinical findings included thinness and abnormal breathing in $25 \mathrm{ppm}$ males and abnormal breathing, thinness, and ventral torso mass in all exposed groups of females.

The incidences of renal tubule adenoma, renal tubule carcinoma, and renal tubule adenoma or carcinoma (combined) were significantly increased in all exposed groups of males; the incidences of renal tubule hyperplasia were also significantly increased in all exposed groups of males.

The incidences of hemangioma (all organs) in all exposed groups of females were increased compared to that in the chamber controls, and the incidence of hemangioma or hemangiosarcoma (combined) in $25 \mathrm{ppm}$ females was significantly greater than that in the chamber controls.

The incidences of hepatocellular adenoma in $12.5 \mathrm{ppm}$ females, hepatocellular carcinoma in $25 \mathrm{ppm}$ females, and hepatocellular adenoma or carcinoma (combined) in 12.5 and $25 \mathrm{ppm}$ females were significantly greater than those in the chamber control group. In addition, hepatocholangiocarcinoma occurred in all exposed groups of females. The incidences of hepatocholangiocarcinoma in exposed groups of males were increased compared to that in the concurrent chamber control group and exceeded the historical control range for inhalation studies. In females, this neoplasm is much less common than in males; it has not been observed in 300 inhalation controls or 948 controls from all routes of exposure. In males, hepatocholangiocarcinoma has been reported in two of 299 inhalation controls and in 10 of 949 from all routes of exposure.

The incidence of alveolar/bronchiolar carcinoma was significantly increased in $12.5 \mathrm{ppm}$ females.

In $25 \mathrm{ppm}$ females, the incidence of carcinoma of the small intestine (ileum) exceeded the historical control ranges for inhalation studies and all routes of administration.

Turbinate atrophy, hyperostosis, and olfactory epithelium respiratory metaplasia occurred in the nose of the vast majority of exposed male and female mice, and the severity of these lesions increased with increasing exposure concentration. The incidences of olfactory epithelium hyaline droplet accumulation in 12.5 and $25 \mathrm{ppm}$ males and $25 \mathrm{ppm}$ females and respiratory epithelium hyperplasia in $25 \mathrm{ppm}$ females were significantly increased compared to chamber controls.

\section{Genetic Toxicology}

Vinylidene chloride was not mutagenic in any of several strains of Salmonella typhimurium when testing occurred with or without exogenous metabolic activation using a preincubation protocol. However, when tested in a closed system as a vapor, vinylidene chloride was mutagenic in mouse lymphoma L5178Y $\mathrm{tk}^{+/-}$cells in the presence of exogenous metabolic activation provided by induced male rat liver $\mathrm{S} 9 \mathrm{mix}$ and questionable without $\mathrm{S} 9$. In vivo, no increase in sex-linked recessive lethal mutations was seen in germ cells of adult male Drosophila melanogaster exposed via feeding or injection to vinylidene chloride. No increase in the frequency of micronucleated erythrocytes was observed in peripheral blood of male or female B6C3F1/N mice exposed to vinylidene chloride by inhalation for a period of 3 months.

\section{Conclusions}

Under the conditions of this 2-year inhalation study, there was clear evidence of carcinogenic activity (see Explanation of Levels of Evidence of Carcinogenic Activity; see summary of the peer review panel comments and the public discussion on this Technical Report in Appendix M) of vinylidene chloride in male $\mathrm{F} 344 / \mathrm{N}$ rats based on increased incidences of malignant 
mesothelioma. Increased incidences of renal tubule carcinoma and respiratory epithelium adenoma in the nose of male rats were also considered to be related to vinylidene chloride exposure. There was some evidence of carcinogenic activity of vinylidene chloride in female F344/N rats based on increased incidences of C-cell adenoma or carcinoma in the thyroid gland and systemic mononuclear cell leukemia. Occurrences of malignant mesothelioma may have been related to vinylidene chloride exposure. There was clear evidence of carcinogenic activity of vinylidene chloride in male $\mathrm{B} 6 \mathrm{C} 3 \mathrm{~F} 1 / \mathrm{N}$ mice based on increased incidences of renal tubule adenoma and carcinoma. Increased incidences of hepatocholangiocarcinoma may have been related to vinylidene chloride exposure. There was clear evidence of carcinogenic activity of vinylidene chloride in female $\mathrm{B} 6 \mathrm{C} 3 \mathrm{~F} 1 / \mathrm{N}$ mice based on increased incidences of systemic hemangioma or hemangiosarcoma (combined). Hepatocholangiocarcinoma and hepatocellular adenoma or carcinoma (combined) in the liver of female mice were also considered to be related to vinylidene chloride exposure. Increased incidences of alveolar/bronchiolar carcinoma in the lungs and carcinoma of the small intestine may have been related to treatment.

Exposure to vinylidene chloride caused increases in the incidences of nonneoplastic lesions in the nose of rats and mice, the liver of rats, the lung of male rats, and the kidney of male mice.

Synonyms: 1, 1-dichloroethene; 1, 1-dichloroethylene 
Summary of the Two-year Carcinogenesis and Genetic Toxicology Studies of Vinylidene Chloride

\begin{tabular}{|c|c|c|c|c|}
\hline & $\begin{array}{c}\text { Male } \\
\text { F344/N Rats }\end{array}$ & $\begin{array}{c}\text { Female } \\
\text { F344/N Rats }\end{array}$ & $\begin{array}{c}\text { Male } \\
\text { B6C3F1/N Mice }\end{array}$ & $\begin{array}{c}\text { Female } \\
\text { B6C3F1/N Mice }\end{array}$ \\
\hline Concentrations in Air & $\begin{array}{l}0,25,50, \text { or } \\
100 \mathrm{ppm}\end{array}$ & $\begin{array}{l}0,25,50, \text { or } \\
100 \mathrm{ppm}\end{array}$ & $\begin{array}{l}0,6.25,12.5, \text { or } \\
25 \mathrm{ppm}\end{array}$ & $\begin{array}{l}0,6.25,12.5, \text { or } \\
25 \mathrm{ppm}\end{array}$ \\
\hline Body Weights & $\begin{array}{l}\text { Exposed groups } \\
\text { similar to the } \\
\text { chamber control } \\
\text { group }\end{array}$ & $\begin{array}{l}\text { Exposed groups } \\
\text { similar to the } \\
\text { chamber control } \\
\text { group }\end{array}$ & $\begin{array}{l}12.5 \text { and } 25 \mathrm{ppm} \\
\text { groups } 10 \% \text { less } \\
\text { than the chamber } \\
\text { control group } \\
\text { after weeks } 17 \text { and } \\
13 \text {, respectively }\end{array}$ & $\begin{array}{l}25 \text { ppm group } 10 \% \\
\text { less than the } \\
\text { chamber control } \\
\text { group after week } \\
21\end{array}$ \\
\hline Survival Rates & $\begin{array}{l}25 / 50,27 / 50 \\
22 / 50,19 / 50\end{array}$ & $\begin{array}{l}30 / 50,26 / 50 \\
30 / 50,19 / 50\end{array}$ & $\begin{array}{l}29 / 50,40 / 50, \\
32 / 50,19 / 50\end{array}$ & $\begin{array}{l}36 / 50,25 / 50 \\
30 / 50,24 / 50\end{array}$ \\
\hline Nonneoplastic Effects & $\begin{array}{l}\text { Nose: turbinate, } \\
\text { atrophy }(0 / 49, \\
\text { 50/50, 50/50, } \\
\text { 50/50); turbinate, } \\
\text { hyperostosis }(0 / 49, \\
\text { 49/50, 50/50, } \\
\text { 50/50); olfactory } \\
\text { epithelium, } \\
\text { metaplasia, } \\
\text { respiratory }(3 / 49, \\
\text { 49/50, 49/50, } \\
\text { 48/50); respiratory } \\
\text { epithelium, } \\
\text { hyperplasia }(5 / 49, \\
\text { 8/50, 22/50, 31/50); } \\
\text { inflammation, } \\
\text { chronic active } \\
\text { (9/49, 36/50, 45/50, } \\
\text { 48/50) } \\
\text { Lung: alveolar } \\
\text { epithelium } \\
\text { hyperplasia }(7 / 50, \\
\text { 18/50, 14/50, } \\
\text { 14/50) } \\
\text { Liver: chronic } \\
\text { inflammation } \\
\text { (28/50, 46/50, } \\
\text { 46/50, 44/50); } \\
\text { diffuse fatty change } \\
\text { (4/50, 19/50, 18/50, } \\
\text { 26/50); cystic } \\
\text { degeneration ( } 2 / 50, \\
\text { 5/50, 7/50, 12/50) }\end{array}$ & $\begin{array}{l}\text { Nose: turbinate, } \\
\text { atrophy }(0 / 50, \\
\text { 50/50, 50/50, } \\
\text { 50/50); turbinate, } \\
\text { hyperostosis }(0 / 50, \\
\text { 50/50, 50/50, } \\
\text { 50/50); olfactory } \\
\text { epithelium, } \\
\text { metaplasia, } \\
\text { respiratory (1/50, } \\
\text { 50/50, 50/50, } \\
\text { 50/50); respiratory } \\
\text { epithelium, } \\
\text { hyperplasia (4/50, } \\
\text { 12/50, 14/50, } \\
\text { 27/50); } \\
\text { inflammation, } \\
\text { chronic active } \\
\text { (7/50, 45/50, 46/50, } \\
\text { 46/50) } \\
\text { Liver: chronic } \\
\text { inflammation } \\
\text { (42/50, 48/50, } \\
\text { 49/50, 48/50); } \\
\text { diffuse fatty change } \\
(19 / 50,30 / 50, \\
\text { 26/50, 30/50); } \\
\text { cystic degeneration } \\
(0 / 50,2 / 50,4 / 50, \\
7 / 50) ; \text { necrosis } \\
(0 / 50,3 / 50,5 / 50, \\
11 / 50)\end{array}$ & $\begin{array}{l}\text { Kidney: renal } \\
\text { tubule hyperplasia } \\
(0 / 50,8 / 50,22 / 50, \\
16 / 50) \\
\text { Nose: turbinate, } \\
\text { atrophy }(0 / 50, \\
46 / 50,46 / 49, \\
47 / 49) ; \\
\text { hyperostosis }(1 / 50 \text {, } \\
27 / 50,45 / 49, \\
48 / 49) ; \text { olfactory } \\
\text { epithelium, } \\
\text { metaplasia, } \\
\text { respiratory (17/50, } \\
\text { 39/50, 47/49, } \\
48 / 49) ; \text { olfactory } \\
\text { epithelium, } \\
\text { accumulation, } \\
\text { hyaline droplet } \\
\text { (2/50, 5/50, 13/49, } \\
11 / 49) ;\end{array}$ & $\begin{array}{l}\text { Nose: turbinate, } \\
\text { atrophy }(0 / 50, \\
\text { 46/50, 50/50, } \\
\text { 49/50); } \\
\text { hyperostosis }(0 / 50, \\
\text { 13/50, 45/50, } \\
\text { 48/50); olfactory } \\
\text { epithelium, } \\
\text { metaplasia, } \\
\text { respiratory (3/50, } \\
\text { 29/50, 49/50, } \\
\text { 50/50); olfactory } \\
\text { epithelium, } \\
\text { accumulation, } \\
\text { hyaline droplet } \\
(18 / 50,18 / 50, \\
\text { 13/50, 32/50); } \\
\text { respiratory } \\
\text { epithelium, } \\
\text { hyperplasia } \\
(33 / 50,41 / 50, \\
\text { 39/50, 43/50) }\end{array}$ \\
\hline
\end{tabular}




\begin{tabular}{|c|c|c|c|c|}
\hline & $\begin{array}{c}\text { Male } \\
\text { F344/N Rats }\end{array}$ & $\begin{array}{c}\text { Female } \\
\text { F344/N Rats }\end{array}$ & $\begin{array}{c}\text { Male } \\
\text { B6C3F1/N Mice }\end{array}$ & $\begin{array}{c}\text { Female } \\
\text { B6C3F1/N Mice }\end{array}$ \\
\hline Neoplastic Effects & $\begin{array}{l}\text { All organs: } \\
\text { malignant } \\
\text { mesothelioma } \\
(1 / 50,12 / 50,28 / 50, \\
23 / 50) \\
\text { Kidney: renal } \\
\text { tubule carcinoma } \\
(0 / 50,2 / 50,1 / 49 \text {, } \\
\text { 1/50) } \\
\text { Nose: respiratory } \\
\text { epithelium, } \\
\text { adenoma }(0 / 49, \\
0 / 50,1 / 50,4 / 50)\end{array}$ & $\begin{array}{l}\text { Thyroid gland } \\
\text { (C-cell): adenoma } \\
\text { (3/50, 4/50, 6/48, } \\
11 / 50) ; \text { carcinoma } \\
(0 / 50,6 / 50,2 / 48, \\
\text { 2/50); adenoma or } \\
\text { carcinoma }(3 / 50, \\
\text { 10/50, 8/48, 13/50) } \\
\text { All organs: } \\
\text { mononuclear cell } \\
\text { leukemia }(10 / 50, \\
11 / 50,13 / 50, \\
25 / 50)\end{array}$ & $\begin{array}{l}\text { Kidney: renal } \\
\text { tubule adenoma } \\
(0 / 50,5 / 50,19 / 50, \\
\text { 10/50); renal tubule } \\
\text { carcinoma }(0 / 50, \\
7 / 50,31 / 50,18 / 50) \text {; } \\
\text { renal tubule } \\
\text { adenoma or } \\
\text { carcinoma }(0 / 50, \\
11 / 50,37 / 50, \\
27 / 50)\end{array}$ & $\begin{array}{l}\text { All Organs: } \\
\text { hemangioma or } \\
\text { hemangiosarcoma } \\
(4 / 50,6 / 50,6 / 50, \\
11 / 50) \\
\text { Liver: } \\
\text { hepatocellular } \\
\text { adenoma }(25 / 50, \\
21 / 50,36 / 50, \\
29 / 50) \text {; } \\
\text { hepatocellular } \\
\text { carcinoma }(8 / 50, \\
14 / 50,12 / 50, \\
17 / 50) \text {; } \\
\text { hepatocellular } \\
\text { adenoma or } \\
\text { carcinoma }(28 / 50, \\
\text { 30/50, 37/50, } \\
\text { 38/50); } \\
\text { hepatocholangioca } \\
\text { rcinoma }(0 / 50, \\
1 / 50,1 / 50,2 / 50)\end{array}$ \\
\hline Equivocal Findings & None & $\begin{array}{l}\text { All organs: } \\
\text { malignant } \\
\text { mesothelioma } \\
(0 / 50,1 / 50,1 / 50, \\
0 / 50)\end{array}$ & $\begin{array}{l}\text { Liver: } \\
\text { hepatocholangiocar } \\
\text { cionoma }(1 / 50, \\
\text { 2/50, 2/50, 3/50) } \\
\end{array}$ & $\begin{array}{l}\text { Lung: } \\
\text { alveolar/bronchiol } \\
\text { ar carcinoma } \\
(1 / 50,2 / 50,7 / 50, \\
5 / 49) \\
\text { Small Intestine } \\
\text { (ileum): carcinoma } \\
(1 / 50,1 / 50,1 / 50, \\
3 / 50)\end{array}$ \\
\hline $\begin{array}{l}\text { Level of Evidence of } \\
\text { Carcinogenic Activity }\end{array}$ & Clear evidence & Some evidence & Clear evidence & Clear evidence \\
\hline \multicolumn{5}{|l|}{ Genetic Toxicology } \\
\hline Bacterial gene mutations: & & \multicolumn{3}{|c|}{$\begin{array}{l}\text { Negative in Salmonella typhimurium strains TA98, TA100, } \\
\text { TA1535, and TA1537 }\end{array}$} \\
\hline Mouse lymphoma gene $\mathrm{m}$ & tations: & \multicolumn{3}{|c|}{$\begin{array}{l}\text { Positive in mouse lymphoma L5178Y } t k^{+/} \text {cells with S9, } \\
\text { questionable in the absence of S9 }\end{array}$} \\
\hline \multicolumn{5}{|c|}{ Sex-linked recessive lethal mutations } \\
\hline Drosophila melanogast & & \multicolumn{3}{|c|}{ No induction of sex-linked recessive lethal mutations } \\
\hline \multicolumn{5}{|c|}{ Micronucleated erythrocytes } \\
\hline Mouse peripheral blood & n vivo: & \multicolumn{3}{|c|}{ Negative in males and females } \\
\hline
\end{tabular}




\section{Introduction}

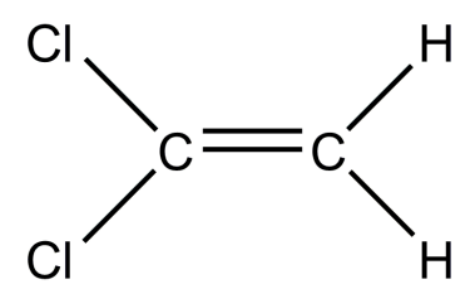

Figure 1. Vinylidene Chloride (CASRN: 75-35-4; Chemical Formula: C2H2Cl2; Molecular Weight: 96.94)

Synonyms: 1, 1-dichloroethene; 1, 1-dichloroethylene.

\section{Chemical and Physical Properties}

Vinylidene chloride is a clear, volatile liquid that has a sweet odor and a melting point of $-122.1^{\circ} \mathrm{C}$, a boiling point of $31.7^{\circ} \mathrm{C}$, and a vapor pressure of $400 \mathrm{~mm}$ at $14.8^{\circ} \mathrm{C}^{1-5}$. Vinylidene chloride is insoluble in water, but miscible with most organic solvents ${ }^{5}$. In the absence of an added inhibitor, monomethyl ether of hydroquinone, vinylidene chloride readily polymerizes. In the presence of air or oxygen, shock-sensitive and explosive peroxides are formed.

\section{Production, Use, and Human Exposure}

Vinylidene chloride is a man-made chemical that is not known to occur naturally. It is produced commercially via the dehydrochlorination of 1,1,2-trichloroethane with an aqueous alkali, like sodium hydroxide or lime ${ }^{1}$. Vinylidene chloride can be purified through distillation and extraction. Commercial grade vinylidene chloride contains up to $200 \mathrm{ppm}$ MEHQ that is added to prevent polymerization and the formation of explosive peroxides. In order to manufacture vinylidene chloride polymers, polymerization initiators are added.

The annual production of vinylidene chloride in the United States has varied between 68,000 and 90,000 tons $^{1-3 ; 6 ; 7}$ with the most recent estimate of 79,000 tons ${ }^{7}$. In 1990 , the world-wide production was estimated at 290,000 tons ${ }^{7 ; 8}$.

Vinylidene chloride is used as an intermediate in organic synthesis reactions and is widely used in the production of a variety of polymers. For increased polymer stability, it is usually copolymerized with other chemicals, such as vinyl chloride, acrylonitrile, meth-acrylonitrile, and methacrylate $^{1}$. Most of the vinylidene chloride in the plastics industry is used in the production of copolymers with polyvinylidene polymers that have a broad spectrum of application in film form and as solvent-soluble resins, water dispersions, and latexes ${ }^{1-3 ; 9 ; 10}$. These polymers are used extensively in films for household and industrial food packaging based on their oxygenbarrier properties. Solvent-soluble resins are used as coatings on other polymer films; paper cups and plates; pipes; ship, railroad, and fuel storage tanks; and binders in coatings for various tapes ${ }^{11}$. Latexes and extruded fibers made from vinylidene chloride copolymers are used in coating plastics, in flame-resistant fiber and carpet backing, as binders in paints, and to fabricate filaments, pipes, pipe liners, and gaskets ${ }^{11}$. 
The highest potential for human exposure to vinylidene chloride is at its point of production and formulation. Occupational exposure may occur via inhalation or dermal $\operatorname{contact}^{3 ; 7 ; 9}$. The U.S. Environmental Protection Agency reported that 6,500 workers in monomer and polymer plants were exposed to air levels of 25 to $100 \mu \mathrm{g} / \mathrm{m}^{32}$. The primary source of vinylidene chloride in the environment is through volatile air emissions in the atmosphere and in effluent waters from plants synthesizing vinylidene chloride and its copolymers, or manufacturing products containing vinylidene chloride. The general population is exposed via inhalation and ingestion of contaminated drinking water. Based on personal air sampling in the general population, Wallace $^{12}$ estimated mean vinylidene chloride exposure to be $6.5 \mu \mathrm{g} / \mathrm{m}^{3}$. Consumers may also be exposed via migration of vinylidene chloride from the films and coatings of packaging materials into foods contained in the packaging. The recommended threshold limit value for occupational exposure to vinylidene chloride is currently 5 ppm for 8 hours based on effects involving the liver and kidney ${ }^{7 ; 13}$.

\section{Absorption, Distribution, Metabolism, and Excretion}

\section{Experimental Animals}

Following inhalation exposure in rats, the absorption of vinylidene chloride was rapid and concentration-dependent. The uptake was linear for concentrations up to $150 \mathrm{ppm}$, above which the uptake decreased with the increasing concentration ${ }^{14 ; 15}$. The compound was found in blood of rats within 2 minutes following exposure. Following exposure to concentrations up to $2,000 \mathrm{ppm}\left[{ }^{14} \mathrm{C}\right]$ vinylidene chloride, the highest level of total radioactivity was found in the liver and kidney, with only very small amounts present in other tissues ${ }^{14 ; 16 ; 17}$. Covalently bound radioactivity was also highest in the liver and the kidney with fasted rats having higher levels than nonfasted ${ }^{14 ; 17}$. Following exposure to 10 ppm for 6 hours, a higher body burden was observed in mice than in rats exposed under similar conditions. The bound radioactivity was higher in mouse liver and kidney than in corresponding tissues in rats ${ }^{17}$. Elimination of vinylidene chloride following inhalation exposure in rats was rapid with the majority of the dose eliminated in the urine. Steady state levels in expired air were achieved following exposure to 25 to $150 \mathrm{ppm}$ vinylidene chloride, indicating that the elimination is first order at these levels; about $1 \%$ of the dose was excreted unchanged in the expired air at these exposure concentrations. At concentrations greater than $150 \mathrm{ppm}$, levels in expired air increased indicating saturation of metabolism ${ }^{15}$. The pulmonary elimination was biphasic in rats following inhalation exposure; the half-lives for the first and second phases, respectively, based on the unchanged compound were 20 and 217 minutes following exposure to $10 \mathrm{ppm}$ and 21 and 133 minutes following exposure to 200 ppm $\left[{ }^{14} \mathrm{C}\right]$ vinylidene chloride. Urinary elimination followed a similar pattern; the half-lives for the first and second phases, respectively, based on the total $\left[{ }^{14} \mathrm{C}\right]$ excretion in urine were 3.1 and 19.3 hours following exposure to $10 \mathrm{ppm}$ and 3.8 and 23.9 hours following exposure to $200 \mathrm{ppm}\left[{ }^{14} \mathrm{C}\right]$ vinylidene chloride. The major portion of the dose was eliminated in both the breath and the urine during the rapid first phase. Fasting did not affect the elimination kinetics of vinylidene chloride in rats ${ }^{14 ; 17}$. Limited data in mice following inhalation exposure to $10 \mathrm{ppm}$ vinylidene chloride indicated that the elimination of unchanged compound in the expired air is smaller and elimination via urine is larger compared to rats, indicating that mice metabolize vinylidene chloride at a greater rate than $\operatorname{rats}^{17}$. 
An investigation of the plasma toxicokinetics of vinylidene chloride in Sprague Dawley rats showed that the $\mathrm{C}_{\max }$ and $\mathrm{AUC}_{0-\infty}$, respectively, following inhalation exposure to $300 \mathrm{ppm}$ were $2.8 \mathrm{mg} / \mathrm{L}$ and $279 \mu \mathrm{g} \cdot \mathrm{min} / \mathrm{mL}$; the elimination half-life and bioavailability, respectively, were 50 minutes and $55.7 \%^{18}$.

Following oral administration of doses ranging from 0.5 to $100 \mathrm{mg} / \mathrm{kg}$, vinylidene chloride was rapidly and almost completely absorbed in rats and mice and distributed to all tissues examined ${ }^{4}$; ${ }^{19-23}$. Peak blood levels were observed in rats within 2 to 8 minutes $^{23}$. Vinylidene chloride was distributed to all tissues following administration with the highest amount found in the liver and kidney $^{20 ; 24}$. The pattern of elimination was similar to that following inhalation exposure.

Following a single administration of $1 \mathrm{mg} / \mathrm{kg}$ in rats, about $1 \%$ to $3 \%$ of the dose was excreted in expired air as unchanged chemical, with $21 \%$ recovered as carbon dioxide ${ }^{20}$. The majority of the dose was eliminated in urine $(63 \%)$ and some in feces $(16 \%)$ within 72 hours, with the majority excreted within the first 24 hours. Following administration of $50 \mathrm{mg} / \mathrm{kg}, 16 \%$ to $30 \%$ of the dose was excreted in expired air as the parent with concomitant reductions in the expired carbon dioxide (3\% to $6 \%$ ) and urinary excretion (35\% to $47 \%$ ) suggesting that metabolism saturates at rather low doses ${ }^{20 ; 21 ; 24}$. Fasting slightly modified the elimination of vinylidene chloride in rats after oral administration; $29 \%$ of a $50 \mathrm{mg} / \mathrm{kg}$ dose was excreted unchanged in expired air compared to $19 \%$ in fed rats ${ }^{20}$. Mice eliminated less in expired air as unchanged chemical and more in urine than rats following oral administration of $50 \mathrm{mg} / \mathrm{kg}^{19}$. The elimination of vinylidene chloride following oral administration in rats was biphasic ${ }^{20 ; 21}$. Half-lives for the two phases, respectively, for pulmonary elimination were 25 and 117 minutes for a $1 \mathrm{mg} / \mathrm{kg}$ dose and 21 and 66 minutes for $50 \mathrm{mg} / \mathrm{kg}^{20}$. For urinary elimination of total radioactivity, the estimated half-lives for the first and second phases were 6 and 17 hours for both doses. Plasma toxicokinetics of vinylidene chloride in Sprague Dawley rats following gavage exposure showed a similar behavior to inhalation exposure ${ }^{18}$. The $\mathrm{C}_{\max }$ and $\mathrm{AUC}_{0-\infty}$ following gavage exposure to $30 \mathrm{mg} / \mathrm{kg}$ were $8.9 \mathrm{mg} / \mathrm{L}$ and $233 \mu \mathrm{g} \cdot \mathrm{min} / \mathrm{mL}$, respectively; the elimination half-life and bioavailability were 88 minutes and $46.5 \%$, respectively.

In a study where mice were administered a single intraperitoneal injection of $125 \mathrm{mg} / \mathrm{kg}$ [14C] vinylidene chloride, radioactivity was distributed to all examined tissues with the highest levels of radioactivity found in the kidney, liver, and lung 6 hours after administration ${ }^{25}$.

The metabolism of vinylidene chloride is saturable, and unmetabolized vinylidene chloride is primarily eliminated via exhalation from the lung regardless of the method of administration ${ }^{15 ; 17}$; 26. The proposed pathway for the metabolism of vinylidene chloride in rodents is shown in Figure 2. Vinylidene chloride is metabolized in rodents via pathways involving CYP2E1 to yield three reactive metabolites: vinylidene chloride epoxide, 2-chloroacetyl chloride, and 2,2dichloroacetaldehyde. These electrophilic metabolites undergo oxidation, hydrolysis, and reactions with glutathione and cellular macromolecules. The oxidative metabolism of vinylidene chloride has been reported to saturate in rats at around $200 \mathrm{ppm}$ following inhalation and between 10 to $50 \mathrm{mg} / \mathrm{kg}$ following oral exposure ${ }^{15 ; 17 ; 26 ; 27}$. The involvement of glutathione in the detoxification of vinylidene chloride was consistent with the observation that exposure to vinylidene chloride depletes liver glutathione levels ${ }^{28-30}$. Urinary metabolites identified were $N$ acetyl-S-(2-hydroxyethyl)cysteine, $S$-(cysteinyl acetyl) glutathione, $N$-acetyl- $S$-(2carboxymethyl) cysteine, thiodiglycolic acid, dithioglycolic acid, dithiodiglycolic acid, chloroacetic acid, and biliary metabolites identified were $S$-(2-carboxymethyl) glutathione, $S$-(cysteinyl acetyl)glutathione, and a product of the intramolecular rearrangement of the 
metabolite, $S$-(2-chloroacetyl)glutathione ${ }^{4 ; 19 ; 24 ; 25 ; 31-39}$. In addition, several carboxymethylated proteins were identified in bile from vinylidene chloride-treated rats ${ }^{38}$. Mice metabolized a greater portion of the orally administered vinylidene chloride than rats ${ }^{24 ; 35}$. Although the types of metabolites observed in rats and mice were similar, $N$-acetyl- $S$-(2-carboxymethyl)cysteine arising likely from the 2-chloroacetyl chloride pathway was detected in mice but not in rats. In addition, quantitatively, mice produced more $S$-(2-hydroxyethyl)- $N$-acetyl cysteine [previously identified by Jones and Hathway ${ }^{24}$ as $N$-acetyl-S-cysteinyl acetyl derivative], a product of the reaction between vinylidene chloride epoxide with glutathione, than rats suggesting that the formation of vinylidene chloride epoxide is higher in mice than in rats.

In addition, several investigations in rat liver microsome incubations and mouse liver and lung microsomal incubations have shown that vinylidene chloride epoxide is the major and likely the most important cytotoxic metabolite; minor metabolites identified were 2,2,-

dichloroacetaldehyde and 2-chloroacetylchloride ${ }^{31 ; 32 ; 35 ; 39-42}$. As seen in vivo, these metabolites undergo secondary reactions including oxidation, glutathione conjugation and hydrolysis. The levels of the acetal observed in lung microsomes were higher than those in the liver microsomal incubations ${ }^{41}$. It was also demonstrated that the mean rate of formation of the epoxide was twofold higher in mouse lung microsomal incubations compared to human lung microsomal incubations ${ }^{41}$. Simmonds et al. ${ }^{39}$ showed that both CYP2E1 and CYP2F2 catalyze the bioactivation of vinylidene chloride to its epoxide in the mouse lung microsomes. Using incubations of mouse lung microsomes, and recombinant CYP2E1 (rat and human), CYP2F2 (mouse), CYP2F3 (goat), and CYP2F4 (rat), they further demonstrated that vinylidene chloride metabolism occurred with different affinities and catalytic efficiencies in different species, suggesting species differences in the severities of toxicities by vinylidene chloride. Recombinant rat CYP2E1 showed greater affinity and efficiency for vinylidene chloride than human CYP2E1, mouse CYP2F2, goat CYP2F3, or rat CYP2F4. 


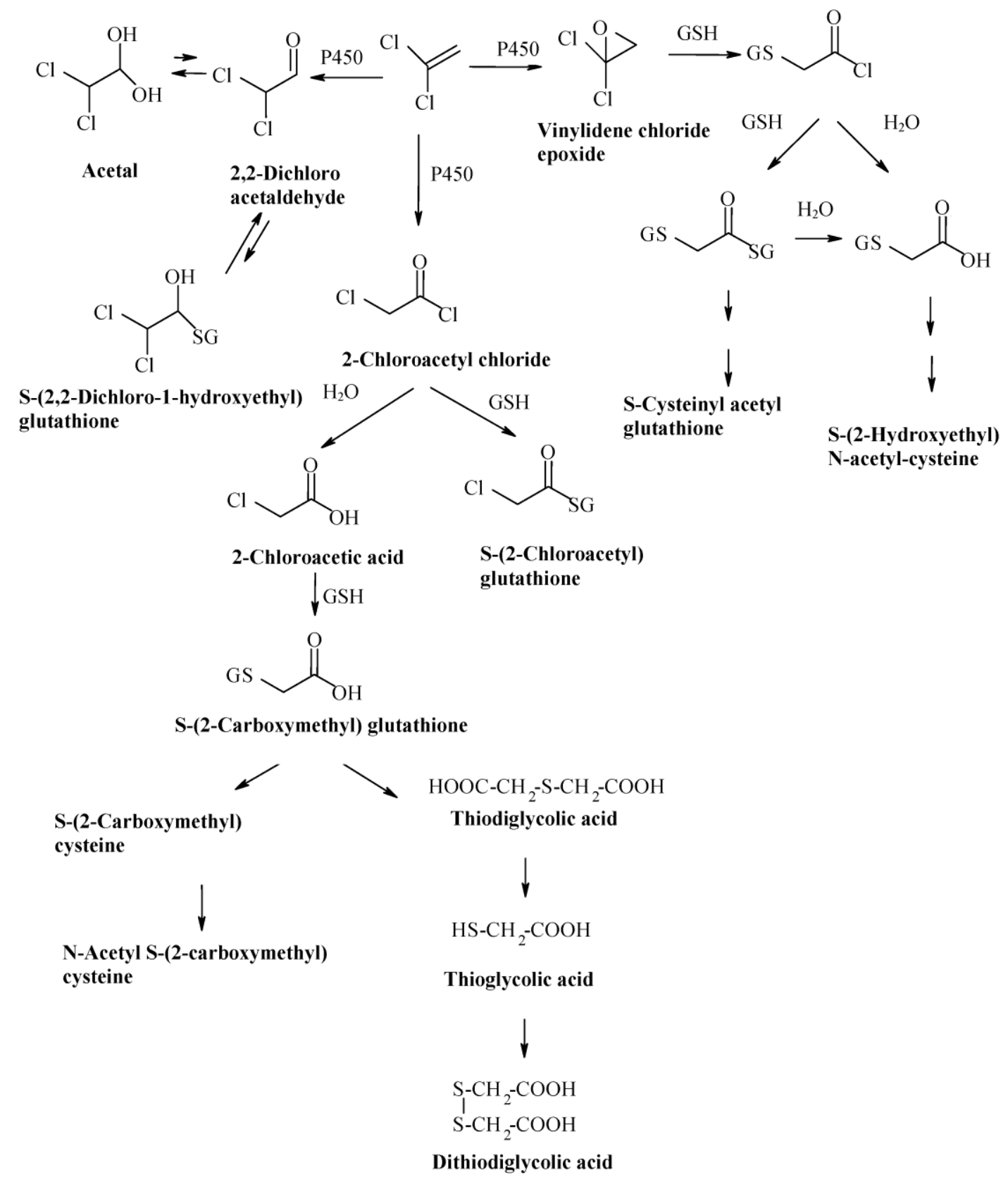

Figure 2. The Proposed Metabolic Pathway of Vinylidene Chloride in Rodents

There are several critical factors that contribute to the metabolism of vinylidene chloride. Glutathione levels and glutathione $S$-transferase activity ${ }^{25 ; 43}$, nutritional status (fasting and nonfasting), and changes in CYP2E1 are important factors. Inducers and inhibitors of CYP2E1 alter metabolic activation of vinylidene chloride to reactive intermediates ${ }^{41 ; 44-46}$. In rodents, vinylidene chloride epoxide and 2-chloroacetylchloride are proposed as the reactive intermediates which are subsequently detoxified via the reaction with glutathione and produced in the liver following exposure. These electrophilic intermediates are also capable of reacting with cellular macromolecules to form adducts in the liver, which may partially explain the observed liver toxicity in rodents. The glutathione conjugates are secreted from the hepatocytes 
and delivered to the kidney where they undergo glomerular filtration ${ }^{47}$. In the kidney, glutathione conjugates may be metabolized to the corresponding cysteine conjugate, which is acetylated and excreted in urine. Alternately, glutathione conjugates can be metabolized by $\beta$-lyase, an enzyme located in the renal proximal tubule, to release an electrophilic product that can subsequently interact with cellular macromolecules in the kidney. This mechanism has been shown to be associated with the observed nephrotoxicity of other halogenated ethylenes and ethanes ${ }^{48}$. It has been shown that fasting significantly reduces detoxification and enhances covalent binding of toxic metabolites in the liver and kidney ${ }^{14 ; 16 ; 17 ; 28 .}$

\section{Humans}

No studies are available for the disposition of vinylidene chloride in humans. In human liver and lung microsomal incubations, epoxide-derived glutathione conjugates were the major metabolites detected along with low levels of 2,2,-dichloroacetaldehyde ${ }^{49}$. Liver microsomes from three out of five human samples metabolized vinylidene chloride to the epoxide-derived glutathione conjugates. Studies using human recombinant enzymes have demonstrated the involvement of CYP2E1 in vinylidene chloride metabolism in humans ${ }^{39}$.

\section{Toxicity}

\section{Experimental Animals}

Vinylidene chloride toxicity, including lethality, varies considerably with species, sex, strain, and nutritional status. Mice are more sensitive than rats to vinylidene chloride toxicity. The oral $\mathrm{LD}_{50}$ ranges from 1,500 to $1,800 \mathrm{mg} / \mathrm{kg}$ in rats ${ }^{50 ; 51}$ compared to 194 to $217 \mathrm{mg} / \mathrm{kg}$ in mice . The $^{24}$ reported values for inhalation $\mathrm{LC}_{50}$ are $6,350 \mathrm{ppm}$ in rats ${ }^{52}$ and 98 to $105 \mathrm{ppm}$ in mice ${ }^{53}$.

A major contributing factor to the variability of vinylidene chloride toxicity involves food intake (fasted/ nonfasted). Lethal inhalation concentrations for fed rats are higher than those in fasted rats $^{28 ; 52 ; 54}$. Vinylidene chloride toxicity is enhanced in fasted animals ${ }^{28 ; 55-57}$ and in glutathionedepleted rats and mice $28 ; 58-61$. Toxicity is decreased when the capacity of P450 metabolic activation is decreased $^{62 ; 63}$.

In short-term studies in laboratory animals, the liver and kidney are the main target organs of

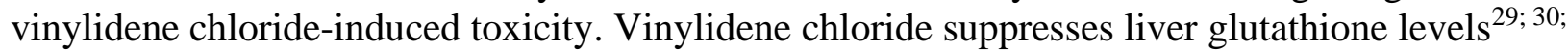
64; 65 and induces hepatotoxicity. Exposure to vinylidene chloride increases serum markers for liver damage and hepatic histopathologic lesions, including hepatocellular degeneration, necrosis, and bile duct hyperplasia ${ }^{30 ; 53 ; 66}$. Exposure to vinylidene chloride increases kidney weights and serum markers for nephrotoxicity and induces histopathologic lesions, including tubular dilation and necrosis in rats ${ }^{66 ; 67}$ and mice ${ }^{53}$. Vinylidene chloride-mediated renal toxicity correlates to metabolic activation by CYP2E1 in the proximal tubules, decreased glutathione concentrations, and increased covalent binding in the kidney. In the kidneys, glutathione conjugates and/or their derivatives may undergo secondary modification by $\beta$-lyase to reactive metabolites ${ }^{68 ; 69}$. In mice, exposure to vinylidene chloride has also been shown to induce morphologic changes in Clara cells, including dilation of cisternae, endoplasmic reticulum degeneration, and cytoplasmic vacuolization ${ }^{70}$.

The National Toxicology Program (NTP) previously conducted 14-day and 13-week subchronic toxicology and 2-year chronic toxicology and carcinogenesis studies for vinylidene chloride 
administered via gavage to $\mathrm{F} 344$ rats and $\mathrm{B} 6 \mathrm{C} 3 \mathrm{~F} 1$ mice $^{71}$. In the 14-day studies, decreased survival was observed at 500 and $1,000 \mathrm{mg} / \mathrm{kg}$ in rats and $500 \mathrm{mg} / \mathrm{kg}$ in mice. Hemorrhagic necrosis in the liver corresponded with increased mortality in both rats and mice. In rats, significantly decreased body weights were also observed at these doses. In the 13-week studies, decreased mean body weights and increased incidences of hepatocytomegaly and hepatic centrilobular necrosis were observed in rats exposed to $250 \mathrm{mg} / \mathrm{kg}$. Hepatocytomegaly with less severity was also observed at $100 \mathrm{mg} / \mathrm{kg}$. In mice, increased mortality in both sexes exposed to $250 \mathrm{mg} / \mathrm{kg}$ was associated with necrosis, hemorrhage, and congestion of the liver. At $100 \mathrm{mg} / \mathrm{kg}$, survival was slightly decreased (8/10 males; $7 / 10$ females) and increased incidences of cellular atypia of the liver were observed in males and females. A dose-dependent decrease in mean body weight gain was observed in male mice.

\section{Humans}

In humans, vinylidene chloride is an irritant and a central nervous system depressant, and it induces toxicity in liver, lung, and kidney ${ }^{4 ; 10}$. The irritant properties have been attributed to the polymerization inhibitor $\mathrm{MEHQ}^{3 ; 10}$.

\section{Reproductive and Developmental Toxicity}

In studies assessing reproduction, exposure to vinylidene chloride via inhalation or drinking water had no effects on reproduction in male mice or in either sex of rats ${ }^{72-74}$. No evidence of maternal toxicity or teratogenic effects was observed in rats exposed to $200 \mathrm{ppm}$ vinylidene chloride on gestation days 6 to 15 in the drinking water ${ }^{75}$. In inhalation studies, maternal toxicity was observed at $15 \mathrm{ppm}$ or greater in CD-1 rats, $30 \mathrm{ppm}$ or greater in CD-1 mice, $80 \mathrm{ppm}$ or greater in Sprague Dawley rats, and $160 \mathrm{ppm}$ or greater in New Zealand white rabbits ${ }^{44 ; 75}$. In these studies, inhalation exposure to vinylidene chloride during gestation clearly induced embryo- and fetotoxicity at concentrations that induced maternal toxicity. In CD-1 mice, fetal toxicity in the absence of significant maternal toxicity was observed at $15 \mathrm{ppm}$ vinylidene chloride. In this study, there was an increase in fetuses with an unossified incus, incompletely ossified sternebrae, hydrocephalus, occluded nasal passages, microphthalmia, cleft palate, small liver, and hydronephrosis.

\section{Carcinogenicity}

\section{Experimental Animals}

The chronic toxicity and carcinogenicity of vinylidene chloride in rats and mice have been investigated in eight rat and three mouse inhalation studies and five rat and one mouse oral studies $^{6 ; 11 ; 51 ; 71 ; 76-80}$. Overall, none of the results from these studies demonstrate a significant increase in neoplasms following exposure to vinylidene chloride. Despite this broad database of research from other published studies, these studies are insufficient for determining the carcinogenic risk. Problems associated with the results from these studies include the lack of statistical analysis, inadequate control of dosing or exposure, changing or discontinuing dosing or exposure levels during the study, excessive mortality, inadequate study duration or overall study design, and a lack of dose response. 
In the previous $\mathrm{NTP}^{71}$ studies, no significant effects were observed on survival, clinical signs, or body weights in rats or mice administered vinylidene chloride by gavage. When rats were administered 1 or $5 \mathrm{mg} / \mathrm{kg}$, the incidence of chronic inflammation of the kidney was higher in $5 \mathrm{mg} / \mathrm{kg}$ males than in the vehicle controls. There was no increased incidence of neoplasms at any site in rats administered vinylidene chloride. When mice were administered 2 or $10 \mathrm{mg} / \mathrm{kg}$, a significant increase in the incidence of lymphoma or leukemia at $2 \mathrm{mg} / \mathrm{kg}$ that was not observed at $10 \mathrm{mg} / \mathrm{kg}$ was not considered to be related to vinylidene chloride administration in females. There was no increased incidence of neoplasms at any other site in male or female mice administered vinylidene chloride.

\section{Humans}

Major limitations in the two cohort studies conducted in vinylidene chloride-exposed workers restrict the value of the results. No specific association has been found between exposure to vinylidene chloride in a synthetic chemical plant and excess cancer ${ }^{3}$.

\section{Genetic Toxicity}

The literature suggests that vinylidene chloride, which is a gas at temperatures above $31.7^{\circ} \mathrm{C}$, demonstrates consistent mutagenic activity in vitro when tests are conducted with an exogenous metabolic activation system. No evidence of genotoxicity was seen in the few in vivo assays that were reported for vinylidene chloride.

Increases in mutant colonies were observed in Salmonella typhimurium strains TA100 and TA1530 following exposure to vinylidene chloride concentrations of $0.2 \%, 2 \%$, and $20 \%$ in air $(\mathrm{v} / \mathrm{v})$ in the closed environment of a desiccator in the presence of noninduced rat or mouse liver microsomal mix (S9) ${ }^{81}$; mutagenicity was greater in the presence of mouse S9. Mouse kidney and lung S9 fractions were also effective at producing mutagenic metabolites of vinylidene chloride in strain TA100, although the responses were lower than those observed with liver S9 activation $^{81}$. Strongly positive results were also observed in S. typhimurium strains TA92, TA98, TA100, and TA1537 and Escherichia coli strain WP2 uvrA exposed to vinylidene chloride (375 to $22,500 \mathrm{ppm}$ ) in the presence of noninduced mouse liver S9 in a sealed desiccator ${ }^{82}$. In this study, the effectiveness of vinylidene chloride-induced mouse liver S9 and rat liver S9 was examined, and no additional increase in mutagenicity was observed compared with use of the noninduced S9.

Other studies of the effect of S9 preparation from different species on the mutagenicity of vinylidene chloride (5\% in air, sealed culture system) in S. typhimurium strain TA1535 demonstrated that pretreatment with Aroclor 1254 increased the effectiveness of mouse liver and kidney S9, and that induced mouse liver S9 was more effective than induced rat liver S9 at generating mutagenic metabolites of vinylidene chloride ${ }^{83}$.

Vinylidene chloride (3\%) has also been used as a positive control for strains TA100 and TA1530 in experiments conducted in a closed environment, in the presence of metabolic activation, with gaseous test agents ${ }^{84}$. The need to control for volatility is demonstrated by the failure of vinylidene chloride (tested up to $6,667 \mu \mathrm{g} / \mathrm{mL}$ ) to induce revertants in S. typhimurium strains TA98, TA100, TA1535, or TA1537, with or without S9, when a preincubation protocol was employed $^{85}$. 
Consistent with the other studies in bacteria, vinylidene chloride $(2.5 \mathrm{mM})$ induced a mutagenic response in $E$. coli $\mathrm{K}-12$ in the presence, but not the absence, of mouse $\mathrm{S} 9^{86 ; 87}$.

In yeast test systems, vinylidene chloride was shown to be toxic but not mutagenic in the diploid Saccharomyces cerevisiae strain D7 in the absence of S9 ${ }^{88}$. However, in the presence of Aroclor 1254-induced mouse liver S9, dose-related increases in both point mutations and mitotic gene conversions were seen in strain D7 at doses above $20 \mathrm{mM}^{88 ; 89}$. Significant increases in mitotic gene conversion were also seen in logarithmic phase $S$. cerevisiae D7 cells with a high level of cytochrome P450 that provided for metabolic activation of vinylidene chloride ${ }^{88}$. Vinylidene chloride induced a highly significant, dose-related increase in aneuploidy in $S$. cerevisiae strain D61.M, with and without $S 9^{88}$.

Inconsistent mutagenic responses were seen in L5178Y mouse lymphoma $t k^{+/-}$cells with vinylidene chloride in the absence of metabolic activation; with activation, both cytotoxicity and mutagenicity were consistently positive at concentrations of $0.16 \%$ and above in repeat experiments $^{90}$. Concentrations of $2 \%$ or $10 \%$ vinylidene chloride by air (5-hour exposure) with or without S9 mix did not increase resistance to ovabain (membrane sodium-potassium ATPase locus) or $\gamma$-azocytidine (HGPRT locus) in Chinese hamster V9 cells ${ }^{91}$.

Dose-related increases in chromosomal aberrations were seen in cultured Chinese hamster lung cells exposed to vinylidene chloride over a concentration range of 0.125 to $1.5 \mathrm{mg} / \mathrm{mL}$ in the presence of $15 \%$ PCB-induced male F344 rat liver $\mathrm{S} 9^{92}$. In addition, sister chromatid exchanges were increased in these same cells when treatment was carried out in the presence of S9.

Limited evidence of genotoxicity was seen with vinylidene chloride in vivo. Bone marrow micronucleus tests in ddY male mice following single ( 25 to $200 \mathrm{mg} / \mathrm{kg}$ ) or multiple ( 25 to $100 \mathrm{mg} / \mathrm{kg}$ ) daily gavage treatments with vinylidene chloride were negative, and no increases in micronucleated cells of fetal liver or fetal blood were seen 24 hours after a single intraperitoneal injection ( 25 to $100 \mathrm{mg} / \mathrm{kg}$ ) administered to pregnant ICR mice on gestational day $18^{92}$. Negative results were also reported in dominant lethal tests (germ cell mutagenicity assays) in male CD-1 mice treated with 3,000 to 30,000 ppm vinylidene chloride 6 hours/day for 5 days followed by mating $^{72}$, and male CD rats exposed to $55 \mathrm{ppm}$ vinylidene chloride for at least 11 weeks prior to mating ${ }^{73}$. However, evidence of vinylidene chloride interaction with DNA was seen in one study in which alkylated DNA was recovered from the livers and kidneys of mice and rats exposed to radiolabeled vinylidene chloride (10 or $50 \mathrm{ppm}$ for 6 hours), although the number of alkylated nucleotides recovered was very low compared to those recovered after intraperitoneal dosing with $10 \mathrm{mg} / \mathrm{kg}$ of the potent alkylating agent dimethylnitrosamine ${ }^{93}$.

\section{Study Rationale}

The toxicology and carcinogenicity of inhaled vinylidene chloride were investigated based on insufficient critical information concerning its health effects and the need to fill critical data gaps. Previously conducted $\mathrm{NTP}^{71}$ studies were considered insufficient to evaluate carcinogenicity because selected doses failed to include a maximum tolerated dose. The conclusion of those studies was that the lack of carcinogenicity observed should not be taken as proof that vinylidene chloride was not a carcinogen. 


\section{Materials and Methods}

\section{Procurement and Characterization}

\section{Vinylidene Chloride}

Vinylidene chloride, manufactured by Dow Chemical Company (Freeport, TX), was obtained in one lot from Sigma-Aldrich and was used in the 2-week, 3-month, and 2-year studies. The material was identified as lot SB20019301. Identity and purity analyses were conducted by the analytical chemistry laboratory at Chemir Pharma Services (Maryland Heights, MO) and the study laboratory at Battelle Toxicology Northwest (Richland, WA) (Appendix I). Reports on analyses performed in support of the vinylidene chloride studies are on file at the National Institute of Environmental Health Sciences.

The chemical, a colorless, low viscosity liquid with a sweet odor, was identified as vinylidene chloride by infrared and proton nuclear magnetic resonance spectroscopy. Purity of lot SB20019301 was determined by elemental analyses, Karl Fisher titration, anion exchange chromatography, a potassium iodide (KI) titration, a turbidity assay, and gas chromatography with flame ionization detection (GC/FID). Elemental analyses for carbon and hydrogen were consistent with theoretical values for vinylidene chloride. Karl Fischer titration indicated a water content of $74 \mathrm{ppm}$. KI titration indicated that peroxide was less than $1 \mathrm{ppm}$ by weight as active oxygen compared to vinylidene chloride. Anion exchange chromatography indicated that residual chloride content was less than $2 \mathrm{ppm}$. The turbidity assay showed that the concentration of polymer was less than $9 \mathrm{ppm}$. GC/FID indicated that the test article was stabilized with approximately 300 ppm monomethyl ether hydroquinone (MEHQ). Purity analysis by GC/FID indicated the overall purity of lot SB20019301 was greater than $99.9 \%$.

To ensure stability, the bulk chemical was stored under a nitrogen headspace in the original shipping containers (400-L steel mini-Bulk ${ }^{\mathrm{TM}}$ containers) at a temperature of approximately $63^{\circ} \mathrm{F}$. Periodic reanalyses of the bulk chemical were performed during the 2-week, 3-month, and 2-year studies by the study laboratory using the same turbidity and GC/FID assays used in the initial bulk chemical purity assays, and no degradation of the bulk chemical was detected.

\section{Vapor Generation and Exposure System}

Vinylidene chloride was pumped from a disposable 4 liter amber glass generator reservoir into a heated glass flask. Nitrogen entered the flask and assisted in vaporizing the chemical while conveying it from the generator into a short vapor distribution manifold. Concentration in the manifold was determined by the chemical pump and nitrogen flow rates. Pressure in the distribution manifold was kept fixed to ensure constant flows through the manifold and into all chambers as the flow of vapor to each chamber was adjusted.

Individual Teflon ${ }^{\circledR}$ delivery lines carried the vapor from the manifold to three-way exposure valves at the chamber inlets. The exposure valves diverted vapor delivery to the exposure chamber exhaust until the generation system stabilized and exposure could proceed. The flow rate to each chamber was controlled by a metering valve at the manifold. To initiate exposure, the chamber exposure valves were rotated to allow the vinylidene chloride vapor to flow to each 
exposure chamber inlet duct where it was diluted with conditioned chamber air to achieve the desired exposure concentration.

The study laboratory designed the inhalation exposure chamber so that uniform vapor concentrations could be maintained throughout the chamber with the catch pans in place. The total active mixing volume of each chamber was $1.7 \mathrm{~m}^{3}$. A small particle detector was used with and without animals in the exposure chambers to ensure that vinylidene chloride vapor, and not aerosol, was produced. No particle counts above the minimum resolvable level (approximately 200 particles $/ \mathrm{cm}^{3}$ ) were detected.

\section{Vapor Concentration Monitoring}

Chamber and room concentrations of vinylidene chloride were monitored by an on-line gas chromatograph. Samples were drawn from each exposure chamber approximately three times (2week and 3-month studies) or twice (2-year studies) per hour during each 6-hour exposure period using Hastelloy ${ }^{\circledR}$-C stream-select and gas-sampling valves in a separate, heated oven. The sample lines composing each sample loop were made from Teflon ${ }^{\circledR}$ tubing and were connected to the exposure chamber relative humidity sampling lines at a location close to the gas chromatograph. A vacuum regulator maintained a constant vacuum in the sample loop to compensate for variations in sample line pressure. An in-line flow meter between the vacuum regulator and the gas chromatograph allowed digital measurement of sample flow.

The on-line gas chromatograph was checked throughout each exposure day for instrument drift against an on-line standard vapor of methylene chloride in nitrogen supplied by a standard generator. The on-line gas chromatograph was recalibrated as required to meet acceptance criteria. Calibration was performed by a comparison of chamber concentration data to data from grab samples collected with activated coconut charcoal gas-sampling tubes, extracted with toluene containing an internal standard of methylene chloride and analyzed using an off-line gas chromatograph equipped with an electron capture detector. Known volumes of chamber atmosphere were sampled at a constant flow rate ensured by a calibrated critical orifice. The offline gas chromatograph was calibrated with gravimetrically prepared standard solutions of the test chemical containing methylene chloride as an internal standard in toluene.

\section{Chamber Atmosphere Characterization}

Buildup and decay rates for chamber vapor concentrations were determined with (all studies) and without (3-month and 2-year studies) animals present in the chambers. At a chamber airflow rate of 15 air changes per hour, the theoretical value for the time to achieve $90 \%$ of the target concentration after the beginning of vapor generation $\left(\mathrm{T}_{90}\right)$ and the time for the chamber concentration to decay to $10 \%$ of the target concentration after vapor generation was terminated $\left(\mathrm{T}_{10}\right)$ was approximately 9.4 minutes. Based on experimental data, a $\mathrm{T}_{90}$ value of 12 minutes was selected for the 2-week studies and a $\mathrm{T}_{90}$ value of 10 minutes was selected for the 3-month and 2year studies.

The uniformity of vinylidene chloride vapor concentration in the inhalation exposure chambers without animals present was evaluated before the 3-month and 2-year studies began; in addition, concentration uniformity with animals present in the chambers was measured once during the 2week studies, once during the 3-month studies, and approximately quarterly during the 2-year 
studies. The vapor concentration was measured using the on-line gas chromatograph. Chamber concentration uniformity was maintained throughout the studies.

The persistence of vinylidene chloride in the chambers after vapor delivery ended was determined by monitor-ing the vapor concentration in the 400 ppm chambers in the 2-week studies, the $100 \mathrm{ppm}$ chambers in the 3 -month studies, and the $100 \mathrm{ppm}$ rat and $25 \mathrm{ppm}$ mouse chambers in the 2-year studies with (all studies) and without (3-month and 2-year studies) animals present in the chambers. In the 2 -week studies, the concentration decreased to $1 \%$ of the target concentration within 21 minutes with animals present. In the 3-month studies, the concentration decreased to $1 \%$ of the target concentration within 21 minutes without animals present and within 23 minutes with animals present. For the 2-year rat studies, the concentration decreased to $1 \%$ of the target concentration within 22 minutes with and without animals present; for mice, the concentration decreased to $1 \%$ of the target concentration within 18 minutes without animals present and within 21 minutes with animals present.

Samples of the test atmosphere from the distribution lines and the low and high exposure concentration chambers for each species were collected prior to the study without animals present (3-month and 2-year studies) and at the beginning and end of one generation day with animals present during the 2-week, 3-month, and 2-year studies. Additional samples were collected from the generator reservoir, and all of the samples were analyzed using GC/FID to measure the stability and purity of vinylidene chloride in the generation and delivery system. To assess whether impurities or degradation products co-eluted with vinylidene chloride or the solvent, a second GC/FID analysis of the samples was performed using a polar column capable of resolving compounds with similar boiling points and polarities. Separate atmosphere samples were collected in these studies using toluene bubblers; MEHQ inhibitor was assayed in these distribution line samples using GC/FID, and peroxide was assayed in these distribution line and low (except 2-week studies) and high exposure concentration chamber samples by KI titration. Hydrochloric acid, formaldehyde, and phosgene concentrations were measured in atmosphere samples collected during the last 2 hours of a 6-hour generation day. Fourier transform IR spectroscopy was used to measure the presence of HCL in samples collected prior to the 3-month studies and during the 2-week, 3-month, and 2-year studies. Formaldehyde and phosgene were measured in atmosphere samples collected on silica adsorbent sampling tubes coated with 2,4dinitrophenyl-hydrazine prior to the 3-month and 2-year studies and during the 2-week, 3-month, and 2-year studies. These samples were analyzed using a liquid chromatography procedure. Samples were collected from the generator reservoir 3 to 14 days after the reservoir was placed in use in studies conducted without animals present prior to the 3-month and 2-year studies and at the same timepoints during the 2-week, 3-month, and 2-year studies. These samples were analyzed for area percent purity, polymer formation, peroxide content, and MEHQ concentration using the same methodologies employed for the initial bulk chemical characterization assays.

No evidence of degradation of vinylidene chloride was noted in any part of the exposure system in any of the samples collected prior to the 3-month and 2-year studies or during the 2-week, 3month, and 2-year studies. No impurity peaks with areas greater than $0.1 \%$ of the total peak area were detected in atmosphere or generator reservoir samples, and no additional impurities were found in any of the atmosphere or reservoir samples using the polar column. HCL concentrations in the atmosphere samples were consistently less than the detection limit. Formaldehyde and phosgene concentrations were less than $0.1 \%$ by weight compared to vinylidene chloride in all distribution line and chamber atmosphere samples. Acceptable, low concentrations of peroxide 
as active oxygen relative to vinylidene chloride were found in all atmosphere samples. All distribution line samples contained concentrations within the acceptable range for the inhibitor MEHQ relative to vinylidene chloride. No evidence of degradation, peroxide formation, or polymer formation was noted in any samples taken from the generator reservoir after multiple days of use.

\section{Animal Source}

Male and female F344/N rats were obtained from the commercial colony at Taconic Farms, Inc. (Germantown, NY), and B6C3F1/N mice were obtained from the NTP colony maintained at Taconic Farms, Inc., for the 2-week, 3-month, and 2-year studies.

\section{Animal Welfare}

Animal care and use are in accordance with the Public Health Service Policy on Humane Care and Use of Animals. All animal studies were conducted in an animal facility accredited by the Association for the Assessment and Accreditation of Laboratory Animal Care International. Studies were approved by the Battelle Toxicology Northwest Animal Care and Use Committee and conducted in accordance with all relevant NIH and NTP animal care and use policies and applicable federal, state, and local regulations and guidelines.

\section{Two-week Studies}

On receipt, the rats and mice were 4 to 5 weeks old. Animals were quarantined for 11 days and were 5 to 6 weeks old on the first day of the studies. Before the studies began, five male and five female rats and mice were randomly selected for parasite evaluation and gross observation for evidence of disease. At the end of the studies, serologic analyses were performed on five male and five female chamber control rats and mice using the protocols of the NTP Sentinel Animal Program (Appendix K).

Groups of five male and five female rats and mice were exposed by whole body inhalation to vinylidene chloride vapor at concentrations of 0,25, 50,100, 200, or 400 ppm, 6 hours plus T90 (12 minutes) per day, 5 days per week for 16 (rats) or 17 (mice) days. These wide-ranging exposure concentrations were selected based on reports in the literature that indicated significant differences in species- and strain-related sensitivity to the toxicity of vinylidene chloride. Feed was available ad libitum except during exposure periods; water was available ad libitum. Rats and mice were housed individually. Clinical findings were recorded daily before and after exposure and at the end of the studies. The animals were weighed initially, on days 6 and 13, and at the end of the studies. Details of the study design and animal maintenance are summarized in Table 1 .

At the end of the 2-week studies, necropsies were performed on all rats and mice. The heart, right kidney, liver, lung, right testis, and thymus were weighed. Histopathologic examinations were performed on $0,100,200$, and $400 \mathrm{ppm}$ rats and 0, 50, 100, 200, and $400 \mathrm{ppm}$ mice; the eyes, kidney (except 50 ppm female mice), liver, lung, and nose were examined. Table 1 lists the tissues and organs examined. 


\section{Three-month Studies}

The 3-month studies were conducted to evaluate the cumulative toxic effects of repeated exposure to vinylidene chloride and to determine the appropriate exposure concentrations to be used in the 2-year studies.

On receipt, the rats were 4 weeks old, and the mice were 4 or 5 weeks old. Animals were quarantined for 12 or 13 days and were 5 to 7 weeks old on the first day of the studies. Before the studies began, five male and five female rats and mice were randomly selected for parasite evaluation and gross observation for evidence of disease. During week 2 and at the end of the studies, serologic analyses were performed on five male and five female sentinel rats and mice using the protocols of the NTP Sentinel Animal Program (Appendix K).

Groups of 10 male and 10 female rats and mice were exposed by whole body inhalation to vinylidene chloride vapor at concentrations of $0,6.25,12.5,25,50$, or 100 (rats and female mice) ppm, 6 hours plus T90 (10 minutes) per day, 5 days per week for 14 weeks. Groups of 10 male and 10 female clinical pathology rats were exposed to the same concentrations for 23 days. Feed was available ad libitum except during exposure periods; water was available ad libitum. Rats and mice were housed individually. Clinical findings were recorded on day 9 (female rats) or day 10, weekly thereafter, and at the end of the studies. The animals were weighed initially, day 9 (female rats) or day 10, weekly thereafter, and at the end of the studies. Details of the study design and animal maintenance are summarized in Table 1.

Blood was collected from the retroorbital sinus of clinical pathology rats on days 3 and 23 and from core study rats and mice at the end of the studies for hematology and clinical chemistry (rats only) analyses. For the hematology samples, blood was collected in a tube (Vacutainer, Becton Dickinson; Franklin Lakes, NJ) containing potassium-EDTA; for the clinical chemistry samples, the blood was collected in a tube devoid of anticoagulant but containing a separator gel for serum. An Abbott Cell-Dyn 3700 (Abbott Diagnostics Systems, Abbott Park, IL) was used to determine packed cell volume; hemoglobin concentration; erythrocyte, platelet, and leukocyte counts; mean cell volume; mean cell hemoglobin; and mean cell hemoglobin concentration. Manual hematocrit values were determined using a microcentrifuge (Heraeus haemofuge, Germany) and a Damon/IEC capillary reader (International Equipment Company, Needham Heights, MA) for comparison to Cell-Dyn values for packed cell volume. Leukocyte, erythrocyte, and platelet morphology were assessed on blood smears stained with Romanowskytype aqueous stain in a Wescor 7100 slide stainer (Wescor, Inc., Logan UT), and when observed, nucleated erythrocytes were counted per 100 leukocytes from the same stained blood smear. Reticulocytes were stained supravitally with new methylene blue and enumerated as reticulocytes per 1,000 erythrocytes using the Miller disc method ${ }^{94}$. Howell-Jolly bodies were counted per 1,000 erythrocytes. For clinical chemistry analyses, serum samples were analyzed using a Roche Hitachi 912 System (Roche Diagnostic Corporation, Indianapolis, IN). The hematology and clinical chemistry parameters measured are listed in Table 1.

At the end of the 3-month studies, samples were collected for sperm motility and vaginal cytology evaluations on rats exposed to $0,25,50$, or $100 \mathrm{ppm}$ and mice exposed to $0,12.5,25$, or $50 \mathrm{ppm}$. The parameters evaluated are listed in Table 1. For 12 consecutive days prior to scheduled terminal kill, the vaginal vaults of the females were moistened with saline, if necessary, and samples of vaginal fluid and cells were stained.Relative numbers of leukocytes, 
nucleated epithelial cells, and large squamous epithelial cells were determined and used to ascertain estrous cycle stage (i.e., diestrus, proestrus, estrus, and metestrus). Male animals were evaluated for sperm count and motility. The left testis and left epididymis were isolated and weighed. The tail of the epididymis (cauda epididymis) was then removed from the epididymal body (corpus epididymis) and weighed. Test yolk (rats) or modified Tyrode's buffer (mice) was applied to slides and a small incision was made at the distal border of the cauda epididymis. The sperm effluxing from the incision were dispersed in the buffer on the slides, and the numbers of motile and nonmotile spermatozoa were counted for five fields per slide by two observers. Following completion of sperm motility estimates, each left cauda epididymis was placed in buffered saline solution. Caudae were finely minced, and the tissue was incubated in the saline solution and then heat fixed at $65^{\circ} \mathrm{C}$. Sperm density was then determined microscopically with the aid of a hemacytometer. To quantify spermatogenesis, the testicular spermatid head count was determined by removing the tunica albuginea and homogenizing the left testis in phosphatebuffered saline containing 10\% dimethyl sulfoxide. Homogenization-resistant spermatid nuclei were counted with a hemacytometer.

Necropsies were performed on all core study animals. The heart, right kidney, liver, lungs, right testis, and thymus were weighed. Tissues for microscopic examination were fixed and preserved in $10 \%$ neutral buffered formalin (except eyes were first fixed in Davidson's solution), processed and trimmed, embedded in paraffin, sectioned to a thickness of 4 to $6 \mu \mathrm{m}$, and stained with hematoxylin and eosin. Complete histopathologic examinations were performed by the study laboratory pathologist on 0 and $100 \mathrm{ppm}$ core study rats and 0, 50 (male), and 100 (female) ppm mice. Table 1 lists the tissues and organs routinely examined.

After a review of the laboratory reports and selected histopathology slides by a quality assessment (QA) pathologist, the findings and reviewed slides were submitted to a NTP Pathology Working Group (PWG) coordinator for a second independent review. Any inconsistencies in the diagnoses made by the study laboratory and QA pathologists were resolved by the NTP pathology peer review process. Final diagnoses for reviewed lesions represent a consensus of the PWG or a consensus between the study laboratory pathologist, NTP pathologist, QA pathologist(s), and the PWG coordinator. Details of these review procedures have been described, in part, by Maronpot and Boorman ${ }^{95}$ and Boorman et al. ${ }^{96}$.

\section{Two-year Studies}

\section{Study Design}

Groups of 50 male and 50 female rats and mice were exposed by whole body inhalation to vinylidene chloride vapor at concentrations of $0,25,50$, or 100 (rats) or $0,6.25,12.5$, or 25 (mice) ppm, 6 hours plus $\mathrm{T}_{90}(10$ minutes $)$ per day, 5 days per week for 105 weeks.

Rats and mice were quarantined for 12 days before the beginning of the studies. Five male and five female rats and mice were randomly selected for parasite evaluation and gross observation of disease. Rats and mice were 5 to 6 weeks old at the beginning of the studies. The health of the animals was monitored during the studies according to the protocols of the NTP Sentinel Animal Program (Appendix K). 
Rats and mice were housed individually. Feed was available ad libitum except during exposure periods; water was available ad libitum. Chambers and racks were rotated weekly. Further details of animal maintenance are given in Table 1. Information on feed composition and contaminants is provided in Appendix $\mathbf{J}$.

\section{Clinical Examinations and Pathology}

All animals were observed twice daily. Body weights were recorded on day 1 , weekly for the first 13 weeks, every 4 weeks through week 93, every 2 weeks thereafter, and at terminal kill. Clinical findings were recorded every 4 weeks through week 93, then every 2 weeks, and at terminal kill.

Complete necropsies and microscopic examinations were performed on all core study rats and mice. At necropsy, all organs and tissues were examined for grossly visible lesions, and all major tissues were fixed and preserved in $10 \%$ neutral buffered formalin (except eyes were first fixed in Davidson's Solution), processed and trimmed, embedded in paraffin, sectioned to a thickness of 4 to $6 \mu \mathrm{m}$, and stained with hematoxylin and eosin for microscopic examination. For all paired organs (e.g., adrenal gland, kidney, ovary), samples from each organ were examined. For extended evaluation of renal proliferative lesions, kidneys were step sectioned at $1 \mathrm{~mm}$ intervals from the residual cross sectional half of the right kidney and the longitudinal half of the left kidney of male rats, and four additional sections were obtained from each kidney. Tissues examined microscopically are listed in Table 1. Samples of tumor tissues collected at necropsy for molecular analysis (mesotheliomas) were flash frozen in liquid nitrogen and stored at $-80^{\circ} \mathrm{C}$ (Appendix L).

Microscopic evaluations were completed by the study laboratory pathologist, and the pathology data were entered into the Toxicology Data Management System. The report, slides, paraffin blocks, residual wet tissues, and pathology data were sent to the NTP Archives for inventory, slide/block match, wet tissue audit, and storage. The slides, individual animal data records, and pathology tables were evaluated by an independent quality assessment laboratory. The individual animal records and tables were compared for accuracy, the slide and tissue counts were verified, and the histotechnique was evaluated. For the 2-year studies, a quality assessment pathologist evaluated slides from all tumors and all potential target organs, which included the nose of rats and mice, the kidney of male rats and male and female mice, and the liver of rats.

The quality assessment report and the reviewed slides were submitted to the NTP PWG coordinator, who reviewed the selected tissues and addressed any inconsistencies in the diagnoses made by the laboratory and quality assessment pathologists. Representative histopathology slides containing examples of lesions related to chemical administration, examples of disagreements in diagnoses between the laboratory and quality assessment pathologists, or lesions of general interest were presented by the coordinator to the PWG for review. The PWG consisted of the quality assessment pathologist and other pathologists experienced in rodent toxicologic pathology. This group examined the tissues without any knowledge of dose groups. When the PWG consensus differed from the opinion of the laboratory pathologist, the diagnosis was changed. Final diagnoses for reviewed lesions represent a consensus between the laboratory pathologist, reviewing pathologist(s), and the PWG. Details of these review procedures have been described, in part, by Maronpot and Boorman ${ }^{95}$ and Boorman et al. ${ }^{96}$. For subsequent analyses of the pathology data, the decision of whether to evaluate the 
diagnosed lesions for each tissue type separately or combined was generally based on the guidelines of McConnell et al. ${ }^{97}$.

Table 1. Experimental Design and Materials and Methods in the Inhalation Studies of Vinylidene Chloride

\begin{tabular}{lll}
\hline Two-week Studies & Three-month Studies & Two-year Studies
\end{tabular}

\section{Study Laboratory}

Battelle Toxicology Northwest

(Richland, WA)

Battelle Toxicology Northwest

(Richland, WA)

\section{Strain and Species}

F344/N rats

$\mathrm{B} 6 \mathrm{C} 3 \mathrm{~F} 1 / \mathrm{N}$ mice

$\mathrm{F} 344 / \mathrm{N}$ rats

$\mathrm{B} 6 \mathrm{C} 3 \mathrm{~F} 1 / \mathrm{N}$ mice

Animal Source

Taconic Farms, Inc. (Germantown, Taconic Farms, Inc. (Germantown, NY) NY)

Taconic Farms, Inc. (Germantown,

\section{Time Held Before Studies}

11 days

\section{Age When Studies Began}

5 to 6 weeks

Rats: 5 to 7 weeks

Mice: 5 to 6 weeks

Rats: 12 (males) or 13 (females) days 12 days

Mice: 12 days

\section{Date of First Exposure}

June 14, 2004

Rats: October 11 (males) or 12

(females), 2004

Mice: October 11, 2004

\section{Duration of Exposure}

6 hours plus $\mathrm{T}_{90}$ (12 minutes) per day, 5 days per week for 16 (rats) or 17 (mice) days

6 hours plus $\mathrm{T}_{90}$ (10 minutes) per day, 5 days per week, for 14 weeks

6 hours plus $\mathrm{T}_{90}$ (10 minutes) per day, 5 days per week, for 105 weeks

\section{Date of Last Exposure}

Rats: June 29, 2004

Mice: June 30, 2004

\section{Necropsy Dates}

Rats: June 30, 2004

Mice: July 1, 2004

\section{Age at Necropsy}

8 to 9 weeks
Rats: January 10 (males) or 11 (females), 2005

Mice: January 12 (males) or 13

(females), 2005

Rats: January 11 (males) or 12 (females), 2005

Mice: January 13 (males) or 14

(females), 2005 NY)

Battelle Toxicology Northwest

(Richland, WA)

$\mathrm{F} 344 / \mathrm{N}$ rats

B6C3F1/N mice

Rats: 5 to 6 weeks

Mice: 5 to 6 weeks

Rats: June 6, 2005

Mice: June 20, 2005

Rats: June 7, 2007

Mice: June 21, 2007

Rats: June 4-8, 2007

Mice: June 18-22, 2007
109 to 111 weeks 
Vinylidene Chloride, NTP TR 582

\begin{tabular}{|c|c|c|}
\hline Two-week Studies & Three-month Studies & Two-year Studies \\
\hline \multicolumn{3}{|l|}{ Size of Study Groups } \\
\hline 5 males and 5 females & 10 males and 10 females & 50 males and 50 females \\
\hline \multicolumn{3}{|l|}{ Method of Distribution } \\
\hline $\begin{array}{l}\text { Animals were distributed } \\
\text { randomly into groups of } \\
\text { approximately equal initial mean } \\
\text { body weights. }\end{array}$ & Same as 2-week studies & Same as 2-week studies \\
\hline \multicolumn{3}{|l|}{ Animals per Cage } \\
\hline 1 & 1 & 1 \\
\hline \multicolumn{3}{|l|}{ Method of Animal Identification } \\
\hline Tail tattoo & Tail tattoo & Tail tattoo \\
\hline \multicolumn{3}{|l|}{ Diet } \\
\hline $\begin{array}{l}\text { Irradiated NTP-2000 open formula } \\
\text { wafers (Zeigler Brothers, Inc., } \\
\text { Gardners, PA), available ad } \\
\text { libitum except during exposure } \\
\text { periods, changed weekly }\end{array}$ & Same as 2-week studies & Same as 2-week studies \\
\hline \multicolumn{3}{|l|}{ Water } \\
\hline $\begin{array}{l}\text { Tap water (Richland, WA, } \\
\text { municipal supply) via automatic } \\
\text { watering system (Edstrom } \\
\text { Industries, Waterford, MI), } \\
\text { available ad libitum }\end{array}$ & Same as 2-week studies & Same as 2-week studies \\
\hline \multicolumn{3}{|l|}{ Cages } \\
\hline $\begin{array}{l}\text { Stainless steel wire-bottom (Lab } \\
\text { Products, Inc., Seaford. DE), } \\
\text { changed weekly with chambers, } \\
\text { rotated daily in chambers }\end{array}$ & $\begin{array}{l}\text { Same as } 2 \text {-week studies, except } \\
\text { rotated weekly in chambers }\end{array}$ & Same as 3-month studies \\
\hline \multicolumn{3}{|l|}{ Cageboard } \\
\hline $\begin{array}{l}\text { Untreated paper cage pan liner } \\
\text { (Techboard, Shepherd Specialty } \\
\text { Papers, Kalamazoo, MI), changed } \\
\text { daily }\end{array}$ & Same as 2-week studies & Same as 3-month studies \\
\hline \multicolumn{3}{|l|}{ Chamber Air Supply Filters } \\
\hline $\begin{array}{l}\text { Single HEPA (open stock), } \\
\text { charcoal (RSE, Inc., New } \\
\text { Baltimore, MI), Purafil } \\
\text { (Environmental Systems, } \\
\text { Lynnwood, WA), all new at study } \\
\text { start }\end{array}$ & Same as 2-week studies & $\begin{array}{l}\text { Same as } 2 \text {-week studies, except } \\
\text { HEPA filter changed annually }\end{array}$ \\
\hline
\end{tabular}


Vinylidene Chloride, NTP TR 582

Two-week Studies

Three-month Studies

Two-year Studies

Chambers

Stainless steel chambers, excreta

Same as 2-week studies

Same as 2-week studies

pan at each occupied level (Lab

Products, Inc., Seaford, DE)

chambers changed weekly, excreta

pans changed daily

\section{Chamber Environment}

Temperature: $75^{\circ} \pm 3^{\circ} \mathrm{F}$

Relative humidity: $55 \% \pm 15 \%$

Same as 2-week studies

Same as 2-week studies

Room fluorescent light:

12 hours/day

Chamber air changes: $15 \pm 2$ /hour

Exposure Concentrations

$0,25,50,100,200$, or $400 \mathrm{ppm}$ in air

$0,6.25,12.5,25,50$, or 100 (except male mice) ppm in air
Rats: $0,25,50$, or $100 \mathrm{ppm}$ in air Mice: $0,6.25,12.5$, or $25 \mathrm{ppm}$ in air

Observed twice daily. Animals were weighed initially, weekly for the first 13 weeks, every 4 weeks through week 93, every 2 weeks thereafter, and at the end of the studies. Clinical findings were recorded every 4 weeks through week 93, then every 2 weeks, and at the end of the studies.

Same as 2-week studies

Necropsies were performed on all animals. animals. Organs weighed were heart, right kidney, liver, lung, right testis, and thymus.
Same as 2-week studies

Necropsies were performed on all core study animals. Organs weighed were heart, right kidney, liver, lung, right testis, and thymus. 
Vinylidene Chloride, NTP TR 582

Two-week Studies

\section{Clinical Pathology}

None

\section{Histopathology}

Histopathology was performed on $0,100,200$, and 400 ppm rats and $0,50,100,200$, and $400 \mathrm{ppm}$ mice. In addition to gross lesions and tissue masses, the eyes, kidney (except $50 \mathrm{ppm}$ female mice), liver, lung, and nose were examined to a no-effect level.
Three-month Studies

Two-year Studies
Blood was collected from the
retroorbital sinus of clinical pathology rats on days 3 and 23 and from core study animals at the end of the studies for hematology and clinical chemistry (rats only).

Hematology: hematocrit; hemoglobin concentration; erythrocyte, reticulocyte, and platelet counts; erythrocyte and platelet morphology; mean cell volume; mean cell hemoglobin; mean cell hemoglobin concentration; and leukocyte count and differentials

Clinical chemistry: urea nitrogen, creatinine, glucose, total protein, albumin, globulin, alanine aminotransferase, alkaline phosphatase, creatine kinase, sorbitol dehydrogenase, bile acids,

Complete histopathology was performed on 0 and $100 \mathrm{ppm}$ core study rats, 0 and $50 \mathrm{ppm}$ male mice and 0 and $100 \mathrm{ppm}$ female mice. In addition to gross lesions and tissue masses, the following tissues were examined to a no-effect level: adrenal gland, bone with marrow, brain, clitoral gland, esophagus, eyes, gallbladder (mice), Harderian gland, heart, large intestine (cecum, colon, rectum), small intestine (duodenum, jejunum, ileum), kidney, larynx, liver, lung, lymph nodes (mandibular, mesenteric, bronchial, and mediastinal), mammary gland, nose, ovary, pancreas, parathyroid gland, pituitary gland, preputial gland, prostate gland, salivary gland, skin, spleen, stomach (forestomach and glandular), testis with epididymis and seminal vesicle, thymus, thyroid gland, trachea, urinary bladder, and uterus.
None

Complete histopathology was performed on all rats and mice. In addition to gross lesions and tissue masses, the following tissues were examined: adrenal gland, bone with marrow, brain, clitoral gland, esophagus, eyes, gallbladder (mice), Harderian gland, heart, large intestine (cecum, colon, rectum), small intestine (duodenum, jejunum, ileum), kidney, larynx, liver, lung, lymph nodes (mandibular, mesenteric, bronchial, and mediastinal), mammary gland, nose, ovary, pancreas, parathyroid gland, pituitary gland, preputial gland, prostate gland, salivary gland, skin, spleen, stomach (forestomach and glandular), testis with epididymis and seminal vesicle, thymus, thyroid gland, trachea, urinary bladder, and uterus. 


\begin{tabular}{|c|c|c|}
\hline Two-week Studies & Three-month Studies & Two-year Studies \\
\hline \multicolumn{3}{|c|}{ Sperm Motility and Vaginal Cytology } \\
\hline None & $\begin{array}{l}\text { At the end of the studies, spermatid } \\
\text { and sperm samples were collected } \\
\text { from male animals in the } 0,12.5 \\
\text { (mice), } 25,50 \text {, and } 100 \text { (rats) ppm } \\
\text { groups. The following parameters } \\
\text { were evaluated: spermatid heads per } \\
\text { testis and per gram testis, sperm } \\
\text { motility, and sperm per cauda } \\
\text { epididymis and per gram cauda } \\
\text { epididymis. The left cauda, left } \\
\text { epididymis, and left testis were } \\
\text { weighed. Vaginal samples were } \\
\text { collected for up to } 12 \\
\text { consecutive days prior to the end of } \\
\text { the studies from females exposed to } 0 \text {, } \\
12.5 \text { (mice), } 25,50 \text { or } 100 \text { (rats) ppm. }\end{array}$ & None \\
\hline
\end{tabular}

\section{Statistical Methods}

\section{Survival Analyses}

The probability of survival was estimated by the product-limit procedure of Kaplan and Meier ${ }^{98}$ and is presented in the form of graphs. Animals found dead of other than natural causes were censored; animals dying from natural causes were not censored. Statistical analyses for possible dose-related effects on survival used Cox's ${ }^{99}$ method for testing two groups for equality and Tarone's ${ }^{100}$ life table test to identify dose-related trends. All reported $\mathrm{P}$ values for the survival analyses are two sided.

\section{Calculation of Incidence}

The incidences of neoplasms or nonneoplastic lesions are presented in Table A-1, Table A-5, Table B-1, Table B-6, Table C-1, Table C-4, Table D-1, and Table D-4 as the numbers of animals bearing such lesions at a specific anatomic site and the numbers of animals with that site examined microscopically. For calculation of statistical significance, the incidences of most neoplasms (Table A-2, Table B-2, Table C-2, and Table D-2) and all nonneoplastic lesions are given as the numbers of animals affected at each site examined microscopically. However, when macroscopic examination was required to detect neoplasms in certain tissues (e.g., mesentery, pleura, peripheral nerve, skeletal muscle, tongue, tooth, and Zymbal's gland) before microscopic evaluation, the denominators consist of the number of animals that had a gross abnormality. When neoplasms had multiple potential sites of occurrence (e.g., leukemia or lymphoma), the denominators consist of the number of animals on which a necropsy was performed. Table A-2, Table B-2, Table C-2, and Table D-2 also give the survival-adjusted neoplasm rate for each group and each site-specific neoplasm. This survival-adjusted rate (based on the Poly-3 method described below) accounts for differential mortality by assigning a reduced risk of neoplasm, proportional to the third power of the fraction of time on study, only to site-specific, lesion-free animals that do not reach terminal kill. 


\section{Analysis of Neoplasm and Nonneoplastic Lesion Incidences}

The Poly-k test ${ }^{101-103}$ was used to assess neoplasm and nonneoplastic lesion prevalence. This test is a survival-adjusted quantal-response procedure that modifies the Cochran-Armitage linear trend test to take survival differences into account. More specifically, this method modifies the denominator in the quantal estimate of lesion incidence to approximate more closely the total number of animal years at risk. For analysis of a given site, each animal is assigned a risk weight. This value is one if the animal had a lesion at that site or if it survived until terminal kill; if the animal died prior to terminal kill and did not have a lesion at that site, its risk weight is the fraction of the entire study time that it survived, raised to the kth power.

This method yields a lesion prevalence rate that depends only upon the choice of a shape parameter for a Weibull hazard function describing cumulative lesion incidence over time ${ }^{101}$. Unless otherwise specified, a value of $\mathrm{k}=3$ was used in the analysis of site-specific lesions. This value was recommended by Bailer and Portier ${ }^{101}$ following an evaluation of neoplasm onset time distributions for a variety of site-specific neoplasms in control $\mathrm{F} 344 / \mathrm{N}$ rats and $\mathrm{B} 6 \mathrm{C} 3 \mathrm{~F} 1 / \mathrm{N}$ mice ${ }^{104}$. Bailer and Portier ${ }^{101}$ showed that the Poly-3 test gave valid results if the true value of $\mathrm{k}$ was anywhere in the range from 1 to 5. A further advantage of the Poly-3 method is that it does not require lesion lethality assumptions. Variation introduced by the use of risk weights, which reflect differential mortality, was accommodated by adjusting the variance of the Poly-3 statistic as recommended by Bieler and Williams ${ }^{105}$.

Tests of significance included pairwise comparisons of each dosed group with controls and a test for an overall dose-related trend. Continuity-corrected Poly-3 tests were used in the analysis of lesion incidence, and reported $\mathrm{P}$ values are one sided. The significance of lower incidences or decreasing trends in lesions is represented as $1-\mathrm{P}$ with the letter $\mathrm{N}$ added (e.g., $\mathrm{P}=0.99$ is presented as $\mathrm{P}=0.01 \mathrm{~N})$.

\section{Analysis of Continuous Variables}

Two approaches were employed to assess the significance of pairwise comparisons between dosed and control groups in the analysis of continuous variables. Organ and body weight data, which historically have approximately normal distributions, were analyzed with the parametric multiple comparison procedures of Dunnett ${ }^{106}$ and Williams ${ }^{107 ; 108}$. Hematology, clinical chemistry, spermatid, and epididymal spermatozoal data, which have typically skewed distributions, were analyzed using the nonparametric multiple comparison methods of Shirley ${ }^{109}$ (as modified by Williams ${ }^{110}$ ) and Dunn ${ }^{111}$. Jonckheere's test ${ }^{112}$ was used to assess the significance of the dose-related trends and to determine whether a trend-sensitive test (Williams' or Shirley's test) was more appropriate for pairwise comparisons than a test that does not assume a mono-tonic dose-related trend (Dunnett's or Dunn's test). Prior to statistical analysis, extreme values identified by the outlier test of Dixon and Massey ${ }^{113}$ were examined by NTP personnel, and implausible values were eliminated from the analysis. Proportions of regular cycling females in each dosed group were compared to the control group using the Fisher exact test ${ }^{114}$. Tests for extended periods of estrus, diestrus, metestrus, and proestrus, as well as skipped estrus and skipped diestrus, were constructed based on a Markov chain model proposed by Girard and Sager $^{115}$. For each dose group, a transition probability matrix was estimated for transitions among the proestrus, estrus, metestrus, and diestrus stages, with provision for extended stays within each stage as well as for skipping estrus or diestrus within a cycle. Equality of transition 
matrices among dose groups and between the control group and each dosed group was tested using chi-square statistics.

\section{Historical Control Data}

The concurrent control group represents the most valid comparison to the treated groups and is the only control group analyzed statistically in NTP bioassays. However, historical control data are often helpful in interpreting potential treatment-related effects, particularly for uncommon or rare neoplasm types. For meaningful comparisons, the conditions for studies in the historical database must be generally similar. Significant factors affecting the background incidences of neoplasms at a variety of sites are diet, sex, strain/stock, and route of exposure. The NTP historical control database contains all 2-year studies for each species, sex, and strain/stock with histopathology findings in control animals completed within the most recent 5-year period ${ }^{116 ; 117 .}$ In general, the historical control database for a given study includes studies using the same route of administration, and the overall incidences of neoplasms in controls for all routes of administration are included for comparison, including the present study.

\section{Quality Assurance Methods}

The 2-week, 3-month, and 2-year studies were conducted in compliance with Food and Drug Administration Good Laboratory Practice Regulations ${ }^{118}$. In addition, as records from the 3month and 2-year studies were submitted to the NTP Archives, these studies were audited retrospectively by an independent quality assessment contractor. Separate audits covered completeness and accuracy of the pathology data, pathology specimens, final pathology tables, and a draft of this NTP Technical Report. Audit procedures and findings are presented in the reports and are on file at NIEHS. The audit findings were reviewed and assessed by NTP staff, and all comments were resolved or otherwise addressed during the preparation of this Technical Report.

\section{Genetic Toxicology}

The genetic toxicity of vinylidene chloride was assessed by testing the ability of the chemical to induce mutations in various strains of Salmonella typhimurium, mutations in L5178Y mouse lymphoma cells, sex-linked recessive lethal mutations in Drosophila melanogaster, and increases in the frequency of micronucleated erythrocytes in mouse peripheral blood. Micronuclei (literally "small nuclei" or Howell-Jolly bodies) are biomarkers of induced structural or numerical chromosomal alterations and are formed when acentric fragments or whole chromosomes fail to incorporate into either of two daughter nuclei during cell division ${ }^{119 ;}{ }^{120}$. The protocols for these studies and the results are given in Appendix E.

The genetic toxicity studies have evolved from an earlier effort by NTP to develop a comprehensive database permitting a critical anticipation of a chemical's carcinogenicity in experimental animals based on numerous considerations, including the molecular structure of the chemical and its observed effects in short-term in vitro and in vivo genetic toxicity tests (structure-activity relationships). The short-term tests were originally developed to clarify proposed mecha-nisms of chemical-induced DNA damage based on the relationship between electrophilicity and mutagenicity ${ }^{121}$ and the somatic mutation theory of cancer ${ }^{122 ; 123}$. However, it should be noted that not all cancers arise through genotoxic mechanisms. 
DNA reactivity combined with Salmonella mutagenicity is highly correlated with induction of carcinogenicity in multiple species/sexes of rodents and at multiple tissue sites ${ }^{124}$. A positive response in the Salmonella test was shown to be the most predictive in vitro indicator for rodent carcinogenicity ( $89 \%$ of the Salmonella mutagens are rodent carcinogens) ${ }^{125 ; 126}$. Additionally, no battery of tests that included the Salmonella test improved the predictivity of the Salmonella test alone. However, these other tests can provide useful information on the types of DNA and chromosomal damage induced by the chemical under investigation.

The predictivity for carcinogenicity of a positive response in acute in vivo bone marrow chromosome aberration or micronucleus tests appears to be less than that in the Salmonella test $^{127 ; 128}$. However, clearly positive results in long-term peripheral blood micronucleus tests have high predictivity for rodent carcinogenicity; a weak response in one sex only or negative results in both sexes in this assay do not correlate well with either negative or positive results in rodent carcinogenicity studies ${ }^{129}$. Because of the theoretical and observed associations between induced genetic damage and adverse effects in somatic and germ cells, the determination of in vivo genetic effects is important to the overall understanding of the risks associated with exposure to a particular chemical. 


\section{Results}

\section{Rats}

\section{Two-week Study}

All male and nine of 10 female rats in the 200 and 400 ppm groups were found dead by day 2; one 400 ppm female was found dead on day 4 (Table 2). All other rats survived the entire study except one $25 \mathrm{ppm}$ male removed from the study due to chylothorax (nonexposure-related condition). The mean body weight gain of $100 \mathrm{ppm}$ females was significantly less than that of the chamber controls. Final mean body weights of male and female rats exposed to $100 \mathrm{ppm}$ were $3 \%$ and $6 \%$ less, respectively, than those of the chamber control groups. All females and nine of 10 males exposed to 200 or 400 ppm became lethargic, while all females and four of five males exposed to $400 \mathrm{ppm}$ developed ataxia.

Absolute and relative kidney weights of all surviving groups of exposed males and females were significantly greater than those of the chamber controls (Table G-1). In males, relative lung weights were increased at $100 \mathrm{ppm}$ compared to controls, and an increasing trend was observed in absolute and relative lung weights.

Table 2. Survival and Body Weights of Rats in the Two-week Inhalation Study of Vinylidene Chloride $^{\mathrm{a}}$

\begin{tabular}{|c|c|c|c|c|c|}
\hline $\begin{array}{c}\text { Concentration } \\
(\mathbf{p p m})\end{array}$ & Survival $^{\text {b }}$ & $\begin{array}{c}\text { Initial Body } \\
\text { Weight (g) }\end{array}$ & $\begin{array}{l}\text { Final Body } \\
\text { Weight (g) }\end{array}$ & $\begin{array}{l}\text { Change in Body } \\
\text { Weight (g) }\end{array}$ & $\begin{array}{c}\text { Final Weight } \\
\text { Relative to } \\
\text { Controls (\%) }\end{array}$ \\
\hline \multicolumn{6}{|l|}{ Male } \\
\hline 0 & $5 / 5$ & $93 \pm 2$ & $158 \pm 2$ & $66 \pm 3$ & \\
\hline 25 & $4 / 5^{\mathrm{c}}$ & $91 \pm 1$ & $150 \pm 3$ & $60 \pm 4$ & 95 \\
\hline 50 & $5 / 5$ & $92 \pm 3$ & $159 \pm 5$ & $67 \pm 3$ & 100 \\
\hline 100 & $5 / 5$ & $93 \pm 1$ & $154 \pm 2$ & $62 \pm 2$ & 97 \\
\hline 200 & $0 / 5^{\mathrm{d}}$ & $92 \pm 2$ & - & - & - \\
\hline 400 & $0 / 5^{\mathrm{e}}$ & $91 \pm 2$ & - & - & - \\
\hline \multicolumn{6}{|l|}{ Female } \\
\hline 0 & $5 / 5$ & $84 \pm 1$ & $124 \pm 2$ & $40 \pm 1$ & \\
\hline 25 & $5 / 5$ & $84 \pm 1$ & $125 \pm 3$ & $40 \pm 3$ & 101 \\
\hline 50 & $5 / 5$ & $84 \pm 2$ & $122 \pm 1$ & $38 \pm 2$ & 98 \\
\hline 100 & $5 / 5$ & $83 \pm 2$ & $117 \pm 3$ & $34 \pm 1^{*}$ & 94 \\
\hline 200 & $0 / 5^{\mathrm{d}}$ & $83 \pm 1$ & - & - & - \\
\hline 400 & $0 / 5^{\mathrm{f}}$ & $84 \pm 1$ & - & - & - \\
\hline
\end{tabular}

*Significantly different $(\mathrm{P} \leq 0.05)$ from the chamber control group by Williams' test.

${ }^{a}$ Weights and weight changes are given as mean \pm standard error. Subsequent calculations are based on animals surviving to the end of the study.

${ }^{\mathrm{b}}$ Number of animals surviving at 16 days/number initially in group.

'Day of death: 10 .

dDay of deaths: 2 .

eDays of deaths: $1,2,2,2,2$.

fDays of deaths: 2, 2, 2, 2, 4. 
In the liver, centrilobular necrosis was associated with early deaths in male and female rats exposed to 200 or $400 \mathrm{ppm}$ vinylidene chloride and was characterized as partial or complete disintegration of hepatocytes within the central areas of hepatic lobules, sparing only the periportal areas (Table 3). Necrotic hepatocytes were replaced with hemorrhage and necrotic debris, and the remaining viable hepatocytes had pale or vacuolated cytoplasm and margination of nuclear chromatin. Mild centrilobular necrosis was also observed in one $25 \mathrm{ppm}$ male rat, and it was characterized by shrunken, eosinophilic hepatocytes with complete or partial loss of nuclear and cell membranes and karyorrhexis. Centrilobular cytoplasmic alteration of hepatocytes occurred in all exposed male and female rats that survived to terminal kill. Hepatocytic centrilobular cytoplasmic alteration was characterized by decreased cytoplasmic staining, perinuclear halos, and flocculent cytoplasm. Mean severity of this alteration was slightly higher in males. Centrilobular cytoplasmic alteration likely represents a form of hepatocellular degeneration, because rats exposed to 200 and $400 \mathrm{ppm}$ did not have cytoplasmic alteration, but rather centrilobular necrosis, consistent with a more severe stage of hepatocellular damage.

Renal tubule casts occurred in the renal papillae of 200 and 400 ppm rats, characterized by the presence of variable amounts of finely granular, brightly eosinophilic material in dilated tubule lumens of the renal papillae (Table 3).

Exposure Concentration Selection Rationale: Based on decreased survival of males and females exposed to 200 or $400 \mathrm{ppm}$ in the 2-week study, vinylidene chloride exposure concentrations selected for the 3-month inhalation study in rats were 6.25, 12.5, 25, 50, and $100 \mathrm{ppm}$. Doses were also partially based on the lack of hepatocellular necrosis in the 25,50 , and $100 \mathrm{ppm}$ groups. Cytoplasmic alteration was not considered to be dose limiting.

Table 3. Incidences of Selected Nonneoplastic Lesions in Rats in the Two-week Inhalation Study of Vinylidene Chloride

\begin{tabular}{|c|c|c|c|c|c|c|}
\hline & $\begin{array}{l}\text { Chamber } \\
\text { Control }\end{array}$ & 25 ppm & 50 ppm & 100 ppm & 200 ppm & 400 ppm \\
\hline \multicolumn{7}{|l|}{ Male } \\
\hline Liver $^{\mathrm{a}}$ & 5 & 5 & 5 & 5 & 5 & 5 \\
\hline Centrilobular, Necrosis ${ }^{\mathrm{b}}$ & 0 & $1(2.0)^{\mathrm{c}}$ & 0 & 0 & $5 * *(4.0)$ & $5 * *(4.0)$ \\
\hline $\begin{array}{c}\text { Hepatocyte, Centrilobular, } \\
\text { Cytoplasmic Alteration }\end{array}$ & 0 & $4 *(2.8)$ & $5 * *(3.0)$ & $5 * *(3.0)$ & 0 & 0 \\
\hline Kidney & 5 & 0 & 0 & 5 & 5 & 5 \\
\hline Papilla, Renal Tubule, Casts & 0 & - & - & 0 & $5 * *(3.2)$ & $4 *(2.5)$ \\
\hline \multicolumn{7}{|l|}{ Female } \\
\hline Liver & 5 & 5 & 5 & 5 & 5 & 5 \\
\hline Centrilobular, Necrosis & 0 & 0 & 0 & 0 & $5 * *(4.0)$ & $5 * *(4.0)$ \\
\hline $\begin{array}{c}\text { Hepatocyte, Centrilobular, } \\
\text { Cytoplasmic Alteration }\end{array}$ & 0 & $5 * *(2.4)$ & $5 * *(3.0)$ & $5 * *(2.6)$ & 0 & 0 \\
\hline Kidney & 5 & 0 & 0 & 5 & 5 & 5 \\
\hline Papilla, Renal Tubule, Casts & 0 & - & - & 0 & $5 * *(3.0)$ & $5 * *(3.2)$ \\
\hline
\end{tabular}




\section{Three-month Study}

All rats survived until the end of the study (Table 4). Final mean body weights and body weight gains of exposed groups were similar to those of the chamber control groups (Table 4 and Figure 3). No exposure-related clinical findings or gross lesions were observed.

The hematology and clinical chemistry data for rats are presented in Table F-1. Slight increases $(\leq 6 \%)$ in hemoglobin concentrations and red blood cell (erythrocyte) counts were observed in $100 \mathrm{ppm}$ male and female rats on day 3 . In addition, on day 3 the hematocrit was also slightly increased in $100 \mathrm{ppm}$ males. These changes ameliorated by day 23 and were consistent with a transient hemoconcentration associated with mild dehydration as the rats acclimated to exposure. No other hematological changes were considered toxicologically or biologically relevant.

Exposure concentration-related minimal to mild $(\leq 10 \%)$ increases were observed in total protein and globulin concentrations on days 3 and 23 in both male and female rats in various exposed groups, but most consistently at $100 \mathrm{ppm}$. In addition, albumin was minimally increased $(\leq 5 \%)$ in $100 \mathrm{ppm}$ males and $25 \mathrm{ppm}$ or greater female rats on day 23 . Urea nitrogen concentrations were minimally increased in 50 and $100 \mathrm{ppm}$ male and female rats on day 3, and 50 and $100 \mathrm{ppm}$ males and $6.25 \mathrm{ppm}$ or greater females on day 23. Similar to the observed changes in the erythron, the total protein, albumin, globulin, and urea nitrogen concentrations returned to chamber control levels by week 14 and were consistent with mild dehydration.

Table 4. Survival and Body Weights of Rats in the Three-month Inhalation Study of Vinylidene Chloride $^{\mathrm{a}}$

\begin{tabular}{cccccc}
\hline $\begin{array}{c}\text { Concentration } \\
(\mathbf{p p m})\end{array}$ & Survival $^{\mathbf{b}}$ & $\begin{array}{c}\text { Initial Body } \\
\text { Weight }(\mathbf{g})\end{array}$ & $\begin{array}{c}\text { Final Body } \\
\text { Weight }(\mathbf{g})\end{array}$ & $\begin{array}{c}\text { Change in Body } \\
\text { Weight (g) }\end{array}$ & $\begin{array}{c}\text { Final Weight } \\
\text { Relative to } \\
\text { Controls (\%) }\end{array}$ \\
\hline Male & & & & & \\
0 & $10 / 10$ & $111 \pm 2$ & $326 \pm 7$ & $216 \pm 6$ & 102 \\
6.25 & $10 / 10$ & $110 \pm 2$ & $332 \pm 6$ & $222 \pm 6$ & 103 \\
12.5 & $10 / 10$ & $111 \pm 2$ & $337 \pm 5$ & $226 \pm 5$ & 98 \\
25 & $10 / 10$ & $110 \pm 2$ & $319 \pm 6$ & $209 \pm 6$ & 104 \\
50 & $10 / 10$ & $111 \pm 1$ & $340 \pm 6$ & $230 \pm 6$ & 99 \\
100 & $10 / 10$ & $111 \pm 2$ & $322 \pm 5$ & $212 \pm 6$ & \\
\hline Female & & & & & 101 \\
0 & $10 / 10$ & $96 \pm 2$ & $203 \pm 3$ & $108 \pm 2$ & 99 \\
6.25 & $10 / 10$ & $96 \pm 2$ & $205 \pm 6$ & $109 \pm 5$ & 101 \\
12.5 & $10 / 10$ & $95 \pm 2$ & $206 \pm 4$ & $111 \pm 3$ & 96 \\
25 & $10 / 10$ & $95 \pm 2$ & $201 \pm 4$ & $106 \pm 3$ & \\
50 & $10 / 10$ & $95 \pm 2$ & $205 \pm 4$ & $110 \pm 3$ & \\
100 & $10 / 10$ & $96 \pm 1$ & $195 \pm 2$ & $100 \pm 2$ & \\
\hline
\end{tabular}

${ }^{a}$ Weights and weight changes are given as mean \pm standard error.

bNumber of animals surviving at 14 weeks/number initially in group. 
Vinylidene Chloride, NTP TR 582
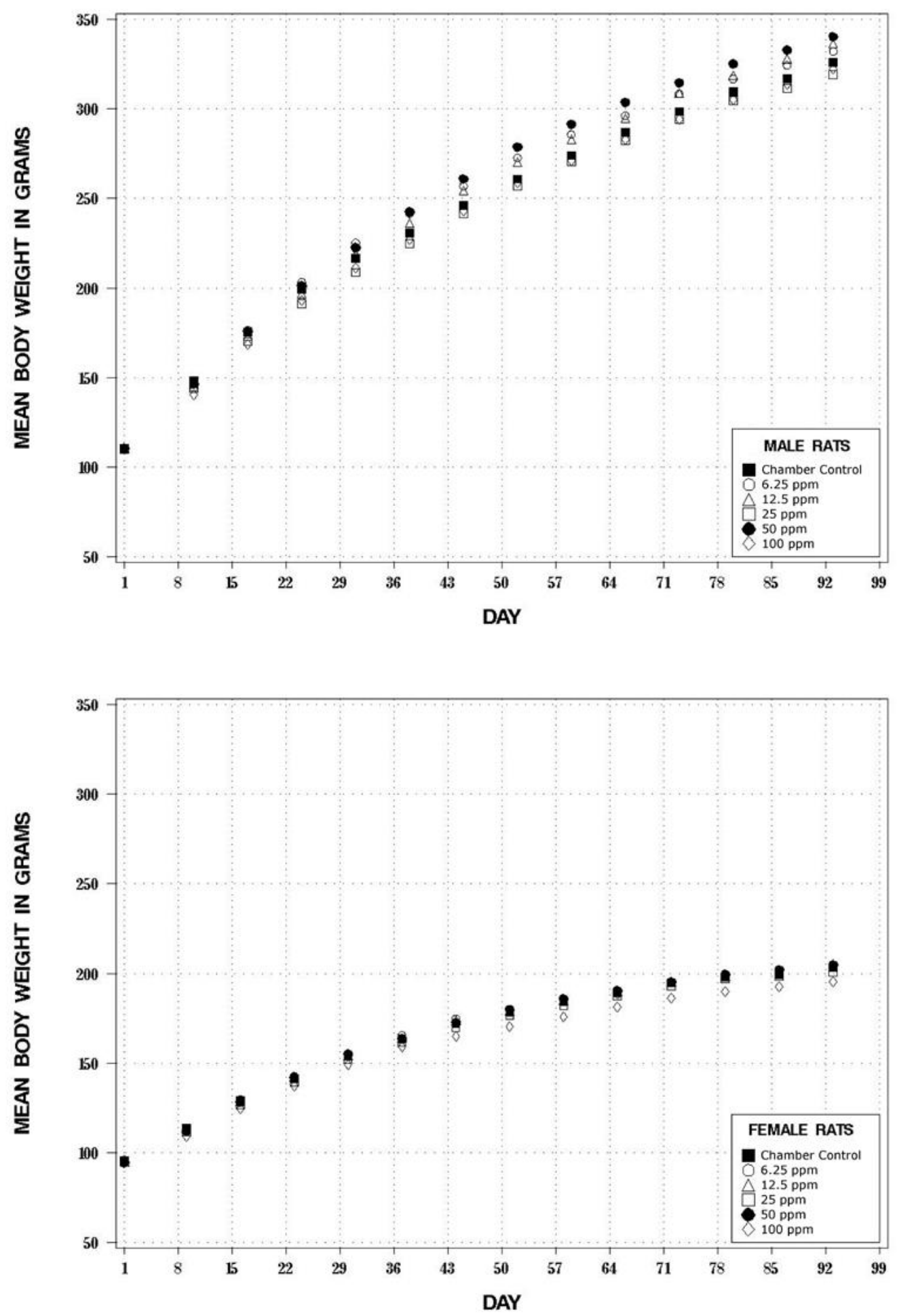

Figure 3. Growth Curves for Rats Exposed to Vinylidene Chloride by Inhalation for Three Months 
Increased alkaline phosphatase activities were observed in the 50 and $100 \mathrm{ppm}$ groups on days 3 and 23 in male rats and on day 23 in female rats. While increased alkaline phosphatase activity is considered an indicator of cholestasis, the increases were of minimal severity and transient, and bile acid concentrations, another marker for cholestasis, were unchanged or decreased, suggesting that these changes represent a transient alteration in hepatic metabolism rather than cholestasis.

Sorbitol dehydrogenase (SDH) activities were increased in $100 \mathrm{ppm}$ females on day 3 and in $100 \mathrm{ppm}$ males and 50 and $100 \mathrm{ppm}$ females on day 23. In addition, alanine aminotransferase (ALT) activities were increased on day 3 in 50 and $100 \mathrm{ppm}$ male rats and day 23 in $100 \mathrm{ppm}$ male rats. Both SDH and ALT are considered markers of hepatocellular injury. These increases were transient, not being observed at week 14, and minimal histopathologic changes were observed in the liver at study termination; therefore, these changes are consistent with mild transient hepatocellular injury.

Relative kidney weights of $6.25,12.5$, and $100 \mathrm{ppm}$ males and absolute and relative kidney weights of $12.5 \mathrm{ppm}$ or greater females were significantly greater than those of the chamber controls (Table G-2).

Male rats exposed to $100 \mathrm{ppm}$ exhibited significantly lower sperm motility (approximately $5 \%$ less than chamber controls) (Table H-1). Rats in this exposed group also exhibited lower spermatid/g testis and total spermatid/testis values (15\% and $16 \%$, respectively, compared to chamber controls). At necropsy, rats did not display any histopathologic change in the contralateral organ; however, fixation quality of the rat testes was poor. There were no vinylidene chloride-related changes in estrous cyclicity in female rats (Table H-2). Therefore, vinylidene chloride exhibits the potential to be a reproductive toxicant in male rats but not in female rats.

Microscopic lesions of the nose were noted in both sexes of rats (Table 5). A combination of lesions in the nasal epithelium composed of olfactory epithelium atrophy, mineralization, and necrosis and turbinate atrophy was observed with generally increasing severity with increasing exposure to vinylidene chloride. A no-effect level was not observed, although turbinate atrophy was not seen in rats exposed to $6.25 \mathrm{ppm}$, and most of the lesions were minimal in rats exposed to $12.5 \mathrm{ppm}$ or less. Atrophy of the olfactory epithelium was characterized by a decrease in the number of olfactory epithelial cells lining the turbinates, usually in the dorsal meatus of Level III, and by replacement with a single layer of respiratory-type epithelium (metaplasia). This lesion was often associated with a corresponding decrease in nerve fibers and glands in the underlying lamina propria. Mineralization of the olfactory epithelium was characterized by linear to irregular, oval to elongate laminated deposits of greyish-blue material in the basement membrane, often underlying an atrophic epithelium or disrupting the epithelium, and most often affecting the lateral walls and turbinates. Olfactory epithelial necrosis occurred at the dorsal meatus, dorsal septum, and all regions of ethmoturbinates in Level III of the nose. Necrosis of the olfactory epithelium was characterized by areas of nuclear pyknosis of the epithelium, fragmentation, and hypereosinophilia, and in some areas, full-thickness sloughing of the epithelium and cell debris into the nasal passages at Level III. Necrosis was not associated with inflammation. Turbinate atrophy was characterized by thinning and blunting of primarily the ethmoid turbinates of Level III, often with bony remodeling. 
In the liver of male rats, centrilobular cytoplasmic alteration was significantly increased at $12.5 \mathrm{ppm}$ or greater. In females, cytoplasmic vacuolization was observed at 50 and $100 \mathrm{ppm}$ (Table 5). Centrilobular cytoplasmic alteration was characterized by a decrease in cytoplasmic eosinophilia of hepatocytes located in centrilobular areas; this lesion was not observed in female rats. Cytoplasmic vacuolization was characterized by single to multiple clear, wellcircumscribed, round, 1 to $15 \mu \mathrm{m}$ diameter vacuoles in the cytoplasm of hepatocytes.

Decreased incidences of nephropathy were observed in male rats exposed to vinylidene chloride $(6 / 10,3 / 10,4 / 10,4 / 10,3 / 10,1 / 10)$. All incidences of nephropathy in the chamber controls were graded as minimal, and the lesion was characterized by single to few clusters of regenerative tubules with minimal thickening of the basement membrane. The higher exposure concentration groups had histologically normal kidneys. This lesion is a common background finding in the F344/N rat and was unrelated to vinylidene chloride exposure. The decreasing incidence of nephropathy in exposed animals is of uncertain biologic significance.

Exposure Concentration Selection Rationale: In the 3-month studies, minimal changes in clinical chemistry parameters were considered reflective of possible mild dehydration. While increased kidney weights were observed in males and females, there were no corresponding histopathologic changes in the kidney. The nose and the liver were target organs in both sexes. However, the observed lesions were not considered preclusive for chronic administration at these exposures. Exposure concentrations greater than $100 \mathrm{ppm}$ were not considered due to increased mortality observed at greater than $100 \mathrm{ppm}$ in the 2-week study. Based on the overall minimal chemical-related toxicity in the 3-month study, vinylidene chloride exposure concentrations selected for the 2-year inhalation study in rats were 25,50 , and $100 \mathrm{ppm}$. 
Table 5. Incidences of Selected Nonneoplastic Lesions in Rats in the Three-month Inhalation Study of Vinylidene Chloride

\begin{tabular}{|c|c|c|c|c|c|c|}
\hline & $\begin{array}{c}\text { Chamber } \\
\text { Control }\end{array}$ & $6.25 \mathrm{ppm}$ & $12.5 \mathrm{ppm}$ & 25 ppm & $50 \mathrm{ppm}$ & 100 ppm \\
\hline \multicolumn{7}{|l|}{ Male } \\
\hline Nose $^{a}$ & 10 & 10 & 10 & 10 & 10 & 10 \\
\hline Olfactory Epithelium, Atrophy ${ }^{\mathrm{b}}$ & 0 & $4^{*}(1.0)^{\mathrm{c}}$ & $10^{* *}(1.0)$ & $10 * *(1.7)$ & $10 * *(2.2)$ & $10 * *(2.7)$ \\
\hline Olfactory Epithelium, Mineralization & 0 & $10^{* *}(1.3)$ & $10 * *(2.0)$ & $10 * *(2.9)$ & $10 * *(3.0)$ & $10 * *(2.6)$ \\
\hline Olfactory Epithelium, Necrosis & 0 & $2(1.0)$ & $6^{* *}(1.0)$ & $9 * *(1.0)$ & $7 * *(1.7)$ & $10 * *(1.6)$ \\
\hline Turbinate, Atrophy & 0 & 0 & $10 * *(1.0)$ & $10 * *(2.0)$ & $10 * *(2.2)$ & $10 * *(3.0)$ \\
\hline Liver & 10 & 10 & 10 & 10 & 10 & 10 \\
\hline Centrilobular, Cytoplasmic Alteration & $1(1.0)$ & $1(1.0)$ & $6^{*}(1.7)$ & $10 * *(1.8)$ & $10 * *(2.0)$ & $10 * *(1.9)$ \\
\hline \multicolumn{7}{|l|}{ Female } \\
\hline Nose & 10 & 10 & 10 & 10 & 10 & 10 \\
\hline Olfactory Epithelium, Atrophy & 0 & $2(1.0)$ & $10 * *(1.0)$ & $10 * *(1.3)$ & $10 * *(1.7)$ & $10 * *(2.4)$ \\
\hline Olfactory Epithelium, Mineralization & 0 & $5 *(1.0)$ & $9 * *(1.3)$ & $10 * *(1.9)$ & $10 * *(2.1)$ & $10 * *(2.3)$ \\
\hline Olfactory Epithelium, Necrosis & 0 & $1(1.0)$ & $3(1.3)$ & $6^{* *}(1.5)$ & $10 * *(2.2)$ & $10 * *(1.6)$ \\
\hline Turbinate, Atrophy & 0 & 0 & $10 * *(1.0)$ & $10 * *(2.0)$ & $10 * *(2.2)$ & $10 * *(3.0)$ \\
\hline Liver & 10 & 10 & 10 & 10 & 10 & 10 \\
\hline Vacuolization, Cytoplasmic & 0 & 0 & 0 & 0 & $10 * *(1.1)$ & $10 * *(1.0)$ \\
\hline
\end{tabular}

*Significantly different $(\mathrm{P} \leq 0.05)$ from the chamber control group by the Fisher exact test.

$* * \mathrm{P} \leq 0.01$.

${ }^{a}$ Number of animals with tissue examined microscopically.

${ }^{b}$ Number of animals with lesion.

${ }^{\mathrm{c}}$ Average severity grade of lesions in affected animals: $1=$ minimal, $2=$ mild, $3=$ moderate, $4=$ marked.

\section{Two-year Study}

\section{Survival}

Estimates of 2-year survival probabilities for male and female rats are shown in Table 6 and in the Kaplan-Meier survival curves (Figure 4). Survival of exposed groups of males was similar to that of the chamber control group. Survival of 100 ppm females was significantly less than that of the chamber controls.

\section{Body Weights and Clinical Findings}

Mean body weights of exposed groups of male and female rats were similar to those of the chamber control groups throughout the study (Figure 5, Table 7, and Table 8). No clinical findings related to vinylidene chloride exposure were observed in male rats; thinness was observed in approximately half of the 100 ppm females.

\section{Gross Findings}

Fluid in the abdomen and multiple nodules on the peritoneum, particularly on the testicular tunics and epididymides, were grossly observed. These findings were associated with exposure to vinylidene chloride and resulted from the occurrence of mesothelioma. 
Vinylidene Chloride, NTP TR 582

Table 6. Survival of Rats in the Two-year Inhalation Study of Vinylidene Chloride

\begin{tabular}{|c|c|c|c|c|}
\hline & $\begin{array}{c}\text { Chamber } \\
\text { Control }\end{array}$ & $25 \mathrm{ppm}$ & $50 \mathrm{ppm}$ & 100 ppm \\
\hline \multicolumn{5}{|l|}{ Male } \\
\hline Animals initially in study & 50 & 50 & 50 & 50 \\
\hline Moribund & 21 & 15 & 23 & 27 \\
\hline Natural deaths & 4 & 8 & 5 & 4 \\
\hline Animals surviving to study termination & 25 & 27 & 22 & 19 \\
\hline Percent probability of survival at end of study & 50 & 54 & 44 & 38 \\
\hline Mean survival (days) ${ }^{\mathrm{b}}$ & 680 & 662 & 650 & 646 \\
\hline Survival analysis ${ }^{\mathrm{c}}$ & $P=0.121$ & $\mathrm{P}=1.000$ & $P=0.372$ & $P=0.207$ \\
\hline \multicolumn{5}{|l|}{ Female } \\
\hline Animals initially in study & 50 & 50 & 50 & 50 \\
\hline Moribund & 19 & 22 & 18 & 28 \\
\hline Natural deaths & 1 & 2 & 2 & 3 \\
\hline Animals surviving to study termination & 30 & 26 & $30^{\mathrm{d}}$ & 19 \\
\hline Percent probability of survival at end of study & 60 & 52 & 58 & 38 \\
\hline Mean survival (days) & 705 & 681 & 678 & 675 \\
\hline Survival analysis & $P=0.046$ & $P=0.337$ & $P=0.709$ & $P=0.029$ \\
\hline
\end{tabular}

${ }^{\mathrm{a}}$ Kaplan-Meier determinations.

${ }^{b}$ Mean of all deaths (uncensored, censored, and terminal kill).

${ }^{\mathrm{c}}$ The result of the life table trend test ${ }^{100}$ is in the chamber control column, and the results of the life table pairwise comparisons ${ }^{99}$ with the chamber controls are in the exposed group columns.

dincludes one animal that died during the last week of the study. 

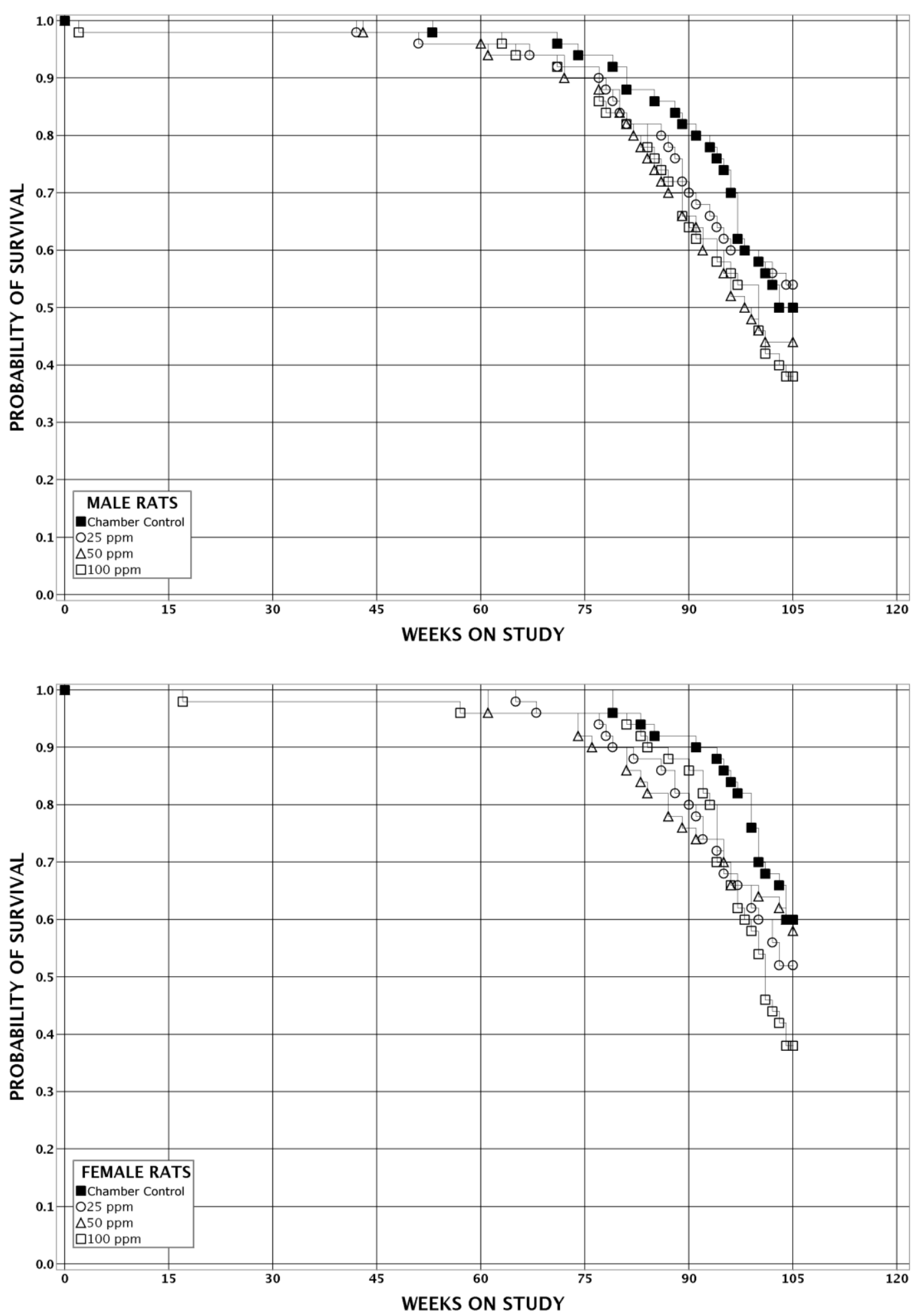

Figure 4. Kaplan-Meier Survival Curves for Rats Exposed to Vinylidene Chloride by Inhalation for Two Years 

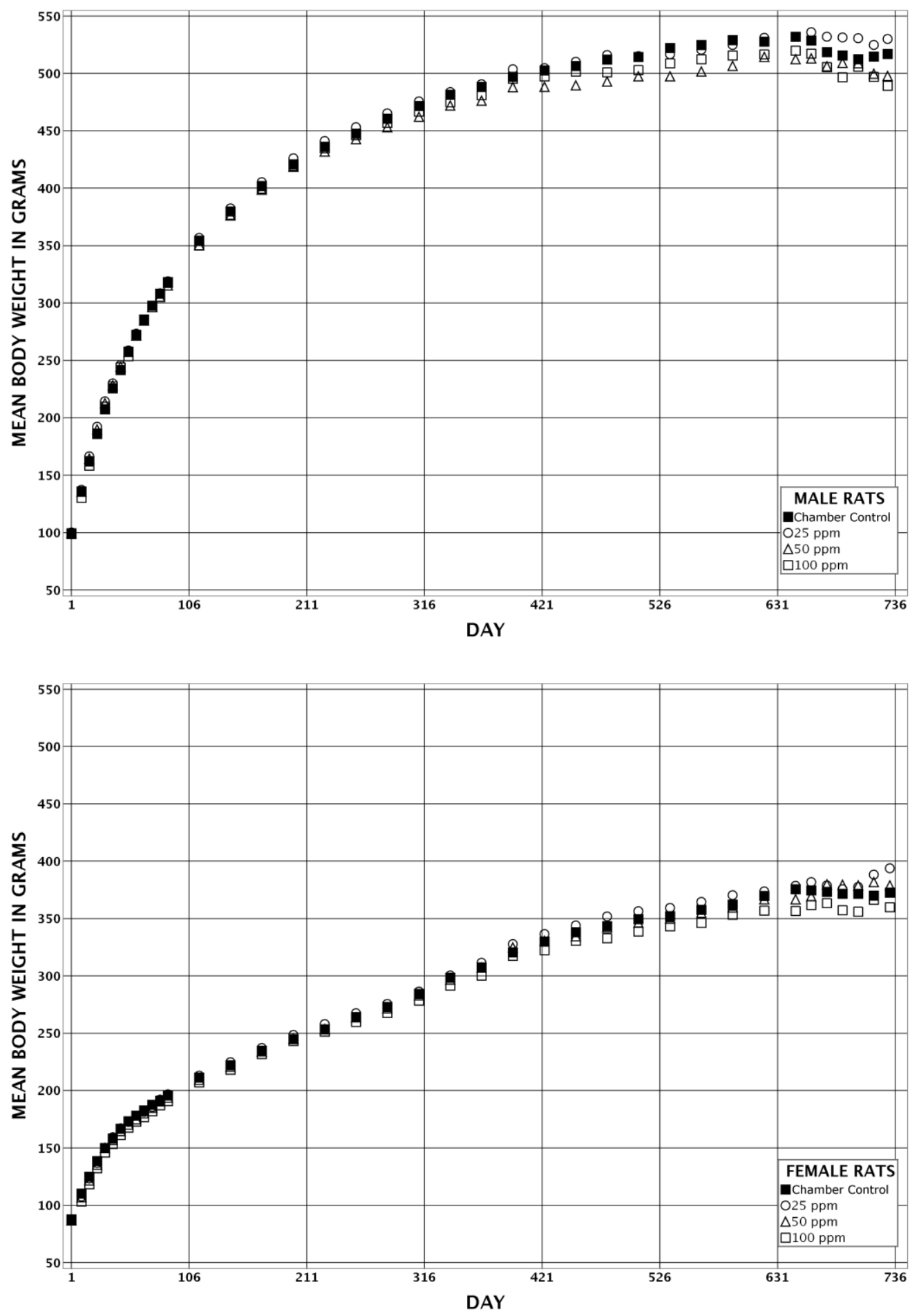

Figure 5. Growth Curves for Rats Exposed to Vinylidene Chloride by Inhalation for Two Years 
Table 7. Mean Body Weights and Survival of Male Rats in the Two-year Inhalation Study of Vinylidene Chloride

\begin{tabular}{|c|c|c|c|c|c|c|c|c|c|c|c|}
\hline \multirow[b]{2}{*}{ Day } & \multicolumn{2}{|c|}{ Chamber Control } & \multicolumn{3}{|c|}{$25 \mathrm{ppm}$} & \multicolumn{3}{|c|}{$50 \mathrm{ppm}$} & \multicolumn{3}{|c|}{100 ppm } \\
\hline & $\begin{array}{l}\text { Av. } \\
\text { Wt. } \\
\text { (g) }\end{array}$ & $\begin{array}{c}\text { No. of } \\
\text { Survivors }\end{array}$ & $\begin{array}{l}\text { Av. } \\
\text { Wt. } \\
\text { (g) }\end{array}$ & $\begin{array}{l}\text { Wt. (\% of } \\
\text { Controls) }\end{array}$ & $\begin{array}{c}\text { No. of } \\
\text { Survivors }\end{array}$ & $\begin{array}{l}\text { Av. } \\
\text { Wt. } \\
\text { (g) }\end{array}$ & $\begin{array}{l}\text { Wt. (\% of } \\
\text { Controls) }\end{array}$ & $\begin{array}{l}\text { No. of } \\
\text { Survivors }\end{array}$ & $\begin{array}{l}\text { Av. } \\
\text { Wt. } \\
\text { (g) }\end{array}$ & $\begin{array}{l}\text { Wt. (\% of } \\
\text { Controls) }\end{array}$ & $\begin{array}{c}\text { No. of } \\
\text { Survivors }\end{array}$ \\
\hline 1 & 100 & 50 & 100 & 101 & 50 & 100 & 100 & 50 & 99 & 99 & 50 \\
\hline 10 & 136 & 50 & 137 & 101 & 50 & 136 & 100 & 50 & 131 & 96 & 49 \\
\hline 17 & 162 & 50 & 167 & 103 & 50 & 164 & 101 & 50 & 159 & 98 & 49 \\
\hline 24 & 186 & 50 & 192 & 103 & 50 & 190 & 102 & 50 & 186 & 100 & 49 \\
\hline 31 & 208 & 50 & 214 & 103 & 50 & 213 & 103 & 50 & 210 & 101 & 49 \\
\hline 38 & 226 & 50 & 230 & 102 & 50 & 228 & 101 & 50 & 227 & 101 & 49 \\
\hline 45 & 242 & 50 & 246 & 102 & 50 & 245 & 101 & 50 & 244 & 101 & 49 \\
\hline 52 & 258 & 50 & 259 & 100 & 50 & 258 & 100 & 50 & 254 & 99 & 49 \\
\hline 59 & 272 & 50 & 273 & 100 & 50 & 272 & 100 & 50 & 272 & 100 & 49 \\
\hline 66 & 286 & 50 & 286 & 100 & 50 & 285 & 100 & 50 & 285 & 100 & 49 \\
\hline 73 & 298 & 50 & 298 & 100 & 50 & 296 & 100 & 50 & 297 & 100 & 49 \\
\hline 80 & 308 & 50 & 309 & 100 & 50 & 306 & 99 & 50 & 305 & 99 & 49 \\
\hline 87 & 318 & 50 & 319 & 100 & 50 & 315 & 99 & 50 & 318 & 100 & 49 \\
\hline 115 & 354 & 50 & 357 & 101 & 50 & 351 & 99 & 50 & 350 & 99 & 49 \\
\hline 143 & 380 & 50 & 383 & 101 & 50 & 376 & 99 & 50 & 377 & 99 & 49 \\
\hline 171 & 402 & 50 & 405 & 101 & 50 & 399 & 99 & 50 & 400 & 100 & 49 \\
\hline 199 & 421 & 50 & 426 & 101 & 50 & 419 & 99 & 50 & 420 & 100 & 49 \\
\hline 227 & 436 & 50 & 441 & 101 & 50 & 432 & 99 & 50 & 435 & 100 & 49 \\
\hline 255 & 448 & 50 & 453 & 101 & 50 & 443 & 99 & 50 & 446 & 100 & 49 \\
\hline 283 & 461 & 50 & 465 & 101 & 50 & 453 & 98 & 50 & 457 & 99 & 49 \\
\hline 311 & 472 & 50 & 476 & 101 & 49 & 463 & 98 & 49 & 467 & 99 & 49 \\
\hline 339 & 482 & 50 & 484 & 101 & 49 & 472 & 98 & 49 & 475 & 99 & 49 \\
\hline 367 & 488 & 49 & 491 & 101 & 48 & 476 & 98 & 49 & 481 & 99 & 49 \\
\hline 395 & 497 & 49 & 504 & 101 & 48 & 488 & 98 & 49 & 496 & 100 & 49 \\
\hline 423 & 503 & 49 & 505 & 100 & 48 & 489 & 97 & 47 & 498 & 99 & 49 \\
\hline 451 & 507 & 49 & 510 & 101 & 48 & 490 & 97 & 47 & 502 & 99 & 47 \\
\hline 479 & 512 & 49 & 516 & 101 & 47 & 493 & 96 & 47 & 501 & 98 & 47 \\
\hline 507 & 515 & 48 & 515 & 100 & 46 & 498 & 97 & 45 & 503 & 98 & 46 \\
\hline 535 & 522 & 47 & 517 & 99 & 45 & 498 & 95 & 44 & 509 & 98 & 43 \\
\hline 563 & 525 & 45 & 521 & 99 & 41 & 502 & 96 & 41 & 513 & 98 & 41 \\
\hline 591 & 529 & 43 & 525 & 99 & 41 & 507 & 96 & 37 & 516 & 97 & 39 \\
\hline 619 & 528 & 42 & 531 & 101 & 36 & 514 & 97 & 33 & 517 & 98 & 33 \\
\hline
\end{tabular}




\begin{tabular}{|c|c|c|c|c|c|c|c|c|c|c|c|}
\hline \multirow[b]{2}{*}{ Day } & \multicolumn{2}{|c|}{ Chamber Control } & \multicolumn{3}{|c|}{25 ppm } & \multicolumn{3}{|c|}{$50 \mathrm{ppm}$} & \multicolumn{3}{|c|}{100 ppm } \\
\hline & $\begin{array}{l}\text { Av. } \\
\text { Wt. } \\
\text { (g) }\end{array}$ & $\begin{array}{c}\text { No. of } \\
\text { Survivors }\end{array}$ & $\begin{array}{l}\text { Av. } \\
\text { Wt. } \\
\text { (g) }\end{array}$ & $\begin{array}{l}\text { Wt. (\% of } \\
\text { Controls) }\end{array}$ & $\begin{array}{c}\text { No. of } \\
\text { Survivors }\end{array}$ & $\begin{array}{l}\text { Av. } \\
\text { Wt. } \\
\text { (g) }\end{array}$ & $\begin{array}{l}\text { Wt. (\% of } \\
\text { Controls) }\end{array}$ & $\begin{array}{c}\text { No. of } \\
\text { Survivors }\end{array}$ & $\begin{array}{l}\text { Av. } \\
\text { Wt. } \\
(g)\end{array}$ & $\begin{array}{l}\text { Wt. (\% of } \\
\text { Controls) }\end{array}$ & $\begin{array}{c}\text { No. of } \\
\text { Survivors }\end{array}$ \\
\hline 647 & 532 & 39 & 532 & 100 & 34 & 513 & 96 & 30 & 520 & 98 & 31 \\
\hline 661 & 529 & 37 & 536 & 101 & 31 & 513 & 97 & 28 & 518 & 98 & 29 \\
\hline 675 & 519 & 34 & 532 & 103 & 30 & 506 & 98 & 26 & 506 & 98 & 28 \\
\hline 689 & 516 & 30 & 532 & 103 & 30 & 509 & 99 & 24 & 497 & 96 & 27 \\
\hline 703 & 512 & 29 & 531 & 104 & 29 & 509 & 99 & 23 & 506 & 99 & 21 \\
\hline 717 & 515 & 26 & 525 & 102 & 28 & 500 & 97 & 22 & 497 & 97 & 21 \\
\hline \multicolumn{12}{|c|}{ Mean for Weeks } \\
\hline $1-13$ & 231 & - & 233 & 101 & - & 231 & 100 & - & 230 & 100 & - \\
\hline $14-52$ & 428 & - & 432 & 101 & - & 423 & 99 & - & 425 & 99 & - \\
\hline $53-103$ & 516 & - & 520 & 101 & - & 500 & 97 & - & 505 & 98 & - \\
\hline
\end{tabular}

Table 8. Mean Body Weights and Survival of Female Rats in the Two-year Inhalation Study of Vinylidene Chloride

\begin{tabular}{|c|c|c|c|c|c|c|c|c|c|c|c|}
\hline \multirow[b]{2}{*}{ Day } & \multicolumn{2}{|c|}{ Chamber Control } & \multicolumn{3}{|c|}{25 ppm } & \multicolumn{3}{|c|}{50 ppm } & \multicolumn{3}{|c|}{100 ppm } \\
\hline & $\begin{array}{l}\text { Av. } \\
\text { Wt. } \\
\text { (g) }\end{array}$ & $\begin{array}{c}\text { No. of } \\
\text { Survivors }\end{array}$ & $\begin{array}{l}\text { Av. } \\
\text { Wt. } \\
\text { (g) }\end{array}$ & $\begin{array}{l}\text { Wt. (\% of } \\
\text { Controls) }\end{array}$ & $\begin{array}{c}\text { No. of } \\
\text { Survivors }\end{array}$ & $\begin{array}{l}\text { Av. } \\
\text { Wt. } \\
\text { (g) }\end{array}$ & $\begin{array}{l}\text { Wt. (\% of } \\
\text { Controls) }\end{array}$ & $\begin{array}{c}\text { No. of } \\
\text { Survivors }\end{array}$ & $\begin{array}{l}\text { Av. } \\
\text { Wt. } \\
\text { (g) }\end{array}$ & $\begin{array}{l}\text { Wt. (\% of } \\
\text { Controls) }\end{array}$ & $\begin{array}{c}\text { No. of } \\
\text { Survivors }\end{array}$ \\
\hline 1 & 88 & 50 & 87 & 99 & 50 & 87 & 99 & 50 & 87 & 99 & 50 \\
\hline 10 & 111 & 50 & 108 & 98 & 50 & 107 & 97 & 50 & 104 & 94 & 50 \\
\hline 17 & 125 & 50 & 123 & 99 & 50 & 122 & 98 & 50 & 119 & 95 & 50 \\
\hline 24 & 139 & 50 & 137 & 99 & 50 & 135 & 98 & 50 & 132 & 95 & 50 \\
\hline 31 & 150 & 50 & 150 & 100. & 50 & 150 & 100 & 50 & 146 & 97 & 50 \\
\hline 38 & 158 & 50 & 159 & 101 & 50 & 157 & 99 & 50 & 154 & 97 & 50 \\
\hline 45 & 167 & 50 & 167 & 100 & 50 & 165 & 99 & 50 & 162 & 97 & 50 \\
\hline 52 & 173 & 50 & 173 & 100 & 50 & 170 & 98 & 50 & 168 & 97 & 50 \\
\hline 59 & 178 & 50 & 178 & 100 & 50 & 175 & 98 & 50 & 173 & 97 & 50 \\
\hline 66 & 183 & 50 & 181 & 99 & 50 & 180 & 99 & 50 & 177 & 97 & 50 \\
\hline 73 & 188 & 50 & 186 & 99 & 50 & 185 & 99 & 50 & 182 & 97 & 50 \\
\hline 80 & 191 & 50 & 192 & 101 & 50 & 191 & 100 & 50 & 187 & 98 & 50 \\
\hline 87 & 196 & 50 & 197 & 100 . & 50 & 194 & 99 & 50 & 191 & 98 & 50 \\
\hline 115 & 211 & 50 & 213 & 101 & 50 & 210 & 99 & 50 & 207 & 98 & 50 \\
\hline 143 & 222 & 50 & 225 & 101 & 50 & 221 & 99 & 50 & 218 & 98 & 49 \\
\hline 171 & 235 & 50 & 237 & 101 & 50 & 234 & 100 & 50 & 232 & 99 & 49 \\
\hline 199 & 245 & 50 & 249 & 102 & 50 & 245 & 100 & 50 & 243 & 99 & 49 \\
\hline
\end{tabular}


Vinylidene Chloride, NTP TR 582

\begin{tabular}{|c|c|c|c|c|c|c|c|c|c|c|c|}
\hline \multirow[b]{2}{*}{ Day } & \multicolumn{2}{|c|}{ Chamber Control } & \multicolumn{3}{|c|}{25 ppm } & \multicolumn{3}{|c|}{50 ppm } & \multicolumn{3}{|c|}{100 ppm } \\
\hline & $\begin{array}{l}\text { Av. } \\
\text { Wt. } \\
\text { (g) }\end{array}$ & $\begin{array}{l}\text { No. of } \\
\text { Survivors }\end{array}$ & $\begin{array}{l}\text { Av. } \\
\text { Wt. } \\
\text { (g) }\end{array}$ & $\begin{array}{l}\text { Wt. (\% of } \\
\text { Controls) }\end{array}$ & $\begin{array}{c}\text { No. of } \\
\text { Survivors }\end{array}$ & $\begin{array}{l}\text { Av. } \\
\text { Wt. } \\
\text { (g) }\end{array}$ & $\begin{array}{l}\text { Wt. (\% of } \\
\text { Controls) }\end{array}$ & $\begin{array}{c}\text { No. of } \\
\text { Survivors }\end{array}$ & $\begin{array}{l}\text { Av. } \\
\text { Wt. } \\
\text { (g) }\end{array}$ & $\begin{array}{l}\text { Wt. (\% of } \\
\text { Controls) }\end{array}$ & $\begin{array}{c}\text { No. of } \\
\text { Survivors }\end{array}$ \\
\hline 227 & 254 & 50 & 258 & 102 & 50 & 254 & 100 & 50 & 252 & 99 & 49 \\
\hline 255 & 264 & 50 & 267 & 101 & 50 & 264 & 100 & 50 & 260 & 99 & 49 \\
\hline 283 & 273 & 50 & 276 & 101 & 50 & 272 & 100 & 50 & 268 & 98 & 49 \\
\hline 311 & 284 & 50 & 286 & 101 & 50 & 283 & 100 & 50 & 279 & 98 & 49 \\
\hline 339 & 298 & 50 & 301 & 101 & 50 & 297 & 100 & 50 & 292 & 98 & 49 \\
\hline 367 & 308 & 50 & 312 & 101 & 50 & 307 & 100 & 50 & 300 & 98 & 49 \\
\hline 395 & 321 & 50 & 328 & 102 & 50 & 325 & 101 & 50 & 318 & 99 & 48 \\
\hline 423 & 330 & 50 & 337 & 102 & 50 & 331 & 100 & 48 & 323 & 98 & 48 \\
\hline 451 & 338 & 50 & 344 & 102 & 49 & 335 & 99 & 48 & 331 & 98 & 48 \\
\hline 479 & 343 & 50 & 352 & 103 & 48 & 342 & 100 & 48 & 333 & 97 & 48 \\
\hline 507 & 350 & 50 & 357 & 102 & 48 & 346 & 99 & 48 & 339 & 97 & 48 \\
\hline 535 & 352 & 50 & 359 & 102 & 47 & 350 & 99 & 45 & 343 & 98 & 48 \\
\hline 563 & 358 & 48 & 365 & 102 & 45 & 355 & 99 & 43 & 346 & 97 & 48 \\
\hline 591 & 362 & 47 & 371 & 102 & 44 & 360 & 99 & 41 & 354 & 98 & 45 \\
\hline 619 & 370 & 46 & 374 & 101 & 41 & 367 & 99 & 39 & 357 & 97 & 44 \\
\hline 647 & 376 & 45 & 379 & 101 & 37 & 367 & 98 & 37 & 357 & 95 & 40 \\
\hline 661 & 375 & 43 & 382 & 102 & 34 & 370 & 99 & 36 & 362 & 97 & 35 \\
\hline 675 & 374 & 41 & 379 & 102 & 33 & 380 & 102 & 33 & 364 & 97 & 33 \\
\hline 689 & 372 & 39 & 376 & 101 & 32 & 380 & 102 & 33 & 358 & 96 & 30 \\
\hline 703 & 372 & 34 & 378 & 102 & 30 & 379 & 102 & 32 & 356 & 96 & 25 \\
\hline 717 & 370 & 34 & 389 & 105 & 27 & 382 & 103 & 31 & 366 & 99 & 21 \\
\hline \multicolumn{12}{|c|}{ Mean for Weeks } \\
\hline $1-13$ & 157 & - & 157 & 100 & - & 155 & 99 & - & 152 & 97 & - \\
\hline $14-52$ & 254 & - & 257 & 101 & - & 253 & 100 & - & 250 & 98 & - \\
\hline $53-103$ & 354 & - & 361 & 102 & - & 355 & 100 & - & 344 & 97 & - \\
\hline
\end{tabular}

\section{Pathology and Statistical Analyses}

This section describes the statistically significant or biologically noteworthy changes in the incidences of malignant mesothelioma and mononuclear cell leukemia, and neoplasms and/or nonneoplastic lesions of the thyroid gland, kidney, urinary bladder, nose, lung, liver, ovary, clitoral gland, and mesentery. Summaries of the incidences of neoplasms and nonneoplastic lesions, statistical analyses of primary neoplasms that occurred with an incidence of at least $5 \%$ in at least one animal group, and historical incidences for the neoplasms mentioned in this section are presented in Appendix A for male rats and Appendix B for female rats. 
Malignant Mesothelioma: The incidences of malignant mesothelioma occurred with a positive trend and were significantly increased in all exposed groups of males (Table 9, Table A-1, and Table A-2). The peritoneal mesothelium covering the testis and epididymis was most often affected, similar to spontaneous mesothelioma. One male exposed to $25 \mathrm{ppm}$ also had mesotheliomas on the pleura and pericardium in addition to the testicular and epididymal sites. Malignant mesothelioma occurred in one $25 \mathrm{ppm}$ female (pleura, pericardium) and one exposed to $50 \mathrm{ppm}$ (peritoneum); these incidences were greater than those in the chamber control group, and no malignant mesotheliomas have occurred in 700 females in the historical control database (Table 9 and Table B-1). Malignant mesothelioma was characterized by sessile to arboriform and papillary proliferations of large, plump mesothelial cells with large nuclei, prominent nucleoli, and scant to moderate cytoplasm, supported by a fibrovascular stroma (Figure 9). In males, these neoplasms originated in the epididymis and testes, and disseminated throughout the peritoneum to multiple organs including the intestines, mesentery, pancreas, prostate gland, spleen, and liver.

Global gene expression profiling of mesotheliomas arising in male F344/N rats exposed to vinylidene chloride, spontaneous mesotheliomas in $\mathrm{F} 344 / \mathrm{N}$ rats, and cultured rat mesothelial cells (Fred-PE cells) showed that mesotheliomas from vinylidene chloride-exposed animals and control animals could be differentiated based on their genomic profiles, despite indistinguishable morphology (Appendix L). Moreover, while spontaneous mesotheliomas and mesotheliomas from vinylidene chloride-exposed animals harbored many similarities in pathway and gene dysregulation, including those associated with oncogenesis, growth factor pathways, embryonic development, matrix remodeling, and mesothelial markers, mesotheliomas from vinylidene chloride-exposed animals were distinguished from spontaneous mesotheliomas based on overrepresentation of genes associated with a proinflammatory response and immune dysregulation, including alterations in pathways associated with proinflammatory cytokines and chemokines, Jak/Stat mediators, complement factors, pattern recognition receptors and damageassociated molecular pattern molecules, interferon pathway mediators, activated macrophage products, cell surface receptors, and a variety of inflammatory mediators. 
Table 9. Incidences of Malignant Mesothelioma in Rats in the Two-year Inhalation Study of Vinylidene Chloride

\begin{tabular}{|c|c|c|c|c|}
\hline & $\begin{array}{l}\text { Chamber } \\
\text { Control }\end{array}$ & 25 ppm & $50 \mathrm{ppm}$ & 100 ppm \\
\hline \multicolumn{5}{|l|}{ Male } \\
\hline \multicolumn{5}{|c|}{ All Organs: Malignant Mesothelioma ${ }^{a}$} \\
\hline Overall rate & $1 / 50(2 \%)$ & $12 / 50(24 \%)$ & $28 / 50(56 \%)$ & $23 / 50(46 \%)$ \\
\hline Adjusted rate ${ }^{c}$ & $2.4 \%$ & $27.9 \%$ & $63.4 \%$ & $52.7 \%$ \\
\hline Terminal rate ${ }^{\mathrm{d}}$ & $0 / 25(0 \%)$ & $5 / 27(19 \%)$ & $10 / 22(46 \%)$ & $7 / 19(37 \%)$ \\
\hline First incidence (days) & 562 & 535 & 500 & 449 \\
\hline Poly-3 test ${ }^{\mathrm{e}}$ & $\mathrm{P}<0.001$ & $\mathrm{P}<0.001$ & $\mathrm{P}<0.001$ & $\mathrm{P}<0.001$ \\
\hline \multicolumn{5}{|l|}{ Female } \\
\hline \multicolumn{5}{|c|}{ All Organs: Malignant Mesothelioma ${ }^{f}$} \\
\hline Overall rate & $0 / 50(0 \%)$ & $1 / 50(2 \%)$ & $1 / 50(2 \%)$ & $0 / 50(0 \%)$ \\
\hline Adjusted rate & $0.0 \%$ & $2.4 \%$ & $2.4 \%$ & $0.0 \%$ \\
\hline Terminal rate & $0 / 30(0 \%)$ & $1 / 26(4 \%)$ & $0 / 29(0 \%)$ & $0 / 19(0 \%)$ \\
\hline First incidence (days) & $\_\mathrm{g}$ & $731(\mathrm{~T})$ & 634 & - \\
\hline Poly-3 test & $-{ }^{\mathrm{h}}$ & - & - & - \\
\hline
\end{tabular}

$\mathrm{T}=$ terminal kill.

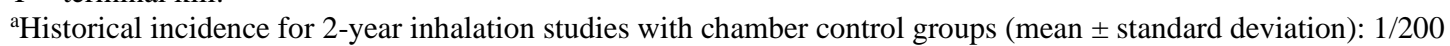

$(0.5 \% \pm 1.0 \%)$, range $0 \%-2 \%$; all routes: $26 / 699(3.7 \% \pm 3.1 \%)$, range $0 \%-8 \%$.

${ }^{\mathrm{b}}$ Number of animals with malignant mesothelioma per number of animals necropsied.

'Poly-3 estimated neoplasm incidence after adjustment for intercurrent mortality.

${ }^{\mathrm{d}}$ Observed incidence at terminal kill.

${ }^{\text {e} B e n e a t h ~ t h e ~ c h a m b e r ~ c o n t r o l ~ i n c i d e n c e ~ i s ~ t h e ~} \mathrm{P}$ value associated with the trend test. Beneath the exposed group incidence are the $\mathrm{P}$ values corresponding to pairwise comparisons between the chamber controls and that exposed group. The Poly-3 test accounts for differential mortality in animals that do not reach terminal kill.

${ }^{\mathrm{f}}$ Historical incidence for inhalation studies 0/200; all routes: 0/700.

gNot applicable; no neoplasms in animal group.

${ }^{\text {h}}$ Value of statistic not computed because all exposure groups have fewer than two neoplasms.

Thyroid Gland ( $\mathrm{C}$-Cell): The incidence of C-cell adenoma was significantly increased in $100 \mathrm{ppm}$ females, exceeded the historical control range for inhalation studies, and was at the upper end of the historical control range for all routes of administration (Table 10, Table B-1, Table B-2, and Table B-3). Incidences of carcinoma were increased in all exposed groups of females, and the incidence in the $25 \mathrm{ppm}$ group was significantly greater than that in the chamber controls The incidences of carcinoma in all exposed groups of females exceeded the historical control range for inhalation studies, and the incidence in the $25 \mathrm{ppm}$ group exceeded the historical control range for all routes of administration. The incidences of adenoma or carcinoma (combined) were significantly increased in 25 and 100 ppm females.

Thyroid gland C-cell adenomas were characterized by a discrete, small, well-demarcated focal proliferation of well-differentiated C-cells that comprised greater than the diameter of five contiguous follicles and caused variable compression of the adjacent thyroid gland parenchyma (Figure 10). Carcinomas were more infiltrative, less well-differentiated, and typically showed evidence of cellular atypia and mitotic activity (Figure 11). 
Table 10. Incidences of Neoplasms of the Thyroid Gland (C-Cell) in Female Rats in the Two-year Inhalation Study of Vinylidene Chloride

\begin{tabular}{|c|c|c|c|c|}
\hline & $\begin{array}{c}\text { Chamber } \\
\text { Control }\end{array}$ & 25 ppm & 50 ppm & 100 ppm \\
\hline \multicolumn{5}{|l|}{ Adenoma $^{a}$} \\
\hline Overall rate ${ }^{b}$ & $3 / 50(6 \%)$ & $4 / 50(8 \%)$ & $6 / 48(13 \%)$ & $11 / 50(22 \%)$ \\
\hline Adjusted rate ${ }^{c}$ & $6.6 \%$ & $9.5 \%$ & $14.6 \%$ & $26.2 \%$ \\
\hline Terminal rate ${ }^{\mathrm{d}}$ & $3 / 30(10 \%)$ & $2 / 26(8 \%)$ & $4 / 28(14 \%)$ & $6 / 19(32 \%)$ \\
\hline First incidence (days) & $731(\mathrm{~T})$ & 625 & 579 & 669 \\
\hline Poly-3 test ${ }^{\mathrm{e}}$ & $P=0.004$ & $P=0.461$ & $P=0.195$ & $P=0.012$ \\
\hline \multicolumn{5}{|l|}{ Carcinoma $^{\mathrm{f}}$} \\
\hline Overall rate & $0 / 50(0 \%)$ & $6 / 50(12 \%)$ & $2 / 48(4 \%)$ & $2 / 50(4 \%)$ \\
\hline Adjusted rate & $0.0 \%$ & $14.4 \%$ & $4.9 \%$ & $4.8 \%$ \\
\hline Terminal rate & $0 / 30(0 \%)$ & $6 / 26(23 \%)$ & $1 / 28(4 \%)$ & $1 / 19(5 \%)$ \\
\hline First incidence (days) & $\_\mathrm{g}$ & $731(\mathrm{~T})$ & 670 & 670 \\
\hline Poly-3 test & $P=0.474$ & $P=0.011$ & $P=0.213$ & $P=0.218$ \\
\hline \multicolumn{5}{|l|}{ Adenoma or Carcinoma $^{\mathrm{h}}$} \\
\hline Overall rate & $3 / 50(6 \%)$ & $10 / 50(20 \%)$ & $8 / 48(17 \%)$ & $13 / 50(26 \%)$ \\
\hline Adjusted rate & $6.6 \%$ & $23.7 \%$ & $19.3 \%$ & $30.8 \%$ \\
\hline Terminal rate & $3 / 30(10 \%)$ & $8 / 26(31 \%)$ & $5 / 28(18 \%)$ & $7 / 19(37 \%)$ \\
\hline First incidence (days) & $731(\mathrm{~T})$ & 625 & 579 & 669 \\
\hline Poly-3 test & $P=0.006$ & $\mathrm{P}=0.023$ & $\mathrm{P}=0.071$ & $P=0.003$ \\
\hline
\end{tabular}

$\mathrm{T}=$ terminal kill.

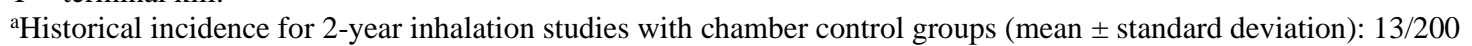

$(6.5 \% \pm 1.0 \%)$, range $6 \%-8 \%$; all routes: $81 / 690(11.7 \% \pm 5.5 \%)$, range $6 \%-22 \%$.

${ }^{b}$ Number of animals with neoplasm per number of animals with thyroid gland examined microscopically.

'Poly-3 estimated neoplasm incidence after adjustment for intercurrent mortality.

${ }^{\mathrm{d} O b s e r v e d ~ i n c i d e n c e ~ a t ~ t e r m i n a l ~ k i l l . ~}$

${ }^{\mathrm{e} B e n e a t h}$ the chamber control incidence is the $\mathrm{P}$ value associated with the trend test. Beneath the exposed group incidence are the $\mathrm{P}$ values corresponding to pairwise comparisons between the chamber controls and that exposed group. The Poly-3 test accounts for differential mortality in animals that do not reach terminal kill.

${ }^{\mathrm{f}}$ Historical incidence for inhalation studies: $1 / 200(0.5 \% \pm 1.0 \%)$, range $0 \%-2 \%$; all routes: $6 / 690(0.9 \% \pm 2.0 \%)$, range $0 \%-7 \%$. gNot applicable; no neoplasms in animal group.

hHistorical incidence for inhalation studies: $14 / 200$ (7.0\% $\pm 1.2 \%)$, range 6\%-8\%; all routes: 87/690 (12.7\% $\pm 5.8 \%)$, range 6\%$22 \%$.

Mononuclear Cell Leukemia: The incidence of mononuclear cell leukemia was significantly increased in $100 \mathrm{ppm}$ females and exceeded the historical control ranges for inhalation studies and all routes of administration (Table 11, Table B-1, Table B-2, and Table B-4). 
Table 11. Incidences of Mononuclear Cell Leukemia in Female Rats in the Two-year Inhalation Study of Vinylidene Chloride

\begin{tabular}{lcccc}
\hline & $\begin{array}{c}\text { Chamber } \\
\text { Control }\end{array}$ & $\mathbf{2 5} \mathbf{~ p p m}$ & $\mathbf{5 0 ~ p p m}$ & $\mathbf{1 0 0} \mathbf{~ p p m}$ \\
\hline All Organs: Mononuclear Cell Leukemia $^{\mathrm{a}}$ & & & & \\
Overall rate $^{\mathrm{b}}$ & $10 / 50(20 \%)$ & $11 / 50(22 \%)$ & $13 / 50(26 \%)$ & $25 / 50(50 \%)$ \\
Adjusted rate $^{\mathrm{c}}$ & $21.4 \%$ & $24.6 \%$ & $28.3 \%$ & $54.6 \%$ \\
Terminal rate $^{\mathrm{d}}$ & $3 / 30(10 \%)$ & $4 / 26(15 \%)$ & $3 / 29(10 \%)$ & $8 / 19(42 \%)$ \\
First incidence (days) & 631 & 451 & 421 & 395 \\
Poly-3 test $^{\mathrm{e}}$ & $\mathrm{P}<0.001$ & $\mathrm{P}=0.457$ & $\mathrm{P}=0.300$ & $\mathrm{P}<0.001$ \\
\hline
\end{tabular}

${ }^{\mathrm{a}}$ Historical incidence for 2-year inhalation studies with chamber control groups (mean \pm standard deviation): 58/200

$(29.0 \% \pm 6.2 \%)$, range $20 \%-34 \%$; all routes: $165 / 700(23.6 \% \pm 8.2 \%)$, range $10 \%-36 \%$.

${ }^{b}$ Number of animals with mononuclear cell leukemia per number necropsied.

'Poly-3 estimated neoplasm incidence after adjustment for intercurrent mortality.

${ }^{\mathrm{d}}$ Observed incidence at terminal kill.

${ }^{\mathrm{e} B e n e a t h}$ the chamber control incidence is the $\mathrm{P}$ value associated with the trend test. Beneath the exposed group incidence are the $\mathrm{P}$ values corresponding to pairwise comparisons between the chamber controls and that exposed group. The Poly- 3 test accounts for differential mortality in animals that do not reach terminal kill.

Kidney: In the standard evaluation of the kidney, two 25 ppm males, one 50 ppm male, and one 100 ppm male had renal tubule carcinomas (Table 12 and Table A-1). Carcinomas were characterized by large, infiltrative proliferations of lobules and tubules of poorly differentiated renal tubule epithelial cells (Figure 12). Although not statistically significant, the incidence in the $25 \mathrm{ppm}$ group exceeded the historical control ranges for inhalation studies and all routes of administration (Table 12 and Table A-4). There was a single incidence of renal tubule adenoma in 50 ppm females; no renal tubule adenomas have occurred in 692 females in the historical control database (Table 12 and Table B-1). Renal tubule adenoma was composed of a small, expansile proliferation of fairly well-differentiated renal tubule epithelial cells causing compression of adjacent renal parenchyma (Figure 13).

Single incidences of renal tubule hyperplasia occurred in each exposed group of males, and slight increases in the incidences of this lesion occurred in 25 and 100 ppm females (Table 12, Table A-5, and Table B-6). This lesion did not occur in the concurrent chamber control males and was increased in severity in 100 ppm males. Renal tubule hyperplasia was characterized by few multifocal foci of enlarged tubule epithelial cells piling and filling the tubule lumen, often expanding to involve multiple tubule profiles (Figure 14). Hyperplasia of the transitional epithelium of the kidney occurred in one $50 \mathrm{ppm}$ and two $100 \mathrm{ppm}$ males and was characterized by similar crowding and piling of well-differentiated transitional epithelial cells.

Since there was evidence of a treatment-related effect in male rats, kidney step sections were performed to evaluate for additional proliferative lesions. The findings of the kidney step section evaluation in male rats (Table 12) indicated increased incidences of renal tubule hyperplasia in all exposed groups. Several newly diagnosed incidences of renal tubule adenoma were observed as a result of kidney step section review in male rats, although there was not a significant difference between exposed animals and chamber controls. No additional carcinomas were observed as the result of step section review. The final combined incidences of renal tubule adenoma or carcinoma resulting from the kidney step section review indicated slightly increased incidences in 25 and $50 \mathrm{ppm}$ male rats compared with concurrent chamber controls, but not in the 100 ppm group; one 25 ppm male had both an adenoma and a carcinoma. 
Table 12. Incidences of Neoplasms and Nonneoplastic Lesions of the Kidney in Rats in the Twoyear Inhalation Study of Vinylidene Chloride

\begin{tabular}{|c|}
\hline $\begin{array}{l}\text { Chamber } \\
\text { Control }\end{array}$ \\
\hline
\end{tabular}

\section{Male}

\section{Single Sections (Standard Evaluation)}

Number Examined Microscopically

Renal Tubule, Hyperplasia ${ }^{a}$

Transitional Epithelium, Hyperplasia

Renal Tubule, Carcinoma ${ }^{\mathrm{c}}$

50
0
0
0

50
$1(2.0)^{\mathrm{b}}$
0
2

49
$1(1.0)$
$1(3.0)$
1

Step Sections (Extended Evaluation)
Number Examined Microscopically
Renal Tubule Hyperplasia
Renal Tubule Adenoma

$$
50
$$

$$
3
$$

$5(2.2)$

\section{Single and Step Sections (Combined)}

Number Examined Microscopically

Renal Tubule Hyperplasia

Renal Tubule Adenoma

Renal Tubule Carcinoma

$1-1$

Renal Tubule Adenoma or Carcinoma

Overall rate $^{\mathrm{d}}$
Adjusted rate $^{\mathrm{e}}$
Terminal rate
First incidence (days)
Poly-3 test $^{\mathrm{g}}$

$\begin{array}{cc}3 / 50(6 \%) & 4 / 50(8 \%) \\ 7.2 \% & 9.8 \%\end{array}$

$$
6 / 49(12 \%)
$$

\section{Female}

Number Examined Microscopically

\begin{tabular}{ccccc} 
Renal Tubule, Hyperplasia & $1(2.0)$ & $2(2.5)$ & 0 & $2(3.0)$ \\
Renal Tubule, Adenoma $^{\mathrm{h}}$ & 0 & 0 & 1 & 0 \\
\hline
\end{tabular}

\section{$\mathrm{T}=$ terminal kill.}

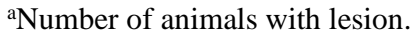

${ }^{\mathrm{b}}$ Average severity grade of lesions in affected animals: $1=$ minimal, $2=$ mild, $3=$ moderate, $4=$ marked.

${ }^{c}$ Historical incidence for 2 -year inhalation studies with chamber control groups (mean \pm standard deviation): 0/200; all routes: $1 / 697(0.1 \% \pm 0.5 \%)$, range $0 \%-2 \%$.

${ }^{\mathrm{d}}$ Number of animals with neoplasm per number of animals with kidney examined microscopically.

'Poly-3 estimated neoplasm incidence after adjustment for intercurrent mortality.

fObserved incidence at terminal kill.

${ }^{g}$ Beneath the chamber control incidence is the $\mathrm{P}$ value associated with the trend test. Beneath the exposed group incidence are the $\mathrm{P}$ values corresponding to pairwise comparisons between the chamber controls and that exposed group. The Poly- 3 test accounts for differential mortality in animals that do not reach terminal kill. A negative trend or a lower incidence in an exposure group is indicated by $\mathrm{N}$.

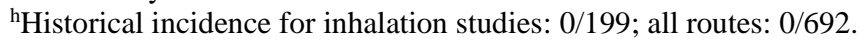


Urinary Bladder: Carcinoma of the transitional epithelium occurred in two $25 \mathrm{ppm}$ males (Table A-1); this incidence exceeded the historical control ranges for inhalation studies $(0 \%$; $0 / 199$ ) and all routes of administration ( $0 \%$ to $2 \% ; 1 / 698)$. Hyperplasia of the transitional epithelium of the urinary bladder, characterized by increased layers of well-differentiated transitional epithelial cells lining the mucosa, occurred in one $50 \mathrm{ppm}$ and two $100 \mathrm{ppm}$ males (Table A-5). The biologic significance of this neoplasm is uncertain; the incidence of this neoplasm was not believed to be related to vinylidene chloride exposure.

Nose: The only exposure-related primary nasal neoplasm observed was adenoma of the respiratory epithelium that was diagnosed in one $50 \mathrm{ppm}$ and four $100 \mathrm{ppm}$ male rats and one 100 ppm female rat (Table 13, Table A-1, Table A-2, and Table B-1). No respiratory epithelium adenomas have been seen in male historical controls, and the incidence in $100 \mathrm{ppm}$ females exceeded the historical control range for inhalation studies (Table 13 and Table B-5). Adenomas were typically small, polypoid masses arranged in glandular or papillary patterns and arose from the transitional epithelium lining the nasotubinates or the lateral wall of Level I (Figure 15). Neoplastic cells were relatively well differentiated, moderately sized, and polygonal with moderate amounts of lightly granular eosinophilic cytoplasm. Nuclei were also moderately sized and round to oval, with lightly stippled chromatin and one to two prominent basophilic to amphophilic nucleoli.

A variety of nonneoplastic lesions were observed in the nose of male and female rats exposed to vinylidene chloride. Exposure-related nonneoplastic nasal lesions primarily affected Level III, but often extended into Levels II and/or I in $100 \mathrm{ppm}$ rats, depending on the lesion. Turbinate atrophy was a striking lesion that occurred in every exposed male and female rat (Table 13, Table A-5, and Table B-6). This lesion was accompanied in most cases with turbinate hyperostosis, and the severity of both lesions increased with increasing exposure concentration. These lesions were not observed in chamber control rats. Turbinate atrophy was characterized by blunting, shortening, and sometimes loss of turbinates, particularly in Level III. Turbinate hyperostosis was characterized by bony remodeling resulting in thickened, nodular, misshapen turbinate bones. The turbinate changes were observed with and without extensive changes to the overlying epithelium, including respiratory metaplasia.

Olfactory epithelium respiratory metaplasia occurred in most exposed rats with exposure concentration-related increases in severity (Table 13, Table A-5, and Table B-6). This lesion was characterized by atrophy and replacement of the multilayered olfactory epithelium by a single layer of ciliated columnar epithelium. The metaplastic epithelium was often hyperplastic, with numerous folds in the mucosa, extending into the underlying lamina propria (pseudogland formation). Olfactory epithelium squamous metaplasia was less commonly observed, and the incidence in the $100 \mathrm{ppm}$ males was significantly increased. This lesion was characterized by loss of olfactory epithelium and replacement by single to multiple layers of flattened squamous epithelial cells.

Exposure concentration-related increased incidences of respiratory epithelium hyperplasia occurred in male and female rats, and the incidences in 50 and $100 \mathrm{ppm}$ males and in all exposed groups of females were significantly greater than those in the chamber controls (Table 13, Table A-5, and Table B-6). This lesion was characterized by thickening of the respiratory epithelium by increased numbers of cuboidal to ciliated columnar epithelial cells crowded in 
multiple layers, sometimes forming undulations with invaginations into the underlying lamina propria.

Incidences of chronic active inflammation were significantly increased in all exposed groups of male and female rats compared to the concurrent chamber controls, and the severities of the lesion increased with increasing exposure concentration (Table 13, Table A-5, and Table B-6). Chronic active inflammation was most prominent in Level III, but also affected Levels II and/or I when it was most severe. Inflammation was characterized by collections of neutrophils and mononuclear inflammatory cells in the airways or in the nasal mucosae. Incidences of thrombosis were sporadically observed in nasal vessels of male and female rats, particularly in the dorsal aspects of Level I; incidences of this lesion were significantly increased in $50 \mathrm{ppm}$ males and 100 ppm females. Inflammatory polyp occurred in three 100 ppm females; this lesion was characterized by exophytic and pedunculated masses within the nasal cavity, composed of loose connective tissue covered by a single layer of respiratory epithelium.

Lung: The incidences of alveolar epithelium hyperplasia were significantly increased in all exposed groups of males (Table 13 and Table A-5). In addition, an exposure concentrationrelated increase in severities of this lesion occurred. The alveolar epithelium hyperplasia was characterized by focal, discrete proliferations of flat to cuboidal, low columnar or hypertrophied epithelial cells (Type II pneumocytes) lining the alveolar septae that were thickened by increased amounts of interstitial collagen.

Table 13. Incidences of Neoplasms and Nonneoplastic Lesions of the Nose and Lung in Rats in the Two-year Inhalation Study of Vinylidene Chloride

\begin{tabular}{|c|c|c|c|c|}
\hline & $\begin{array}{c}\text { Chamber } \\
\text { Control }\end{array}$ & 25 ppm & 50 ppm & 100 ppm \\
\hline \multicolumn{5}{|l|}{ Male } \\
\hline Nose $^{a}$ & 49 & 50 & 50 & 50 \\
\hline Turbinate, Atrophy ${ }^{\mathrm{b}}$ & 0 & $50 * *(2.2)^{\mathrm{c}}$ & $50 * *(3.2)$ & $50 * *(3.8)$ \\
\hline Turbinate, Hyperostosis & 0 & $49 * *(2.1)$ & $50 * *(2.6)$ & $50 * *(2.9)$ \\
\hline Olfactory Epithelium, Metaplasia, Respiratory & $3(1.0)$ & $49 * *(2.5)$ & $49 * *(3.2)$ & $48 * *(3.5)$ \\
\hline Olfactory Epithelium, Metaplasia, Squamous & 0 & 0 & $1(2.0)$ & $5 *(1.2)$ \\
\hline Respiratory Epithelium, Hyperplasia & $5(1.6)$ & $8(1.5)$ & $22 * *(2.5)$ & $31 * *(2.3)$ \\
\hline Inflammation, Chronic Active & $9(1.2)$ & $36 * *(2.0)$ & $45 * *(2.7)$ & $48 * *(3.2)$ \\
\hline Thrombosis & $4(2.3)$ & $4(3.0)$ & $11 *(3.3)$ & $7(2.7)$ \\
\hline \multicolumn{5}{|l|}{ Respiratory Epithelium, Adenoma ${ }^{\mathrm{d}}$} \\
\hline Overall rate $^{\mathrm{e}}$ & $0 / 49(0 \%)$ & $0 / 50(0 \%)$ & $1 / 50(2 \%)$ & $4 / 50(8 \%)$ \\
\hline Adjusted rate ${ }^{\mathrm{f}}$ & $0.0 \%$ & $0.0 \%$ & $2.7 \%$ & $10.5 \%$ \\
\hline Terminal rate ${ }^{g}$ & $0 / 25(0 \%)$ & $0 / 27(0 \%)$ & $1 / 22(5 \%)$ & $3 / 19(16 \%)$ \\
\hline First incidence (days) & $-^{\mathrm{i}}$ & - & $729(\mathrm{~T})$ & 635 \\
\hline Poly-3 test ${ }^{\mathrm{h}}$ & $P=0.004$ & $-\mathrm{j}$ & $\mathrm{P}=0.483$ & $\mathrm{P}=0.051$ \\
\hline Lung & 50 & 50 & 50 & 50 \\
\hline Alveolar Epithelium Hyperplasia & $7(1.1)$ & $18 * *(1.5)$ & $14 *(1.6)$ & $14 *(2.3)$ \\
\hline
\end{tabular}




\begin{tabular}{|c|c|c|c|c|}
\hline & $\begin{array}{c}\text { Chamber } \\
\text { Control }\end{array}$ & 25 ppm & 50 ppm & 100 ppm \\
\hline \multicolumn{5}{|l|}{ Female } \\
\hline Nose & 50 & 50 & 50 & 50 \\
\hline Turbinate, Atrophy & 0 & $50 * *(2.8)$ & $50 * *(3.3)$ & $50 * *(4.0)$ \\
\hline Turbinate, Hyperostosis & 0 & $50 * *(1.9)$ & $50 * *(2.6)$ & $50 * *(2.8)$ \\
\hline Olfactory Epithelium, Metaplasia, Respiratory & $1(1.0)$ & $50 * *(2.8)$ & $50 * *(3.1)$ & $50 * *(3.6)$ \\
\hline Respiratory Epithelium, Hyperplasia & $4(1.3)$ & $12 *(1.6)$ & $14 * *(1.7)$ & $27 * *(2.1)$ \\
\hline Inflammation, Chronic Active & $7(1.4)$ & $45^{* *}(1.8)$ & $46 * *(2.0)$ & $46 * *(2.9)$ \\
\hline Thrombosis & 0 & $3(2.3)$ & $2(2.0)$ & $7 * *(2.3)$ \\
\hline Polyp, Inflammatory & 0 & 0 & 0 & $3(3.0)$ \\
\hline Respiratory Epithelium, Adenoma ${ }^{\mathrm{k}}$ & 0 & 0 & 0 & 1 \\
\hline \multicolumn{5}{|c|}{$\begin{array}{l}\text { *Significantly different }(\mathrm{P} \leq 0.05) \text { from the chamber control group by the Poly-3 test. } \\
* * \mathrm{P} \leq 0.01 \text {. }\end{array}$} \\
\hline \multicolumn{5}{|l|}{$\begin{array}{l}\text { anumber of animals with tissue examined microscopically. } \\
\text { bNumber of animals with lesion. }\end{array}$} \\
\hline \multicolumn{5}{|c|}{$\begin{array}{l}{ }^{\mathrm{d}} \text { Historical incidence for 2-year inhalation studies with chamber control groups (mean } \pm \text { standard deviation): 0/198; all routes: } \\
0 / 697 \text {. }\end{array}$} \\
\hline $\begin{array}{l}\text { eNumber of animals with neoplasm per number of anin } \\
\text { fPoly-3 estimated neoplasm incidence after adjustment } \\
\text { gobserved incidence at terminal kill. }\end{array}$ & $\begin{array}{l}\text { with tissue ex } \\
\text { ntercurrent } \mathrm{m}\end{array}$ & $\begin{array}{l}\text { ned microscop } \\
\text { lity. }\end{array}$ & lly. & \\
\hline \multicolumn{5}{|c|}{$\begin{array}{l}{ }^{h} \text { Beneath the chamber control incidence is the } \mathrm{P} \text { value associated with the trend test. Beneath the exposed group incidence are the } \\
\mathrm{P} \text { values corresponding to pairwise comparisons between the chamber controls and that exposed group. The Poly- } 3 \text { test accounts } \\
\text { for differential mortality in animals that do not reach terminal kill. }\end{array}$} \\
\hline
\end{tabular}

Liver: Significantly increased incidences of chronic inflammation occurred in all exposed groups of rats (Table 14, Table A-5, and Table B-6). While chamber control rats of both sexes had infiltrates composed of histiocytes and lymphocytes, chronic inflammation in exposed animals was characterized by lipid-laden macrophages as a predominant component of the inflammatory reaction. Severities of inflammation increased with increasing exposure concentration. In some rat livers, a granulomatous reaction characterized by histiocytes and variably sized multinucleated giant cells with abundant cytoplasm was observed. Increased incidences of diffuse fatty change occurred in all exposed groups of rats and severities of the lesion were increased in exposed groups of females. This lesion consisted of individual cells with micro and macrovesicular accumulation of intracellular lipid scattered throughout the parenchyma. Areas of diffuse fatty change often coalesced and bridged into bands throughout the tissue. Significantly increased incidences of necrosis occurred in the $50 \mathrm{ppm}$ male and 50 and $100 \mathrm{ppm}$ female rats.

Necrosis was characterized by focal hypereosinophilia, nuclear pyknosis and karyolysis, and loss of normal hepatic cord architecture. Incidences of cystic degeneration were significantly increased in the $100 \mathrm{ppm}$ male and 50 and $100 \mathrm{ppm}$ female rats compared to concurrent chamber controls. This lesion was characterized by hepatocellular dropout resulting in the formation of multifocal cyst-like structures sometimes containing finely granular or flocculent eosinophilic material or erythrocytes. 
Table 14. Incidences of Nonneoplastic Lesions of the Liver in Rats in the Two-year Inhalation Study of Vinylidene Chloride

\begin{tabular}{|c|c|c|c|c|}
\hline & $\begin{array}{c}\text { Chamber } \\
\text { Control }\end{array}$ & 25 ppm & $50 \mathrm{ppm}$ & 100 ppm \\
\hline \multicolumn{5}{|l|}{ Male } \\
\hline Number Examined Microscopically & 50 & 50 & 50 & 50 \\
\hline Inflammation Chronic ${ }^{a}$ & $28(1.0)^{\mathrm{b}}$ & $46^{* *}(1.2)$ & $46^{* *}(1.3)$ & $44 * *(1.9)$ \\
\hline Fatty Change, Diffuse & $4(2.0)$ & $19 * *(1.7)$ & $18^{* *}(1.7)$ & $26^{* *}(2.0)$ \\
\hline Necrosis & $2(2.5)$ & $6(2.8)$ & $8^{*}(2.6)$ & $6(2.3)$ \\
\hline Degeneration, Cystic & $2(2.0)$ & $5(2.8)$ & $7(1.9)$ & $12 * *(2.1)$ \\
\hline \multicolumn{5}{|l|}{ Female } \\
\hline Number Examined Microscopically & 50 & 50 & 50 & 50 \\
\hline Inflammation, Chronic & $42(1.0)$ & $48 *(1.4)$ & $49 * *(1.4)$ & $48 * *(2.1)$ \\
\hline Fatty Change, Diffuse & $19(1.2)$ & $30 *(1.7)$ & $26(1.7)$ & $30 * *(2.0)$ \\
\hline Necrosis & 0 & $3(1.7)$ & $5^{*}(2.2)$ & $11 * *(1.8)$ \\
\hline Degeneration, Cystic & 0 & $2(3.0)$ & $4 *(2.3)$ & $7 * *(2.7)$ \\
\hline \multicolumn{5}{|c|}{$\begin{array}{l}\text { *Significantly different }(\mathrm{P} \leq 0.05) \text { from the chamber control group by the Poly }-3 \text { test. } \\
* * \mathrm{P} \leq 0.01 \text {. } \\
\text { aNumber of animals with lesion. } \\
\text { bAverage severity grade of lesions in affected animals: } 1=\text { minimal, } 2=\text { mild, } 3=\text { moderate, } 4=\text { marked. }\end{array}$} \\
\hline \multicolumn{5}{|c|}{$\begin{array}{l}\text { Ovary: Incidences of bursa dilatation increased in an exposure concentration-related manner } \\
\text { (chamber control, } 5 / 50 ; 25 \mathrm{ppm}, 11 / 50 ; 50 \mathrm{ppm}, 17 / 50 ; 100 \mathrm{ppm}, 24 / 50 ; \text { Table B-6). Severities } \\
\text { of bursa dilatation were increased in all exposed female groups }(1.8,3.1,3.1,3.2) \text {. This lesion } \\
\text { was characterized by a diffuse distension of the space between the ovary and its bursal covering, } \\
\text { with thinning of the bursal wall. The biologic relevance of this lesion in exposed rats is } \\
\text { uncertain. }\end{array}$} \\
\hline
\end{tabular}

Other Organs: The incidence of clitoral gland adenoma in $25 \mathrm{ppm}$ females was greater than that in the chamber controls $(4 / 47,8 / 48,3 / 45,4 / 48$; Table B-1 and Table B-2) and exceeded the historical control range for inhalation studies $[8 / 196(4.2 \% \pm 3.9 \%$, range $0 \%-9 \%]$, but was within the historical control range for all routes of administration [56/696 $(8.1 \% \pm 6.1 \%$, range $0 \%$ to $24 \%$ ). In addition, the incidence of this neoplasm in the concurrent chamber controls is the highest incidence in inhalation studies in the historical database. The incidence of clitoral gland carcinoma was increased in $100 \mathrm{ppm}$ females $(1 / 47,0 / 48,0 / 45,5 / 48)$. The biologic significance of this neoplasm is uncertain; the incidence of this neoplasm was not believed to be related to vinylidene chloride exposure.

Incidences of fat necrosis of the mesentery were prevalent in all exposed groups of female rats $(13 / 13,19 / 20,22 / 23,23 / 24$; Table B-6), and severities of the lesion were unaffected by exposure concentration $(2.0,2.0,2.0,2.0)$. Histologic evaluation of this lesion was only performed when gross lesions in the mesenteric fat were observed. Fat necrosis of the mesentery was characterized by saponification and loss of normal adipocyte architecture admixed with karyorrhectic and mineralized debris. The pathogenesis of this lesion and its biologic significance are uncertain. There is also a treatment- and exposure concentration-related increase 
in fat necrosis in the companion mouse study. Localized fat necrosis may be related to the inflammatory lesions in the liver; however, this needs to be further substantiated.

\section{Mice}

\section{Two-week Study}

All male mice exposed to $100 \mathrm{ppm}$ or greater died within the first 4 days of exposure (Table 15). All females exposed to 200 or $400 \mathrm{ppm}$ were found dead following exposure on day 1 . One $50 \mathrm{ppm}$ male and one $100 \mathrm{ppm}$ female were removed dead before exposure on day 5 . The mean body weight gains of 25 and $50 \mathrm{ppm}$ males were significantly less than that of the chamber controls; the final mean body weights of these groups were $8 \%$ and $7 \%$ less, respectively, than that of the chamber control group. Two of five $50 \mathrm{ppm}$ males and all $100 \mathrm{ppm}$ males were lethargic. Abnormal breathing occurred in one of five $50 \mathrm{ppm}$ males and four of five $100 \mathrm{ppm}$ males. All 100 ppm female mice became thin, while one female exposed at this level also became lethargic, developed tremors, and was breathing abnormally.

Table 15. Survival and Body Weights of Mice in the Two-week Inhalation Study of Vinylidene Chloride $^{\text {a }}$

\begin{tabular}{|c|c|c|c|c|c|}
\hline $\begin{array}{c}\text { Concentration } \\
(\mathbf{p p m})\end{array}$ & Survival $^{b}$ & $\begin{array}{l}\text { Initial Body } \\
\text { Weight (g) }\end{array}$ & $\begin{array}{l}\text { Final Body } \\
\text { Weight (g) }\end{array}$ & $\begin{array}{l}\text { Change in Body } \\
\text { Weight (g) }\end{array}$ & $\begin{array}{c}\text { Final Weight } \\
\text { Relative to } \\
\text { Controls (\%) }\end{array}$ \\
\hline \multicolumn{6}{|l|}{ Male } \\
\hline 0 & $5 / 5$ & $23.1 \pm 0.6$ & $26.6 \pm 0.9$ & $3.6 \pm 0.6$ & \\
\hline 25 & $5 / 5$ & $23.6 \pm 0.3$ & $24.4 \pm 0.9$ & $0.8 \pm 0.6^{*}$ & 92 \\
\hline 50 & $4 / 5^{\mathrm{c}}$ & $23.6 \pm 0.4$ & $24.9 \pm 0.2$ & $1.3 \pm 0.6^{*}$ & 93 \\
\hline 100 & $0 / 5^{\mathrm{d}}$ & $23.7 \pm 0.2$ & - & - & - \\
\hline 200 & $0 / 5^{\mathrm{e}}$ & $23.3 \pm 0.4$ & - & - & - \\
\hline 400 & $0 / 5^{\mathrm{e}}$ & $23.3 \pm 0.6$ & - & - & - \\
\hline \multicolumn{6}{|l|}{ Female } \\
\hline 0 & $5 / 5$ & $19.7 \pm 0.4$ & $22.2 \pm 0.4$ & $2.5 \pm 0.4$ & \\
\hline 25 & $5 / 5$ & $19.9 \pm 0.2$ & $21.8 \pm 0.5$ & $2.0 \pm 0.5$ & 98 \\
\hline 50 & $5 / 5$ & $19.4 \pm 0.4$ & $21.4 \pm 0.3$ & $2.0 \pm 0.4$ & 96 \\
\hline 100 & $4 / 5^{\mathrm{c}}$ & $19.6 \pm 0.4$ & $22.2 \pm 0.7$ & $2.5 \pm 0.2$ & 100 \\
\hline 200 & $0 / 5^{\mathrm{e}}$ & $19.7 \pm 0.4$ & - & - & - \\
\hline 400 & $0 / 5^{\mathrm{e}}$ & $19.1 \pm 0.2$ & - & - & - \\
\hline
\end{tabular}

*Significantly different $(\mathrm{P} \leq 0.05)$ from the chamber control group by Dunnett's test.

${ }^{a}$ Weights and weight changes are given as mean \pm standard error. Subsequent calculations are based on animals surviving to the end of the study.

${ }^{b}$ Number of animals surviving at 17 days/number initially in group.

'Day of death: 5 .

${ }^{\mathrm{d}}$ Days of deaths: $3,4,4,4,4$.

e Day of deaths: 1 . 
In all surviving groups of exposed females, absolute and relative lung weights were significantly greater than those of the chamber controls (Table G-3). Absolute and relative liver weights of 50 and $100 \mathrm{ppm}$ females and relative liver weights of $25 \mathrm{ppm}$ females and 25 and $50 \mathrm{ppm}$ males were significantly greater than those of the chamber controls.

Gross lesions were observed at $100 \mathrm{ppm}$ and included pale or mottled livers in one male and one female, and pale kidney in one male mouse that survived more than 1 day of exposure.

In the nose, minimal necrosis of the respiratory epithelium occurred in all early-death male and female mice (Table 16). Necrosis involved the respiratory epithelium of the turbinates and lateral wall in Level I of the nose. Necrotic cells had increased cytoplasmic eosinophilia and were often sloughed into the nasal passages.

In the liver, necrosis occurred in all males and females exposed to $100 \mathrm{ppm}$ or greater, and in one male exposed to $50 \mathrm{ppm}$; in addition, regeneration occurred in the four $100 \mathrm{ppm}$ females that survived to the end of study (Table 16). Hepatic necrosis was moderate to marked in all earlydeath mice exposed to $100 \mathrm{ppm}$ or greater and minimal in the one $50 \mathrm{ppm}$ male. In the earlydeath animals, hepatic necrosis was characterized by hypereosinophilic coagulum in centrilobular or midzonal areas that often extended to periportal regions. It was minimal in the four 100 ppm female mice that survived to terminal kill and was characterized by individual hypereosinophilic hepatocytes that demonstrated nuclear karyolysis in centrilobular areas. Hepatic regeneration in these animals was most prominent in the midzonal region and was characterized by an increased density of hepatocytes that had increased cytoplasmic basophilia, rare binucleate forms, and mild to moderate anisokaryosis (variation in nuclear size).

Table 16. Incidences of Selected Nonneoplastic Lesions in Mice in the Two-week Inhalation Study of Vinylidene Chloride

\begin{tabular}{|c|c|c|c|c|c|c|}
\hline & $\begin{array}{c}\text { Chamber } \\
\text { Control }\end{array}$ & 25 ppm & 50 ppm & 100 ppm & 200 ppm & 400 ppm \\
\hline \multicolumn{7}{|l|}{ Male } \\
\hline Nose $^{\mathrm{a}}$ & 5 & 5 & 5 & 5 & 5 & 5 \\
\hline Respiratory Epithelium, Necrosis ${ }^{\mathrm{b}}$ & 0 & 0 & $1(1.0)^{\mathrm{c}}$ & $5 * *(1.0)$ & $5 * *(1.0)$ & $5 * *(1.0)$ \\
\hline Liver & 5 & 5 & 5 & 5 & 5 & 5 \\
\hline Necrosis & 0 & 0 & $1(1.0)$ & $5 * *(3.0)$ & $5 * *(4.0)$ & $5 * *(4.0)$ \\
\hline Kidney & 5 & 5 & 5 & 5 & 5 & 5 \\
\hline Renal Tubule, Necrosis & 0 & $5 * *(1.2)$ & $5 * *(1.6)$ & $5 * *(4.0)$ & $5 * *(4.0)$ & $5 * *(4.0)$ \\
\hline Cast Granular & 0 & $5 * *(1.8)$ & $5 * *(2.2)$ & $5 * *(3.0)$ & $5 * *(4.0)$ & $5 * *(4.0)$ \\
\hline Renal Tubule, Regeneration & 0 & $5 * *(2.8)$ & $4 *(3.0)$ & 0 & 0 & 0 \\
\hline \multicolumn{7}{|l|}{ Female } \\
\hline Nose & 5 & 0 & 5 & 5 & 5 & 5 \\
\hline Respiratory Epithelium, Necrosis & 0 & - & 0 & $1(1.0)$ & $5 * *(1.0)$ & $5 * *(1.0)$ \\
\hline Liver & 5 & 0 & 5 & 5 & 5 & 5 \\
\hline Necrosis & 0 & - & 0 & $5^{* *}(1.6)$ & $5^{* *}(4.0)$ & $5 * *(4.0)$ \\
\hline
\end{tabular}




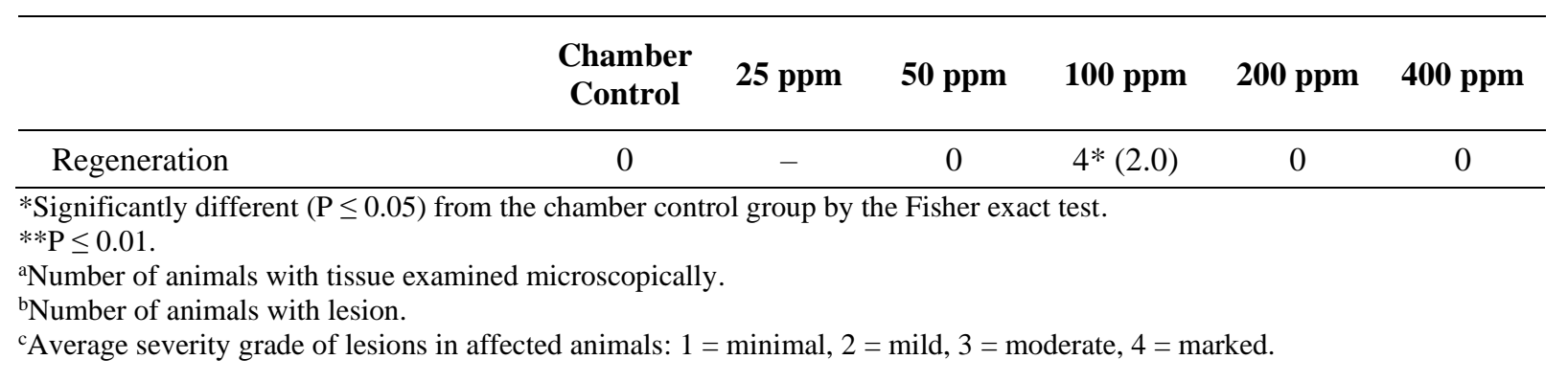

In the kidney, renal tubule necrosis and granular casts occurred in every exposed male (Table 16). The occurrence of granular casts and renal tubule necrosis and regeneration in all $25 \mathrm{ppm}$ males precluded the determination of a no-effect level. Incidences of marked renal tubule necrosis coincided with early deaths in all male mice exposed to $100 \mathrm{ppm}$ or greater. Incidences of minimal to moderate renal tubule necrosis and granular casts occurred in the 25 and $50 \mathrm{ppm}$ male groups. Mild to moderate renal tubule regeneration occurred in 25 and $50 \mathrm{ppm}$ males that survived until terminal sacrifice. Microscopically, renal tubule necrosis was characterized by attenuation, hypereosinophilia, nuclear pyknosis, and loss of tubular epithelium with sloughing into tubular lumens. Granular casts were composed of homogenous eosinophilic material, which often contained granular basophilic debris. Renal tubule regeneration was characterized by tubules with densely packed cuboidal tubule epithelium that often obscured the lumen, with deeply basophilic cytoplasm and prominent vesicular nuclei. Mitotic figures were occasionally seen. Additionally, these animals often had a mild interstitial to subscapular mononuclear inflammatory infiltrate.

Exposure Concentration Selection Rationale: Based on decreased survival of males in the 2week study, vinylidene chloride exposure concentrations selected for the 3-month inhalation study in male mice were $6.25,12.5,25$, and $50 \mathrm{ppm}$. Due to decreased survival of female mice in the 2-week study, vinylidene chloride exposure concentrations selected for the 3-month inhalation study in female mice were $6.25,12.5,25,50$, and $100 \mathrm{ppm}$.

\section{Three-month Study}

Two 50 ppm males and four 100 ppm females died during the first week of the study; all other mice survived until terminal kill (Table 17). The final mean body weights and body weight gains of all exposed groups of females and of males exposed to $12.5 \mathrm{ppm}$ or greater were significantly less than the those of the chamber control groups (Table 17 and Figure 6). There were no exposure-related clinical findings.

Gross lesions potentially related to exposure were observed in the lung (5/10) and liver (1/10) of $100 \mathrm{ppm}$ female mice and the liver (1/10) and kidney (2/10) of $50 \mathrm{ppm}$ male mice. Lung lesions included pale to white, 1 to $7 \mathrm{~mm}$ diameter foci; affected livers were mottled and/or red, and affected kidneys were diffusely pale and/or granular. 
Vinylidene Chloride, NTP TR 582

Table 17. Survival and Body Weights of Mice in the Three-month Inhalation Study of Vinylidene Chloride $^{\mathrm{a}}$

\begin{tabular}{|c|c|c|c|c|c|}
\hline $\begin{array}{c}\text { Concentration } \\
(\mathbf{p p m})\end{array}$ & Survival $^{b}$ & $\begin{array}{c}\text { Initial Body } \\
\text { Weight (g) }\end{array}$ & $\begin{array}{l}\text { Final Body } \\
\text { Weight (g) }\end{array}$ & $\begin{array}{l}\text { Change in Body } \\
\text { Weight (g) }\end{array}$ & $\begin{array}{c}\text { Final Weight } \\
\text { Relative to } \\
\text { Controls (\%) }\end{array}$ \\
\hline \multicolumn{6}{|l|}{ Male } \\
\hline 0 & $10 / 10$ & $23.2 \pm 0.4$ & $39.4 \pm 1.2$ & $16.2 \pm 1.1$ & \\
\hline 6.25 & $10 / 10$ & $23.4 \pm 0.3$ & $37.8 \pm 0.5$ & $14.3 \pm 0.3$ & 96 \\
\hline 12.5 & $10 / 10$ & $23.2 \pm 0.2$ & $35.5 \pm 0.6^{* *}$ & $12.3 \pm 0.6^{* *}$ & 90 \\
\hline 25 & $10 / 10$ & $23.4 \pm 0.2$ & $33.5 \pm 0.8 * *$ & $10.1 \pm 0.8 * *$ & 85 \\
\hline 50 & $8 / 10^{c}$ & $22.9 \pm 0.2$ & $33.0 \pm 0.5^{* *}$ & $10.0 \pm 0.4 * *$ & 84 \\
\hline \multicolumn{6}{|l|}{ Female } \\
\hline 0 & $10 / 10$ & $19.6 \pm 0.2$ & $35.2 \pm 1.2$ & $15.6 \pm 1.2$ & \\
\hline 6.25 & $10 / 10$ & $19.5 \pm 0.4$ & $30.8 \pm 0.6^{* *}$ & $11.4 \pm 0.7 * *$ & 88 \\
\hline 12.5 & $10 / 10$ & $20.1 \pm 0.3$ & $31.9 \pm 0.9 * *$ & $11.8 \pm 0.7 * *$ & 91 \\
\hline 25 & $10 / 10$ & $19.8 \pm 0.3$ & $30.9 \pm 0.8^{* *}$ & $11.1 \pm 0.6^{* *}$ & 88 \\
\hline 50 & $10 / 10$ & $19.6 \pm 0.4$ & $28.7 \pm 0.6^{* *}$ & $9.2 \pm 0.6^{* *}$ & 82 \\
\hline 100 & $6 / 10^{c}$ & $19.5 \pm 0.4$ & $29.9 \pm 0.8^{* *}$ & $10.0 \pm 0.4 * *$ & 85 \\
\hline
\end{tabular}

**Significantly different $(\mathrm{P} \leq 0.01)$ from the chamber control group by Williams' test.

${ }^{a}$ Weights and weight changes are given as mean \pm standard error. Subsequent calculations are based on animals surviving to the end of the study.

bumber of animals surviving at 14 weeks/number initially in group.

${ }^{c}$ Week of deaths: 1 . 
Vinylidene Chloride, NTP TR 582
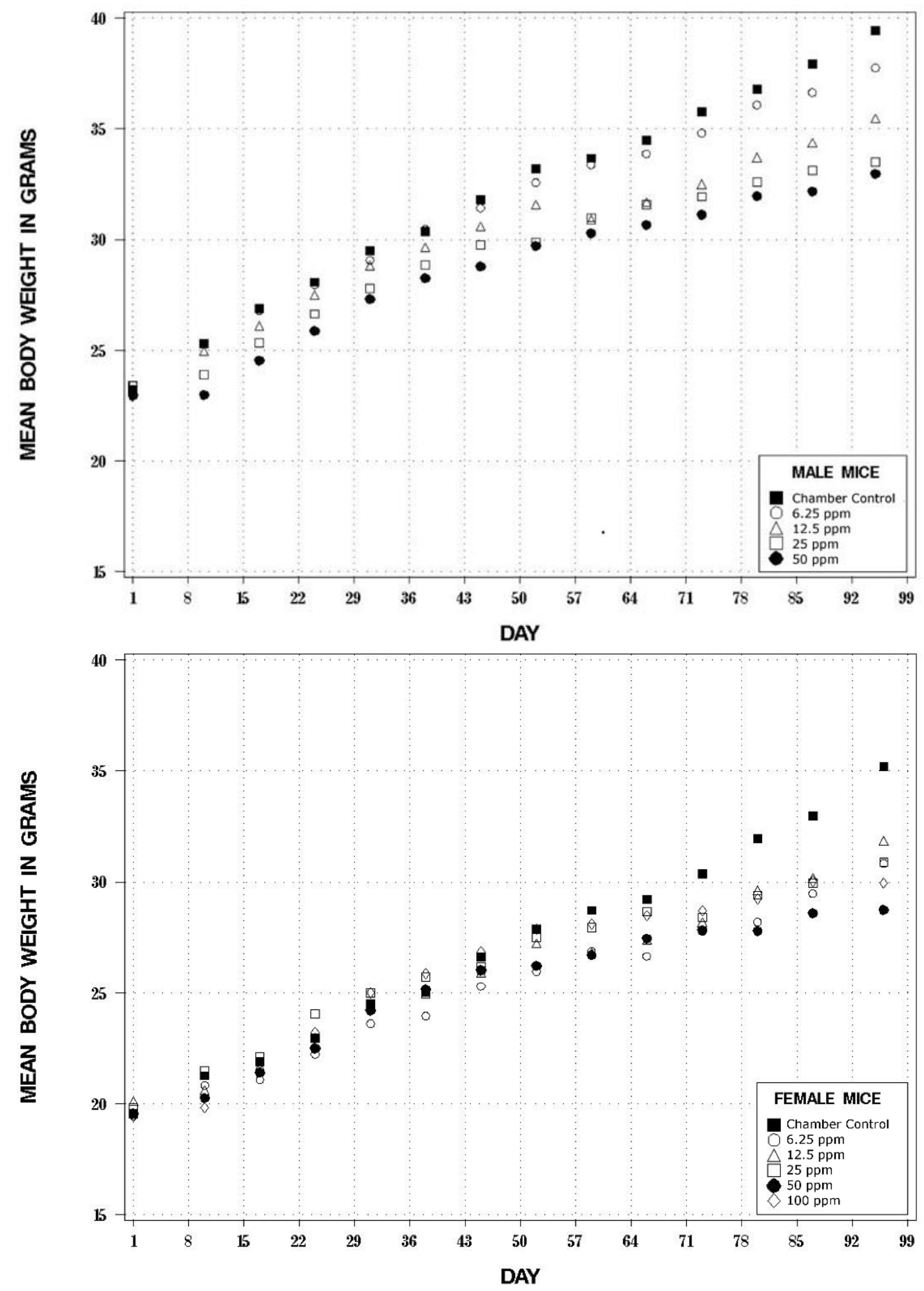

Figure 6. Growth Curves for Mice Exposed to Vinylidene Chloride by Inhalation for Three Months 
Hematology data for mice are presented in Table 18 and Table F-2. Exposure concentrationrelated decreases $(\leq 8 \%)$ in erythrocyte counts, hemoglobin concentrations, and hematocrit values occurred at the end of the study in 12.5, 25, and $50 \mathrm{ppm}$ male mice. Female mice had decreased erythrocyte counts in the 50 and 100 ppm groups, but the decreases $(\leq 4 \%)$ were less than those in males. In addition, hemoglobin concentration and the hematocrit value were decreased in $50 \mathrm{ppm}$ female mice, but not in the $100 \mathrm{ppm}$ group. The erythron decreases in the $12.5 \mathrm{ppm}$ and greater males and in the $50 \mathrm{ppm}$ females may be related to the observed decreases in body weight.

Absolute kidney weights of all exposed groups of males were significantly less than that of the chamber control group (Table G-4). Absolute and relative liver weights of $12.5 \mathrm{ppm}$ or greater females were significantly greater than those of the chamber controls. Relative liver weights were also increased in $6.25 \mathrm{ppm}$ females. Absolute and relative kidney and lung weights of $100 \mathrm{ppm}$ females were significantly greater than those of the chamber controls. Other organ weight differences were related to reduced body weight.

Relative to the chamber controls, male mice exposed to 25 or $50 \mathrm{ppm}$ exhibited nonsignificant decreases in cauda epididymis weights (18\% and 10\%, respectively) (Table H-3). Males exposed to $12.5,25$, or $50 \mathrm{ppm}$ had significant decreases in total sperm/cauda epididymis. No histopathologic changes in the contralateral organ were observed at necropsy. There were no changes in estrous cyclicity in females attributed to vinylidene chloride (Table H-4). These data suggest that vinylidene chloride has the potential to be a reproductive toxicant in male mice.

Table 18. Selected Hematology Data for Mice in the Three-month Inhalation Study of Vinylidene Chloride $^{\text {a }}$

\begin{tabular}{lcccccc}
\hline & $\begin{array}{c}\text { Chamber } \\
\text { Control }\end{array}$ & $\mathbf{6 . 2 5} \mathbf{~ p p m}$ & $\mathbf{1 2 . 5} \mathbf{~ p p m}$ & $\mathbf{2 5} \mathbf{~ p p m}$ & $\mathbf{5 0} \mathbf{~ p p m}$ & $\mathbf{1 0 0} \mathbf{~ p p m}$ \\
\hline Male & & & & & & \\
$\mathbf{n}$ & 10 & 10 & 10 & 10 & 8 & - \\
\hline Erythrocytes $\left(10^{6} / \mu \mathrm{L}\right)$ & $10.18 \pm 0.09$ & $9.96 \pm 0.09$ & $9.74 \pm 0.07^{* *}$ & $9.54 \pm 0.07^{* *}$ & $9.40 \pm 0.08^{* *}$ & - \\
Hemoglobin $(\mathrm{g} / \mathrm{dL})$ & $15.5 \pm 0.1$ & $15.1 \pm 0.1$ & $14.9 \pm 0.1^{* *}$ & $14.5 \pm 0.1^{* *}$ & $14.2 \pm 0.1^{* *}$ & - \\
Hematocrit (manual) $(\%)$ & $49.9 \pm 0.5$ & $48.6 \pm 0.3$ & $47.8 \pm 0.4^{* *}$ & $46.5 \pm 0.4^{* *}$ & $45.9 \pm 0.4^{* *}$ & - \\
\hline
\end{tabular}

\section{Female}

\begin{tabular}{|c|c|c|c|c|c|c|}
\hline $\mathbf{n}$ & 10 & 9 & 10 & 10 & 10 & 6 \\
\hline Erythrocytes $\left(10^{6} / \mu \mathrm{L}\right)$ & $10.19 \pm 0.09$ & $10.08 \pm 0.06$ & $10.02 \pm 0.07$ & $9.97 \pm 0.11$ & $9.73 \pm 0.09 * *$ & $9.80 \pm 0.08 * *$ \\
\hline Hemoglobin (g/dL) & $15.9 \pm 0.1$ & $15.7 \pm 0.1$ & $15.7 \pm 0.1$ & $15.6 \pm 0.2$ & $15.3 \pm 0.1^{*}$ & $15.7 \pm 0.1$ \\
\hline Hematocrit (manual) (\%) & $50.2 \pm 0.4$ & $49.8 \pm 0.4$ & $49.8 \pm 0.3$ & $49.3 \pm 0.4$ & $48.3 \pm 0.5^{* *}$ & $50.3 \pm 0.4$ \\
\hline
\end{tabular}

*Significantly different $(\mathrm{P} \leq 0.05)$ from the chamber control group by Dunn's or Shirley's test.

$* * \mathrm{P} \leq 0.01$.

${ }^{\text {aD }}$ ata are given as mean \pm standard error. Statistical tests were performed on unrounded data.

Kidney lesions, limited to males, consisted of renal tubule necrosis and protein cast formation in mice that experienced early death and nephropathy in those that survived to terminal kill (Table 19). Marked necrosis of the renal tubules and protein cast formation occurred in two $50 \mathrm{ppm}$ males. Minimal to moderate nephropathy occurred in the $12.5,25$, and $50 \mathrm{ppm}$ male 
groups. Decreases in the erythrocyte counts, hemoglobin concentration and hematocrit values also occurred in the same exposed groups. Renal tubule necrosis was seen as attenuation and/or loss of tubule epithelial cells with sloughing of pyknotic epithelial cells into tubule lumens. Renal tubule protein casts were present multifocally in tubule lumens as homogeneous, eosinophilic deposits that often contained granular basophilic cellular debris. Nephropathy was composed of minimal to mild tubule necrosis and cast formation; renal tubule regeneration; mild inflammatory infiltrates of lymphocytes, macrophages, and neutrophils within the interstitium and subcapsular areas; and occasional tubule mineralization.

Laryngeal lesions consisted of necrosis and respiratory epithelium hyperplasia and squamous metaplasia (Table 19). Necrosis was minimal and was only seen in early death 100 ppm females. Respiratory epithelium hyperplasia occurred in most 100 ppm females and respiratory epithelium squamous metaplasia occurred in a few males and many females exposed to 25 ppm or greater, with slight increases in severities and incidences in the female mice. Necrosis was characterized by marked cytoplasmic vacuolation of respiratory epithelium with flocculent to wispy cytoplasm containing eosinophilic droplets, and individual pyknotic, hypereosinophilic cells that sloughed into the laryngeal lumen. Necrosis was most prominent dorsolateral to the ventral pouch. Respiratory epithelium hyperplasia consisted of increased size and number of respiratory epithelial cells, and was most prominent in the epithelium overlying the submucosal glands at the base of the epiglottis. Respiratory epithelium squamous metaplasia was characterized by replacement of the normal ciliated columnar epithelium overlying the submucosal glands at the base of the epiglottis with approximately two to four layers of nonkeratinized, polygonal to flattened squamous epithelial cells.

Nonneoplastic lesions of the liver included necrosis in male and female mice and centrilobular hepatocyte hypertrophy in female mice (Table 19). Necrosis was marked in early death 100 ppm females and mild in early death $50 \mathrm{ppm}$ males. Hepatic necrosis was not evident in the $50 \mathrm{ppm}$ mice that survived to terminal kill. Mild to moderate centrilobular hepatocyte hypertrophy was observed in six 100 ppm female mice. Necrosis in mice that died early ranged from piecemeal necrosis (individual hypereosinophilic hepatocytes with nuclear pyknosis and karyolysis) to more extensive necrosis, characterized by a hypereosinophilic coagulum within the centrilobular to midzonal regions that often extended into periportal areas. Centrilobular hepatocyte hypertrophy was characterized by increased numbers of enlarged hepatocytes within centrilobular areas containing more deeply basophilic cytoplasm and enlarged, occasionally binucleate nuclei, moderate variation in nuclear size (anisokaryosis), and mitotic figures.

Exposure-related lung lesions were limited to $100 \mathrm{ppm}$ female mice and consisted of bronchial epithelium necrosis and histiocytic inflammation (Table 19). Bronchial epithelium necrosis occurred in four early-death females and two females that survived to terminal kill, and histiocytic inflammation occurred in all of the females that survived to terminal kill. Microscopically, bronchial epithelium necrosis was characterized by fragmentation and hypereosinophilia of bronchial epithelial cells, with sloughing into bronchial lumens. Histiocytic inflammation was characterized by focal alveolar infiltrates of foamy macrophages, often containing eosinophilic globular material, and associated with extracellular basophilic fibrillar or eosinophilic globular material. Small numbers of neutrophils were present within alveoli, the interstitium, and bordering vessels. 
Several females exposed to $100 \mathrm{ppm}$ vinylidene chloride had minimal to moderate necrosis of the nasal respiratory epithelium and minimal turbinate atrophy (Table 19). Male mice did not develop exposure-related nasal lesions. Respiratory epithelium necrosis occurred on the nasoturbinates and lateral wall of Level I of the nose in all early-death female mice and was characterized by hypereosinophilia and sloughing of cells and debris into the nasal passages. Turbinate atrophy occurred in four $100 \mathrm{ppm}$ females and consisted of blunting and attenuation of scrolls with bone loss and remodeling in Level III of the nose.

Table 19. Incidences of Selected Nonneoplastic Lesions in Mice in the Three-month Inhalation Study of Vinylidene Chloride

\begin{tabular}{|c|c|c|c|c|c|c|}
\hline & $\begin{array}{l}\text { Chamber } \\
\text { Control }\end{array}$ & $6.25 \mathrm{ppm}$ & $12.5 \mathrm{ppm}$ & 25 ppm & 50 ppm & 100 ppm \\
\hline \multicolumn{7}{|l|}{ Male } \\
\hline Kidney $^{\mathrm{a}}$ & 10 & 10 & 10 & 10 & 10 & - \\
\hline Renal Tubule Necrosis ${ }^{b}$ & 0 & 0 & 0 & 0 & $2(4.0)^{\mathrm{c}}$ & - \\
\hline Renal Tubule, Casts Protein & 0 & 0 & 0 & 0 & $2(4.0)$ & - \\
\hline Nephropathy & 0 & 0 & $5^{*}(1.2)$ & $10 * *(1.9)$ & $8 * *(2.5)$ & - \\
\hline Larynx & 10 & 10 & 10 & 10 & 10 & - \\
\hline $\begin{array}{l}\text { Respiratory Epithelium, Metaplasia, } \\
\text { Squamous }\end{array}$ & 0 & 0 & 0 & $1(1.0)$ & $4 *(1.0)$ & - \\
\hline Liver & 10 & 10 & 10 & 10 & 10 & - \\
\hline Necrosis & 0 & 0 & 0 & 0 & $2(2.0)$ & - \\
\hline \multicolumn{7}{|l|}{ Female } \\
\hline Larynx & 10 & 10 & 10 & 10 & 9 & 10 \\
\hline Respiratory Epithelium, Hyperplasia & 0 & 0 & 0 & 0 & 0 & $8^{* *}(1.4)$ \\
\hline $\begin{array}{l}\text { Respiratory Epithelium, Metaplasia, } \\
\text { Squamous }\end{array}$ & $1(1.0)$ & 0 & $1(2.0)$ & $3(1.3)$ & $9 * *(1.8)$ & $7 * *(2.4)$ \\
\hline Necrosis & 0 & 0 & 0 & 0 & 0 & $4 *(1.0)$ \\
\hline Liver & 10 & 10 & 10 & 10 & 10 & 10 \\
\hline Necrosis & 0 & 0 & $1(1.0)$ & 0 & 0 & $4 *(4.0)$ \\
\hline Hepatocyte, Centrilobular, Hypertrophy & 0 & 0 & 0 & 0 & 0 & $6^{* *}(2.8)$ \\
\hline Lung & 10 & 10 & 10 & 10 & 10 & 10 \\
\hline Bronchus, Epithelium, Necrosis & 0 & 0 & 0 & 0 & 0 & $6^{* *}(2.7)$ \\
\hline Inflammation, Histiocytic & 0 & 0 & 0 & 0 & 0 & $6^{* *}(1.7)$ \\
\hline Nose & 10 & 10 & 10 & 10 & 10 & 10 \\
\hline Respiratory Epithelium, Necrosis & 0 & 0 & 0 & 0 & 0 & $4 *(2.5)$ \\
\hline Turbinate, Atrophy & 0 & 0 & 0 & 0 & 0 & $4 *(1.0)$ \\
\hline
\end{tabular}

*Significantly different $(\mathrm{P} \leq 0.05)$ from the chamber control group by the Fisher exact test.

$* * \mathrm{P} \leq 0.01$.

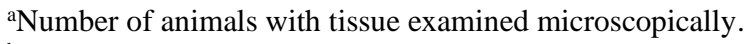

${ }^{b}$ Number of animals with lesion.

${ }^{\mathrm{c}}$ Average severity grade of lesions in affected animals: $1=$ minimal, $2=$ mild, $3=$ moderate, $4=$ marked.

Exposure Concentration Selection Rationale: In the 3-month study, there was increased mortality in $50 \mathrm{ppm}$ males and $100 \mathrm{ppm}$ females. Terminal body weights were reduced in all 
groups of males and females exposed to $12.5 \mathrm{ppm}$ or greater compared to the chamber control groups. In male mice, the incidences of nephropathy were significantly increased in the $12.5 \mathrm{ppm}$ or greater groups, and two $50 \mathrm{ppm}$ males had renal tubule necrosis and protein casts. The severity of nephropathy also increased with exposure. The incidence of respiratory epithelium squamous metaplasia of the larynx was also significantly increased in the $50 \mathrm{ppm}$ males. In female mice, exposure-related lesions occurred in the larynx, nose, and lung primarily in the $100 \mathrm{ppm}$ group. Based on these findings in the 3-month study, vinylidene chloride exposure concentrations selected for the 2-year inhalation study in mice were $6.25,12.5$, and $25 \mathrm{ppm}$.

\section{Two-year Study}

\section{Survival}

Estimates of 2-year survival probabilities for male and female mice are shown in Table 20 and in the Kaplan-Meier survival curves (Figure 7). Survival of $6.25 \mathrm{ppm}$ males was significantly greater than that of the chamber controls. Survival of $25 \mathrm{ppm}$ males and 6.25 and $25 \mathrm{ppm}$ females was significantly less than that of the chamber control groups.

\section{Body Weights and Clinical Findings}

Mean body weights of 12.5 and 25 ppm males were at least $10 \%$ less than those of the chamber control group after weeks 17 and 13, respectively (Table 21 and Table 22, Figure 8). Mean body weights of 25 ppm females were at least $10 \%$ less after week 21, and $20 \%$ less for weeks 48 to 93 of the study. Exposure-related clinical findings were observed in $25 \mathrm{ppm}$ males and included thinness and abnormal breathing. Exposure-related clinical findings observed in all exposed groups of females included abnormal breathing, thinness, and torso ventral mass.

\section{Gross Findings}

Gross lesions potentially related to vinylidene chloride exposure were observed in the kidney of male mice and ranged from pale, $1 \mathrm{~mm}$ cortical foci to large, occasionally bilateral masses that often replaced normal renal parenchyma.

Table 20. Incidences of Selected Nonneoplastic Lesions in Mice in the Two-year Inhalation Study of Vinylidene Chloride

\begin{tabular}{lcccc}
\hline & $\begin{array}{c}\text { Chamber } \\
\text { Control }\end{array}$ & $\mathbf{6 . 2 5} \mathbf{~ p p m}$ & $\mathbf{1 2 . 5} \mathbf{~ p p m}$ & $\mathbf{2 5} \mathbf{~ p p m}$ \\
\hline Male & & & & \\
Animals initially in study & 50 & 50 & 50 & 50 \\
Moribund & 12 & 5 & 14 & 19 \\
Natural deaths & 9 & 5 & 4 & 12 \\
Animals surviving to study termination & 29 & $40^{\mathrm{d}}$ & 32 & $19^{\mathrm{d}}$ \\
Percent probability of survival at end of study & $\mathrm{a}$ & 80 & 64 & 38 \\
Mean survival (days) $^{\mathrm{b}}$ & 68 & 713 & 674 & 645 \\
Survival analysis $^{\mathrm{c}}$ & $\mathrm{P}=0.001$ & $\mathrm{P}=0.022 \mathrm{~N}$ & $\mathrm{P}=0.791 \mathrm{~N}$ & $\mathrm{P}=0.038$ \\
\hline
\end{tabular}


Vinylidene Chloride, NTP TR 582

\begin{tabular}{lcccc}
\hline & $\begin{array}{c}\text { Chamber } \\
\text { Control }\end{array}$ & $\mathbf{6 . 2 5} \mathbf{~ p p m}$ & $\mathbf{1 2 . 5} \mathbf{~ p p m}$ & $\mathbf{2 5} \mathbf{~ p p m}$ \\
\hline Female & & & & \\
Animals initially in study & 50 & 50 & 50 & 50 \\
Moribund & 11 & 20 & 14 & 17 \\
Natural deaths & 3 & 5 & 6 & 9 \\
Animals surviving to study termination & 36 & 25 & 30 & $24^{\mathrm{d}}$ \\
Percent probability of survival at end of study & 72 & 50 & 60 & 48 \\
Mean survival (days) & 687 & 667 & 688 & 653 \\
Survival analysis & $\mathrm{P}=0.064$ & $\mathrm{P}=0.046$ & $\mathrm{P}=0.399$ & $\mathrm{P}=0.027$ \\
\hline
\end{tabular}

${ }^{a}$ Kaplan-Meier determinations

${ }^{b}$ Mean of all deaths (uncensored, censored, and terminal kill).

${ }^{\mathrm{c}}$ The result of the life table trend test ${ }^{100}$ is in the chamber control column, and the results of the life table pairwise comparisons ${ }^{99}$ with the chamber controls are in the exposed group columns. A lower mortality in an exposure group is indicated by $\mathrm{N}$.

dincludes one animal that died during the last week of the study. 

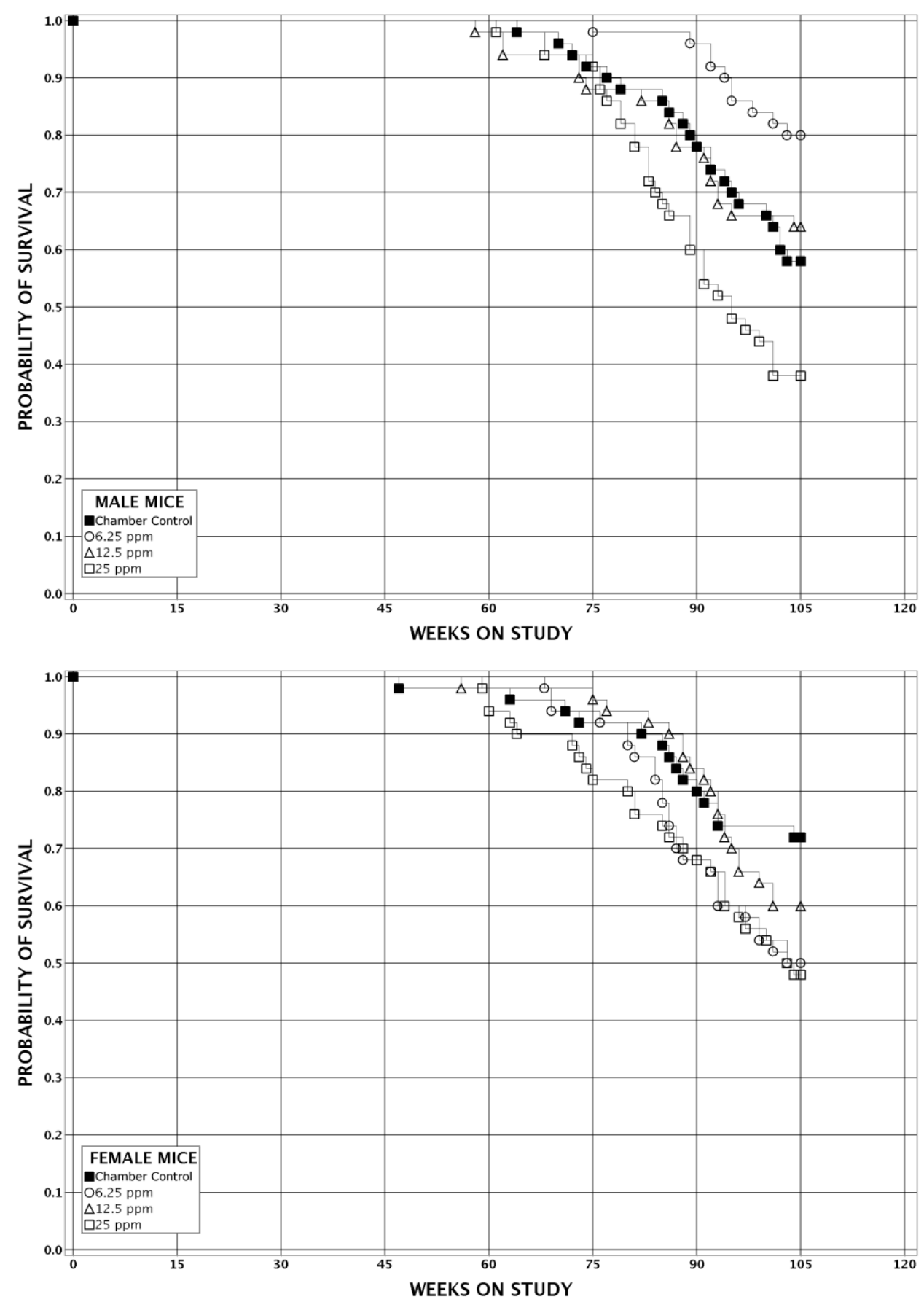

Figure 7. Kaplan-Meier Survival Curves for Mice Exposed to Vinylidene Chloride by Inhalation for Two Years 
Vinylidene Chloride, NTP TR 582

Table 21. Mean Body Weights and Survival of Male Mice in the Two-year Inhalation Study of Vinylidene Chloride

\begin{tabular}{|c|c|c|c|c|c|c|c|c|c|c|c|}
\hline \multirow[b]{2}{*}{ Day } & \multicolumn{2}{|c|}{$\begin{array}{c}\text { Chamber } \\
\text { Control }\end{array}$} & \multicolumn{3}{|c|}{6.25 ppm } & \multicolumn{3}{|c|}{$12.5 \mathrm{ppm}$} & \multicolumn{3}{|c|}{25 ppm } \\
\hline & $\begin{array}{l}\text { Av. } \\
\text { Wt. } \\
\text { (g) }\end{array}$ & $\begin{array}{c}\text { No. of } \\
\text { Survivors }\end{array}$ & $\begin{array}{l}\text { Av. } \\
\text { Wt. } \\
\text { (g) }\end{array}$ & $\begin{array}{l}\text { Wt. (\% of } \\
\text { Controls) }\end{array}$ & $\begin{array}{l}\text { No. of } \\
\text { Survivors }\end{array}$ & $\begin{array}{l}\text { Av. } \\
\text { Wt. } \\
\text { (g) }\end{array}$ & $\begin{array}{l}\text { Wt. (\% of } \\
\text { Controls) }\end{array}$ & $\begin{array}{c}\text { No. of } \\
\text { Survivors }\end{array}$ & $\begin{array}{l}\text { Av. } \\
\text { Wt. } \\
\text { (g) }\end{array}$ & $\begin{array}{l}\text { Wt. (\% of } \\
\text { Controls) }\end{array}$ & $\begin{array}{c}\text { No. of } \\
\text { Survivors }\end{array}$ \\
\hline 1 & 22.8 & 50 & 22.7 & 99 & 50 & 22.0 & 96 & 50 & 22.2 & 97 & 50 \\
\hline 11 & 24.6 & 50 & 24.8 & 101 & 50 & 23.9 & 97 & 50 & 23.3 & 95 & 50 \\
\hline 18 & 26.0 & 50 & 26.2 & 101 & 50 & 25.3 & 97 & 50 & 24.7 & 95 & 50 \\
\hline 25 & 27.3 & 50 & 27.5 & 101 & 50 & 26.8 & 98 & 50 & 26.4 & 97 & 50 \\
\hline 32 & 28.3 & 50 & 28.5 & 101 & 50 & 27.6 & 97 & 50 & 27.5 & 97 & 50 \\
\hline 39 & 29.5 & 50 & 29.8 & 101 & 50 & 28.8 & 98 & 50 & 28.5 & 97 & 50 \\
\hline 46 & 30.4 & 50 & 30.5 & 100 & 50 & 29.6 & 97 & 50 & 29.3 & 96 & 50 \\
\hline 53 & 31.6 & 50 & 31.2 & 99 & 50 & 30.0 & 95 & 50 & 29.9 & 95 & 50 \\
\hline 60 & 32.4 & 50 & 32.2 & 99 & 50 & 31.0 & 96 & 50 & 30.8 & 95 & 50 \\
\hline 67 & 33.5 & 50 & 33.1 & 99 & 50 & 31.6 & 95 & 50 & 31.4 & 94 & 50 \\
\hline 74 & 34.1 & 50 & 33.7 & 99 & 50 & 32.3 & 95 & 50 & 32.1 & 94 & 50 \\
\hline 81 & 35.5 & 50 & 34.7 & 98 & 50 & 33.0 & 93 & 50 & 32.9 & 93 & 50 \\
\hline 88 & 36.4 & 50 & 35.4 & 98 & 50 & 34.1 & 94 & 50 & 33.6 & 93 & 50 \\
\hline 116 & 39.8 & 50 & 38.3 & 96 & 50 & 36.6 & 92 & 50 & 36.0 & 90 & 50 \\
\hline 144 & 43.3 & 50 & 40.9 & 94 & 50 & 39.2 & 90 & 50 & 37.6 & 87 & 50 \\
\hline 172 & 46.1 & 50 & 43.5 & 94 & 50 & 41.3 & 90 & 50 & 38.4 & 83 & 50 \\
\hline 200 & 48.0 & 50 & 45.2 & 94 & 50 & 41.9 & 87 & 50 & 39.7 & 83 & 50 \\
\hline 228 & 49.5 & 50 & 47.3 & 96 & 50 & 43.6 & 88 & 50 & 40.7 & 82 & 50 \\
\hline 256 & 50.7 & 50 & 48.4 & 96 & 50 & 44.3 & 88 & 50 & 41.3 & 82 & 50 \\
\hline 284 & 51.2 & 50 & 49.3 & 96 & 50 & 44.9 & 88 & 50 & 41.7 & 82 & 50 \\
\hline 312 & 51.7 & 50 & 50.1 & 97 & 50 & 45.5 & 88 & 50 & 42.3 & 82 & 50 \\
\hline 341 & 52.0 & 50 & 50.5 & 97 & 50 & 45.9 & 88 & 50 & 42.3 & 81 & 50 \\
\hline 368 & 52.5 & 50 & 51.2 & 98 & 50 & 46.4 & 88 & 50 & 43.1 & 82 & 50 \\
\hline 396 & 52.1 & 50 & 51.6 & 99 & 50 & 46.7 & 90 & 50 & 43.3 & 83 & 50 \\
\hline 424 & 52.8 & 50 & 51.7 & 98 & 50 & 46.8 & 89 & 49 & 43.1 & 82 & 50 \\
\hline 452 & 52.9 & 49 & 52.1 & 99 & 50 & 46.9 & 89 & 47 & 43.3 & 82 & 49 \\
\hline 480 & 53.0 & 49 & 52.2 & 99 & 50 & 46.9 & 89 & 47 & 43.5 & 82 & 47 \\
\hline 508 & 52.4 & 47 & 51.7 & 99 & 50 & 47.0 & 90 & 46 & 43.1 & 82 & 47 \\
\hline 536 & 52.7 & 45 & 51.8 & 98 & 49 & 47.2 & 89 & 44 & 43.0 & 82 & 44 \\
\hline 564 & 52.4 & 44 & 51.6 & 99 & 49 & 46.8 & 89 & 44 & 43.3 & 83 & 39 \\
\hline 592 & 52.3 & 43 & 51.0 & 98 & 49 & 46.1 & 88 & 43 & 43.4 & 83 & 34 \\
\hline
\end{tabular}




\begin{tabular}{|c|c|c|c|c|c|c|c|c|c|c|c|}
\hline \multirow[b]{2}{*}{ Day } & \multicolumn{2}{|c|}{$\begin{array}{l}\text { Chamber } \\
\text { Control }\end{array}$} & \multicolumn{3}{|c|}{$6.25 \mathrm{ppm}$} & \multicolumn{3}{|c|}{12.5 ppm } & \multicolumn{3}{|c|}{25 ppm } \\
\hline & $\begin{array}{l}\text { Av. } \\
\text { Wt. } \\
\text { (g) }\end{array}$ & $\begin{array}{c}\text { No. of } \\
\text { Survivors }\end{array}$ & $\begin{array}{l}\text { Av. } \\
\text { Wt. } \\
\text { (g) }\end{array}$ & $\begin{array}{l}\text { Wt. (\% of } \\
\text { Controls) }\end{array}$ & $\begin{array}{c}\text { No. of } \\
\text { Survivors }\end{array}$ & $\begin{array}{l}\text { Av. } \\
\text { Wt. } \\
\text { (g) }\end{array}$ & $\begin{array}{l}\text { Wt. (\% of } \\
\text { Controls) }\end{array}$ & $\begin{array}{c}\text { No. of } \\
\text { Survivors }\end{array}$ & $\begin{array}{l}\text { Av. } \\
\text { Wt. } \\
\text { (g) }\end{array}$ & $\begin{array}{l}\text { Wt. (\% of } \\
\text { Controls) }\end{array}$ & $\begin{array}{c}\text { No. of } \\
\text { Survivors }\end{array}$ \\
\hline 620 & 52.0 & 41 & 50.4 & 97 & 48 & 46.2 & 89 & 39 & 42.7 & 82 & 30 \\
\hline 648 & 52.2 & 37 & 50.8 & 97 & 46 & 46.5 & 89 & 34 & 43.0 & 82 & 26 \\
\hline 662 & 52.9 & 35 & 50.9 & 96 & 44 & 46.0 & 87 & 33 & 42.5 & 81 & 25 \\
\hline 676 & 53.1 & 34 & 50.6 & 95 & 43 & 45.5 & 86 & 33 & 42.2 & 80 & 23 \\
\hline 690 & 52.5 & 34 & 50.3 & 96 & 42 & 45.0 & 86 & 33 & 41.5 & 79 & 23 \\
\hline 704 & 52.2 & 32 & 49.6 & 95 & 41 & 43.9 & 84 & 33 & 41.0 & 79 & 20 \\
\hline 718 & 52.5 & 30 & 49.4 & 94 & 40 & 43.6 & 83 & 33 & 40.1 & 76 & 19 \\
\hline \multicolumn{12}{|c|}{ Mean for Weeks } \\
\hline $1-13$ & 30.2 & - & 30.0 & 99 & - & 28.9 & 96 & - & 28.7 & 95 & - \\
\hline $14-52$ & 48.0 & - & 45.9 & 96 & - & 42.6 & 89 & - & 40.0 & 83 & - \\
\hline 53-103 & 52.5 & - & 51.1 & 97 & - & 46.1 & 88 & - & 42.6 & 81 & - \\
\hline
\end{tabular}

Table 22. Mean Body Weights and Survival Female Mice in the Two-year Inhalation Study of Vinylidene Chloride

\begin{tabular}{|c|c|c|c|c|c|c|c|c|c|c|c|}
\hline \multirow[b]{2}{*}{ Day } & \multicolumn{2}{|c|}{$\begin{array}{c}\text { Chamber } \\
\text { Control }\end{array}$} & \multicolumn{3}{|c|}{6.25 ppm } & \multicolumn{3}{|c|}{$12.5 \mathrm{ppm}$} & \multicolumn{3}{|c|}{$25 \mathrm{ppm}$} \\
\hline & $\begin{array}{l}\text { Av. } \\
\text { Wt. } \\
\text { (g) }\end{array}$ & $\begin{array}{c}\text { No. of } \\
\text { Survivors }\end{array}$ & $\begin{array}{l}\text { Av. } \\
\text { Wt. } \\
\text { (g) }\end{array}$ & $\begin{array}{l}\text { Wt. (\% of } \\
\text { Controls) }\end{array}$ & $\begin{array}{c}\text { No. of } \\
\text { Survivors }\end{array}$ & $\begin{array}{l}\text { Av. } \\
\text { Wt. } \\
\text { (g) }\end{array}$ & $\begin{array}{l}\text { Wt. (\% of } \\
\text { Controls) }\end{array}$ & $\begin{array}{c}\text { No. of } \\
\text { Survivors }\end{array}$ & $\begin{array}{l}\text { Av. } \\
\text { Wt. } \\
\text { (g) }\end{array}$ & $\begin{array}{l}\text { Wt. }(\% \text { of } \\
\text { Controls) }\end{array}$ & $\begin{array}{c}\text { No. of } \\
\text { Survivors }\end{array}$ \\
\hline 1 & 19.1 & 50 & 19.1 & 100 & 50 & 18.7 & 98 & 50 & 18.8 & 99 & 50 \\
\hline 11 & 21.0 & 50 & 21.1 & 101 & 50 & 20.9 & 100 & 50 & 20.5 & 98 & 50 \\
\hline 18 & 21.7 & 50 & 21.9 & 101 & 50 & 21.6 & 100 & 50 & 21.5 & 99 & 50 \\
\hline 25 & 22.5 & 50 & 23.0 & 102 & 50 & 22.9 & 102 & 50 & 23.0 & 102 & 50 \\
\hline 32 & 23.8 & 50 & 24.2 & 102 & 50 & 23.9 & 100 & 50 & 23.9 & 100 & 50 \\
\hline 39 & 25.0 & 50 & 25.1 & 100 & 50 & 25.2 & 101 & 50 & 24.9 & 99 & 50 \\
\hline 46 & 25.9 & 50 & 26.0 & 101 & 50 & 26.1 & 101 & 50 & 25.6 & 99 & 50 \\
\hline 53 & 26.1 & 50 & 27.1 & 104 & 50 & 26.8 & 103 & 50 & 26.5 & 102 & 50 \\
\hline 60 & 26.7 & 50 & 27.6 & 103 & 50 & 27.4 & 103 & 50 & 26.8 & 100 & 50 \\
\hline 67 & 27.8 & 50 & 28.6 & 103 & 50 & 28.2 & 101 & 50 & 27.4 & 99 & 50 \\
\hline 74 & 28.7 & 50 & 29.2 & 102 & 50 & 28.9 & 101 & 50 & 27.7 & 97 & 50 \\
\hline 81 & 29.0 & 50 & 30.4 & 105 & 50 & 29.9 & 103 & 50 & 28.8 & 99 & 50 \\
\hline 88 & 29.6 & 50 & 30.6 & 104 & 50 & 30.9 & 105 & 50 & 29.5 & 100 & 50 \\
\hline 116 & 32.5 & 50 & 34.9 & 107 & 50 & 34.9 & 107 & 50 & 31.9 & 98 & 50 \\
\hline 144 & 36.9 & 50 & 38.7 & 105 & 50 & 38.6 & 104 & 50 & 34.3 & 93 & 50 \\
\hline
\end{tabular}


Vinylidene Chloride, NTP TR 582

\begin{tabular}{|c|c|c|c|c|c|c|c|c|c|c|c|}
\hline \multirow[b]{2}{*}{ Day } & \multicolumn{2}{|c|}{$\begin{array}{c}\text { Chamber } \\
\text { Control }\end{array}$} & \multicolumn{3}{|c|}{$6.25 \mathrm{ppm}$} & \multicolumn{3}{|c|}{$12.5 \mathrm{ppm}$} & \multicolumn{3}{|c|}{$25 \mathrm{ppm}$} \\
\hline & $\begin{array}{l}\text { Av. } \\
\text { Wt. } \\
\text { (g) }\end{array}$ & $\begin{array}{c}\text { No. of } \\
\text { Survivors }\end{array}$ & $\begin{array}{l}\text { Av. } \\
\text { Wt. } \\
\text { (g) }\end{array}$ & $\begin{array}{l}\text { Wt. (\% of } \\
\text { Controls) }\end{array}$ & $\begin{array}{c}\text { No. of } \\
\text { Survivors }\end{array}$ & $\begin{array}{l}\text { Av. } \\
\text { Wt. } \\
\text { (g) }\end{array}$ & $\begin{array}{l}\text { Wt. (\% of } \\
\text { Controls) }\end{array}$ & $\begin{array}{c}\text { No. of } \\
\text { Survivors }\end{array}$ & $\begin{array}{l}\text { Av. } \\
\text { Wt. } \\
\text { (g) }\end{array}$ & $\begin{array}{l}\text { Wt. (\% of } \\
\text { Controls) }\end{array}$ & $\begin{array}{c}\text { No. of } \\
\text { Survivors }\end{array}$ \\
\hline 172 & 40.4 & 50 & 41.5 & 103 & 50 & 41.3 & 102 & 50 & 35.6 & 88 & 50 \\
\hline 200 & 43.3 & 50 & 45.0 & 104 & 50 & 43.3 & 100 & 50 & 38.0 & 88 & 50 \\
\hline 228 & 46.4 & 50 & 47.8 & 103 & 50 & 46.4 & 100 & 50 & 39.8 & 86 & 50 \\
\hline 256 & 49.1 & 50 & 50.9 & 104 & 50 & 49.5 & 101 & 50 & 41.4 & 84 & 50 \\
\hline 284 & 51.5 & 50 & 53.6 & 104 & 50 & 52.1 & 101 & 50 & 43.3 & 84 & 50 \\
\hline 312 & 54.7 & 50 & 56.6 & 103 & 50 & 54.3 & 99 & 50 & 44.6 & 82 & 50 \\
\hline 341 & 57.4 & 49 & 58.1 & 101 & 50 & 55.6 & 97 & 50 & 44.9 & 78 & 50 \\
\hline 368 & 60.0 & 49 & 60.3 & 101 & 50 & 57.6 & 96 & 50 & 47.3 & 79 & 50 \\
\hline 396 & 62.3 & 49 & 61.7 & 99 & 50 & 59.0 & 95 & 49 & 48.0 & 77 & 50 \\
\hline 424 & 63.3 & 49 & 62.5 & 99 & 50 & 60.2 & 95 & 49 & 48.8 & 77 & 47 \\
\hline 452 & 64.2 & 48 & 63.8 & 100 & 50 & 61.2 & 95 & 49 & 49.5 & 77 & 45 \\
\hline 480 & 64.8 & 48 & 64.5 & 100 & 47 & 61.5 & 95 & 49 & 50.2 & 77 & 45 \\
\hline 508 & 64.6 & 47 & 64.0 & 99 & 47 & 61.9 & 96 & 49 & 51.2 & 79 & 43 \\
\hline 536 & 65.1 & 46 & 64.2 & 99 & 46 & 62.7 & 96 & 47 & 51.3 & 79 & 41 \\
\hline 564 & 65.1 & 46 & 63.8 & 98 & 43 & 62.2 & 96 & 47 & 52.2 & 80 & 38 \\
\hline 592 & 65.2 & 44 & 63.4 & 97 & 39 & 61.7 & 95 & 46 & 52.3 & 80 & 37 \\
\hline 620 & 65.2 & 41 & 63.7 & 98 & 34 & 61.3 & 94 & 42 & 51.6 & 79 & 35 \\
\hline 648 & 66.0 & 38 & 61.1 & 93 & 31 & 60.9 & 92 & 38 & 51.6 & 78 & 33 \\
\hline 662 & 64.5 & 37 & 59.9 & 93 & 30 & 61.1 & 95 & 36 & 52.0 & 81 & 30 \\
\hline 676 & 63.8 & 37 & 60.1 & 94 & 29 & 60.9 & 96 & 33 & 52.3 & 82 & 28 \\
\hline 690 & 62.9 & 37 & 58.9 & 94 & 27 & 60.0 & 96 & 32 & 51.9 & 83 & 28 \\
\hline 704 & 61.4 & 37 & 58.1 & 95 & 27 & 59.8 & 97 & 30 & 51.1 & 83 & 27 \\
\hline 718 & 60.3 & 37 & 57.4 & 95 & 26 & 58.8 & 97 & 30 & 50.2 & 83 & 26 \\
\hline \multicolumn{12}{|c|}{ Mean for Weeks } \\
\hline $1-13$ & 25.1 & - & 25.7 & 102 & - & 25.5 & 101 & - & 25.0 & 99 & - \\
\hline $14-52$ & 45.8 & - & 47.5 & 104 & - & 46.2 & 101 & - & 39.3 & 86 & - \\
\hline 53-103 & 63.7 & - & 61.7 & 97 & - & 60.7 & 95 & - & 50.7 & 80 & - \\
\hline
\end{tabular}



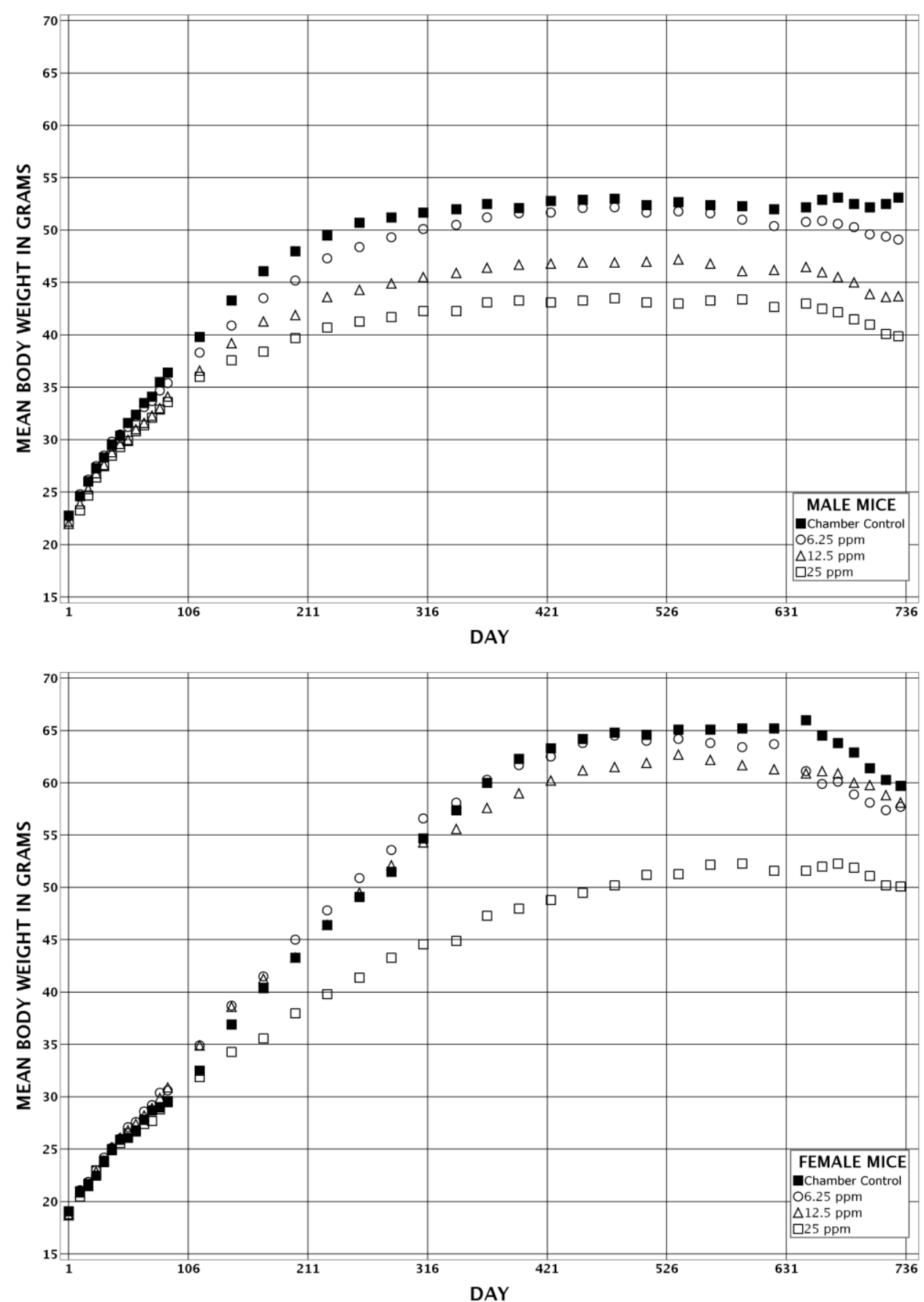

Figure 8. Growth Curves for Mice Exposed to Vinylidene Chloride by Inhalation for Two Years 


\section{Pathology and Statistical Analyses}

This section describes the statistically significant or biologically noteworthy changes in the incidences of hemangioma and hemangiosarcoma and neoplasms and/or nonneoplastic lesions of the kidney, liver, lung, small intestine, nose, mesentery, and uterus. Summaries of the incidences of neoplasms and nonneoplastic lesions, statistical analyses of primary neoplasms that occurred with an incidence of at least 5\% in at least one animal group, and historical incidences for the neoplasms mentioned in this section are presented in Appendix $\mathrm{C}$ for male mice and Appendix D for female mice.

Kidney: Microscopic chemical-related lesions in the kidney of males consisted of renal tubule hyperplasia, renal tubule adenoma, and renal tubule carcinoma. The incidences of adenoma, carcinoma, and adenoma or carcinoma (combined) were significantly increased in all exposed groups of males compared to those in the concurrent chamber control group (Table 23, Table C-1, and Table C-2). The incidences of adenoma, carcinoma, and adenoma or carcinoma (combined) in exposed groups of males exceeded the historical control ranges for inhalation studies, where none have occurred, and for all routes of administration (Table 23 and Table C-3). A renal tubule adenoma occurred in one $25 \mathrm{ppm}$ female mouse (Table D-1), no such adenoma had been observed in 947 historical control male mice by all routes of exposure. No renal tubule neoplasms were observed in any other treated female mice, and no adenomas or carcinomas were observed in male or female chamber control mice. Adenomas were most often solitary and unilateral; one incidence of bilateral renal tubule adenoma and three incidences of multiple renal tubule adenoma occurred in 12.5 ppm males. Similar to adenomas, most carcinomas occurred as solitary masses, but the incidences of bilateral carcinoma increased with increasing exposure concentration. In addition, three $12.5 \mathrm{ppm}$ males had multiple carcinomas in one kidney, and four $12.5 \mathrm{ppm}$ males had multiple carcinomas bilaterally.

Renal tubule adenomas were variably sized, well-circumscribed, solitary and discrete, expansile masses composed of fairly well-differentiated neoplastic tubule epithelial cells greater than five tubules in diameter, which compressed the adjacent renal parenchyma. The masses were solid, papillary to cystic, and arranged in tubules, rows, papillae, or sheets composed of tightly packed cuboidal to ovoid, occasionally markedly vacuolated cells overlying a fine fibrovascular stroma (Figure 16). Mitoses were rare or absent. Renal tubule carcinomas shared many of the morphologic features present within adenomas, but were generally larger, more compressive to locally invasive, had solid, papillary, cystic, or anaplastic growth patterns, prominent vascular ingrowth, and occasionally large areas of necrosis, hemorrhage, or proteinaceous fluid accumulation, and displayed nuclear and cellular pleomorphism, atypia, and numerous mitoses (Figure 17).

The incidences of renal tubule hyperplasia were significantly increased in all exposed groups of males compared to that in the chamber controls (Table 23 and Table C-4). Hyperplasia was characterized by enlarged tubules (approximately two to five tubules in diameter) containing increased numbers of epithelial cells with eosinophilic, basophilic, or clear cytoplasm, which exhibited piling and crowding, variable nuclear and cellular pleomorphism, and multilayered or solid growth that partially or completely filled the tubule lumen (Figure 18). The incidence of kidney cyst was significantly increased in $25 \mathrm{ppm}$ males; this lesion also occurred in two females and one female in the 6.25 and 12.5 ppm groups, respectively (Table D-4). Kidney cysts were characterized by variably sized dilations lined by flattened cuboidal epithelial cells which often compressed adjacent renal parenchyma. The incidence of kidney nephropathy was significantly decreased in 12.5 ppm males. 
Table 23. Incidences of Neoplasms and Nonneoplastic Lesions of the Kidney in Male Mice in the Two-year Inhalation Study of Vinylidene Chloride

\begin{tabular}{|c|c|c|c|c|}
\hline & Chamber Control & $6.25 \mathrm{ppm}$ & $12.5 \mathrm{ppm}$ & 25 ppm \\
\hline Number Examined Microscopically & 50 & 50 & 50 & 50 \\
\hline Renal Tubule, Hyperplasia ${ }^{a}$ & 0 & $8 * *(1.8)^{\mathrm{b}}$ & $22 * *(1.7)$ & $16^{* *}(1.7)$ \\
\hline Cyst & $1(2.0)$ & $1(2.0)$ & $5(2.0)$ & $7 *(2.6)$ \\
\hline Nephropathy & $44(1.9)$ & $46(1.6)$ & $37 *(2.2)$ & $44(2.2)$ \\
\hline Renal Tubule, Adenoma, Single & 0 & 5 & $15^{* *}$ & $10 * *$ \\
\hline Renal Tubule, Adenoma, Bilateral & 0 & 0 & 1 & 0 \\
\hline Renal Tubule, Adenoma, Multiple & 0 & 0 & 3 & 0 \\
\hline \multicolumn{5}{|c|}{ Renal Tubule, Adenoma (includes single, bilateral, and multiple) ${ }^{\mathrm{c}}$} \\
\hline Overall rate ${ }^{\mathrm{d}}$ & $0 / 50(0 \%)$ & $5 / 50(10 \%)$ & $19 / 50(38 \%)$ & $10 / 50(20 \%)$ \\
\hline Adjusted rate & $0.0 \%$ & $10.6 \%$ & $44.2 \%$ & $26.7 \%$ \\
\hline Terminal rate $\mathrm{f}^{\mathrm{f}}$ & $0 / 29(0 \%)$ & $5 / 40(13 \%)$ & $15 / 32(47 \%)$ & $8 / 19(42 \%)$ \\
\hline First incidence (days) & $-^{\mathrm{h}}$ & $729(\mathrm{~T})$ & 600 & 525 \\
\hline Poly-3 test $\mathrm{t}^{\mathrm{g}}$ & $\mathrm{P}<0.001$ & $\mathrm{P}=0.041$ & $\mathrm{P}<0.001$ & $\mathrm{P}<0.001$ \\
\hline Renal Tubule, Carcinoma, Single & 0 & 6 & $17 * *$ & $12^{* *}$ \\
\hline Renal Tubule, Carcinoma, Bilateral & 0 & 1 & $7 *$ & $6^{*}$ \\
\hline Renal Tubule, Carcinoma, Multiple & 0 & 0 & 3 & 0 \\
\hline Renal Tubule, Carcinoma, Multiple Bilateral & 0 & 0 & 4 & 0 \\
\hline \multicolumn{5}{|c|}{ Renal Tubule, Carcinoma (includes single, bilateral, multiple, and multiple bilateral) ${ }^{\mathrm{i}}$} \\
\hline Overall rate & $0 / 50(0 \%)$ & $7 / 50(14 \%)$ & $31 / 50(62 \%)$ & $18 / 50(36 \%)$ \\
\hline Adjusted rate & $0.0 \%$ & $14.7 \%$ & $70.5 \%$ & $45.8 \%$ \\
\hline Terminal rate & $0 / 29(0 \%)$ & $5 / 40(13 \%)$ & $24 / 32(75 \%)$ & $10 / 19(53 \%)$ \\
\hline First incidence (days) & - & 619 & 429 & 537 \\
\hline Poly-3 test & $\mathrm{P}<0.001$ & $\mathrm{P}=0.012$ & $\mathrm{P}<0.001$ & $\mathrm{P}<0.001$ \\
\hline \multicolumn{5}{|l|}{ Renal Tubule, Adenoma or Carcinoma ${ }^{j}$} \\
\hline Overall rate & $0 / 50(0 \%)$ & $11 / 50(22 \%)$ & $37 / 50(74 \%)$ & $27 / 50(54 \%)$ \\
\hline Adjusted rate & $0.0 \%$ & $23.1 \%$ & $81.9 \%$ & $67.0 \%$ \\
\hline Terminal rate & $0 / 29(0 \%)$ & $9 / 40(23 \%)$ & $27 / 32(84 \%)$ & $17 / 19(90 \%)$ \\
\hline First incidence (days) & - & 619 & 429 & 525 \\
\hline Poly-3 test & $\mathrm{P}<0.001$ & $\mathrm{P}<0.001$ & $\mathrm{P}<0.001$ & $\mathrm{P}<0.001$ \\
\hline
\end{tabular}

*Significantly different $(\mathrm{P} \leq 0.05)$ from the chamber control group by the Poly-3 test.

$* * \mathrm{P} \leq 0.01$.

$\mathrm{T}=$ terminal kill.

${ }^{\mathrm{a} N u m b e r}$ of animals with lesion.

${ }^{\mathrm{b}}$ Average severity grade of lesions in affected animals: $1=$ minimal, $2=$ mild, $3=$ moderate, $4=$ marked.

${ }^{\mathrm{c}}$ Historical incidence for 2 -year inhalation studies with chamber control groups (mean \pm standard deviation): 0/298; all routes: $8 / 944(0.9 \% \pm 1.4 \%)$, range $0 \%-4 \%$.

${ }^{\mathrm{d}}$ Number of animals with neoplasm per number of animals with kidney examined microscopically.

ePoly-3 estimated neoplasm incidence after adjustment for intercurrent mortality. 
${ }_{\mathrm{f}}$ Observed incidence at terminal kill.

${ }^{g}$ Beneath the chamber control incidence is the $\mathrm{P}$ value associated with the trend test. Beneath the exposed group incidence are the $P$ values corresponding to pairwise comparisons between the chamber controls and that exposed group. The Poly-3 test accounts for differential mortality in animals that do not reach terminal kill.

hot applicable; no neoplasms in animal group.

${ }^{i}$ Historical incidence for inhalation studies: 0/298; all routes: 3/944 $(0.3 \% \pm 1.0 \%)$, range 0\%-4\%.

${ }^{\mathrm{j} H i s t o r i c a l}$ incidence for inhalation studies: 0/298; all routes: $11 / 944(1.2 \% \pm 1.8 \%)$, range $0 \%-6 \%$.

Liver: The incidence of hepatocellular adenoma (including multiple) was significantly increased in $12.5 \mathrm{ppm}$ female mice compared to that in concurrent chamber controls and the incidence of hepatocellular carcinoma (including multiple) was significantly increased in $25 \mathrm{ppm}$ females (Table 24, Table D-1, and Table D-2). When combined, the incidences of hepatocellular adenoma or carcinoma were significantly increased in 12.5 and $25 \mathrm{ppm}$ females. The incidences of hepatocellular adenoma in 12.5 and $25 \mathrm{ppm}$ females and hepatocellular carcinoma and hepatocellular adenoma or carcinoma (combined) in all exposed female groups exceeded the historical control ranges for inhalation studies, but were within the historical control ranges for all routes of administration (Table 24 and Table D-3). Hepatocellular adenomas were generally discrete, expansile proliferations of solid sheets of fairly well-differentiated hepatocytes that caused compression of the adjacent hepatic parenchyma. Hepatocellular carcinomas were characterized by large, infiltrative proliferations of solid lobules or trabeculae generally greater than three hepatocytes thick, composed of poorly differentiated hepatocytes effacing the normal lobular architecture of the liver.

The incidences of hepatocholangiocarcinoma in exposed groups of males were higher than in the concurrent chamber control groups, and exceeded the historical control range for inhalation studies but not that for all routes of administration (Table 24, Table C-1, and Table C-2). In females, hepatocholangiocarcinoma occurred in all exposed groups; this neoplasm has not been seen in 300 inhalation controls or 948 controls from all routes of study. Hepatocholangiocarcinomas were characterized by infiltrative proliferations of trabeculae and solid sheets of poorly differentiated hepatocytes admixed with neoplastic biliary structures that effaced the normal lobular architecture of the liver.

The incidences of hepatocellular adenoma (including multiple) were decreased in males in an exposure concentration-dependent fashion, and the incidences of hepatocellular carcinoma (including multiple) were decreased in 6.25 and $12.5 \mathrm{ppm}$ males (Table 24, Table C-1, and Table C-2). The incidence of basophilic focus of the liver was significantly increased in $25 \mathrm{ppm}$ males (Table 24 and Table C-4). 
Table 24. Incidences of Neoplasms and Nonneoplastic Lesions of the Liver in Mice in the Two-year Inhalation Study of Vinylidene Chloride

\begin{tabular}{|c|c|c|c|c|}
\hline & $\begin{array}{l}\text { Chamber } \\
\text { Control }\end{array}$ & $6.25 \mathrm{ppm}$ & 12.5 ppm & 25 ppm \\
\hline \multicolumn{5}{|l|}{ Male } \\
\hline Number Examined Microscopically & 50 & 50 & 50 & 50 \\
\hline Basophilic Focus $^{\mathrm{a}}$ & 2 & 4 & 2 & $7^{*}$ \\
\hline Hepatocellular Adenoma, Multiple & 20 & 19 & 17 & 13 \\
\hline \multicolumn{5}{|c|}{ Hepatocellular Adenoma (includes multiple) } \\
\hline Overall rate ${ }^{\mathrm{b}}$ & $37 / 50(74 \%)$ & $35 / 50(70 \%)$ & $33 / 50(66 \%)$ & $25 / 50(50 \%)$ \\
\hline Adjusted rate ${ }^{c}$ & $77.6 \%$ & $72.5 \%$ & $73.8 \%$ & $60.0 \%$ \\
\hline Terminal rate ${ }^{\mathrm{d}}$ & $21 / 29(72 \%)$ & $31 / 40(78 \%)$ & $25 / 32(78 \%)$ & $12 / 19(63 \%)$ \\
\hline First incidence (days) & 443 & 619 & 429 & 471 \\
\hline Poly-3 test ${ }^{\mathrm{e}}$ & $\mathrm{P}=0.040 \mathrm{~N}$ & $\mathrm{P}=0.361 \mathrm{~N}$ & $\mathrm{P}=0.422 \mathrm{~N}$ & $\mathrm{P}=0.046 \mathrm{~N}$ \\
\hline Hepatocellular Carcinoma, Multiple & 8 & 1 & 4 & 8 \\
\hline \multicolumn{5}{|c|}{ Hepatocellular Carcinoma (includes multiple) } \\
\hline Overall rate & $26 / 50(52 \%)$ & $19 / 50(38 \%)$ & $15 / 50(30 \%)$ & $29 / 50(58 \%)$ \\
\hline Adjusted rate & $55.0 \%$ & $38.1 \%$ & $33.2 \%$ & $64.4 \%$ \\
\hline Terminal rate & $11 / 29(38 \%)$ & $11 / 40(28 \%)$ & $7 / 32(22 \%)$ & $10 / 19(53 \%)$ \\
\hline First incidence (days) & 443 & 521 & 508 & 425 \\
\hline Poly-3 test & $P=0.118$ & $\mathrm{P}=0.070 \mathrm{~N}$ & $\mathrm{P}=0.026 \mathrm{~N}$ & $P=0.234$ \\
\hline Hepatocholangiocarcinoma $^{\mathrm{f}}$ & 1 & 2 & 2 & 3 \\
\hline \multicolumn{5}{|l|}{ Female } \\
\hline Number Examined Microscopically & 50 & 50 & 50 & 50 \\
\hline Hepatocellular Adenoma, Multiple & 12 & 9 & $26^{*}$ & 17 \\
\hline \multicolumn{5}{|c|}{ Hepatocellular Adenoma (includes multiple) ${ }^{\mathrm{g}}$} \\
\hline Overall rate & $25 / 50(50 \%)$ & $21 / 50(42 \%)$ & $36 / 50(72 \%)$ & $29 / 50(58 \%)$ \\
\hline Adjusted rate & $55.3 \%$ & $49.0 \%$ & $77.6 \%$ & $69.0 \%$ \\
\hline Terminal rate & $20 / 36(56 \%)$ & $13 / 25(52 \%)$ & $25 / 30(83 \%)$ & $19 / 24(79 \%)$ \\
\hline First incidence (days) & 509 & 471 & 524 & 443 \\
\hline Poly-3 test & $P=0.026$ & $\mathrm{P}=0.347 \mathrm{~N}$ & $P=0.015$ & $P=0.126$ \\
\hline Hepatocellular Carcinoma, Multiple & 1 & 2 & 2 & 3 \\
\hline \multicolumn{5}{|c|}{ Hepatocellular Carcinoma (includes multiple) ${ }^{\mathrm{h}}$} \\
\hline Overall rate & $8 / 50(16 \%)$ & $14 / 50(28 \%)$ & $12 / 50(24 \%)$ & $17 / 50(34 \%)$ \\
\hline Adjusted rate & $18.2 \%$ & $32.4 \%$ & $27.2 \%$ & $41.3 \%$ \\
\hline Terminal rate & $6 / 36(17 \%)$ & $4 / 25(16 \%)$ & $8 / 30(27 \%)$ & $9 / 24(38 \%)$ \\
\hline First incidence (days) & 611 & 478 & 611 & 415 \\
\hline Poly-3 test & $\mathrm{P}=0.022$ & $\mathrm{P}=0.097$ & $\mathrm{P}=0.223$ & $\mathrm{P}=0.015$ \\
\hline
\end{tabular}




\begin{tabular}{lcccc}
\hline & $\begin{array}{c}\text { Chamber } \\
\text { Control }\end{array}$ & $\mathbf{6 . 2 5} \mathbf{~ p p m}$ & $\mathbf{1 2 . 5} \mathbf{~ p p m}$ & $\mathbf{2 5} \mathbf{~ p p m}$ \\
\hline Hepatocellular Adenoma or Carcinoma & & & & \\
Overall rate & $28 / 50(56 \%)$ & $30 / 50(60 \%)$ & $37 / 50(74 \%)$ & $38 / 50(76 \%)$ \\
Adjusted rate & $61.5 \%$ & $65.4 \%$ & $79.3 \%$ & $84.4 \%$ \\
Terminal rate & $22 / 36(61 \%)$ & $14 / 25(56 \%)$ & $25 / 30(83 \%)$ & $21 / 24(88 \%)$ \\
First incidence (days) & 509 & 471 & 524 & 415 \\
Poly-3 test & $\mathrm{P}=0.003$ & $\mathrm{P}=0.434$ & $\mathrm{P}=0.041$ & $\mathrm{P}=0.009$ \\
Hepatocholangiocarcinoma $^{\mathrm{j}}$ & 0 & 1 & 1 & 2 \\
\hline
\end{tabular}

*Significantly different $(\mathrm{P} \leq 0.05)$ from the chamber control group by the Poly-3 test.

${ }^{\text {a}}$ Number of animals with lesion.

${ }^{b}$ Number of animals with neoplasm per number of animals with liver examined microscopically.

'Poly-3 estimated neoplasm incidence after adjustment for intercurrent mortality.

${ }^{\mathrm{d}}$ Observed incidence at terminal kill.

${ }^{\text {e}}$ Beneath the chamber control incidence is the $\mathrm{P}$ value associated with the trend test. Beneath the exposed group incidence are the $\mathrm{P}$ values corresponding to pairwise comparisons between the chamber controls and that exposed group. The Poly-3 test accounts for differential mortality in animals that do not reach terminal kill. A negative trend or a lower incidence in an exposure group is indicated by $\mathrm{N}$.

${ }^{f}$ Historical incidence for 2-year inhalation studies with chamber control groups (mean \pm standard deviation): 2/299 $(0.7 \% \pm 1.0 \%)$, range $0 \%-2 \%$; all routes: $10 / 949(1.1 \% \pm 2.2 \%)$, range $0 \%-8 \%$.

${ }^{g}$ Historical incidence for inhalation studies: 105/300 (35.0\% $\left.\pm 8.8 \%\right)$, range 28\%-50\%; all routes: $378 / 948(39.9 \% \pm 18.7 \%)$, range $14 \%-78 \%$.

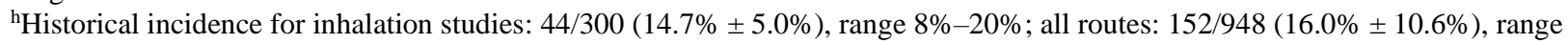
$4 \%-46 \%$.

${ }^{\mathrm{i}}$ Historical incidence for inhalation studies: $133 / 300(44.3 \% \pm 8.6 \%)$, range $32 \%-56 \%$; all routes: $448 / 948(47.3 \% \pm 19.3 \%)$, range $20 \%-82 \%$.

${ }^{\mathrm{j} H i s t o r i c a l ~ i n c i d e n c e ~ f o r ~ i n h a l a t i o n ~ s t u d i e s: ~ 0 / 300 ; ~ a l l ~ r o u t e s: ~ 0 / 948 . ~}$

Hemangioma and Hemangiosarcoma: The incidences of hemangioma in all exposed groups of females were increased compared to that in the concurrent chamber controls, and these incidences exceeded the historical control ranges for inhalation studies and all routes of administration (Table 25 and Table D-1). This neoplasm occurred in the liver, ovary, and uterus of exposed females and in the liver, bone marrow, and testes of exposed males (Table C-1 and Table D-1). Hemangiomas were composed of expansile proliferations of dilated to cavernous vascular spaces lined with well-differentiated endothelial cells. When all organs were combined, the incidence of hemangiosarcoma in $25 \mathrm{ppm}$ females was greater than that in the concurrent chamber controls and exceeded the historical control ranges for inhalation studies and all routes of administration (Table 25, Table D-1, and Table D-2). Incidences of hemangiosarcoma in female mice were primarily driven by the incidences of this neoplasm in the liver, in which the incidence of hemangiosarcoma in the $25 \mathrm{ppm}$ group was significantly greater than that in the concurrent chamber controls. Hemangiosarcomas occurred in the liver, spleen, mediastinal lymph node, and skeletal muscle of males and females, in the bone marrow, lung, kidney, and thymus of males, and mesentery, ovary, uterus, urinary bladder, and in subcutaneous skin tissues of females. When all organs were combined, the incidence of hemangioma or hemangiosarcoma (combined) in 25 ppm females was significantly greater than that in the concurrent chamber controls. Hemangiosarcomas were composed of infiltrative or invasive proliferations of poorly differentiated endothelial cells forming haphazard vascular channels within multiple organs. 
Table 25. Incidences of Hemangioma and Hemangiosarcoma in Female Mice in the Two-year Inhalation Study of Vinylidene Chloride

\begin{tabular}{|c|c|c|c|c|}
\hline & $\begin{array}{l}\text { Chamber } \\
\text { Control }\end{array}$ & $6.25 \mathrm{ppm}$ & $12.5 \mathrm{ppm}$ & 25 ppm \\
\hline Liver $^{\mathrm{a}}$ & 50 & 50 & 50 & 50 \\
\hline Hemangioma $^{\mathrm{b}}$ & 0 & 1 & 0 & 2 \\
\hline \multicolumn{5}{|l|}{ Hemangiosarcoma } \\
\hline Overall rate ${ }^{c}$ & $1 / 50(2 \%)$ & $1 / 50(2 \%)$ & $1 / 50(2 \%)$ & $6 / 50(12 \%)$ \\
\hline Adjusted rate $^{\mathrm{d}}$ & $2.3 \%$ & $2.5 \%$ & $2.3 \%$ & $15.2 \%$ \\
\hline Terminal rate $e^{e}$ & $1 / 36(3 \%)$ & $1 / 25(4 \%)$ & $1 / 30(3 \%)$ & $3 / 24(13 \%)$ \\
\hline First incidence (days) & $731(\mathrm{~T})$ & $731(\mathrm{~T})$ & $731(\mathrm{~T})$ & 508 \\
\hline Poly-3 test ${ }^{\mathrm{f}}$ & $P=0.007$ & $P=0.740$ & $P=0.758$ & $P=0.041$ \\
\hline All Organs & 50 & 50 & 50 & 50 \\
\hline Hemangioma ${ }^{\mathrm{g}}$ & 0 & 2 & 2 & 2 \\
\hline Hemangiosarcoma $^{\mathrm{h}}$ & 4 & 4 & 4 & 9 \\
\hline \multicolumn{5}{|c|}{ Hemangioma or Hemangiosarcoma ${ }^{i}$} \\
\hline Overall rate ${ }^{j}$ & $4 / 50(8 \%)$ & $6 / 50(12 \%)$ & $6 / 50(12 \%)$ & $11 / 50(22 \%)$ \\
\hline Adjusted rate & $9.2 \%$ & $14.9 \%$ & $13.9 \%$ & $27.5 \%$ \\
\hline Terminal rate & $4 / 36(11 \%)$ & $4 / 25(16 \%)$ & $4 / 30(13 \%)$ & $7 / 24(29 \%)$ \\
\hline First incidence (days) & $731(\mathrm{~T})$ & 471 & 620 & 508 \\
\hline Poly-3 test & $P=0.018$ & $P=0.324$ & $P=0.368$ & $\mathrm{P}=0.027$ \\
\hline
\end{tabular}

$\mathrm{T}=$ terminal kill.

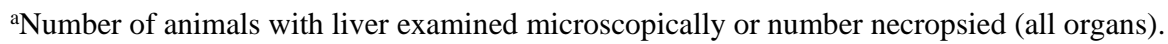

${ }^{b}$ Number of animals with neoplasm.

${ }^{\mathrm{c}}$ Number of animals with neoplasm per number of animals with liver examined microscopically.

${ }^{\mathrm{d} P o l y-3}$ estimated neoplasm incidence after adjustment for intercurrent mortality.

${ }^{\mathrm{e} O b s e r v e d ~ i n c i d e n c e ~ a t ~ t e r m i n a l ~ k i l l . ~}$

${ }^{f}$ Beneath the chamber control incidence is the $\mathrm{P}$ value associated with the trend test. Beneath the exposed group incidence are the $\mathrm{P}$ values corresponding to pairwise comparisons between the chamber controls and that exposed group. The Poly-3 test accounts for differential mortality in animals that do not reach terminal kill.

${ }^{g}$ Historical incidence for 2-year inhalation studies with chamber control groups (mean \pm standard deviation): 0/300; all routes: $5 / 950(0.5 \% \pm 0.9 \%)$, range $0 \%-2 \%$.

${ }^{\text {h} H i s t o r i c a l ~ i n c i d e n c e ~ f o r ~ i n h a l a t i o n ~ s t u d i e s: ~} 21 / 300(7.0 \% \pm 2.1 \%)$, range 4\%-10\%; all routes: 50/950 $(5.3 \% \pm 3.9 \%)$, range $0 \%-12 \%$.

${ }^{\mathrm{i}}$ Historical incidence for inhalation studies: $21 / 300(7.0 \% \pm 2.1 \%)$, range $4 \%-10 \%$; all routes: $55 / 950(5.8 \% \pm 3.7 \%)$, range $2 \%-14 \%$.

${ }^{\mathrm{j} N u m b e r}$ of animals with neoplasm per number of animals necropsied.

Lung: The incidence of alveolar/bronchiolar carcinoma (including multiple) in $12.5 \mathrm{ppm}$ females was significantly increased and exceeded the historical control range for inhalation studies (Table 26, Table D-1, and Table D-2). Alveolar/bronchiolar carcinomas were characterized by discrete expansile to locally infiltrative irregularly shaped masses composed of solid lobules, papillary projections, and tubular structures composed of fairly well- to poorly differentiated epithelial cells, which effaced the normal alveolar parenchyma.There were slight increases in the incidences of alveolar epithelium hyperplasia in the lung of exposed groups of males (Table 26 and Table C-4). However, there were no increased incidences of lung neoplasms in any exposed 
groups of males (Table C-1), despite the significantly increased incidence of alveolar/bronchiolar carcinoma in $12.5 \mathrm{ppm}$ females.

Table 26. Incidences of Neoplasms and Nonneoplastic Lesions of the Lung in Mice in the Two-year Inhalation Study of Vinylidene Chloride

\begin{tabular}{|c|c|c|c|c|}
\hline & $\begin{array}{l}\text { Chamber } \\
\text { Control }\end{array}$ & $6.25 \mathrm{ppm}$ & $12.5 \mathrm{ppm}$ & 25 ppm \\
\hline \multicolumn{5}{|l|}{ Male } \\
\hline Number Examined Microscopically & 50 & 50 & 50 & 50 \\
\hline Alveolar Epithelium Hyperplasia ${ }^{\mathrm{a}}$ & $3(1.3)^{b}$ & $7(1.3)$ & $4(1.8)$ & $6(2.3)$ \\
\hline \multicolumn{5}{|l|}{ Female } \\
\hline Number Examined Microscopically & 50 & 50 & 50 & 49 \\
\hline Alveolar/bronchiolar Adenoma, Multiple & 1 & 0 & 0 & 0 \\
\hline $\begin{array}{l}\text { Alveolar/bronchiolar Adenoma } \\
\text { (includes multiple) }\end{array}$ & 3 & 4 & 2 & 2 \\
\hline Alveolar/bronchiolar Carcinoma, Multiple & 0 & 0 & 1 & 0 \\
\hline \multicolumn{5}{|c|}{ Alveolar/bronchiolar Carcinoma (includes multiple) ${ }^{\mathrm{c}}$} \\
\hline Overall rate ${ }^{\mathrm{d}}$ & $1 / 50(2 \%)$ & $2 / 50(4 \%)$ & $7 / 50(14 \%)$ & $5 / 49(10 \%)$ \\
\hline Adjusted rate ${ }^{\mathrm{e}}$ & $2.3 \%$ & $4.9 \%$ & $16.1 \%$ & $12.7 \%$ \\
\hline Terminal rate ${ }^{\mathrm{f}}$ & $1 / 36(3 \%)$ & $0 / 25(0 \%)$ & $6 / 30(20 \%)$ & $1 / 24(4 \%)$ \\
\hline First incidence (days) & $731(\mathrm{~T})$ & 558 & 392 & 502 \\
\hline Poly-3 test ${ }^{\mathrm{g}}$ & $\mathrm{P}=0.038$ & $\mathrm{P}=0.477$ & $\mathrm{P}=0.030$ & $\mathrm{P}=0.080$ \\
\hline Alveolar/bronchiolar Adenoma or Carcinoma & 4 & 5 & 9 & 7 \\
\hline \multicolumn{5}{|c|}{ 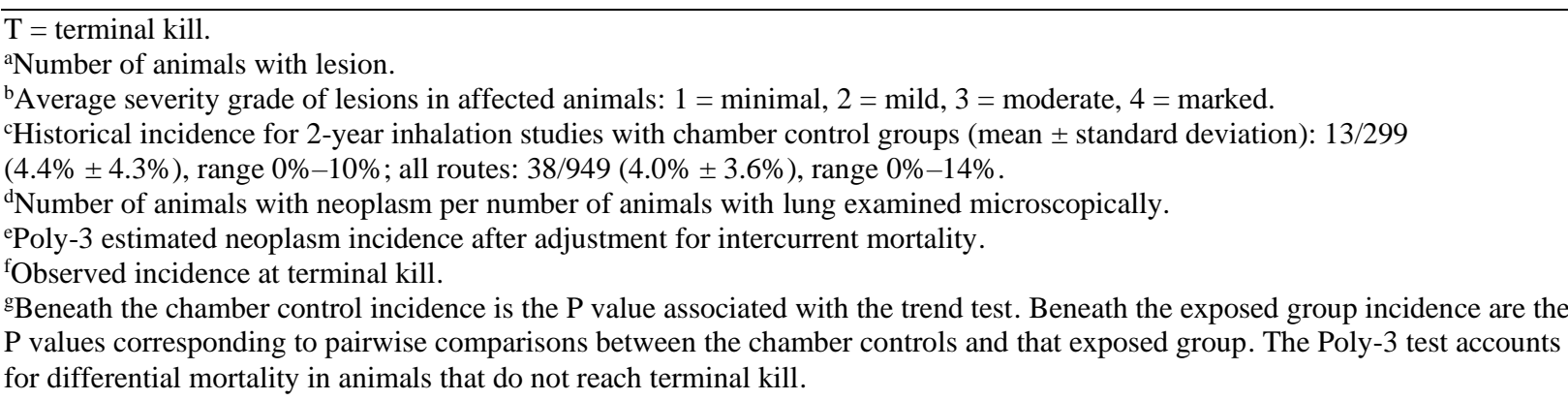 } \\
\hline
\end{tabular}

Small Intestine: Carcinoma of the duodenum occurred in two $25 \mathrm{ppm}$ males (Table 27 and Table C-1). One carcinoma occurred in the ileum of a $6.25 \mathrm{ppm}$ male. Carcinomas of the duodenum or ileum have not been reported in the six inhalation studies included in the 2013 historical control database. Carcinoma also occurred in the jejunum of two 6.25 ppm males. Adenoma occurred in the ileum of a chamber control male and in the duodenum of one $12.5 \mathrm{ppm}$ male. The overall combined incidences of small intestine (duodenum, jejunum, or ileum) carcinoma in males were within the historical control ranges for inhalation studies and all routes of administration (Table 27, Table C-1, and Table C-2).

One adenoma occurred in the duodenum of a $12.5 \mathrm{ppm}$ female, one adenoma and three carcinomas occurred in the ileum of $25 \mathrm{ppm}$ females, and one ileum carcinoma occurred in a 
6.25 ppm and a $12.5 \mathrm{ppm}$ female (Table 27, Table D-1, and Table D-2). In 25 ppm females, the incidence of carcinomas of the ileum exceeded the historical control ranges for inhalation studies and all routes of administration as did the incidence of adenoma or carcinoma in all small intestine sites. Small intestine adenomas were typically discrete, exophytic masses composed of well-differentiated glandular epithelial cells that did not invade the underlying lamina propria. Carcinomas of the small intestine were characterized by polypoid to sessile proliferations of tubules and acini composed of generally fairly well differentiated epithelium showing local infiltration into the underlying lamina propria or deeper muscle layers. Carcinomas often exhibited regional or local atypia and pleomorphism, including alterations in architectural pattern and increased mitotic figures.

Table 27. Incidences of Neoplasms of the Small Intestine in Mice in the Two-year Inhalation Study of Vinylidene Chloride

\begin{tabular}{|c|c|c|c|c|}
\hline & $\begin{array}{c}\text { Chamber } \\
\text { Control }\end{array}$ & $6.25 \mathrm{ppm}$ & $12.5 \mathrm{ppm}$ & 25 ppm \\
\hline \multicolumn{5}{|l|}{ Male } \\
\hline Duodenum $^{\mathrm{a}}$ & 50 & 50 & 50 & 50 \\
\hline Adenoma $^{\mathrm{b}}$ & 0 & 0 & 1 & 0 \\
\hline Carcinoma $^{\mathrm{c}}$ & 0 & 0 & 0 & 2 \\
\hline Jejunum & 50 & 50 & 50 & 50 \\
\hline Carcinoma $^{\mathrm{d}}$ & 0 & 2 & 0 & 0 \\
\hline Ileum & 50 & 50 & 50 & 50 \\
\hline Adenoma & 1 & 0 & 0 & 0 \\
\hline Carcinoma $^{\mathrm{e}}$ & 0 & 1 & 0 & 0 \\
\hline Small Intestine (Duodenum, Jejunum, or Ileum) & 50 & 50 & 50 & 50 \\
\hline Adenoma & 1 & 0 & 1 & 0 \\
\hline Carcinoma $^{\mathrm{f}}$ & 0 & 3 & 0 & 2 \\
\hline \multicolumn{5}{|c|}{ Small Intestine (Duodenum, Jejunum, or Ileum): Adenoma or Carcinoma ${ }^{\mathrm{g}}$} \\
\hline Overall rate re $^{\mathrm{h}}$ & $1 / 50(2 \%)$ & $3 / 50(6 \%)$ & $1 / 50(2 \%)$ & $2 / 50(4 \%)$ \\
\hline Adjusted rate ${ }^{\mathrm{i}}$ & $2.4 \%$ & $6.4 \%$ & $2.4 \%$ & $5.4 \%$ \\
\hline Terminal rate ${ }^{\mathrm{j}}$ & $1 / 29(3 \%)$ & $3 / 40(8 \%)$ & $1 / 32(3 \%)$ & $1 / 19(5 \%)$ \\
\hline First incidence (days) & $729(\mathrm{~T})$ & $729(\mathrm{~T})$ & $729(\mathrm{~T})$ & 563 \\
\hline Poly-3 test ${ }^{\mathrm{k}}$ & $P=0.463$ & $\mathrm{P}=0.348$ & $\mathrm{P}=0.758$ & $\mathrm{P}=0.455$ \\
\hline \multicolumn{5}{|l|}{ Female } \\
\hline Duodenum & 50 & 50 & 50 & 50 \\
\hline Adenoma & 0 & 0 & 1 & 0 \\
\hline Ileum & 50 & 50 & 50 & 50 \\
\hline Adenoma & 1 & 0 & 0 & 1 \\
\hline Carcinoma $^{1}$ & 1 & 1 & 1 & 3 \\
\hline
\end{tabular}




\begin{tabular}{|c|c|c|c|c|}
\hline & $\begin{array}{c}\text { Chamber } \\
\text { Control }\end{array}$ & $6.25 \mathrm{ppm}$ & $12.5 \mathrm{ppm}$ & $25 \mathrm{ppm}$ \\
\hline \multicolumn{5}{|c|}{ Small Intestine (Duodenum or Ileum): Adenoma or Carcinoma ${ }^{\mathrm{m}}$} \\
\hline Overall rate & $2 / 50(4 \%)$ & $1 / 50(2 \%)$ & $2 / 50(4 \%)$ & $4 / 50(8 \%)$ \\
\hline Adjusted rate & $4.6 \%$ & $2.5 \%$ & $4.6 \%$ & $10.4 \%$ \\
\hline Terminal rate & $1 / 36(3 \%)$ & $0 / 25(0 \%)$ & $1 / 30(3 \%)$ & $3 / 24(13 \%)$ \\
\hline First incidence (days) & 599 & 584 & 536 & 640 \\
\hline Poly-3 test & $P=0.141$ & $P=0.531 N$ & $P=0.691$ & $P=0.279$ \\
\hline 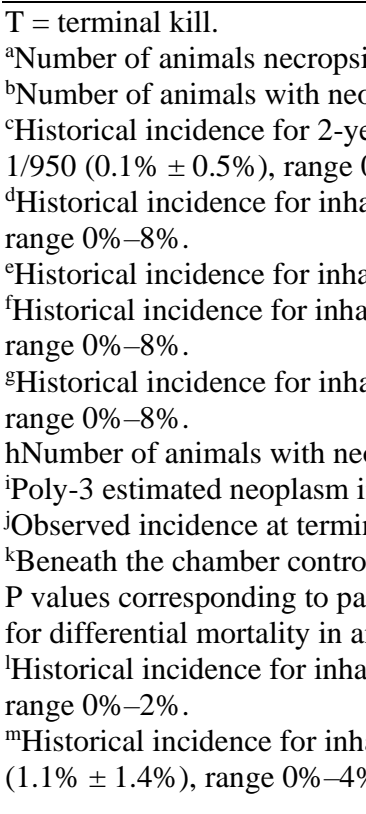 & $\begin{array}{l}\text { mber control g } \\
3.4 \% \text { ), range ( } \\
\text { s: } 0 / 950 \text {. } \\
3.4 \% \text { ), range } 0 \\
2.7 \% \text { ), range } \\
\text { necropsied. } \\
\text { intercurrent m } \\
\text { ciated with the } \\
\text { ne chamber co } \\
\text { nal kill. A low } \\
1.0 \% \text { ), range } 0 \\
\text { um): } 4 / 300 \text { (1. }\end{array}$ & $\begin{array}{l}\text { ps (mean } \pm \text { star } \\
-8 \% \text {; all routes: } \\
8 \% \text {; all routes: } \\
-8 \% \text {; all routes } \\
\text { lity. } \\
\text { nd test. Beneatl } \\
1 \mathrm{~s} \text { and that exp } \\
\text { ncidence in an } \\
2 \% \text {; all routes: } \\
\pm 1.6 \% \text { ), range }\end{array}$ & $\begin{array}{l}\text { d deviation }) \text { : } \\
950(1.9 \% \pm 2 \\
50(2.0 \% \pm 2 \\
1950(3.3 \% \pm\end{array}$ & $\begin{array}{l}\text { hcidence are the } \\
3 \text { test accounts } \\
\text { cated by N. } \\
0 / 950\end{array}$ \\
\hline
\end{tabular}

Nose: Exposure-related nonneoplastic lesions occurring in the nose included turbinate atrophy, hyperostosis, olfactory epithelium respiratory metaplasia, and olfactory epithelium hyaline droplet accumulation (Table 28, Table C-4, and Table D-4). These lesions primarily affected Level III, but often, depending on the lesion, extended into Levels II and/or I in mice exposed to $25 \mathrm{ppm}$. Turbinate atrophy occurred in the vast majority of male and female mice exposed to vinylidene chloride and the severity of the lesion increased with increasing exposure concentration. Turbinate atrophy was characterized by blunting, attenuation, or loss of turbinates. Incidences of hyperostosis increased in an exposure concentration-related fashion, and occurred in most male and female mice in the 12.5 and 25 ppm groups. Hyperostosis occurred in one chamber control male. This lesion was characterized by extensive bony remodeling of turbinate bones, resulting in misshapen and often thickened, nodular turbinates. Additionally, hyperostosis was often present in the ventral portion of the nasal septum of Level III. Accompanying the septal and turbinate changes were significantly increased incidences of respiratory metaplasia in the olfactory epithelium in all exposed groups of males and females, with exposure concentration-related increases in severities. This lesion was characterized by replacement of the multilayered olfactory epithelium by a single layer of nonciliated or ciliated cuboidal to columnar epithelium. Attenuation of the olfactory epithelium and loss of nerves in the underlying lamina propria often accompanied respiratory metaplasia. The incidences of olfactory epithelium hyaline droplet accumulation were increased in all exposed groups of males and in $25 \mathrm{ppm}$ females; the increases were significant in $12.5 \mathrm{ppm}$ males and $25 \mathrm{ppm}$ males and females. This 
lesion was characterized by the accumulation of globular, homogeneous, eosinophilic material within the cytoplasm of olfactory epithelial cells. The incidence of respiratory epithelium hyperplasia was significantly increased in 25 ppm females (Table 28 and Table D-4). This lesion occurred in Levels I and II of the nose, and was characterized by increased numbers and crowding of respiratory epithelial cells, with folding of the mucosa and extension of infolding into the underlying submucosa (pseudogland formation).

Table 28. Incidences of Nonneoplastic Lesions of the Nose in Mice in the Two-year Inhalation Study of Vinylidene Chloride

\begin{tabular}{|c|c|c|c|c|}
\hline & $\begin{array}{l}\text { Chamber } \\
\text { Control }\end{array}$ & $6.25 \mathrm{ppm}$ & $12.5 \mathrm{ppm}$ & 25 ppm \\
\hline \multicolumn{5}{|l|}{ Male } \\
\hline Number Examined Microscopically & 50 & 50 & 49 & 49 \\
\hline Turbinate, Atrophy ${ }^{\mathrm{a}}$ & 0 & $46^{* *}(1.1)^{\mathrm{b}}$ & $46 * *(2.1)$ & $47 * *(2.8)$ \\
\hline Hyperostosis & $1(2.0)$ & $27 * *(1.3)$ & $45^{* *}(2.1)$ & $48 * *(2.2)$ \\
\hline $\begin{array}{l}\text { Olfactory Epithelium, } \\
\text { Metaplasia, Respiratory }\end{array}$ & $17(1.2)$ & $39 * *(1.2)$ & $47 * *(1.6)$ & $48 * *(1.8)$ \\
\hline $\begin{array}{l}\text { Olfactory Epithelium, } \\
\text { Accumulation, Hyaline Droplet }\end{array}$ & $2(1.0)$ & $5(1.0)$ & $13^{* *}(1.3)$ & $11 * *(1.3)$ \\
\hline \multicolumn{5}{|l|}{ Female } \\
\hline Number Examined Microscopically & 50 & 50 & 50 & 50 \\
\hline Turbinate, Atrophy & 0 & $46 * *(1.0)$ & $50 * *(2.3)$ & $49 * *(2.8)$ \\
\hline Hyperostosis & 0 & $13 * *(1.2)$ & $45 * *(2.0)$ & $48 * *(2.2)$ \\
\hline $\begin{array}{l}\text { Olfactory Epithelium, } \\
\text { Metaplasia, Respiratory }\end{array}$ & $3(1.0)$ & $29 * *(1.1)$ & $49 * *(1.6)$ & $50 * *(1.9)$ \\
\hline $\begin{array}{l}\text { Olfactory Epithelium, } \\
\text { Accumulation, Hyaline Droplet }\end{array}$ & $18(1.6)$ & $18(1.5)$ & $13(1.4)$ & $32 * *(1.8)$ \\
\hline $\begin{array}{l}\text { Respiratory Epithelium, } \\
\text { Hyperplasia }\end{array}$ & $33(1.1)$ & $41(1.2)$ & $39(1.5)$ & $43 * *(1.8)$ \\
\hline
\end{tabular}

**Significantly different $(\mathrm{P} \leq 0.01)$ from the chamber control group by the Poly-3 test.

${ }^{a}$ Number of animals with lesion.

${ }^{\mathrm{b}}$ Average severity grade of lesions in affected animals: $1=$ minimal, $2=$ mild, $3=$ moderate, $4=$ marked

Other Organs: Increased incidences of fat necrosis of the mesentery occurred in exposed groups of females $(8 / 10,14 / 16,15 / 19,33 / 37$; Table D-4). Because this lesion was microscopically examined only in cases in which a gross lesion was observed in the mesenteric fat at the time of necropsy, the true incidence of this lesion is uncertain. There were also treatment- and exposure concentration-related increases in the incidences of fat necrosis in the companion rat study.

Significantly increased incidences of uterus endometrium cystic hyperplasia occurred in all exposed groups of females (36/50, 41/49, 46/50, 46/50; Table D-4). Cystic endometrial hyperplasia was characterized by increased numbers of glandular profiles and variably sized cystic structures lined by flattened to cuboidal endometrial epithelium causing dilatation of the uterine lumen and variable compression of the endometrial stroma. This is a common 
background lesion in aged mice, and its biologic relevance in this study is uncertain. The incidences of this lesion were not considered to be related to vinylidene chloride exposure.

\section{Genetic Toxicology}

Vinylidene chloride in liquid form tested over a concentration range of 33.3 to $6,666 \mu \mathrm{g} / \mathrm{plate}$ was not mutagenic in Salmonella typhimurium strains TA98, TA100, TA1535, or TA1537 when testing occurred with or without exogenous metabolic activation (10\% induced hamster or rat liver S9 mix) using a preincubation protocol (Table E-1; Mortelmans et al ${ }^{85}$ ). However, when tested in a closed system as a vapor, vinylidene chloride ( $0.16 \%$ to $2.5 \%$ in air) demonstrated clear mutagenic activity in mouse lymphoma L5178Y $\mathrm{tk}^{+/-}$cells in trials conducted with $10 \%$ induced male rat liver S9 mix (Table E-2; McGregor et al. ${ }^{90}$ ); in the absence of S9, a positive response was seen at a concentration of $30 \%$ vinylidene chloride in one of three trials. In vivo, no increase in sex-linked recessive lethal mutations was seen in germ cells of adult male Drosophila melanogaster exposed via feeding (20,000 or 25,000 ppm) or injection $(5,000 \mathrm{ppm})$ to vinylidene chloride ${ }^{130}$ (Table E-2). No increase in the frequency of micronucleated normochromatic erythrocytes was observed in peripheral blood of male or female $\mathrm{B} 6 \mathrm{C} 3 \mathrm{~F} 1 / \mathrm{N}$ mice exposed to vinylidene chloride by inhalation for a period of 3 months, and no change in the percentage of immature polychromatic erythrocytes (reticulocytes) was seen in these mice following exposure to vinylidene chloride, suggesting the absence of chemical-induced bone marrow toxicity (Table E-3). 


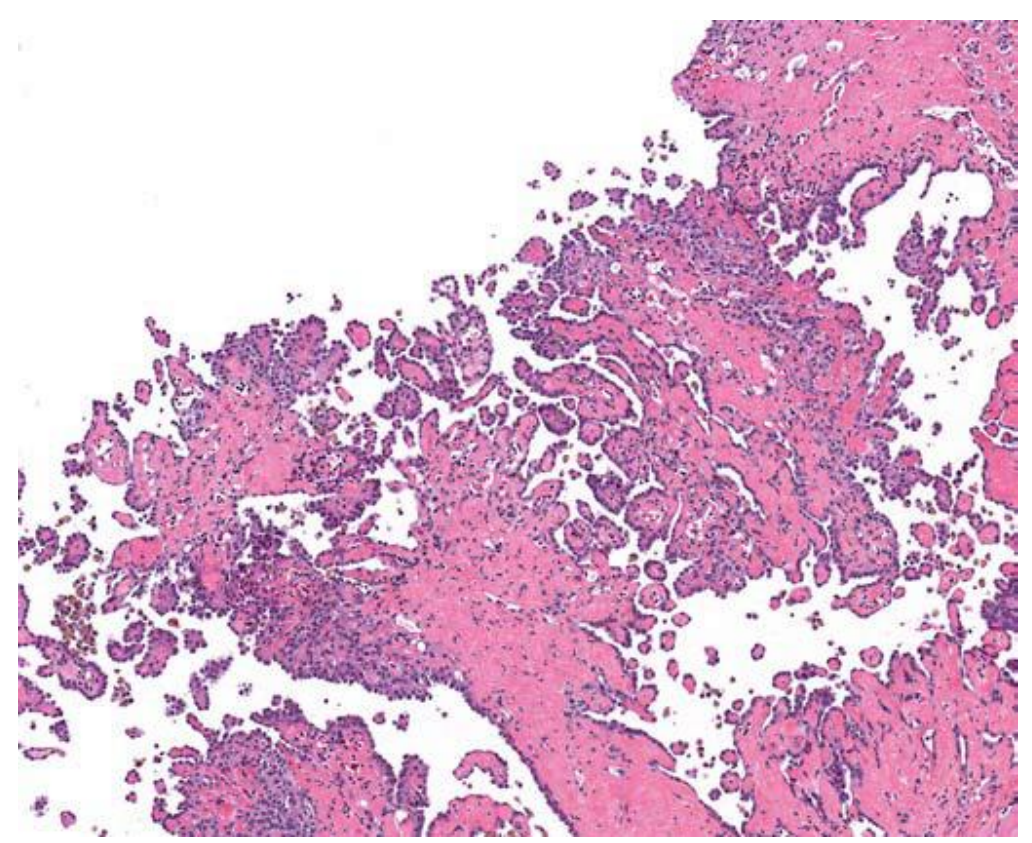

Figure 9. Malignant Mesothelioma in a Male F344/N Rat Exposed to 100 ppm Vinylidene Chloride by Whole Body Inhalation for Two Years $(\mathrm{H} \& \mathrm{E})$

Malignant mesotheliomas were characterized by arboriform proliferations of plump, poorly differentiated mesothelial cells supported by a fibrovascular stroma.

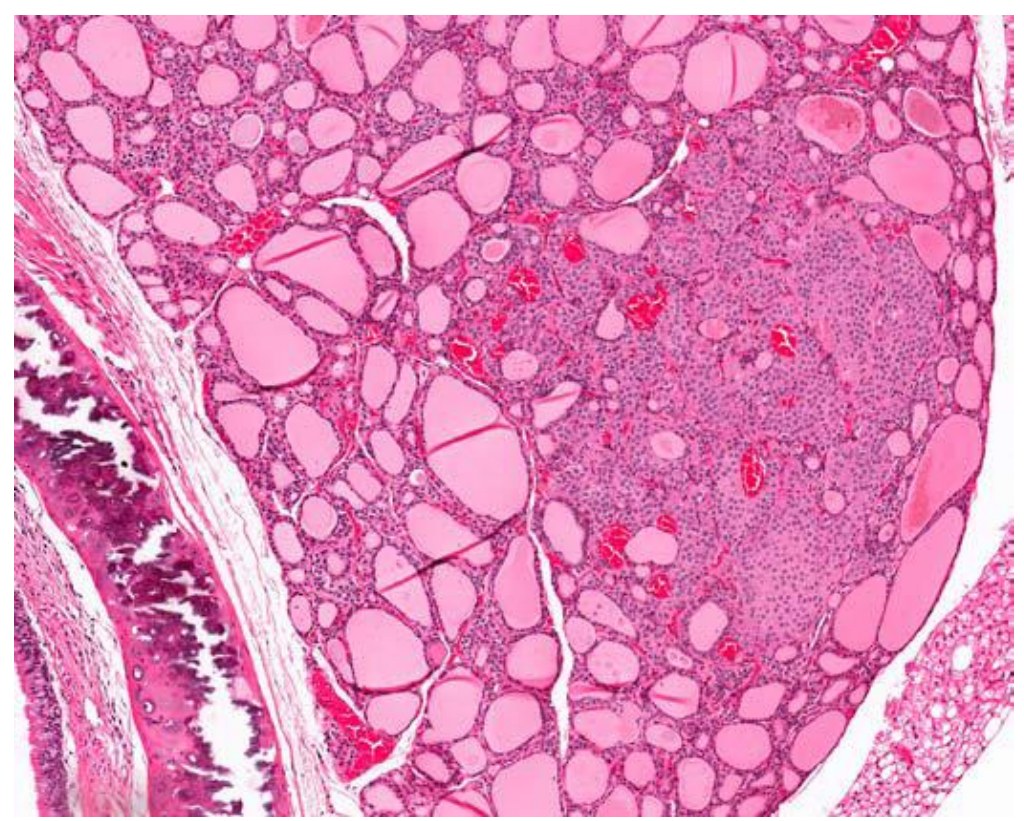

Figure 10. Thyroid Gland C-Cell Adenoma in a Female F344/N Rat Exposed to 100 ppm Vinylidene Chloride by Whole Body Inhalation for Two Years (H\&E)

C-cell adenomas were discrete, expansile proliferations of clusters and lobules of fairly well differentiated C-cells, causing mild compression of adjacent thyroid gland follicular parenchyma. 


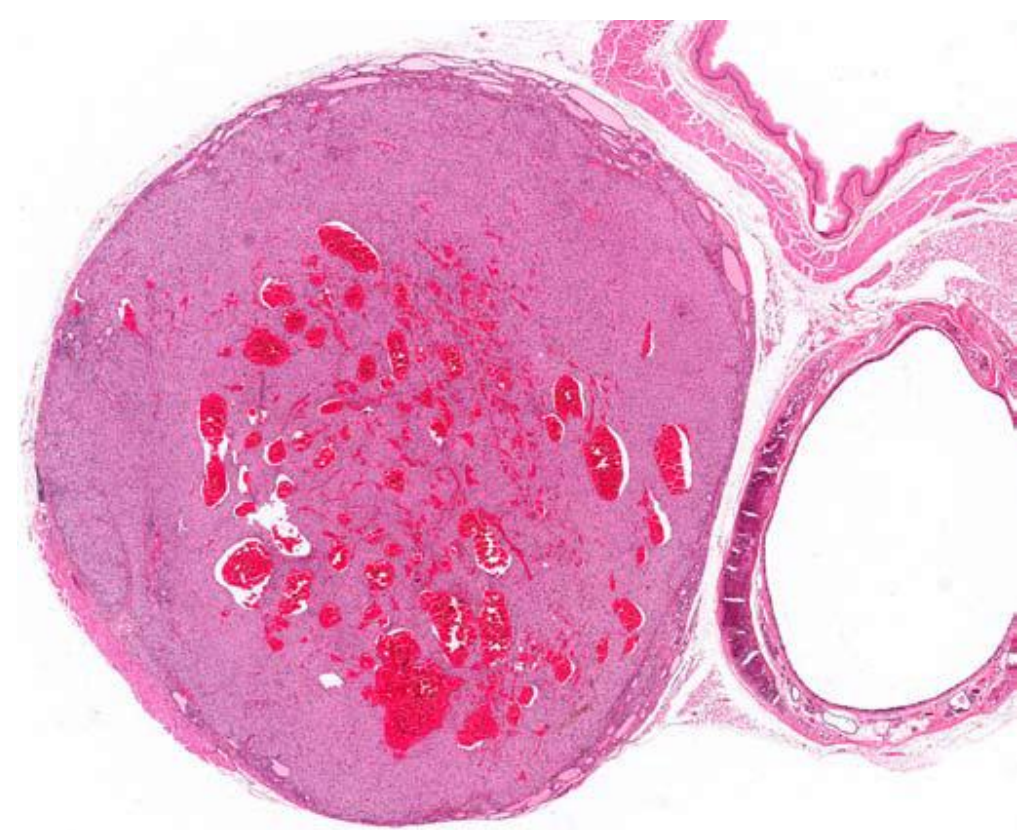

Figure 11. Thyroid Gland C-Cell Carcinoma in a Female F344/N Rat Exposed to 50 ppm Vinylidene Chloride by Whole Body Inhalation for Two Years (H\&E)

C-cell carcinomas were large, effaced normal thyroid gland parenchyma, and often invaded adjacent tissues beyond the thyroid capsule.

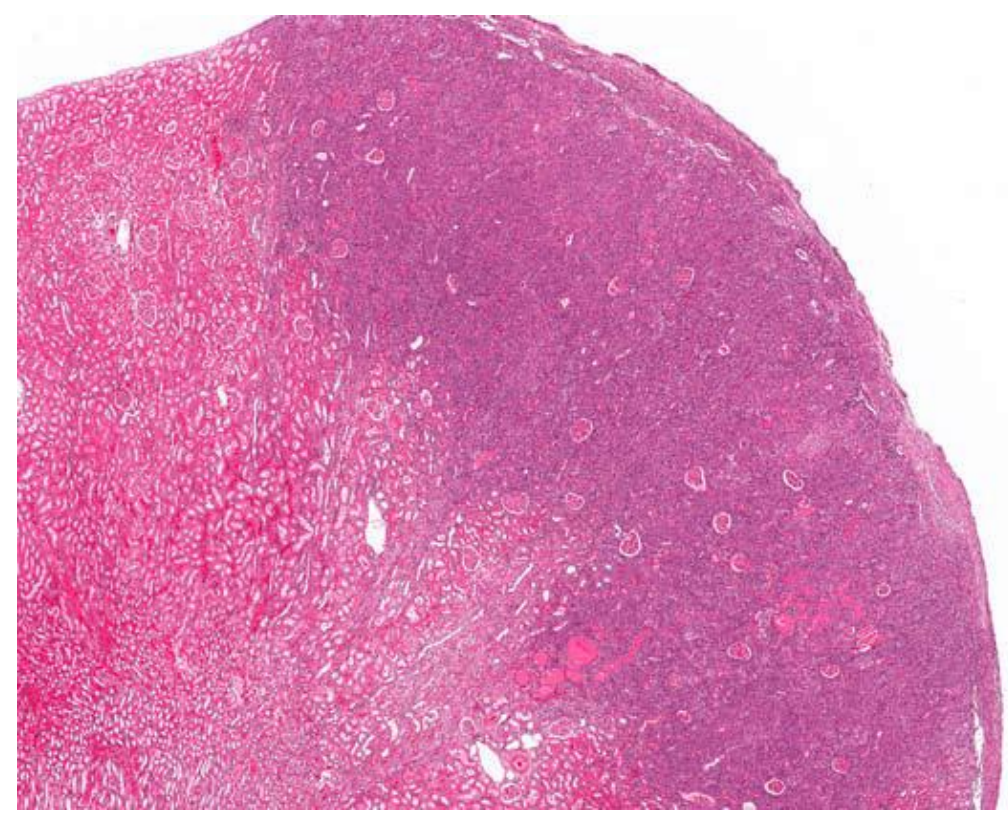

Figure 12. Renal Tubule Carcinoma in a Male F344/N Rat Exposed to 100 ppm Vinylidene Chloride by Whole Body Inhalation for Two Years (H\&E)

Renal tubule carcinomas were invariably large, invasive neoplasms composed of infiltrative clusters and lobules of poorly differentiated renal tubule epithelial cells that effaced and infiltrated normal renal parenchyma, sometimes sparing glomeruli. 


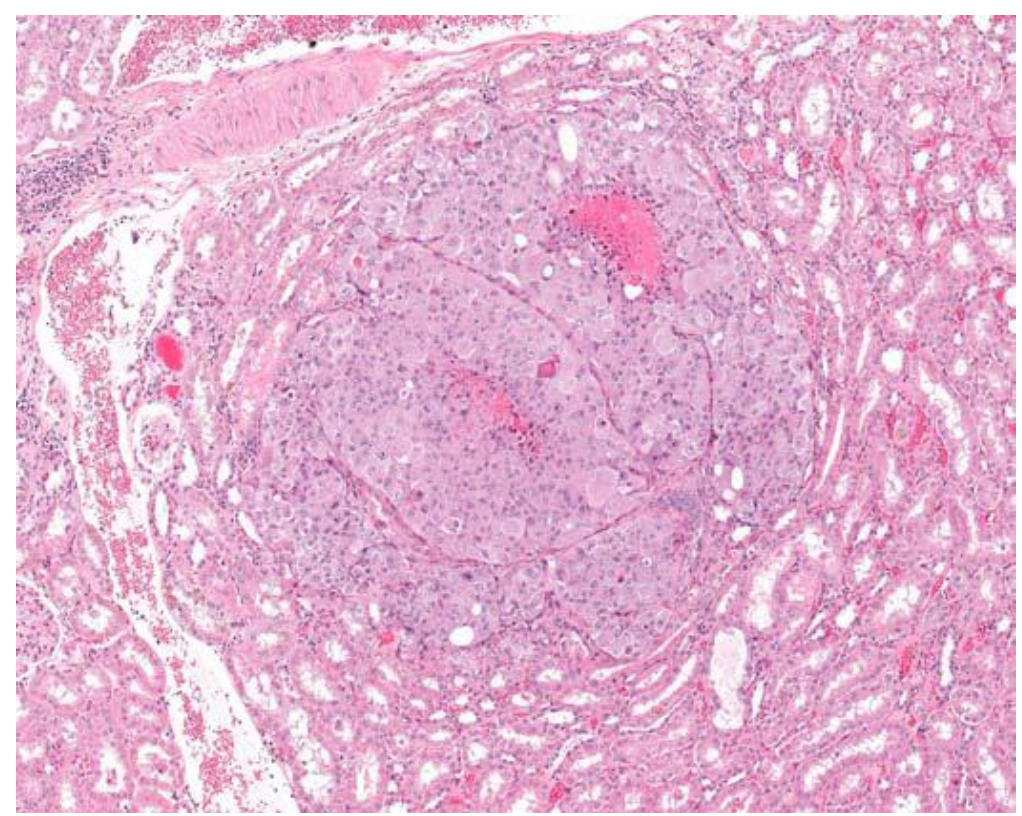

\section{Figure 13. Renal Tubule Adenoma in a Male F344/N Rat Exposed to 100 ppm Vinylidene Chloride by Whole Body Inhalation for Two Years $(\mathrm{H} \& \mathrm{E})$}

Renal tubule adenomas were variably sized, expansile masses composed of clusters and lobules of large epithelial cells with variable atypia, causing compression of the adjacent renal parenchyma.

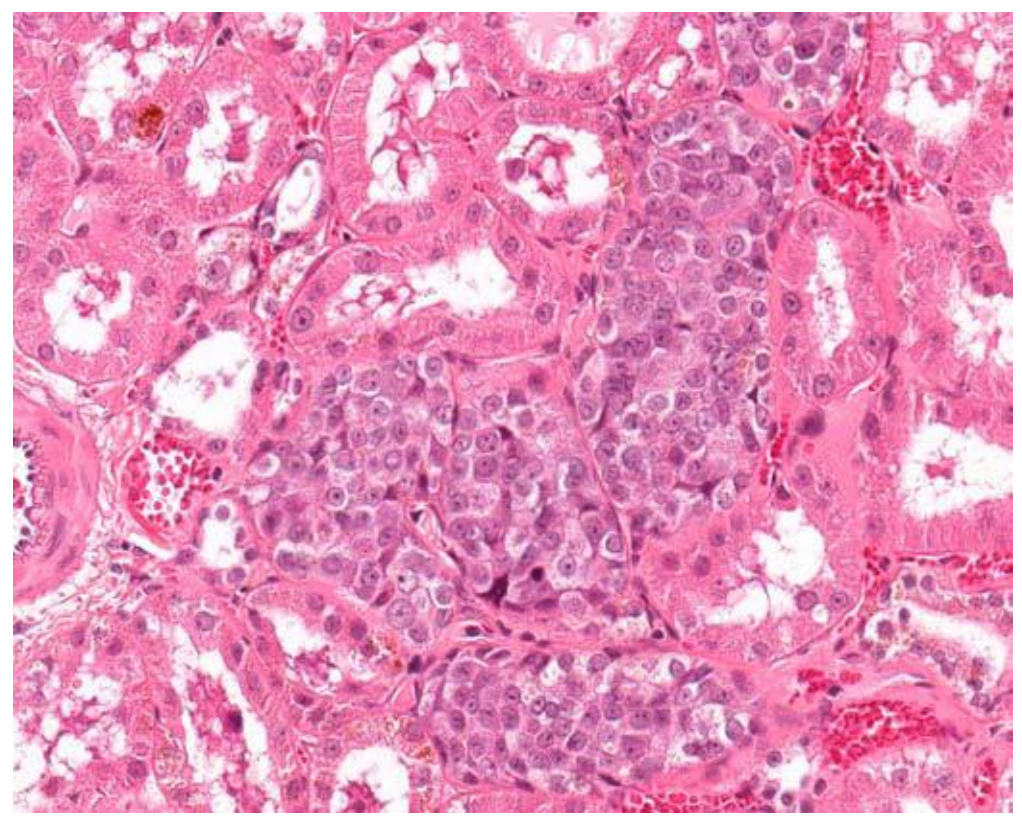

Figure 14. Renal Tubule Hyperplasia in a Male F344/N Rat Exposed to 25 ppm Vinylidene Chloride by Whole Body Inhalation for Two Years (H\&E)

Renal tubule hyperplasias characterized by piling and filling of one or more tubule lumens with enlarged, well-differentiated epithelial cells. 


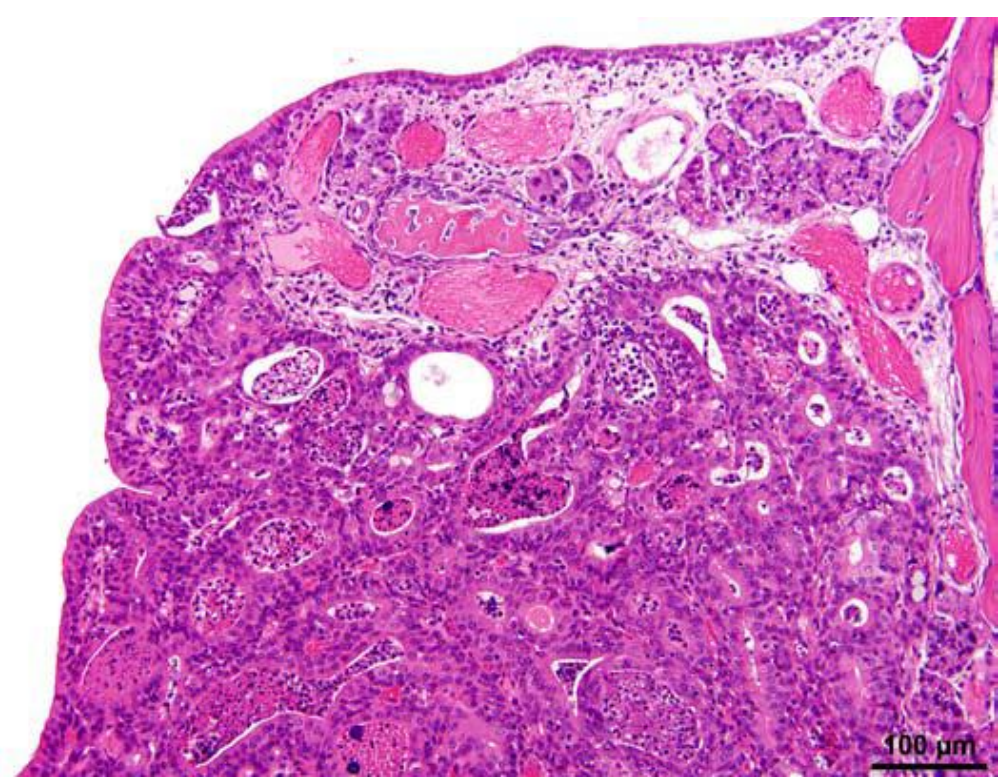

Figure 15. Nasal Adenoma in a Male F344/N Rat Exposed to 100 ppm Vinylidene Chloride by Whole Body Inhalation for Two Years (H\&E)

The nasal adenoma was expansile, causing partial obstruction of the nasal passage, and was composed of clusters and tubules of fairly well differentiated nasal epithelial cells supported by a fine fibrovascular stroma.

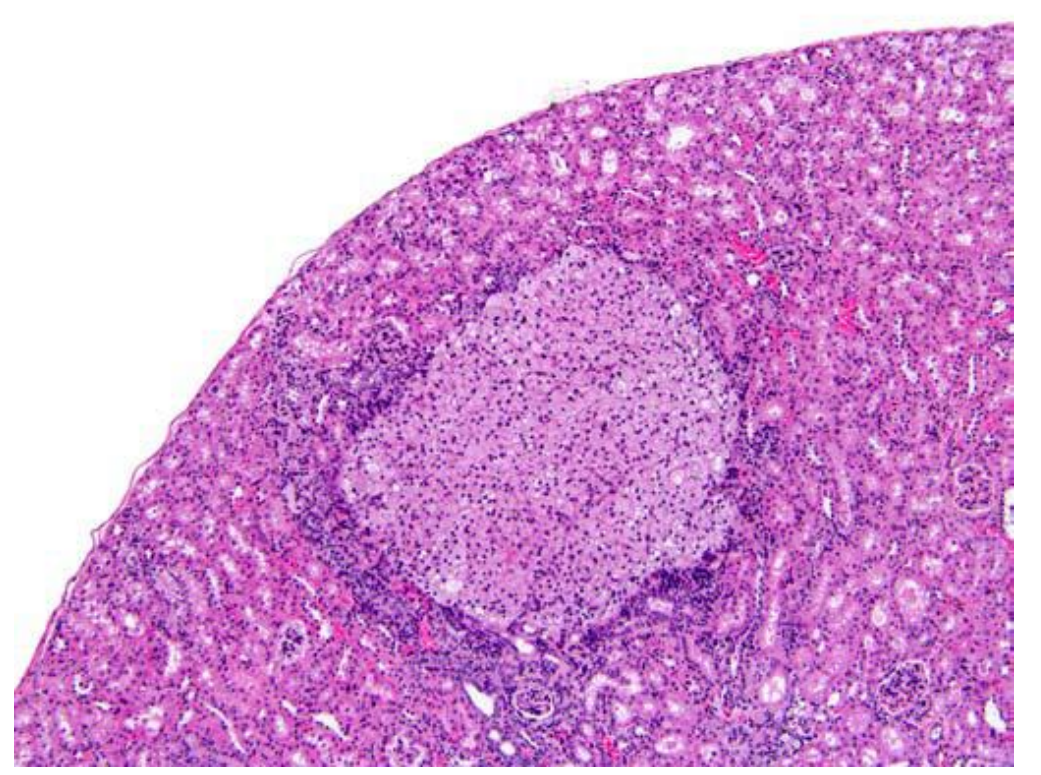

Figure 16. Renal Tubule Adenoma in a Male B6C3F1/N Mouse Exposed to 12.5 ppm Vinylidene Chloride by Whole Body Inhalation for Two Years (H\&E)

Renal tubule adenomas were discrete, expansile lesions that compressed adjacent parenchyma. 


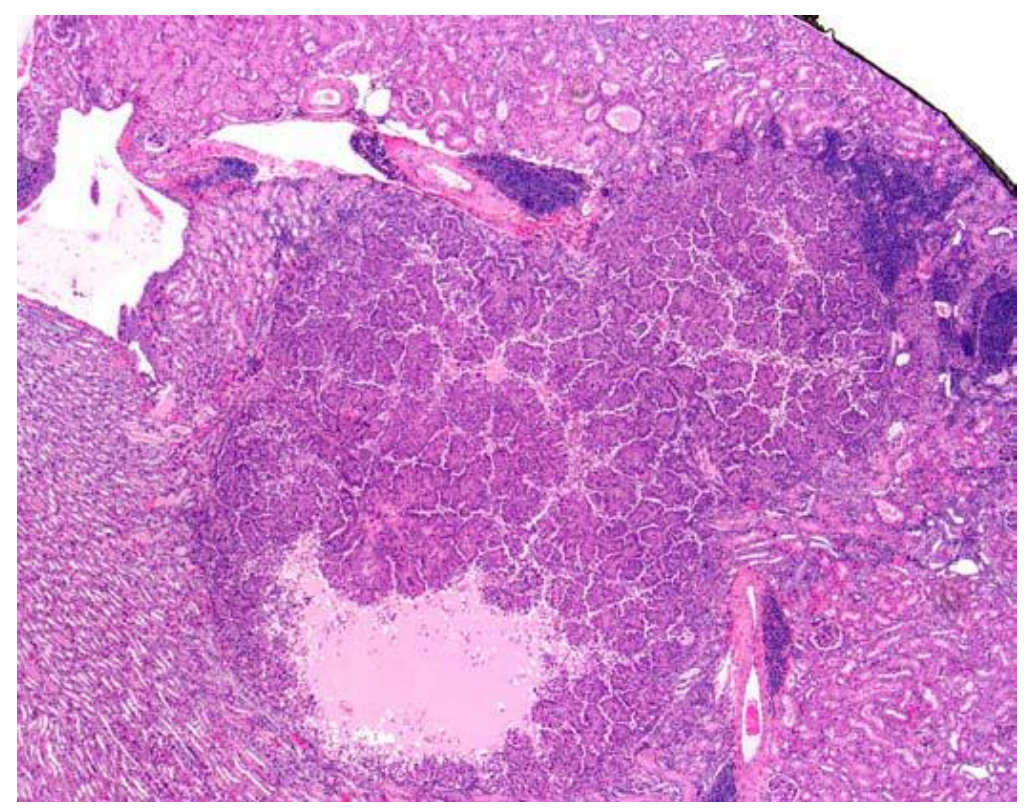

\section{Figure 17. Renal Tubule Carcinoma in a Male B6C3F1/N Mouse Exposed to 12.5 ppm Vinylidene Chloride by Whole Body Inhalation for Two Years (H\&E)}

Renal tubule carcinomas were infiltrative proliferations of tubules, lobules, and papillary projections of poorly differentiated renal tubule epithelial cells that infiltrated and effaced normal renal architecture, and were often associated with hemorrhage and necrosis.

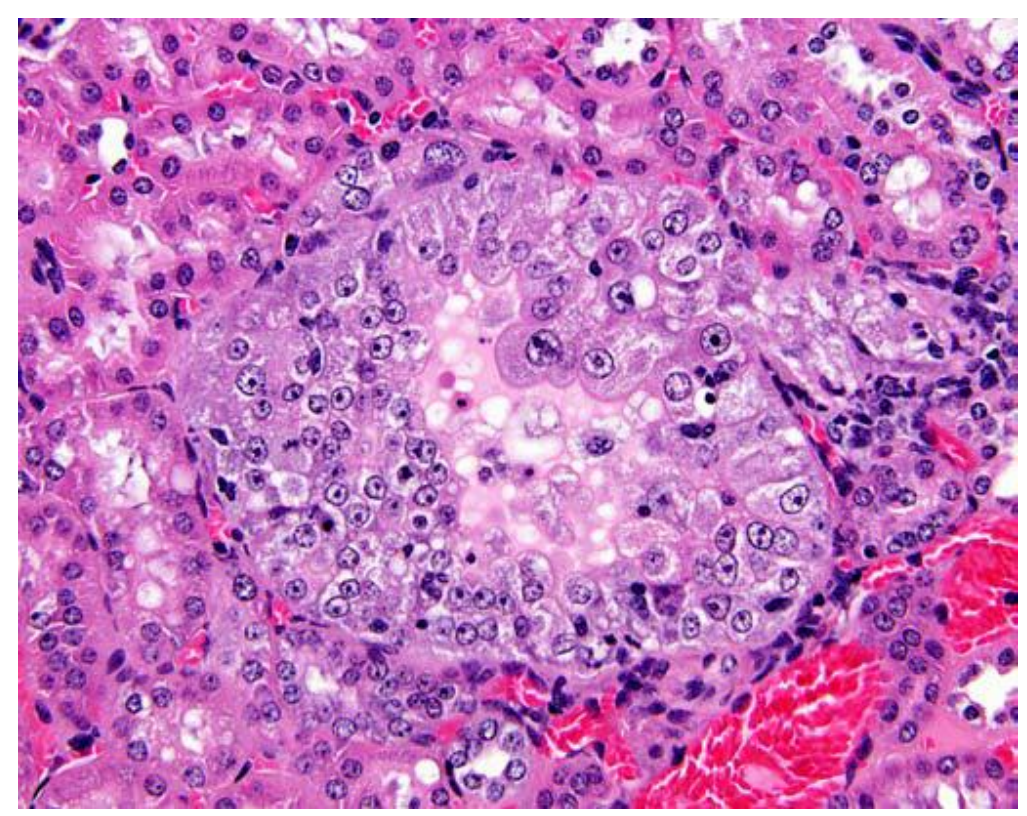

Figure 18. Renal Tubule Hyperplasia in a Male B6C3F1 Mouse Exposed to 6.25 ppm Vinylidene Chloride by Whole Body Inhalation for Two Years (H\&E)

Renal tubule hyperplasias were discrete lesions characterized by partial to complete filling of one or more tubular lumens by variably pleomorphic epithelial cells exhibiting mild to moderate atypia. 


\section{Discussion}

Vinylidene chloride was nominated for study by the Agency for Toxic Substances and Disease Registry (ATSDR), based on insufficient critical information regarding its health effects as a priority hazardous substance under the Substance Specific Applied Research Program at ATSDR. The findings of previous gavage studies conducted by $\mathrm{NTP}^{71}$ were considered no evidence of carcinogenicity in male or female $\mathrm{F} 344 / \mathrm{N}$ rats or B6C3F1 mice. However, because a maximum tolerated dose was not clearly demonstrated and previous studies suggested carcinogenicity associated with inhalation exposure, it was concluded that the studies should not be interpreted that vinylidene chloride is not a carcinogen. Despite a broad database of research from other published studies, adequate data do not exist regarding the carcinogenicity of vinylidene chloride. Although there have been many chronic inhalation and gavage studies reported in the literature, nearly all of these studies are insufficient to accurately evaluate the carcinogenicity of vinylidene chloride. The primary issue with the previously reported studies was that exposure durations were inadequate (12 months or less). However, other issues included changing or discontinuing dosing or exposure concentrations during the study, excessive mortality, inappropriate range of exposures, presence of potential contaminants (vinyl chloride), and lack of statistical description or analysis. The current United States Environmental Protection Agency (USEPA) carcinogen risk assessment is based on increased incidences of adrenal pheochromocytomas that were not statistically significant and thereby not considered treatment related in the previously conducted NTP gavage study ${ }^{71 ; 131}$.

The effects of whole body inhalation exposure to vinylidene chloride for 2 weeks, 3 months, or 2 years were studied in male and female $\mathrm{F} 344 / \mathrm{N}$ rats and $\mathrm{B} 6 \mathrm{C} 3 \mathrm{~F} 1 / \mathrm{N}$ mice. Overall, mice were more sensitive to vinylidene chloride-induced toxicity than rats. Species- and strain-specific differences in vinylidene chloride-induced mor-tality have been widely reported. For the current 2-week study of B6C3F1/N mice, exposure concentrations of $50 \mathrm{ppm}$ or greater in males and 100 ppm or greater in females caused decreased survival; in F344/N rats, decreased survival was observed at 200 and $400 \mathrm{ppm}$. In both rats and mice, the liver and kidney were target organs in early-death animals. Early deaths in both sexes of rats and mice were associated with marked centrilobular necrosis in the liver and granular casts in the kidney. In male mice, necrosis was observed in the renal tubules. These hepatic and nephrotoxic effects associated with mortality occurred quickly after the start of exposure. Kanz et al. ${ }^{132}$ demonstrated that, within 12 hours of a single oral administration of $100 \mathrm{mg} / \mathrm{kg}$ in Sprague Dawley rats, vinylidene chloride induced the formation of pyknotic hepatocytes, prenecrotic or preapoptotic cells identifiable by the condensation of chromatin in the nucleus. These data suggest that the observed liver effects may be a contributing factor in vinylidene chloride-induced mortality. In the 2-week mouse studies, necrosis of the respiratory epithelium in the nose also occurred in all of the early-death males and females. In the 3-month study, decreased survival in female mice exposed to $100 \mathrm{ppm}$ was also associated with increased incidences of necrosis in the liver, nose, lung, and larynx.

In the 2-week studies, the liver was a target organ for male and female rats and mice. In rats, liver lesions consisted of centrilobular hepatocellular cytoplasmic alteration in 25,50 , and $100 \mathrm{ppm}$ males and females and centrilobular hepatocellular necrosis in the 200 and $400 \mathrm{ppm}$ groups. The cytoplasmic alteration is suggestive of a degenerative lesion in the lower dose groups, which culminates in hepatocellular necrosis at higher doses. In mice, liver lesions consisted of hepatocellular necrosis in males and females exposed to 100, 200, or 400 ppm 
vinylidene chloride, and there was evidence of hepatocellular regeneration in the $100 \mathrm{ppm}$ female group.

The kidney was also a target organ for male and female rats and male mice in the 2-week studies. In rats, increased kidney weights were observed in both sexes. Kidney lesions consisted of tubule cast formation in the renal papillae in the 200 and 400 ppm males and females. In male mice, lesions were more severe, characterized not only by granular cast formation, but also proximal renal tubule necrosis in all dosed males.

The nose was also a target organ for male and female mice in the 2-week study. Lesions in the nose included respiratory epithelial necrosis in all 100, 200, and $400 \mathrm{ppm}$ males and 200 and 400 ppm females.

In the 3-month studies, no effects on survival or body weights were observed in rats exposed to concentrations of vinylidene chloride up to $100 \mathrm{ppm}$; in mice, decreased survival was observed in $50 \mathrm{ppm}$ males and $100 \mathrm{ppm}$ females. Final mean body weights in all vinylidene chlorideexposed groups of female mice were significantly less than that of the chamber controls ( $9 \%$ to $18 \%$ ), and in male mice there were exposure concentration-dependent decreases (10\% to $16 \%$ ) at 12.5 ppm or greater.

In the 3-month studies, the liver was a target organ in both sexes of rats and in female mice. In male rats, liver lesions consistent with cytoplasmic alteration as observed in the 2-week study occurred at $12.5 \mathrm{ppm}$ or greater, whereas in females, cytoplasmic vacuolization consistent with fatty change was observed at 50 and $100 \mathrm{ppm}$, suggesting a potential sex-related difference in liver pathology induced by vinylidene chloride. The biologic significance of this difference is unknown. In female mice, liver necrosis and centrilobular hypertrophy were observed at $100 \mathrm{ppm}$. Although mild liver necrosis occurred in two $50 \mathrm{ppm}$ males, this was not statistically significant; however, given the response in females, this may be related to exposure to vinylidene chloride. Hepatotoxicity was also reflected in mild transient treatment-related increases in sorbitol dehydrogenase and alanine aminotransferase activities. These effects in the liver are consistent with previously reported and well-established vinylidene chloride-induced hepatotoxicity. Various inhalation studies in rodents have demonstrated hepatocellular degeneration, necrosis, and cytoplasmic vacuolization following exposure to vinylidene chloride at concentrations ranging from 15 to $200 \mathrm{ppm}^{30 ; 71 ; 133 ; 134}$. In male and female Sprague Dawley rats exposed to 25 and $75 \mathrm{ppm}$ vinylidene chloride by inhalation for 6 or 12 months, midzonal hepatocellular fatty changes were observed ${ }^{80}$. Alteration in serum markers of hepatocellular injury, including sorbitol dehydrogenase, alanine aminotransferase, aspartate transaminase, and ornithine carbomyl transferase activities, have also been widely reported following acute inhalation of vinylidene chloride $55 ; 67 ; 135$ or oral administration ${ }^{56 ; 63 ; 66}$.

In the nose at 3 months, rats were more sensitive than mice to the treatment-related effects of vinylidene chloride. Increased incidences of atrophy, mineralization, and necrosis of olfactory epithelium were observed in both sexes of rats, whereas only respiratory epithelial necrosis was observed in female mice exposed to $100 \mathrm{ppm}$. In rats exposed to $6.25 \mathrm{ppm}$ or greater, significant increases in the incidences of olfactory epithelium mineralization in both sexes and of atrophy in males were observed. In males, necrosis of the olfactory epithelium was increased at $12.5 \mathrm{ppm}$ or greater. In females, olfactory epithelium atrophy at $12.5 \mathrm{ppm}$ or greater and olfactory epithelium 
necrosis at $25 \mathrm{ppm}$ or greater were increased. In general, the severity of these lesions increased with increasing exposure concentration.

In the 3-month studies, nasal turbinate atrophy occurred in all rats exposed to $12.5 \mathrm{ppm}$ or greater, and the severities increased with increasing exposure concentration, whereas an increased incidence was observed only in $100 \mathrm{ppm}$ female mice. Turbinate atrophy was not observed in any of the chamber controls, $6.25 \mathrm{ppm}$ male or female rats, or at $50 \mathrm{ppm}$ or less in female mice. In the lung of $100 \mathrm{ppm}$ female mice, minimal to marked necrosis of the bronchial epithelium and minimal to mild histiocytic inflammation occurred. In contrast to rats, lesions were observed in the larynx of high dose male and female mice and in the lung of high dose female mice, which is consistent with involvement of both the upper and lower respiratory tract. Increased incidences of squamous metaplasia of the respiratory epithelium were observed at $50 \mathrm{ppm}$ in both sexes of mice and at $100 \mathrm{ppm}$ in females, and lesion incidences and severities were greater in females than males. Additional lesions of respiratory epithelial hyperplasia and necrosis in the larynx were observed in $100 \mathrm{ppm}$ female mice. These species differences in pulmonary injury are consistent with those reported in male C57BL/6 mice ${ }^{136}$, but not in male Sprague Dawley rats ${ }^{22}$ administered a single gavage dose of $200 \mathrm{mg} / \mathrm{kg}$ vinylidene chloride. In male C57BL/6 mice, Forkert et al. ${ }^{136}$ showed that exposure to vinylidene chloride increased lung weights, induced necrosis and exfoliation of Clara cells in the bronchiolar epithelium, and resulted in peribronchiolar and perivascular edema. This pulmonary injury in mice was transient, and a regenerative response was observed 3 days after exposure, with the integrity of the epithelium substantially restored by 7 days. While neither of these studies included females for evaluation, these data are consistent with species-specific sensitivity between rats and mice.

In the current 3-month studies, the kidney was a target organ in male mice, but not rats or female mice. Increased incidences of minimal to moderate nephropathy were observed in male mice at $12.5 \mathrm{ppm}$ or greater with exposure concentration-dependent increases in the severities. In addition, two $50 \mathrm{ppm}$ males had proximal renal tubule necrosis and cast formation, consistent with the kidney findings in the 2-week study. While the incidences of necrosis and cast formation were not statistically significant, they were considered to be related to exposure to vinylidene chloride. In rats, dose-dependent increases (8\% to 16\%) in kidney weights were observed in females exposed to $12.5 \mathrm{ppm}$ or greater; however, no corresponding changes in histopathology were observed. In the previous $\mathrm{NTP}^{71}$ gavage studies, chronic renal inflammation was observed in both sexes of F344/N rats exposed to $5 \mathrm{mg} / \mathrm{kg}$ following 2 years of exposure.

Corresponding to the nephropathy, there were mild exposure concentration-dependent decreases in the erythrocyte counts, hemoglobin concentration, and hematocrit values of the $12.5 \mathrm{ppm}$ and greater male mice in the 3-month study. These decreases may be related to the decreases in body weight as well as the nephropathy, as the kidneys are the primary source of erythropoietin production. Specifically, erythropoietin is produced by interstitial peritubular cells within interstitial foci mostly adjacent to the proximal convoluted tubules ${ }^{137}$. Injury to these areas of the kidney, like that observed in this study, can lead to decreased production of erythropoietin with a subsequent decrease in erythropoiesis and total red blood cell mass. In addition, reductions in erythropoiesis with renal injury are also attributed to the effects of uremic toxins ${ }^{138}$.

The observed species differences in the current 2-week and 3-month studies are consistent with previous reports that mice are more susceptible than rats to vinylidene chloride-induced nephrotoxicity. In male CD-1 mice, kidney nephrosis was observed within 24 hours of inhalation 
exposure to $50 \mathrm{ppm}^{93}$. Moderate-to-severe nephrosis was also observed in four strains of mice exposed to 55, 100, or 200 ppm 6 hours/day, 5 days per week for 10 days $^{134}$. Nephrotoxicity has also been observed in rats, but at higher exposure concentrations. In male Sprague Dawley rats, exposure to greater than $300 \mathrm{ppm}$ vinylidene chloride induced tubular necrosis with calcium deposits $^{67}$. At $250 \mathrm{ppm}$, vinylidene chloride induced moderate cellular swelling in the renal cortex. In fasted males, which are more sensitive to the toxicity of vinylidene chloride, marked degeneration of proximal tubular epithelium was observed at $200 \mathrm{ppm}^{20}$. In male and female Sprague Dawley rats fasted overnight, oral administration of a single gavage dose of $400 \mathrm{mg} / \mathrm{kg}$ vinylidene chloride increased serum markers of renal toxicity and induced dose-related histopathologic changes in the kidney, including vacuolization, pigmentation, tubular dilation, and necrosis ${ }^{66}$.

In the 2-year study in rats, increased incidences of neoplasms were observed in the nose and kidney of males and in the thyroid gland of females exposed to vinylidene chloride. Increased incidences of systemic neoplasms were also observed in both sexes, including malignant mesotheliomas in males and mononuclear cell leukemias in females. In males, vinylidene chloride induced marked increases in the incidences of malignant mesothelioma in all exposed groups with a concentration-dependent decrease in the time to first incidence. These neoplasms were associated with gross observations of fluid in the abdomen and multiple nodules throughout the peritoneum, particularly on the testicular tunics and epididymides, but also involved a variety of abdominal organs including the intestines, mesentery, pancreas, prostate gland, spleen, and liver. One $25 \mathrm{ppm}$ male had mesothelioma within the pleura and pericardium in addition to the testicular and epididymal sites. In addition, mesotheliomas were observed in the thoracic cavity of one $25 \mathrm{ppm}$ and the abdominal cavity of one $50 \mathrm{ppm}$ female. Malignant mesothelioma is an uncommon background neoplasm in male F344/N rats, most often arising from the testicular tunics. This neoplasm is very rare in female rats. Therefore, the vinylidene chloride-induced increase in the incidences of malignant mesothelioma in male rats was considered clear evidence for carcinogenicity. The malignant mesotheliomas observed in two female rats may have been related to vinylidene chloride exposure.

Compared to spontaneous mesotheliomas in control animals, mesotheliomas arising in vinylidene chloride-exposed animals had overrepresentation of pathways associated with a proinflammatory response and immune dysregulation. These global gene changes allowed separation of background spontaneous mesotheliomas from those arising in vinylidene chlorideexposed animals based on genomic signatures, despite indistinguishable morphology between these neoplasm groups.

A molecular phenotype consistent with a proinflammatory response, immune dysregulation, or tissue damage has been shown to be associated with mechanisms of tumorigenesis, including development of mesothelioma. Inflammation is a well-known contributor to mesotheliomagenesis ${ }^{139-141}$. Exposure to vinylidene chloride results in saturation of the glutathione pathway and the generation of reactive vinylidene chloride metabolites $(1,1$ diethylene oxide, chloroacetyl chloride), which have the potential to cause tissue damage ${ }^{142}$. Although there was not a significant inflammatory response observed in either spontaneous or vinylidene chloride-treated mesotheliomas nor a significant difference in necrosis, apoptosis, or tissue damage between the tumor groups, molecular features suggest a proinflammatory microenvironment. Anti-inflammatory cytokines and chemokines were underrepresented in vinylidene chloride-exposed mesotheliomas compared to spontaneous tumors, while pattern 
recognition receptors and damage-associated molecular pattern molecules were upregulated, consistent with immune dysregulation and a proinflammatory response. Responses such as these have been associated with mesothelial cell proliferation ${ }^{143}$. The overrepresentation of these complex pathways supports the observation of a proinflammatory environment associated with mesotheliomas in vinylidene chloride-exposed animals.

In female rats, the incidence of mononuclear cell leukemia in the $100 \mathrm{ppm}$ group was significantly increased, and the time to first incidence was markedly shorter (by 236 days) than in the chamber controls. The time to first incidence was also decreased in the 25 and $50 \mathrm{ppm}$ groups; however, the incidences in these groups were comparable to the chamber control incidence. Mononuclear cell leukemia is a relatively common background neoplasm in F344/N rats, but there was a significant increase in the $100 \mathrm{ppm}$ females that exceeded the historical control ranges for studies by inhalation exposure and all routes combined. There was also an exposure-dependent decrease in the time to first incidence of the neoplasms. Therefore, the increased incidence of mononuclear cell leukemia in females exposed to $100 \mathrm{ppm}$ was considered to be related to vinylidene chloride exposure. Cotti et al. ${ }^{6}$ also reported increased incidences of leukemia in male and female Sprague Dawley rats exposed to $100 \mathrm{ppm}$ vinylidene chloride in utero starting on gestation day 12 for a duration of 104 weeks. These leukemias were described as a variety of hemolymphoreticular neoplastic diseases at different sites. In the NTP ${ }^{71}$ gavage study, there was a higher incidence of lymphoma or leukemia observed at $1 \mathrm{mg} / \mathrm{kg}$ but not at $5 \mathrm{mg} / \mathrm{kg}$ when compared to chamber controls, but these lesions were not considered related to vinylidene chloride exposure.

In the thyroid gland, C-cell adenomas were increased in the $100 \mathrm{ppm}$ female rats and occurred with a positive exposure concentration-dependent trend. C-cell carcinomas were observed in all groups of exposed females with a significant increased incidence occurring at $25 \mathrm{ppm}$, but not at 50 or $100 \mathrm{ppm}$. C-cell carcinomas are rare neoplasms in the F344/N rat. The incidences at 50 and 100 ppm, while not statistically significant, exceeded the historical control range for the inhalation route of exposure in female rats. The combined incidences of adenoma or carcinoma were increased in all exposed female groups compared to controls, with significant increases observed at 25 and 100 ppm. However, there was no accompanying increase in the incidences of hyperplasia, and the increases were not exposure concentration-dependent. Exposure to vinylidene chloride did not induce $\mathrm{C}$-cell neoplasms in males. The increases in C-cell neoplasms in female rats were considered to be related to vinylidene chloride exposure. These findings were considered some evidence of carcinogenic activity.

In the kidney, renal tubule carcinomas were observed in male rats exposed to vinylidene chloride for 2 years. While the incidences were not statistically significant, these neoplasms are exceedingly rare in male F344/N rats and have not been observed in 200 historical controls from inhalation studies. Furthermore, after single and step section evaluations were combined, a doserelated increase in the incidences of renal tubule hyperplasia were observed in exposed male rats; this lesion may be considered a precursor to neoplasm formation. In addition, there was a robust kidney neoplasm response in vinylidene chloride-exposed male mice in the corresponding mouse study, further supporting the kidney as a target of carcinogenesis in rats.

As observed in the 3-month study, the nose was a target organ for toxicity in the 2-year study in rats. In males, there was a positive trend in the incidences of adenoma of the respiratory epithelium. While the incidences of this neoplasm were low, no nasal adenomas were observed 
in any of the 697 historical controls from studies with all routes of exposure in F344/ $\mathrm{N}$ rats. In addition, nonneoplastic lesions occurred in both sexes with increased incidences and severities with increasing exposure concentration. These lesions included turbinate atrophy and hyperostosis, respiratory metaplasia of olfactory epithelium, chronic active inflammation, respiratory epithelial hyperplasia, and thrombosis. These nonneoplastic lesions are consistent with chronic injury and repair, a process that has been linked with carcinogenesis; therefore, the nasal adenomas in males were considered to be related to exposure to vinylidene chloride. In the lower respiratory tract, there was an increased incidence of alveolar epithelium hyperplasia in all exposed male groups with an exposure concentration-dependent increase in severity. However, no neoplasms were observed in the lung, indicating that the nose was the primary target of vinylidene chloride exposure.

The liver was a target organ for toxicity in 2-year rats, but exposure to vinylidene chloride did not induce any treatment-related hepatic neoplasms. Vinylidene chloride induced chronic inflammation and diffuse fatty change in both sexes at all exposure concentrations. Necrosis and cystic degeneration were also observed at higher exposure concentrations.

Nonneoplastic lesions observed at increased incidences included ovarian bursal dilatation and mesenteric fat necrosis. The incidences of bursal dilatation of the ovary were significantly increased in an exposure concentration-related manner, and the severities were increased in the exposed groups. The etiology of bursal dilatation may involve obstruction of the oviduct or other lower reproductive tract structures due to chronic inflammation or other abnormality; however, no such predisposing factor was noted grossly or on histopathologic examination. As such, the cause of increase in the incidences of ovarian bursal dilatation remains uncertain, and its biologic significance in this study is unknown. Increased incidences of fat necrosis of the mesentery were observed in all groups of exposed female rats. Localized fat necrosis may occur secondary to peritonitis or inflammatory lesions in the liver and other organs; however, this needs to be further substantiated, as the definitive cause of this lesion could not be determined, and, thus, its biologic relevance is uncertain. There are also treatment- and exposure concentration-related increases in the companion mouse study, which suggest a similar effect across species. However, because histopathologic examination of this lesion was only performed when gross lesions in the mesenteric fat were observed, the true incidence and biologic relevance of this lesion remain unknown.

The current 2-year rat study demonstrates that vinylidene chloride induced malignant mesotheliomas, renal tubule carcinomas, and nasal respiratory epithelium adenomas in males, and mononuclear cell leukemia and thyroid gland $\mathrm{C}$-cell adenomas and carcinomas in females. Previously reported carcinogenicity studies with vinylidene chloride in rats failed to demonstrate carcinogenicity in a variety of rat strains, including Wistar, Sprague Dawley, and CD rats. In those studies, no treatment-related tumors were reported following exposure to vinylidene chloride by inhalation $6 ; 11 ; 77 ; 78 ; 144 ; 145$ or by oral administration ${ }^{11 ; 51 ; 144}$. With the exception of two studies ${ }^{51 ; 145}$, rats in those studies were only exposed for 1 year, an exposure period that is too short to adequately determine carcinogenicity. In the studies conducted by Quast et al. ${ }^{145}$, inhalation exposures up to 75 ppm vinylidene chloride were carried out for 18 months in Sprague Dawley rats followed by a 6-month recovery period. Ponomarkov and Tomatis ${ }^{51}$ exposed pregnant female BD IV rats to $150 \mathrm{mg} / \mathrm{kg}$ vinylidene chloride by gavage on gestation day 17 and exposed the offspring once weekly at $50 \mathrm{mg} / \mathrm{kg}$ for up to 120 weeks. No exposure-related tumors were observed in the studies conducted by Ponomarkov and Tomatis ${ }^{51}$ or Quast et al. ${ }^{145}$. 
In the current 2-year mouse study, decreases in body weight occurred in males at 12.5 and $25 \mathrm{ppm}$ and females at $25 \mathrm{ppm}$. Decreased survival was observed at $25 \mathrm{ppm}$ in males and in 6.25 and $25 \mathrm{ppm}$ females. Increased survival was observed in $6.25 \mathrm{ppm}$ males. Similar to the 3 -month study, the kidney, liver, and nose were target organs. Following exposure to vinylidene chloride for 2 years, treatment-related neoplasms were observed in the kidney of males, in the liver of males and females, and in the lung and small intestine and systemically in females.

In all exposed groups of males, there were significant increases in the incidences of renal tubule hyperplasia, adenoma, and carcinoma. Additionally, bilateral and multiple adenomas and carcinomas were observed in some animals at $12.5 \mathrm{ppm}$. Grossly observed neoplastic lesions ranged from $1 \mathrm{~mm}$ pale cortical foci to large, occasionally bilateral masses that often replaced normal parenchyma. No renal tubule hyperplasia, adenomas, or carcinomas were observed in chamber control male mice or in 298 historical control mice from inhalation studies. In addition, one renal tubule adenoma occurred in a $25 \mathrm{ppm}$ female mouse; this is an exceedingly rare neoplasm in female mice. Based on the marked treatment-related increase in the incidences of renal tubule adenoma and carcinoma and concurrent increases in the incidences of renal tubule hyperplasia, renal cell adenoma and carcinoma were considered to be related to vinylidene chloride exposure.

The mechanism by which vinylidene chloride induces adverse effects in the liver and kidney may be related to the deactivation in the liver and reactivation in the kidney. Vinylidene chloride is metabolized in the liver by CYP2E1 and undergoes subsequent conjugation by glutathione or cysteine and is then transported to the kidney for excretion. This metabolic pathway is similar to that of trichloroethylene, a structurally similar chemical that also yields glutathione- and cysteine-conjugated metabolites. For trichloroethylene, glutathione conjugation leads to the formation of $S$-(1,2-dichlorovinyl) glutathione (DCVG), which can be further metabolized to the cysteine conjugate, $S$-(1,2-dichlorovinyl)-L-cysteine (DCVC) ${ }^{48 ; 146}$. Exposure to DCVC has been associated with nephrotoxicity and is believed to be associated with nephrocarcinogenicity ${ }^{48 ; 147 ;}$ ${ }^{148}$. The mechanism for kidney effects has been associated with cysteine conjugate $\beta$-lyase activity in the kidney. $\beta$-lyase bioactivation of DCVC to S-(1,2-dichlorovinyl)thiol (DCVSH), a chemically unstable compound that undergoes rearrangement to reactive species that alkylate cellular nucleophiles, is considered to be the major metabolic pathway of $\mathrm{DCVC}^{47 ; 48}$. According to this proposed metabolic pathway, vinylidene chloride may undergo metabolism by hepatic cytochrome $\mathrm{P} 450$ and conjugation to deactivated products that are transported to the kidney. In the kidney, cysteine-conjugated products become ideal substrates for $\beta$-lyase bioactivation to reactive metabolites. Eyre et al. ${ }^{149 ; 150}$ found that the activation of trichloroethylene by $\beta$-lyase was greater in mice than in rats, which is consistent with the more potent responses observed in the mice than the rats.

In the liver of female mice, there were positive trends in the incidences of hepatocellular adenoma, carcinoma, and adenoma or carcinoma (combined); the combined incidences were significantly increased at 12.5 and $25 \mathrm{ppm}$. The incidence of hepatocellular carcinoma was significantly increased in the $25 \mathrm{ppm}$ females compared to chamber controls. The increased incidences of these neoplasms may have been related to exposure to vinylidene chloride; however, these neoplasms are common background neoplasms in B6C3F1 mice with a wide range in incidence. Furthermore, there is not a corresponding hepatocellular adenoma or carcinoma response in male mice. Hepatocholangiocarcinomas were observed in one $6.25 \mathrm{ppm}$, one $12.5 \mathrm{ppm}$, and one $25 \mathrm{ppm}$ female, while none were observed in chamber controls or in any 
of the 948 historical controls by all route of exposure, which includes 300 from inhalation studies. Therefore, these neoplasms were considered to also be related to vinylidene chloride exposure.

In male mice, a single hepatocholangiocarcinoma was observed in chamber controls, two each in the $6.25 \mathrm{ppm}$ and $12.5 \mathrm{ppm}$ dose groups, and three in the $25 \mathrm{ppm}$ group. These neoplasms are not as rare in males, with 10 observed in 949 historical controls by all routes of exposure, including 2 of 299 from inhalation studies. Additionally, the incidences did not exceed the historical controls for all routes of exposure. The hepatocholangiocarcinomas in males may have been related to vinylidene exposure. In males, there was an exposure concentration-dependent decreasing trend in the incidence of hepatocellular adenoma, and significant decreases in the incidences of adenoma at $25 \mathrm{ppm}$ and carcinoma at $12.5 \mathrm{ppm}$. The incidence of basophilic focus was significantly increased in $25 \mathrm{ppm}$ males. The biological significance of these lesions is unclear.

In $25 \mathrm{ppm}$ female mice, there was an increase in the incidence of systemic hemangiosarcoma, predominantly driven by the statistically significant increase in the incidence of this neoplasm in the liver. Systemic hemangiomas were also observed in two females in each exposed group.

None were observed in the control group, or in any of the 300 historical controls from inhalation studies. The incidences also exceeded the historical control range for all routes of exposure. Based on the increased incidence of hemangioma or hemangiosarcoma (combined) for all organs, which occurred with a positive trend among exposure groups and was significantly increased in the $25 \mathrm{ppm}$ group, these neoplasms were considered related to vinylidene chloride exposure.

The incidence of alveolar/bronchiolar carcinoma in $12.5 \mathrm{ppm}$ female mice was significantly increased compared to chamber controls, and the incidence in the $25 \mathrm{ppm}$ females was at the upper end of the the historical control range for inhalation studies. Additionally, a positive trend in carcinoma incidence was observed. The time to first incidence for alveolar/ bronchiolar carcinoma was shorter in all exposed groups of females when compared to chamber controls. However, there was no supporting increase in the incidences of alveolar/bronchiolar adenoma, no neoplastic effect in males, and no accompanying increase in incidence or severity of hyperplastic lesions. Alveolar/ bronchiolar carcinomas are also fairly common background neoplasms. Given these data, and the fact that this was an inhalation route of exposure, it was considered that the incidence of alveolar/bronchiolar carcinoma in female mice may have been related to vinylidene chloride treatment. The induction of pulmonary adenomas by vinylidene chloride was previously reported in both male and female Swiss mice, with increased incidences in males at $10 \mathrm{ppm}$ and both sexes at $25 \mathrm{ppm}^{11 ; 144}$. Lee et al. ${ }^{77}$ also report increased incidences of alveolar/bronchiolar adenomas in male CD-1 mice. These increases were not statistically significant, however exposures in this study were only conducted for 1 year, not 2 years as in the current study.

A few uncommon carcinomas of the small intestine occurred in both male and female mice. The incidences in males fell within the historical control ranges, but the incidence in the $25 \mathrm{ppm}$ group of females was outside the historical control ranges both for inhalation studies and all routes of exposure. Therefore, the incidence of small intestine neoplasms in female mice may have been related to vinylidene chloride exposure. 
Similar to the effects observed in rats, nonneoplastic lesions were observed in the nose of male and female mice with generally increased incidence and severity with increasing exposure concentration. Signficantly increased incidences of atrophy of the turbinate, hyperstosis, and respiratory metaplasia in the olfactory epithelium were observed in all exposed groups. In females, the incidences of hyaline droplet accumulation in the olfactory epithelium and respiratory epithelium hyperplasia were increased at $25 \mathrm{ppm}$. In males, the incidences of hyaline droplet accumulation in the olfactory epithelium were increased at 12.5 and $25 \mathrm{ppm}$.

Treatment-related increases in other nonneoplastic lesions were observed in female mice. There were increased incidences of fat necrosis of the mesentery in exposed groups of female mice, similar to those observed in the companion rat study; however, because this lesion was only examined microscopically when a gross lesion in the mesentery was observed at necropsy, the true incidence of this lesion is uncertain. Localized fat necrosis may occur with inflammatory lesions in the liver or other closely associated abdominal organs; however, this needs to be further substantiated, and the true biologic significance of this lesion remains uncertain. Cystic endometrial hyperplasia of the uterus was significantly increased in incidence in exposed groups of female mice. However, the cause of this increase could not be determined based on histopathologic examination, and therefore the biologic relevance between this increased incidence and vinylidene chloride exposure remains unknown.

Results from a variety of published in vitro genetic toxicology studies with vinylidene chloride, including approaches such as bacterial mutagenicity assays, yeast test systems, and mammalian cell lines, demonstrate that under appropriate exposure conditions that control for the volatility of vinylidene chloride, the chemical has mutagenic, clastogenic, and aneugenic properties. In in vivo studies, the limited available genotoxicity test data are negative, with the exception of one study that detected low levels of DNA alkylation in liver and kidney, tissues associated with vinylidene chloride-induced tumorigenesis ${ }^{93}$. Because alkylating agents in general possess mutagenic, clastogenic, and aneugenic properties, and many are known carcinogens, DNA alkylation may be one possible mode of action for vinylidene chloride associated tumorigenesis, consistent with the results obtained in well-conducted in vitro assays but not captured in the micronucleus studies that rely on exposure of proerythrocytes in the bone marrow. 


\section{Conclusions}

Under the conditions of this 2-year inhalation study, there was clear evidence of carcinogenic activity $^{\mathrm{a}}$ of vinylidene chloride in male $\mathrm{F} 344 / \mathrm{N}$ rats based on increased incidences of malignant mesothelioma. Increased incidences of renal tubule carcinoma and respiratory epithelium adenoma in the nose of male rats were also considered to be related to vinylidene chloride exposure. There was some evidence of carcinogenic activity of vinylidene chloride in female $\mathrm{F} 344 / \mathrm{N}$ rats based on increased incidences of C-cell adenoma or carcinoma in the thyroid gland and systemic mononuclear cell leukemia. Occurrences of malignant mesothelioma may have been related to vinylidene chloride exposure. There was clear evidence of carcinogenic activity of vinylidene chloride in male $\mathrm{B} 6 \mathrm{C} 3 \mathrm{~F} 1 / \mathrm{N}$ mice based on increased incidences of renal tubule adenoma and carcinoma. Increased incidences of hepatocholangiocarcinoma may have been related to vinylidene chloride exposure. There was clear evidence of carcinogenic activity of vinylidene chloride in female $\mathrm{B} 6 \mathrm{C} 3 \mathrm{~F} 1 / \mathrm{N}$ mice based on increased incidences of systemic hemangioma or hemangiosarcoma (combined). Hepatocholangiocarcinoma and hepatocellular adenoma or carcinoma (combined) in the liver of female mice were also considered to be related to vinylidene chloride exposure. Increased incidences of alveolar/bronchiolar carcinoma in the lungs and carcinoma of the small intestine may have been related to treatment.

Exposure to vinylidene chloride caused increases in the incidences of nonneoplastic lesions in the nose of rats and mice, the liver of rats, the lung of male rats, and the kidney of male mice.

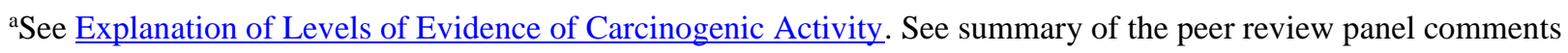
and the public discussion on this Technical Report in Appendix M. 


\section{References}

1. Gibbs DS, Wessling RA. Vinylidene chloride and poly(vinylidene chloride). Kirk-Othmer Encyclopedia of Chemical Technology. 3 ed. New York: Wiley-Interscience; 1983. p. 764-798.

2. International Agency for Research on Cancer (IARC). IARC Monographs on the Evaluation of the Carcinogenic Risk of Chemicals to Humans. Some Chemicals Used in Plastics and Elastomers. Lyon, France. 1986; 39:195-226.

3. International Agency for Research on Cancer (IARC). IARC Monographs on the Evaluation of Carcinogenic Risks to Humans. Re-evaluation of Some Organic Chemicals, Hydrazine and Hydrogen Peroxide. Lyon, France. 1999; 71:1163-1180.

4. Torkelson TR. Halogenated aliphatic hydrocarbons containing chlorine, bromine, and iodine In: Clayton GD, Clayton FE, editors. Patty's Industrial Hygiene and Toxicology. 4th ed. New York: Wiley-Interscience; 1994. p. 181-4189.

5. The Merck Index. O'Neil, MJ editor. 14th ed. Whitehouse Station, NJ: Merck and Company Inc.; 2006.

6. Cotti G, Maltoni C, Lefemine G. Long-term carcinogenicity bioassay on vinylidene chloride administered by inhalation to Sprague-Dawley rats: New results. Ann N Y Acad Sci. 1988; 534(1):160-168. http://dx.doi.org/10.1111/j.1749-6632.1988.tb30109.x

7. Hazardous Substances Data Bank (HSDB). 1,1 Dichloroethylene. National Institute for Occupational Safety and Health; 2003.

8. International Programme on Chemical Safety (IPCS). Environmental Health Criteria 100, Vinylidene Chloride. Geneva, Switzerland: World Health Organization; 1990.

9. Agency for Toxic Substances and Disease Registry (ATSDR). Toxicological profile for 1, 1dichloroethene. U.S. Department of Health and Human Services, Public Health Service, Agency for Toxic Substances and Disease Registry; 1994.

10. U.S. Environmental Protection Agency (USEPA). Toxicological Review of 1,1Dichloroethylene (CAS No. 75-35-4) in Support of Summary Information on the Integrated Risk Information System (IRIS). Washington, DC: U.S. Environmental Protection Agency; 2002. EPA Report No. EPA/635/R02/002.

11. Maltoni CG, Lefemine G, Patella F. Experimental research on vinylidene chloride carcinogenesis. Archives of Research on Industrial Carcino-genesis, Vol. III. Maltoni C, Mehlman MA, editors. Princeton, NJ: Princeton Scientific; 1985.

12. Wallace LA. Comparison of risks from outdoor and indoor exposure to toxic chemicals. Environ Health Perspect. 1991; 95:7-13. http://dx.doi.org/10.1289/ehp.91957

13. American Conference of Governmental Industrial Hygienists (ACGIH). TLVs and BEIs Threshold Limit Values for Chemical Substances and Physical Agents and Biological Exposure Indices. Cincinnati, OH; 2013. p. 60. 
14. McKenna M, Zempel J, Madrid E, Gehring P. The pharmacokinetics of [14C] vinylidene chloride in rats following inhalation exposure. Toxicol Appl Pharmacol. 1978; 45(2):599-610. http://dx.doi.org/10.1016/0041-008X(78)90121-7

15. Dallas C, Weir F, Feldman S, Putcha L, Bruckner J. The uptake and disposition of 1,1dichloroethylene in rats during inhalation exposure. Toxicol Appl Pharmacol. 1983; 68(1):140151. http://dx.doi.org/10.1016/0041-008X(83)90363-0

16. Jaeger RJ, Shoner LG, Coffman L. 1,1-Dichloroethylene hepatotoxicity: Proposed mechanism of action and distribution and binding of 14C radio-activity following inhalation exposure in rats. Environ Health Perspect. 1977; 21:113-119. http://dx.doi.org/10.1289/ehp.7721113

17. McKenna M, Watanabe P, Gehring P. Pharmacokinetics of vinylidene chloride in the rat. Environ Health Perspect. 1977; 21:99-105. http://dx.doi.org/10.1289/ehp.772199

18. Bruckner J, White C, Muralidhara S, Hines C, Dallas C. Influence of exposure route and oral dosage regimen on 1, 1-dichloroethylene toxicokinetics and target organ toxicity. $\mathrm{J}$ Pharmacol Exp Ther. 2010; 333(2):519-527. http://dx.doi.org/10.1124/jpet.109.162479

19. Jones B, Hathway D. The biological fate of vinylidene chloride in rats. Chem Biol Interact. 1978; 20(1):27-41. http://dx.doi.org/10.1016/0009-2797(78)90078-9

20. McKenna M, Zempel J, Madrid E, Braun W, Gehring P. Metabolism and pharmacokinetic profile of vinylidene chloride in rats following oral administration. Toxicol Appl Pharmacol. 1978; 45(3):821-835. http://dx.doi.org/10.1016/0041-008X(78)90173-4

21. Reichert D, Werner H, Metzler M, Henschler D. Molecular mechanism of 1,1dichloroethylene toxicity: excreted metabolites reveal different pathways of reactive intermediates. Arch Toxicol. 1978; 42(3):159-169. http://dx.doi.org/10.1007/BF00353707

22. Chieco P, Moslen MT, Reynolds ES. Effect of administrative vehicle on oral 1,1dichloroethylene toxicity. Toxicol Appl Pharmacol. 1981; 57(2):146-155.

http://dx.doi.org/10.1016/0041-008X(81)90274-X

23. Putcha L, Bruckner J, D'Souza R, Desai F, Feldman S. Toxicokinetics and bioavailability of oral and intravenous 1, 1-dichloroethylene. Fundam Appl Toxicol. 1986; 6(2):240-250. http://dx.doi.org/10.1016/0272-0590(86)90237-X

24. Jones B, Hathway D. Differences in metabolism of vinylidene chloride between mice and rats. Br J Cancer. 1978; 37(3):411-417. http://dx.doi.org/10.1038/bjc.1978.61

25. Okine LK, Goochee JM, Gram TE. Studies on the distribution and co valent binding of 1, 1dichloroethylene in the mouse: Effect of various pretreatments on covalent binding in vivo. Biochem Pharmacol. 1985; 34(22):4051-4057. http://dx.doi.org/10.1016/0006-2952(85)90386-7

26. Andersen ME, French JE, Gargas ML, Jones RA, Jenkins LJ, Jr. Saturable metabolism and the acute toxicity of 1,1-dichloroethylene. Toxicol Appl Pharmacol. 1979; 47(2):385-393. http://dx.doi.org/10.1016/0041-008X(79)90334-X 
27. D'Souza R, Andersen M. Physiologically based pharmacokinetic model for vinylidene chloride. Toxicol Appl Pharmacol. 1988; 95(2):230-240. http://dx.doi.org/10.1016/0041$\underline{008 X(88) 90159-7}$

28. Jaeger RJ, Conolly RB, Murphy SD. Effect of $18 \mathrm{hr}$ fast and glutathione depletion on 1, 1dichloroethylene-induced hepatotoxicity and lethality in rats. Exp Mol Pathol. 1974; 20(2):187198. http://dx.doi.org/10.1016/0014-4800(74)90053-7

29. Reichert D, Werner H, Henschler D. Role of liver glutathione in 1, 1-dichloroethylene metabolism and hepatotoxicity in intact rats and isolated perfused rat liver. Arch Toxicol. 1978; 41(3):169-178. http://dx.doi.org/10.1007/BF00354088

30. Reynolds ES, Moslen MT, Boor PJ, Jaeger RJ. 1, 1-Dichloroethylene hepatotoxicity. Time course of GSH changes and biochemical aberrations. Am J Pathol. 1980; 101(2):331-342.

31. Costa AK, Ivanetich KM. Vinylidene chloride: its metabolism by hepatic microsomal cytochrome P-450 in vitro. Biochem Pharmacol. 1982; 31(11):2083-2092. http://dx.doi.org/10.1016/0006-2952(82)90425-7

32. Liebler DC, Meredith MJ, Guengerich FP. Formation of glutathione conjugates by reactive metabolites of vinylidene chloride in microsomes and isolated hepatocytes. Cancer Res. 1985; 45(1):186-193.

33. Liebler DC, Latwesen DG, Reeder TC. S-(2-chloroacetyl) glutathione, a reactive glutathione thiol ester and a putative metabolite of 1, 1-dichloroethylene. Biochemistry. 1988; 27(10):36523657. http://dx.doi.org/10.1021/bi00410a020

34. Okine LK, Gram TE. In vitro studies on the metabolism and covalent binding of [14C] 1, 1dichloroethylene by mouse liver, kidney and lung. Biochem Pharmacol. 1986; 35(16):27892795. http://dx.doi.org/10.1016/0006-2952(86)90191-7

35. Dowsley TF, Forkert P-G, Benesch LA, Bolton JL. Reaction of glutathione with the electrophilic metabolites of 1, 1-dichloroethylene. Chem Biol Interact. 1995; 95(3):227-244. http://dx.doi.org/10.1016/0009-2797(94)03563-N

36. Forkert P-G. In vivo formation and localization of 1,1-dichloroethylene epoxide in murine liver: identification of its glutathione conjugate 2-S-glutathionyl acetate. J Pharmacol Exp Ther. 1999; 290(3):1299-1306.

37. Forkert P-G. 1,1-Dichloroethylene-induced Clara cell damage is associated with in situ formation of the reactive epoxide: Immunohistochemical detection of its glutathione conjugate. Am J Respir Cell Mol Biol. 1999; 20(6):1310-1318. http://dx.doi.org/10.1165/ajrcmb.20.6.3525

38. Jones JA, Kaphalia L, Treinen-Moslen M, Liebler DC. Proteomic characterization of metabolites, protein adducts, and biliary proteins in rats exposed to 1,1-dichloroethylene or diclofenac. Chem Res Toxicol. 2003; 16(10):1306-1317. http://dx.doi.org/10.1021/tx0340807

39. Simmonds AC, Reilly CA, Baldwin RM, Ghanayem BI, Lanza DL, Yost GS, Collins KS, Forkert PG. Bioactivation of 1,1-dichloroethylene to its epoxide by CYP2E1 and CYP2F enzymes. Drug Metab Dispos. 2004; 32(9):1032-1039. 
40. Liebler DC, Guengerich FP. Olefin oxidation by cytochrome P-450: evidence for group migration in catalytic intermediates formed with vinylidene chloride and trans-1-phenyl-1butene. Biochemistry. 1983; 22(24):5482-5489. http://dx.doi.org/10.1021/bi00293a005

41. Dowsley TF, Ulreich JB, Bolton JL, Park SS, Forkert P-G. CYP2E1-dependent bioactivation of 1,1-dichloroethylene in murine lung: formation of reactive intermediates and glutathione conjugates. Toxicol Appl Pharmacol. 1996; 139(1):42-48.

http://dx.doi.org/10.1006/taap.1996.0141

42. Forkert P-G. Mechanisms of 1,1-dichloroethylene-induced cytotoxicity in lung and liver. Drug Metab Rev. 2001; 33(1):49-80. http://dx.doi.org/10.1081/DMR-100000140

43. Cossec B, Cavelier L, Moitessier-Bergé N, Morel G, de Ceaurriz J. Formation of GSHderivatives as a pathway for inactive intermediates in vinylidene chloride-treated rats. Toxicol Lett. 1996; 89(3):223-229. http://dx.doi.org/10.1016/S0378-4274(96)03819-2

44. Short RD, Winston JM, Minor JL, Seifter J, Lee C-C. Effect of various treatments on toxicity of inhaled vinylidene chloride. Environ Health Perspect. 1977; 21:125-129. http://dx.doi.org/10.1289/ehp.7721125

45. Kainz A, Cross H, Freeman S, Gescher A, Chipman JK. Effects of 1,1-dichloroethene and of some of its metabolites on the functional viability of mouse hepatocytes. Fundam Appl Toxicol. 1993; 21(2):140-148. http://dx.doi.org/10.1006/faat.1993.1083

46. Lee RP, Forkert P-G. In vitro biotransformation of 1,1-dichloroethylene by hepatic cytochrome P-450 2E1 in mice. J Pharmacol Exp Ther. 1994; 270(1):371-376.

47. Dekant W, Berthold K, Vamvakas S, Henschler D, Anders M. Thioacylating intermediates as metabolites of S-(1, 2-dichlorovinyl)-L-cysteine and S-(1, 2, 2-trichlorovinyl)-L-cysteine formed by cysteine conjugate beta-lyase. Chem Res Toxicol. 1988; 1:175-178.

http://dx.doi.org/10.1021/tx00003a008

48. Lash LH, Fisher JW, Lipscomb JC, Parker JC. Metabolism of trichloroethylene. Environ Health Perspect. 2000; 108:177-200. http://dx.doi.org/10.1289/ehp.00108s2177

49. Dowsley TF, Reid K, Petsikas D, Ulreich JB, Fisher RL, Forkert P-G. Cytochrome P-450dependent bioactivation of 1, 1-dichloroethylene to a reactive epoxide in human lung and liver microsomes. J Pharmacol Exp Ther. 1999; 289(2):641-648.

50. Jenkins LJ, Trabulus M, Murphy S. Biochemical effects of 1,1-dichloroethylene in rats: comparison with carbon tetrachloride and 1, 2-dichloroethylene. Toxicol Appl Pharmacol. 1972; 23(3):501-510. http://dx.doi.org/10.1016/0041-008X(72)90052-X

51. Ponomarkov V, Tomatis L. Long-term testing of vinylidene chloride and chloroprene for carcinogenicity in rats. Oncology. 1980; 37(3):136-141. http://dx.doi.org/10.1159/000225422

52. Siegel J, Jones R, Coon R, Lyon J. Effects on experimental animals of acute, repeated and continuous inhalation exposures to dichloroacetylene mixtures. Toxicol Appl Pharmacol. 1971; 18(1):168-174. http://dx.doi.org/10.1016/0041-008X(71)90326-7 
53. Short RD, Winston JM, Minor JL, Hong CB, Seifter J, Lee CC. Toxicity of vinylidene chloride in mice and rats and its alteration by various treatments. J Toxicol Environ Health. 1977; 3(5-6):913-921. http://dx.doi.org/10.1080/15287397709529625

54. Jaeger R, Trabulus M, Murphy S. The interaction of adrenalectomy, partial adrenal replacement therapy, and starvation with hepatotoxicity and lethality after 1,1-dichloroethylene intoxication. Toxicol Appl Pharmacol. 1973; 25(3):491.

55. Jaeger RJ, Conolly RB, Murphy SD. Short-term inhalation toxicity of halogenated hydrocarbons: effects on fasting rats. Arch Environ Health. 1975; 30(1):26-31. http://dx.doi.org/10.1080/00039896.1975.10666628

56. Andersen ME, Jenkins LJ, Jr. Oral toxicity of 1,1-dichloroethylene in the rat: Effects of sex, age, and fasting. Environ Health Perspect. 1977; 21:157-163. http://dx.doi.org/10.1289/ehp.7721157

57. Moslen MT, Poisson LR, Reynolds ES. Cholestasis and increased biliary excretion of inulin in rats given 1,1-dichloroethylene. Toxicology. 1985; 34(3):201-209. http://dx.doi.org/10.1016/0300-483X(85)90171-4

58. Andersen ME, Thomas OE, Gargas ML, Jones RA, Jenkins LJ, Jr. The significance of multiple detoxification pathways for reactive metabolites in the toxicity of 1,1-dichloroethylene. Toxicol Appl Pharmacol. 1980; 52(3):422-432. http://dx.doi.org/10.1016/0041-008X(80)90337$\underline{3}$

59. Siegers CP, Horn W, Younes M. Effect of phorone-induced glutathione depletion on the metabolism and hepatotoxicity of carbon tetrachloride and vinylidene chloride in rats. J Appl Toxicol. 1985; 5(6):352-356. http://dx.doi.org/10.1002/jat.2550050603

60. Kanz MF, Whitehead RF, Ferguson AE, Moslen MT. Potentiation of 1,1-dichloroethylene hepatotoxicity: comparative effects of hyperthyroidism and fasting. Toxicol Appl Pharmacol. 1988; 95(1):93-103. http://dx.doi.org/10.1016/S0041-008X(88)80011-5

61. Moussa M, Forkert PG. 1,1-dichloroethylene-induced alterations in glutathione and covalent binding in murine lung: Morphological, histochemical, and biochemical studies. J Pathol. 1992; 166(2):199-207. http://dx.doi.org/10.1002/path.1711660218

62. Andersen ME, Jones RA, Jenkins LJ, Jr. The acute toxicity of single, oral doses of 1,1dichloroethylene in the fasted, male rat: Effect of induction and inhibition of microsomal enzyme activities on mortality. Toxicol Appl Pharmacol. 1978; 46(1):227-234.

http://dx.doi.org/10.1016/0041-008X(78)90153-9

63. Moslen MT, Whitehead RF, Ferguson A, Kanz MF. Protection by L-2-oxothiazolidine-4carboxylate, a cysteine prodrug, against 1,1-dichloroethylene hepatotoxicity in rats is associated with decreases in toxin metabolism and cytochrome P-450. J Pharmacol Exp Ther. 1989; 248(1):157-163.

64. Forkert P-G, Moussa M. 1,1-Dichloroethylene elicits dose-dependent alterations in covalent binding and glutathione in murine liver. Drug Metab Dispos. 1991; 19(3):580-586. 
65. Forkert P-G, Moussa M. Temporal effects of 1,1-dichloroethylene on nonprotein sulfhydryl content in murine lung and liver. Drug Metab Dispos. 1993; 21(5):770-776.

66. Jenkins L, Jr., Andersen M. 1,1-Dichloroethylene nephrotoxicity in the rat. Toxicol Appl Pharmacol. 1978; 46(1):131-142. http://dx.doi.org/10.1016/0041-008X(78)90144-8

67. Jackson N, Conolly RB. Acute nephrotoxicity of 1,1-dichloroethylene in the rat after inhalation exposure. Toxicol Lett. 1985; 29(2-3):191-199. http://dx.doi.org/10.1016/0378$\underline{4274(85) 90041-4}$

68. Ban M, Hettich D, Huguet N, Cavelier L. Nephrotoxicity mechanism of 1,1-dichloroethylene in mice. Toxicol Lett. 1995; 78(2):87-92. http://dx.doi.org/10.1016/0378-4274(94)03237-2

69. Cavelier L, Bonnet P, Morel G, de Ceaurriz J. Role of cysteine conjugation in vinylidene chloride-induced nephrotoxicity and hepatotoxicity in fasted rats. J Appl Toxicol. 1996; 16(2):109-113. http://dx.doi.org/10.1002/(SICI)1099-1263(199603)16:2<109::AIDJAT308>3.0.CO;2-9

70. Forkert P-G, Reynolds ES. 1,1-Dichloroethylene-induced pulmonary injury. Exp Lung Res. 1982; 3(1):57-68. http://dx.doi.org/10.3109/01902148209115816

71. National Toxicology Program (NTP). Carcinogenesis Bioassay of Vinylidene Chloride (CAS No. 75-35-4) in F344 Rats and B6C3F1 Mice (Gavage Study). Research Triangle Park, NC and Bethesda, MD: U.S. Department of Health and Human Services, Public Health Service, National Institutes of Health; 1982. NIH Publication No. 82-1784. Technical Report Series No. 228.

72. Anderson D, Hodge MC, Purchase IF. Dominant lethal studies with the halogenated olefins vinyl chloride and vinylidene dichloride in male CD-1 mice. Environ Health Perspect. 1977; 21:71-78. http://dx.doi.org/10.1289/ehp.772171

73. Short RD, Minor JL, Winston JM, Lee CC. A dominant lethal study in male rats after repeated exposures to vinyl chloride or vinylidene chloride. J Toxicol Environ Health. 1977; 3(56):965-968. http://dx.doi.org/10.1080/15287397709529630

74. Nitschke K, Smith F, Quast J, Norris J, Schwetz B. A three-generation rat reproductive toxicity study of vinylidene chloride in the drinking water. Fundam Appl Toxicol. 1983; 3(2):7579. http://dx.doi.org/10.1016/S0272-0590(83)80059-1

75. Murray F, Nitschke K, Rampy L, Schwetz B. Embryotoxicity and fetotoxicity of inhaled or ingested vinylidene chloride in rats and rabbits. Toxicol Appl Pharmacol. 1979; 30:189-202. http://dx.doi.org/10.1016/0041-008X(79)90241-2

76. Lee C, Bhandari J, Winston J, House W, Peters P, Dixon R, Woods J. Inhalation toxicity of vinyl chloride and vinylidene chloride. Environ Health Perspect. 1977; 21:25-32. http://dx.doi.org/10.1289/ehp.772125

77. Lee C, Bhandari J, Winston J, House W, Dixon R, Woods J. Carcinogenicity of vinyl chloride and vinylidene chloride. J Toxicol Environ Health. 1978; 4(1):15-30. http://dx.doi.org/10.1080/15287397809529640 
78. Viola P, Caputo A. Carcinogenicity studies on vinylidene chloride. Environ Health Perspect. 1977; 21:45-47. http://dx.doi.org/10.1289/ehp.772145

79. Hong C, Winston J, Thornburg L, Lee C, Woods J. Follow-up study on the carcinogenicity of vinyl chloride and vinylidene chloride in rats and mice: Tumor incidence and mortality subsequent to exposure. J Toxicol Environ Health. 1981; 7(6):909-924. http://dx.doi.org/10.1080/15287398109530034

80. Quast J, Humiston C, Wade C, Ballard J, Beyer J, Schwetz R, Norris J. A chronic toxicity and oncogenicity study in rats and subchronic toxicity study in dogs on ingested vinylidene chloride. Fundam Appl Toxicol. 1983; 3(1):55-62. http://dx.doi.org/10.1016/S0272$\underline{0590(83) 80173-0}$

81. Bartsch H, Malaveille C, Montesano R, Tomatis L. Tissue-mediated mutagenicity of vinylidene chloride and 2-chlorobutadiene in Salmonella typhimurium. Nature. 1975; 255:641643. http://dx.doi.org/10.1038/255641a0

82. Oesch F, Protić-Sabljić M, Friedberg T, Klimisch H-J, Glatt H. Vinylidene chloride: changes in drug-metabolizing enzymes, mutagenicity and relation to its targets for carcinogenesis. Carcinogenesis. 1983; 4(8):1031-1038. http://dx.doi.org/10.1093/carcin/4.8.1031

83. Jones BK, Hathway DE. Tissue-mediated mutagenicity of vinylidene chloride in Salmonella typhimurium TA1535. Cancer Lett. 1978; 5(1):1-6. http://dx.doi.org/10.1016/S0304$\underline{3835(78) 80002-0}$

84. Baden JM, Kelley M, Simmon VF, Rice SA, Mazze RI. Fluroxene mutagenicity. Mutat Res. 1978; 58(2-3):183-191. http://dx.doi.org/10.1016/0165-1218(78)90008-3

85. Mortelmans K, Haworth S, Lawlor T, Speck W, Tainer B, Zeiger E. Salmonella mutagenicity tests: II. Results from the testing of 270 chemicals. Environ Mutagen. 1986; 8(S7 ):56-119. https://doi.org/10.1002/em.2860080703

86. Greim H, Bonse G, Radwan Z, Reichert D, Henschler D. Mutagenicity in vitro and potential carcinogenicity of chlorinated ethylenes as a function of metabolic oxirane formation. Biochem Pharmacol. 1975; 24(21):2013-2017. http://dx.doi.org/10.1016/0006-2952(75)90396-2

87. Henschler D. Metabolism and mutagenicity of halogenated olefins--a comparison of structure and activity. Environ Health Perspect. 1977; 21:61-64.

88. Koch R, Schlegelmilch R, Wolf H. Genetic effects of chlorinated ethylenes in the yeast Saccharomyces cerevisiae. Mutat Res. 1988; 206(2):209-216. http://dx.doi.org/10.1016/0165$\underline{1218(88) 90162-0}$

89. Bronzetti G, Bauer C, Corsi C, Leporini C, Nieri R, del Carratore R. Genetic activity of vinylidene chloride in yeast. Mutat Res. 1981; 89(2):179-185. http://dx.doi.org/10.1016/0165$\underline{1218(81) 90123-3}$

90. McGregor D, Brown AG, Cattanach P, Edwards I, McBride D, Riach C, Shepherd W, Caspary WJ, Van Zeeland A. Responses of the L5178Y mouse lymphoma forward mutation assay: V. Gases and vapors. Environ Mol Mutagen. 1991; 17(2):122-129. http://dx.doi.org/10.1002/em.2850170209 
91. Drevon C, Kuroki T. Mutagenecity of vinyl chloride, vinylidene chloride and chloroprene in V79 Chinese hamster cells. Mutat Res. 1979; 67(2):173-182. http://dx.doi.org/10.1016/0165$\underline{1218(79) 90129-0}$

92. Sawada M, Sofuni T, Ishidate Jr M. Cytogenetic studies on 1,1-dichloroethylene and its two isomers in mammalian cells in vitro and in vivo. Mutat Res. 1987; 187(3):157-163. http://dx.doi.org/10.1016/0165-1218(87)90083-8

93. Reitz R, Watanabe P, McKenna M, Quast J, Gehring P. Effects of vinylidene chloride on DNA synthesis and DNA repair in the rat and mouse: A comparative study with dimethylnitrosamine. Toxicol Appl Pharmacol. 1980; 52(3):357-370. http://dx.doi.org/10.1016/0041-008X(80)90329-4

94. Brecher G, Schneiderman M. A time-saving device for the counting of reticulocytes. Am J Clin Pathol. 1950; 20(11_ts):2079-2084. http://dx.doi.org/10.1093/ajcp/20.11_ts.1079

95. Maronpot R, Boorman G. Interpretation of rodent hepatocellular proliferative alterations and hepatocellular tumors in chemical safety assessment. Toxicol Pathol. 1982; 10(2):71-80. http://dx.doi.org/10.1177/019262338201000210

96. Boorman GA, Montgomery CA, Jr., Eustis SL, Wolfe MJ, McConnell EE, Hardisty JF. Quality assurance in pathology for rodent carcinogenicity studies In: Milman HA, Weisburger EK, editors. Handbook of Carcinogen Testing Park Ridge, NJ: Noyes Publications; 1985. p. 345357.

97. McConnell EE, Solleveld HA, Swenberg JA, Boorman GA. Guidelines for combining neoplasms for evaluation of rodent carcinogenesis studies. JNCI 1986; 76(2):283-289.

98. Kaplan EL, Meier P. Nonparametric estimation from incomplete observations. J Am Stat Assoc. 1958; 53(282):457-481. http://dx.doi.org/10.1080/01621459.1958.10501452

99. Cox DR. Regression models and life-tables. J Roy Stat Soc B Met. 1972; 34(2):187-220.

100. Tarone RE. Tests for trend in life table analysis. Biometrika. 1975; 62(3):679-690. http://dx.doi.org/10.1093/biomet/62.3.679

101. Bailer AJ, Portier CJ. Effects of treatment-induced mortality and tumor-induced mortality on tests for carcinogenicity in small samples. Biometrics. 1988; 44:417-431.

http://dx.doi.org/10.2307/2531856

102. Portier C, Bailer A. Testing for increased carcinogenicity using a survival-adjusted quantal response test. Fundam Appl Toxicol. 1989; 12(4):731-737. http://dx.doi.org/10.1016/0272$\underline{0590(89) 90004-3}$

103. Piegorsch WW, Bailer AJ. Statistics for Environmental Biology and Toxicology. Section 6.3.2. London: Chapman and Hall; 1997.

104. Portier CJ, Hedges JC, Hoel DG. Age-specific models of mortality and tumor onset for historical control animals in the National Toxicology Program's carcinogenicity experiments. Cancer Res. 1986; 46(9):4372-4378. 
105. Bieler GS, Williams RL. Ratio estimates, the delta method, and quantal response tests for increased carcinogenicity. Biometrics. 1993; 49:793-801. http://dx.doi.org/10.2307/2532200

106. Dunnett CW. A multiple comparison procedure for comparing several treatments with a control. J Am Stat Assoc. 1955; 50(272):1096-1121. http://dx.doi.org/10.1080/01621459.1955.10501294

107. Williams DA. The comparison of several dose levels with a zero dose control. Biometrics. 1972; 28:519-531. http://dx.doi.org/10.2307/2556164

108. Williams DA. A test for differences between treatment means when several dose levels are compared with a zero dose control. Biometrics. 1971; 27:103-117.

http://dx.doi.org/10.2307/2528930

109. Shirley E. A non-parametric equivalent of Williams' test for contrasting increasing dose levels of a treatment. Biometrics. 1977; 33:386-389. http://dx.doi.org/10.2307/2529789

110. Williams DA. A note on Shirley's nonparametric test for comparing several dose levels with a zero-dose control. Biometrics. 1986; 42:183-186. http://dx.doi.org/10.2307/2531254

111. Dunn OJ. Multiple comparisons using rank sums. Technometrics. 1964; 6(3):241-252. http://dx.doi.org/10.1080/00401706.1964.10490181

112. Jonckheere AR. A distribution-free k-sample test against ordered alternatives. Biometrika. 1954; 41(1/2):133-145. http://dx.doi.org/10.2307/2333011

113. Dixon WJ, Massey FJ, Jr. Introduction to Statistical Analysis. 2 ed. New York: McGraw Hill Book Company Inc.; 1957. p. 276-278, 412.

114. Gart JJ, Chu KC, Tarone RE. Statistical issues in interpretation of chronic bioassay tests for carcinogenicity. JNCI 1979; 62(4):957-974.

115. Girard D, Sager D. The use of Markov chains to detect subtle variation in reproductive cycling. Biometrics. 1987; 43:225-234. http://dx.doi.org/10.2307/2531963

116. Haseman JK. Data analysis: Statistical analysis and use of historical control data. Regul Toxicol Pharmacol. 1995; 21(1):52-59. http://dx.doi.org/10.1006/rtph.1995.1009

117. Haseman JK, Rao GN. Effects of corn oil, time-related changes, and inter-laboratory variability on tumor occurrence in control Fischer 344 (F344/N) rats. Toxicol Pathol. 1992; 20(1):52-60. http://dx.doi.org/10.1177/019262339202000107

118. Code of Federal Regulations (CFR). 21:Part 58.

119. Schmid W. The micronucleus test. Mutat Res. 1975; 31:9-15.

http://dx.doi.org/10.1016/0165-1161(75)90058-8

120. Heddle JA, Hite M, Kirkhart B, Mavournin K, MacGregor JT, Newell GW, Salamone MF. The induction of micronuclei as a measure of genotoxicity: A report of the US Environmental Protection Agency Gene-Tox Program. Mutat Res. 1983; 123(1):61-118. http://dx.doi.org/10.1016/0165-1110(83)90047-7 
121. Miller JA, Miller EC. Ultimate chemical carcinogens as reactive mutagenic electrophiles In: Hiatt HH, Watson JD, Winsten JA, editors. Origins of Human Cancer. Cold Spring Harbor, NY: Cold Spring Harbor Laboratory; 1977. p. 605-627.

122. Straus DS. Somatic mutation, cellular differentiation, and cancer causation. JNCI. 1981; 67:233-241.

123. Crawford BD. Perspectives on the somatic mutation model of carcinogenesis In: Mehlman MA, Flamm WG, Lorentzen RJ, editors. Advances in Modern Environmental Toxicology Mechanisms and Toxicity of Chemical Carcinogens and Mutagens. Princeton, NJ: Princeton Scientific Publishing Co. Inc.; 1985. p. 13-59.

124. Ashby J, Tennant RW. Definitive relationships among chemical structure, carcinogenicity and mutagenicity for 301 chemicals tested by the U.S. NTP. Mutat Res. 1991; 257(3):229-306. http://dx.doi.org/10.1016/0165-1110(91)90003-E

125. Tennant RW, Margolin BH, Shelby MD, Zeiger E, Haseman JK, Spalding J, Caspary W, Resnick M, Stasiewicz S, Anderson B et al. Prediction of chemical carcinogenicity in rodents from in vitro genetic toxicity assays. Science. 1987; 236(4804):933-941. http://dx.doi.org/10.1126/science.3554512

126. Zeiger E, Haseman JK, Shelby MD, Margolin BH, Tennant RW. Evaluation of four in vitro genetic toxicity tests for predicting rodent carcinogenicity: Confirmation of earlier results with 41 additional chemicals. Environ Mol Mutagen. 1990; 16(S18):1-14. http://dx.doi.org/10.1002/em.2850160502

127. Shelby M, Erexson G, Hook G, Tice R. Evaluation of a three-exposure mouse bone marrow micronucleus protocol: Results with 49 chemicals. Environ Mol Mutagen. 1993; 21(2):160-179. http://dx.doi.org/10.1002/em.2850210210

128. Shelby MD, Witt KL. Comparison of results from mouse bone marrow chromosome aberration and micronucleus tests. Environ Mol Mutagen. 1995; 25(4):302-313. http://dx.doi.org/10.1002/em.2850250407

129. Witt KL, Knapton A, Wehr CM, Hook GJ, Mirsalis J, Shelby MD, MacGregor JT. Micronucleated erythrocyte frequency in peripheral blood of $\mathrm{B} 6 \mathrm{C} 3 \mathrm{~F} 1$ mice from short-term, prechronic, and chronic studies of the NTP carcinogenesis bioassay program. Environ Mol Mutagen. 2000; 36(3):163-194. http://dx.doi.org/10.1002/1098-2280(2000)36:3<163::AIDEM1>3.0.CO;2-P

130. Foureman P, Mason J, Valencia R, Zimmering S. Chemical mutagenesis testing in Drosophila. IX. Results of 50 coded compounds tested for the National Toxicology Program. Environ Mol Mutagen. 1994; 23(1):51-63. http://dx.doi.org/10.1002/em.2850230109

131. Roberts SM, Jordan KE, Warren DA, Britt JK, James RC. Evaluation of the carcinogenicity of 1,1-dichloroethylene (vinylidene chloride). Regul Toxicol Pharmacol. 2002; 35(1):44-55. http://dx.doi.org/10.1006/rtph.2001.1518 
132. Kanz MF, Taj Z, Moslen MT. 1,1-Dichloroethylene hepatotoxicity: Hypothyroidism decreases metabolism and covalent binding but not injury in the rat. Toxicology. 1991; 70(2):213-229. http://dx.doi.org/10.1016/0300-483X(91)90048-6

133. Rampy L, Quast J, Humiston C, Balmer M, Schwetz B. Interim results of two-year toxicological studies in rats of vinylidene chloride incorporated in the drinking water or administered by repeated inhalation. Environ Health Perspect. 1977; 21:33-43. http://dx.doi.org/10.1289/ehp.772133

134. Agency for Toxic Substances and Disease Registry (ATSDR). Toxicological profile for 1,1dichloroethene. U.S. Department of Health and Human Services, Public Health Service, Agency for Toxic Substances and Disease Registry; 2009.

135. Jaeger RJ, Conolly RB, Reynolds E, Murphy SD. Biochemical toxicology of unsaturated halogenated monomers. Environ Health Perspect. 1975; 11:121-128.

http://dx.doi.org/10.1289/ehp.7511121

136. Forkert P-G, Forkert L, Farooqui M, Reynolds E. Lung injury and repair: DNA synthesis following 1,1-dichloroethylene. Toxicology. 1985; 36(2-3):199-214.

http://dx.doi.org/10.1016/0300-483X(85)90054-X

137. Krantz SB. Erythropoietin. Blood. 1991; 77(3):419-434.

138. Hall RL, Everds NE. Principles of clinical pathology for toxicology studies In: Hayes AW, editor. Principles and Methods of Toxicology. 5th ed. Boca Raton, FL: CRC press; 2008. p. 1317-1358.

139. Colotta F, Allavena P, Sica A, Garlanda C, Mantovani A. Cancer-related inflammation, the seventh hallmark of cancer: links to genetic instability. Carcinogenesis. 2009; 30(7):1073-1081. http://dx.doi.org/10.1093/carcin/bgp127

140. Hanahan D, Weinberg RA. The hallmarks of cancer. Cell. 2000; 100(1):57-70. http://dx.doi.org/10.1016/S0092-8674(00)81683-9

141. Hanahan D, Weinberg RA. Hallmarks of cancer: the next generation. Cell. 2011; 144(5):646-674. http://dx.doi.org/10.1016/j.cell.2011.02.013

142. Hathway DE. Comparative mammalian metabolism of vinyl chloride and vinylidene chloride in relation to oncogenic potential. Environ Health Perspect. 1977; 21:55-59. http://dx.doi.org/10.1289/ehp.772155

143. Mutsaers S, McAnulty R, Laurent G, Versnel M, Whitaker D, Papadimitriou J. Cytokine regulation of mesothelial cell proliferation in vitro and in vivo. Eur J Cell Biol. 1997; 72(1):2429.

144. Maltoni C, Cotti G, Morisi L, Chieco P. Carcinogenicity bio-assays of vînylidene chloride. Research plan and early results. Med Lav. 1977; 68(4):241-262.

145. Quast J, McKenna M, Rampy L, Norris J. Chronic toxicity and oncogenicity study on inhaled vinylidene chloride in rats. Fundam Appl Toxicol. 1986; 6(1):105-144.

http://dx.doi.org/10.1016/0272-0590(86)90269-1 
146. Lash LH, Jones D, Anders M. Glutathione homeostasis and glutathione S-conjugate toxicity in the kidney. Reviews in Biochemical Toxicology. New York: Elsevier; 1988. p. 29-67.

147. Elfarra AA, Anders M. Renal processing of glutathione conjugates: role in nephrotoxicity. Biochem Pharmacol. 1984; 33(23):3729-3732. http://dx.doi.org/10.1016/0006-2952(84)90032-7

148. Elfarra AA, Jakobson I, Anders M. Mechanism of S-(1,2-dichlorovinyl)glutathione-induced nephrotoxicity. Biochem Pharmacol. 1986; 35(2):283-288. http://dx.doi.org/10.1016/0006$\underline{2952(86) 90527-7}$

149. Eyre RJ, Stevens DK, Parker JC, Bull RJ. Renal activation of trichloroethene and S-(1,2dichlorovinyl)-L-cysteine and cell proliferative responses in the kidneys of F344 rats and B6C3F1 mice. J Toxicol Environ Health. 1995; 46(4):465-481.

http://dx.doi.org/10.1080/15287399509532049

150. Eyre RJ, Stevens DK, Parker JC, Bull RJ. Acid-labile adducts to protein can be used as indicators of the cysteine S-conjugate pathway of trichloroethene metabolism. J Toxicol Environ Health. 1995; 46(4):443-464. http://dx.doi.org/10.1080/15287399509532048

151. Caspary WJ, Lee YJ, Poulton S, Myhr BC, Mitchell AD, Rudd CJ. Evaluation of the L5178y mouse lymphoma cell mutagenesis assay: Quality-control guidelines and response categories. Environ Mol Mutagen. 1988; 12(S13):19-36.

http://dx.doi.org/10.1002/em.2860120503

152. Mason J, Valencia R, Zimmering S. Chemical mutagenesis testing in Drosophila: VIII. Reexamination of equivocal results. Environ Mol Mutagen. 1992; 19(3):227-234. http://dx.doi.org/10.1002/em.2850190307

153. Margolin BH, Collings BJ, Mason JM. Statistical analysis and sample-size determinations for mutagenicity experiments with binomial responses. Environ Mutagen. 1983; 5(5):705-716. http://dx.doi.org/10.1002/em.2860050509

154. MacGregor JT, Wehr CM, Henika PR, Shelby MD. The in vivo erythrocyte micronucleus test: measurement at steady state increases assay efficiency and permits integration with toxicity studies. Fundam Appl Toxicol. 1990; 14(3):513-522. http://dx.doi.org/10.1016/0272$\underline{0590(90) 90255-\mathrm{I}}$

155. Aldrich Chemical Company Inc. In: Pouchert C, Behnke J, editors. The Aldrich Library ${ }^{13} \mathrm{C}$ and ${ }^{1}$ H FT-NMR Spectra. 1 ed. Milwaukee, WI; 1993. p. 142.

156. Aldrich Chemical Company Inc. In: Pouchert C, editor. The Aldrich Library of FT IR Spectra 2ed. Milwaukee, WI; 1997. p. 140D.

157. National Toxicology Program (NTP). Toxicology and carcinogenesis studies of codeine (CAS No. 76-57-3) in F344 rats and B6C3F1 mice (feed studies). Research Triangle Park, NC: U.S. Department of Health and Human Services, Public Health Service, National Institutes of Health; 1996. Technical Report Series No. 455. NIH Publication No. 96-3360.

https://ntp.niehs.nih.gov/results/pubs/longterm/reports/longterm/tr400499/abstracts/tr455/index.h $\underline{\mathrm{tml}}$ 
158. National Toxicology Program (NTP). Toxicology and carcinogenesis studies of riddelliine (CAS No. 23246-96-0) in F344/N rats and B6C3F1 mice (gavage studies). Research Triangle Park, NC: U.S. Department of Health and Human Services, Public Health Service, National Institutes of Health; 2003. Technical Report Series No. 508. NIH Publication No. 03-4442.

159. National Toxicology Program (NTP). Toxicology studies of cobalt metal (CAS No. 744048-4) in F344/N rats and B6C3F1 mice and toxicology and carcinogenesis studies of cobalt metal in F344/NTac rats and B6C3F1 mice (inhalation studies). Research Triangle Park, NC: U.S. Department of Health and Human Services, Public Health Service, National Institutes of Health; 2014. Technical Report Series No. 581. NIH Publication No. 98-3961.

160. Crosby LM, Hyder KS, DeAngelo AB, Kepler TB, Gaskill B, Benavides GR, Yoon L, Morgan KT. Morphologic analysis correlates with gene expression changes in cultured F344 rat mesothelial cells. Toxicol Appl Pharmacol. 2000; 169(3):205-221.

http://dx.doi.org/10.1006/taap.2000.9049

161. Kim Y, Ton TV, DeAngelo AB, Morgan K, Devereux TR, Anna C, Collins JB, Paules RS, Crosby LM, Sills RC. Major carcinogenic pathways identified by gene expression analysis of peritoneal mesotheliomas following chemical treatment in F344 rats. Toxicol Appl Pharmacol. 2006; 214(2):144-151. http://dx.doi.org/10.1016/j.taap.2005.12.009

162. Gautier L, Cope L, Bolstad BM, Irizarry RA. Affy-analysis of Affymetrix GeneChip data at the probe level. Bioinformatics. 2004; 20(3):307-315.

http://dx.doi.org/10.1093/bioinformatics/btg405

163. Irizarry RA, Bolstad BM, Collin F, Cope LM, Hobbs B, Speed TP. Summaries of Affymetrix GeneChip probe level data. Nucleic Acids Res. 2003; 31(4):e15. http://dx.doi.org/10.1093/nar/gng015

164. Guo W, Sarkar SK, Peddada SD. Controlling false discoveries in multidimensional directional decisions, with applications to gene expression data on ordered categories. Biometrics. 2010; 66(2):485-492. http://dx.doi.org/10.1111/j.1541-0420.2009.01292.x

165. Peddada S, Harris S, Zajd J, Harvey E. ORIOGEN: Order restricted inference for ordered gene expression data. Bioinformatics. 2005; 21(20):3933-3934. http://dx.doi.org/10.1093/bioinformatics/bti637

166. Garlepp M, Leong C. Biological and immunological aspects of malignant mesothelioma. Eur Respir J. 1995; 8(4):643-650.

167. Okamoto O, Fujiwara S, Abe M, Sato Y. Dermatopontin interacts with transforming growth factor beta and enhances its biological activity. Biochem J. 1999; 337(3):537-541.

http://dx.doi.org/10.1042/bj3370537

168. Mantovani A. Molecular pathways linking inflammation and cancer. Curr Mol Med. 2010; 10(4):369-373. http://dx.doi.org/10.2174/156652410791316968

169. Mukaida N. Pathophysiological roles of interleukin-8/CXCL8 in pulmonary diseases. Am J Physiol Lung Cell Mol Physiol. 2003; 284(4):L566-577.

http://dx.doi.org/10.1152/ajplung.00233.2002 
170. Wang KS, Frank DA, Ritz J. Interleukin-2 enhances the response of natural killer cells to interleukin-12 through up-regulation of the interleukin-12 receptor and STAT4. Blood. 2000; 95(10):3183-3190.

171. Blackshear PE, Pandiri AR, Ton TV, Clayton NP, Shockley KR, Peddada SD, Gerrish KE, Sills RC, Hoenerhoff MJ. Spontaneous mesotheliomas in F344/N rats are characterized by dysregulation of cellular growth and immune function pathways. Toxicol Pathol. 2014; 42(5):863-876. http://dx.doi.org/10.1177/0192623313501894 


\section{Appendix A. Summary of Lesions in Male Rats in the Two-year Inhalation Study of Vinylidene Chloride}

\section{Tables}

Table A-1. Summary of the Incidence of Neoplasms in Male Rats in the Two-year Inhalation Study of Vinylidene Chloride

Table A-2. Statistical Analysis of Primary Neoplasms in Male Rats in the Two-year Inhalation Study of Vinylidene Chloride

Table A-3. Historical Incidence of Malignant Mesothelioma in Control Male F344/N Rats.

Table A-4. Historical Incidence of Renal Tubule Neoplasms in Control Male F344/N Rats......

Table A-5. Summary of the Incidence of Nonneoplastic Lesions in Male Rats in the Twoyear Inhalation Study of Vinylidene Chloride 
Table A-1. Summary of the Incidence of Neoplasms in Male Rats in the Two-year Inhalation Study of Vinylidene Chloride ${ }^{\mathrm{a}}$

\begin{tabular}{|c|c|c|c|c|}
\hline & $\begin{array}{c}\text { Chamber } \\
\text { Control }\end{array}$ & 25 ppm & $50 \mathrm{ppm}$ & $100 \mathrm{ppm}$ \\
\hline \multicolumn{5}{|l|}{ Disposition Summary } \\
\hline Animals initially in study & 50 & 50 & 50 & 50 \\
\hline \multicolumn{5}{|l|}{ Early deaths } \\
\hline Moribund & 21 & 15 & 23 & 27 \\
\hline Natural deaths & 4 & 8 & 5 & 4 \\
\hline \multicolumn{5}{|l|}{ Survivors } \\
\hline Terminal kill & 25 & 27 & 22 & 19 \\
\hline Animals examined microscopically & 50 & 50 & 50 & 50 \\
\hline \multicolumn{5}{|l|}{ Alimentary System } \\
\hline Esophagus & $(50)$ & $(49)$ & $(49)$ & $(50)$ \\
\hline Carcinoma, metastatic, thyroid gland & - & - & $1(2 \%)$ & - \\
\hline Intestine large, cecum & (48) & (44) & $(45)$ & $(46)$ \\
\hline Intestine large, colon & $(47)$ & $(46)$ & $(47)$ & $(48)$ \\
\hline Adenoma & - & - & - & $1(2 \%)$ \\
\hline Intestine large, rectum & (46) & (47) & $(46)$ & $(49)$ \\
\hline Intestine small, duodenum & (47) & $(45)$ & $(45)$ & $(49)$ \\
\hline Intestine small, ileum & $(47)$ & $(45)$ & $(45)$ & $(47)$ \\
\hline Intestine small, jejunum & (47) & $(43)$ & $(45)$ & $(47)$ \\
\hline Sarcoma, stromal & - & $1(2 \%)$ & - & - \\
\hline Liver & (50) & $(50)$ & $(50)$ & $(50)$ \\
\hline Carcinoma, metastatic, urinary bladder & - & $1(2 \%)$ & - & - \\
\hline Cholangiocarcinoma & - & - & - & $1(2 \%)$ \\
\hline Hepatocellular adenoma & $1(2 \%)$ & $1(2 \%)$ & - & - \\
\hline Mesentery & $(16)$ & $(15)$ & $(21)$ & $(23)$ \\
\hline Carcinoma, metastatic, urinary bladder & - & $1(7 \%)$ & - & - \\
\hline Pancreas & $(50)$ & $(50)$ & $(50)$ & $(49)$ \\
\hline Carcinoma, metastatic, urinary bladder & - & $1(2 \%)$ & - & - \\
\hline Acinus, adenoma & - & - & $1(2 \%)$ & - \\
\hline Acinus, carcinoma & - & - & - & $1(2 \%)$ \\
\hline Duct, carcinoma & - & - & $1(2 \%)$ & - \\
\hline Salivary glands & $(50)$ & $(50)$ & $(50)$ & $(50)$ \\
\hline Stomach, forestomach & $(50)$ & $(50)$ & $(50)$ & $(50)$ \\
\hline Stomach, glandular & (49) & $(50)$ & (49) & $(50)$ \\
\hline
\end{tabular}


Vinylidene Chloride, NTP TR 582

\begin{tabular}{|c|c|c|c|c|}
\hline & $\begin{array}{l}\text { Chamber } \\
\text { Control }\end{array}$ & 25 ppm & 50 ppm & 100 ppm \\
\hline Tongue & (0) & (1) & $(0)$ & (2) \\
\hline Squamous cell papilloma & - & $1(100 \%)$ & - & - \\
\hline Tooth & (1) & (0) & $(0)$ & $(0)$ \\
\hline \multicolumn{5}{|l|}{ Cardiovascular System } \\
\hline Blood vessel & (1) & (0) & (1) & (0) \\
\hline Heart & $(50)$ & $(50)$ & (50) & (50) \\
\hline Fibrous histiocytoma, metastatic, skin & - & - & - & $1(2 \%)$ \\
\hline Pericardium, osteosarcoma, metastatic, bone & $1(2 \%)$ & - & - & - \\
\hline \multicolumn{5}{|l|}{ Endocrine System } \\
\hline Adrenal cortex & $(49)$ & $(50)$ & (49) & (50) \\
\hline Adenoma & $4(8 \%)$ & $4(8 \%)$ & $1(2 \%)$ & - \\
\hline Adrenal medulla & (49) & (50) & (48) & (50) \\
\hline Pheochromocytoma benign & $5(10 \%)$ & $9(18 \%)$ & $5(10 \%)$ & $7(14 \%)$ \\
\hline Pheochromocytoma malignant & $2(4 \%)$ & $1(2 \%)$ & - & $1(2 \%)$ \\
\hline Bilateral, pheochromocytoma benign & - & $2(4 \%)$ & $3(6 \%)$ & $1(2 \%)$ \\
\hline Islets, pancreatic & $(50)$ & $(50)$ & (50) & (49) \\
\hline Adenoma & $2(4 \%)$ & $2(4 \%)$ & $3(6 \%)$ & $1(2 \%)$ \\
\hline Carcinoma & $2(4 \%)$ & $2(4 \%)$ & $4(8 \%)$ & $4(8 \%)$ \\
\hline Parathyroid gland & $(50)$ & (49) & (47) & (45) \\
\hline Adenoma & - & - & $1(2 \%)$ & - \\
\hline Pituitary gland & $(50)$ & (49) & (49) & (50) \\
\hline Pars distalis, adenoma & $34(68 \%)$ & $28(57 \%)$ & $26(53 \%)$ & $33(66 \%)$ \\
\hline Thyroid gland & (50) & (49) & (49) & (48) \\
\hline C-cell, adenoma & $4(8 \%)$ & $5(10 \%)$ & $4(8 \%)$ & $1(2 \%)$ \\
\hline C-cell, carcinoma & $3(6 \%)$ & $3(6 \%)$ & $3(6 \%)$ & $3(6 \%)$ \\
\hline Follicular cell, carcinoma & - & - & $1(2 \%)$ & - \\
\hline \multicolumn{5}{|l|}{ General Body System } \\
\hline Peritoneum & $(0)$ & (2) & (4) & (3) \\
\hline Osteosarcoma, metastatic, uncertain primary site & - & - & - & $1(33 \%)$ \\
\hline Tissue, NOS & $(0)$ & $(0)$ & $(0)$ & (1) \\
\hline \multicolumn{5}{|l|}{ Genital System } \\
\hline Coagulating gland & $(0)$ & $(0)$ & $(0)$ & (3) \\
\hline Epididymis & $(50)$ & $(50)$ & $(50)$ & (50) \\
\hline Penis & (0) & $(0)$ & (1) & (0) \\
\hline
\end{tabular}


Vinylidene Chloride, NTP TR 582

\begin{tabular}{|c|c|c|c|c|}
\hline & $\begin{array}{c}\text { Chamber } \\
\text { Control }\end{array}$ & $25 \mathrm{ppm}$ & $50 \mathrm{ppm}$ & $100 \mathrm{ppm}$ \\
\hline Preputial gland & $(50)$ & (49) & (49) & $(50)$ \\
\hline Adenoma & $2(4 \%)$ & - & $2(4 \%)$ & - \\
\hline Carcinoma & $2(4 \%)$ & $1(2 \%)$ & $3(6 \%)$ & - \\
\hline Prostate & $(50)$ & (50) & (50) & $(50)$ \\
\hline Adenoma & - & - & - & $1(2 \%)$ \\
\hline Carcinoma, metastatic, urinary bladder & - & $1(2 \%)$ & - & - \\
\hline Seminal vesicle & (48) & (50) & $(48)$ & $(48)$ \\
\hline Adenoma & - & - & $1(2 \%)$ & $1(2 \%)$ \\
\hline Carcinoma, metastatic, urinary bladder & - & $1(2 \%)$ & - & - \\
\hline Testes & $(50)$ & (50) & (50) & (50) \\
\hline Bilateral, interstitial cell, adenoma & $20(40 \%)$ & $24(48 \%)$ & $17(34 \%)$ & $14(28 \%)$ \\
\hline Interstitial cell, adenoma & $12(24 \%)$ & $11(22 \%)$ & $22(44 \%)$ & $11(22 \%)$ \\
\hline \multicolumn{5}{|l|}{ Hematopoietic System } \\
\hline Bone marrow & (49) & (49) & $(48)$ & $(49)$ \\
\hline Lymph node & (6) & (4) & (9) & (7) \\
\hline Lymph node, bronchial & (8) & (9) & (9) & (9) \\
\hline Carcinoma, metastatic, thyroid gland & - & $1(11 \%)$ & - & - \\
\hline Osteosarcoma, metastatic, bone & $1(13 \%)$ & - & - & - \\
\hline Lymph node, mandibular & (1) & (1) & (1) & (0) \\
\hline Lymph node, mediastinal & (28) & (21) & (24) & $(30)$ \\
\hline Lymph node, mesenteric & $(50)$ & $(50)$ & $(50)$ & $(50)$ \\
\hline Spleen & $(50)$ & (50) & (50) & $(50)$ \\
\hline Thymus & $(42)$ & (43) & (41) & $(44)$ \\
\hline Carcinoma, metastatic, thyroid gland & - & - & $1(2 \%)$ & - \\
\hline \multicolumn{5}{|l|}{ Integumentary System } \\
\hline Mammary gland & (36) & $(29)$ & (24) & $(32)$ \\
\hline Carcinoma & - & - & $1(4 \%)$ & - \\
\hline Fibroadenoma & $1(3 \%)$ & $1(3 \%)$ & $1(4 \%)$ & $2(6 \%)$ \\
\hline Skin & $(50)$ & $(50)$ & $(49)$ & $(50)$ \\
\hline Basal cell, adenoma & $1(2 \%)$ & - & - & $1(2 \%)$ \\
\hline Basal cell, carcinoma & $1(2 \%)$ & - & - & - \\
\hline Keratoacanthoma & $3(6 \%)$ & $3(6 \%)$ & $3(6 \%)$ & $2(4 \%)$ \\
\hline Squamous cell papilloma & $3(6 \%)$ & $1(2 \%)$ & $1(2 \%)$ & $1(2 \%)$ \\
\hline Trichoepithelioma & $1(2 \%)$ & - & $2(4 \%)$ & - \\
\hline Subcutaneous tissue, fibroma & $1(2 \%)$ & $4(8 \%)$ & $2(4 \%)$ & $3(6 \%)$ \\
\hline
\end{tabular}


Vinylidene Chloride, NTP TR 582

\begin{tabular}{|c|c|c|c|c|}
\hline & $\begin{array}{c}\text { Chamber } \\
\text { Control }\end{array}$ & 25 ppm & 50 ppm & 100 ppm \\
\hline Subcutaneous tissue, fibroma, multiple & - & - & $1(2 \%)$ & - \\
\hline Subcutaneous tissue, fibrosarcoma & - & - & - & $1(2 \%)$ \\
\hline Subcutaneous tissue, fibrous histiocytoma & - & - & - & $1(2 \%)$ \\
\hline Subcutaneous tissue, lipoma & - & - & - & $1(2 \%)$ \\
\hline Subcutaneous tissue, sarcoma & - & $2(4 \%)$ & - & - \\
\hline Subcutaneous tissue, schwannoma malignant & - & - & $1(2 \%)$ & - \\
\hline \multicolumn{5}{|l|}{ Musculoskeletal System } \\
\hline Bone & (50) & $(50)$ & $(50)$ & $(50)$ \\
\hline Osteoma & $1(2 \%)$ & - & - & - \\
\hline Osteosarcoma & $1(2 \%)$ & - & - & $1(2 \%)$ \\
\hline Skeletal muscle & (3) & (4) & (7) & $(11)$ \\
\hline Carcinoma, metastatic, urinary bladder & - & $1(25 \%)$ & - & - \\
\hline Lipoma & $1(33 \%)$ & - & - & - \\
\hline Osteosarcoma, metastatic, bone & $1(33 \%)$ & - & - & - \\
\hline \multicolumn{5}{|l|}{ Nervous System } \\
\hline Brain & (50) & $(50)$ & (50) & (50) \\
\hline Granular cell tumor benign & - & - & $1(2 \%)$ & - \\
\hline Peripheral nerve & (2) & $(0)$ & (1) & $(0)$ \\
\hline Spinal cord & (2) & $(0)$ & (1) & $(0)$ \\
\hline \multicolumn{5}{|l|}{ Respiratory System } \\
\hline Larynx & $(50)$ & $(49)$ & (49) & $(49)$ \\
\hline Carcinoma, metastatic, thyroid gland & - & $1(2 \%)$ & $1(2 \%)$ & - \\
\hline Lung & (50) & $(50)$ & (50) & $(50)$ \\
\hline Alveolar/bronchiolar adenoma & $3(6 \%)$ & $1(2 \%)$ & $3(6 \%)$ & $3(6 \%)$ \\
\hline Alveolar/bronchiolar carcinoma & - & $1(2 \%)$ & $1(2 \%)$ & $1(2 \%)$ \\
\hline Carcinoma, metastatic, kidney & - & - & $1(2 \%)$ & $1(2 \%)$ \\
\hline Carcinoma, metastatic, thyroid gland & - & $1(2 \%)$ & $1(2 \%)$ & - \\
\hline Carcinoma, metastatic, urinary bladder & - & $1(2 \%)$ & - & - \\
\hline Fibrous histiocytoma, metastatic, skin & - & - & - & $1(2 \%)$ \\
\hline Osteosarcoma, metastatic, bone & $1(2 \%)$ & - & - & - \\
\hline Osteosarcoma, metastatic, uncertain primary site & - & - & - & $1(2 \%)$ \\
\hline Squamous cell carcinoma & - & $1(2 \%)$ & - & - \\
\hline Nose & (49) & $(50)$ & $(50)$ & $(50)$ \\
\hline Sarcoma & - & - & $1(2 \%)$ & - \\
\hline Respiratory epithelium, adenoma & - & - & $1(2 \%)$ & $4(8 \%)$ \\
\hline
\end{tabular}


Vinylidene Chloride, NTP TR 582

\begin{tabular}{|c|c|c|c|c|}
\hline & $\begin{array}{l}\text { Chamber } \\
\text { Control }\end{array}$ & $25 \mathrm{ppm}$ & $50 \mathrm{ppm}$ & 100 ppm \\
\hline Pleura & (0) & (1) & $(0)$ & (1) \\
\hline Trachea & $(50)$ & (49) & $(49)$ & $(48)$ \\
\hline Carcinoma, metastatic, thyroid gland & - & - & $1(2 \%)$ & - \\
\hline \multicolumn{5}{|l|}{ Special Senses System } \\
\hline Eye & $(48)$ & (48) & $(47)$ & $(49)$ \\
\hline Harderian gland & $(50)$ & (49) & $(48)$ & $(49)$ \\
\hline Zymbal's gland & (0) & (1) & (0) & (0) \\
\hline Carcinoma & - & $1(100 \%)$ & - & - \\
\hline \multicolumn{5}{|l|}{ Urinary System } \\
\hline Kidney & $(50)$ & $(50)$ & $(49)$ & (50) \\
\hline Mesenchymal tumor malignant & $1(2 \%)$ & - & - & $1(2 \%)$ \\
\hline Renal tubule, carcinoma & - & $2(4 \%)$ & $1(2 \%)$ & $1(2 \%)$ \\
\hline Urinary bladder & (49) & $(50)$ & $(49)$ & $(50)$ \\
\hline Transitional epithelium, carcinoma & - & $2(4 \%)$ & - & - \\
\hline \multicolumn{5}{|l|}{ Systemic Lesions } \\
\hline Multiple organs ${ }^{b}$ & $(50)$ & $(50)$ & $(50)$ & $(50)$ \\
\hline Histiocytic sarcoma & - & $2(4 \%)$ & $1(2 \%)$ & - \\
\hline Leukemia mononuclear & $17(34 \%)$ & $17(34 \%)$ & $16(32 \%)$ & $20(40 \%)$ \\
\hline Mesothelioma malignant & $1(2 \%)$ & $12(24 \%)$ & $28(56 \%)$ & $23(46 \%)$ \\
\hline \multicolumn{5}{|l|}{ Neoplasm Summary } \\
\hline Total animals with primary neoplasms ${ }^{c}$ & 50 & 50 & 49 & 49 \\
\hline Total primary neoplasms & 129 & 145 & 163 & 147 \\
\hline Total animals with benign neoplasms & 47 & 48 & 47 & 48 \\
\hline Total benign neoplasms & 99 & 97 & 101 & 88 \\
\hline Total animals with malignant neoplasms & 27 & 35 & 39 & 42 \\
\hline Total malignant neoplasms & 30 & 48 & 62 & 59 \\
\hline Total animals with metastatic neoplasms & 1 & 2 & 2 & 3 \\
\hline Total metastatic neoplasms & 4 & 10 & 6 & 5 \\
\hline $\begin{array}{l}\text { Total animals with malignant neoplasms } \\
\text { of uncertain primary site }\end{array}$ & - & - & - & 1 \\
\hline
\end{tabular}


Vinylidene Chloride, NTP TR 582

Table A-2. Statistical Analysis of Primary Neoplasms in Male Rats in the Two-year Inhalation Study of Vinylidene Chloride

\begin{tabular}{|c|c|c|c|c|}
\hline & $\begin{array}{l}\text { Chamber } \\
\text { Control }\end{array}$ & 25 ppm & 50 ppm & 100 ppm \\
\hline \multicolumn{5}{|c|}{ Adrenal Cortex: Adenoma } \\
\hline Overall rate ${ }^{a}$ & $4 / 49(8 \%)$ & $4 / 50(8 \%)$ & $1 / 49(2 \%)$ & $0 / 50(0 \%)$ \\
\hline Adjusted rate ${ }^{b}$ & $9.6 \%$ & $9.9 \%$ & $2.6 \%$ & $0.0 \%$ \\
\hline Terminal rate ${ }^{c}$ & $3 / 25(12 \%)$ & $3 / 27(11 \%)$ & $0 / 22(0 \%)$ & $0 / 19(0 \%)$ \\
\hline First incidence (days) & 661 & 535 & 555 & $-^{\mathrm{e}}$ \\
\hline Poly-3 test ${ }^{\mathrm{d}}$ & $\mathrm{P}=0.026 \mathrm{~N}$ & $P=0.629$ & $\mathrm{P}=0.207 \mathrm{~N}$ & $\mathrm{P}=0.072 \mathrm{~N}$ \\
\hline \multicolumn{5}{|c|}{ Adrenal Medulla: Benign Pheochromocytoma } \\
\hline Overall rate & $5 / 49(10 \%)$ & $11 / 50(22 \%)$ & $8 / 48(17 \%)$ & $8 / 50(16 \%)$ \\
\hline Adjusted rate & $12.0 \%$ & $26.6 \%$ & $21.5 \%$ & $20.7 \%$ \\
\hline Terminal rate & $2 / 25(8 \%)$ & $7 / 27(26 \%)$ & $4 / 21(19 \%)$ & $5 / 19(26 \%)$ \\
\hline First incidence (days) & 654 & 466 & 642 & 628 \\
\hline Poly-3 test & $P=0.301$ & $P=0.076$ & $P=0.201$ & $P=0.223$ \\
\hline \multicolumn{5}{|c|}{ Adrenal Medulla: Benign or Malignant Pheochromocytoma } \\
\hline Overall rate & $6 / 49(12 \%)$ & $12 / 50(24 \%)$ & $8 / 48(17 \%)$ & $9 / 50(18 \%)$ \\
\hline Adjusted rate & $14.3 \%$ & $28.8 \%$ & $21.5 \%$ & $23.2 \%$ \\
\hline Terminal rate & $2 / 25(8 \%)$ & $7 / 27(26 \%)$ & $4 / 21(19 \%)$ & $6 / 19(32 \%)$ \\
\hline First incidence (days) & 654 & 466 & 642 & 628 \\
\hline Poly-3 test & $\mathrm{P}=0.311$ & $P=0.087$ & $P=0.296$ & $\mathrm{P}=0.228$ \\
\hline \multicolumn{5}{|c|}{ Kidney (Renal Tubule): Adenoma (Step Sections) } \\
\hline Overall rate & $3 / 50(6 \%)$ & $3 / 50(6 \%)$ & $5 / 49(10 \%)$ & $1 / 50(2 \%)$ \\
\hline Adjusted rate & $7.2 \%$ & $7.4 \%$ & $13.1 \%$ & $2.6 \%$ \\
\hline Terminal rate & $3 / 25(12 \%)$ & $1 / 27(4 \%)$ & $3 / 22(14 \%)$ & $0 / 19(0 \%)$ \\
\hline First incidence (days) & $729(\mathrm{~T})$ & 631 & 502 & 718 \\
\hline Poly-3 test & $\mathrm{P}=0.328 \mathrm{~N}$ & $P=0.647$ & $P=0.304$ & $\mathrm{P}=0.341 \mathrm{~N}$ \\
\hline \multicolumn{5}{|c|}{ Kidney (Renal Tubule): Adenoma or Carcinoma (Single and Step Sections) } \\
\hline Overall rate & $3 / 50(6 \%)$ & $4 / 50(8 \%)$ & $6 / 49(12 \%)$ & $2 / 50(4 \%)$ \\
\hline Adjusted rate & $7.2 \%$ & $9.8 \%$ & $15.7 \%$ & $5.3 \%$ \\
\hline Terminal rate & $3 / 25(12 \%)$ & $1 / 27(4 \%)$ & $4 / 22(18 \%)$ & $1 / 19(5 \%)$ \\
\hline First incidence (days) & $729(\mathrm{~T})$ & 631 & 502 & 718 \\
\hline Poly-3 test & $\mathrm{P}=0.485 \mathrm{~N}$ & $\mathrm{P}=0.484$ & $\mathrm{P}=0.194$ & $\mathrm{P}=0.546 \mathrm{~N}$ \\
\hline \multicolumn{5}{|c|}{ Lung: Alveolar/bronchiolar Adenoma } \\
\hline Overall rate & $3 / 50(6 \%)$ & $1 / 50(2 \%)$ & $3 / 50(6 \%)$ & $3 / 50(6 \%)$ \\
\hline Adjusted rate & $7.0 \%$ & $2.5 \%$ & $7.9 \%$ & $7.8 \%$ \\
\hline
\end{tabular}


Vinylidene Chloride, NTP TR 582

\begin{tabular}{|c|c|c|c|c|}
\hline & $\begin{array}{c}\text { Chamber } \\
\text { Control }\end{array}$ & 25 ppm & 50 ppm & 100 ppm \\
\hline Terminal rate & $1 / 25(4 \%)$ & $1 / 27(4 \%)$ & $2 / 22(9 \%)$ & $2 / 19(11 \%)$ \\
\hline First incidence (days) & 614 & $729(\mathrm{~T})$ & 683 & 593 \\
\hline Poly-3 test & $P=0.413$ & $\mathrm{P}=0.330 \mathrm{~N}$ & $P=0.606$ & $P=0.612$ \\
\hline \multicolumn{5}{|c|}{ Lung: Alveolar/bronchiolar Adenoma or Carcinoma } \\
\hline Overall rate & $3 / 50(6 \%)$ & $2 / 50(4 \%)$ & $4 / 50(8 \%)$ & $4 / 50(8 \%)$ \\
\hline Adjusted rate & $7.0 \%$ & $5.0 \%$ & $10.6 \%$ & $10.4 \%$ \\
\hline Terminal rate & $1 / 25(4 \%)$ & $2 / 27(7 \%)$ & $3 / 22(14 \%)$ & $3 / 19(16 \%)$ \\
\hline First incidence (days) & 614 & $729(\mathrm{~T})$ & 683 & 593 \\
\hline Poly-3 test & $P=0.281$ & $\mathrm{P}=0.532 \mathrm{~N}$ & $P=0.435$ & $P=0.441$ \\
\hline \multicolumn{5}{|l|}{ Nose: Adenoma } \\
\hline Overall rate & $0 / 49(0 \%)$ & $0 / 50(0 \%)$ & $1 / 50(2 \%)$ & $4 / 50(8 \%)$ \\
\hline Adjusted rate & $0.0 \%$ & $0.0 \%$ & $2.7 \%$ & $10.5 \%$ \\
\hline Terminal rate & $0 / 25(0 \%)$ & $0 / 27(0 \%)$ & $1 / 22(5 \%)$ & $3 / 19(16 \%)$ \\
\hline First incidence (days) & - & - & $729(\mathrm{~T})$ & 635 \\
\hline Poly-3 test & $P=0.004$ & $-^{f}$ & $P=0.483$ & $P=0.051$ \\
\hline \multicolumn{5}{|c|}{ Pancreatic Islets: Adenoma } \\
\hline Overall rate & $2 / 50(4 \%)$ & $2 / 50(4 \%)$ & $3 / 50(6 \%)$ & $1 / 49(2 \%)$ \\
\hline Adjusted rate & $4.7 \%$ & $5.0 \%$ & $8.0 \%$ & $2.7 \%$ \\
\hline Terminal rate & $0 / 25(0 \%)$ & $2 / 27(7 \%)$ & $3 / 22(14 \%)$ & $1 / 19(5 \%)$ \\
\hline First incidence (days) & 676 & $729(\mathrm{~T})$ & $729(\mathrm{~T})$ & $729(\mathrm{~T})$ \\
\hline Poly-3 test & $\mathrm{P}=0.455 \mathrm{~N}$ & $P=0.674$ & $P=0.449$ & $\mathrm{P}=0.541 \mathrm{~N}$ \\
\hline \multicolumn{5}{|c|}{ Pancreatic Islets: Carcinoma } \\
\hline Overall rate & $2 / 50(4 \%)$ & $2 / 50(4 \%)$ & $4 / 50(8 \%)$ & $4 / 49(8 \%)$ \\
\hline Adjusted rate & $4.8 \%$ & $5.0 \%$ & $10.6 \%$ & $10.6 \%$ \\
\hline Terminal rate & $2 / 25(8 \%)$ & $1 / 27(4 \%)$ & $3 / 22(14 \%)$ & $1 / 19(5 \%)$ \\
\hline First incidence (days) & $729(\mathrm{~T})$ & 723 & 683 & 676 \\
\hline Poly-3 test & $P=0.170$ & $P=0.677$ & $P=0.290$ & $P=0.290$ \\
\hline \multicolumn{5}{|c|}{ Pancreatic Islets: Adenoma or Carcinoma } \\
\hline Overall rate & $4 / 50(8 \%)$ & $4 / 50(8 \%)$ & $7 / 50(14 \%)$ & $5 / 49(10 \%)$ \\
\hline Adjusted rate & $9.5 \%$ & $10.0 \%$ & $18.5 \%$ & $13.2 \%$ \\
\hline Terminal rate & $2 / 25(8 \%)$ & $3 / 27(11 \%)$ & $6 / 22(27 \%)$ & $2 / 19(11 \%)$ \\
\hline First incidence (days) & 676 & 723 & 683 & 676 \\
\hline Poly-3 test & $P=0.298$ & $P=0.613$ & $\mathrm{P}=0.199$ & $P=0.432$ \\
\hline \multicolumn{5}{|c|}{ Pituitary Gland (Pars Distalis): Adenoma } \\
\hline Overall rate & $34 / 50(68 \%)$ & $28 / 49(57 \%)$ & $26 / 49(53 \%)$ & $33 / 50(66 \%)$ \\
\hline
\end{tabular}


Vinylidene Chloride, NTP TR 582

\begin{tabular}{|c|c|c|c|c|}
\hline & $\begin{array}{l}\text { Chamber } \\
\text { Control }\end{array}$ & 25 ppm & 50 ppm & 100 ppm \\
\hline Adjusted rate & $73.5 \%$ & $64.5 \%$ & $63.9 \%$ & $74.4 \%$ \\
\hline Terminal rate & $17 / 25(68 \%)$ & $16 / 27(59 \%)$ & $16 / 21(76 \%)$ & $15 / 19(79 \%)$ \\
\hline First incidence (days) & 562 & 548 & 418 & 437 \\
\hline Poly-3 test & $\mathrm{P}=0.429$ & $\mathrm{P}=0.235 \mathrm{~N}$ & $\mathrm{P}=0.217 \mathrm{~N}$ & $\mathrm{P}=0.561$ \\
\hline \multicolumn{5}{|c|}{ Preputial Gland: Carcinoma } \\
\hline Overall rate & $2 / 50(4 \%)$ & $1 / 49(2 \%)$ & $3 / 49(6 \%)$ & $0 / 50(0 \%)$ \\
\hline Adjusted rate & $4.6 \%$ & $2.6 \%$ & $7.9 \%$ & $0.0 \%$ \\
\hline Terminal rate & $0 / 25(0 \%)$ & $0 / 26(0 \%)$ & $1 / 22(5 \%)$ & $0 / 19(0 \%)$ \\
\hline First incidence (days) & 492 & 694 & 555 & - \\
\hline Poly-3 test & $\mathrm{P}=0.281 \mathrm{~N}$ & $\mathrm{P}=0.536 \mathrm{~N}$ & $P=0.443$ & $\mathrm{P}=0.268 \mathrm{~N}$ \\
\hline \multicolumn{5}{|c|}{ Preputial Gland: Adenoma or Carcinoma } \\
\hline Overall rate & $4 / 50(8 \%)$ & $1 / 49(2 \%)$ & $5 / 49(10 \%)$ & $0 / 50(0 \%)$ \\
\hline Adjusted rate & $9.3 \%$ & $2.6 \%$ & $13.1 \%$ & $0.0 \%$ \\
\hline Terminal rate & $2 / 25(8 \%)$ & $0 / 26(0 \%)$ & $3 / 22(14 \%)$ & $0 / 19(0 \%)$ \\
\hline First incidence (days) & 492 & 694 & 555 & - \\
\hline Poly-3 test & $\mathrm{P}=0.141 \mathrm{~N}$ & $\mathrm{P}=0.211 \mathrm{~N}$ & $P=0.422$ & $\mathrm{P}=0.078 \mathrm{~N}$ \\
\hline \multicolumn{5}{|c|}{ Skin: Squamous Cell Papilloma } \\
\hline Overall rate & $3 / 50(6 \%)$ & $1 / 50(2 \%)$ & $1 / 50(2 \%)$ & $1 / 50(2 \%)$ \\
\hline Adjusted rate & $7.2 \%$ & $2.5 \%$ & $2.7 \%$ & $2.6 \%$ \\
\hline Terminal rate & $3 / 25(12 \%)$ & $1 / 27(4 \%)$ & $0 / 22(0 \%)$ & $1 / 19(5 \%)$ \\
\hline First incidence (days) & $729(\mathrm{~T})$ & $729(\mathrm{~T})$ & 705 & $729(\mathrm{~T})$ \\
\hline Poly-3 test & $\mathrm{P}=0.258 \mathrm{~N}$ & $\mathrm{P}=0.323 \mathrm{~N}$ & $\mathrm{P}=0.343 \mathrm{~N}$ & $\mathrm{P}=0.342 \mathrm{~N}$ \\
\hline \multicolumn{5}{|c|}{ Skin: Keratoacanthoma } \\
\hline Overall rate & $3 / 50(6 \%)$ & $3 / 50(6 \%)$ & $3 / 50(6 \%)$ & $2 / 50(4 \%)$ \\
\hline Adjusted rate & $7.1 \%$ & $7.4 \%$ & $7.9 \%$ & $5.2 \%$ \\
\hline Terminal rate & $1 / 25(4 \%)$ & $2 / 27(7 \%)$ & $2 / 22(9 \%)$ & $0 / 19(0 \%)$ \\
\hline First incidence (days) & 675 & 492 & 574 & 535 \\
\hline Poly-3 test & $\mathrm{P}=0.441 \mathrm{~N}$ & $P=0.645$ & $\mathrm{P}=0.617$ & $\mathrm{P}=0.541 \mathrm{~N}$ \\
\hline \multicolumn{5}{|c|}{ Skin: Squamous Cell Papilloma or Keratoacanthoma } \\
\hline Overall rate & $6 / 50(12 \%)$ & $4 / 50(8 \%)$ & $4 / 50(8 \%)$ & $3 / 50(6 \%)$ \\
\hline Adjusted rate & $14.2 \%$ & $9.9 \%$ & $10.4 \%$ & $7.8 \%$ \\
\hline Terminal rate & $4 / 25(16 \%)$ & $3 / 27(11 \%)$ & $2 / 22(9 \%)$ & $1 / 19(5 \%)$ \\
\hline First incidence (days) & 675 & 492 & 574 & 535 \\
\hline Poly-3 test & $\mathrm{P}=0.244 \mathrm{~N}$ & $\mathrm{P}=0.394 \mathrm{~N}$ & $\mathrm{P}=0.431 \mathrm{~N}$ & $\mathrm{P}=0.286 \mathrm{~N}$ \\
\hline
\end{tabular}


Vinylidene Chloride, NTP TR 582

\begin{tabular}{|c|c|c|c|c|}
\hline & $\begin{array}{l}\text { Chamber } \\
\text { Control }\end{array}$ & 25 ppm & 50 ppm & 100 ppm \\
\hline \multicolumn{5}{|c|}{ Skin: Trichoepithelioma, Basal Cell Adenoma, or Basal Cell Carcinoma } \\
\hline Overall rate & $3 / 50(6 \%)$ & $0 / 50(0 \%)$ & $2 / 50(4 \%)$ & $1 / 50(2 \%)$ \\
\hline Adjusted rate & $7.1 \%$ & $0.0 \%$ & $5.3 \%$ & $2.6 \%$ \\
\hline Terminal rate & $1 / 25(4 \%)$ & $0 / 27(0 \%)$ & $1 / 22(5 \%)$ & $1 / 19(5 \%)$ \\
\hline First incidence (days) & 661 & - & 637 & $729(\mathrm{~T})$ \\
\hline Poly-3 test & $\mathrm{P}=0.356 \mathrm{~N}$ & $\mathrm{P}=0.129 \mathrm{~N}$ & $\mathrm{P}=0.548 \mathrm{~N}$ & $\mathrm{P}=0.345 \mathrm{~N}$ \\
\hline \multicolumn{5}{|c|}{$\begin{array}{l}\text { Skin: Squamous Cell Papilloma, Keratoacanthoma, Trichoepithelioma, Basal Cell Adenoma, or Basal Cell } \\
\text { Carcinoma }\end{array}$} \\
\hline Overall rate & $9 / 50(18 \%)$ & $4 / 50(8 \%)$ & $6 / 50(12 \%)$ & $4 / 50(8 \%$ \\
\hline Adjusted rate & $21.2 \%$ & $9.9 \%$ & $15.5 \%$ & $10.4 \%$ \\
\hline Terminal rate & $5 / 25(20 \%)$ & $3 / 27(11 \%)$ & $3 / 22(14 \%)$ & $2 / 19(11 \%)$ \\
\hline First incidence (days) & 661 & 492 & 574 & 535 \\
\hline Poly-3 test & $\mathrm{P}=0.169 \mathrm{~N}$ & $\mathrm{P}=0.131 \mathrm{~N}$ & $\mathrm{P}=0.357 \mathrm{~N}$ & $\mathrm{P}=0.152 \mathrm{~N}$ \\
\hline \multicolumn{5}{|c|}{ Skin (Subcutaneous Tissue): Fibroma } \\
\hline Overall rate & $1 / 50(2 \%)$ & $4 / 50(8 \%)$ & $3 / 50(6 \%)$ & $3 / 50(6 \%)$ \\
\hline Adjusted rate & $2.4 \%$ & $10.0 \%$ & $7.9 \%$ & $7.9 \%$ \\
\hline Terminal rate & $0 / 25(0 \%)$ & $4 / 27(15 \%)$ & $2 / 22(9 \%)$ & $3 / 19(16 \%)$ \\
\hline First incidence (days) & 679 & $729(\mathrm{~T})$ & 705 & $729(\mathrm{~T})$ \\
\hline Poly-3 test & $\mathrm{P}=0.293$ & $\mathrm{P}=0.161$ & $\mathrm{P}=0.267$ & $\mathrm{P}=0.267$ \\
\hline \multicolumn{5}{|c|}{ Skin (Subcutaneous Tissue): Fibroma, Fibrous Histiocytoma, Fibrosarcoma, or Sarcoma } \\
\hline Overall rate & $1 / 50(2 \%)$ & $6 / 50(12 \%)$ & $3 / 50(6 \%)$ & $5 / 50(10 \%)$ \\
\hline Adjusted rate & $2.4 \%$ & $14.6 \%$ & $7.9 \%$ & $13.1 \%$ \\
\hline Terminal rate & $0 / 25(0 \%)$ & $4 / 27(15 \%)$ & $2 / 22(9 \%)$ & $4 / 19(21 \%)$ \\
\hline First incidence (days) & 679 & 294 & 705 & 617 \\
\hline Poly-3 test & $\mathrm{P}=0.143$ & $\mathrm{P}=0.051$ & $\mathrm{P}=0.267$ & $\mathrm{P}=0.079$ \\
\hline \multicolumn{5}{|l|}{ Testes: Adenoma } \\
\hline Overall rate & $32 / 50(64 \%)$ & $35 / 50(70 \%)$ & $39 / 50(78 \%)$ & $25 / 50(50 \%)$ \\
\hline Adjusted rate & $70.8 \%$ & $80.5 \%$ & $87.9 \%$ & $58.8 \%$ \\
\hline Terminal rate & $21 / 25(84 \%)$ & $24 / 27(89 \%)$ & $21 / 22(96 \%)$ & $11 / 19(58 \%)$ \\
\hline First incidence (days) & 551 & 535 & 500 & 449 \\
\hline Poly-3 test & $\mathrm{P}=0.072 \mathrm{~N}$ & $\mathrm{P}=0.186$ & $\mathrm{P}=0.026$ & $\mathrm{P}=0.155 \mathrm{~N}$ \\
\hline \multicolumn{5}{|c|}{ Thyroid Gland (C-Cell): Adenoma } \\
\hline Overall rate & $4 / 50(8 \%)$ & $5 / 49(10 \%)$ & $4 / 49(8 \%)$ & $1 / 48(2 \%)$ \\
\hline Adjusted rate & $9.4 \%$ & $12.5 \%$ & $10.9 \%$ & $2.7 \%$ \\
\hline Terminal rate & $3 / 25(12 \%)$ & $3 / 27(11 \%)$ & $4 / 21(19 \%)$ & $1 / 19(5 \%)$ \\
\hline
\end{tabular}


Vinylidene Chloride, NTP TR 582

\begin{tabular}{|c|c|c|c|c|}
\hline & $\begin{array}{l}\text { Chamber } \\
\text { Control }\end{array}$ & 25 ppm & 50 ppm & 100 ppm \\
\hline First incidence (days) & 591 & 611 & $729(\mathrm{~T})$ & $729(\mathrm{~T})$ \\
\hline Poly-3 test & $\mathrm{P}=0.152 \mathrm{~N}$ & $P=0.462$ & $P=0.563$ & $\mathrm{P}=0.219 \mathrm{~N}$ \\
\hline \multicolumn{5}{|c|}{ Thyroid Gland (C-Cell): Carcinoma } \\
\hline Overall rate & $3 / 50(6 \%)$ & $3 / 49(6 \%)$ & $3 / 49(6 \%)$ & $3 / 48(6 \%)$ \\
\hline Adjusted rate & $7.2 \%$ & $7.6 \%$ & $8.0 \%$ & $8.0 \%$ \\
\hline Terminal rate & $2 / 25(8 \%)$ & $2 / 27(7 \%)$ & $1 / 21(5 \%)$ & $1 / 19(5 \%)$ \\
\hline First incidence (days) & 717 & 563 & 586 & 635 \\
\hline Poly-3 test & $P=0.523$ & $P=0.638$ & $P=0.609$ & $P=0.613$ \\
\hline \multicolumn{5}{|c|}{ Thyroid Gland (C-Cell): Adenoma or Carcinoma } \\
\hline Overall rate & $7 / 50(14 \%)$ & $8 / 49(16 \%)$ & $6 / 49(12 \%)$ & $4 / 48(8 \%)$ \\
\hline Adjusted rate & $16.5 \%$ & $19.8 \%$ & $16.0 \%$ & $10.6 \%$ \\
\hline Terminal rate & $5 / 25(20 \%)$ & $5 / 27(19 \%)$ & $4 / 21(19 \%)$ & $2 / 19(11 \%)$ \\
\hline First incidence (days) & 591 & 563 & 586 & 635 \\
\hline Poly-3 test & $\mathrm{P}=0.227 \mathrm{~N}$ & $P=0.459$ & $\mathrm{P}=0.597 \mathrm{~N}$ & $\mathrm{P}=0.330 \mathrm{~N}$ \\
\hline \multicolumn{5}{|c|}{ All Organs: Mononuclear Cell Leukemia } \\
\hline Overall rate & $17 / 50(34 \%)$ & $17 / 50(34 \%)$ & $16 / 50(32 \%)$ & $20 / 50(40 \%)$ \\
\hline Adjusted rate & $38.1 \%$ & $39.8 \%$ & $38.9 \%$ & $46.5 \%$ \\
\hline Terminal rate & $8 / 25(32 \%)$ & $9 / 27(33 \%)$ & $6 / 22(27 \%)$ & $7 / 19(37 \%)$ \\
\hline First incidence (days) & 551 & 560 & 563 & 437 \\
\hline Poly-3 test & $P=0.237$ & $P=0.522$ & $P=0.560$ & $P=0.278$ \\
\hline \multicolumn{5}{|c|}{ All Organs: Malignant Mesothelioma } \\
\hline Overall rate & $1 / 50(2 \%)$ & $12 / 50(24 \%)$ & $28 / 50(56 \%)$ & $23 / 50(46 \%)$ \\
\hline Adjusted rate & $2.4 \%$ & $27.9 \%$ & $63.4 \%$ & $52.7 \%$ \\
\hline Terminal rate & $0 / 25(0 \%)$ & $5 / 27(19 \%)$ & $10 / 22(46 \%)$ & $7 / 19(37 \%)$ \\
\hline First incidence (days) & 562 & 535 & 500 & 449 \\
\hline Poly-3 test & $\mathrm{P}<0.001$ & $\mathrm{P}<0.001$ & $\mathrm{P}<0.001$ & $\mathrm{P}<0.001$ \\
\hline \multicolumn{5}{|c|}{ All Organs: Benign Neoplasms } \\
\hline Overall rate & $47 / 50(94 \%)$ & $48 / 50(96 \%)$ & $47 / 50(94 \%)$ & $48 / 50(96 \%)$ \\
\hline Adjusted rate & $98.4 \%$ & $99.6 \%$ & $98.2 \%$ & $99.2 \%$ \\
\hline Terminal rate & $25 / 25(100 \%)$ & $27 / 27(100 \%)$ & $22 / 22(100 \%)$ & $19 / 19(100 \%)$ \\
\hline First incidence (days) & 551 & 466 & 418 & 437 \\
\hline Poly-3 test & $P=0.685$ & $P=0.780$ & $\mathrm{P}=0.890 \mathrm{~N}$ & $P=0.831$ \\
\hline \multicolumn{5}{|c|}{ All Organs: Malignant Neoplasms } \\
\hline Overall rate & $27 / 50(54 \%)$ & $35 / 50(70 \%)$ & $39 / 50(78 \%)$ & $42 / 50(84 \%)$ \\
\hline Adjusted rate & $56.6 \%$ & $73.2 \%$ & $83.9 \%$ & $89.1 \%$ \\
\hline
\end{tabular}


Vinylidene Chloride, NTP TR 582

\begin{tabular}{lcccc}
\hline & $\begin{array}{c}\text { Chamber } \\
\text { Control }\end{array}$ & $\mathbf{2 5} \mathbf{~ p p m}$ & $\mathbf{5 0 ~} \mathbf{~ p m}$ & $\mathbf{1 0 0} \mathbf{~ p p m}$ \\
\hline Terminal rate & $11 / 25(44 \%)$ & $16 / 27(59 \%)$ & $16 / 22(73 \%)$ & $17 / 19(90 \%)$ \\
First incidence (days) & 367 & 294 & 500 & 437 \\
Poly-3 test & $\mathrm{P}<0.001$ & $\mathrm{P}=0.064$ & $\mathrm{P}=0.002$ & $\mathrm{P}<0.001$ \\
\hline All Organs: Benign or Malignant Neoplasms & & & & \\
Overall rate & $50 / 50(100 \%)$ & $50 / 50(100 \%)$ & $49 / 50(98 \%)$ & $49 / 50(98 \%)$ \\
Adjusted rate & $100.0 \%$ & $100.0 \%$ & $99.9 \%$ & $100.0 \%$ \\
Terminal rate & $25 / 25(100 \%)$ & $27 / 27(100 \%)$ & $22 / 22(100 \%)$ & $19 / 19(100 \%)$ \\
First incidence (days) & 367 & 294 & 418 & 437 \\
Poly-3 test & $\mathrm{P}=1.000$ & - & $\mathrm{P}=1.000$ & $\mathrm{P}=1.000$ \\
\hline
\end{tabular}

$\mathrm{T}=$ terminal kill.

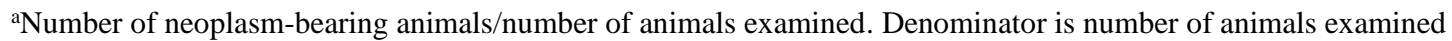

microscopically for adrenal gland, kidney, lung, nose, pancreatic islets, pituitary gland, preputial gland, testes, and thyroid gland; for other tissues, denominator is number of animals necropsied.

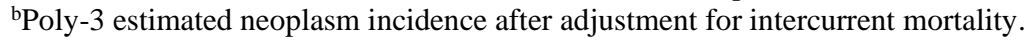

${ }^{\mathrm{c}}$ Observed incidence at terminal kill.

${ }^{\mathrm{d} B e n e a t h}$ the chamber control incidence is the $\mathrm{P}$ value associated with the trend test. Beneath the exposed group incidence are the $\mathrm{P}$ values corresponding to pairwise comparisons between the chamber controls and that exposed group. The Poly-3 test accounts for differential mortality in animals that do not reach terminal kill. A negative trend or a lower incidence in an exposure group is indicated by $\mathrm{N}$.

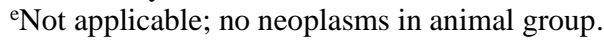

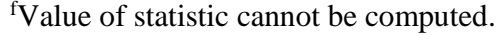


Table A-3. Historical Incidence of Malignant Mesothelioma in Control Male F344/N Rats ${ }^{\mathrm{a}}$

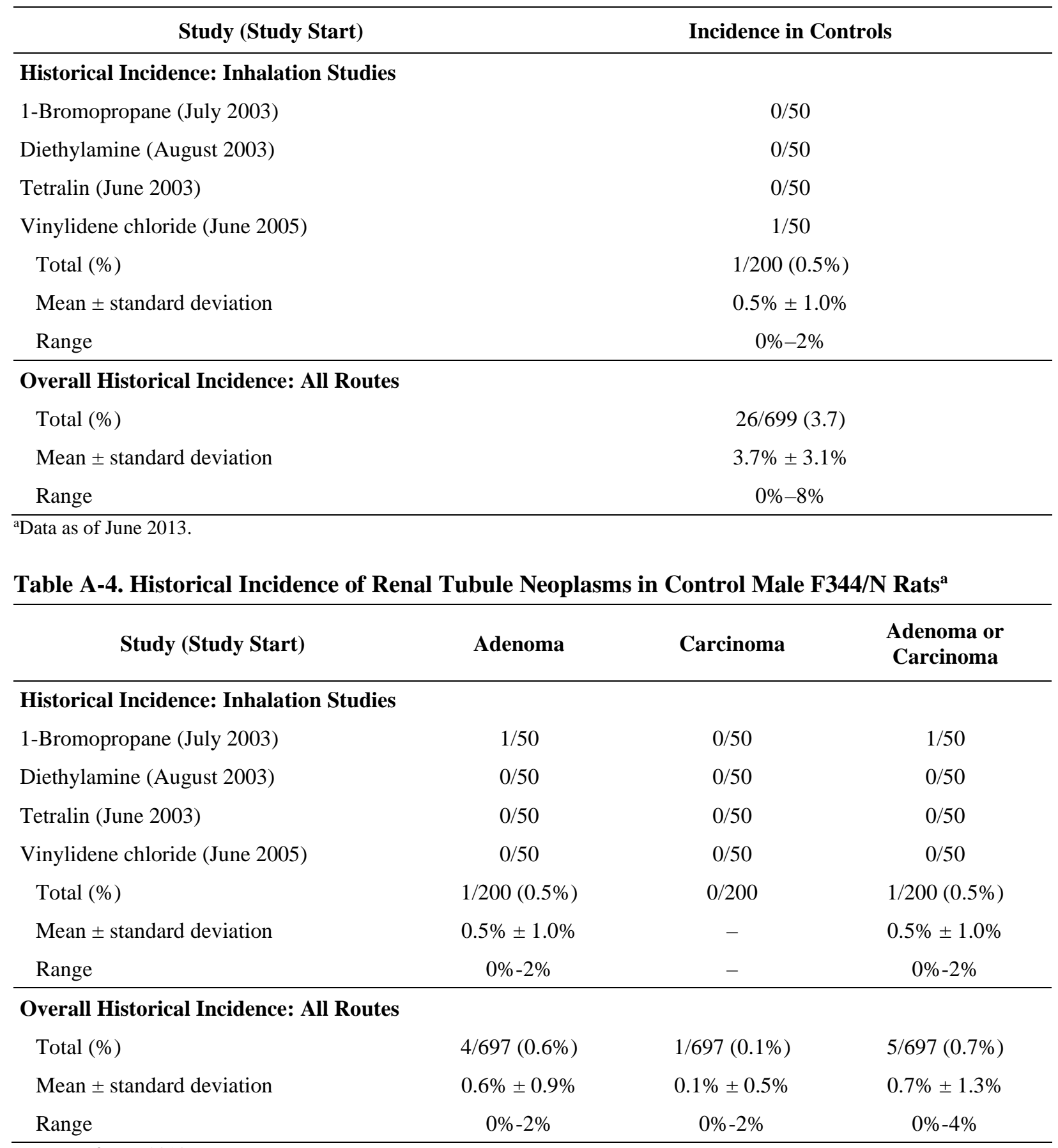

Data as of June 2013. 
Table A-5. Summary of the Incidence of Nonneoplastic Lesions in Male Rats in the Two-year Inhalation Study of Vinylidene Chloride ${ }^{\mathrm{a}}$

\begin{tabular}{|c|c|c|c|c|}
\hline & $\begin{array}{c}\text { Chamber } \\
\text { Control }\end{array}$ & $25 \mathrm{ppm}$ & 50 ppm & 100 ppm \\
\hline \multicolumn{5}{|l|}{ Disposition Summary } \\
\hline Animals initially in study & 50 & 50 & 50 & 50 \\
\hline \multicolumn{5}{|l|}{ Early deaths } \\
\hline Moribund & 21 & 15 & 23 & 27 \\
\hline Natural deaths & 4 & 8 & 5 & 4 \\
\hline \multicolumn{5}{|l|}{ Survivors } \\
\hline Terminal kill & 25 & 27 & 22 & 19 \\
\hline Animals examined microscopically & 50 & 50 & 50 & 50 \\
\hline \multicolumn{5}{|l|}{ Alimentary System } \\
\hline Esophagus & $(50)$ & $(49)$ & $(49)$ & $(50)$ \\
\hline Hyperplasia, squamous & - & - & - & $1(2 \%)$ \\
\hline Intestine large, cecum & (48) & (44) & $(45)$ & $(46)$ \\
\hline Inflammation, acute & $1(2 \%)$ & $1(2 \%)$ & - & - \\
\hline Necrosis & $1(2 \%)$ & - & - & - \\
\hline Arteriole, inflammation & - & - & $1(2 \%)$ & - \\
\hline Intestine large, colon & (47) & (46) & (47) & $(48)$ \\
\hline Arteriole, inflammation & - & - & $1(2 \%)$ & - \\
\hline Intestine large, rectum & (46) & (47) & (46) & (49) \\
\hline Thrombosis & - & - & $1(2 \%)$ & - \\
\hline Intestine small, duodenum & (47) & $(45)$ & $(45)$ & (49) \\
\hline Intestine small, ileum & $(47)$ & $(45)$ & $(45)$ & (47) \\
\hline Intestine small, jejunum & (47) & (43) & $(45)$ & (47) \\
\hline Liver & $(50)$ & $(50)$ & $(50)$ & $(50)$ \\
\hline Angiectasis & - & $2(4 \%)$ & - & - \\
\hline Basophilic focus & $15(30 \%)$ & $7(14 \%)$ & $5(10 \%)$ & $5(10 \%)$ \\
\hline Clear cell focus & $22(44 \%)$ & $23(46 \%)$ & $19(38 \%)$ & $15(30 \%)$ \\
\hline Cyst & - & - & $1(2 \%)$ & - \\
\hline Degeneration, cystic & $2(4 \%)$ & $5(10 \%)$ & $7(14 \%)$ & $12(24 \%)$ \\
\hline Eosinophilic focus & $3(6 \%)$ & $6(12 \%)$ & $7(14 \%)$ & $5(10 \%)$ \\
\hline Fatty change, diffuse & $4(8 \%)$ & $19(38 \%)$ & $18(36 \%)$ & $26(52 \%)$ \\
\hline Hepatodiaphragmatic nodule & $1(2 \%)$ & $1(2 \%)$ & $1(2 \%)$ & $5(10 \%)$ \\
\hline Inflammation, acute & - & - & - & $1(2 \%)$ \\
\hline Inflammation, chronic & $28(56 \%)$ & $46(92 \%)$ & $46(92 \%)$ & $44(88 \%)$ \\
\hline Inflammation, chronic active & $1(2 \%)$ & - & - & - \\
\hline
\end{tabular}


Vinylidene Chloride, NTP TR 582

\begin{tabular}{|c|c|c|c|c|}
\hline & $\begin{array}{c}\text { Chamber } \\
\text { Control }\end{array}$ & $25 \mathrm{ppm}$ & $50 \mathrm{ppm}$ & 100 ppm \\
\hline Mixed cell focus & $1(2 \%)$ & $1(2 \%)$ & $8(16 \%)$ & $6(12 \%)$ \\
\hline Necrosis & $2(4 \%)$ & $6(12 \%)$ & $8(16 \%)$ & $6(12 \%)$ \\
\hline Bile duct, hyperplasia & $38(76 \%)$ & $23(46 \%)$ & $16(32 \%)$ & $14(28 \%)$ \\
\hline Bile duct, inflammation, suppurative & - & - & $1(2 \%)$ & - \\
\hline Mesentery & (16) & $(15)$ & $(21)$ & (23) \\
\hline Inflammation, chronic active & $2(13 \%)$ & - & $1(5 \%)$ & - \\
\hline Fat, necrosis & $13(81 \%)$ & $10(67 \%)$ & $14(67 \%)$ & $12(52 \%)$ \\
\hline Pancreas & $(50)$ & $(50)$ & $(50)$ & $(49)$ \\
\hline Atrophy & $21(42 \%)$ & $16(32 \%)$ & $25(50 \%)$ & $20(41 \%)$ \\
\hline Basophilic focus & $1(2 \%)$ & - & - & - \\
\hline Hyperplasia & $4(8 \%)$ & $5(10 \%)$ & $2(4 \%)$ & $7(14 \%)$ \\
\hline Inflammation, chronic active & - & - & $1(2 \%)$ & $1(2 \%)$ \\
\hline Salivary glands & $(50)$ & (50) & $(50)$ & (50) \\
\hline Atrophy & - & $1(2 \%)$ & - & - \\
\hline Stomach, forestomach & $(50)$ & $(50)$ & $(50)$ & $(50)$ \\
\hline Hyperplasia, squamous & - & $2(4 \%)$ & $2(4 \%)$ & $1(2 \%)$ \\
\hline Inflammation, chronic active & - & $2(4 \%)$ & - & - \\
\hline Mineralization & $1(2 \%)$ & - & - & - \\
\hline Ulcer & $4(8 \%)$ & $3(6 \%)$ & $1(2 \%)$ & $6(12 \%)$ \\
\hline Stomach, glandular & $(49)$ & $(50)$ & (49) & $(50)$ \\
\hline Mineralization & $1(2 \%)$ & - & $1(2 \%)$ & - \\
\hline Necrosis & - & - & $3(6 \%)$ & $3(6 \%)$ \\
\hline Ulcer & - & - & $1(2 \%)$ & $1(2 \%)$ \\
\hline Tongue & (0) & (1) & $(0)$ & (2) \\
\hline Hyperplasia, squamous & - & - & - & $2(100 \%)$ \\
\hline Tooth & (1) & (0) & (0) & $(0)$ \\
\hline Dysplasia & $1(100 \%)$ & - & - & - \\
\hline \multicolumn{5}{|l|}{ Cardiovascular System } \\
\hline Blood vessel & (1) & (0) & (1) & $(0)$ \\
\hline Aorta, mineralization & $1(100 \%)$ & - & $1(100 \%)$ & - \\
\hline Heart & $(50)$ & $(50)$ & (50) & $(50)$ \\
\hline Cardiomyopathy & $42(84 \%)$ & $41(82 \%)$ & $39(78 \%)$ & $35(70 \%)$ \\
\hline Inflammation, chronic active & - & $1(2 \%)$ & - & - \\
\hline Mineralization & $1(2 \%)$ & - & - & - \\
\hline Thrombosis & $3(6 \%)$ & $3(6 \%)$ & $6(12 \%)$ & $8(16 \%)$ \\
\hline
\end{tabular}


Vinylidene Chloride, NTP TR 582

\begin{tabular}{|c|c|c|c|c|}
\hline & $\begin{array}{c}\text { Chamber } \\
\text { Control }\end{array}$ & 25 ppm & 50 ppm & 100 ppm \\
\hline \multicolumn{5}{|l|}{ Endocrine System } \\
\hline Adrenal cortex & $(49)$ & $(50)$ & $(49)$ & $(50)$ \\
\hline Hyperplasia & $26(53 \%)$ & $27(54 \%)$ & $27(55 \%)$ & $27(54 \%)$ \\
\hline Hypertrophy & $1(2 \%)$ & $2(4 \%)$ & $2(4 \%)$ & $4(8 \%)$ \\
\hline Necrosis & - & $2(4 \%)$ & - & - \\
\hline Adrenal medulla & (49) & $(50)$ & $(48)$ & $(50)$ \\
\hline Hyperplasia & $25(51 \%)$ & $22(44 \%)$ & $17(35 \%)$ & $29(58 \%)$ \\
\hline Bilateral, hyperplasia & - & - & $1(2 \%)$ & - \\
\hline Islets, pancreatic & $(50)$ & $(50)$ & $(50)$ & (49) \\
\hline Hyperplasia & $1(2 \%)$ & $3(6 \%)$ & $3(6 \%)$ & $3(6 \%)$ \\
\hline Parathyroid gland & $(50)$ & $(49)$ & $(47)$ & $(45)$ \\
\hline Hyperplasia & $1(2 \%)$ & $2(4 \%)$ & $1(2 \%)$ & $2(4 \%)$ \\
\hline Pituitary gland & $(50)$ & $(49)$ & $(49)$ & $(50)$ \\
\hline Angiectasis & - & - & - & $1(2 \%)$ \\
\hline Pars distalis, angiectasis & $2(4 \%)$ & - & - & $1(2 \%)$ \\
\hline Pars distalis, hemorrhage & - & $1(2 \%)$ & - & - \\
\hline Pars distalis, hyperplasia & $10(20 \%)$ & $13(27 \%)$ & $14(29 \%)$ & $9(18 \%)$ \\
\hline Pars intermedia, angiectasis & $1(2 \%)$ & - & - & - \\
\hline Pars intermedia, hyperplasia & $1(2 \%)$ & - & - & - \\
\hline Thyroid gland & $(50)$ & $(49)$ & (49) & $(48)$ \\
\hline C-cell, hyperplasia & $15(30 \%)$ & $16(33 \%)$ & $19(39 \%)$ & $19(40 \%)$ \\
\hline Follicular cell, hyperplasia & $2(4 \%)$ & - & $2(4 \%)$ & $1(2 \%)$ \\
\hline \multicolumn{5}{|l|}{ General Body System } \\
\hline Peritoneum & (0) & (2) & (4) & (3) \\
\hline Mesothelium, hyperplasia & - & $1(50 \%)$ & - & - \\
\hline Tissue, NOS & (0) & $(0)$ & $(0)$ & (1) \\
\hline \multicolumn{5}{|l|}{ Genital System } \\
\hline Coagulating gland & $(0)$ & $(0)$ & $(0)$ & (3) \\
\hline Hyperplasia & - & - & - & $2(67 \%)$ \\
\hline Inflammation, suppurative & - & - & - & $1(33 \%)$ \\
\hline Epididymis & $(50)$ & $(50)$ & $(50)$ & $(50)$ \\
\hline Degeneration & - & - & - & $1(2 \%)$ \\
\hline Granuloma sperm & - & $1(2 \%)$ & - & - \\
\hline Hyperplasia, mesothelium & - & $3(6 \%)$ & $1(2 \%)$ & - \\
\hline
\end{tabular}


Vinylidene Chloride, NTP TR 582

\begin{tabular}{|c|c|c|c|c|}
\hline & $\begin{array}{c}\text { Chamber } \\
\text { Control }\end{array}$ & $25 \mathrm{ppm}$ & $50 \mathrm{ppm}$ & $100 \mathrm{ppm}$ \\
\hline Penis & $(0)$ & (0) & (1) & $(0)$ \\
\hline Inflammation, suppurative & - & - & $1(100 \%)$ & - \\
\hline Preputial gland & (50) & (49) & (49) & $(50)$ \\
\hline Hyperplasia & $1(2 \%)$ & $1(2 \%)$ & - & - \\
\hline Prostate & $(50)$ & $(50)$ & $(50)$ & $(50)$ \\
\hline Hyperplasia & $5(10 \%)$ & $4(8 \%)$ & $7(14 \%)$ & $5(10 \%)$ \\
\hline Inflammation, suppurative & $4(8 \%)$ & $5(10 \%)$ & $9(18 \%)$ & $8(16 \%)$ \\
\hline Seminal vesicle & (48) & $(50)$ & (48) & (48) \\
\hline Hyperplasia & - & - & $1(2 \%)$ & - \\
\hline Testes & $(50)$ & $(50)$ & (50) & $(50)$ \\
\hline Atrophy & $9(18 \%)$ & $10(20 \%)$ & $13(26 \%)$ & $4(8 \%)$ \\
\hline Hemorrhage & $1(2 \%)$ & $1(2 \%)$ & - & - \\
\hline Hyperplasia, mesothelium & - & $2(4 \%)$ & - & - \\
\hline Arteriole, inflammation & - & $1(2 \%)$ & $1(2 \%)$ & - \\
\hline Interstitial cell, hyperplasia & $4(8 \%)$ & $4(8 \%)$ & $6(12 \%)$ & $3(6 \%)$ \\
\hline Tunic, hyperplasia & - & $2(4 \%)$ & $2(4 \%)$ & $2(4 \%)$ \\
\hline \multicolumn{5}{|l|}{ Hematopoietic System } \\
\hline Bone marrow & (49) & $(49)$ & $(48)$ & (49) \\
\hline Hyperplasia, reticulum cell & $1(2 \%)$ & - & - & - \\
\hline Lymph node & (6) & (4) & (9) & (7) \\
\hline Pancreatic, congestion & - & - & $1(11 \%)$ & - \\
\hline Pancreatic, hyperplasia, lymphoid & $1(17 \%)$ & - & - & $1(14 \%)$ \\
\hline Pancreatic, infiltration cellular, histiocyte & - & - & - & - \\
\hline Lymph node, bronchial & (8) & (9) & (9) & (9) \\
\hline Congestion & - & - & $1(11 \%)$ & - \\
\hline Ectasia & - & $1(11 \%)$ & $2(22 \%)$ & - \\
\hline Hyperplasia, lymphoid & $1(13 \%)$ & - & - & - \\
\hline Infiltration cellular, histocyte & - & - & - & $1(11 \%)$ \\
\hline Lymph node, mandibular & (1) & (1) & (1) & (0) \\
\hline Lymph node, mediastinal & $(28)$ & $(21)$ & (24) & $(30)$ \\
\hline Congestion & - & - & $1(4 \%)$ & - \\
\hline Ectasia & $1(4 \%)$ & - & - & - \\
\hline Hyperplasia, lymphoid & $2(7 \%)$ & - & $2(8 \%)$ & $2(7 \%)$ \\
\hline Lymph node, mesenteric & $(50)$ & $(50)$ & $(50)$ & $(50)$ \\
\hline Congestion & - & - & $1(2 \%)$ & - \\
\hline
\end{tabular}


Vinylidene Chloride, NTP TR 582

\begin{tabular}{|c|c|c|c|c|}
\hline & $\begin{array}{c}\text { Chamber } \\
\text { Control }\end{array}$ & 25 ppm & 50 ppm & 100 ppm \\
\hline Ectasia & - & - & - & $1(2 \%)$ \\
\hline Hyperplasia, lymphoid & $1(2 \%)$ & - & $1(2 \%)$ & $1(2 \%)$ \\
\hline Inflammation, granulomatous & - & - & - & $1(2 \%)$ \\
\hline Spleen & (50) & $(50)$ & $(50)$ & $(50)$ \\
\hline Fibrosis & $3(6 \%)$ & - & $2(4 \%)$ & $4(8 \%)$ \\
\hline Hematopoietic cell proliferation & $3(6 \%)$ & $1(2 \%)$ & $1(2 \%)$ & - \\
\hline Hyperplasia, lymphoid & - & - & - & $1(2 \%)$ \\
\hline Hyperplasia, stromal & $1(2 \%)$ & - & - & - \\
\hline Necrosis & - & $1(2 \%)$ & $2(4 \%)$ & $2(4 \%)$ \\
\hline Capsule, hyperplasia & - & - & $1(2 \%)$ & - \\
\hline Thymus & $(42)$ & (43) & $(41)$ & (44) \\
\hline Infiltration cellular, polymorphonuclear & - & - & - & $1(2 \%)$ \\
\hline \multicolumn{5}{|l|}{ Integumentary System } \\
\hline Mammary gland & $(36)$ & $(29)$ & $(24)$ & $(32)$ \\
\hline Hyperplasia & - & $1(3 \%)$ & - & - \\
\hline Skin & $(50)$ & $(50)$ & $(49)$ & $(50)$ \\
\hline Cyst epithelial inclusion & $4(8 \%)$ & $2(4 \%)$ & $2(4 \%)$ & - \\
\hline Hyperkeratosis & - & $1(2 \%)$ & - & - \\
\hline Hyperplasia, squamous & $1(2 \%)$ & - & - & - \\
\hline Inflammation, acute & - & - & $1(2 \%)$ & - \\
\hline Inflammation, chronic active & $2(4 \%)$ & - & $1(2 \%)$ & - \\
\hline \multicolumn{5}{|l|}{ Musculoskeletal System } \\
\hline Bone & $(50)$ & $(50)$ & $(50)$ & $(50)$ \\
\hline Skeletal muscle & (3) & (4) & (7) & (11) \\
\hline \multicolumn{5}{|l|}{ Nervous System } \\
\hline Brain & $(50)$ & $(50)$ & $(50)$ & $(50)$ \\
\hline Hemorrhage & $1(2 \%)$ & - & - & - \\
\hline Peripheral nerve & (2) & (0) & (1) & (0) \\
\hline Spinal cord & (2) & $(0)$ & (1) & $(0)$ \\
\hline \multicolumn{5}{|l|}{ Respiratory System } \\
\hline Larynx & $(50)$ & (49) & (49) & (49) \\
\hline Inflammation, chronic active & $1(2 \%)$ & $1(2 \%)$ & - & $1(2 \%)$ \\
\hline Metaplasia, squamous & - & - & - & $1(2 \%)$ \\
\hline Lung & $(50)$ & $(50)$ & $(50)$ & $(50)$ \\
\hline Foreign body & $1(2 \%)$ & - & - & - \\
\hline
\end{tabular}


Vinylidene Chloride, NTP TR 582

\begin{tabular}{|c|c|c|c|c|}
\hline & $\begin{array}{l}\text { Chamber } \\
\text { Control }\end{array}$ & 25 ppm & 50 ppm & 100 ppm \\
\hline Inflammation, acute & - & $1(2 \%)$ & - & - \\
\hline Inflammation, chronic active & $2(4 \%)$ & - & $1(2 \%)$ & - \\
\hline Metaplasia, osseous & - & - & - & $1(2 \%)$ \\
\hline Mineralization & $1(2 \%)$ & - & $1(2 \%)$ & - \\
\hline Thrombosis & $1(2 \%)$ & $1(2 \%)$ & $2(4 \%)$ & - \\
\hline Alveolar epithelium, hyperplasia & $7(14 \%)$ & $18(36 \%)$ & $14(28 \%)$ & $14(28 \%)$ \\
\hline $\begin{array}{l}\text { Alveolar epithelium, metaplasia, } \\
\text { squamous }\end{array}$ & - & - & $1(2 \%)$ & - \\
\hline Alveolar epithelium, metaplasia, mucous & - & - & $1(2 \%)$ & - \\
\hline $\begin{array}{l}\text { Mediastinum, inflammation, } \\
\text { granulomatous }\end{array}$ & - & - & - & - \\
\hline Nose & $(49)$ & $(50)$ & $(50)$ & $(50)$ \\
\hline Foreign body & $2(4 \%)$ & $2(4 \%)$ & $2(4 \%)$ & $5(10 \%)$ \\
\hline Hyperplasia & - & - & - & $1(2 \%)$ \\
\hline Inflammation, acute & $2(4 \%)$ & - & - & - \\
\hline Inflammation, chronic active & $9(18 \%)$ & $36(72 \%)$ & $45(90 \%)$ & $48(96 \%)$ \\
\hline Thrombosis & $4(8 \%)$ & $4(8 \%)$ & $11(22 \%)$ & $7(14 \%)$ \\
\hline $\begin{array}{l}\text { Olfactory epithelium, metaplasia, } \\
\text { respiratory }\end{array}$ & $3(6 \%)$ & $49(98 \%)$ & $49(98 \%)$ & $48(96 \%)$ \\
\hline $\begin{array}{l}\text { Olfactory epithelium, metaplasia, } \\
\text { squamous }\end{array}$ & - & - & $1(2 \%)$ & $5(10 \%)$ \\
\hline Respiratory epithelium, hyperplasia & $5(10 \%)$ & $8(16 \%)$ & $22(44 \%)$ & $31(62 \%)$ \\
\hline $\begin{array}{l}\text { Respiratory epithelium, metaplasia, } \\
\text { squamous }\end{array}$ & - & - & $1(2 \%)$ & $3(6 \%)$ \\
\hline Turbinate, atrophy & - & $50(100 \%)$ & $50(100 \%)$ & $50(100 \%)$ \\
\hline Turbinate, hyperostosis & - & $49(98 \%)$ & $50(100 \%)$ & $50(100 \%)$ \\
\hline Pleura & (0) & (1) & (0) & $(1)$ \\
\hline Hyperplasia & - & - & - & $1(100 \%)$ \\
\hline Infiltration cellular, mononuclear cell & - & - & - & $1(100 \%)$ \\
\hline Trachea & $(50)$ & $(49)$ & $(49)$ & $(48)$ \\
\hline \multicolumn{5}{|l|}{ Special Senses System } \\
\hline Eye & $(48)$ & $(48)$ & $(47)$ & $(49)$ \\
\hline Cataract & $3(6 \%)$ & $1(2 \%)$ & $1(2 \%)$ & $1(2 \%)$ \\
\hline Degeneration & - & $1(2 \%)$ & - & $1(2 \%)$ \\
\hline Cornea, inflammation, acute & $1(2 \%)$ & $1(2 \%)$ & - & - \\
\hline Cornea, inflammation, chronic active & $1(2 \%)$ & - & - & $1(2 \%)$ \\
\hline Retina, atrophy & $2(4 \%)$ & - & $1(2 \%)$ & $1(2 \%)$ \\
\hline
\end{tabular}


Vinylidene Chloride, NTP TR 582

\begin{tabular}{lcccc}
\hline & $\begin{array}{c}\text { Chamber } \\
\text { Control }\end{array}$ & $\mathbf{2 5} \mathbf{~ p p m}$ & $\mathbf{5 0 ~} \mathbf{~ p p m}$ & $\mathbf{1 0 0} \mathbf{~ p p m}$ \\
\hline Harderian gland & $(50)$ & $(49)$ & $(48)$ & $(49)$ \\
Degeneration & - & - & - & $1(2 \%)$ \\
Hyperplasia & - & $2(4 \%)$ & $1(2 \%)$ & - \\
Zymbal's gland & $(0)$ & $(1)$ & $(0)$ & $(0)$ \\
\hline Urinary System & & & & \\
Kidney & $(50)$ & $(50)$ & $(49)$ & $(50)$ \\
Cyst & - & $1(2 \%)$ & - & - \\
Hydronephrosis & - & $1(2 \%)$ & - & - \\
Infarct & - & - & $1(2 \%)$ & $2(4 \%)$ \\
Inflammation, suppurative & - & $2(4 \%)$ & $1(2 \%)$ & $2(4 \%)$ \\
Mineralization & $1(2 \%)$ & - & - & - \\
Nephropathy & $(100 \%)$ & $47(94 \%)$ & $47(96 \%)$ & $47(94 \%)$ \\
Thrombosis & - & $1(2 \%)$ & - & - \\
Renal tubule, hyperplasia & - & $1(2 \%)$ & $1(2 \%)$ & $1(2 \%)$ \\
Renal tubule, necrosis & - & - & $2(4 \%)$ & - \\
Transitional epithelium, hyperplasia & - & - & $1(2 \%)$ & $2(4 \%)$ \\
Urinary bladder & $(49)$ & $(50)$ & $(49)$ & $(50)$ \\
Inflammation, acute & - & - & - & $1(2 \%)$ \\
Inflammation, chronic active & - & - & $1(2 \%)$ & - \\
Transitional epithelium, hyperplasia & - & - & $2(4 \%)$ \\
\hline Num & - & - & - \\
\hline
\end{tabular}

${ }^{a}$ Number of animals examined microscopically at the site and the number of animals with lesion. 


\section{Appendix B. Summary of Lesions in Female Rats in the Two-year Inhalation Study of Vinylidene Chloride}

\section{Tables}

Table B-1. Summary of the Incidence of Neoplasms in Female Rats in the Two-year Inhalation Study of Vinylidene Chloride

Table B-2. Statistical Analysis of Primary Neoplasms in Female Rats in the Two-year Inhalation Study of Vinylidene Chloride

Table B-3. Historical Incidence of Thyroid Gland (C-Cell) Neoplasms in Control Female F344/N Rats

Table B-4. Historical Incidence of Mononuclear Cell Leukemia in Control Female F344/N Rats

Table B-5. Historical Incidence of Adenoma of the Nose in Control Female F344/N Rats .....B-12

Table B-6. Summary of the Incidence of Nonneoplastic Lesions in Female Rats in the Two-year Inhalation Study of Vinylidene Chloride. 
Table B-1. Summary of the Incidence of Neoplasms in Female Rats in the Two-year Inhalation Study of Vinylidene Chloride ${ }^{\mathrm{a}}$

\begin{tabular}{|c|c|c|c|c|}
\hline & $\begin{array}{c}\text { Chamber } \\
\text { Control }\end{array}$ & $25 \mathrm{ppm}$ & $50 \mathrm{ppm}$ & $100 \mathrm{ppm}$ \\
\hline \multicolumn{5}{|l|}{ Disposition Summary } \\
\hline Animals initially in study & 50 & 50 & 50 & 50 \\
\hline \multicolumn{5}{|l|}{ Early deaths } \\
\hline Moribund & 19 & 22 & 18 & 28 \\
\hline Natural deaths & 1 & 2 & 2 & 3 \\
\hline \multicolumn{5}{|l|}{ Survivors } \\
\hline Died last week of study & - & - & 1 & - \\
\hline Terminal kill & 30 & 26 & 29 & 19 \\
\hline Animals examined microscopically & 50 & 50 & 50 & 50 \\
\hline \multicolumn{5}{|l|}{ Alimentary System } \\
\hline Esophagus & $(50)$ & $(50)$ & $(50)$ & $(50)$ \\
\hline Intestine large, cecum & (49) & $(48)$ & $(48)$ & $(48)$ \\
\hline Intestine large, colon & (50) & (49) & $(48)$ & $(50)$ \\
\hline Intestine large, rectum & (49) & $(50)$ & (49) & (49) \\
\hline Adenoma & - & - & $1(2 \%)$ & - \\
\hline Leiomyosarcoma, metastatic, vagina & - & $1(2 \%)$ & - & - \\
\hline Intestine small, duodenum & $(50)$ & $(50)$ & (49) & $(50)$ \\
\hline Intestine small, ileum & (50) & $(48)$ & (49) & $(49)$ \\
\hline Intestine small, jejunum & (50) & $(48)$ & (49) & $(49)$ \\
\hline Liver & (50) & $(50)$ & $(50)$ & $(50)$ \\
\hline Hepatocellular adenoma & $1(2 \%)$ & - & $1(2 \%)$ & $1(2 \%)$ \\
\hline Hepatocellular adenoma, multiple & - & - & - & $1(2 \%)$ \\
\hline Sarcoma, metastatic, uncertain primary site & $1(2 \%)$ & - & - & - \\
\hline Mesentery & (13) & $(20)$ & $(23)$ & $(24)$ \\
\hline Oral mucosa & $(0)$ & (1) & $(0)$ & (1) \\
\hline Squamous cell papilloma & - & $1(100 \%)$ & - & - \\
\hline Pancreas & $(50)$ & $(50)$ & $(50)$ & $(50)$ \\
\hline Acinus, adenoma & - & $1(2 \%)$ & - & - \\
\hline Salivary glands & $(50)$ & $(50)$ & $(50)$ & $(50)$ \\
\hline Schwannoma malignant, metastatic, heart & - & $1(2 \%)$ & - & - \\
\hline Stomach, forestomach & (50) & $(50)$ & $(50)$ & $(50)$ \\
\hline Stomach, glandular & (50) & $(50)$ & $(50)$ & $(50)$ \\
\hline Tongue & (1) & $(0)$ & $(0)$ & $(0)$ \\
\hline Squamous cell papilloma & $1(100 \%)$ & - & - & - \\
\hline
\end{tabular}


Vinylidene Chloride, NTP TR 582

\begin{tabular}{|c|c|c|c|c|}
\hline & $\begin{array}{l}\text { Chamber } \\
\text { Control }\end{array}$ & 25 ppm & 50 ppm & 100 ppm \\
\hline \multicolumn{5}{|l|}{ Cardiovascular System } \\
\hline Blood vessel & (1) & (1) & $(0)$ & $(0)$ \\
\hline Leiomyosarcoma & $1(100 \%)$ & - & - & - \\
\hline $\begin{array}{l}\text { Aorta, schwannoma malignant, metastatic, } \\
\text { heart }\end{array}$ & - & $1(100 \%)$ & - & - \\
\hline Heart & $(50)$ & $(50)$ & $(50)$ & $(50)$ \\
\hline Schwannoma malignant & - & $1(2 \%)$ & - & - \\
\hline \multicolumn{5}{|l|}{ Endocrine System } \\
\hline Adrenal cortex & $(50)$ & (50) & $(50)$ & $(50)$ \\
\hline Adenoma & $1(2 \%)$ & $3(6 \%)$ & $1(2 \%)$ & $1(2 \%)$ \\
\hline Carcinoma & $1(2 \%)$ & $1(2 \%)$ & - & - \\
\hline Bilateral, adenoma & $1(2 \%)$ & - & - & - \\
\hline Adrenal medulla & $(50)$ & $(50)$ & $(50)$ & $(49)$ \\
\hline Pheochromocytoma benign & - & $5(10 \%)$ & $1(2 \%)$ & $1(2 \%)$ \\
\hline Pheochromocytoma malignant & $1(2 \%)$ & - & $2(4 \%)$ & - \\
\hline Bilateral, pheochromocytoma benign & - & - & $1(2 \%)$ & $1(2 \%)$ \\
\hline Islets, pancreatic & $(50)$ & $(50)$ & $(50)$ & $(50)$ \\
\hline Adenoma & - & - & $1(2 \%)$ & $1(2 \%)$ \\
\hline Carcinoma & - & $1(2 \%)$ & $1(2 \%)$ & - \\
\hline Parathyroid gland & $(49)$ & $(46)$ & $(45)$ & $(47)$ \\
\hline Adenoma & - & $1(2 \%)$ & - & - \\
\hline Pituitary gland & $(50)$ & $(49)$ & $(49)$ & $(49)$ \\
\hline Pars distalis, adenoma & $32(64 \%)$ & $36(73 \%)$ & $25(51 \%)$ & $28(57 \%)$ \\
\hline Pars distalis, carcinoma & $1(2 \%)$ & $2(4 \%)$ & - & $1(2 \%)$ \\
\hline Thyroid gland & $(50)$ & $(50)$ & $(48)$ & $(50)$ \\
\hline Schwannoma malignant, metastatic, heart & - & $1(2 \%)$ & - & - \\
\hline C-cell, adenoma & $3(6 \%)$ & $4(8 \%)$ & $6(13 \%)$ & $11(22 \%)$ \\
\hline C-cell, carcinoma & - & $6(12 \%)$ & $2(4 \%)$ & $2(4 \%)$ \\
\hline Follicular cell, adenoma & - & $2(4 \%)$ & - & $1(2 \%)$ \\
\hline \multicolumn{5}{|l|}{ General Body System } \\
\hline Peritoneum & $(0)$ & (1) & (1) & (1) \\
\hline \multicolumn{5}{|l|}{ Genital System } \\
\hline Clitoral gland & $(47)$ & $(48)$ & $(45)$ & $(48)$ \\
\hline Adenoma & $4(9 \%)$ & $8(17 \%)$ & $3(7 \%)$ & $4(8 \%)$ \\
\hline Carcinoma & $1(2 \%)$ & - & - & $5(10 \%)$ \\
\hline Ovary & $(50)$ & $(50)$ & $(50)$ & $(50)$ \\
\hline Granulosa cell tumor benign & - & $1(2 \%)$ & - & - \\
\hline
\end{tabular}


Vinylidene Chloride, NTP TR 582

\begin{tabular}{|c|c|c|c|c|}
\hline & $\begin{array}{c}\text { Chamber } \\
\text { Control }\end{array}$ & 25 ppm & 50 ppm & 100 ppm \\
\hline Granulosa cell tumor malignant & - & - & $1(2 \%)$ & - \\
\hline Granulosa-theca tumor benign & - & $1(2 \%)$ & - & - \\
\hline Granulosa-theca tumor malignant & $1(2 \%)$ & - & - & - \\
\hline Sertoli cell tumor malignant & $1(2 \%)$ & - & - & - \\
\hline Yolk sac carcinoma & - & - & $1(2 \%)$ & - \\
\hline Uterus & $(50)$ & $(50)$ & $(50)$ & $(50)$ \\
\hline Polyp stromal & $10(20 \%)$ & $9(18 \%)$ & $4(8 \%)$ & $8(16 \%)$ \\
\hline Sarcoma stromal & - & - & $2(4 \%)$ & - \\
\hline Bilateral, polyp stromal & $1(2 \%)$ & - & - & - \\
\hline Endometrium, carcinoma & - & - & $1(2 \%)$ & $1(2 \%)$ \\
\hline Vagina & (0) & (2) & $(0)$ & $(1)$ \\
\hline Granulosa cell tumor benign & - & $1(50 \%)$ & - & - \\
\hline Leiomyosarcoma & - & $1(50 \%)$ & - & - \\
\hline Polyp & - & - & - & $1(100 \%)$ \\
\hline \multicolumn{5}{|l|}{ Hematopoietic System } \\
\hline Bone marrow & $(50)$ & $(50)$ & $(50)$ & $(50)$ \\
\hline Lymph node & (2) & (2) & (4) & (9) \\
\hline Lymph node, bronchial & (4) & (7) & (4) & (10) \\
\hline Lymph node, mandibular & (2) & $(0)$ & (1) & (4) \\
\hline Lymph node, mediastinal & (33) & (26) & (29) & (38) \\
\hline Carcinoma, metastatic, thyroid gland & - & $1(4 \%)$ & - & - \\
\hline Lymph node, mesenteric & $(50)$ & $(50)$ & $(50)$ & (50) \\
\hline Spleen & $(50)$ & $(50)$ & $(50)$ & $(50)$ \\
\hline Schwannoma malignant, metastatic, heart & - & $1(2 \%)$ & - & - \\
\hline Thymus & $(46)$ & $(45)$ & $(42)$ & $(42)$ \\
\hline Sarcoma, metastatic, uncertain primary site & $1(2 \%)$ & - & - & - \\
\hline Thymoma benign & - & $1(2 \%)$ & - & - \\
\hline Thymoma malignant & - & - & $1(2 \%)$ & - \\
\hline \multicolumn{5}{|l|}{ Integumentary System } \\
\hline Mammary gland & $(50)$ & $(50)$ & $(50)$ & $(50)$ \\
\hline Carcinoma & $4(8 \%)$ & - & $2(4 \%)$ & $4(8 \%)$ \\
\hline Carcinoma, multiple & $1(2 \%)$ & $1(2 \%)$ & - & - \\
\hline Fibroadenoma & $26(52 \%)$ & $18(36 \%)$ & $21(42 \%)$ & $25(50 \%)$ \\
\hline Fibroadenoma, multiple & $11(22 \%)$ & $16(32 \%)$ & $10(20 \%)$ & $14(28 \%)$ \\
\hline Schwannoma malignant, metastatic, heart & - & $1(2 \%)$ & - & - \\
\hline Skin & $(50)$ & $(50)$ & $(50)$ & (50) \\
\hline Basal cell, adenoma & $1(2 \%)$ & $1(2 \%)$ & - & - \\
\hline
\end{tabular}


Vinylidene Chloride, NTP TR 582

\begin{tabular}{|c|c|c|c|c|}
\hline & $\begin{array}{l}\text { Chamber } \\
\text { Control }\end{array}$ & 25 ppm & $50 \mathrm{ppm}$ & 100 ppm \\
\hline Keratoacanthoma & $1(2 \%)$ & - & $1(2 \%)$ & - \\
\hline Subcutaneous tissue, fibroma & $1(2 \%)$ & $2(4 \%)$ & $2(4 \%)$ & - \\
\hline Subcutaneous tissue, neural crest tumor & - & $1(2 \%)$ & - & - \\
\hline Subcutaneous tissue, sarcoma & - & - & $1(2 \%)$ & - \\
\hline Subcutaneous tissue, schwannoma malignant & - & $1(2 \%)$ & - & - \\
\hline \multicolumn{5}{|l|}{ Musculoskeletal System } \\
\hline Bone & $(50)$ & $(50)$ & $(50)$ & $(50)$ \\
\hline Chondroma & - & - & $1(2 \%)$ & - \\
\hline Osteoma & - & $1(2 \%)$ & - & - \\
\hline Osteosarcoma & $1(2 \%)$ & - & - & - \\
\hline Sarcoma, metastatic, uncertain primary site & $1(2 \%)$ & - & - & - \\
\hline Skeletal muscle & (1) & (2) & (3) & $(0)$ \\
\hline Sarcoma & - & - & $1(33 \%)$ & - \\
\hline Sarcoma, metastatic, uncertain primary site & $1(100 \%)$ & - & - & - \\
\hline Schwannoma malignant, metastatic, heart & - & $1(50 \%)$ & - & - \\
\hline \multicolumn{5}{|l|}{ Nervous System } \\
\hline Brain & $(50)$ & $(50)$ & $(50)$ & $(50)$ \\
\hline Carcinoma, metastatic, pituitary gland & $1(2 \%)$ & $2(4 \%)$ & - & $1(2 \%)$ \\
\hline Oligodendroglioma benign & - & $1(2 \%)$ & - & - \\
\hline Oligodendroglioma malignant & - & - & - & $1(2 \%)$ \\
\hline \multicolumn{5}{|l|}{ Respiratory System } \\
\hline Larynx & $(50)$ & $(50)$ & $(50)$ & (50) \\
\hline Schwannoma malignant, metastatic, heart & - & $1(2 \%)$ & - & - \\
\hline Lung & $(50)$ & $(50)$ & $(50)$ & $(50)$ \\
\hline Alveolar/bronchiolar adenoma & $1(2 \%)$ & - & $4(8 \%)$ & - \\
\hline Alveolar/bronchiolar carcinoma, multiple & - & - & - & $1(2 \%)$ \\
\hline $\begin{array}{l}\text { Mesenchymal tumor malignant, metastatic, } \\
\text { kidney }\end{array}$ & - & $1(2 \%)$ & - & - \\
\hline $\begin{array}{l}\text { Pheochromocytoma malignant, metastatic, } \\
\text { adrenal medulla }\end{array}$ & $1(2 \%)$ & - & $1(2 \%)$ & - \\
\hline Sarcoma, metastatic, skeletal muscle & - & - & $1(2 \%)$ & - \\
\hline Sarcoma, metastatic, uncertain primary site & $1(2 \%)$ & - & - & - \\
\hline Schwannoma malignant, metastatic, heart & - & $1(2 \%)$ & - & - \\
\hline Nose & $(50)$ & $(50)$ & $(50)$ & $(50)$ \\
\hline Chondroma & - & - & - & $1(2 \%)$ \\
\hline Respiratory epithelium, adenoma & - & - & - & $12 \%)$ \\
\hline Pleura & $(0)$ & (1) & $(0)$ & $(1)$ \\
\hline
\end{tabular}


Vinylidene Chloride, NTP TR 582

\begin{tabular}{|c|c|c|c|c|}
\hline & $\begin{array}{l}\text { Chamber } \\
\text { Control }\end{array}$ & 25 ppm & 50 ppm & 100 ppm \\
\hline Trachea & $(50)$ & (50) & $(50)$ & $(50)$ \\
\hline Schwannoma malignant, metastatic, heart & - & $1(2 \%)$ & - & - \\
\hline \multicolumn{5}{|l|}{ Special Senses System } \\
\hline Eye & $(50)$ & $(49)$ & $(50)$ & $(49)$ \\
\hline Harderian gland & $(50)$ & (50) & $(50)$ & $(50)$ \\
\hline Schwannoma malignant, metastatic, heart & - & $1(2 \%)$ & - & - \\
\hline Lacrimal gland & (0) & $(0)$ & (1) & (1) \\
\hline Zymbal's gland & (0) & $(0)$ & (1) & $(0)$ \\
\hline Carcinoma & - & - & $1(100 \%)$ & - \\
\hline \multicolumn{5}{|l|}{ Urinary System } \\
\hline Kidney & $(50)$ & (50) & $(50)$ & $(50)$ \\
\hline Mesenchymal tumor malignant & - & $1(2 \%)$ & - & - \\
\hline Schwannoma malignant, metastatic, heart & - & $1(2 \%)$ & - & - \\
\hline Renal tubule, adenoma & - & - & $1(2 \%)$ & - \\
\hline Urinary bladder & $(50)$ & (50) & $(50)$ & (50) \\
\hline Leiomyosarcoma, metastatic, vagina & - & $1(2 \%)$ & - & - \\
\hline \multicolumn{5}{|l|}{ Systemic Lesions } \\
\hline Multiple organs ${ }^{b}$ & $(50)$ & $(50)$ & $(50)$ & $(50)$ \\
\hline Histiocytic sarcoma & - & - & - & $1(2 \%)$ \\
\hline Leukemia mononuclear & $10(20 \%)$ & $11(22 \%)$ & $13(26 \%)$ & $25(50 \%)$ \\
\hline Lymphoma malignant & $1(2 \%)$ & - & - & $1(2 \%)$ \\
\hline Mesothelioma malignant & - & $1(2 \%)$ & $1(2 \%)$ & - \\
\hline \multicolumn{5}{|l|}{ Neoplasm Summary } \\
\hline Total animals with primary neoplasms ${ }^{c}$ & 49 & 49 & 47 & 49 \\
\hline Total primary neoplasms & 119 & 141 & 114 & 142 \\
\hline Total animals with benign neoplasms & 47 & 47 & 44 & 45 \\
\hline Total benign neoplasms & 94 & 113 & 84 & 100 \\
\hline Total animals with malignant neoplasms & 23 & 25 & 26 & 38 \\
\hline Total malignant neoplasms & 25 & 27 & 30 & 42 \\
\hline Total animals with metastatic neoplasms & 3 & 6 & 2 & 1 \\
\hline Total metastatic neoplasms & 7 & 17 & 2 & 1 \\
\hline $\begin{array}{l}\text { Total animals with malignant neoplasms } \\
\text { of uncertain primary site }\end{array}$ & 1 & - & - & - \\
\hline $\begin{array}{l}\text { Total animals with uncertain neoplasms- } \\
\text { benign or malignant }\end{array}$ & - & 1 & - & - \\
\hline Total uncertain neoplasms & - & 1 & - & - \\
\hline
\end{tabular}

${ }^{a}$ Number of animals examined microscopically at the site and the number of animals with neoplasm.

${ }^{b}$ Number of animals with any tissue examined microscopically.

cPrimary neoplasms: all neoplasms except metastatic neoplasms. 
Vinylidene Chloride, NTP TR 582

Table B-2. Statistical Analysis of Primary Neoplasms in Female Rats in the Two-year Inhalation Study of Vinylidene Chloride

\begin{tabular}{|c|c|c|c|c|}
\hline & $\begin{array}{l}\text { Chamber } \\
\text { Control }\end{array}$ & 25 ppm & $50 \mathrm{ppm}$ & 100 ppm \\
\hline \multicolumn{5}{|c|}{ Adrenal Cortex: Adenoma } \\
\hline Overall rate $^{\mathrm{a}}$ & $2 / 50(4 \%)$ & $3 / 50(6 \%)$ & $1 / 50(2 \%)$ & $1 / 50(2 \%)$ \\
\hline Adjusted rate ${ }^{b}$ & $4.4 \%$ & $7.2 \%$ & $2.4 \%$ & $2.4 \%$ \\
\hline Terminal rate $^{c}$ & $2 / 30(7 \%)$ & $3 / 26(12 \%)$ & $1 / 29(3 \%)$ & $0 / 19(0 \%)$ \\
\hline First incidence (days) & $731(\mathrm{~T})$ & $731(\mathrm{~T})$ & $731(\mathrm{~T})$ & 670 \\
\hline Poly-3 test ${ }^{\mathrm{d}}$ & $\mathrm{P}=0.307 \mathrm{~N}$ & $P=0.462$ & $\mathrm{P}=0.531 \mathrm{~N}$ & $\mathrm{P}=0.530 \mathrm{~N}$ \\
\hline \multicolumn{5}{|c|}{ Adrenal Medulla: Benign Pheochromocytoma } \\
\hline Overall rate & $0 / 50(0 \%)$ & $5 / 50(10 \%)$ & $2 / 50(4 \%)$ & $2 / 49(4 \%)$ \\
\hline Adjusted rate & $0.0 \%$ & $12.0 \%$ & $4.8 \%$ & $4.9 \%$ \\
\hline Terminal rate & $0 / 30(0 \%)$ & $5 / 26(19 \%)$ & $2 / 29(7 \%)$ & $2 / 19(11 \%)$ \\
\hline First incidence (days) & $-{ }^{\mathrm{e}}$ & $731(\mathrm{~T})$ & $731(\mathrm{~T})$ & $731(\mathrm{~T}$ \\
\hline Poly-3 test & $\mathrm{P}=0.411$ & $\mathrm{P}=0.024$ & $\mathrm{P}=0.218$ & $\mathrm{P}=0.216$ \\
\hline \multicolumn{5}{|c|}{ Adrenal Medulla: Benign or Malignant Pheochromocytoma } \\
\hline Overall rate & $1 / 50(2 \%)$ & $5 / 50(10 \%)$ & $3 / 50(6 \%)$ & $2 / 49(4 \%)$ \\
\hline Adjusted rate & $2.2 \%$ & $12.0 \%$ & $7.2 \%$ & $4.9 \%$ \\
\hline Terminal rate & $1 / 30(3 \%)$ & $5 / 26(19 \%)$ & $2 / 29(7 \%)$ & $2 / 19(11 \%)$ \\
\hline First incidence (days) & $731(\mathrm{~T})$ & $731(\mathrm{~T})$ & 715 & $731(\mathrm{~T})$ \\
\hline Poly-3 test & $P=0.541$ & $P=0.083$ & $P=0.275$ & $P=0.467$ \\
\hline \multicolumn{5}{|c|}{ Clitoral Gland: Adenoma } \\
\hline Overall rate & $4 / 47(9 \%)$ & $8 / 48(17 \%)$ & $3 / 45(7 \%)$ & $4 / 48(8 \%)$ \\
\hline Adjusted rate & $9.4 \%$ & $19.8 \%$ & $7.9 \%$ & $10.0 \%$ \\
\hline Terminal rate & $3 / 28(11 \%)$ & $6 / 24(25 \%)$ & $3 / 26(12 \%)$ & $0 / 18(0 \%)$ \\
\hline First incidence (days) & 724 & 535 & $731(\mathrm{~T})$ & 670 \\
\hline Poly-3 test & $\mathrm{P}=0.401 \mathrm{~N}$ & $\mathrm{P}=0.151$ & $\mathrm{P}=0.564 \mathrm{~N}$ & $\mathrm{P}=0.613$ \\
\hline \multicolumn{5}{|c|}{ Clitoral Gland: Carcinoma } \\
\hline Overall rate & $1 / 47(2 \%)$ & $0 / 48(0 \%)$ & $0 / 45(0 \%)$ & $5 / 48(10 \%)$ \\
\hline Adjusted rate & $2.4 \%$ & $0.0 \%$ & $0.0 \%$ & $12.4 \%$ \\
\hline Terminal rate & $1 / 28(4 \%)$ & $0 / 24(0 \%)$ & $0 / 26(0 \%)$ & $3 / 18(17 \%)$ \\
\hline First incidence (days) & $731(\mathrm{~T})$ & - & - & 579 \\
\hline Poly-3 test & $P=0.008$ & $\mathrm{P}=0.513 \mathrm{~N}$ & $\mathrm{P}=0.523 \mathrm{~N}$ & $\mathrm{P}=0.088$ \\
\hline \multicolumn{5}{|c|}{ Clitoral Gland: Adenoma or Carcinoma } \\
\hline Overall rate & $5 / 47(11 \%)$ & $8 / 48(17 \%)$ & $3 / 45(7 \%)$ & $8 / 48(17 \%)$ \\
\hline Adjusted rate & $11.8 \%$ & $19.8 \%$ & $7.9 \%$ & $19.7 \%$ \\
\hline Terminal rate & $4 / 28(14 \%)$ & $6 / 24(25 \%)$ & $3 / 26(12 \%)$ & $3 / 18(17 \%)$ \\
\hline First incidence (days) & 724 & 535 & $731(\mathrm{~T})$ & 579 \\
\hline
\end{tabular}


Vinylidene Chloride, NTP TR 582

\begin{tabular}{|c|c|c|c|c|}
\hline & $\begin{array}{l}\text { Chamber } \\
\text { Control }\end{array}$ & 25 ppm & 50 ppm & 100 ppm \\
\hline Poly-3 test & $P=0.294$ & $P=0.243$ & $\mathrm{P}=0.422 \mathrm{~N}$ & $\mathrm{P}=0.245$ \\
\hline \multicolumn{5}{|c|}{ Lung: Alveolar/bronchiolar Adenoma } \\
\hline Overall rate & $1 / 50(2 \%)$ & $0 / 50(0 \%)$ & $4 / 50(8 \%)$ & $0 / 50(0 \%)$ \\
\hline Adjusted rate & $2.2 \%$ & $0.0 \%$ & $9.4 \%$ & $0.0 \%$ \\
\hline Terminal rate & $1 / 30(3 \%)$ & $0 / 26(0 \%)$ & $2 / 29(7 \%)$ & $0 / 19(0 \%)$ \\
\hline First incidence (days) & $731(\mathrm{~T})$ & - & 526 & - \\
\hline Poly-3 test & $\mathrm{P}=0.564 \mathrm{~N}$ & $\mathrm{P}=0.516 \mathrm{~N}$ & $P=0.159$ & $\mathrm{P}=0.518 \mathrm{~N}$ \\
\hline \multicolumn{5}{|c|}{ Lung: Alveolar/bronchiolar Adenoma or Carcinoma } \\
\hline Overall rate & $1 / 50(2 \%)$ & $0 / 50(0 \%)$ & $4 / 50(8 \%)$ & $1 / 50(2 \%)$ \\
\hline Adjusted rate & $2.2 \%$ & $0.0 \%$ & $9.4 \%$ & $2.4 \%$ \\
\hline Terminal rate & $1 / 30(3 \%)$ & $0 / 26(0 \%)$ & $2 / 29(7 \%)$ & $1 / 19(5 \%)$ \\
\hline First incidence (days) & $731(\mathrm{~T})$ & - & 526 & $731(\mathrm{~T})$ \\
\hline Poly-3 test & $\mathrm{P}=0.405$ & $\mathrm{P}=0.516 \mathrm{~N}$ & $\mathrm{P}=0.159$ & $\mathrm{P}=0.740$ \\
\hline \multicolumn{5}{|c|}{ Mammary Gland: Fibroadenoma } \\
\hline Overall rate & $37 / 50(74 \%)$ & $34 / 50(68 \%)$ & $31 / 50(62 \%)$ & $39 / 50(78 \%)$ \\
\hline Adjusted rate & $76.6 \%$ & $73.8 \%$ & $68.7 \%$ & $85.2 \%$ \\
\hline Terminal rate & $22 / 30(73 \%)$ & $19 / 26(73 \%)$ & $20 / 29(69 \%)$ & $17 / 19(90 \%)$ \\
\hline First incidence (days) & 547 & 541 & 423 & 607 \\
\hline Poly-3 test & $P=0.167$ & $\mathrm{P}=0.469 \mathrm{~N}$ & $\mathrm{P}=0.260 \mathrm{~N}$ & $\mathrm{P}=0.198$ \\
\hline \multicolumn{5}{|c|}{ Mammary Gland: Carcinoma } \\
\hline Overall rate & $5 / 50(10 \%)$ & $1 / 50(2 \%)$ & $2 / 50(4 \%)$ & $4 / 50(8 \%)$ \\
\hline Adjusted rate & $10.9 \%$ & $2.4 \%$ & $4.8 \%$ & $9.7 \%$ \\
\hline Terminal rate & $2 / 30(7 \%)$ & $1 / 26(4 \%)$ & $1 / 29(3 \%)$ & $3 / 19(16 \%)$ \\
\hline First incidence (days) & 592 & $731(\mathrm{~T})$ & 726 & 712 \\
\hline Poly-3 test & $\mathrm{P}=0.558$ & $\mathrm{P}=0.124 \mathrm{~N}$ & $\mathrm{P}=0.258 \mathrm{~N}$ & $\mathrm{P}=0.564 \mathrm{~N}$ \\
\hline \multicolumn{5}{|c|}{ Mammary Gland: Fibroadenoma or Carcinoma } \\
\hline Overall rate & $38 / 50(76 \%)$ & $34 / 50(68 \%)$ & $31 / 50(62 \%)$ & $40 / 50(80 \%)$ \\
\hline Adjusted rate & $77.9 \%$ & $73.8 \%$ & $68.7 \%$ & $87.3 \%$ \\
\hline Terminal rate & $22 / 30(73 \%)$ & $19 / 26(73 \%)$ & $20 / 29(69 \%)$ & $17 / 19(90 \%)$ \\
\hline First incidence (days) & 547 & 541 & 423 & 607 \\
\hline Poly-3 test & $\mathrm{P}=0.135$ & $\mathrm{P}=0.408 \mathrm{~N}$ & $\mathrm{P}=0.212 \mathrm{~N}$ & $\mathrm{P}=0.163$ \\
\hline \multicolumn{5}{|c|}{ Pituitary Gland (Pars Distalis): Adenoma } \\
\hline Overall rate & $32 / 50(64 \%)$ & $36 / 49(73 \%)$ & $25 / 49(51 \%)$ & $28 / 49(57 \%)$ \\
\hline Adjusted rate & $66.1 \%$ & $79.4 \%$ & $57.3 \%$ & $63.3 \%$ \\
\hline Terminal rate & $18 / 30(60 \%)$ & $20 / 25(80 \%)$ & $16 / 29(55 \%)$ & $11 / 19(58 \%)$ \\
\hline First incidence (days) & 551 & 535 & 514 & 642 \\
\hline Poly-3 test & $\mathrm{P}=0.215 \mathrm{~N}$ & $\mathrm{P}=0.105$ & $\mathrm{P}=0.252 \mathrm{~N}$ & $\mathrm{P}=0.473 \mathrm{~N}$ \\
\hline
\end{tabular}


Vinylidene Chloride, NTP TR 582

\begin{tabular}{|c|c|c|c|c|}
\hline & $\begin{array}{l}\text { Chamber } \\
\text { Control }\end{array}$ & 25 ppm & 50 ppm & 100 ppm \\
\hline \multicolumn{5}{|c|}{ Pituitary Gland (Pars Distalis): Adenoma or Carcinoma } \\
\hline Overall rate & $33 / 50(66 \%)$ & $38 / 49(78 \%)$ & $25 / 49(51 \%)$ & $29 / 49(59 \%)$ \\
\hline Adjusted rate & $68.1 \%$ & $83.0 \%$ & $57.3 \%$ & $65.5 \%$ \\
\hline Terminal rate & $18 / 30(60 \%)$ & $20 / 25(80 \%)$ & $16 / 29(55 \%)$ & $12 / 19(63 \%)$ \\
\hline First incidence (days) & 551 & 535 & 514 & 642 \\
\hline Poly-3 test & $\mathrm{P}=0.191 \mathrm{~N}$ & $P=0.067$ & $\mathrm{P}=0.189 \mathrm{~N}$ & $\mathrm{P}=0.482 \mathrm{~N}$ \\
\hline \multicolumn{5}{|c|}{ Skin (Subcutaneous Tissue): Fibroma or Sarcoma } \\
\hline Overall rate & $1 / 50(2 \%)$ & $2 / 50(4 \%)$ & $3 / 50(6 \%)$ & $0 / 50(0 \%)$ \\
\hline Adjusted rate & $2.2 \%$ & $4.7 \%$ & $7.2 \%$ & $0.0 \%$ \\
\hline Terminal rate & $1 / 30(3 \%)$ & $1 / 26(4 \%)$ & $3 / 29(10 \%)$ & $0 / 19(0 \%)$ \\
\hline First incidence (days) & $731(\mathrm{~T})$ & 613 & $731(\mathrm{~T})$ & - \\
\hline Poly-3 test & $\mathrm{P}=0.378 \mathrm{~N}$ & $P=0.475$ & $\mathrm{P}=0.274$ & $\mathrm{P}=0.518 \mathrm{~N}$ \\
\hline \multicolumn{5}{|c|}{ Thyroid Gland (C-Cell): Adenoma } \\
\hline Overall rate & $3 / 50(6 \%)$ & $4 / 50(8 \%)$ & $6 / 48(13 \%)$ & $11 / 50(22 \%)$ \\
\hline Adjusted rate & $6.6 \%$ & $9.5 \%$ & $14.6 \%$ & $26.2 \%$ \\
\hline Terminal rate & $3 / 30(10 \%)$ & $2 / 26(8 \%)$ & $4 / 28(14 \%)$ & $6 / 19(32 \%)$ \\
\hline First incidence (days) & $731(\mathrm{~T})$ & 625 & 579 & 669 \\
\hline Poly-3 test & $\mathrm{P}=0.004$ & $\mathrm{P}=0.461$ & $\mathrm{P}=0.195$ & $\mathrm{P}=0.012$ \\
\hline \multicolumn{5}{|c|}{ Thyroid Gland (C-Cell): Carcinoma } \\
\hline Overall rate & $0 / 50(0 \%)$ & $6 / 50(12 \%)$ & $2 / 48(4 \%)$ & $2 / 50(4 \%)$ \\
\hline Adjusted rate & $0.0 \%$ & $14.4 \%$ & $4.9 \%$ & $4.8 \%$ \\
\hline Terminal rate & $0 / 30(0 \%)$ & $6 / 26(23 \%)$ & $1 / 28(4 \%)$ & $1 / 19(5 \%)$ \\
\hline First incidence (days) & - & $731(\mathrm{~T})$ & 670 & 670 \\
\hline Poly-3 test & $\mathrm{P}=0.474$ & $\mathrm{P}=0.011$ & $P=0.213$ & $\mathrm{P}=0.218$ \\
\hline \multicolumn{5}{|c|}{ Thyroid Gland (C-Cell): Adenoma or Carcinoma } \\
\hline Overall rate & $3 / 50(6 \%)$ & $10 / 50(20 \%)$ & $8 / 48(17 \%)$ & $13 / 50(26 \%)$ \\
\hline Adjusted rate & $6.6 \%$ & $23.7 \%$ & $19.3 \%$ & $30.8 \%$ \\
\hline Terminal rate & $3 / 30(10 \%)$ & $8 / 26(31 \%)$ & $5 / 28(18 \%)$ & $7 / 19(37 \%)$ \\
\hline First incidence (days) & $731(\mathrm{~T})$ & 625 & 579 & 669 \\
\hline Poly-3 test & $\mathrm{P}=0.006$ & $\mathrm{P}=0.023$ & $\mathrm{P}=0.071$ & $\mathrm{P}=0.003$ \\
\hline \multicolumn{5}{|l|}{ Uterus: Stromal Polyp } \\
\hline Overall rate & $11 / 50(22 \%)$ & $9 / 50(18 \%)$ & $4 / 50(8 \%)$ & $8 / 50(16 \%)$ \\
\hline Adjusted rate & $23.7 \%$ & $20.9 \%$ & $9.4 \%$ & $18.9 \%$ \\
\hline Terminal rate & $8 / 30(27 \%)$ & $5 / 26(19 \%)$ & $2 / 29(7 \%)$ & $5 / 19(26 \%)$ \\
\hline First incidence (days) & 579 & 610 & 514 & 567 \\
\hline Poly-3 test & $\mathrm{P}=0.258 \mathrm{~N}$ & $\mathrm{P}=0.475 \mathrm{~N}$ & $\mathrm{P}=0.062 \mathrm{~N}$ & $\mathrm{P}=0.385 \mathrm{~N}$ \\
\hline
\end{tabular}


Vinylidene Chloride, NTP TR 582

\begin{tabular}{|c|c|c|c|c|}
\hline & $\begin{array}{c}\text { Chamber } \\
\text { Control }\end{array}$ & 25 ppm & $50 \mathrm{ppm}$ & 100 ppm \\
\hline \multicolumn{5}{|c|}{ Uterus: Stromal Polyp or Stromal Sarcoma } \\
\hline Overall rate & $11 / 50(22 \%)$ & $9 / 50(18 \%)$ & $6 / 50(12 \%)$ & $8 / 50(16 \%)$ \\
\hline Adjusted rate & $23.7 \%$ & $20.9 \%$ & $13.9 \%$ & $18.9 \%$ \\
\hline Terminal rate & $8 / 30(27 \%)$ & $5 / 26(19 \%)$ & $3 / 29(10 \%)$ & $5 / 19(26 \%)$ \\
\hline First incidence (days) & 579 & 610 & 514 & 567 \\
\hline Poly-3 test & $\mathrm{P}=0.290 \mathrm{~N}$ & $\mathrm{P}=0.475 \mathrm{~N}$ & $\mathrm{P}=0.179 \mathrm{~N}$ & $\mathrm{P}=0.385 \mathrm{~N}$ \\
\hline \multicolumn{5}{|c|}{ All Organs: Mononuclear Cell Leukemia } \\
\hline Overall rate & $10 / 50(20 \%)$ & $11 / 50(22 \%)$ & $13 / 50(26 \%)$ & $25 / 50(50 \%)$ \\
\hline Adjusted rate & $21.4 \%$ & $24.6 \%$ & $28.3 \%$ & $54.6 \%$ \\
\hline Terminal rate & $3 / 30(10 \%)$ & $4 / 26(15 \%)$ & $3 / 29(10 \%)$ & $8 / 19(42 \%)$ \\
\hline First incidence (days) & 631 & 451 & 421 & 395 \\
\hline Poly-3 test & $\mathrm{P}<0.001$ & $P=0.457$ & $P=0.300$ & $\mathrm{P}<0.001$ \\
\hline \multicolumn{5}{|c|}{ All Organs: Benign Neoplasms } \\
\hline Overall rate & $47 / 50(94 \%)$ & $47 / 50(94 \%)$ & $44 / 50(88 \%)$ & $45 / 50(90 \%)$ \\
\hline Adjusted rate & $94.9 \%$ & $98.0 \%$ & $90.7 \%$ & $96.0 \%$ \\
\hline Terminal rate & $29 / 30(97 \%)$ & $26 / 26(100 \%)$ & $26 / 29(90 \%)$ & $19 / 19(100 \%)$ \\
\hline First incidence (days) & 547 & 535 & 423 & 567 \\
\hline Poly-3 test & $\mathrm{P}=0.541 \mathrm{~N}$ & $P=0.380$ & $\mathrm{P}=0.325 \mathrm{~N}$ & $P=0.612$ \\
\hline \multicolumn{5}{|c|}{ All Organs: Malignant Neoplasms } \\
\hline Overall rate & $24 / 50(48 \%)$ & $25 / 50(50 \%)$ & $26 / 50(52 \%)$ & $38 / 50(76 \%)$ \\
\hline Adjusted rate & $49.3 \%$ & $53.7 \%$ & $55.1 \%$ & $80.3 \%$ \\
\hline Terminal rate & $8 / 30(27 \%)$ & $13 / 26(50 \%)$ & $12 / 29(41 \%)$ & $15 / 19(79 \%)$ \\
\hline First incidence (days) & 547 & 451 & 421 & 395 \\
\hline Poly-3 test & $\mathrm{P}<0.001$ & $P=0.413$ & $P=0.361$ & $\mathrm{P}<0.001$ \\
\hline \multicolumn{5}{|c|}{ All Organs: Benign or Malignant Neoplasms } \\
\hline Overall rate & $49 / 50(98 \%)$ & $49 / 50(98 \%)$ & $47 / 50(94 \%)$ & $49 / 50(98 \%)$ \\
\hline Adjusted rate & $98.0 \%$ & $99.0 \%$ & $94.4 \%$ & $100.0 \%$ \\
\hline Terminal rate & $29 / 30(97 \%)$ & $26 / 26(100 \%)$ & $27 / 29(93 \%)$ & $19 / 19(100 \%)$ \\
\hline First incidence (days) & 547 & 451 & 421 & 395 \\
\hline Poly-3 test & $\mathrm{P}=0.452$ & $P=0.669$ & $\mathrm{P}=0.338 \mathrm{~N}$ & $P=0.506$ \\
\hline \multicolumn{5}{|c|}{ 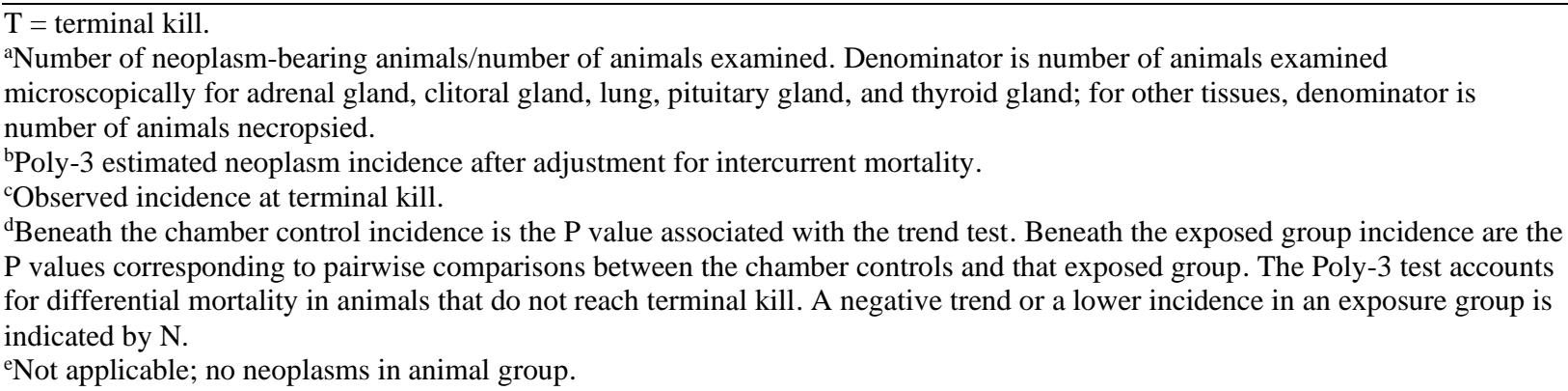 } \\
\hline
\end{tabular}


Table B-3. Historical Incidence of Thyroid Gland (C-Cell) Neoplasms in Control Female F344/N Rats $^{\text {a }}$

\begin{tabular}{lccc}
\hline \multicolumn{1}{c}{ Study (Study Start) } & Adenoma & Carcinoma & $\begin{array}{c}\text { Adenoma or } \\
\text { Carcinoma }\end{array}$ \\
\hline Historical Incidence: Inhalation Studies & & & $4 / 50$ \\
1-Bromopropane (July 2003) & $3 / 50$ & $0 / 50$ & $4 / 50$ \\
Diethylamine (August 2003) & $4 / 50$ & $0 / 50$ & $3 / 50$ \\
Tetralin (June 2003) & $3 / 50$ & $0 / 50$ & $3 / 50$ \\
Vinylidene chloride (June 2005) & $3 / 50$ & $1 / 200(0.5 \%)$ & $14 / 200(7.0 \%)$ \\
Total (\%) & $13 / 200(6.5 \%)$ & $0.5 \% \pm 1.0 \%$ & $7.0 \% \pm 1.2 \%$ \\
Mean \pm standard deviation & $6.5 \% \pm 1.0 \%$ & $0 \%-2 \%$ & $6 \%-8 \%$ \\
Range & $6 \%-8 \%$ & & $87 / 690(12.6 \%)$ \\
\hline Overall Historical Incidence: All Routes & $81 / 690(11.7 \%)$ & $6 / 690(0.9 \%)$ & $12.7 \% \pm 5.8 \%$ \\
Total (\%) & $11.7 \% \pm 5.5 \%$ & $0.9 \% \pm 2.0 \%$ & $6 \%-22 \%$ \\
Mean \pm standard deviation & $6 \%-22 \%$ & $0 \%-7 \%$ &
\end{tabular}

Table B-4. Historical Incidence of Mononuclear Cell Leukemia in Control Female F344/N Rats ${ }^{a}$

\begin{tabular}{lc}
\multicolumn{1}{c}{ Study (Study Start) } & Incidence in Controls \\
\hline Historical Incidence: Inhalation Studies & $16 / 50$ \\
1-Bromopropane (July 2003) & $15 / 50$ \\
Diethylamine (August 2003) & $17 / 50$ \\
Tetralin (June 2003) & $10 / 50$ \\
Vinylidene chloride (June 2005) & $58 / 200(29.0 \%)$ \\
Total (\%) & $29.0 \% \pm 6.2 \%$ \\
Mean \pm standard deviation & $20 \%-34 \%$ \\
Range & \\
\hline Overall Historical Incidence: All Routes & $165 / 700(23.6 \%)$ \\
Total (\%) & $23.6 \% \pm 8.2 \%$ \\
Mean \pm standard deviation & $10 \%-36 \%$ \\
Range &
\end{tabular}


Table B-5. Historical Incidence of Adenoma of the Nose in Control Female F344/N Rats ${ }^{\mathrm{a}}$

\begin{tabular}{|c|c|c|c|c|}
\hline Study (Study Start) & \multicolumn{4}{|c|}{ Incidence in Controls } \\
\hline \multicolumn{5}{|l|}{ Historical Incidence: Inhalation Studies } \\
\hline 1-Bromopropane (July 2003) & \multicolumn{4}{|c|}{$0 / 50$} \\
\hline Diethylamine (August 2003) & \multicolumn{4}{|c|}{$0 / 50$} \\
\hline Tetralin (June 2003) & \multicolumn{4}{|c|}{$0 / 50$} \\
\hline Vinylidene chloride (June 2005) & \multicolumn{4}{|c|}{$0 / 50$} \\
\hline Total $(\%)$ & \multicolumn{4}{|c|}{$0 / 200$} \\
\hline \multicolumn{5}{|l|}{ Overall Historical Incidence: All Routes } \\
\hline Total $(\%)$ & \multicolumn{4}{|c|}{$1 / 697(0.1 \%)$} \\
\hline Mean \pm standard deviation & \multicolumn{4}{|c|}{$0.1 \% \pm 0.5 \%$} \\
\hline Range & \multicolumn{4}{|c|}{$0 \%-2 \%$} \\
\hline \multicolumn{5}{|l|}{ Data as of June 2013.} \\
\hline \multicolumn{5}{|c|}{$\begin{array}{l}\text { Table B-6. Summary of the Incidence of Nonneoplastic Lesions in Female Rats in the Two-year } \\
\text { Inhalation Study of Vinylidene Chloride }\end{array}$} \\
\hline & $\begin{array}{l}\text { Chamber } \\
\text { Control }\end{array}$ & $25 \mathrm{ppm}$ & $50 \mathrm{ppm}$ & $100 \mathrm{ppm}$ \\
\hline \multicolumn{5}{|l|}{ Disposition Summary } \\
\hline Animals initially in study & 50 & 50 & 50 & 50 \\
\hline \multicolumn{5}{|l|}{ Early deaths } \\
\hline Moribund & 19 & 22 & 18 & 28 \\
\hline Natural deaths & 1 & 2 & 2 & 3 \\
\hline \multicolumn{5}{|l|}{ Survivors } \\
\hline Died last week of study & - & - & 1 & - \\
\hline Terminal kill & 30 & 26 & 29 & 19 \\
\hline Animals examined microscopically & 50 & 50 & 50 & 50 \\
\hline \multicolumn{5}{|l|}{ Alimentary System } \\
\hline Esophagus & $(50)$ & $(50)$ & $(50)$ & $(50)$ \\
\hline Intestine large, cecum & (49) & $(48)$ & $(48)$ & $(48)$ \\
\hline Intestine large, colon & $(50)$ & (49) & (48) & $(50)$ \\
\hline Cyst & - & - & $1(2 \%)$ & - \\
\hline Intestine large, rectum & (49) & $(50)$ & (49) & (49) \\
\hline Intestine small, duodenum & $(50)$ & $(50)$ & (49) & $(50)$ \\
\hline Intestine small, ileum & $(50)$ & $(48)$ & (49) & (49) \\
\hline Intestine small, jejunum & $(50)$ & $(48)$ & (49) & (49) \\
\hline Liver & $(50)$ & $(50)$ & $(50)$ & $(50)$ \\
\hline Angiectasis & $2(4 \%)$ & $4(8 \%)$ & $4(8 \%)$ & $5(10 \%)$ \\
\hline
\end{tabular}


Vinylidene Chloride, NTP TR 582

\begin{tabular}{|c|c|c|c|c|}
\hline & $\begin{array}{c}\text { Chamber } \\
\text { Control }\end{array}$ & $25 \mathrm{ppm}$ & $50 \mathrm{ppm}$ & 100 ppm \\
\hline Basophilic focus & $46(92 \%)$ & $41(82 \%)$ & $32(64 \%)$ & $29(58 \%)$ \\
\hline Clear cell focus & $15(30 \%)$ & $19(38 \%)$ & $22(44 \%)$ & $18(36 \%)$ \\
\hline Degeneration, cystic & - & $2(4 \%)$ & $4(8 \%)$ & $7(14 \%)$ \\
\hline Eosinophilic focus & $6(12 \%)$ & $11(22 \%)$ & $7(14 \%)$ & $16(32 \%)$ \\
\hline Fatty change & $1(2 \%)$ & - & - & - \\
\hline Fatty change, focal & $2(4 \%)$ & $1(2 \%)$ & $3(6 \%)$ & - \\
\hline Fatty change, diffuse & $19(38 \%)$ & $30(60 \%)$ & $26(52 \%)$ & $30(60 \%)$ \\
\hline Fibrosis, focal & - & $1(2 \%)$ & - & - \\
\hline Hepatodiaphragmatic nodule & $3(6 \%)$ & $6(12 \%)$ & $4(8 \%)$ & $5(10 \%)$ \\
\hline Inflammation, chronic & $42(84 \%)$ & $48(96 \%)$ & $49(98 \%)$ & $48(96 \%)$ \\
\hline Mixed cell focus & $4(8 \%)$ & $16(32 \%)$ & $12(24 \%)$ & $13(26 \%)$ \\
\hline Necrosis & - & $3(6 \%)$ & $5(10 \%)$ & $11(22 \%)$ \\
\hline Bile duct, hyperplasia & $7(14 \%)$ & - & $1(2 \%)$ & $6(12 \%)$ \\
\hline Mesentery & (13) & $(20)$ & $(23)$ & $(24)$ \\
\hline Inflammation, chronic active & - & $1(5 \%)$ & - & - \\
\hline Fat, hemorrhage & - & - & $1(4 \%)$ & - \\
\hline Fat, necrosis & $13(100 \%)$ & $19(95 \%)$ & $22(96 \%)$ & $23(96 \%)$ \\
\hline Oral mucosa & (0) & (1) & (0) & (1) \\
\hline Pharyngeal, hyperplasia, squamous & - & - & - & $1(100 \%)$ \\
\hline Pancreas & $(50)$ & $(50)$ & (50) & $(50)$ \\
\hline Basophilic focus & $1(2 \%)$ & - & - & - \\
\hline Inflammation, granulomatous & - & - & $1(2 \%)$ & - \\
\hline Acinus, atrophy & $9(18 \%)$ & $13(26 \%)$ & $11(22 \%)$ & $11(22 \%)$ \\
\hline Acinus, hyperplasia & - & $1(2 \%)$ & $3(6 \%)$ & $3(6 \%)$ \\
\hline Salivary glands & (50) & $(50)$ & $(50)$ & $(50)$ \\
\hline Atropy & - & - & - & $1(2 \%)$ \\
\hline Basophilic focus & - & - & $2(4 \%)$ & $1(2 \%)$ \\
\hline Stomach, forestomach & (50) & $(50)$ & $(50)$ & $(50)$ \\
\hline Hyperplasia, squamous & - & $1(2 \%)$ & $2(4 \%)$ & $2(4 \%)$ \\
\hline Necrosis & - & $1(2 \%)$ & - & - \\
\hline Ulcer & $3(6 \%)$ & $1(2 \%)$ & $1(2 \%)$ & $3(6 \%)$ \\
\hline Stomach, glandular & $(50)$ & $(50)$ & $(50)$ & $(50)$ \\
\hline Mineralization & - & $1(2 \%)$ & - & - \\
\hline Necrosis & $1(2 \%)$ & $4(8 \%)$ & $1(2 \%)$ & $6(12 \%)$ \\
\hline Tongue & (1) & $(0)$ & $(0)$ & (0) \\
\hline
\end{tabular}


Vinylidene Chloride, NTP TR 582

\begin{tabular}{|c|c|c|c|c|}
\hline & $\begin{array}{c}\text { Chamber } \\
\text { Control }\end{array}$ & 25 ppm & 50 ppm & 100 ppm \\
\hline \multicolumn{5}{|l|}{ Cardiovascular System } \\
\hline Blood vessel & (1) & (1) & (0) & (0) \\
\hline Heart & (50) & $(50)$ & $(50)$ & $(50)$ \\
\hline Cardiomyopathy & $33(66 \%)$ & $34(68 \%)$ & $32(64 \%)$ & $27(54 \%)$ \\
\hline Thrombosis & - & $1(2 \%)$ & - & $1(2 \%)$ \\
\hline Pericardium, fibrosis & - & - & - & $1(2 \%)$ \\
\hline \multicolumn{5}{|l|}{ Endocrine System } \\
\hline Adrenal cortex & (50) & $(50)$ & (50) & $(50)$ \\
\hline Degeneration, cystic & - & - & - & $1(2 \%)$ \\
\hline Hematopoietic cell proliferation & - & $2(4 \%)$ & - & - \\
\hline Hyperplasia & $30(60 \%)$ & $28(56 \%)$ & $20(40 \%)$ & $25(50 \%)$ \\
\hline Hypertrophy & $7(14 \%)$ & $3(6 \%)$ & $1(2 \%)$ & $4(8 \%)$ \\
\hline Metaplasia, osseous & - & - & - & $1(2 \%)$ \\
\hline Necrosis & - & - & - & $1(2 \%)$ \\
\hline Vacuolization cytoplasmic & $1(2 \%)$ & - & - & - \\
\hline Adrenal medulla & $(50)$ & $(50)$ & (50) & (49) \\
\hline Hyperplasia & $7(14 \%)$ & $10(20 \%)$ & $9(18 \%)$ & $12(24 \%)$ \\
\hline Islets, pancreatic & (50) & $(50)$ & (50) & $(50)$ \\
\hline Hyperplasia & - & $1(2 \%)$ & - & - \\
\hline Parathyroid gland & (49) & $(46)$ & (45) & $(47)$ \\
\hline Angiectasis & - & - & $1(2 \%)$ & - \\
\hline Hyperplasia & $1(2 \%)$ & - & - & - \\
\hline Pituitary gland & (50) & (49) & (49) & (49) \\
\hline Pars distalis, angiectasis & $4(8 \%)$ & $4(8 \%)$ & $4(8 \%)$ & $1(2 \%)$ \\
\hline Pars distalis, hyperplasia & $12(24 \%)$ & $6(12 \%)$ & $12(24 \%)$ & $11(22 \%)$ \\
\hline Thyroid gland & (50) & (50) & (48) & $(50)$ \\
\hline C-cell, hyperplasia & $35(70 \%)$ & $30(60 \%)$ & $32(67 \%)$ & $27(54 \%)$ \\
\hline Follicular cell, hyperplasia & - & $1(2 \%)$ & - & $1(2 \%)$ \\
\hline \multicolumn{5}{|l|}{ General Body System } \\
\hline Peritoneum & (0) & (1) & (1) & (1) \\
\hline Inflammation, acute & - & $1(100 \%)$ & - & - \\
\hline Mesothelium, hyperplasia & - & - & - & $1(100 \%)$ \\
\hline \multicolumn{5}{|l|}{ Genital System } \\
\hline Clitoral gland & (47) & $(48)$ & $(45)$ & $(48)$ \\
\hline Hyperplasia & - & $4(8 \%)$ & $1(2 \%)$ & $1(2 \%)$ \\
\hline
\end{tabular}


Vinylidene Chloride, NTP TR 582

\begin{tabular}{|c|c|c|c|c|}
\hline & $\begin{array}{l}\text { Chamber } \\
\text { Control }\end{array}$ & 25 ppm & 50 ppm & 100 ppm \\
\hline Inflammation, chronic active & - & $1(2 \%)$ & - & - \\
\hline Ovary & $(50)$ & $(50)$ & (50) & $(50)$ \\
\hline Cyst & - & - & $1(2 \%)$ & $1(2 \%)$ \\
\hline Bursa, dilatation & $5(10 \%)$ & $11(22 \%)$ & $17(34 \%)$ & $24(48 \%)$ \\
\hline Follicle, cyst & - & - & $1(2 \%)$ & - \\
\hline Interstitial cell, hyperplasia & $1(2 \%)$ & - & - & - \\
\hline Periovarian tissue, cyst & - & - & $1(2 \%)$ & - \\
\hline Uterus & $(50)$ & $(50)$ & $(50)$ & $(50)$ \\
\hline Inflammation, chronic active & $1(2 \%)$ & - & - & - \\
\hline Endometrium, hyperplasia, cystic & $1(2 \%)$ & $1(2 \%)$ & $1(2 \%)$ & $1(2 \%)$ \\
\hline Vagina & $(0)$ & (2) & $(0)$ & (1) \\
\hline \multicolumn{5}{|l|}{ Hematopoietic System } \\
\hline Bone marrow & (50) & $(50)$ & $(50)$ & $(50)$ \\
\hline Hyperplasia, reticulum cell & $1(2 \%)$ & - & - & - \\
\hline Lymph node & (2) & (2) & (4) & (9) \\
\hline Deep cervical, hemorrhage & - & - & $1(25 \%)$ & - \\
\hline Deep cervical, hyperplasia, lymphoid & - & - & $1(25 \%)$ & - \\
\hline Lymph node, bronchial & (4) & (7) & (4) & $(10)$ \\
\hline Congestion & $1(25 \%)$ & - & - & - \\
\hline Hyperplasia, lymphoid & - & $1(14 \%)$ & - & $1(10 \%)$ \\
\hline Infiltration cellular, histiocyte & - & - & - & $1(10 \%)$ \\
\hline Lymph node, mandibular & (2) & $(0)$ & (1) & (4) \\
\hline Lymph node, mediastinal & $(33)$ & $(26)$ & (29) & $(38)$ \\
\hline Ectasia & $1(3 \%)$ & - & - & $1(3 \%)$ \\
\hline Hemorrhage & $1(3 \%)$ & - & $1(3 \%)$ & - \\
\hline Hyperplasia, lymphoid & $1(3 \%)$ & $1(4 \%)$ & - & - \\
\hline Hyperplasia, plasma cell & - & $1(4 \%)$ & - & - \\
\hline Lymph node, mesenteric & (50) & $(50)$ & (50) & $(50)$ \\
\hline Congestion & $1(2 \%)$ & - & - & - \\
\hline Hyperplasia, lymphoid & $1(2 \%)$ & $1(2 \%)$ & - & $1(2 \%)$ \\
\hline Inflammation, granulomatous & - & - & - & $1(2 \%)$ \\
\hline Spleen & $(50)$ & $(50)$ & $(50)$ & $(50)$ \\
\hline Fibrosis & $2(4 \%)$ & $1(2 \%)$ & $2(4 \%)$ & $4(8 \%)$ \\
\hline Hematopoietic cell proliferation & - & - & $2(4 \%)$ & $1(2 \%)$ \\
\hline Hemorrhage & - & $1(2 \%)$ & - & - \\
\hline
\end{tabular}


Vinylidene Chloride, NTP TR 582

\begin{tabular}{|c|c|c|c|c|}
\hline & $\begin{array}{c}\text { Chamber } \\
\text { Control }\end{array}$ & 25 ppm & 50 ppm & 100 ppm \\
\hline Hyperplasia, lymphoid & - & $1(2 \%)$ & - & - \\
\hline Inflammation, granulomatous & - & $1(2 \%)$ & - & - \\
\hline Inflammation, acute & - & $1(2 \%)$ & - & - \\
\hline Necrosis & - & - & - & $3(6 \%)$ \\
\hline Thymus & (46) & $(45)$ & $(42)$ & $(42)$ \\
\hline \multicolumn{5}{|l|}{ Integumentary System } \\
\hline Mammary gland & $(50)$ & $(50)$ & $(50)$ & (50) \\
\hline Galactocele & $1(2 \%)$ & $2(4 \%)$ & $2(4 \%)$ & - \\
\hline Hyperplasia & $1(2 \%)$ & $1(2 \%)$ & - & - \\
\hline Skin & $(50)$ & $(50)$ & (50) & (50) \\
\hline Cyst epithelial inclusion & $1(2 \%)$ & - & - & - \\
\hline Hyperkeratosis & - & - & $1(2 \%)$ & - \\
\hline Inflammation, chronic active & - & $1(2 \%)$ & $1(2 \%)$ & $1(2 \%)$ \\
\hline \multicolumn{5}{|l|}{ Musculoskeletal System } \\
\hline Bone & (50) & $(50)$ & $(50)$ & (50) \\
\hline Hyperostosis & - & - & $1(2 \%)$ & - \\
\hline Skeletal muscle & (1) & (2) & (3) & (0) \\
\hline Fibrosis & - & - & $1(33 \%)$ & - \\
\hline Nervous System & & & & - \\
\hline Brain & $(50)$ & $(50)$ & $(50)$ & $(50)$ \\
\hline Hydrocephalus & - & $1(2 \%)$ & - & - \\
\hline Necrosis & - & - & - & $1(2 \%)$ \\
\hline \multicolumn{5}{|l|}{ Respiratory System } \\
\hline Larynx & $(50)$ & $(50)$ & $(50)$ & $(50)$ \\
\hline Inflammation, chronic active & $2(4 \%)$ & $2(4 \%)$ & $1(2 \%)$ & - \\
\hline Metaplasia, squamous & $1(2 \%)$ & $3(6 \%)$ & - & - \\
\hline Lung & $(50)$ & $(50)$ & $(50)$ & $(50)$ \\
\hline Hemorrhage & - & - & $1(2 \%)$ & - \\
\hline Inflammation, chronic active & $1(2 \%)$ & $1(2 \%)$ & $1(2 \%)$ & - \\
\hline Thrombosis & - & - & - & $1(2 \%)$ \\
\hline Alveolar epithelium, hyperplasia & $12(24 \%)$ & $13(26 \%)$ & $13(26 \%)$ & $8(16 \%)$ \\
\hline Alveolar epithelium, metaplasia, squamous & $1(2 \%)$ & - & $2(4 \%)$ & $2(4 \%)$ \\
\hline Alveolus, infiltration cellular, histiocyte & - & - & $2(4 \%)$ & $1(2 \%)$ \\
\hline Bronchiole, hyperplasia & - & $2(4 \%)$ & $1(2 \%)$ & $1(2 \%)$ \\
\hline
\end{tabular}


Vinylidene Chloride, NTP TR 582

\begin{tabular}{|c|c|c|c|c|}
\hline & $\begin{array}{l}\text { Chamber } \\
\text { Control }\end{array}$ & 25 ppm & 50 ppm & 100 ppm \\
\hline Nose & $(50)$ & $(50)$ & $(50)$ & $(50)$ \\
\hline Foreign body & $2(4 \%)$ & $4(8 \%)$ & - & $5(10 \%)$ \\
\hline Inflammation, acute & $1(2 \%)$ & - & - & - \\
\hline Inflammation, chronic active & $7(14 \%)$ & $45(90 \%)$ & $46(92 \%)$ & $46(92 \%)$ \\
\hline Polyp, inflammatory & - & - & - & $3(6 \%)$ \\
\hline Thrombosis & - & $3(6 \%)$ & $2(4 \%)$ & $7(14 \%)$ \\
\hline Olfactory epithelium, metaplasia, respiratory & $1(2 \%)$ & $50(100 \%)$ & $50(100 \%)$ & $50(100 \%)$ \\
\hline Olfactory epithelium, metaplasia, squamous & - & - & $1(2 \%)$ & $1(2 \%)$ \\
\hline Respiratory epithelium, hyperplasia & $4(8 \%)$ & $12(24 \%)$ & $14(28 \%)$ & $27(54 \%)$ \\
\hline $\begin{array}{l}\text { Respiratory epithelium, metaplasia, } \\
\text { squamous }\end{array}$ & - & - & - & $3(6 \%)$ \\
\hline Turbinate, atrophy & - & $50(100 \%)$ & $50(100 \%)$ & $50(100 \%)$ \\
\hline Turbinate, hyperostosis & - & $50(100 \%)$ & $50(100 \%)$ & $50(100 \%)$ \\
\hline Pleura & $(0)$ & (1) & (0) & (1) \\
\hline Hyperplasia & - & - & - & $1(100 \%)$ \\
\hline Infiltration cellular, mononuclear cell & - & - & - & $1(100 \%)$ \\
\hline Trachea & (50) & $(50)$ & $(50)$ & $(50)$ \\
\hline \multicolumn{5}{|l|}{ Special Senses System } \\
\hline Eye & $(50)$ & (49) & $(50)$ & (49) \\
\hline Cataract & $1(2 \%)$ & $1(2 \%)$ & $3(6 \%)$ & $1(2 \%)$ \\
\hline Degeneration & $1(2 \%)$ & $3(6 \%)$ & $1(2 \%)$ & - \\
\hline Cornea, inflammation, chronic active & $1(2 \%)$ & - & - & - \\
\hline Retina, atrophy & $1(2 \%)$ & $4(8 \%)$ & $3(6 \%)$ & $2(4 \%)$ \\
\hline Harderian gland & $(50)$ & (50) & $(50)$ & $(50)$ \\
\hline Hyperplasia & $2(4 \%)$ & - & $1(2 \%)$ & - \\
\hline Inflammation, chronic & $1(2 \%)$ & - & - & - \\
\hline Lacrimal gland & $(0)$ & $(0)$ & (1) & (1) \\
\hline Cytoplasmic alteration & - & - & $1(100 \%)$ & - \\
\hline Degeneration & - & - & - & $1(100 \%)$ \\
\hline Zymbal's gland & $(0)$ & $(0)$ & (1) & $(0)$ \\
\hline \multicolumn{5}{|l|}{ Urinary System } \\
\hline Kidney & $(50)$ & (50) & $(50)$ & $(50)$ \\
\hline Fibrosis & - & $1(2 \%)$ & - & - \\
\hline Hydronephrosis & $1(2 \%)$ & $1(2 \%)$ & - & - \\
\hline Hyperplasia, oncocytic & $1(2 \%)$ & - & $1(2 \%)$ & - \\
\hline Infarct & $1(2 \%)$ & $1(2 \%)$ & - & $2(4 \%)$ \\
\hline
\end{tabular}


Vinylidene Chloride, NTP TR 582

\begin{tabular}{|c|c|c|c|c|}
\hline & $\begin{array}{c}\text { Chamber } \\
\text { Control }\end{array}$ & 25 ppm & 50 ppm & 100 ppm \\
\hline Mineralization & - & $1(2 \%)$ & - & - \\
\hline Nephropathy & $45(90 \%)$ & $40(80 \%)$ & $43(86 \%)$ & $42(84 \%)$ \\
\hline Papilla, necrosis & - & $1(2 \%)$ & - & - \\
\hline Renal tubule, hyperplasia & $1(2 \%)$ & $2(4 \%)$ & - & $2(4 \%)$ \\
\hline Renal tubule, necrosis & - & - & $1(2 \%)$ & - \\
\hline Urinary bladder & $(50)$ & $(50)$ & $(50)$ & $(50)$ \\
\hline Inflammation, chronic active & $1(2 \%)$ & - & - & - \\
\hline
\end{tabular}

${ }^{a}$ Number of animals examined microscopically at the site and the number of animals with lesion. 


\section{Appendix C. Summary of Lesions in Male Mice in the Two-year Inhalation Study of Vinylidene Chloride}

\section{Tables}

Table C-1. Summary of the Incidence of Neoplasms in Male Mice in the Two-year Inhalation Study of Vinylidene Chloride

Table C-2. Statistical Analysis of Primary Neoplasms in Male Mice in the Two-year Inhalation Study of Vinylidene Chloride . -8

Table C-3. Historical Incidence of Renal Tubule Neoplasms in Control Male B6C3F1/N Mice.

Table C-4. Summary of the Incidence of Nonneoplastic Lesions in Male Mice in the Two-year Inhalation Study of Vinylidene Chloride. 
Table C-1. Summary of the Incidence of Neoplasms in Male Mice in the Two-year Inhalation Study of Vinylidene Chloride ${ }^{\mathrm{a}}$

\begin{tabular}{|c|c|c|c|c|}
\hline & $\begin{array}{l}\text { Chamber } \\
\text { Control }\end{array}$ & $6.25 \mathrm{ppm}$ & $12.5 \mathrm{ppm}$ & 25 ppm \\
\hline \multicolumn{5}{|l|}{ Disposition Summary } \\
\hline Animals initially in study & 50 & 50 & 50 & 50 \\
\hline \multicolumn{5}{|l|}{ Early deaths } \\
\hline Moribund & 12 & 5 & 14 & 19 \\
\hline Natural deaths & 9 & 5 & 4 & 12 \\
\hline \multicolumn{5}{|l|}{ Survivors } \\
\hline Died last week of study & - & 1 & - & 1 \\
\hline Terminal kill & 29 & 39 & 32 & 18 \\
\hline Animals examined microscopically & 50 & 50 & 50 & 50 \\
\hline \multicolumn{5}{|l|}{ Alimentary System } \\
\hline Esophagus & $(50)$ & $(50)$ & (50) & $(50)$ \\
\hline Gallbladder & $(42)$ & $(45)$ & (47) & $(41)$ \\
\hline Intestine large, cecum & $(47)$ & $(48)$ & (48) & $(40)$ \\
\hline Carcinoma & $1(2 \%)$ & - & - & - \\
\hline Intestine large, colon & $(47)$ & $(48)$ & (48) & $(42)$ \\
\hline Intestine large, rectum & $(48)$ & $(48)$ & (48) & $(42)$ \\
\hline Intestine small, duodenum & (44) & $(47)$ & (47) & $(38)$ \\
\hline Adenoma & - & - & $1(2 \%)$ & - \\
\hline Carcinoma & - & - & - & $2(5 \%)$ \\
\hline Intestine small, ileum & (44) & $(47)$ & (47) & (39) \\
\hline Adenoma & $1(2 \%)$ & - & - & - \\
\hline Carcinoma & - & $1(2 \%)$ & - & - \\
\hline Intestine small, jejunum & $(43)$ & $(47)$ & $(47)$ & $(39)$ \\
\hline Carcinoma & - & $2(4 \%)$ & - & - \\
\hline Hepatocholangiocarcinoma, metastatic, liver & $1(2 \%)$ & - & - & - \\
\hline Liver & $(50)$ & $(50)$ & (50) & $(50)$ \\
\hline Carcinoma, metastatic, testes & - & - & $1(2 \%)$ & - \\
\hline Hemangioma & - & $1(2 \%)$ & $2(4 \%)$ & - \\
\hline Hemangiosarcoma & $2(4 \%)$ & $2(4 \%)$ & $3(6 \%)$ & $3(6 \%)$ \\
\hline Hepatoblastoma & $1(2 \%)$ & - & - & - \\
\hline Hepatocellular adenoma & $17(34 \%)$ & $16(32 \%)$ & $16(32 \%)$ & $12(24 \%)$ \\
\hline Hepatocellular adenoma, multiple & $20(40 \%)$ & $19(38 \%)$ & $17(34 \%)$ & $13(26 \%)$ \\
\hline Hepatocellular carcinoma & $18(36 \%)$ & $18(36 \%)$ & $11(22 \%)$ & $21(42 \%)$ \\
\hline Hepatocellular carcinoma, multiple & $8(16 \%)$ & $1(2 \%)$ & $4(8 \%)$ & $8(16 \%)$ \\
\hline
\end{tabular}


Vinylidene Chloride, NTP TR 582

\begin{tabular}{|c|c|c|c|c|}
\hline & $\begin{array}{l}\text { Chamber } \\
\text { Control }\end{array}$ & $6.25 \mathrm{ppm}$ & $12.5 \mathrm{ppm}$ & 25 ppm \\
\hline Hepatocholangiocarcinoma & $1(2 \%)$ & $2(4 \%)$ & $2(4 \%)$ & $3(6 \%)$ \\
\hline $\begin{array}{l}\text { Rhabdomyosarcoma, metastatic, } \\
\text { skeletal muscle }\end{array}$ & - & - & $1(2 \%)$ & - \\
\hline Sarcoma, metastatic, stomach, glandular & - & - & - & $1(2 \%)$ \\
\hline Mesentery & (6) & (9) & (6) & (3) \\
\hline Hepatocellular carcinoma, metastatic, liver & - & - & - & $1(33 \%)$ \\
\hline Hepatocholangiocarcinoma, metastatic, liver & - & $1(11 \%)$ & - & $1(33 \%)$ \\
\hline Pancreas & (50) & $(49)$ & (50) & $(48)$ \\
\hline Hepatocellular carcinoma, metastatic, liver & - & $1(2 \%)$ & - & - \\
\hline Hepatocholangiocarcinoma, metastatic, liver & - & $1(2 \%)$ & - & $1(2 \%)$ \\
\hline $\begin{array}{l}\text { Rhabdomyosarcoma, metastatic, } \\
\text { skeletal muscle }\end{array}$ & - & - & $1(2 \%)$ & - \\
\hline Sarcoma, metastatic, stomach, glandular & - & - & - & $1(2 \%)$ \\
\hline Salivary glands & (50) & $(50)$ & (50) & $(50)$ \\
\hline Stomach, forestomach & (49) & $(50)$ & (50) & $(49)$ \\
\hline Squamous cell papilloma & $1(2 \%)$ & - & - & $1(2 \%)$ \\
\hline Stomach, glandular & $(48)$ & $(49)$ & (49) & $(48)$ \\
\hline Hepatocholangiocarcinoma, metastatic, liver & - & - & - & $1(2 \%)$ \\
\hline Sarcoma & - & - & - & $1(2 \%)$ \\
\hline Tongue & $(0)$ & (0) & (1) & (0) \\
\hline Tooth & (2) & (2) & $(0)$ & (1) \\
\hline \multicolumn{5}{|l|}{ Cardiovascular System } \\
\hline Blood vessel & $(0)$ & (0) & (1) & (3) \\
\hline Heart & $(50)$ & $(50)$ & $(50)$ & $(50)$ \\
\hline Carcinoma, metastatic, Harderian gland & - & $1(2 \%)$ & - & - \\
\hline Hepatocellular carcinoma, metastatic, liver & $1(2 \%)$ & $1(2 \%)$ & - & - \\
\hline Hepatocholangiocarcinoma, metastatic, liver & $1(2 \%)$ & - & - & - \\
\hline \multicolumn{5}{|l|}{ Endocrine System } \\
\hline Adrenal cortex & (50) & $(50)$ & $(50)$ & $(50)$ \\
\hline Adenoma & - & - & $1(2 \%)$ & - \\
\hline Carcinoma & - & $1(2 \%)$ & - & - \\
\hline Sarcoma, metastatic, stomach, glandular & - & - & - & $1(2 \%)$ \\
\hline $\begin{array}{l}\text { Capsule, hepatocholangiocarcinoma, } \\
\text { metastatic, liver }\end{array}$ & - & - & $1(2 \%)$ & - \\
\hline Subcapsular, adenoma & $1(2 \%)$ & $1(2 \%)$ & $3(6 \%)$ & $2(4 \%)$ \\
\hline
\end{tabular}


Vinylidene Chloride, NTP TR 582

\begin{tabular}{lcccc}
\hline & $\begin{array}{c}\text { Chamber } \\
\text { Control }\end{array}$ & $\mathbf{6 . 2 5} \mathbf{~ p p m}$ & $\mathbf{1 2 . 5} \mathbf{~ p p m}$ & $\mathbf{2 5} \mathbf{~ p p m}$ \\
\hline Adrenal medulla & $(50)$ & $(50)$ & $(50)$ & $(50)$ \\
Pheochromocytoma benign & $1(2 \%)$ & $1(2 \%)$ & - & $1(2 \%)$ \\
Pheochromocytoma malignant & $1(2 \%)$ & - & - & - \\
Islets, pancreatic & $(50)$ & $(49)$ & $(49)$ & $(49)$ \\
Adenoma & $2(4 \%)$ & $1(2 \%)$ & $1(2 \%)$ & - \\
Hepatocholangiocarcinoma, metastatic, liver & - & - & - & $1(2 \%)$ \\
Parathyroid gland & $(26)$ & $(22)$ & $(26)$ & $(24)$ \\
Pituitary gland & $(49)$ & $(49)$ & $(50)$ & $(46)$ \\
Pars intermedia, adenoma & $1(2 \%)$ & - & - & - \\
Thyroid gland & $(50)$ & $(49)$ & $(50)$ & $(49)$ \\
Follicular cell, adenoma & - & - & $1(2 \%)$ & - \\
Follicular cell, carcinoma & - & - & $1(2 \%)$ & - \\
\hline
\end{tabular}

\section{General Body System}

None

\section{Genital System}

\begin{tabular}{lcccc} 
Epididymis & $(50)$ & $(50)$ & $(50)$ & $(50)$ \\
Preputial gland & $(50)$ & $(50)$ & $(50)$ & $(50)$ \\
Prostate & $(50)$ & $(50)$ & $(50)$ & $(50)$ \\
Hepatocellular carcinoma, metastatic, liver & - & $1(2 \%)$ & - & - \\
$\quad$ Hepatocholangiocarcinoma, metastatic, liver & - & - & - & $1(2 \%)$ \\
Seminal vesicle & $(50)$ & $(50)$ & $(50)$ & $(50)$ \\
$\quad$ Hepatocholangiocarcinoma, metastatic, liver & - & - & $1(2 \%)$ & - \\
Testes & $(50)$ & $(50)$ & $(50)$ & $(50)$ \\
Hemangioma & $1(2 \%)$ & - & - & $1(2 \%)$ \\
Interstitial cell, adenoma & $1(2 \%)$ & $2(4 \%)$ & $1(2 \%)$ & $1(2 \%)$ \\
Interstitial cell, carcinoma & - & - & $1(2 \%)$ & - \\
\hline $\begin{array}{l}\text { Hematopoietic System } \\
\text { Bone marrow }\end{array}$ & & & & $(50)$ \\
Hemangioma & $(50)$ & $(50)$ & $(50)$ & - \\
Hemangiosarcoma & - & - & $1(2 \%)$ & $2(4 \%)$ \\
Lymph node \\
$\begin{array}{l}\text { Pancreatic, sarcoma, metastatic, } \\
\text { stomach, glandular } \\
\text { Renal, hepatocholangiocarcinoma, } \\
\text { metastatic, liver }\end{array}$ & $1(2 \%)$ & - & $1(2 \%)$ & $(2)$ \\
\hline
\end{tabular}


Vinylidene Chloride, NTP TR 582

\begin{tabular}{|c|c|c|c|c|}
\hline & $\begin{array}{l}\text { Chamber } \\
\text { Control }\end{array}$ & $6.25 \mathrm{ppm}$ & $12.5 \mathrm{ppm}$ & $25 \mathrm{ppm}$ \\
\hline Lymph node, bronchial & (33) & (34) & (31) & (19) \\
\hline Hepatocholangiocarcinoma, metastatic, liver & $1(3 \%)$ & $1(3 \%)$ & - & - \\
\hline Lymph node, mandibular & (17) & (29) & (19) & $(25)$ \\
\hline Lymph node, mediastinal & (43) & $(29)$ & (43) & $(38)$ \\
\hline $\begin{array}{l}\text { Alveolar/bronchiolar carcinoma, } \\
\text { metastatic, lung }\end{array}$ & - & - & - & $1(3 \%)$ \\
\hline Carcinoma, metastatic, Harderian gland & - & $1(3 \%)$ & - & - \\
\hline Hemangiosarcoma & - & - & $1(2 \%)$ & - \\
\hline Hepatocholangiocarcinoma, metastatic, liver & $1(2 \%)$ & - & $1(2 \%)$ & $1(3 \%)$ \\
\hline $\begin{array}{l}\text { Rhabdomyosarcoma, metastatic, } \\
\text { skeletal muscle }\end{array}$ & - & - & $1(2 \%)$ & - \\
\hline Lymph node, mesenteric & (46) & $(48)$ & (48) & $(47)$ \\
\hline $\begin{array}{l}\text { Carcinoma, metastatic, intestine large, } \\
\text { cecum }\end{array}$ & $1(2 \%)$ & - & - & - \\
\hline $\begin{array}{l}\text { Carcinoma, metastatic, intestine small, } \\
\text { duodenum }\end{array}$ & - & - & - & $1(2 \%)$ \\
\hline Hepatocholangiocarcinoma, metastatic, liver & - & $1(2 \%)$ & - & $1(2 \%)$ \\
\hline Spleen & (50) & (49) & (50) & $(50)$ \\
\hline Hemangiosarcoma & $24 \%)$ & $3(6 \%)$ & $1(2 \%)$ & $4(8 \%)$ \\
\hline Thymus & (39) & $(37)$ & (38) & $(26)$ \\
\hline Hemangiosarcoma & - & $1(3 \%)$ & - & - \\
\hline \multicolumn{5}{|l|}{ Integumentary System } \\
\hline Mammary gland & (1) & (2) & $(0)$ & (1) \\
\hline Skin & (50) & $(50)$ & (50) & $(50)$ \\
\hline Fibrous histiocytoma & $1(2 \%)$ & $2(4 \%)$ & $1(2 \%)$ & $2(4 \%)$ \\
\hline Keratoacanthoma & $1(2 \%)$ & - & - & - \\
\hline Subcutaneous tissue, liposarcoma & $1(2 \%)$ & - & - & - \\
\hline $\begin{array}{l}\text { Subcutaneous tissue, } \\
\text { schwannoma malignant }\end{array}$ & - & - & - & $1(2 \%)$ \\
\hline \multicolumn{5}{|l|}{ Musculoskeletal System } \\
\hline Bone & $(50)$ & $(50)$ & $(50)$ & $(50)$ \\
\hline Skeletal muscle & (1) & (1) & (2) & (2) \\
\hline Hemangiosarcoma & $1(100 \%)$ & - & - & $1(50 \%)$ \\
\hline Hepatocholangiocarcinoma, metastatic, liver & - & $1(100 \%)$ & $1(50 \%)$ & $1(50 \%)$ \\
\hline Rhabdomyosarcoma & - & - & $1(50 \%)$ & - \\
\hline
\end{tabular}


Vinylidene Chloride, NTP TR 582

\begin{tabular}{|c|c|c|c|c|}
\hline & $\begin{array}{l}\text { Chamber } \\
\text { Control }\end{array}$ & $6.25 \mathrm{ppm}$ & $12.5 \mathrm{ppm}$ & 25 ppm \\
\hline \multicolumn{5}{|l|}{ Nervous System } \\
\hline Brain & $(50)$ & $(50)$ & (50) & $(50)$ \\
\hline Carcinoma, metastatic, Harderian gland & - & $1(2 \%)$ & - & - \\
\hline \multicolumn{5}{|l|}{ Respiratory System } \\
\hline Larynx & (50) & $(50)$ & (50) & $(49)$ \\
\hline Lung & (50) & $(50)$ & (50) & $(50)$ \\
\hline Alveolar/bronchiolar adenoma & $7(14 \%)$ & $7(14 \%)$ & $8(16 \%)$ & $7(14 \%)$ \\
\hline Alveolar/bronchiolar adenoma, multiple & - & $1(2 \%)$ & - & - \\
\hline Alveolar/bronchiolar carcinoma & $8(16 \%)$ & $8(16 \%)$ & $8(16 \%)$ & $6(12 \%)$ \\
\hline Alveolar/bronchiolar carcinoma, multiple & $1(2 \%)$ & $1(2 \%)$ & - & - \\
\hline Carcinoma, metastatic, Harderian gland & - & $1(2 \%)$ & - & - \\
\hline $\begin{array}{l}\text { Carcinoma, metastatic, intestine small, } \\
\text { duodenum }\end{array}$ & - & - & - & $1(2 \%)$ \\
\hline Hemangiosarcoma & $1(2 \%)$ & - & - & - \\
\hline Hepatocellular carcinoma, metastatic, liver & $10(20 \%)$ & $11(22 \%)$ & $8(16 \%)$ & $4(8 \%)$ \\
\hline Hepatocholangiocarcinoma, metastatic, liver & $1(2 \%)$ & $1(2 \%)$ & $1(2 \%)$ & $2(4 \%)$ \\
\hline $\begin{array}{l}\text { Rhabdomyosarcoma, metastatic, } \\
\text { skeletal muscle }\end{array}$ & - & - & $1(2 \%)$ & - \\
\hline Nose & (50) & $(50)$ & (49) & $(49)$ \\
\hline Pleura & (1) & (1) & $(0)$ & (0) \\
\hline Carcinoma, metastatic, Harderian gland & - & $1(100 \%)$ & - & - \\
\hline Hepatocholangiocarcinoma, metastatic, liver & $1(100 \%)$ & - & - & - \\
\hline Trachea & $(50)$ & $(50)$ & (50) & $(50)$ \\
\hline \multicolumn{5}{|l|}{ Special Senses System } \\
\hline Eye & (50) & $(50)$ & (50) & $(48)$ \\
\hline Harderian gland & $(50)$ & $(50)$ & $(50)$ & $(50)$ \\
\hline Adenoma & $7(14 \%)$ & $6(12 \%)$ & $8(16 \%)$ & $8(16 \%)$ \\
\hline Carcinoma & - & $2(4 \%)$ & $1(2 \%)$ & - \\
\hline \multicolumn{5}{|l|}{ Urinary System } \\
\hline Kidney & $(50)$ & $(50)$ & $(50)$ & $(50)$ \\
\hline Hemangiosarcoma & $1(2 \%)$ & - & - & - \\
\hline Hepatocellular carcinoma, metastatic, liver & - & $1(2 \%)$ & - & $1(2 \%)$ \\
\hline Hepatocholangiocarcinoma, metastatic, liver & $1(2 \%)$ & $1(2 \%)$ & $1(2 \%)$ & $1(2 \%)$ \\
\hline $\begin{array}{l}\text { Rhabdomyosarcoma, metastatic, } \\
\text { skeletal muscle }\end{array}$ & - & - & $1(2 \%)$ & - \\
\hline Bilateral, renal tubule, adenoma & - & - & $1(2 \%)$ & - \\
\hline
\end{tabular}


Vinylidene Chloride, NTP TR 582

\begin{tabular}{|c|c|c|c|c|}
\hline & $\begin{array}{l}\text { Chamber } \\
\text { Control }\end{array}$ & $6.25 \mathrm{ppm}$ & $12.5 \mathrm{ppm}$ & 25 ppm \\
\hline Bilateral, renal tubule, carcinoma & - & $1(2 \%)$ & $7(14 \%)$ & $6(12 \%)$ \\
\hline Bilateral, renal tubule, carcinoma, multiple & - & - & $4(8 \%)$ & - \\
\hline $\begin{array}{l}\text { Capsule, sarcoma, metastatic, } \\
\text { stomach, glandular }\end{array}$ & - & - & - & $1(2 \%)$ \\
\hline Renal tubule, adenoma & - & $5(10 \%)$ & $15(30 \%)$ & $10(20 \%)$ \\
\hline Renal tubule, adenoma, multiple & - & - & $3(6 \%)$ & - \\
\hline Renal tubule, carcinoma & - & $6(12 \%)$ & $17(34 \%)$ & $12(24 \%)$ \\
\hline Renal tubule, carcinoma, multiple & - & - & $3(6 \%)$ & - \\
\hline Urinary bladder & (50) & $(50)$ & (50) & (49) \\
\hline \multicolumn{5}{|l|}{ Systemic Lesions } \\
\hline Multiple organs ${ }^{b}$ & (50) & $(50)$ & (50) & $(50)$ \\
\hline Histiocytic sarcoma & $2(4 \%)$ & $1(2 \%)$ & $1(2 \%)$ & $1(2 \%)$ \\
\hline Lymphoma malignant & $2(4 \%)$ & $2(4 \%)$ & $4(8 \%)$ & - \\
\hline \multicolumn{5}{|l|}{ Neoplasm Summary } \\
\hline Total animals with primary neoplasms ${ }^{\mathrm{c}}$ & 49 & 49 & 49 & 48 \\
\hline Total primary neoplasms & 114 & 114 & 151 & 130 \\
\hline Total animals with benign neoplasms & 43 & 41 & 43 & 35 \\
\hline Total benign neoplasms & 61 & 60 & 79 & 57 \\
\hline Total animals with malignant neoplasms & 37 & 38 & 42 & 43 \\
\hline Total malignant neoplasms & 53 & 54 & 72 & 73 \\
\hline Total animals with metastatic neoplasms & 11 & 13 & 11 & 7 \\
\hline Total metastatic neoplasms & 19 & 28 & 20 & 25 \\
\hline
\end{tabular}

${ }^{a}$ Number of animals examined microscopically at the site and the number of animals with neoplasm.

${ }^{b}$ Number of animals with any tissue examined microscopically.

'Primary neoplasms: all neoplasms except metastatic neoplasms. 
Vinylidene Chloride, NTP TR 582

Table C-2. Statistical Analysis of Primary Neoplasms in Male Mice in the Two-year Inhalation Study of Vinylidene Chloride

\begin{tabular}{|c|c|c|c|c|}
\hline & $\begin{array}{l}\text { Chamber } \\
\text { Control }\end{array}$ & $6.25 \mathrm{ppm}$ & $12.5 \mathrm{ppm}$ & 25 ppm \\
\hline \multicolumn{5}{|c|}{ Adrenal Cortex: Adenoma } \\
\hline Overall rate ${ }^{\mathrm{a}}$ & $1 / 50(2 \%)$ & $1 / 50(2 \%)$ & $4 / 50(8 \%)$ & $2 / 50(4 \%)$ \\
\hline Adjusted rate ${ }^{\mathrm{b}}$ & $2.4 \%$ & $2.1 \%$ & $9.6 \%$ & $5.5 \%$ \\
\hline Terminal rate ${ }^{\mathrm{c}}$ & $1 / 29(3 \%)$ & $1 / 40(3 \%)$ & $4 / 32(13 \%)$ & $1 / 19(5 \%)$ \\
\hline First incidence (days) & $729(\mathrm{~T})$ & $729(\mathrm{~T})$ & $729(\mathrm{~T})$ & 705 \\
\hline Poly-3 test ${ }^{\mathrm{d}}$ & $P=0.218$ & $\mathrm{P}=0.734 \mathrm{~N}$ & $P=0.173$ & $\mathrm{P}=0.451$ \\
\hline \multicolumn{5}{|c|}{ Harderian Gland: Adenoma } \\
\hline Overall rate & $7 / 50(14 \%)$ & $6 / 50(12 \%)$ & $8 / 50(16 \%)$ & $8 / 50(16 \%)$ \\
\hline Adjusted rate & $16.5 \%$ & $12.7 \%$ & $18.9 \%$ & $21.2 \%$ \\
\hline Terminal rate & $5 / 29(17 \%)$ & $6 / 40(15 \%)$ & $5 / 32(16 \%)$ & $4 / 19(21 \%)$ \\
\hline First incidence (days) & 694 & $729(\mathrm{~T})$ & 599 & 575 \\
\hline Poly-3 test & $P=0.252$ & $\mathrm{P}=0.416 \mathrm{~N}$ & $P=0.498$ & $P=0.401$ \\
\hline \multicolumn{5}{|c|}{ Harderian Gland: Adenoma or Carcinoma } \\
\hline Overall rate & $7 / 50(14 \%)$ & $8 / 50(16 \%)$ & $9 / 50(18 \%)$ & $8 / 50(16 \%)$ \\
\hline Adjusted rate & $16.5 \%$ & $16.9 \%$ & $21.3 \%$ & $21.2 \%$ \\
\hline Terminal rate & $5 / 29(17 \%)$ & $7 / 40(18 \%)$ & $6 / 32(19 \%)$ & $4 / 19(21 \%)$ \\
\hline First incidence (days) & 694 & 680 & 599 & 575 \\
\hline Poly-3 test & $P=0.302$ & $\mathrm{P}=0.594$ & $\mathrm{P}=0.389$ & $P=0.401$ \\
\hline \multicolumn{5}{|c|}{ Small Intestine (Duodenum, Jejunum, or Ileum): Carcinoma } \\
\hline Overall rate & $0 / 50(0 \%)$ & $3 / 50(6 \%)$ & $0 / 50(0 \%)$ & $2 / 50(4 \%)$ \\
\hline Adjusted rate & $0.0 \%$ & $6.4 \%$ & $0.0 \%$ & $5.4 \%$ \\
\hline Terminal rate & $0 / 29(0 \%)$ & $3 / 40(8 \%)$ & $0 / 32(0 \%)$ & $1 / 19(5 \%)$ \\
\hline First incidence (days) & $-^{\mathrm{e}}$ & $729(\mathrm{~T})$ & - & 563 \\
\hline Poly-3 test & $\mathrm{P}=0.311$ & $\mathrm{P}=0.141$ & $-^{\mathrm{f}}$ & $\mathrm{P}=0.209$ \\
\hline \multicolumn{5}{|c|}{ Small Intestine (Duodenum, Jejunum, or Ileum): Adenoma or Carcinoma } \\
\hline Overall rate & $1 / 50(2 \%)$ & $3 / 50(6 \%)$ & $1 / 50(2 \%)$ & $2 / 50(4 \%)$ \\
\hline Adjusted rate & $2.4 \%$ & $6.4 \%$ & $2.4 \%$ & $5.4 \%$ \\
\hline Terminal rate & $1 / 29(3 \%)$ & $3 / 40(8 \%)$ & $1 / 32(3 \%)$ & $1 / 19(5 \%)$ \\
\hline First incidence (days) & $729(\mathrm{~T})$ & $729(\mathrm{~T})$ & $729(\mathrm{~T})$ & 563 \\
\hline Poly-3 test & $P=0.463$ & $\mathrm{P}=0.348$ & $\mathrm{P}=0.758$ & $\mathrm{P}=0.455$ \\
\hline \multicolumn{5}{|c|}{ Kidney (Renal Tubule): Adenoma } \\
\hline Overall rate & $0 / 50(0 \%)$ & $5 / 50(10 \%)$ & $19 / 50(38 \%)$ & $10 / 50(20 \%)$ \\
\hline Adjusted rate & $0.0 \%$ & $10.6 \%$ & $44.2 \%$ & $26.7 \%$ \\
\hline Terminal rate & $0 / 29(0 \%)$ & $5 / 40(13 \%)$ & $15 / 32(47 \%)$ & $8 / 19(42 \%)$ \\
\hline First incidence (days) & - & $729(\mathrm{~T})$ & 600 & 525 \\
\hline
\end{tabular}


Vinylidene Chloride, NTP TR 582

\begin{tabular}{|c|c|c|c|c|}
\hline & $\begin{array}{l}\text { Chamber } \\
\text { Control }\end{array}$ & $6.25 \mathrm{ppm}$ & 12.5 ppm & 25 ppm \\
\hline Poly-3 test & $\mathrm{P}<0.001$ & $\mathrm{P}=0.041$ & $\mathrm{P}<0.001$ & $\mathrm{P}<0.001$ \\
\hline \multicolumn{5}{|c|}{ Kidney (Renal Tubule): Carcinoma } \\
\hline Overall rate & $0 / 50(0 \%)$ & $7 / 50(14 \%)$ & $31 / 50(62 \%)$ & $18 / 50(36 \%)$ \\
\hline Adjusted rate & $0.0 \%$ & $14.7 \%$ & $70.5 \%$ & $45.8 \%$ \\
\hline Terminal rate & $0 / 29(0 \%)$ & $5 / 40(13 \%)$ & $24 / 32(75 \%)$ & $10 / 19(53 \%)$ \\
\hline First incidence (days) & - & 619 & 429 & 537 \\
\hline Poly-3 test & $\mathrm{P}<0.001$ & $\mathrm{P}=0.012$ & $\mathrm{P}<0.001$ & $\mathrm{P}<0.001$ \\
\hline \multicolumn{5}{|c|}{ Kidney (Renal Tubule): Adenoma or Carcinoma } \\
\hline Overall rate & $0 / 50(0 \%)$ & $11 / 50(22 \%)$ & $37 / 50(74 \%)$ & $27 / 50(54 \%)$ \\
\hline Adjusted rate & $0.0 \%$ & $23.1 \%$ & $81.9 \%$ & $67.0 \%$ \\
\hline Terminal rate & $0 / 29(0 \%)$ & $9 / 40(23 \%)$ & $27 / 32(84 \%)$ & $17 / 19(90 \%)$ \\
\hline First incidence (days) & - & 619 & 429 & 525 \\
\hline Poly-3 test & $\mathrm{P}<0.001$ & $\mathrm{P}<0.001$ & $\mathrm{P}<0.001$ & $\mathrm{P}<0.001$ \\
\hline \multicolumn{5}{|c|}{ Liver: Hemangiosarcoma } \\
\hline Overall rate & $2 / 50(4 \%)$ & $2 / 50(4 \%)$ & $3 / 50(6 \%)$ & $3 / 50(6 \%)$ \\
\hline Adjusted rate & $4.7 \%$ & $4.2 \%$ & $7.2 \%$ & $7.9 \%$ \\
\hline Terminal rate & $0 / 29(0 \%)$ & $2 / 40(5 \%)$ & $3 / 32(9 \%)$ & $0 / 19(0 \%)$ \\
\hline First incidence (days) & 596 & $729(\mathrm{~T})$ & $729(\mathrm{~T})$ & 470 \\
\hline Poly-3 test & $P=0.292$ & $\mathrm{P}=0.659 \mathrm{~N}$ & $P=0.484$ & $P=0.443$ \\
\hline \multicolumn{5}{|c|}{ Liver: Hepatocellular Adenoma } \\
\hline Overall rate & $37 / 50(74 \%)$ & $35 / 50(70 \%)$ & $33 / 50(66 \%)$ & $25 / 50(50 \%)$ \\
\hline Adjusted rate & $77.6 \%$ & $72.5 \%$ & $73.8 \%$ & $60.0 \%$ \\
\hline Terminal rate & $21 / 29(72 \%)$ & $31 / 40(78 \%)$ & $25 / 32(78 \%)$ & $12 / 19(63 \%)$ \\
\hline First incidence (days) & 443 & 619 & 429 & 471 \\
\hline Poly-3 test & $\mathrm{P}=0.040 \mathrm{~N}$ & $\mathrm{P}=0.361 \mathrm{~N}$ & $\mathrm{P}=0.422 \mathrm{~N}$ & $\mathrm{P}=0.046 \mathrm{~N}$ \\
\hline \multicolumn{5}{|c|}{ Liver: Hepatocellular Carcinoma } \\
\hline Overall rate & $26 / 50(52 \%)$ & $19 / 50(38 \%)$ & $15 / 50(30 \%)$ & $29 / 50(58 \%)$ \\
\hline Adjusted rate & $55.0 \%$ & $38.1 \%$ & $33.2 \%$ & $64.4 \%$ \\
\hline Terminal rate & $11 / 29(38 \%)$ & $11 / 40(28 \%)$ & $7 / 32(22 \%)$ & $10 / 19(53 \%)$ \\
\hline First incidence (days) & 443 & 521 & 508 & 425 \\
\hline Poly-3 test & $\mathrm{P}=0.118$ & $\mathrm{P}=0.070 \mathrm{~N}$ & $\mathrm{P}=0.026 \mathrm{~N}$ & $\mathrm{P}=0.234$ \\
\hline \multicolumn{5}{|c|}{ Liver: Hepatocellular Adenoma or Carcinoma } \\
\hline Overall rate & $44 / 50(88 \%)$ & $41 / 50(82 \%)$ & $41 / 50(82 \%)$ & $42 / 50(84 \%)$ \\
\hline Adjusted rate & $89.2 \%$ & $82.1 \%$ & $86.8 \%$ & $89.2 \%$ \\
\hline Terminal rate & $24 / 29(83 \%)$ & $32 / 40(80 \%)$ & $28 / 32(88 \%)$ & $17 / 19(90 \%)$ \\
\hline First incidence (days) & 443 & 521 & 429 & 425 \\
\hline Poly-3 test & $P=0.425$ & $\mathrm{P}=0.233 \mathrm{~N}$ & $\mathrm{P}=0.481 \mathrm{~N}$ & $P=0.634$ \\
\hline
\end{tabular}


Vinylidene Chloride, NTP TR 582

\begin{tabular}{|c|c|c|c|c|}
\hline & $\begin{array}{l}\text { Chamber } \\
\text { Control }\end{array}$ & $6.25 \mathrm{ppm}$ & 12.5 ppm & 25 ppm \\
\hline \multicolumn{5}{|c|}{ Liver: Hepatocellular Carcinoma or Hepatoblastoma } \\
\hline Overall rate & $27 / 50(54 \%)$ & $19 / 50(38 \%)$ & $15 / 50(30 \%)$ & $29 / 50(58 \%)$ \\
\hline Adjusted rate & $57.1 \%$ & $38.1 \%$ & $33.2 \%$ & $64.4 \%$ \\
\hline Terminal rate & $12 / 29(41 \%)$ & $11 / 40(28 \%)$ & $7 / 32(22 \%)$ & $10 / 19(53 \%)$ \\
\hline First incidence (days) & 443 & 521 & 508 & 425 \\
\hline Poly-3 test & $\mathrm{P}=0.156$ & $\mathrm{P}=0.045 \mathrm{~N}$ & $\mathrm{P}=0.015 \mathrm{~N}$ & $\mathrm{P}=0.302$ \\
\hline \multicolumn{5}{|c|}{ Liver: Hepatocellular Adenoma, Hepatocellular Carcinoma, or Hepatoblastoma } \\
\hline Overall rate & $45 / 50(90 \%)$ & $41 / 50(82 \%)$ & $41 / 50(82 \%)$ & $42 / 50(84 \%)$ \\
\hline Adjusted rate & $91.2 \%$ & $82.1 \%$ & $86.8 \%$ & $89.2 \%$ \\
\hline Terminal rate & $25 / 29(86 \%)$ & $32 / 40(80 \%)$ & $28 / 32(88 \%)$ & $17 / 19(90 \%)$ \\
\hline First incidence (days) & 443 & 521 & 429 & 425 \\
\hline Poly-3 test & $P=0.529$ & $\mathrm{P}=0.146 \mathrm{~N}$ & $\mathrm{P}=0.350 \mathrm{~N}$ & $\mathrm{P}=0.506 \mathrm{~N}$ \\
\hline \multicolumn{5}{|c|}{ Liver: Hepatocholangiocarcinoma } \\
\hline Overall rate & $1 / 50(2 \%)$ & $2 / 50(4 \%)$ & $2 / 50(4 \%)$ & $3 / 50(6 \%)$ \\
\hline Adjusted rate & $2.4 \%$ & $4.2 \%$ & $4.7 \%$ & $8.0 \%$ \\
\hline Terminal rate & $0 / 29(0 \%)$ & $1 / 40(3 \%)$ & $0 / 32(0 \%)$ & $1 / 19(5 \%)$ \\
\hline First incidence (days) & 704 & 701 & 429 & 563 \\
\hline Poly-3 test & $\mathrm{P}=0.181$ & $P=0.540$ & $P=0.503$ & $\mathrm{P}=0.262$ \\
\hline \multicolumn{5}{|c|}{ Lung: Alveolar/bronchiolar Adenoma } \\
\hline Overall rate & $7 / 50(14 \%)$ & $8 / 50(16 \%)$ & $8 / 50(16 \%)$ & $7 / 50(14 \%)$ \\
\hline Adjusted rate & $16.6 \%$ & $16.9 \%$ & $18.4 \%$ & $18.8 \%$ \\
\hline Terminal rate & $6 / 29(21 \%)$ & $7 / 40(18 \%)$ & $5 / 32(16 \%)$ & $5 / 19(26 \%)$ \\
\hline First incidence (days) & 694 & 658 & 404 & 548 \\
\hline Poly-3 test & $\mathrm{P}=0.430$ & $\mathrm{P}=0.597$ & $\mathrm{P}=0.524$ & $\mathrm{P}=0.512$ \\
\hline \multicolumn{5}{|c|}{ Lung: Alveolar/bronchiolar Carcinoma } \\
\hline Overall rate & $9 / 50(18 \%)$ & $9 / 50(18 \%)$ & $8 / 50(16 \%)$ & $6 / 50(12 \%)$ \\
\hline Adjusted rate & $21.1 \%$ & $19.0 \%$ & $18.6 \%$ & $16.3 \%$ \\
\hline Terminal rate & $8 / 29(28 \%)$ & $8 / 40(20 \%)$ & $5 / 32(16 \%)$ & $5 / 19(26 \%)$ \\
\hline First incidence (days) & 512 & 664 & 508 & 633 \\
\hline Poly-3 test & $\mathrm{P}=0.350 \mathrm{~N}$ & $\mathrm{P}=0.506 \mathrm{~N}$ & $\mathrm{P}=0.497 \mathrm{~N}$ & $\mathrm{P}=0.400 \mathrm{~N}$ \\
\hline \multicolumn{5}{|c|}{ Lung: Alveolar/bronchiolar Adenoma or Carcinoma } \\
\hline Overall rate & $13 / 50(26 \%)$ & $16 / 50(32 \%)$ & $14 / 50(28 \%)$ & $12 / 50(24 \%)$ \\
\hline Adjusted rate & $30.3 \%$ & $33.5 \%$ & $31.4 \%$ & $32.0 \%$ \\
\hline Terminal rate & $11 / 29(38 \%)$ & $14 / 40(35 \%)$ & $9 / 32(28 \%)$ & $9 / 19(47 \%)$ \\
\hline First incidence (days) & 512 & 658 & 404 & 548 \\
\hline Poly-3 test & $\mathrm{P}=0.513$ & $P=0.459$ & $\mathrm{P}=0.547$ & $\mathrm{P}=0.531$ \\
\hline
\end{tabular}


Vinylidene Chloride, NTP TR 582

\begin{tabular}{|c|c|c|c|c|}
\hline & $\begin{array}{c}\text { Chamber } \\
\text { Control }\end{array}$ & $6.25 \mathrm{ppm}$ & $12.5 \mathrm{ppm}$ & 25 ppm \\
\hline \multicolumn{5}{|c|}{ Spleen: Hemangiosarcoma } \\
\hline Overall rate & $2 / 50(4 \%)$ & $3 / 49(6 \%)$ & $1 / 50(2 \%)$ & $4 / 50(8 \%)$ \\
\hline Adjusted rate & $4.7 \%$ & $6.5 \%$ & $2.4 \%$ & $10.8 \%$ \\
\hline Terminal rate & $0 / 29(0 \%)$ & $3 / 40(8 \%)$ & $0 / 32(0 \%)$ & $2 / 19(11 \%)$ \\
\hline First incidence (days) & 596 & $729(\mathrm{~T})$ & 648 & 548 \\
\hline Poly-3 test & $P=0.236$ & $\mathrm{P}=0.537$ & $\mathrm{P}=0.509 \mathrm{~N}$ & $\mathrm{P}=0.272$ \\
\hline \multicolumn{5}{|c|}{ All Organs: Hemangioma } \\
\hline Overall rate & $1 / 50(2 \%)$ & $1 / 50(2 \%)$ & $3 / 50(6 \%)$ & $1 / 50(2 \%)$ \\
\hline Adjusted rate & $2.4 \%$ & $2.1 \%$ & $7.2 \%$ & $2.7 \%$ \\
\hline Terminal rate & $1 / 29(3 \%)$ & $1 / 40(3 \%)$ & $2 / 32(6 \%)$ & $1 / 19(5 \%)$ \\
\hline First incidence (days) & $729(\mathrm{~T})$ & $729(\mathrm{~T})$ & 726 & $729(\mathrm{~T})$ \\
\hline Poly-3 test & $P=0.452$ & $\mathrm{P}=0.734 \mathrm{~N}$ & $P=0.300$ & $P=0.728$ \\
\hline \multicolumn{5}{|c|}{ All Organs: Hemangiosarcoma } \\
\hline Overall rate & $2 / 50(4 \%)$ & $5 / 50(10 \%)$ & $5 / 50(10 \%)$ & $6 / 50(12 \%)$ \\
\hline Adjusted rate & $4.7 \%$ & $10.6 \%$ & $12.0 \%$ & $15.6 \%$ \\
\hline Terminal rate & $0 / 29(0 \%)$ & $5 / 40(13 \%)$ & $4 / 32(13 \%)$ & $2 / 19(11 \%)$ \\
\hline First incidence (days) & 596 & $729(\mathrm{~T})$ & 648 & 470 \\
\hline Poly-3 test & $\mathrm{P}=0.088$ & $P=0.257$ & $P=0.204$ & $\mathrm{P}=0.098$ \\
\hline \multicolumn{5}{|c|}{ All Organs: Hemangioma or Hemangiosarcoma } \\
\hline Overall rate & $3 / 50(6 \%)$ & $6 / 50(12 \%)$ & $8 / 50(16 \%)$ & $6 / 50(12 \%)$ \\
\hline Adjusted rate & $7.0 \%$ & $12.7 \%$ & $19.1 \%$ & $15.6 \%$ \\
\hline Terminal rate & $1 / 29(3 \%)$ & $6 / 40(15 \%)$ & $6 / 32(19 \%)$ & $2 / 19(11 \%)$ \\
\hline First incidence (days) & 596 & $729(\mathrm{~T})$ & 648 & 470 \\
\hline Poly-3 test & $\mathrm{P}=0.148$ & $\mathrm{P}=0.291$ & $\mathrm{P}=0.088$ & $\mathrm{P}=0.188$ \\
\hline \multicolumn{5}{|c|}{ All Organs: Malignant Lymphoma } \\
\hline Overall rate & $2 / 50(4 \%)$ & $2 / 50(4 \%)$ & $4 / 50(8 \%)$ & $0 / 50(0 \%)$ \\
\hline Adjusted rate & $4.7 \%$ & $4.2 \%$ & $9.6 \%$ & $0.0 \%$ \\
\hline Terminal rate & $1 / 29(3 \%)$ & $0 / 40(0 \%)$ & $4 / 32(13 \%)$ & $0 / 19(0 \%)$ \\
\hline First incidence (days) & 661 & 639 & $729(\mathrm{~T})$ & - \\
\hline Poly-3 test & $\mathrm{P}=0.321 \mathrm{~N}$ & $\mathrm{P}=0.651 \mathrm{~N}$ & $\mathrm{P}=0.327$ & $\mathrm{P}=0.272 \mathrm{~N}$ \\
\hline \multicolumn{5}{|c|}{ All Organs: Benign Neoplasms } \\
\hline Overall rate & $43 / 50(86 \%)$ & $41 / 50(82 \%)$ & $43 / 50(86 \%)$ & $35 / 50(70 \%)$ \\
\hline Adjusted rate & $90.2 \%$ & $84.4 \%$ & $89.8 \%$ & $81.4 \%$ \\
\hline Terminal rate & $27 / 29(93 \%)$ & $36 / 40(90 \%)$ & $29 / 32(91 \%)$ & $18 / 19(95 \%)$ \\
\hline First incidence (days) & 443 & 619 & 404 & 471 \\
\hline Poly-3 test & $\mathrm{P}=0.176 \mathrm{~N}$ & $\mathrm{P}=0.280 \mathrm{~N}$ & $\mathrm{P}=0.621 \mathrm{~N}$ & $\mathrm{P}=0.144 \mathrm{~N}$ \\
\hline
\end{tabular}


Vinylidene Chloride, NTP TR 582

\begin{tabular}{|c|c|c|c|c|}
\hline & $\begin{array}{l}\text { Chamber } \\
\text { Control }\end{array}$ & $6.25 \mathrm{ppm}$ & $12.5 \mathrm{ppm}$ & 25 ppm \\
\hline \multicolumn{5}{|c|}{ All Organs: Malignant Neoplasms } \\
\hline Overall rate & $37 / 50(74 \%)$ & $38 / 50(76 \%)$ & $42 / 50(84 \%)$ & $43 / 50(86 \%)$ \\
\hline Adjusted rate & $76.6 \%$ & $76.0 \%$ & $89.0 \%$ & $90.0 \%$ \\
\hline Terminal rate & $19 / 29(66 \%)$ & $28 / 40(70 \%)$ & $28 / 32(88 \%)$ & $17 / 19(90 \%)$ \\
\hline First incidence (days) & 443 & 521 & 429 & 425 \\
\hline Poly-3 test & $\mathrm{P}=0.020$ & $\mathrm{P}=0.567 \mathrm{~N}$ & $\mathrm{P}=0.082$ & $\mathrm{P}=0.058$ \\
\hline \multicolumn{5}{|c|}{ All Organs: Benign or Malignant Neoplasms } \\
\hline Overall rate & $49 / 50(98 \%)$ & $49 / 50(98 \%)$ & $49 / 50(98 \%)$ & $48 / 50(96 \%)$ \\
\hline Adjusted rate & $99.3 \%$ & $98.0 \%$ & $99.0 \%$ & $98.2 \%$ \\
\hline Terminal rate & $29 / 29(100 \%)$ & $39 / 40(98 \%)$ & $32 / 32(100 \%)$ & $19 / 19(100 \%)$ \\
\hline First incidence (days) & 443 & 521 & 404 & 425 \\
\hline Poly-3 test & $\mathrm{P}=0.541 \mathrm{~N}$ & $\mathrm{P}=0.624 \mathrm{~N}$ & $\mathrm{P}=0.927 \mathrm{~N}$ & $\mathrm{P}=0.732 \mathrm{~N}$ \\
\hline \multicolumn{5}{|c|}{$\begin{array}{l}\mathrm{T}=\text { terminal kill. } \\
\text { aNumber of neoplasm-bearing animals/number of animals examined. Denominator is number of animals examined } \\
\text { microscopically for adrenal gland, kidney, liver, lung, and spleen; for other tissues, denominator is number of animals } \\
\text { necropsied. } \\
\text { bPoly-3 estimated neoplasm incidence after adjustment for intercurrent mortality. } \\
\text { 'Observed incidence at terminal kill. } \\
\text { dBeneath the chamber control incidence is the } P \text { value associated with the trend test. Beneath the exposed group incidence are the } \\
\mathrm{P} \text { values corresponding to pairwise comparisons between the chamber controls and that exposed group. The Poly-3 test accounts } \\
\text { for differential mortality in animals that do not reach terminal kill. A negative trend or a lower incidence in an exposure group is } \\
\text { indicated by } \mathrm{N} \text {. } \\
\text { eNot applicable; no neoplasms in animal group. } \\
\text { fValue of statistic cannot be computed. }\end{array}$} \\
\hline
\end{tabular}

Table C-3. Historical Incidence of Renal Tubule Neoplasms in Control Male B6C3F1/N Mice ${ }^{\text {a }}$

\begin{tabular}{lccc}
\hline \multicolumn{1}{c}{ Study (Study Start) } & Adenoma & Carcinoma & $\begin{array}{c}\text { Adenoma or } \\
\text { Carcinoma }\end{array}$ \\
\hline Historical Incidence: Inhalation Studies & & & \\
1-Bromopropane (July 2003) & $0 / 49$ & $0 / 49$ & $0 / 49$ \\
CIMSTAR 3800 (May 2008) & $0 / 50$ & $0 / 50$ & $0 / 50$ \\
Cobalt (May 2006) & $0 / 50$ & $0 / 50$ & $0 / 50$ \\
Diethylamine (August 2003) & $0 / 50$ & $0 / 50$ & $0 / 50$ \\
Tetralin (June 2003) & $0 / 49$ & $0 / 49$ & $0 / 49$ \\
Vinylidene chloride (June 2005) & $0 / 50$ & $0 / 50$ & $0 / 50$ \\
$\quad$ Total (\%) & $0 / 298$ & $0 / 298$ & $0 / 298$ \\
\hline Overall Historical Incidence: All Routes & & & $11 / 944(1.2 \%)$ \\
Total (\%) & $8 / 944(0.9 \%)$ & $3 / 944(0.3 \%)$ & $1.2 \% \pm 1.8 \%$ \\
Mean \pm standard deviation & $0.9 \% \pm 1.4 \%$ & $0.3 \% \pm 1.0 \%$ & $0 \%-6 \%$ \\
Range & $0 \%-4 \%$ & $0 \%-4 \%$ & \\
\hline
\end{tabular}

Data as of June 2013. 
Table C-4. Summary of the Incidence of Nonneoplastic Lesions in Male Mice in the Two-year Inhalation Study of Vinylidene Chloride ${ }^{\mathrm{a}}$

\begin{tabular}{|c|c|c|c|c|}
\hline & $\begin{array}{c}\text { Chamber } \\
\text { Control }\end{array}$ & $6.25 \mathrm{ppm}$ & $12.5 \mathrm{ppm}$ & 25 ppm \\
\hline \multicolumn{5}{|l|}{ Disposition Summary } \\
\hline Animals initially in study & 50 & 50 & 50 & 50 \\
\hline \multicolumn{5}{|l|}{ Early deaths } \\
\hline Moribund & 12 & 5 & 14 & 19 \\
\hline Natural deaths & 9 & 5 & 4 & 12 \\
\hline \multicolumn{5}{|l|}{ Survivors } \\
\hline Died last week of study & - & 1 & - & 1 \\
\hline Terminal kill & 29 & 39 & 32 & 18 \\
\hline Animals examined microscopically & 50 & 50 & 50 & 50 \\
\hline \multicolumn{5}{|l|}{ Alimentary System } \\
\hline Esophagus & $(50)$ & $(50)$ & $(50)$ & $(50)$ \\
\hline Gallbladder & $(42)$ & $(45)$ & $(47)$ & $(41)$ \\
\hline Intestine large, cecum & $(47)$ & $(48)$ & $(48)$ & $(40)$ \\
\hline Artery, inflammation & - & - & - & $1(3 \%)$ \\
\hline Intestine large, colon & $(47)$ & $(48)$ & $(48)$ & (42) \\
\hline Intestine large, rectum & $(48)$ & $(48)$ & $(48)$ & $(42)$ \\
\hline Intestine small, duodenum & (44) & (47) & $(47)$ & $(38)$ \\
\hline Necrosis & $1(2 \%)$ & - & $1(2 \%)$ & - \\
\hline Intestine small, ileum & (44) & (47) & $(47)$ & (39) \\
\hline Hyperplasia & - & - & $1(2 \%)$ & - \\
\hline Intestine small, jejunum & $(43)$ & $(47)$ & $(47)$ & (39) \\
\hline Liver & $(50)$ & $(50)$ & $(50)$ & (50) \\
\hline Angiectasis & $1(2 \%)$ & $1(2 \%)$ & - & - \\
\hline Basophilic focus & $2(4 \%)$ & $4(8 \%)$ & $2(4 \%)$ & $7(14 \%)$ \\
\hline Clear cell focus & $16(32 \%)$ & $11(22 \%)$ & $10(20 \%)$ & $8(16 \%)$ \\
\hline Cyst & - & - & $2(4 \%)$ & $2(4 \%)$ \\
\hline Degeneration, cystic & - & - & $1(2 \%)$ & $1(2 \%)$ \\
\hline Eosinophilic focus & $9(18 \%)$ & $7(14 \%)$ & $4(8 \%)$ & $6(12 \%)$ \\
\hline Fatty change & $1(2 \%)$ & - & - & - \\
\hline Infarct & - & $1(2 \%)$ & - & - \\
\hline Mineralization & - & - & - & $1(2 \%)$ \\
\hline Mixed cell focus & $2(4 \%)$ & $2(4 \%)$ & $1(2 \%)$ & $1(2 \%)$ \\
\hline Necrosis & $5(10 \%)$ & $1(2 \%)$ & $2(4 \%)$ & $6(12 \%)$ \\
\hline Thrombosis & - & $1(2 \%)$ & - & - \\
\hline
\end{tabular}


Vinylidene Chloride, NTP TR 582

\begin{tabular}{|c|c|c|c|c|}
\hline & $\begin{array}{c}\text { Chamber } \\
\text { Control }\end{array}$ & $6.25 \mathrm{ppm}$ & 12.5 ppm & 25 ppm \\
\hline Mesentery & $(6)$ & (9) & $(6)$ & (3) \\
\hline Fat, necrosis & $6(100 \%)$ & $8(89 \%)$ & $6(100 \%)$ & $1(33 \%)$ \\
\hline Pancreas & $(50)$ & $(49)$ & $(50)$ & $(48)$ \\
\hline Artery, inflammation, chronic active & - & - & $1(2 \%)$ & - \\
\hline Salivary glands & $(50)$ & $(50)$ & $(50)$ & $(50)$ \\
\hline Stomach, forestomach & $(49)$ & $(50)$ & $(50)$ & $(49)$ \\
\hline Hyperplasia, squamous & $4(8 \%)$ & $1(2 \%)$ & $7(14 \%)$ & $10(20 \%)$ \\
\hline Inflammation, chronic active & $2(4 \%)$ & $2(4 \%)$ & $3(6 \%)$ & $7(14 \%)$ \\
\hline Mineralization & - & $1(2 \%)$ & - & - \\
\hline Necrosis & $1(2 \%)$ & $2(4 \%)$ & $2(4 \%)$ & $4(8 \%)$ \\
\hline Ulcer & $1(2 \%)$ & $1(2 \%)$ & - & $2(4 \%)$ \\
\hline Artery, inflammation, chronic active & - & - & - & $1(2 \%)$ \\
\hline Submucosa, necrosis & - & - & $1(2 \%)$ & - \\
\hline Stomach, glandular & $(48)$ & (49) & (49) & $(48)$ \\
\hline Inflammation, acute & - & $1(2 \%)$ & - & - \\
\hline Mineralization & $2(4 \%)$ & $1(2 \%)$ & $1(2 \%)$ & $1(2 \%)$ \\
\hline Necrosis & $4(8 \%)$ & $3(6 \%)$ & $3(6 \%)$ & $5(10 \%)$ \\
\hline Tongue & $(0)$ & $(0)$ & (1) & (0) \\
\hline Angiectasis & - & - & $1(100 \%)$ & - \\
\hline Tooth & (2) & (2) & $(0)$ & (1) \\
\hline Dysplasia & $2(100 \%)$ & $2(100 \%)$ & - & $1(100 \%)$ \\
\hline \multicolumn{5}{|l|}{ Cardiovascular System } \\
\hline Blood vessel & $(0)$ & $(0)$ & (1) & (3) \\
\hline Thrombosis & - & - & - & $1(33 \%)$ \\
\hline Heart & $(50)$ & $(50)$ & $(50)$ & $(50)$ \\
\hline Cardiomyopathy & $11(22 \%)$ & $10(20 \%)$ & $12(24 \%)$ & $13(26 \%)$ \\
\hline Thrombosis & - & - & $2(4 \%)$ & $1(2 \%)$ \\
\hline Artery, inflammation, chronic active & - & - & $1(2 \%)$ & $2(4 \%)$ \\
\hline Endothelium, hyperplasia & - & - & - & $1(2 \%)$ \\
\hline \multicolumn{5}{|l|}{ Endocrine System } \\
\hline Adrenal cortex & $(50)$ & $(50)$ & $(50)$ & $(50)$ \\
\hline Hyperplasia & $5(10 \%)$ & $6(12 \%)$ & $5(10 \%)$ & $3(6 \%)$ \\
\hline Hypertrophy & $18(36 \%)$ & $11(22 \%)$ & $12(24 \%)$ & $10(20 \%)$ \\
\hline Adrenal medulla & $(50)$ & $(50)$ & $(50)$ & $(50)$ \\
\hline Hyperplasia & - & $3(6 \%)$ & $2(4 \%)$ & $3(6 \%)$ \\
\hline
\end{tabular}


Vinylidene Chloride, NTP TR 582

\begin{tabular}{|c|c|c|c|c|}
\hline & $\begin{array}{l}\text { Chamber } \\
\text { Control }\end{array}$ & $6.25 \mathrm{ppm}$ & 12.5 ppm & 25 ppm \\
\hline Islets, pancreatic & $(50)$ & $(49)$ & $(49)$ & $(49)$ \\
\hline Hyperplasia & $3(6 \%)$ & $4(8 \%)$ & $4(8 \%)$ & $2(4 \%)$ \\
\hline Parathyroid gland & (26) & $(22)$ & (26) & (24) \\
\hline Cyst & - & - & $2(8 \%)$ & $1(4 \%)$ \\
\hline Pituitary gland & (49) & (49) & $(50)$ & $(46)$ \\
\hline Pars distalis, hyperplasia & $1(2 \%)$ & $1(2 \%)$ & $1(2 \%)$ & $2(4 \%)$ \\
\hline Thyroid gland & $(50)$ & $(49)$ & $(50)$ & $(49)$ \\
\hline Follicular cell, hyperplasia & - & - & $1(2 \%)$ & - \\
\hline \multicolumn{5}{|l|}{ General Body System } \\
\hline None & - & - & - & - \\
\hline \multicolumn{5}{|l|}{ Genital System } \\
\hline Epididymis & $(50)$ & $(50)$ & $(50)$ & $(50)$ \\
\hline Granuloma sperm & - & $1(2 \%)$ & $1(2 \%)$ & - \\
\hline Inflammation, chronic & $1(2 \%)$ & - & $1(2 \%)$ & - \\
\hline Spermatocele & $1(2 \%)$ & - & - & - \\
\hline Preputial gland & $(50)$ & $(50)$ & $(50)$ & (50) \\
\hline Ectasia & $1(2 \%)$ & $1(2 \%)$ & - & - \\
\hline Inflammation, suppurative & $1(2 \%)$ & - & - & - \\
\hline Inflammation, chronic active & $3(6 \%)$ & $5(10 \%)$ & $3(6 \%)$ & $2(4 \%)$ \\
\hline Prostate & $(50)$ & $(50)$ & $(50)$ & $(50)$ \\
\hline Inflammation, suppurative & $1(2 \%)$ & $1(2 \%)$ & $1(2 \%)$ & $1(2 \%)$ \\
\hline Inflammation, chronic active & - & - & $2(4 \%)$ & $1(2 \%)$ \\
\hline Artery, inflammation, chronic active & - & - & $1(2 \%)$ & $1(2 \%)$ \\
\hline Seminal vesicle & $(50)$ & $(50)$ & $(50)$ & $(50)$ \\
\hline Dilatation & - & - & - & $1(2 \%)$ \\
\hline Inflammation, suppurative & - & $1(2 \%)$ & - & $1(2 \%)$ \\
\hline Testes & $(50)$ & $(50)$ & $(50)$ & $(50)$ \\
\hline Atrophy & - & $2(4 \%)$ & - & - \\
\hline Germinal epithelium, degeneration & $2(4 \%)$ & $5(10 \%)$ & $3(6 \%)$ & $1(2 \%)$ \\
\hline Interstitial cell, hyperplasia & - & $1(2 \%)$ & - & $2(4 \%)$ \\
\hline \multicolumn{5}{|l|}{ Hematopoietic System } \\
\hline Bone marrow & $(50)$ & $(50)$ & $(50)$ & $(50)$ \\
\hline Erythroid cell, depletion cellular & - & - & $1(2 \%)$ & - \\
\hline Lymph node & (2) & (2) & $(0)$ & $(2)$ \\
\hline Lumbar, hyperplasia, lymphoid & - & - & - & $1(50 \%)$ \\
\hline
\end{tabular}


Vinylidene Chloride, NTP TR 582

\begin{tabular}{|c|c|c|c|c|}
\hline & $\begin{array}{c}\text { Chamber } \\
\text { Control }\end{array}$ & $6.25 \mathrm{ppm}$ & 12.5 ppm & 25 ppm \\
\hline Lymph node, bronchial & $(33)$ & (34) & $(31)$ & (19) \\
\hline Lymph node, mandibular & $(17)$ & $(29)$ & (19) & $(25)$ \\
\hline Hyperplasia & $1(6 \%)$ & - & - & - \\
\hline Lymph node, mediastinal & $(43)$ & $(29)$ & $(43)$ & $(38)$ \\
\hline Lymph node, mesenteric & $(46)$ & $(48)$ & $(48)$ & $(47)$ \\
\hline Angiectasis & - & - & - & $2(4 \%)$ \\
\hline Inflammation, granulomatous & - & - & - & $2(2 \%)$ \\
\hline Necrosis & - & $1(2 \%)$ & - & - \\
\hline Artery, inflammation, chronic active & - & - & - & $1(2 \%)$ \\
\hline Spleen & $(50)$ & (49) & $(50)$ & $(50)$ \\
\hline Hematopoietic cell proliferation & $1(2 \%)$ & $4(8 \%)$ & $2(4 \%)$ & $5(10 \%)$ \\
\hline Hyperplasia, lymphoid & $1(2 \%)$ & - & - & - \\
\hline Lymphoid follicle, hyperplasia & - & - & - & $1(2 \%)$ \\
\hline Thymus & (39) & $(37)$ & $(38)$ & $(26)$ \\
\hline Cyst & $1(3 \%)$ & - & - & - \\
\hline Necrosis & $1(3 \%)$ & - & - & - \\
\hline \multicolumn{5}{|l|}{ Integumentary System } \\
\hline Mammary gland & (1) & $(2)$ & $(0)$ & (1) \\
\hline Skin & $(50)$ & $(50)$ & $(50)$ & $(50)$ \\
\hline Inflammation, chronic active & $1(2 \%)$ & - & - & - \\
\hline Necrosis & $4(8 \%)$ & $5(10 \%)$ & $3(6 \%)$ & $3(6 \%)$ \\
\hline Epidermis, hyperplasia, squamous & - & - & $1(2 \%)$ & $1(2 \%)$ \\
\hline \multicolumn{5}{|l|}{ Musculoskeletal System } \\
\hline Bone & $(50)$ & $(50)$ & $(50)$ & $(50)$ \\
\hline Fibrous osteodystrophy & - & - & - & $1(2 \%)$ \\
\hline Hyperostosis & $1(2 \%)$ & - & - & - \\
\hline Cartilage, degeneration & - & $1(2 \%)$ & - & - \\
\hline Skeletal muscle & $(1)$ & $(1)$ & $(2)$ & $(2)$ \\
\hline \multicolumn{5}{|l|}{ Nervous System } \\
\hline Brain & $(50)$ & $(50)$ & $(50)$ & $(50)$ \\
\hline Hemorrhage & - & - & - & $1(2 \%)$ \\
\hline Artery, inflammation, chronic active & - & - & - & $1(2 \%)$ \\
\hline \multicolumn{5}{|l|}{ Respiratory System } \\
\hline Larynx & $(50)$ & $(50)$ & $(50)$ & $(49)$ \\
\hline Foreign body & $1(2 \%)$ & - & - & $2(4 \%)$ \\
\hline
\end{tabular}


Vinylidene Chloride, NTP TR 582

\begin{tabular}{|c|c|c|c|c|}
\hline & $\begin{array}{l}\text { Chamber } \\
\text { Control }\end{array}$ & $6.25 \mathrm{ppm}$ & $12.5 \mathrm{ppm}$ & $25 \mathrm{ppm}$ \\
\hline Inflammation & - & - & - & $1(2 \%)$ \\
\hline Inflammation, suppurative & $1(2 \%)$ & $1(2 \%)$ & - & $2(4 \%)$ \\
\hline Inflammation, chronic active & $1(2 \%)$ & - & $1(2 \%)$ & - \\
\hline Metaplasia, squamous & $1(2 \%)$ & - & - & $1(2 \%)$ \\
\hline Artery, inflammation, chronic active & - & - & - & $1(2 \%)$ \\
\hline Squamous epithelium, necrosis & - & $1(2 \%)$ & - & $1(2 \%)$ \\
\hline Lung & (50) & $(50)$ & $(50)$ & $(50)$ \\
\hline Hemorrhage & $1(2 \%)$ & - & $1(2 \%)$ & - \\
\hline Inflammation, chronic active & $2(4 \%)$ & $1(2 \%)$ & $3(6 \%)$ & $1(2 \%)$ \\
\hline Thrombosis & - & $1(2 \%)$ & - & - \\
\hline Alveolar epithelium, hyperplasia & $3(6 \%)$ & $7(14 \%)$ & $4(8 \%)$ & $6(12 \%)$ \\
\hline $\begin{array}{l}\text { Alveolus, infiltration cellular, } \\
\text { histiocyte }\end{array}$ & $4(8 \%)$ & - & $3(6 \%)$ & $4(8 \%)$ \\
\hline Serosa, hyperplasia & - & - & - & $1(2 \%)$ \\
\hline Nose & (50) & $(50)$ & (49) & $(49)$ \\
\hline Foreign body & $2(4 \%)$ & - & $2(4 \%)$ & $4(8 \%)$ \\
\hline Hemorrhage & - & - & $1(2 \%)$ & - \\
\hline Hyperostosis & $1(2 \%)$ & $27(54 \%)$ & $45(92 \%)$ & $48(98 \%)$ \\
\hline Inflammation, suppurative & $3(6 \%)$ & $2(4 \%)$ & $4(8 \%)$ & $7(14 \%)$ \\
\hline Inflammation, chronic active & - & $1(2 \%)$ & - & - \\
\hline Polyp, inflammatory & - & - & - & $1(2 \%)$ \\
\hline $\begin{array}{l}\text { Olfactory epithelium, accumulation, } \\
\text { hyaline droplet }\end{array}$ & $2(4 \%)$ & $5(10 \%)$ & $13(27 \%)$ & $11(22 \%)$ \\
\hline Olfactory epithelium, atrophy & $1(2 \%)$ & $2(4 \%)$ & $1(2 \%)$ & - \\
\hline $\begin{array}{l}\text { Olfactory epithelium, metaplasia, } \\
\text { respiratory }\end{array}$ & $17(34 \%)$ & $39(78 \%)$ & $47(96 \%)$ & $48(98 \%)$ \\
\hline Olfactory epithelium, necrosis & $4(8 \%)$ & $1(2 \%)$ & $2(4 \%)$ & $4(8 \%)$ \\
\hline $\begin{array}{l}\text { Respiratory epithelium, } \\
\text { accumulation, hyaline droplet }\end{array}$ & $17(34 \%)$ & $21(42 \%)$ & $24(49 \%)$ & $16(33 \%)$ \\
\hline Respiratory epithelium, hyperplasia & $37(74 \%)$ & $36(72 \%)$ & $35(71 \%)$ & $39(80 \%)$ \\
\hline $\begin{array}{l}\text { Respiratory epithelium, metaplasia, } \\
\text { squamous }\end{array}$ & $2(4 \%)$ & - & $3(6 \%)$ & - \\
\hline Respiratory epithelium, necrosis & $2(4 \%)$ & - & $2(4 \%)$ & $3(6 \%)$ \\
\hline Turbinate, atrophy & - & $46(92 \%)$ & $46(94 \%)$ & $47(96 \%)$ \\
\hline Turbinate, necrosis & - & - & $1(2 \%)$ & - \\
\hline Pleura & (1) & (1) & (0) & (0) \\
\hline
\end{tabular}


Vinylidene Chloride, NTP TR 582

\begin{tabular}{|c|c|c|c|c|}
\hline & $\begin{array}{c}\text { Chamber } \\
\text { Control }\end{array}$ & $6.25 \mathrm{ppm}$ & $12.5 \mathrm{ppm}$ & 25 ppm \\
\hline Trachea & $(50)$ & $(50)$ & $(50)$ & $(50)$ \\
\hline Inflammation, suppurative & $1(2 \%)$ & - & - & $1(2 \%)$ \\
\hline Inflammation, chronic active & - & - & - & $1(2 \%)$ \\
\hline Epithelium, necrosis & - & - & - & $1(2 \%)$ \\
\hline \multicolumn{5}{|l|}{ Special Senses System } \\
\hline Eye & $(50)$ & $(50)$ & $(50)$ & $(48)$ \\
\hline Cataract & - & - & - & $1(2 \%)$ \\
\hline Degeneration & - & - & $1(2 \%)$ & - \\
\hline Necrosis & - & - & - & $1(2 \%)$ \\
\hline Cornea, hyperplasia, squamous & - & $1(2 \%)$ & - & - \\
\hline Cornea, inflammation, chronic active & - & $1(2 \%)$ & $1(2 \%)$ & - \\
\hline Harderian gland & $(50)$ & $(50)$ & $(50)$ & $(50)$ \\
\hline Hyperplasia & - & $2(4 \%)$ & $3(6 \%)$ & $1(2 \%)$ \\
\hline Inflammation, suppurative & - & - & - & $1(2 \%)$ \\
\hline Inflammation, chronic active & - & $2(4 \%)$ & - & - \\
\hline \multicolumn{5}{|l|}{ Urinary System } \\
\hline Kidney & $(50)$ & $(50)$ & $(50)$ & $(50)$ \\
\hline Cyst & $1(2 \%)$ & $1(2 \%)$ & $5(10 \%)$ & $7(14 \%)$ \\
\hline Hydronephrosis & $2(4 \%)$ & - & $1(2 \%)$ & $3(6 \%)$ \\
\hline Infarct & $2(4 \%)$ & $2(4 \%)$ & $2(4 \%)$ & $1(2 \%)$ \\
\hline Inflammation, chronic active & - & - & $1(2 \%)$ & - \\
\hline Metaplasia, osseous & $2(4 \%)$ & $1(2 \%)$ & $1(2 \%)$ & - \\
\hline Mineralization & $1(2 \%)$ & - & - & - \\
\hline Nephropathy & $44(88 \%)$ & $46(92 \%)$ & $37(74 \%)$ & $44(88 \%)$ \\
\hline Papilla, necrosis & $1(2 \%)$ & - & - & - \\
\hline Pelvis, inflammation, chronic active & - & - & $1(2 \%)$ & - \\
\hline Renal tubule, hyperplasia & - & $8(16 \%)$ & $22(44 \%)$ & $16(32 \%)$ \\
\hline Renal tubule, pigmentation & - & $1(2 \%)$ & - & - \\
\hline Transitional epithelium, hyperplasia & - & - & $1(2 \%)$ & - \\
\hline Urinary bladder & $(50)$ & $(50)$ & $(50)$ & $(49)$ \\
\hline Inflammation, chronic active & - & $1(2 \%)$ & $1(2 \%)$ & - \\
\hline Necrosis & - & $1(2 \%)$ & - & $1(2 \%)$ \\
\hline Transitional epithelium, hyperplasia & - & $2(4 \%)$ & $3(6 \%)$ & $1(2 \%)$ \\
\hline
\end{tabular}

${ }^{a}$ Number of animals examined microscopically at the site and the number of animals with lesion. 


\section{Appendix D. Summary of Lesions in Female Mice in the Two-year Inhalation Study of Vinylidene Chloride}

\section{Tables}

Table D-1. Summary of the Incidence of Neoplasms in Female Mice in the Two-year Inhalation Study of Vinylidene Chloride

Table D-2. Statistical Analysis of Primary Neoplasms in Female Mice in the Two-year Inhalation Study of Vinylidene Chloride D-8

Table D-3. Historical Incidence of Liver Neoplasms in Control Female B6C3F1/N Mice ..... D-13

Table D-4. Summary of the Incidence of Nonneoplastic Lesions in Female Mice in the Two-year Inhalation Study of Vinylidene Chloride D-14 
Table D-1. Summary of the Incidence of Neoplasms in Female Mice in the Two-year Inhalation Study of Vinylidene Chloride ${ }^{a}$

\begin{tabular}{|c|c|c|c|c|}
\hline & $\begin{array}{l}\text { Chamber } \\
\text { Control }\end{array}$ & $6.25 \mathrm{ppm}$ & $12.5 \mathrm{ppm}$ & $25 \mathrm{ppm}$ \\
\hline \multicolumn{5}{|l|}{ Disposition Summary } \\
\hline Animals initially in study & 50 & 50 & 50 & 50 \\
\hline \multicolumn{5}{|l|}{ Early deaths } \\
\hline Moribund & 11 & 20 & 14 & 17 \\
\hline Natural deaths & 3 & 5 & 6 & 9 \\
\hline \multicolumn{5}{|l|}{ Survivors } \\
\hline Died last week of study & - & - & - & 1 \\
\hline Terminal kill & 36 & 25 & 30 & 23 \\
\hline Animals examined microscopically & 50 & 50 & 50 & 50 \\
\hline \multicolumn{5}{|l|}{ Alimentary System } \\
\hline Esophagus & (50) & (50) & (50) & (50) \\
\hline Gallbladder & (46) & (43) & $(45)$ & (43) \\
\hline Intestine large, cecum & (49) & $(48)$ & $(45)$ & $(45)$ \\
\hline Carcinoma & $1(2 \%)$ & - & - & - \\
\hline $\begin{array}{l}\text { Hepatocholangiocarcinoma, } \\
\text { metastatic, liver }\end{array}$ & - & $1(2 \%)$ & - & - \\
\hline Sarcoma, metastatic, skeletal muscle & - & - & $1(2 \%)$ & - \\
\hline Intestine large, colon & (49) & $(47)$ & $(46)$ & (46) \\
\hline Intestine large, rectum & (49) & $(47)$ & $(47)$ & (46) \\
\hline Intestine small, duodenum & $(49)$ & $(47)$ & (45) & $(46)$ \\
\hline Adenoma & - & - & $1(2 \%)$ & - \\
\hline $\begin{array}{l}\text { Hepatocholangiocarcinoma, } \\
\text { metastatic, liver }\end{array}$ & - & $1(2 \%)$ & - & - \\
\hline Intestine small, ileum & (49) & $(48)$ & $(45)$ & $(45)$ \\
\hline Adenoma & $1(2 \%)$ & - & - & $1(2 \%)$ \\
\hline Carcinoma & $1(2 \%)$ & $1(2 \%)$ & $1(2 \%)$ & $3(7 \%)$ \\
\hline Intestine small, jejunum & (48) & $(47)$ & $(45)$ & (45) \\
\hline Liver & (50) & $(50)$ & $(50)$ & $(50)$ \\
\hline Fibrosarcoma, metastatic, skeletal muscle & - & - & - & $1(2 \%)$ \\
\hline Hemangioma & - & $1(2 \%)$ & - & $2(4 \%)$ \\
\hline Hemangiosarcoma & $1(2 \%)$ & $1(2 \%)$ & $1(2 \%)$ & $6(12 \%)$ \\
\hline Hepatocellular adenoma & $13(26 \%)$ & $12(24 \%)$ & $10(20 \%)$ & $12(24 \%)$ \\
\hline Hepatocellular adenoma, multiple & $12(24 \%)$ & $9(18 \%)$ & $26(52 \%)$ & $17(34 \%)$ \\
\hline Hepatocellular carcinoma & $7(14 \%)$ & $12(24 \%)$ & $10(20 \%)$ & $14(28 \%)$ \\
\hline
\end{tabular}


Vinylidene Chloride, NTP TR 582

\begin{tabular}{|c|c|c|c|c|}
\hline & $\begin{array}{l}\text { Chamber } \\
\text { Control }\end{array}$ & $6.25 \mathrm{ppm}$ & $12.5 \mathrm{ppm}$ & 25 ppm \\
\hline Hepatocellular carcinoma, multiple & $1(2 \%)$ & $2(4 \%)$ & $2(4 \%)$ & $3(6 \%)$ \\
\hline Hepatocholangiocarcinoma & - & $1(2 \%)$ & $1(2 \%)$ & $2(4 \%)$ \\
\hline Sarcoma, metastatic, skeletal muscle & - & - & - & $1(2 \%)$ \\
\hline Mesentery & (10) & (16) & (19) & $(37)$ \\
\hline Hemangiosarcoma & - & - & $1(5 \%)$ & - \\
\hline $\begin{array}{l}\text { Hepatocholangiocarcinoma, } \\
\text { metastatic, liver }\end{array}$ & - & $1(6 \%)$ & - & - \\
\hline Sarcoma & - & $1(6 \%)$ & $1(5 \%)$ & $1(3 \%)$ \\
\hline Sarcoma, metastatic, skeletal muscle & - & - & $1(5 \%)$ & $1(3 \%)$ \\
\hline Sarcoma, metastatic, uterus & - & - & - & $1(3 \%)$ \\
\hline Pancreas & (50) & $(49)$ & $(50)$ & $(50)$ \\
\hline $\begin{array}{l}\text { Hepatocholangiocarcinoma, } \\
\text { metastatic, liver }\end{array}$ & - & $1(2 \%)$ & - & - \\
\hline Sarcoma, metastatic, mesentery & - & $1(2 \%)$ & $1(2 \%)$ & - \\
\hline Sarcoma, metastatic, skeletal muscle & - & - & - & $1(2 \%)$ \\
\hline Duct, carcinoma & $1(2 \%)$ & - & - & - \\
\hline Salivary glands & (50) & (50) & $(50)$ & (50) \\
\hline Myxoma & $1(2 \%)$ & - & - & - \\
\hline Stomach, forestomach & $(50)$ & (49) & $(50)$ & $(50)$ \\
\hline $\begin{array}{l}\text { Hepatocholangiocarcinoma, } \\
\text { metastatic, liver }\end{array}$ & - & $1(2 \%)$ & - & - \\
\hline Sarcoma, metastatic, skeletal muscle & - & - & - & $1(2 \%)$ \\
\hline Squamous cell papilloma & - & $3(6 \%)$ & $1(2 \%)$ & - \\
\hline Stomach, glandular & (49) & $(48)$ & (49) & (49) \\
\hline Carcinoma & $1(2 \%)$ & - & - & - \\
\hline Sarcoma, metastatic, skeletal muscle & - & - & $1(2 \%)$ & $1(2 \%)$ \\
\hline Tooth & (0) & (1) & (0) & $(0)$ \\
\hline \multicolumn{5}{|l|}{ Cardiovascular System } \\
\hline Blood vessel & $(0)$ & (1) & $(0)$ & $(0)$ \\
\hline Heart & $(50)$ & $(50)$ & $(50)$ & $(50)$ \\
\hline $\begin{array}{l}\text { Hepatocholangiocarcinoma, } \\
\text { metastatic, liver }\end{array}$ & - & $1(2 \%)$ & - & - \\
\hline Sarcoma, metastatic, mesentery & - & - & $1(2 \%)$ & - \\
\hline \multicolumn{5}{|l|}{ Endocrine System } \\
\hline Adrenal cortex & $(50)$ & (49) & $(50)$ & (49) \\
\hline $\begin{array}{l}\text { Hepatocholangiocarcinoma, } \\
\text { metastatic, liver }\end{array}$ & - & - & $1(2 \%)$ & - \\
\hline
\end{tabular}


Vinylidene Chloride, NTP TR 582

\begin{tabular}{|c|c|c|c|c|}
\hline & $\begin{array}{l}\text { Chamber } \\
\text { Control }\end{array}$ & $6.25 \mathrm{ppm}$ & $12.5 \mathrm{ppm}$ & 25 ppm \\
\hline Sarcoma, metastatic, skeletal muscle & - & - & - & $1(2 \%)$ \\
\hline Subcapsular, adenoma & $1(2 \%)$ & - & - & - \\
\hline Adrenal medulla & (50) & $(48)$ & $(50)$ & $(49)$ \\
\hline Pheochromocytoma benign & $1(2 \%)$ & - & - & - \\
\hline Pheochromocytoma malignant & $1(2 \%)$ & $1(2 \%)$ & - & - \\
\hline Islets, pancreatic & (50) & $(49)$ & $(50)$ & $(50)$ \\
\hline Adenoma & $1(2 \%)$ & $1(2 \%)$ & $2(4 \%)$ & - \\
\hline Parathyroid gland & (24) & $(22)$ & $(21)$ & $(31)$ \\
\hline Pituitary gland & $(50)$ & $(50)$ & $(48)$ & (47) \\
\hline Pars distalis, adenoma & $8(16 \%)$ & $5(10 \%)$ & $8(17 \%)$ & $4(9 \%)$ \\
\hline Pars distalis, carcinoma & - & - & $1(2 \%)$ & - \\
\hline Thyroid gland & (50) & $(50)$ & $(50)$ & $(50)$ \\
\hline \multicolumn{5}{|l|}{ General Body System } \\
\hline None & - & - & - & - \\
\hline \multicolumn{5}{|l|}{ Genital System } \\
\hline Clitoral gland & (45) & (46) & $(45)$ & $(45)$ \\
\hline Ovary & (50) & (49) & (49) & (49) \\
\hline Cystadenoma & $1(2 \%)$ & $3(6 \%)$ & $1(2 \%)$ & $1(2 \%)$ \\
\hline Hemangioma & - & - & $2(4 \%)$ & - \\
\hline Hemangiosarcoma & - & - & - & $1(2 \%)$ \\
\hline $\begin{array}{l}\text { Hepatocholangiocarcinoma, } \\
\text { metastatic, liver }\end{array}$ & - & $1(2 \%)$ & - & - \\
\hline Luteoma & $1(2 \%)$ & - & - & - \\
\hline Uterus & $(50)$ & $(49)$ & $(50)$ & $(50)$ \\
\hline Adenoma & - & - & - & $1(2 \%)$ \\
\hline Hemangioma & - & $1(2 \%)$ & - & - \\
\hline Hemangiosarcoma & $1(2 \%)$ & - & - & $1(2 \%)$ \\
\hline Polyp stromal & $2(4 \%)$ & $2(4 \%)$ & $1(2 \%)$ & $3(6 \%)$ \\
\hline Sarcoma & - & - & - & $1(2 \%)$ \\
\hline \multicolumn{5}{|l|}{ Hematopoietic System } \\
\hline Bone marrow & $(50)$ & (49) & $(50)$ & $(50)$ \\
\hline Lymph node & (8) & (11) & (1) & (8) \\
\hline $\begin{array}{l}\text { Lumbar, sarcoma, metastatic, } \\
\text { skeletal muscle }\end{array}$ & - & - & - & $1(13 \%)$ \\
\hline Lumbar, sarcoma, metastatic, skin & - & - & - & $1(13 \%)$ \\
\hline Lymph node, bronchial & (25) & $(38)$ & (38) & $(38)$ \\
\hline
\end{tabular}


Vinylidene Chloride, NTP TR 582

\begin{tabular}{|c|c|c|c|c|}
\hline & $\begin{array}{l}\text { Chamber } \\
\text { Control }\end{array}$ & $6.25 \mathrm{ppm}$ & $12.5 \mathrm{ppm}$ & 25 ppm \\
\hline $\begin{array}{l}\text { Hepatocholangiocarcinoma, } \\
\text { metastatic, liver }\end{array}$ & - & $1(3 \%)$ & $1(3 \%)$ & $2(5 \%)$ \\
\hline Myxosarcoma, metastatic, skin & - & $1(3 \%)$ & - & - \\
\hline Lymph node, mandibular & $(31)$ & $(35)$ & (30) & (37) \\
\hline Carcinoma, metastatic, Harderian gland & - & - & - & $1(3 \%)$ \\
\hline Lymph node, mediastinal & $(42)$ & $(45)$ & (45) & $(47)$ \\
\hline Carcinoma, metastatic, Harderian gland & - & $1(2 \%)$ & - & - \\
\hline Hemangiosarcoma & - & - & - & $1(2 \%)$ \\
\hline $\begin{array}{l}\text { Hepatocholangiocarcinoma, } \\
\text { metastatic, liver }\end{array}$ & - & $1(2 \%)$ & $1(2 \%)$ & $1(2 \%)$ \\
\hline Myxosarcoma, metastatic, skin & - & $1(2 \%)$ & - & - \\
\hline Sarcoma, metastatic, mesentery & - & - & $1(2 \%)$ & - \\
\hline Lymph node, mesenteric & $(47)$ & $(48)$ & $(47)$ & $(45)$ \\
\hline $\begin{array}{l}\text { Hepatocholangiocarcinoma, } \\
\text { metastatic, liver }\end{array}$ & - & $1(2 \%)$ & - & - \\
\hline Spleen & (50) & $(49)$ & (50) & $(49)$ \\
\hline Hemangiosarcoma & $3(6 \%)$ & $3(6 \%)$ & $1(2 \%)$ & $1(2 \%)$ \\
\hline Thymus & (47) & $(44)$ & (46) & $(40)$ \\
\hline $\begin{array}{l}\text { Hepatocholangiocarcinoma, } \\
\text { metastatic, liver }\end{array}$ & - & $1(2 \%)$ & - & - \\
\hline \multicolumn{5}{|l|}{ Integumentary System } \\
\hline Mammary gland & (50) & $(50)$ & (50) & $(50)$ \\
\hline Carcinoma & $1(2 \%)$ & $1(2 \%)$ & $2(4 \%)$ & $1(2 \%)$ \\
\hline Skin & $(50)$ & $(50)$ & $(50)$ & $(50)$ \\
\hline Fibrous histiocytoma & - & $2(4 \%)$ & $2(4 \%)$ & $3(6 \%)$ \\
\hline Subcutaneous tissue, fibrosarcoma & $1(2 \%)$ & $1(2 \%)$ & - & - \\
\hline Subcutaneous tissue, hemangiosarcoma & - & - & $1(2 \%)$ & $1(2 \%)$ \\
\hline Subcutaneous tissue, myxosarcoma & - & $1(2 \%)$ & $1(2 \%)$ & - \\
\hline Subcutaneous tissue, sarcoma & $1(2 \%)$ & $1(2 \%)$ & $1(2 \%)$ & $3(6 \%)$ \\
\hline $\begin{array}{l}\text { Subcutaneous tissue, schwannoma } \\
\text { malignant }\end{array}$ & - & - & - & $1(2 \%)$ \\
\hline \multicolumn{5}{|l|}{ Musculoskeletal System } \\
\hline Bone & $(50)$ & $(50)$ & $(50)$ & $(50)$ \\
\hline Osteosarcoma & - & - & - & $1(2 \%)$ \\
\hline Skeletal muscle & (3) & (3) & (2) & (4) \\
\hline Fibrosarcoma & - & - & - & $1(25 \%)$ \\
\hline Hemangiosarcoma & - & $1(33 \%)$ & - & - \\
\hline
\end{tabular}


Vinylidene Chloride, NTP TR 582

\begin{tabular}{|c|c|c|c|c|}
\hline & $\begin{array}{c}\text { Chamber } \\
\text { Control }\end{array}$ & $6.25 \mathrm{ppm}$ & $12.5 \mathrm{ppm}$ & 25 ppm \\
\hline $\begin{array}{l}\text { Hepatocholangiocarcinoma, } \\
\text { metastatic, liver }\end{array}$ & - & $1(33 \%)$ & $1(50 \%)$ & $1(25 \%)$ \\
\hline Sarcoma & $1(33 \%)$ & - & $1(50 \%)$ & $1(25 \%)$ \\
\hline \multicolumn{5}{|l|}{ Nervous System } \\
\hline Brain & $(50)$ & $(50)$ & (50) & $(50)$ \\
\hline Carcinoma, metastatic, pituitary gland & - & - & $1(2 \%)$ & - \\
\hline Peripheral nerve & (2) & (2) & $(0)$ & $(0)$ \\
\hline Spinal cord & (2) & (2) & $(0)$ & (1) \\
\hline \multicolumn{5}{|l|}{ Respiratory System } \\
\hline Larynx & (50) & $(50)$ & $(49)$ & (49) \\
\hline Lung & (50) & $(50)$ & (50) & (49) \\
\hline Alveolar/bronchiolar adenoma & $2(4 \%)$ & $4(8 \%)$ & $2(4 \%)$ & $2(4 \%)$ \\
\hline Alveolar/bronchiolar adenoma, multiple & $1(2 \%)$ & - & - & - \\
\hline Alveolar/bronchiolar carcinoma & $1(2 \%)$ & $2(4 \%)$ & $6(12 \%)$ & $5(10 \%)$ \\
\hline Alveolar/bronchiolar carcinoma, multiple & - & - & $1(2 \%)$ & - \\
\hline Carcinoma, metastatic, Harderian gland & - & $1(2 \%)$ & - & $1(2 \%)$ \\
\hline $\begin{array}{l}\text { Hepatocellular carcinoma, } \\
\text { metastatic, liver }\end{array}$ & $5(10 \%)$ & $9(18 \%)$ & $3(6 \%)$ & $4(8 \%)$ \\
\hline $\begin{array}{l}\text { Hepatocholangiocarcinoma, } \\
\text { metastatic, liver }\end{array}$ & - & $1(2 \%)$ & $1(2 \%)$ & $2(4 \%)$ \\
\hline Myxosarcoma, metastatic, skin & - & $1(2 \%)$ & - & - \\
\hline Sarcoma, metastatic, mesentery & - & - & $1(2 \%)$ & - \\
\hline Sarcoma, metastatic, skin & - & - & - & $1(2 \%)$ \\
\hline Nose & $(50)$ & $(50)$ & $(50)$ & $(50)$ \\
\hline Carcinoma, metastatic, Harderian gland & - & $1(2 \%)$ & $1(2 \%)$ & $1(2 \%)$ \\
\hline Trachea & (50) & $(50)$ & $(50)$ & (49) \\
\hline \multicolumn{5}{|l|}{ Special Senses System } \\
\hline Eye & $(50)$ & $(49)$ & $(50)$ & $(49)$ \\
\hline Harderian gland & (50) & $(50)$ & (50) & $(48)$ \\
\hline Adenoma & $1(2 \%)$ & $5(10 \%)$ & $4(8 \%)$ & $1(2 \%)$ \\
\hline Carcinoma & $3(6 \%)$ & $2(4 \%)$ & $2(4 \%)$ & $2(4 \%)$ \\
\hline \multicolumn{5}{|l|}{ Urinary System } \\
\hline Kidney & (50) & $(50)$ & $(50)$ & $(50)$ \\
\hline Sarcoma, metastatic, skeletal muscle & - & - & - & $1(2 \%)$ \\
\hline Renal tubule, adenoma & - & - & - & $1(2 \%)$ \\
\hline Urinary bladder & (49) & $(49)$ & (48) & (48) \\
\hline
\end{tabular}


Vinylidene Chloride, NTP TR 582

\begin{tabular}{lcccc}
\hline & $\begin{array}{c}\text { Chamber } \\
\text { Control }\end{array}$ & $\mathbf{6 . 2 5} \mathbf{~ p p m}$ & $\mathbf{1 2 . 5} \mathbf{~ p p m}$ & $\mathbf{2 5} \mathbf{~ p p m}$ \\
\hline Hemangiosarcoma & - & - & - & $1(2 \%)$ \\
Sarcoma, metastatic, uterus & - & - & - & $1(2 \%)$ \\
\hline Systemic Lesions & & & & \\
Multiple organs $^{\mathrm{b}}$ & $(50)$ & $(50)$ & $(50)$ & $(50)$ \\
Histiocytic sarcoma & $2(4 \%)$ & $2(4 \%)$ & $2(4 \%)$ & - \\
Lymphoma malignant & $14(28 \%)$ & $20(40 \%)$ & $13(26 \%)$ & $11(22 \%)$ \\
\hline Neoplasm Summary & & & & \\
Total animals with primary neoplasms & $\mathrm{y}$ & 46 & 47 & 47 \\
Total primary neoplasms & 45 & 101 & 109 & 110 \\
Total animals with benign neoplasms & 88 & 34 & 38 & 34 \\
Total benign neoplasms & 32 & 46 & 58 & 45 \\
Total animals with malignant neoplasms & 46 & 39 & 36 & 41 \\
Total malignant neoplasms & 33 & 55 & 51 & 65 \\
Total animals with metastatic neoplasms & 42 & 14 & 8 & 11 \\
Total metastatic neoplasms & 5 & 29 & 17 & 26 \\
\hline
\end{tabular}

${ }^{a}$ Number of animals examined microscopically at the site and the number of animals with neoplasm.

${ }^{b}$ Number of animals with any tissue examined microscopically.

'Primary neoplasms: all neoplasms except metastatic neoplasms. 
Vinylidene Chloride, NTP TR 582

Table D-2. Statistical Analysis of Primary Neoplasms in Female Mice in the Two-year Inhalation Study of Vinylidene Chloride

\begin{tabular}{|c|c|c|c|c|}
\hline & $\begin{array}{l}\text { Chamber } \\
\text { Control }\end{array}$ & $6.25 \mathrm{ppm}$ & $12.5 \mathrm{ppm}$ & $25 \mathrm{ppm}$ \\
\hline \multicolumn{5}{|c|}{ Harderian Gland: Adenoma } \\
\hline Overall rate & $1 / 50(2 \%)$ & $5 / 50(10 \%)$ & $4 / 50(8 \%)$ & $1 / 50(2 \%)$ \\
\hline Adjusted rate $\mathrm{e}^{\mathrm{b}}$ & $2.3 \%$ & $12.6 \%$ & $9.4 \%$ & $2.6 \%$ \\
\hline Terminal rate ${ }^{\mathrm{c}}$ & $1 / 36(3 \%)$ & $4 / 25(16 \%)$ & $4 / 30(13 \%)$ & $1 / 24(4 \%)$ \\
\hline First incidence (days) & $731(\mathrm{~T})$ & 705 & $731(\mathrm{~T})$ & $731(\mathrm{~T})$ \\
\hline Poly-3 test ${ }^{\mathrm{d}}$ & $\mathrm{P}=0.480 \mathrm{~N}$ & $\mathrm{P}=0.081$ & $\mathrm{P}=0.174$ & $\mathrm{P}=0.732$ \\
\hline \multicolumn{5}{|c|}{ Harderian Gland: Carcinoma } \\
\hline Overall rate & $3 / 50(6 \%)$ & $2 / 50(4 \%)$ & $2 / 50(4 \%)$ & $2 / 50(4 \%)$ \\
\hline Adjusted rate & $6.9 \%$ & $5.0 \%$ & $4.6 \%$ & $5.1 \%$ \\
\hline Terminal rate & $3 / 36(8 \%)$ & $0 / 25(0 \%)$ & $1 / 30(3 \%)$ & $0 / 24(0 \%)$ \\
\hline First incidence (days) & $731(\mathrm{~T})$ & 590 & 599 & 443 \\
\hline Poly-3 test & $\mathrm{P}=0.453 \mathrm{~N}$ & $\mathrm{P}=0.532 \mathrm{~N}$ & $\mathrm{P}=0.501 \mathrm{~N}$ & $\mathrm{P}=0.542 \mathrm{~N}$ \\
\hline \multicolumn{5}{|c|}{ Harderian Gland: Adenoma or Carcinoma } \\
\hline Overall rate & $4 / 50(8 \%)$ & $7 / 50(14 \%)$ & $6 / 50(12 \%)$ & $3 / 50(6 \%)$ \\
\hline Adjusted rate & $9.2 \%$ & $17.3 \%$ & $13.9 \%$ & $7.6 \%$ \\
\hline Terminal rate & $4 / 36(11 \%)$ & $4 / 25(16 \%)$ & $5 / 30(17 \%)$ & $1 / 24(4 \%)$ \\
\hline First incidence (days) & $731(\mathrm{~T})$ & 590 & 599 & 443 \\
\hline Poly-3 test & $\mathrm{P}=0.374 \mathrm{~N}$ & $\mathrm{P}=0.221$ & $P=0.367$ & $\mathrm{P}=0.550 \mathrm{~N}$ \\
\hline \multicolumn{5}{|c|}{ Small Intestine (Ileum): Carcinoma } \\
\hline Overall rate & $1 / 50(2 \%)$ & $1 / 50(2 \%)$ & $1 / 50(2 \%)$ & $3 / 50(6 \%)$ \\
\hline Adjusted rate & $2.3 \%$ & $2.5 \%$ & $2.3 \%$ & $7.8 \%$ \\
\hline Terminal rate & $0 / 36(0 \%)$ & $0 / 25(0 \%)$ & $0 / 30(0 \%)$ & $2 / 24(8 \%)$ \\
\hline First incidence (days) & 599 & 584 & 536 & 640 \\
\hline Poly-3 test & $P=0.144$ & $P=0.740$ & $P=0.759$ & $P=0.260$ \\
\hline \multicolumn{5}{|c|}{ Small Intestine (Duodenum or Ileum): Adenoma or Carcinoma } \\
\hline Overall rate & $2 / 50(4 \%)$ & $1 / 50(2 \%)$ & $2 / 50(4 \%)$ & $4 / 50(8 \%)$ \\
\hline Adjusted rate & $4.6 \%$ & $2.5 \%$ & $4.6 \%$ & $10.4 \%$ \\
\hline Terminal rate & $1 / 36(3 \%)$ & $0 / 25(0 \%)$ & $1 / 30(3 \%)$ & $3 / 24(13 \%)$ \\
\hline First incidence (days) & 599 & 584 & 536 & 640 \\
\hline Poly-3 test & $P=0.141$ & $\mathrm{P}=0.531 \mathrm{~N}$ & $P=0.691$ & $P=0.279$ \\
\hline \multicolumn{5}{|c|}{ Liver: Hemangiosarcoma } \\
\hline Overall rate & $1 / 50(2 \%)$ & $1 / 50(2 \%)$ & $1 / 50(2 \%)$ & $6 / 50(12 \%)$ \\
\hline Adjusted rate & $2.3 \%$ & $2.5 \%$ & $2.3 \%$ & $15.2 \%$ \\
\hline Terminal rate & $1 / 36(3 \%)$ & $1 / 25(4 \%)$ & $1 / 30(3 \%)$ & $3 / 24(13 \%)$ \\
\hline
\end{tabular}


Vinylidene Chloride, NTP TR 582

\begin{tabular}{|c|c|c|c|c|}
\hline & $\begin{array}{l}\text { Chamber } \\
\text { Control }\end{array}$ & $6.25 \mathrm{ppm}$ & $12.5 \mathrm{ppm}$ & 25 ppm \\
\hline First incidence (days) & $731(\mathrm{~T})$ & $731(\mathrm{~T})$ & $731(\mathrm{~T})$ & 508 \\
\hline Poly-3 test & $P=0.007$ & $P=0.740$ & $P=0.758$ & $P=0.041$ \\
\hline \multicolumn{5}{|c|}{ Liver: Hepatocellular Adenoma } \\
\hline Overall rate & $25 / 50(50 \%)$ & $21 / 50(42 \%)$ & $36 / 50(72 \%)$ & $29 / 50(58 \%)$ \\
\hline Adjusted rate & $55.3 \%$ & $49.0 \%$ & $77.6 \%$ & $69.0 \%$ \\
\hline Terminal rate & $20 / 36(56 \%)$ & $13 / 25(52 \%)$ & $25 / 30(83 \%)$ & $19 / 24(79 \%)$ \\
\hline First incidence (days) & 509 & 471 & 524 & 443 \\
\hline Poly-3 test & $P=0.026$ & $\mathrm{P}=0.347 \mathrm{~N}$ & $\mathrm{P}=0.015$ & $P=0.126$ \\
\hline \multicolumn{5}{|c|}{ Liver: Hepatocellular Carcinoma } \\
\hline Overall rate & $8 / 50(16 \%)$ & $14 / 50(28 \%)$ & $12 / 50(24 \%)$ & $17 / 50(34 \%)$ \\
\hline Adjusted rate & $18.2 \%$ & $32.4 \%$ & $27.2 \%$ & $41.3 \%$ \\
\hline Terminal rate & $6 / 36(17 \%)$ & $4 / 25(16 \%)$ & $8 / 30(27 \%)$ & $9 / 24(38 \%)$ \\
\hline First incidence (days) & 611 & 478 & 611 & 415 \\
\hline Poly-3 test & $\mathrm{P}=0.022$ & $\mathrm{P}=0.097$ & $P=0.223$ & $\mathrm{P}=0.015$ \\
\hline \multicolumn{5}{|c|}{ Liver: Hepatocellular Adenoma or Carcinoma } \\
\hline Overall rate & $28 / 50(56 \%)$ & $30 / 50(60 \%)$ & $37 / 50(74 \%)$ & $38 / 50(76 \%)$ \\
\hline Adjusted rate & $61.5 \%$ & $65.4 \%$ & $79.3 \%$ & $84.4 \%$ \\
\hline Terminal rate & $22 / 36(61 \%)$ & $14 / 25(56 \%)$ & $25 / 30(83 \%)$ & $21 / 24(88 \%)$ \\
\hline First incidence (days) & 509 & 471 & 524 & 415 \\
\hline Poly-3 test & $\mathrm{P}=0.003$ & $\mathrm{P}=0.434$ & $\mathrm{P}=0.041$ & $\mathrm{P}=0.009$ \\
\hline \multicolumn{5}{|c|}{ Lung: Alveolar/bronchiolar Adenoma } \\
\hline Overall rate & $3 / 50(6 \%)$ & $4 / 50(8 \%)$ & $2 / 50(4 \%)$ & $2 / 49(4 \%)$ \\
\hline Adjusted rate & $6.9 \%$ & $9.8 \%$ & $4.7 \%$ & $5.3 \%$ \\
\hline Terminal rate & $3 / 36(8 \%)$ & $1 / 25(4 \%)$ & $2 / 30(7 \%)$ & $1 / 24(4 \%)$ \\
\hline First incidence (days) & $731(\mathrm{~T})$ & 478 & $731(\mathrm{~T})$ & 508 \\
\hline Poly-3 test & $P=0.369 \mathrm{~N}$ & $\mathrm{P}=0.468$ & $\mathrm{P}=0.506 \mathrm{~N}$ & $\mathrm{P}=0.561 \mathrm{~N}$ \\
\hline \multicolumn{5}{|c|}{ Lung: Alveolar/bronchiolar Carcinoma } \\
\hline Overall rate & $1 / 50(2 \%)$ & $2 / 50(4 \%)$ & $7 / 50(14 \%)$ & $5 / 49(10 \%)$ \\
\hline Adjusted rate & $2.3 \%$ & $4.9 \%$ & $16.1 \%$ & $12.7 \%$ \\
\hline Terminal rate & $1 / 36(3 \%)$ & $0 / 25(0 \%)$ & $6 / 30(20 \%)$ & $1 / 24(4 \%)$ \\
\hline First incidence (days) & $731(\mathrm{~T})$ & 558 & 392 & 502 \\
\hline Poly-3 test & $\mathrm{P}=0.038$ & $\mathrm{P}=0.477$ & $\mathrm{P}=0.030$ & $\mathrm{P}=0.080$ \\
\hline \multicolumn{5}{|c|}{ Lung: Alveolar/bronchiolar Adenoma or Carcinoma } \\
\hline Overall rate & $4 / 50(8 \%)$ & $5 / 50(10 \%)$ & $9 / 50(18 \%)$ & $7 / 49(14 \%)$ \\
\hline Adjusted rate & $9.2 \%$ & $12.1 \%$ & $20.6 \%$ & $17.5 \%$ \\
\hline
\end{tabular}


Vinylidene Chloride, NTP TR 582

\begin{tabular}{|c|c|c|c|c|}
\hline & $\begin{array}{l}\text { Chamber } \\
\text { Control }\end{array}$ & $6.25 \mathrm{ppm}$ & $12.5 \mathrm{ppm}$ & $25 \mathrm{ppm}$ \\
\hline Terminal rate & $4 / 36(11 \%)$ & $1 / 25(4 \%)$ & $8 / 30(27 \%)$ & $2 / 24(8 \%)$ \\
\hline First incidence (days) & $731(\mathrm{~T})$ & 478 & 392 & 502 \\
\hline Poly-3 test & $P=0.141$ & $P=0.472$ & $P=0.115$ & $P=0.216$ \\
\hline \multicolumn{5}{|l|}{ Ovary: Cystadenoma } \\
\hline Overall rate & $1 / 50(2 \%)$ & $3 / 49(6 \%)$ & $1 / 49(2 \%)$ & $1 / 49(2 \%)$ \\
\hline Adjusted rate & $2.3 \%$ & $7.6 \%$ & $2.4 \%$ & $2.6 \%$ \\
\hline Terminal rate & $1 / 36(3 \%)$ & $2 / 25(8 \%)$ & $0 / 30(0 \%)$ & $0 / 24(0 \%)$ \\
\hline First incidence (days) & $731(\mathrm{~T})$ & 673 & 668 & 502 \\
\hline Poly-3 test & $\mathrm{P}=0.488 \mathrm{~N}$ & $P=0.270$ & $P=0.756$ & $P=0.730$ \\
\hline \multicolumn{5}{|c|}{ Pituitary Gland (Pars Distalis): Adenoma } \\
\hline Overall rate & $8 / 50(16 \%)$ & $5 / 50(10 \%)$ & $8 / 48(17 \%)$ & $4 / 47(9 \%)$ \\
\hline Adjusted rate & $18.5 \%$ & $12.4 \%$ & $19.6 \%$ & $10.7 \%$ \\
\hline Terminal rate & $8 / 36(22 \%)$ & $3 / 25(12 \%)$ & $8 / 28(29 \%)$ & $2 / 24(8 \%)$ \\
\hline First incidence (days) & $731(\mathrm{~T})$ & 584 & $731(\mathrm{~T})$ & 556 \\
\hline Poly-3 test & $\mathrm{P}=0.277 \mathrm{~N}$ & $\mathrm{P}=0.319 \mathrm{~N}$ & $P=0.557$ & $\mathrm{P}=0.252 \mathrm{~N}$ \\
\hline \multicolumn{5}{|c|}{ Pituitary Gland (Pars Distalis): Adenoma or Carcinoma } \\
\hline Overall rate & $8 / 50(16 \%)$ & $5 / 50(10 \%)$ & $9 / 48(19 \%)$ & $4 / 47(9 \%)$ \\
\hline Adjusted rate & $18.5 \%$ & $12.4 \%$ & $22.0 \%$ & $10.7 \%$ \\
\hline Terminal rate & $8 / 36(22 \%)$ & $3 / 25(12 \%)$ & $8 / 28(29 \%)$ & $2 / 24(8 \%)$ \\
\hline First incidence (days) & $731(\mathrm{~T})$ & 584 & 670 & 556 \\
\hline Poly-3 test & $\mathrm{P}=0.298 \mathrm{~N}$ & $\mathrm{P}=0.319 \mathrm{~N}$ & $P=0.450$ & $\mathrm{P}=0.252 \mathrm{~N}$ \\
\hline \multicolumn{5}{|c|}{ Skin: Fibrous Histiocytoma } \\
\hline Overall rate & $0 / 50(0 \%)$ & $2 / 50(4 \%)$ & $2 / 50(4 \%)$ & $3 / 50(6 \%)$ \\
\hline Adjusted rate & $0.0 \%$ & $5.0 \%$ & $4.7 \%$ & $7.9 \%$ \\
\hline Terminal rate & $0 / 36(0 \%)$ & $0 / 25(0 \%)$ & $1 / 30(3 \%)$ & $3 / 24(13 \%)$ \\
\hline First incidence (days) & 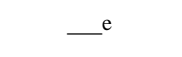 & 563 & 668 & $731(\mathrm{~T})$ \\
\hline Poly-3 test & $P=0.083$ & $P=0.221$ & $P=0.235$ & $P=0.097$ \\
\hline \multicolumn{5}{|c|}{ Skin (Subcutaneous Tissue): Sarcoma } \\
\hline Overall rate & $1 / 50(2 \%)$ & $1 / 50(2 \%)$ & $1 / 50(2 \%)$ & $3 / 50(6 \%)$ \\
\hline Adjusted rate & $2.3 \%$ & $2.5 \%$ & $2.3 \%$ & $7.7 \%$ \\
\hline Terminal rate & $1 / 36(3 \%)$ & $0 / 25(0 \%)$ & $1 / 30(3 \%)$ & $0 / 24(0 \%)$ \\
\hline First incidence (days) & $731(\mathrm{~T})$ & 606 & $731(\mathrm{~T})$ & 592 \\
\hline Poly-3 test & $P=0.148$ & $P=0.743$ & $P=0.758$ & $P=0.269$ \\
\hline \multicolumn{5}{|c|}{ Skin: Fibrous Histiocytoma, Fibrosarcoma, Myxosarcoma, or Sarcoma } \\
\hline Overall rate & $2 / 50(4 \%)$ & $4 / 50(8 \%)$ & $4 / 50(8 \%)$ & $6 / 50(12 \%)$ \\
\hline
\end{tabular}


Vinylidene Chloride, NTP TR 582

\begin{tabular}{|c|c|c|c|c|}
\hline & $\begin{array}{c}\text { Chamber } \\
\text { Control }\end{array}$ & $6.25 \mathrm{ppm}$ & $12.5 \mathrm{ppm}$ & 25 ppm \\
\hline Adjusted rate & $4.6 \%$ & $9.8 \%$ & $9.2 \%$ & $15.4 \%$ \\
\hline Terminal rate & $1 / 36(3 \%)$ & $1 / 25(4 \%)$ & $2 / 30(7 \%)$ & $3 / 24(13 \%)$ \\
\hline First incidence (days) & 605 & 563 & 653 & 592 \\
\hline Poly-3 test & $\mathrm{P}=0.080$ & $\mathrm{P}=0.303$ & $\mathrm{P}=0.332$ & $\mathrm{P}=0.098$ \\
\hline \multicolumn{5}{|c|}{ Spleen: Hemangiosarcoma } \\
\hline Overall rate & $3 / 50(6 \%)$ & $3 / 49(6 \%)$ & $1 / 50(2 \%)$ & $1 / 49(2 \%)$ \\
\hline Adjusted rate & $6.9 \%$ & $7.5 \%$ & $2.3 \%$ & $2.7 \%$ \\
\hline Terminal rate & $3 / 36(8 \%)$ & $2 / 25(8 \%)$ & $1 / 30(3 \%)$ & $1 / 24(4 \%)$ \\
\hline First incidence (days) & $731(\mathrm{~T})$ & 471 & $731(\mathrm{~T})$ & $731(\mathrm{~T})$ \\
\hline Poly-3 test & $\mathrm{P}=0.188 \mathrm{~N}$ & $P=0.624$ & $\mathrm{P}=0.309 \mathrm{~N}$ & $\mathrm{P}=0.356 \mathrm{~N}$ \\
\hline \multicolumn{5}{|c|}{ Stomach (Forestomach): Squamous Cell Papilloma } \\
\hline Overall rate & $0 / 50(0 \%)$ & $3 / 50(6 \%)$ & $1 / 50(2 \%)$ & $0 / 50(0 \%)$ \\
\hline Adjusted rate & $0.0 \%$ & $7.6 \%$ & $2.3 \%$ & $0.0 \%$ \\
\hline Terminal rate & $0 / 36(0 \%)$ & $3 / 25(12 \%)$ & $0 / 30(0 \%)$ & $0 / 24(0 \%)$ \\
\hline First incidence (days) & - & $731(\mathrm{~T})$ & 653 & - \\
\hline Poly-3 test & $\mathrm{P}=0.420 \mathrm{~N}$ & $\mathrm{P}=0.102$ & $\mathrm{P}=0.499$ & $-^{\mathrm{f}}$ \\
\hline \multicolumn{5}{|l|}{ Uterus: Stromal Polyp } \\
\hline Overall rate & $2 / 50(4 \%)$ & $2 / 50(4 \%)$ & $1 / 50(2 \%)$ & $3 / 50(6 \%)$ \\
\hline Adjusted rate & $4.6 \%$ & $5.0 \%$ & $2.3 \%$ & $7.7 \%$ \\
\hline Terminal rate & $2 / 36(6 \%)$ & $1 / 25(4 \%)$ & $1 / 30(3 \%)$ & $0 / 24(0 \%)$ \\
\hline First incidence (days) & $731(\mathrm{~T})$ & 603 & $731(\mathrm{~T})$ & 626 \\
\hline Poly-3 test & $\mathrm{P}=0.376$ & $P=0.665$ & $\mathrm{P}=0.504 \mathrm{~N}$ & $\mathrm{P}=0.453$ \\
\hline \multicolumn{5}{|c|}{ All Organs: Hemangiosarcoma } \\
\hline Overall rate & $4 / 50(8 \%)$ & $4 / 50(8 \%)$ & $4 / 50(8 \%)$ & $9 / 50(18 \%)$ \\
\hline Adjusted rate & $9.2 \%$ & $9.9 \%$ & $9.2 \%$ & $22.5 \%$ \\
\hline Terminal rate & $4 / 36(11 \%)$ & $3 / 25(12 \%)$ & $2 / 30(7 \%)$ & $5 / 24(21 \%)$ \\
\hline First incidence (days) & $731(\mathrm{~T})$ & 471 & 620 & 508 \\
\hline Poly-3 test & $\mathrm{P}=0.044$ & $P=0.603$ & $\mathrm{P}=0.643$ & $\mathrm{P}=0.084$ \\
\hline \multicolumn{5}{|c|}{ All Organs: Hemangioma or Hemangiosarcoma } \\
\hline Overall rate & $4 / 50(8 \%)$ & $6 / 50(12 \%)$ & $6 / 50(12 \%)$ & $11 / 50(22 \%)$ \\
\hline Adjusted rate & $9.2 \%$ & $14.9 \%$ & $13.9 \%$ & $27.5 \%$ \\
\hline Terminal rate & $4 / 36(11 \%)$ & $4 / 25(16 \%)$ & $4 / 30(13 \%)$ & $7 / 24(29 \%)$ \\
\hline First incidence (days) & $731(\mathrm{~T})$ & 471 & 620 & 508 \\
\hline Poly-3 test & $P=0.018$ & $P=0.324$ & $P=0.368$ & $\mathrm{P}=0.027$ \\
\hline
\end{tabular}


Vinylidene Chloride, NTP TR 582

\begin{tabular}{|c|c|c|c|c|}
\hline & $\begin{array}{l}\text { Chamber } \\
\text { Control }\end{array}$ & $6.25 \mathrm{ppm}$ & $12.5 \mathrm{ppm}$ & 25 ppm \\
\hline \multicolumn{5}{|c|}{ All Organs: Malignant Lymphoma } \\
\hline Overall rate & $14 / 50(28 \%)$ & $20 / 50(40 \%)$ & $13 / 50(26 \%)$ & $11 / 50(22 \%)$ \\
\hline Adjusted rate & $31.5 \%$ & $47.0 \%$ & $30.1 \%$ & $28.1 \%$ \\
\hline Terminal rate & $11 / 36(31 \%)$ & $11 / 25(44 \%)$ & $11 / 30(37 \%)$ & $8 / 24(33 \%)$ \\
\hline First incidence (days) & 509 & 563 & 668 & 440 \\
\hline Poly-3 test & $\mathrm{P}=0.231 \mathrm{~N}$ & $\mathrm{P}=0.098$ & $\mathrm{P}=0.538 \mathrm{~N}$ & $\mathrm{P}=0.460 \mathrm{~N}$ \\
\hline \multicolumn{5}{|c|}{ All Organs: Benign Neoplasms } \\
\hline Overall rate & $32 / 50(64 \%)$ & $34 / 50(68 \%)$ & $38 / 50(76 \%)$ & $34 / 50(68 \%)$ \\
\hline Adjusted rate & $70.8 \%$ & $74.1 \%$ & $81.9 \%$ & $77.8 \%$ \\
\hline Terminal rate & $27 / 36(75 \%)$ & $19 / 25(76 \%)$ & $27 / 30(90 \%)$ & $21 / 24(88 \%)$ \\
\hline First incidence (days) & 509 & 471 & 524 & 443 \\
\hline Poly-3 test & $\mathrm{P}=0.210$ & $\mathrm{P}=0.452$ & $\mathrm{P}=0.142$ & $\mathrm{P}=0.292$ \\
\hline \multicolumn{5}{|c|}{ All Organs: Malignant Neoplasms } \\
\hline Overall rate & $33 / 50(66 \%)$ & $39 / 50(78 \%)$ & $36 / 50(72 \%)$ & $41 / 50(82 \%)$ \\
\hline Adjusted rate & $69.2 \%$ & $80.9 \%$ & $74.9 \%$ & $83.7 \%$ \\
\hline Terminal rate & $23 / 36(64 \%)$ & $17 / 25(68 \%)$ & $21 / 30(70 \%)$ & $18 / 24(75 \%)$ \\
\hline First incidence (days) & 440 & 471 & 392 & 413 \\
\hline Poly-3 test & $P=0.091$ & $P=0.132$ & $\mathrm{P}=0.342$ & $P=0.069$ \\
\hline \multicolumn{5}{|c|}{ All Organs: Benign or Malignant Neoplasms } \\
\hline Overall rate & $45 / 50(90 \%)$ & $46 / 50(92 \%)$ & $47 / 50(94 \%)$ & $47 / 50(94 \%)$ \\
\hline Adjusted rate & $94.3 \%$ & $94.0 \%$ & $94.9 \%$ & $95.7 \%$ \\
\hline Terminal rate & $35 / 36(97 \%)$ & $23 / 25(92 \%)$ & $29 / 30(97 \%)$ & $23 / 24(96 \%)$ \\
\hline First incidence (days) & 440 & 471 & 392 & 413 \\
\hline Poly-3 test & $\mathrm{P}=0.434$ & $\mathrm{P}=0.660 \mathrm{~N}$ & $P=0.637$ & $P=0.566$ \\
\hline \multicolumn{5}{|c|}{$\begin{array}{l}\mathrm{T}=\text { terminal kill. } \\
\text { aNumber of neoplasm-bearing animals/number of animals examined. Denominator is number of animals examined } \\
\text { microscopically for liver, lung, ovary, pituitary gland, and spleen; for other tissues, denominator is number of animals } \\
\text { necropsied. } \\
\text { bPoly-3 estimated neoplasm incidence after adjustment for intercurrent mortality. } \\
\text { c Observed incidence at terminal kill. } \\
{ }^{\mathrm{d} B e n e a t h ~ t h e ~ c h a m b e r ~ c o n t r o l ~ i n c i d e n c e ~ i s ~ t h e ~} \mathrm{P} \text { value associated with the trend test. Beneath the exposed group incidence are the } \\
\mathrm{P} \text { values corresponding to pairwise comparisons between the chamber controls and that exposed group. The Poly-3 test accounts } \\
\text { for differential mortality in animals that do not reach terminal kill. A negative trend or a lower incidence in an exposure group is } \\
\text { indicated by N. } \\
\text { eNot applicable; no neoplasms in animal group. } \\
\text { fValue of statistic cannot be computed. }\end{array}$} \\
\hline
\end{tabular}


Table D-3. Historical Incidence of Liver Neoplasms in Control Female B6C3F1/N Mice ${ }^{\text {a }}$

\begin{tabular}{|c|c|c|c|c|}
\hline Study (Study Start) & $\begin{array}{c}\text { Hepatocellular } \\
\text { Adenoma }\end{array}$ & $\begin{array}{c}\text { Hepatocellular } \\
\text { Carcinoma }\end{array}$ & $\begin{array}{c}\text { Hepatocellular } \\
\text { Adenoma or } \\
\text { Carcinoma }\end{array}$ & Hepatocholangiocarcinoma \\
\hline \multicolumn{5}{|c|}{ Historical Incidence: Inhalation Studies } \\
\hline 1-Bromopropane (July 2003) & $19 / 50$ & $5 / 50$ & $24 / 50$ & $0 / 50$ \\
\hline CIMSTAR 3800 (May 2008) & $19 / 50$ & $10 / 50$ & $25 / 50$ & $0 / 50$ \\
\hline Cobalt (May 2006) & $14 / 50$ & $4 / 50$ & $16 / 50$ & $0 / 50$ \\
\hline Diethylamine (August 2003) & $14 / 50$ & $10 / 50$ & $20 / 50$ & $0 / 50$ \\
\hline Tetralin (June 2003) & $14 / 50$ & $7 / 50$ & $20 / 50$ & $0 / 50$ \\
\hline Vinylidene chloride (June 2005) & $25 / 50$ & $8 / 50$ & $28 / 50$ & $0 / 50$ \\
\hline Total $(\%)$ & $\begin{array}{l}105 / 300 \\
(35.0 \%)\end{array}$ & $\begin{array}{c}44 / 300 \\
(14.7 \%)\end{array}$ & $\begin{array}{l}133 / 300 \\
(44.3 \%)\end{array}$ & $0 / 300$ \\
\hline Mean \pm standard deviation & $35.0 \% \pm 8.8 \%$ & $14.7 \% \pm 5.0 \%$ & $44.3 \% \pm 8.6 \%$ & - \\
\hline Range & $28 \%-50 \%$ & $8 \%-20 \%$ & $32 \%-56 \%$ & - \\
\hline \multicolumn{5}{|c|}{ Overall Historical Incidence: All Routes } \\
\hline Total $(\%)$ & $\begin{array}{l}378 / 948 \\
(39.9 \%)\end{array}$ & $\begin{array}{l}152 / 948 \\
(16.0 \%)\end{array}$ & $\begin{array}{l}448 / 948 \\
(47.3 \%)\end{array}$ & $0 / 948$ \\
\hline Mean \pm standard deviation & $39.9 \% \pm 18.7 \%$ & $16.0 \% \pm 10.6 \%$ & $47.3 \% \pm 19.3 \%$ & - \\
\hline Range & $14 \%-78 \%$ & $4 \%-46 \%$ & $20 \%-82 \%$ & - \\
\hline
\end{tabular}


Table D-4. Summary of the Incidence of Nonneoplastic Lesions in Female Mice in the Two-year Inhalation Study of Vinylidene Chloride ${ }^{\mathrm{a}}$

\begin{tabular}{|c|c|c|c|c|}
\hline & $\begin{array}{c}\text { Chamber } \\
\text { Control }\end{array}$ & $6.25 \mathrm{ppm}$ & $12.5 \mathrm{ppm}$ & 25 ppm \\
\hline \multicolumn{5}{|l|}{ Disposition Summary } \\
\hline Animals initially in study & 50 & 50 & 50 & 50 \\
\hline \multicolumn{5}{|l|}{ Early deaths } \\
\hline Moribund & 11 & 20 & 14 & 17 \\
\hline Natural deaths & 3 & 5 & 6 & 9 \\
\hline \multicolumn{5}{|l|}{ Survivors } \\
\hline Died last week of study & - & - & - & 1 \\
\hline Terminal kill & 36 & 25 & 30 & 23 \\
\hline Animals examined microscopically & 50 & 50 & 50 & 50 \\
\hline \multicolumn{5}{|l|}{ Alimentary System } \\
\hline Esophagus & (50) & $(50)$ & $(50)$ & $(50)$ \\
\hline Gallbladder & (46) & $(43)$ & $(45)$ & $(43)$ \\
\hline Degeneration, hyaline & $1(2 \%)$ & - & - & - \\
\hline Hyperplasia & $1(2 \%)$ & - & - & - \\
\hline Intestine large, cecum & $(49)$ & $(48)$ & $(45)$ & $(45)$ \\
\hline Infiltration cellular, mast cell & - & - & $1(2 \%)$ & - \\
\hline Inflammation, chronic active & - & - & $1(2 \%)$ & - \\
\hline Necrosis & - & - & $2(4 \%)$ & - \\
\hline Intestine large, colon & (49) & $(47)$ & $(46)$ & $(46)$ \\
\hline Intestine large, rectum & (49) & (47) & (47) & $(46)$ \\
\hline Intestine small, duodenum & (49) & $(47)$ & $(45)$ & $(46)$ \\
\hline Inflammation, suppurative & $1(2 \%)$ & - & - & - \\
\hline Inflammation, chronic active & - & - & $1(2 \%)$ & - \\
\hline Intestine small, ileum & (49) & $(48)$ & $(45)$ & $(45)$ \\
\hline Hemorrhage & - & - & $1(2 \%)$ & - \\
\hline Hyperplasia & - & $1(2 \%)$ & $2(4 \%)$ & - \\
\hline Inflammation, chronic active & - & - & $1(2 \%)$ & - \\
\hline Ulcer & $1(2 \%)$ & - & - & - \\
\hline Intestine small, jejunum & $(48)$ & $(47)$ & $(45)$ & $(45)$ \\
\hline Liver & $(50)$ & $(50)$ & $(50)$ & $(50)$ \\
\hline Angiectasis & $1(2 \%)$ & $1(2 \%)$ & - & $2(4 \%)$ \\
\hline Basophilic focus & $1(2 \%)$ & $4(8 \%)$ & - & $3(6 \%)$ \\
\hline Clear cell focus & $5(10 \%)$ & $2(4 \%)$ & $6(12 \%)$ & $3(6 \%)$ \\
\hline Cyst & - & - & $1(2 \%)$ & - \\
\hline
\end{tabular}


Vinylidene Chloride, NTP TR 582

\begin{tabular}{|c|c|c|c|c|}
\hline & $\begin{array}{c}\text { Chamber } \\
\text { Control }\end{array}$ & $6.25 \mathrm{ppm}$ & $12.5 \mathrm{ppm}$ & 25 ppm \\
\hline Eosinophilic focus & $9(18 \%)$ & $10(20 \%)$ & $9(18 \%)$ & $4(8 \%)$ \\
\hline Fatty change & $2(4 \%)$ & - & $2(4 \%)$ & - \\
\hline Hemorrhage & $1(2 \%)$ & - & - & - \\
\hline Infarct & $1(2 \%)$ & - & $1(2 \%)$ & - \\
\hline Inflammation, suppurative & $1(2 \%)$ & $1(2 \%)$ & - & - \\
\hline Inflammation, chronic active & - & - & $2(4 \%)$ & - \\
\hline Mixed cell focus & - & - & - & $1(2 \%)$ \\
\hline Necrosis & $2(4 \%)$ & $3(6 \%)$ & $6(12 \%)$ & $3(6 \%)$ \\
\hline Vacuolization cytoplasmic & - & - & - & $1(2 \%)$ \\
\hline Mesentery & (10) & (16) & (19) & (37) \\
\hline Angiectasis & - & - & $1(5 \%)$ & - \\
\hline Infiltration cellular, mononuclear cell & - & - & - & $1(3 \%)$ \\
\hline Artery, inflammation & $1(10 \%)$ & - & - & - \\
\hline Fat, necrosis & $8(80 \%)$ & $14(88 \%)$ & $15(79 \%)$ & $33(89 \%)$ \\
\hline Pancreas & $(50)$ & (49) & (50) & (50) \\
\hline Atrophy & - & - & - & $1(2 \%)$ \\
\hline Cyst & - & $1(2 \%)$ & $1(2 \%)$ & - \\
\hline Fibrosis & - & $1(2 \%)$ & - & - \\
\hline Inflammation, chronic active & $1(2 \%)$ & $1(2 \%)$ & - & - \\
\hline Necrosis & $1(2 \%)$ & - & - & $1(2 \%)$ \\
\hline Artery, inflammation, chronic active & $2(4 \%)$ & - & - & - \\
\hline Salivary glands & $(50)$ & $(50)$ & $(50)$ & $(50)$ \\
\hline Inflammation, suppurative & - & - & $1(2 \%)$ & - \\
\hline Necrosis & - & $1(2 \%)$ & - & - \\
\hline Stomach, forestomach & $(50)$ & $(49)$ & $(50)$ & (50) \\
\hline Hyperplasia, squamous & $2(4 \%)$ & $2(4 \%)$ & - & $2(4 \%)$ \\
\hline Inflammation, chronic active & - & - & - & $1(2 \%)$ \\
\hline Necrosis & - & $1(2 \%)$ & $1(2 \%)$ & $4(8 \%)$ \\
\hline Ulcer & $1(2 \%)$ & - & - & $1(2 \%)$ \\
\hline Artery, inflammation, chronic active & - & $1(2 \%)$ & - & - \\
\hline Stomach, glandular & $(49)$ & $(48)$ & (49) & $(49)$ \\
\hline Mineralization & $2(4 \%)$ & $2(4 \%)$ & $2(4 \%)$ & - \\
\hline Necrosis & - & $1(2 \%)$ & $3(6 \%)$ & $1(2 \%)$ \\
\hline Artery, inflammation, chronic active & $1(2 \%)$ & $1(2 \%)$ & - & - \\
\hline
\end{tabular}


Vinylidene Chloride, NTP TR 582

\begin{tabular}{|c|c|c|c|c|}
\hline & $\begin{array}{l}\text { Chamber } \\
\text { Control }\end{array}$ & $6.25 \mathrm{ppm}$ & $12.5 \mathrm{ppm}$ & $25 \mathrm{ppm}$ \\
\hline Tooth & $(0)$ & (1) & $(0)$ & $(0)$ \\
\hline Dysplasia & - & $1(100 \%)$ & - & - \\
\hline \multicolumn{5}{|l|}{ Cardiovascular System } \\
\hline Blood vessel & $(0)$ & (1) & $(0)$ & $(0)$ \\
\hline Heart & $(50)$ & $(50)$ & (50) & (50) \\
\hline Cardiomyopathy & $9(18 \%)$ & $12(24 \%)$ & $12(24 \%)$ & $9(18 \%)$ \\
\hline Inflammation, suppurative & - & - & $1(2 \%)$ & - \\
\hline Mineralization & $2(4 \%)$ & $1(2 \%)$ & - & - \\
\hline Necrosis, chronic & - & $1(2 \%)$ & - & - \\
\hline Thrombosis & - & $2(4 \%)$ & $1(2 \%)$ & $3(6 \%)$ \\
\hline Artery, inflammation, chronic active & $2(4 \%)$ & $2(4 \%)$ & - & - \\
\hline \multicolumn{5}{|l|}{ Endocrine System } \\
\hline Adrenal cortex & (50) & $(49)$ & $(50)$ & (49) \\
\hline Angiectasis & $1(2 \%)$ & $1(2 \%)$ & - & - \\
\hline Hyperplasia & $6(12 \%)$ & $6(12 \%)$ & $8(16 \%)$ & $8(16 \%)$ \\
\hline Hypertrophy & $4(8 \%)$ & - & $5(10 \%)$ & $3(6 \%)$ \\
\hline Inflammation, suppurative & - & $1(2 \%)$ & - & - \\
\hline Vacuolization cytoplasmic & - & - & $1(2 \%)$ & - \\
\hline Subcapsular, hyperplasia & - & $1(2 \%)$ & - & - \\
\hline Adrenal medulla & (50) & $(48)$ & $(50)$ & (49) \\
\hline Hyperplasia & $1(2 \%)$ & $3(6 \%)$ & $1(2 \%)$ & $4(8 \%)$ \\
\hline Inflammation, suppurative & - & $1(2 \%)$ & - & - \\
\hline Islets, pancreatic & (50) & $(49)$ & $(50)$ & (50) \\
\hline Hyperplasia & $1(2 \%)$ & $1(2 \%)$ & $1(2 \%)$ & $3(6 \%)$ \\
\hline Parathyroid gland & $(24)$ & $(22)$ & $(21)$ & (31) \\
\hline Pituitary gland & (50) & $(50)$ & $(48)$ & (47) \\
\hline Pars distalis, angiectasis & - & - & $2(4 \%)$ & $1(2 \%)$ \\
\hline Pars distalis, cyst & - & - & - & $1(2 \%)$ \\
\hline Pars distalis, hyperplasia & $6(12 \%)$ & $9(18 \%)$ & $8(17 \%)$ & $8(17 \%)$ \\
\hline Thyroid gland & $(50)$ & $(50)$ & $(50)$ & (50) \\
\hline Follicular cell, hyperplasia & - & $2(4 \%)$ & $2(4 \%)$ & - \\
\hline
\end{tabular}

\section{General Body System}

None 
Vinylidene Chloride, NTP TR 582

\begin{tabular}{|c|c|c|c|c|}
\hline & $\begin{array}{l}\text { Chamber } \\
\text { Control }\end{array}$ & $6.25 \mathrm{ppm}$ & $12.5 \mathrm{ppm}$ & 25 ppm \\
\hline \multicolumn{5}{|l|}{ Genital System } \\
\hline Clitoral gland & (45) & $(46)$ & $(45)$ & (45) \\
\hline Hyperplasia & - & - & $1(2 \%)$ & - \\
\hline Inflammation, chronic active & - & - & - & $1(2 \%)$ \\
\hline Ovary & (50) & $(49)$ & (49) & (49) \\
\hline Angiectasis & - & - & $2(4 \%)$ & - \\
\hline Cyst & $6(12 \%)$ & $6(12 \%)$ & $12(24 \%)$ & $2(4 \%)$ \\
\hline Thrombosis & - & $2(4 \%)$ & $2(4 \%)$ & $1(2 \%)$ \\
\hline Uterus & (50) & $(49)$ & $(50)$ & (50) \\
\hline Adenomyosis & - & - & $1(2 \%)$ & - \\
\hline Angiectasis & - & - & $1(2 \%)$ & - \\
\hline Hemorrhage & - & - & $1(2 \%)$ & - \\
\hline Inflammation, suppurative & - & $1(2 \%)$ & $1(2 \%)$ & - \\
\hline Inflammation, histiocytic, chronic active & $1(2 \%)$ & - & - & - \\
\hline Inflammation, chronic active & $1(2 \%)$ & - & - & - \\
\hline Necrosis & - & - & $1(2 \%)$ & - \\
\hline Thrombosis & $1(2 \%)$ & - & $2(4 \%)$ & $1(2 \%)$ \\
\hline Ulcer & - & $1(2 \%)$ & - & - \\
\hline Endometrium, hyperplasia, cystic & $36(72 \%)$ & $41(84 \%)$ & $46(92 \%)$ & $46(92 \%)$ \\
\hline \multicolumn{5}{|l|}{ Hematopoietic System } \\
\hline Bone marrow & (50) & $(49)$ & $(50)$ & (50) \\
\hline Thrombosis & - & - & - & $1(2 \%)$ \\
\hline Myeloid cell hyperplasia & - & $1(2 \%)$ & $2(4 \%)$ & $1(2 \%)$ \\
\hline Lymph node & $(8)$ & $(11)$ & (1) & $(8)$ \\
\hline Hyperplasia, lymphoid & - & - & - & $1(13 \%)$ \\
\hline Iliac, ectasia & - & $1(9 \%)$ & - & - \\
\hline Lumbar, renal, angiectasis & $1(13 \%)$ & - & - & - \\
\hline $\begin{array}{l}\text { Lumbar, renal, inflammation, } \\
\text { granulomatous }\end{array}$ & $1(13 \%)$ & - & - & - \\
\hline Renal, angiectasis & $1(13 \%)$ & - & - & - \\
\hline Renal, ectasia & - & - & - & $1(13 \%)$ \\
\hline Lymph node, bronchial & $(25)$ & $(38)$ & $(38)$ & (38) \\
\hline Lymph node, mandibular & (31) & $(35)$ & $(30)$ & (37) \\
\hline Angiectasis & - & $1(3 \%)$ & - & $1(3 \%)$ \\
\hline Lymph node, mediastinal & (42) & $(45)$ & $(45)$ & (47) \\
\hline Lymph node, mesenteric & $(47)$ & $(48)$ & (47) & (45) \\
\hline
\end{tabular}


Vinylidene Chloride, NTP TR 582

\begin{tabular}{|c|c|c|c|c|}
\hline & $\begin{array}{l}\text { Chamber } \\
\text { Control }\end{array}$ & $6.25 \mathrm{ppm}$ & $12.5 \mathrm{ppm}$ & 25 ppm \\
\hline Hemorrhage & - & - & - & $1(2 \%)$ \\
\hline Hyperplasia, lymphoid & - & $1(2 \%)$ & $1(2 \%)$ & - \\
\hline Spleen & $(50)$ & $(49)$ & $(50)$ & (49) \\
\hline Hematopoietic cell proliferation & $3(6 \%)$ & $6(12 \%)$ & $7(14 \%)$ & $9(18 \%)$ \\
\hline Necrosis & - & $1(2 \%)$ & - & - \\
\hline Thymus & $(47)$ & $(44)$ & $(46)$ & $(40)$ \\
\hline Cyst & - & - & - & $1(3 \%)$ \\
\hline \multicolumn{5}{|l|}{ Integumentary System } \\
\hline Mammary gland & $(50)$ & $(50)$ & $(50)$ & $(50)$ \\
\hline Hyperplasia & - & $1(2 \%)$ & - & $3(6 \%)$ \\
\hline Skin & $(50)$ & $(50)$ & $(50)$ & $(50)$ \\
\hline Hemorrhage & - & $1(2 \%)$ & - & - \\
\hline Inflammation, chronic active & - & - & - & $1(2 \%)$ \\
\hline Necrosis & $3(6 \%)$ & $2(4 \%)$ & $2(4 \%)$ & - \\
\hline \multicolumn{5}{|l|}{ Musculoskeletal System } \\
\hline Bone & $(50)$ & $(50)$ & $(50)$ & $(50)$ \\
\hline Cyst & - & - & - & $1(2 \%)$ \\
\hline Degeneration & - & - & - & $1(2 \%)$ \\
\hline Hyperostosis & - & $1(2 \%)$ & - & - \\
\hline Skeletal muscle & (3) & (3) & (2) & (4) \\
\hline \multicolumn{5}{|l|}{ Nervous System } \\
\hline Brain & $(50)$ & $(50)$ & $(50)$ & $(50)$ \\
\hline $\begin{array}{l}\text { Artery, meninges, inflammation, chronic } \\
\text { active }\end{array}$ & $1(2 \%)$ & - & - & $1(2 \%)$ \\
\hline Peripheral nerve & (2) & (2) & (0) & $(0)$ \\
\hline Spinal cord & $(2)$ & $(2)$ & $(0)$ & $(1)$ \\
\hline \multicolumn{5}{|l|}{ Respiratory System } \\
\hline Larynx & $(50)$ & $(50)$ & (49) & (49) \\
\hline Degeneration, hyaline & $1(2 \%)$ & - & - & - \\
\hline Inflammation, suppurative & - & $1(2 \%)$ & - & - \\
\hline Metaplasia, squamous & $2(4 \%)$ & - & $1(2 \%)$ & $1(2 \%)$ \\
\hline Artery, inflammation, chronic active & $1(2 \%)$ & - & - & - \\
\hline Squamous epithelium, necrosis & - & - & $1(2 \%)$ & - \\
\hline Lung & $(50)$ & $(50)$ & $(50)$ & $(49)$ \\
\hline Degeneration, hyaline & $1(2 \%)$ & - & - & - \\
\hline
\end{tabular}


Vinylidene Chloride, NTP TR 582

\begin{tabular}{|c|c|c|c|c|}
\hline & $\begin{array}{l}\text { Chamber } \\
\text { Control }\end{array}$ & $6.25 \mathrm{ppm}$ & $12.5 \mathrm{ppm}$ & 25 ppm \\
\hline Fibrosis & - & - & - & $1(2 \%)$ \\
\hline Hemorrhage & - & $1(2 \%)$ & $1(2 \%)$ & $1(2 \%)$ \\
\hline Inflammation, chronic active & $2(4 \%)$ & $5(10 \%)$ & $3(6 \%)$ & $4(8 \%)$ \\
\hline Alveolar epithelium, hyperplasia & $3(6 \%)$ & $1(2 \%)$ & $4(8 \%)$ & $3(6 \%)$ \\
\hline Alveolus, infiltration cellular, histiocyte & $3(6 \%)$ & $1(2 \%)$ & $3(6 \%)$ & $3(6 \%)$ \\
\hline Perivascular, inflammation, chronic active & - & - & - & $2(4 \%)$ \\
\hline Vein, necrosis & - & $1(2 \%)$ & - & - \\
\hline Nose & (50) & (50) & (50) & $(50)$ \\
\hline Foreign body & - & $1(2 \%)$ & $1(2 \%)$ & $2(4 \%)$ \\
\hline Hyperostosis & - & $13(26 \%)$ & $45(90 \%)$ & $48(96 \%)$ \\
\hline Inflammation, suppurative & - & $1(2 \%)$ & $3(6 \%)$ & $5(10 \%)$ \\
\hline Inflammation, chronic active & $2(4 \%)$ & $1(2 \%)$ & - & $2(4 \%)$ \\
\hline $\begin{array}{l}\text { Olfactory epithelium, accumulation, } \\
\text { hyaline droplet }\end{array}$ & $18(36 \%)$ & $18(36 \%)$ & $13(26 \%)$ & $32(64 \%)$ \\
\hline $\begin{array}{l}\text { Olfactory epithelium, metaplasia, } \\
\text { respiratory }\end{array}$ & $3(6 \%)$ & $29(58 \%)$ & $49(98 \%)$ & $50(100 \%)$ \\
\hline Olfactory epithelium, necrosis & - & - & $2(4 \%)$ & $1(2 \%)$ \\
\hline $\begin{array}{l}\text { Respiratory epithelium, accumulation, } \\
\text { hyaline droplet }\end{array}$ & $38(76 \%)$ & $33(66 \%)$ & $29(58 \%)$ & $42(84 \%)$ \\
\hline Respiratory epithelium, hyperplasia & $33(66 \%)$ & $41(82 \%)$ & $39(78 \%)$ & $43(86 \%)$ \\
\hline $\begin{array}{l}\text { Respiratory epithelium, metaplasia, } \\
\text { squamous }\end{array}$ & $3(6 \%)$ & $2(4 \%)$ & $3(6 \%)$ & $7(14 \%)$ \\
\hline Respiratory epithelium, necrosis & $1(2 \%)$ & $3(6 \%)$ & $5(10 \%)$ & $4(8 \%)$ \\
\hline Turbinate, atrophy & - & $46(92 \%)$ & $50(100 \%)$ & $49(98 \%)$ \\
\hline Trachea & (50) & $(50)$ & $(50)$ & $(49)$ \\
\hline Degeneration, hyaline & $1(2 \%)$ & - & - & - \\
\hline Foreign body & $1(2 \%)$ & - & - & - \\
\hline Inflammation, chronic active & $1(2 \%)$ & - & - & - \\
\hline Artery, inflammation, chronic active & - & $1(2 \%)$ & - & - \\
\hline \multicolumn{5}{|l|}{ Special Senses System } \\
\hline Eye & $(50)$ & $(49)$ & $(50)$ & $(49)$ \\
\hline Cataract & - & $1(2 \%)$ & $1(2 \%)$ & - \\
\hline Degeneration & - & - & $1(2 \%)$ & - \\
\hline Cornea, inflammation, suppurative & - & - & - & $1(2 \%)$ \\
\hline Cornea, necrosis & - & - & - & $1(2 \%)$ \\
\hline Harderian gland & (50) & $(50)$ & $(50)$ & $(48)$ \\
\hline Hyperplasia & $1(2 \%)$ & $1(2 \%)$ & $2(4 \%)$ & $2(4 \%)$ \\
\hline
\end{tabular}


Vinylidene Chloride, NTP TR 582

\begin{tabular}{lcccc}
\hline & $\begin{array}{c}\text { Chamber } \\
\text { Control }\end{array}$ & $\mathbf{6 . 2 5} \mathbf{~ p p m}$ & $\mathbf{1 2 . 5} \mathbf{~ p p m}$ & $\mathbf{2 5} \mathbf{~ p p m}$ \\
\hline Urinary System & & & & \\
Kidney & $(50)$ & $(50)$ & $(50)$ & $(50)$ \\
Cyst & - & $2(4 \%)$ & $1(2 \%)$ & - \\
Hydronephrosis & $2(4 \%)$ & - & $1(2 \%)$ & $3(6 \%)$ \\
Infarct & $5(10 \%)$ & $5(10 \%)$ & $2(4 \%)$ & - \\
Inflammation, chronic active & - & $1(2 \%)$ & - & - \\
Metaplasia, osseous & $3(6 \%)$ & - & $2(4 \%)$ & $3(6 \%)$ \\
Nephropathy & $26(52 \%)$ & $28(56 \%)$ & $38(76 \%)$ & $35(70 \%)$ \\
Artery, inflammation, chronic active & $2(4 \%)$ & $3(6 \%)$ & - & $1(2 \%)$ \\
Glomerulus, amyloid deposition & - & $1(2 \%)$ & - & $1(2 \%)$ \\
Papilla, inflammation, suppurative & - & - & $1(2 \%)$ & - \\
Renal tubule, necrosis & - & $1(2 \%)$ & - & - \\
Renal tubule, pigmentation & - & - & $1(2 \%)$ & - \\
Urinary bladder & $(49)$ & $(49)$ & $(48)$ & $(48)$ \\
Artery, inflammation, chronic active & $1(2 \%)$ & - & - & - \\
Transitional epithelium, hyperplasia & $1(2 \%)$ & - & - & - \\
\hline aNumber of animals examined microscopically at the site and the number of animals with lesion. & & \\
& & & -
\end{tabular}

${ }^{a}$ Number of animals examined microscopically at the site and the number of animals with lesion. 


\section{Appendix E. Genetic Toxicology}

\section{Table of Contents}

E.1. Bacterial Mutagenicity Test Protocol ...............................................................................2

E.2. Mouse Lymphoma Mutagenicity Test Protocol .............................................................E-2

E.3. Drosophila melanogaster Test Protocol............................................................................

E.4. Mouse Peripheral Blood Micronucleus Test Protocol....................................................

E.5. Evaluation Protocol .................................................................................................. E-4

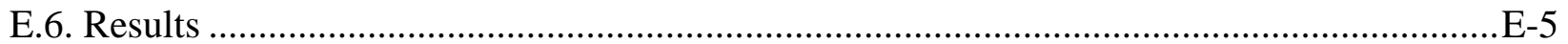

\section{Tables}

Table E-1. Mutagenicity of Vinylidene Chloride in Salmonella typhimurium ..........................E-6

Table E-2. Induction of Trifluorothymidine Resistance in L5178Y Mouse Lymphoma Cells by Vinylidene Chloride ................................................................................... E-8

Table E-3. Induction of Sex-Linked Recessive Lethal Mutations in Drosophila melanogaster by Vinylidene Chloride ................................................................ 11

Table E-4. Frequency of Micronuclei in Peripheral Blood Erythrocytes of Mice Following Treatment with Vinylidene Chloride by Inhalation for Three Months 


\section{E.1. Bacterial Mutagenicity Test Protocol}

Testing was performed as reported by Mortelmans et al. ${ }^{85}$. Vinylidene chloride was sent to the laboratory as a coded aliquot from Radian Corporation (Austin, TX). It was incubated with the Salmonella typhimurium tester strains TA98, TA100, TA1535, and TA1537 either in buffer or S9 mix (metabolic activation enzymes and cofactors from Aroclor 1254-induced male Sprague Dawley rat or Syrian hamster liver) for 20 minutes at $37^{\circ} \mathrm{C}$. Top agar supplemented with Lhistidine and d-biotin was added, and the contents of the tubes were mixed and poured onto the surfaces of minimal glucose agar plates. Histidine-independent mutant colonies arising on these plates were counted following incubation for 2 days at $37^{\circ} \mathrm{C}$.

Each trial consisted of triplicate plates of concurrent positive and negative controls and five doses of vinylidene chloride. The high dose was limited by toxicity. All trials were repeated.

In this assay, a positive response is defined as a reproducible, dose-related increase in histidineindependent (revertant) colonies in any one strain/activation combination. An equivocal response is defined as an increase in revertants that is not dose related, is not reproducible, or is not of sufficient magnitude to support a determination of mutagenicity. A negative response is obtained when no increase in revertant colonies is observed following chemical treatment. There is no minimum percentage or fold increase required for a chemical to be judged positive or weakly positive, although positive calls are typically reserved for increases in mutant colonies that are at least twofold over background.

\section{E.2. Mouse Lymphoma Mutagenicity Test Protocol}

The experimental protocol is presented in detail by McGregor et al. ${ }^{90}$. Vinylidene chloride was supplied as a coded aliquot by Radian Corporation. The high dose of vinylidene chloride was determined by solubility and toxicity. L5178Y mouse lymphoma cells were maintained at $37^{\circ} \mathrm{C}$ as suspension cultures in supplemented Fischer's medium; normal cycling time was approximately 10 hours. To reduce the number of spontaneously occurring cells resistant to trifluorothymidine (TFT), subcultures were exposed to medium containing thymidine, hypoxanthine, methotrexate, and glycine for 1 day; to medium containing thymidine, hypoxanthine, and glycine for 1 day; and to normal medium for 3 to 5 days. For cloning, the horse serum content was increased and Noble agar was added.

All treatment levels within an experiment, including concurrent positive and solvent controls, were replicated. Treated cultures contained $6 \times 10^{6}$ cells in $10 \mathrm{~mL}$ medium. This volume included the $\mathrm{S} 9$ fraction in those experiments performed with metabolic activation. Incubation with vinylidene chloride continued for 4 hours, at which time the medium plus vinylidene chloride was removed, and the cells were resuspended in fresh medium and incubated for an additional 2 days to express the mutant phenotype. Cell density was monitored so that log phase growth was maintained. After the 48-hour expression period, cells were plated in medium and soft agar supplemented with TFT for selection of TFT-resistant cells, and cells were plated in nonselective medium and soft agar to determine cloning efficiency. Plates were incubated at $37^{\circ} \mathrm{C}$ in $5 \% \mathrm{CO}_{2}$ for 10 to 12 days. The test was initially performed without $\mathrm{S} 9$. Because a clearly positive response was not obtained, the test was repeated using freshly prepared S9 from the livers of Aroclor 1254-induced male F344 rats. 
Minimum criteria for accepting an experiment as valid and a detailed description of the statistical analysis and data evaluation are presented by Caspary et al. ${ }^{151}$. All data were evaluated statistically for trend and peak responses. Both responses had to be significant $(\mathrm{P} \leq 0.05)$ for vinylidene chloride to be considered positive, i.e., capable of inducing TFT resistance. A single significant response led to a call of "questionable," and the absence of both a trend and peak response resulted in a "negative" call.

\section{E.3. Drosophila melanogaster Test Protocol}

The assays for induction of sex-linked recessive lethal (SLRL) mutations were performed with adult flies as described by Foureman et al. ${ }^{130}$. Vinylidene chloride was supplied as a coded aliquot by Radian Corporation. Vinylidene chloride was assayed in the SLRL test by feeding for 3 days to adult Canton-S wild-type males no more than 24 hours old at the beginning of treatment. Because no response was obtained, vinylidene chloride was retested by injection into adult males.

To administer vinylidene chloride by injection, a glass Pasteur pipette was drawn out in a flame to a microfine filament, and the tip was broken off to allow delivery of the test solution. Injection was performed either manually, by attaching a rubber bulb to the other end of the pipette and forcing through sufficient solution $(0.2$ to $0.3 \mu \mathrm{L})$ to slightly distend the abdomen of the fly, or by attaching the pipette to a microinjector that automatically delivered a calibrated volume. Flies were anesthetized with ether and immobilized on a strip of tape. Injection into the thorax, under the wing, was performed with the aid of a dissecting microscope.

Toxicity tests were performed to set concentrations of vinylidene chloride at a level that would induce $30 \%$ mortality after 72 hours of feeding or 24 hours after injection, while keeping induced sterility at an acceptable level. Canton-S males were allowed to feed for 72 hours on a solution of vinylidene chloride in 5\% sucrose. In the injection experiments, 24- to 72-hour-old Canton-S males were treated with a solution of vinylidene chloride dissolved in ethanol and allowed to recover for 24 hours. A concurrent ethanol control group was also included. In the adult exposures, treated males were mated to three Basc females for 3 days and were given fresh females at 2-day intervals to produce three matings of 3,2, and 2 days (in each case, sample sperm from successive matings was treated at successively earlier postmeiotic stages). $\mathrm{F}_{1}$ heterozygous females were mated with their siblings and then placed in individual vials. $\mathrm{F}_{1}$ daughters from the same parental male were kept together to identify clusters. (A cluster occurs when a number of mutants from a given male result from a single spontaneous premeiotic mutation event and is identified when the number of mutants from that male exceeds the number predicted by a Poisson distribution.) If a cluster was identified, all data from the male in question were discarded. Presumptive lethal mutations were identified as vials containing fewer than 5\% of the expected number of wild-type males after 17 days; these were retested to confirm the response.

SLRL data were analyzed by simultaneous comparison with the concurrent and historical controls ${ }^{152}$ using a normal approximation to the binomial test ${ }^{153}$. A test result was considered positive if the $\mathrm{P}$ value was less than or equal to 0.01 and the mutation frequency in the tested group was greater than $0.10 \%$ or if the $\mathrm{P}$ value was less than or equal to 0.05 and the frequency in the treatment group was greater than $0.15 \%$. A test was considered to be inconclusive if the $\mathrm{P}$ 
value was between 0.05 and 0.01 but the frequency in the treatment group was between $0.10 \%$ and $0.15 \%$ or if the $\mathrm{P}$ value was between 0.10 and 0.05 but the frequency in the treatment group was greater than $0.10 \%$. A test was considered negative if the $\mathrm{P}$ value was greater than or equal to 0.10 or if the frequency in the treatment group was less than $0.10 \%$.

\section{E.4. Mouse Peripheral Blood Micronucleus Test Protocol}

A detailed discussion of this assay is presented by MacGregor et al. ${ }^{154}$. At the end of the 3-month toxicity study, peripheral blood samples were obtained from male and female B6C3F1/N mice. Smears were immediately prepared and fixed in absolute methanol. Slides were sent to the genetic toxicity testing laboratory where they were stained with acridine orange and coded. Slides were scanned to determine the frequency of micronuclei in 2,000 normochromatic erythrocytes (NCEs; mature erythrocytes) per animal. In addition, the percentage of polychromatic erythrocytes (PCEs; reticulocytes) among the total erythrocyte population in the peripheral blood was scored for each dose group as a measure of bone marrow toxicity.

The results were tabulated as the mean of the pooled results from all animals within a treatment group plus or minus the standard error of the mean. The frequency of micronucleated cells among NCEs was analyzed by a statistical software package that tested for increasing trend over exposure groups with a one-tailed Cochran-Armitage trend test, followed by pairwise comparisons between each exposed group and the control group. In the presence of excess binomial variation, as detected by a binomial dispersion test, the binomial variance of the Cochran-Armitage test was adjusted upward in proportion to the excess variation. In the micronucleus test, an individual trial is considered positive if the trend test $\mathrm{P}$ value is less than or equal to 0.025 or if the $\mathrm{P}$ value for any single exposed group is less than or equal to 0.025 divided by the number of exposed groups. A final call of positive for micronucleus induction is preferably based on reproducibly positive trials (as noted above). Results of the 3-month study were accepted without repeat tests, because additional test data could not be obtained. Ultimately, the final call is determined by the scientific staff after considering the results of statistical analyses, the reproducibility of any effects observed, and the magnitudes of those effects.

\section{E.5. Evaluation Protocol}

These are the basic guidelines for arriving at an overall assay result for assays performed by the National Toxicology Program. Statistical as well as biological factors are considered. For an individual assay, the statistical procedures for data analysis have been described in the preceding protocols. There have been instances, however, in which multiple samples of a chemical were tested in the same assay, and different results were obtained among these samples and/or among laboratories. Results from more than one aliquot or from more than one laboratory are not simply combined into an overall result. Rather, all the data are critically evaluated, particularly with regard to pertinent protocol variations, in determining the weight of evidence for an overall conclusion of chemical activity in an assay. In addition to multiple aliquots, the in vitro assays have another variable that must be considered in arriving at an overall test result. In vitro assays are conducted with and without exogenous metabolic activation. Results obtained in the absence of activation are not combined with results obtained in the presence of activation; each testing condition is evaluated separately. The summary table in the Abstract of this Technical Report 
presents a result that represents a scientific judgement of the overall evidence for activity of the chemical in an assay.

\section{E.6. Results}

Vinylidene chloride tested over a concentration range of 33.3 to $6,666 \mu \mathrm{g} /$ plate was not mutagenic in S. typhimurium strains TA98, TA100, TA1535, or TA1537 when testing occurred with or without exogenous metabolic activation (10\% induced hamster or rat liver S9 mix) using a preincubation protocol (Table E-1; Mortelmans et al. ${ }^{85}$ ). However, when tested in a closed system as a vapor, vinylidene chloride $(0.16 \%$ to $2.5 \%$ in air $)$ demonstrated clear mutagenic activity in mouse lymphoma L5178Y $\mathrm{tk}^{+/-}$cells in trials conducted with $10 \%$ induced male rat liver S9 mix (Table E-2; McGregor et al. ${ }^{90}$ ); in the absence of S9, a positive response was seen at a concentration of $30 \%$ vinylidene chloride in one of three trials. In vivo, no increase in sexlinked recessive lethal mutations was seen in germ cells of adult male Drosophila melanogaster exposed via feeding $(20,000$ or $25,000 \mathrm{ppm})$ or injection $(5,000 \mathrm{ppm})$ to vinylidene chloride ${ }^{130}$ (Table E-3). No increase in the frequency of micronucleated NCEs was observed in peripheral blood of male or female $\mathrm{B} 6 \mathrm{C} 3 \mathrm{~F} 1 / \mathrm{N}$ mice exposed to vinylidene chloride by inhalation for a period of 3 months, and no change in the percentage of immature PCEs (reticulocytes) was seen in these mice following exposure to vinylidene chloride, suggesting the absence of chemicalinduced bone marrow toxicity (Table E-4). 
Table E-1. Mutagenicity of Vinylidene Chloride in Salmonella typhimurium ${ }^{\text {a }}$

\begin{tabular}{|c|c|c|c|c|c|c|c|c|c|c|}
\hline Strain & $\begin{array}{c}\text { Dose } \\
(\mu \mathrm{g} / \text { plate })\end{array}$ & $\begin{array}{l}\text { Without } \\
\text { S9 }\end{array}$ & $\begin{array}{l}\text { Without } \\
\text { S9 }\end{array}$ & $\begin{array}{l}\text { Without } \\
\text { S9 }\end{array}$ & $\begin{array}{c}\text { With 10\% } \\
\text { Hamster S9 }\end{array}$ & $\begin{array}{c}\text { With } 10 \% \\
\text { Hamster S9 }\end{array}$ & $\begin{array}{c}\text { With } 10 \% \\
\text { Hamster S9 }\end{array}$ & $\begin{array}{c}\text { With } 10 \% \\
\text { Rat S9 }\end{array}$ & $\begin{array}{c}\text { With 10\% } \\
\text { Rat S9 }\end{array}$ & $\begin{array}{c}\text { With } 10 \% \\
\text { Rat S9 }\end{array}$ \\
\hline \multicolumn{11}{|l|}{ TA100 } \\
\hline & 0 & $99 \pm 10$ & $81 \pm 8$ & $91 \pm 3$ & $96 \pm 10$ & $93 \pm 6$ & & $92 \pm 4$ & $107 \pm 3$ & $88 \pm 7$ \\
\hline & 33.3 & & & $95 \pm 7$ & & $97 \pm 7$ & & & & $97 \pm 7$ \\
\hline & 100 & $90 \pm 9$ & $85 \pm 5$ & $91 \pm 6$ & $92 \pm 6$ & $98 \pm 7$ & & $106 \pm 7$ & $98 \pm 4$ & $97 \pm 6$ \\
\hline & 333.3 & $87 \pm 6$ & $80 \pm 12$ & $97 \pm 7$ & $94 \pm 9$ & $104 \pm 7$ & & $115 \pm 8$ & $86 \pm 11$ & $104 \pm 4$ \\
\hline & 1,000 & $87 \pm 4$ & $63 \pm 4$ & $106 \pm 2$ & $112 \pm 5$ & $103 \pm 10$ & & $100 \pm 12$ & $105 \pm 10$ & $120 \pm 9$ \\
\hline & 3,333 & $81 \pm 6$ & $79 \pm 3^{b}$ & $82 \pm 4$ & $85 \pm 6^{b}$ & $51 \pm 12^{\mathrm{b}}$ & & $87 \pm 2^{b}$ & $84 \pm 3^{b}$ & $110 \pm 4$ \\
\hline & 6,666 & $89 \pm 4$ & $78 \pm 3^{b}$ & & $41 \pm 21^{b}$ & & & $71 \pm 5^{b}$ & $81 \pm 2^{b}$ & \\
\hline Trial summary & & Negative & Negative & Negative & Negative & Negative & & Negative & Negative & Negative \\
\hline Positive control $^{\mathrm{c}}$ & & $130 \pm 30$ & $376 \pm 18$ & $500 \pm 11$ & $1,238 \pm 91$ & $290 \pm 21$ & & $604 \pm 40$ & $826 \pm 36$ & $1,066 \pm 12$ \\
\hline \multicolumn{11}{|l|}{ TA98 } \\
\hline & 0 & $17 \pm 2$ & $19 \pm 1$ & $14 \pm 3$ & $25 \pm 1$ & $29 \pm 2$ & $22 \pm 2$ & $27 \pm 3$ & $41 \pm 2$ & $22 \pm 3$ \\
\hline & 33.3 & & & $8 \pm 2$ & & & $20 \pm 2$ & & & $28 \pm 5$ \\
\hline & 100 & $15 \pm 2$ & $21 \pm 4$ & $15 \pm 4$ & $24 \pm 3$ & $28 \pm 6$ & $20 \pm 2$ & $25 \pm 2$ & $36 \pm 2$ & $31 \pm 6$ \\
\hline & 333.3 & $17 \pm 4$ & $22 \pm 7$ & $13 \pm 0$ & $28 \pm 2$ & $33 \pm 3$ & $20 \pm 2$ & $22 \pm 3$ & $35 \pm 6$ & $25 \pm 4$ \\
\hline & 1,000 & $21 \pm 2$ & $15 \pm 2$ & $17 \pm 2$ & $35 \pm 6$ & $36 \pm 2$ & $22 \pm 2$ & $23 \pm 4$ & $37 \pm 5$ & $24 \pm 3$ \\
\hline & 3,333 & $23 \pm 4$ & $12 \pm 1$ & $16 \pm 6$ & $37 \pm 3$ & $28 \pm 1^{b}$ & $10 \pm 5^{b}$ & $20 \pm 2^{b}$ & $26 \pm 3^{b}$ & $19 \pm 1$ \\
\hline & 6,666 & $13 \pm 3$ & $15 \pm 5^{\mathrm{b}}$ & & $44 \pm 4$ & $12 \pm 4^{b}$ & & $20 \pm 5^{b}$ & $23 \pm 3^{b}$ & \\
\hline Trial summary & & Negative & Negative & Negative & Negative & Negative & Negative & Negative & Negative & Negative \\
\hline Positive control & & $645 \pm 7$ & $655 \pm 70$ & $693 \pm 39$ & $1,292 \pm 28$ & $198 \pm 10$ & $199 \pm 8$ & $428 \pm 24$ & $542 \pm 13$ & $787 \pm 53$ \\
\hline \multicolumn{11}{|l|}{ TA1535 } \\
\hline & 0 & $17 \pm 2$ & $18 \pm 3$ & $8 \pm 1$ & $10 \pm 0$ & $9 \pm 1$ & $12 \pm 3$ & $6 \pm 1$ & $11 \pm 3$ & $5 \pm 2$ \\
\hline & 33.3 & & & $10 \pm 2$ & & & $8 \pm 0$ & & & $6 \pm 0$ \\
\hline & 100 & $18 \pm 1$ & $17 \pm 1$ & $7 \pm 1$ & $14 \pm 0$ & $13 \pm 3$ & $7 \pm 2$ & $7 \pm 1$ & $7 \pm 2$ & $8 \pm 1$ \\
\hline
\end{tabular}




\begin{tabular}{|c|c|c|c|c|c|c|c|c|c|c|}
\hline Strain & $\begin{array}{c}\text { Dose } \\
(\mu \mathrm{g} / \mathrm{plate})\end{array}$ & $\begin{array}{c}\text { Without } \\
\text { S9 }\end{array}$ & $\begin{array}{c}\text { Without } \\
\text { S9 }\end{array}$ & $\begin{array}{c}\text { Without } \\
\text { S9 }\end{array}$ & $\begin{array}{l}\text { With } 10 \% \\
\text { Hamster S9 }\end{array}$ & $\begin{array}{c}\text { With } 10 \% \\
\text { Hamster S9 }\end{array}$ & $\begin{array}{c}\text { With } 10 \% \\
\text { Hamster S9 }\end{array}$ & $\begin{array}{c}\text { With } 10 \% \\
\text { Rat S9 }\end{array}$ & $\begin{array}{c}\text { With } 10 \% \\
\text { Rat S9 }\end{array}$ & $\begin{array}{c}\text { With } 10 \% \\
\text { Rat S9 }\end{array}$ \\
\hline & 333.3 & $19 \pm 4$ & $14 \pm 3$ & $6 \pm 1$ & $10 \pm 3$ & $11 \pm 2$ & $7 \pm 1$ & $10 \pm 2$ & $5 \pm 0$ & $10 \pm 3$ \\
\hline & 1,000 & $20 \pm 6$ & $15 \pm 1$ & $8 \pm 3$ & $16 \pm 1$ & $17 \pm 1$ & $6 \pm 2$ & $12 \pm 1$ & $11 \pm 2$ & $9 \pm 2$ \\
\hline & 3,333 & $20 \pm 0$ & $18 \pm 1^{\mathrm{b}}$ & $9 \pm 0$ & $22 \pm 2$ & $5 \pm 0^{\mathrm{b}}$ & $4 \pm 2^{b}$ & $7 \pm 1^{\mathrm{b}}$ & $8 \pm 1^{\mathrm{b}}$ & $5 \pm 1$ \\
\hline & 6,666 & $19 \pm 3$ & $19 \pm 3^{b}$ & & $23 \pm 2$ & $8 \pm 3^{b}$ & & $8 \pm 2^{b}$ & $6 \pm 2^{b}$ & \\
\hline Trial summary & & Negative & Negative & Negative & Negative & Negative & Negative & Negative & Negative & Negative \\
\hline Positive control & & $19 \pm 1$ & $300 \pm 21$ & $337 \pm 23$ & $374 \pm 16$ & $326 \pm 21$ & $186 \pm 13$ & $389 \pm 11$ & $355 \pm 11$ & $387 \pm 26$ \\
\hline \multicolumn{11}{|l|}{ TA1537 } \\
\hline & 0 & $7 \pm 1$ & $6 \pm 1$ & $6 \pm 0$ & $16 \pm 2$ & $10 \pm 2$ & $5 \pm 1$ & $14 \pm 1$ & $15 \pm 0$ & $6 \pm 1$ \\
\hline & 33.3 & & & $7 \pm 1$ & & & $8 \pm 1$ & & & $12 \pm 2$ \\
\hline & 100 & $6 \pm 1$ & $8 \pm 1$ & $5 \pm 1$ & $19 \pm 3$ & $18 \pm 3$ & $9 \pm 2$ & $10 \pm 1$ & $13 \pm 2$ & $5 \pm 2$ \\
\hline & 333.3 & $9 \pm 1$ & $8 \pm 1$ & $4 \pm 1$ & $15 \pm 1$ & $19 \pm 3$ & $5 \pm 1$ & $6 \pm 1$ & $13 \pm 1$ & $6 \pm 1$ \\
\hline & 1,000 & $9 \pm 1$ & $5 \pm 2$ & $4 \pm 1$ & $18 \pm 1$ & $15 \pm 0$ & $7 \pm 4$ & $9 \pm 1$ & $11 \pm 2$ & $6 \pm 1$ \\
\hline & 3,333 & $9 \pm 1$ & $5 \pm 1^{b}$ & $5 \pm 2$ & $20 \pm 2$ & $14 \pm 4^{b}$ & $4 \pm 0^{b}$ & $11 \pm 1^{\mathrm{b}}$ & $13 \pm 6^{\mathrm{b}}$ & $5 \pm 1$ \\
\hline & 6,666 & $6 \pm 1$ & $6 \pm 1^{b}$ & & $14 \pm 4$ & $5 \pm 2^{\mathrm{b}}$ & & $10 \pm 3^{\mathrm{b}}$ & $8 \pm 1^{\mathrm{b}}$ & \\
\hline Trial summary & & Negative & Negative & Negative & Negative & Negative & Negative & Negative & Negative & Negative \\
\hline Positive control & & $227 \pm 44$ & $245 \pm 42$ & $258 \pm 17$ & $556 \pm 24$ & $487 \pm 35$ & $362 \pm 20$ & $365 \pm 20$ & $297 \pm 29$ & $461 \pm 16$ \\
\hline
\end{tabular}


Vinylidene Chloride, NTP TR 582

Table E-2. Induction of Trifluorothymidine Resistance in L5178Y Mouse Lymphoma Cells by Vinylidene Chloride ${ }^{a}$

\begin{tabular}{|c|c|c|c|c|c|c|}
\hline Compound & $\begin{array}{c}\text { Concentration } \\
(\%)\end{array}$ & $\begin{array}{c}\text { Cloning } \\
\text { Efficiency } \\
(\%)\end{array}$ & $\begin{array}{c}\text { Relative } \\
\text { Total Growth } \\
(\%)\end{array}$ & $\begin{array}{l}\text { Mutant } \\
\text { Count }\end{array}$ & $\begin{array}{c}\text { Mutant } \\
\text { Fraction }^{\mathrm{b}}\end{array}$ & $\begin{array}{c}\text { Average } \\
\text { Mutant } \\
\text { Fraction }\end{array}$ \\
\hline \multicolumn{7}{|l|}{$-\mathbf{S 9}$} \\
\hline \multicolumn{7}{|l|}{ Trial 1} \\
\hline \multicolumn{7}{|l|}{ Trial call: Questionable } \\
\hline \multirow[t]{4}{*}{$\operatorname{Air}^{\mathrm{c}}$} & & 81 & 101 & 41 & 17 & \\
\hline & & 63 & 103 & 48 & 26 & \\
\hline & & 52 & 80 & 20 & 13 & \\
\hline & & 62 & 117 & 57 & 31 & 22 \\
\hline \multirow[t]{10}{*}{ Vinylidene chloride } & 1 & 78 & 127 & 72 & 31 & \\
\hline & & $71^{\mathrm{d}}$ & 134 & 38 & 18 & 24 \\
\hline & 2 & $0^{\mathrm{e}}$ & 0 & 58 & 0 & \\
\hline & & 65 & 108 & 64 & 33 & \\
\hline & 4 & 69 & 98 & 70 & 34 & \\
\hline & & 69 & 91 & 81 & 39 & $37 *$ \\
\hline & 6 & 70 & 117 & 53 & 25 & \\
\hline & & 58 & 92 & 59 & 34 & 29 \\
\hline & 8 & 71 & 107 & 74 & 35 & \\
\hline & & 76 & 128 & 76 & 33 & 34 \\
\hline \multirow[t]{2}{*}{ Methyl methanesulfonate ${ }^{f}$} & $15 \mu \mathrm{g} / \mathrm{mL}$ & $27^{\mathrm{d}}$ & 27 & 75 & 93 & \\
\hline & & 24 & 23 & 57 & 81 & $87 *$ \\
\hline
\end{tabular}

\section{Trial 2}

Trial call: Inconclusive

\begin{tabular}{|c|c|c|c|c|c|c|}
\hline \multirow[t]{4}{*}{ Air } & & 85 & 100 & 63 & 25 & \\
\hline & & 78 & 99 & 40 & 17 & \\
\hline & & 79 & 109 & 68 & 29 & \\
\hline & & 76 & 93 & 62 & 27 & 25 \\
\hline \multirow[t]{10}{*}{ Vinylidene chloride } & 3 & 68 & 94 & 32 & 16 & \\
\hline & & 65 & 79 & 46 & 24 & 20 \\
\hline & 6 & 72 & 101 & 28 & 13 & \\
\hline & & 74 & 92 & 39 & 18 & 15 \\
\hline & 9 & 61 & 88 & 30 & 16 & \\
\hline & & 67 & 98 & 31 & 15 & 16 \\
\hline & 12 & 66 & 91 & 22 & 11 & \\
\hline & & 68 & 83 & 28 & 14 & 12 \\
\hline & 15 & 67 & 59 & 27 & 13 & \\
\hline & & 71 & 74 & 40 & 19 & 16 \\
\hline \multirow[t]{2}{*}{ Methyl methanesulfonate } & $15 \mu \mathrm{g} / \mathrm{mL}$ & 35 & 21 & 159 & 152 & \\
\hline & & 33 & 21 & 154 & 158 & $155^{*}$ \\
\hline
\end{tabular}


Vinylidene Chloride, NTP TR 582

\begin{tabular}{|c|c|c|c|c|c|c|}
\hline Compound & $\begin{array}{c}\text { Concentration } \\
(\%)\end{array}$ & $\begin{array}{c}\text { Cloning } \\
\text { Efficiency } \\
(\%)\end{array}$ & $\begin{array}{c}\text { Relative } \\
\text { Total Growth } \\
(\%)\end{array}$ & $\begin{array}{l}\text { Mutant } \\
\text { Count }\end{array}$ & $\begin{array}{l}\text { Mutant } \\
\text { Fraction }^{\mathrm{b}}\end{array}$ & $\begin{array}{c}\text { Average } \\
\text { Mutant } \\
\text { Fraction }\end{array}$ \\
\hline \multicolumn{7}{|l|}{$-\mathbf{S 9}$} \\
\hline \multicolumn{7}{|l|}{ Trial 3} \\
\hline \multicolumn{7}{|l|}{ Trial cell: Positive } \\
\hline \multirow[t]{4}{*}{ Air } & & 73 & 130 & 31 & 14 & \\
\hline & & 79 & 89 & 52 & 22 & \\
\hline & & 71 & 78 & 133 & 62 & \\
\hline & & 79 & 103 & 66 & 28 & 32 \\
\hline \multirow[t]{10}{*}{ Vinylidene chloride } & 10 & 60 & 77 & 61 & 34 & \\
\hline & & 63 & 88 & 92 & 49 & 41 \\
\hline & 15 & 82 & 69 & 66 & 27 & \\
\hline & & 60 & 60 & 60 & 33 & 30 \\
\hline & 20 & 65 & 94 & 47 & 24 & \\
\hline & & 56 & 81 & 70 & 42 & 33 \\
\hline & 25 & 64 & 93 & 60 & 31 & \\
\hline & & 63 & 66 & 53 & 28 & 30 \\
\hline & 30 & 43 & 22 & 63 & 49 & \\
\hline & & 32 & 19 & 66 & 69 & $59^{*}$ \\
\hline \multirow[t]{2}{*}{ Methyl methanesulfonate } & $15 \mu \mathrm{g} / \mathrm{mL}$ & 16 & 18 & 137 & 282 & \\
\hline & & 27 & 18 & 202 & 252 & $267^{*}$ \\
\hline \multicolumn{7}{|l|}{$+\mathrm{S9}$} \\
\hline \multicolumn{7}{|l|}{ Trial 1} \\
\hline \multicolumn{7}{|l|}{ Trial call: Positive } \\
\hline \multirow[t]{4}{*}{ Air } & & 68 & 88 & 92 & 45 & \\
\hline & & 77 & 115 & 94 & 41 & \\
\hline & & 67 & 97 & 97 & 48 & \\
\hline & & 73 & 100 & 107 & 49 & 46 \\
\hline \multirow[t]{10}{*}{ Vinylidene chloride } & 0.16 & 68 & 69 & 201 & 99 & \\
\hline & & 81 & 70 & 207 & 86 & $92^{*}$ \\
\hline & 0.31 & 46 & 42 & 210 & 153 & \\
\hline & & 70 & 79 & 213 & 102 & $127 *$ \\
\hline & 0.63 & 52 & 37 & 292 & 188 & \\
\hline & & 47 & 37 & 299 & 211 & $200^{*}$ \\
\hline & 1.25 & 31 & 22 & 308 & 337 & \\
\hline & & 36 & 25 & 294 & 271 & $304^{*}$ \\
\hline & 2.5 & 45 & 22 & 305 & 227 & \\
\hline & & 41 & 16 & 359 & 290 & $258^{*}$ \\
\hline \multirow[t]{2}{*}{ Methyl cholanthrene ${ }^{f}$} & $2.5 \mu \mathrm{g} / \mathrm{mL}$ & 34 & 15 & 458 & 456 & \\
\hline & & 33 & 20 & 393 & 399 & $427 *$ \\
\hline
\end{tabular}


Vinylidene Chloride, NTP TR 582

\begin{tabular}{|c|c|c|c|c|c|c|}
\hline Compound & $\begin{array}{c}\text { Concentration } \\
(\%)\end{array}$ & $\begin{array}{c}\text { Cloning } \\
\text { Efficiency } \\
(\%)\end{array}$ & $\begin{array}{c}\text { Relative } \\
\text { Total Growth } \\
\text { (\%) }\end{array}$ & $\begin{array}{l}\text { Mutant } \\
\text { Count }\end{array}$ & $\begin{array}{c}\text { Mutant } \\
\text { Fraction }^{\mathrm{b}}\end{array}$ & $\begin{array}{c}\text { Average } \\
\text { Mutant } \\
\text { Fraction }\end{array}$ \\
\hline \multicolumn{7}{|l|}{ +S9 } \\
\hline \multicolumn{7}{|l|}{ Trial 2} \\
\hline \multicolumn{7}{|l|}{ Trial call: Positive } \\
\hline \multirow[t]{4}{*}{ Air } & & 79 & 127 & 124 & 52 & \\
\hline & & 60 & 86 & 118 & 66 & \\
\hline & & 81 & 87 & 115 & 48 & \\
\hline & & $83^{\mathrm{d}}$ & 100 & 140 & 56 & 56 \\
\hline \multirow[t]{10}{*}{ Vinylidene chloride } & 1 & 57 & 25 & 293 & 171 & \\
\hline & & 35 & 13 & 251 & 237 & $204 *$ \\
\hline & 1.5 & 23 & 6 & 174 & 249 & \\
\hline & & 44 & 12 & 297 & 227 & $238^{*}$ \\
\hline & 2 & 46 & 11 & 264 & 193 & \\
\hline & & 33 & 10 & 226 & 228 & $211^{*}$ \\
\hline & 2.5 & 22 & 8 & 134 & 205 & \\
\hline & & 43 & 13 & 251 & 195 & $200^{*}$ \\
\hline & 3.5 & $8^{\mathrm{e}}$ & 1 & 184 & 783 & \\
\hline & & $4^{\mathrm{e}}$ & 1 & 87 & 757 & \\
\hline \multirow[t]{2}{*}{ Methyl cholanthrene } & $2.5 \mu \mathrm{g} / \mathrm{mL}$ & 24 & 9 & 495 & 697 & \\
\hline & & 28 & 11 & 422 & 502 & $600 *$ \\
\hline
\end{tabular}

*Positive response $(\mathrm{P} \leq 0.05)$ versus the chamber control.

${ }^{a}$ Study was performed at Inveresk Research International. The detailed protocol and these data are presented by McGregor et al. ${ }^{90}$.

${ }^{\mathrm{b}}$ Mutant fraction $=$ mutant cells $/ 106$ clonable cells.

${ }^{\mathrm{c}}$ Chamber control.

${ }^{\mathrm{d}}$ Reduced sample size due to contamination and loss of one culture.

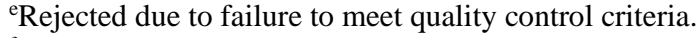

fPositive control. 
Vinylidene Chloride, NTP TR 582

Table E-3. Induction of Sex-Linked Recessive Lethal Mutations in Drosophila melanogaster by Vinylidene Chloride ${ }^{a}$

\begin{tabular}{|c|c|c|c|c|c|c|c|}
\hline $\begin{array}{l}\text { Route of } \\
\text { Exposure }\end{array}$ & $\begin{array}{c}\text { Dose } \\
\text { (ppm) }\end{array}$ & $\begin{array}{c}\text { Incidence of } \\
\text { Death }(\%)\end{array}$ & $\begin{array}{l}\text { Incidence of } \\
\text { Sterility }(\%)\end{array}$ & $\begin{array}{l}\text { No. Lethals } \\
\text { Mating } 1\end{array}$ & $\begin{array}{l}\text { No. Lethals } \\
\text { Mating } 2\end{array}$ & $\begin{array}{c}\text { No. Lethals } \\
\text { Mating } 3\end{array}$ & Total $^{\text {b }}$ \\
\hline \multirow[t]{2}{*}{ Feeding } & 25,000 & 13 & 8 & $0 / 724$ & $0 / 471$ & $1 / 372$ & $1 / 1,567(0.06 \%)$ \\
\hline & 0 & - & - & $0 / 854$ & $0 / 694$ & $0 / 449$ & 0/1,997 (0.00\%) \\
\hline \multirow[t]{3}{*}{ Feeding } & 20,000 & 17 & 4 & $1 / 1,356$ & $1 / 1,215$ & $2 / 1,146$ & $4 / 3,717(0.11 \%)$ \\
\hline & 0 & - & - & $1 / 1,247$ & $0 / 1,014$ & $1 / 1,020$ & $2 / 3,281(0.06 \%)$ \\
\hline & & & & & & & $P=0.129$ \\
\hline \multirow[t]{3}{*}{ Injection } & 5,000 & 1 & 15 & $0 / 2,204$ & $1 / 1653$ & $0 / 1,179$ & $1 / 5,036(0.02 \%)$ \\
\hline & 0 & - & - & $1 / 2,132$ & $1 / 2023$ & $0 / 1,104$ & $2 / 5,259(0.04 \%)$ \\
\hline & & & & & & & $\mathrm{P}=0.705^{\mathrm{c}}$ \\
\hline
\end{tabular}

${ }^{a}$ Study was performed at the University of Wisconsin-Madison. The detailed protocol and these data are presented by Foureman et al. ${ }^{130}$. The mean mutant frequency from 518 negative control experiments is $0.074 \%{ }^{152}$.

${ }^{\mathrm{b}}$ Total number of lethal mutations/total number of $\mathrm{X}$ chromosomes tested for three mating trials.

${ }^{\mathrm{c}}$ Significance of total number of lethal mutations/total number of $\mathrm{X}$ chromosomes tested by a normal approximation to the binomial test ${ }^{153}$.

Table E-4. Frequency of Micronuclei in Peripheral Blood Erythrocytes of Mice Following Treatment with Vinylidene Chloride by Inhalation for Three Months ${ }^{\mathrm{a}}$

\begin{tabular}{|c|c|c|c|c|c|}
\hline & $\begin{array}{l}\text { Dose } \\
(\mathbf{p p m})\end{array}$ & $\begin{array}{l}\text { Number of Mice with } \\
\text { Erythrocytes Scored }\end{array}$ & $\begin{array}{c}\text { Micronucleated } \\
\text { NCEs/1,000 NCEs }{ }^{b}\end{array}$ & P Value ${ }^{c}$ & $\operatorname{PCEs}^{\mathrm{b}}(\%)$ \\
\hline \multicolumn{6}{|l|}{ Male } \\
\hline $\operatorname{Air}^{\mathrm{d}}$ & & 5 & $2.40 \pm 0.33$ & & $2.90 \pm 0.34$ \\
\hline \multirow[t]{5}{*}{ Vinylidene chloride } & 6.25 & 5 & $2.00 \pm 0.32$ & 0.7270 & $2.84 \pm 0.45$ \\
\hline & 12.5 & 5 & $1.40 \pm 0.40$ & 0.9478 & $2.58 \pm 0.32$ \\
\hline & 25 & 5 & $3.20 \pm 0.70$ & 0.1422 & $3.08 \pm 0.14$ \\
\hline & 50 & 5 & $2.10 \pm 0.58$ & 0.6728 & $2.96 \pm 0.22$ \\
\hline & \multicolumn{5}{|c|}{$\mathrm{P}=0.363^{\mathrm{e}}$} \\
\hline \multicolumn{6}{|l|}{ Female } \\
\hline Air & & 5 & $1.20 \pm 0.30$ & & $3.10 \pm 0.38$ \\
\hline \multirow[t]{6}{*}{ Vinylidene chloride } & 6.25 & 5 & $0.90 \pm 0.43$ & 0.6917 & $2.88 \pm 0.41$ \\
\hline & 12.5 & 5 & $1.40 \pm 0.56$ & 0.3821 & $2.74 \pm 0.31$ \\
\hline & 25 & 5 & $1.10 \pm 0.43$ & 0.5634 & $2.56 \pm 0.46$ \\
\hline & 50 & 5 & $1.80 \pm 0.44$ & 0.2010 & $3.14 \pm 0.49$ \\
\hline & 100 & 5 & $1.00 \pm 0.50$ & 0.6278 & $2.80 \pm 0.31$ \\
\hline & \multicolumn{5}{|c|}{$\mathrm{P}=0.481$} \\
\hline \multicolumn{6}{|c|}{ 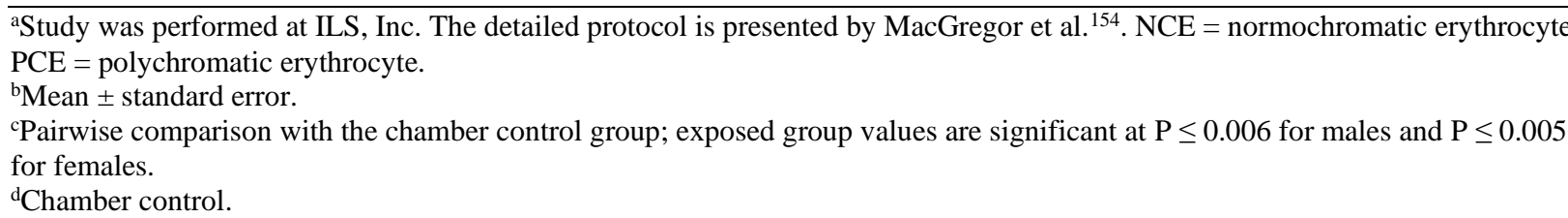 } \\
\hline
\end{tabular}




\section{Appendix F. Clinical Pathology Results}

\section{Tables}

Table F-1. Hematology and Clinical Chemistry Data for Rats in the Three-Month Inhalation Study of Vinylidene Chloride

Table F-2. Hematology Data for Mice in the Three-Month Inhalation Study of Vinylidene Chloride. 
Vinylidene Chloride, NTP TR 582

Table F-1. Hematology and Clinical Chemistry Data for Rats in the Three-Month Inhalation Study of Vinylidene Chloride ${ }^{a}$

\begin{tabular}{|c|c|c|c|c|c|c|}
\hline & $\begin{array}{l}\text { Chamber } \\
\text { Control }\end{array}$ & $6.25 \mathrm{ppm}$ & $12.5 \mathrm{ppm}$ & 25 ppm & $50 \mathrm{ppm}$ & 100 ppm \\
\hline \multicolumn{7}{|l|}{ Male } \\
\hline \multicolumn{7}{|c|}{ Hematology } \\
\hline \multicolumn{7}{|c|}{ n } \\
\hline Day 3 & 10 & 10 & 9 & 10 & 10 & 10 \\
\hline Day 23 & 10 & 10 & 10 & 10 & 10 & 10 \\
\hline Week 14 & 10 & 10 & 10 & 10 & 10 & 10 \\
\hline \multicolumn{7}{|c|}{ Hematocrit (manual) $(\%)$} \\
\hline Day 3 & $46.5 \pm 0.5$ & $46.5 \pm 0.4$ & $45.7 \pm 0.3$ & $46.1 \pm 0.2$ & $47.4 \pm 0.5$ & $48.4 \pm 0.4^{*}$ \\
\hline Day 23 & $48.5 \pm 0.3$ & $48.5 \pm 0.3$ & $47.7 \pm 0.3$ & $48.2 \pm 0.6$ & $48.1 \pm 0.3$ & $48.4 \pm 0.4$ \\
\hline Week 14 & $49.7 \pm 0.3$ & $49.5 \pm 0.5$ & $48.7 \pm 0.4$ & $49.9 \pm 0.4$ & $49.8 \pm 0.3$ & $49.6 \pm 0.2$ \\
\hline \multicolumn{7}{|c|}{ Packed cell volume (auto) (\%) } \\
\hline Day 3 & $45.2 \pm 0.5$ & $45.0 \pm 0.5$ & $44.5 \pm 0.5$ & $44.6 \pm 0.3$ & $45.8 \pm 0.6$ & $46.9 \pm 0.5$ \\
\hline Day 23 & $47.7 \pm 0.3$ & $47.3 \pm 0.3$ & $46.4 \pm 0.4$ & $47.2 \pm 0.5$ & $47.5 \pm 0.4$ & $47.8 \pm 0.4$ \\
\hline Week 14 & $49.1 \pm 0.2$ & $48.3 \pm 0.5$ & $47.8 \pm 0.4$ & $49.0 \pm 0.3$ & $49.0 \pm 0.3$ & $48.9 \pm 0.4$ \\
\hline \multicolumn{7}{|c|}{ Hemoglobin $(\mathrm{g} / \mathrm{dL})$} \\
\hline Day 3 & $13.9 \pm 0.2$ & $13.9 \pm 0.2$ & $13.8 \pm 0.2$ & $14.0 \pm 0.2$ & $14.3 \pm 0.2$ & $14.8 \pm 0.1^{* *}$ \\
\hline Day 23 & $15.2 \pm 0.1$ & $15.1 \pm 0.1$ & $14.8 \pm 0.1$ & $15.0 \pm 0.2$ & $15.2 \pm 0.1$ & $15.2 \pm 0.1$ \\
\hline Week 14 & $15.7 \pm 0.1$ & $15.6 \pm 0.1$ & $15.3 \pm 0.1$ & $15.6 \pm 0.1$ & $15.7 \pm 0.1$ & $15.5 \pm 0.1$ \\
\hline \multicolumn{7}{|c|}{ Erythrocytes $\left(10^{6} / \mu \mathrm{L}\right)$} \\
\hline Day 3 & $7.32 \pm 0.08$ & $7.27 \pm 0.09$ & $7.19 \pm 0.07$ & $7.34 \pm 0.07$ & $7.48 \pm 0.09$ & $7.79 \pm 0.09^{* *}$ \\
\hline Day 23 & $8.29 \pm 0.06$ & $8.16 \pm 0.07$ & $7.99 \pm 0.07^{*}$ & $8.12 \pm 0.10$ & $8.14 \pm 0.07$ & $8.19 \pm 0.09$ \\
\hline Week 14 & $9.21 \pm 0.05$ & $9.11 \pm 0.06$ & $9.01 \pm 0.08$ & $9.17 \pm 0.05$ & $9.25 \pm 0.05$ & $9.08 \pm 0.07$ \\
\hline \multicolumn{7}{|c|}{ Reticulocytes $\left(10^{6} / \mu \mathrm{L}\right)$} \\
\hline Day 3 & $0.32 \pm 0.02$ & $0.40 \pm 0.03$ & $0.34 \pm 0.02$ & $0.33 \pm 0.02$ & $0.33 \pm 0.02$ & $0.30 \pm 0.02$ \\
\hline Day 23 & $0.25 \pm 0.02$ & $0.27 \pm 0.02$ & $0.30 \pm 0.02^{\mathrm{b}}$ & $0.30 \pm 0.02^{\mathrm{c}}$ & $0.33 \pm 0.01 * *$ & $0.31 \pm 0.02^{\mathrm{b} * *}$ \\
\hline Week 14 & $0.17 \pm 0.01$ & $0.20 \pm 0.01$ & $0.18 \pm 0.01$ & $0.18 \pm 0.01$ & $0.19 \pm 0.01$ & $0.21 \pm 0.01$ \\
\hline \multicolumn{7}{|c|}{ Nucleated erythrocytes/100 leukocytes } \\
\hline Day 3 & $1.1 \pm 0.4$ & $0.8 \pm 0.2$ & $0.8 \pm 0.3$ & $0.6 \pm 0.3$ & $0.2 \pm 0.1$ & $0.4 \pm 0.2$ \\
\hline Day 23 & $0.1 \pm 0.1$ & $0.2 \pm 0.1$ & $0.0 \pm 0.0$ & $0.0 \pm 0.0$ & $0.1 \pm 0.1$ & $0.2 \pm 0.1$ \\
\hline Week 14 & $0.2 \pm 0.1$ & $0.0 \pm 0.0$ & $0.5 \pm 0.2$ & $0.2 \pm 0.1$ & $0.1 \pm 0.1$ & $0.5 \pm 0.2$ \\
\hline \multicolumn{7}{|c|}{ Mean cell volume (fL) } \\
\hline Day 3 & $61.8 \pm 0.4$ & $61.9 \pm 0.2$ & $61.8 \pm 0.3$ & $60.9 \pm 0.2$ & $61.2 \pm 0.4$ & $60.2 \pm 0.4^{* *}$ \\
\hline Day 23 & $57.6 \pm 0.3$ & $58.0 \pm 0.2$ & $58.0 \pm 0.2$ & $58.2 \pm 0.2$ & $58.4 \pm 0.2$ & $58.4 \pm 0.3$ \\
\hline Week 14 & $53.3 \pm 0.1$ & $53.0 \pm 0.2$ & $53.1 \pm 0.2$ & $53.4 \pm 0.2$ & $53.0 \pm 0.2$ & $53.9 \pm 0.2$ \\
\hline
\end{tabular}


Vinylidene Chloride, NTP TR 582

\begin{tabular}{|c|c|c|c|c|c|c|}
\hline & $\begin{array}{c}\text { Chamber } \\
\text { Control }\end{array}$ & $6.25 \mathrm{ppm}$ & $12.5 \mathrm{ppm}$ & 25 ppm & 50 ppm & 100 ppm \\
\hline \multicolumn{7}{|c|}{ Mean cell hemoglobin (pg) } \\
\hline Day 3 & $19.0 \pm 0.1$ & $19.2 \pm 0.1$ & $19.2 \pm 0.1$ & $19.0 \pm 0.1$ & $19.2 \pm 0.1$ & $18.9 \pm 0.1$ \\
\hline Day 23 & $18.4 \pm 0.1$ & $18.5 \pm 0.1$ & $18.5 \pm 0.1$ & $18.5 \pm 0.1$ & $18.7 \pm 0.1$ & $18.6 \pm 0.1$ \\
\hline Week 14 & $17.0 \pm 0.1$ & $17.0 \pm 0.1$ & $17.1 \pm 0.0$ & $17.0 \pm 0.1$ & $17.0 \pm 0.1$ & $17.1 \pm 0.1$ \\
\hline \multicolumn{7}{|c|}{ Mean cell hemoglobin concentration $(\mathrm{g} / \mathrm{dL})$} \\
\hline Day 3 & $30.8 \pm 0.1$ & $30.9 \pm 0.1$ & $31.1 \pm 0.2$ & $31.3 \pm 0.2$ & $31.3 \pm 0.2 *$ & $31.5 \pm 0.1 * *$ \\
\hline Day 23 & $31.9 \pm 0.1$ & $31.9 \pm 0.1$ & $31.9 \pm 0.1$ & $31.9 \pm 0.1$ & $32.0 \pm 0.1$ & $31.8 \pm 0.1$ \\
\hline Week 14 & $32.0 \pm 0.1$ & $32.2 \pm 0.2$ & $32.1 \pm 0.1$ & $31.9 \pm 0.1$ & $32.1 \pm 0.1$ & $31.8 \pm 0.1$ \\
\hline \multicolumn{7}{|c|}{ Platelets $\left(10^{3 /} \mu \mathrm{L}\right)$} \\
\hline Day 3 & $855.5 \pm 22.3$ & $902.4 \pm 19.2$ & $852.7 \pm 15.1$ & $851.9 \pm 9.8$ & $869.6 \pm 17.4$ & $899.3 \pm 18.3$ \\
\hline Day 23 & $717.7 \pm 24.5$ & $743.1 \pm 14.4$ & $732.3 \pm 20.0$ & $706.2 \pm 14.9$ & $728.2 \pm 16.9$ & $757.9 \pm 13.2$ \\
\hline Week 14 & $623.1 \pm 13.9$ & $644.4 \pm 8.8$ & $618.2 \pm 11.0$ & $591.4 \pm 10.6$ & $617.2 \pm 18.6$ & $615.0 \pm 9.8$ \\
\hline \multicolumn{7}{|c|}{ Leukocytes $\left(10^{3} / \mu \mathrm{L}\right)$} \\
\hline Day 3 & $8.76 \pm 0.47$ & $9.27 \pm 0.32$ & $9.60 \pm 0.32$ & $9.36 \pm 0.24$ & $9.41 \pm 0.44$ & $9.11 \pm 0.42$ \\
\hline Day 23 & $8.30 \pm 0.55$ & $7.67 \pm 0.55$ & $8.35 \pm 0.42$ & $7.50 \pm 0.45$ & $8.58 \pm 0.67$ & $8.06 \pm 0.59$ \\
\hline Week 14 & $6.19 \pm 0.35$ & $6.92 \pm 0.43$ & $6.05 \pm 0.44$ & $6.02 \pm 0.33$ & $6.60 \pm 0.45$ & $6.17 \pm 0.31$ \\
\hline \multicolumn{7}{|c|}{ Segmented neutrophils $\left(10^{3} / \mu \mathrm{L}\right)$} \\
\hline Day 3 & $0.75 \pm 0.03$ & $0.95 \pm 0.05$ & $1.29 \pm 0.08 * *$ & $1.12 \pm 0.06^{* *}$ & $0.96 \pm 0.04$ & $0.79 \pm 0.04$ \\
\hline Day 23 & $0.94 \pm 0.06$ & $0.94 \pm 0.03$ & $0.92 \pm 0.03$ & $0.87 \pm 0.07$ & $0.94 \pm 0.05$ & $0.97 \pm 0.08$ \\
\hline Week 14 & $1.13 \pm 0.06$ & $1.17 \pm 0.07$ & $1.12 \pm 0.07$ & $1.06 \pm 0.03$ & $1.15 \pm 0.06$ & $1.05 \pm 0.05$ \\
\hline \multicolumn{7}{|c|}{ Bands $\left(10^{3} / \mu \mathrm{L}\right)$} \\
\hline Day 3 & $0.00 \pm 0.00$ & $0.00 \pm 0.00$ & $0.00 \pm 0.00$ & $0.00 \pm 0.00$ & $0.00 \pm 0.00$ & $0.00 \pm 0.00$ \\
\hline Day 23 & $0.00 \pm 0.00$ & $0.00 \pm 0.00$ & $0.00 \pm 0.00$ & $0.00 \pm 0.00$ & $0.00 \pm 0.00$ & $0.00 \pm 0.00$ \\
\hline Week 14 & $0.00 \pm 0.00$ & $0.00 \pm 0.00$ & $0.00 \pm 0.00$ & $0.00 \pm 0.00$ & $0.00 \pm 0.00$ & $0.00 \pm 0.00$ \\
\hline \multicolumn{7}{|c|}{ Lymphocytes $\left(10^{3} / \mu \mathrm{L}\right)$} \\
\hline Day 3 & $7.72 \pm 0.45$ & $8.08 \pm 0.28$ & $8.05 \pm 0.30$ & $8.00 \pm 0.20$ & $8.18 \pm 0.42$ & $7.99 \pm 0.41$ \\
\hline Day 23 & $7.11 \pm 0.53$ & $6.51 \pm 0.51$ & $7.14 \pm 0.39$ & $6.38 \pm 0.47$ & $7.21 \pm 0.58$ & $6.82 \pm 0.53$ \\
\hline Week 14 & $4.54 \pm 0.34$ & $5.30 \pm 0.40$ & $4.34 \pm 0.38$ & $4.47 \pm 0.34$ & $4.99 \pm 0.40$ & $4.69 \pm 0.35$ \\
\hline \multicolumn{7}{|c|}{ Monocytes $\left(10^{3} / \mu \mathrm{L}\right)$} \\
\hline Day 3 & $0.18 \pm 0.03$ & $0.14 \pm 0.03$ & $0.16 \pm 0.07$ & $0.11 \pm 0.04$ & $0.15 \pm 0.03$ & $0.20 \pm 0.05$ \\
\hline Day 23 & $0.16 \pm 0.09$ & $0.15 \pm 0.04$ & $0.20 \pm 0.09$ & $0.16 \pm 0.07$ & $0.34 \pm 0.12$ & $0.18 \pm 0.06$ \\
\hline Week 14 & $0.42 \pm 0.09$ & $0.32 \pm 0.08$ & $0.47 \pm 0.07$ & $0.38 \pm 0.06$ & $0.34 \pm 0.10$ & $0.34 \pm 0.07$ \\
\hline \multicolumn{7}{|c|}{ Basophils $\left(10^{3} / \mu \mathrm{L}\right)$} \\
\hline Day 3 & $0.015 \pm 0.003$ & $0.012 \pm 0.003$ & $0.010 \pm 0.002$ & $0.012 \pm 0.003$ & $0.012 \pm 0.005$ & $0.020 \pm 0.005$ \\
\hline Day 23 & $0.008 \pm 0.005$ & $0.005 \pm 0.002$ & $0.007 \pm 0.003$ & $0.009 \pm 0.002$ & $0.016 \pm 0.005$ & $0.006 \pm 0.002$ \\
\hline
\end{tabular}


Vinylidene Chloride, NTP TR 582

\begin{tabular}{lcccccc}
\hline & $\begin{array}{c}\text { Chamber } \\
\text { Control }\end{array}$ & $\mathbf{6 . 2 5} \mathbf{~ p p m}$ & $\mathbf{1 2 . 5} \mathbf{~ p p m}$ & $\mathbf{2 5} \mathbf{~ p p m}$ & $\mathbf{5 0} \mathbf{~ p p m}$ & $\mathbf{1 0 0} \mathbf{~ p p m}$ \\
\hline Week 14 & $0.010 \pm 0.002$ & $0.013 \pm 0.003$ & $0.014 \pm 0.004$ & $0.011 \pm 0.002$ & $0.012 \pm 0.005$ & $0.008 \pm 0.001$ \\
\multicolumn{2}{l}{ Eosinophils $\left(10^{3} / \mu \mathrm{L}\right)$} & & & & & \\
Day 3 & $0.09 \pm 0.01$ & $0.09 \pm 0.01$ & $0.09 \pm 0.01$ & $0.12 \pm 0.03$ & $0.11 \pm 0.01$ & $0.11 \pm 0.02$ \\
Day 23 & $0.08 \pm 0.01$ & $0.06 \pm 0.01$ & $0.09 \pm 0.01$ & $0.08 \pm 0.01$ & $0.09 \pm 0.01$ & $0.09 \pm 0.01$ \\
Week 14 & $0.09 \pm 0.01$ & $0.12 \pm 0.01$ & $0.10 \pm 0.01$ & $0.09 \pm 0.01$ & $0.11 \pm 0.01$ & $0.09 \pm 0.01$ \\
\hline
\end{tabular}

\section{Clinical Chemistry}

n

10

10

10

10

10

10

Urea nitrogen $(\mathrm{mg} / \mathrm{dL})$

$\begin{array}{lcccccc}\text { Day 3 } & 8.9 \pm 0.4 & 8.5 \pm 0.4 & 9.0 \pm 0.6 & 9.9 \pm 0.4 & 10.7 \pm 0.4^{*} & 14.9 \pm 0.6^{* *} \\ \text { Day 23 } & 10.5 \pm 0.5 & 9.7 \pm 0.3 & 9.9 \pm 0.4 & 11.7 \pm 0.5 & 12.2 \pm 0.4^{*} & 13.4 \pm 0.3^{* *} \\ \text { Week 14 } & 15.6 \pm 0.4 & 14.5 \pm 0.2 & 13.9 \pm 0.3^{* *} & 14.9 \pm 0.3 & 15.6 \pm 0.6 & 13.9 \pm 0.2^{* *} \\ \text { Creatinine (mg/dL) } & & & & & \\ \text { Day 3 } & 0.23 \pm 0.02 & 0.23 \pm 0.02 & 0.25 \pm 0.02 & 0.25 \pm 0.02 & 0.25 \pm 0.02 & 0.27 \pm 0.02 \\ \text { Day 23 } & 0.27 \pm 0.02 & 0.28 \pm 0.01 & 0.27 \pm 0.02 & 0.28 \pm 0.02 & 0.30 \pm 0.00 & 0.30 \pm 0.02 \\ \text { Week 14 } & 0.40 \pm 0.00 & 0.41 \pm 0.02 & 0.38 \pm 0.01 & 0.43 \pm 0.02 & 0.44 \pm 0.02 & 0.44 \pm 0.02\end{array}$

Glucose (mg/dL)

$\begin{array}{lcccccc}\text { Day } 3 & 141 \pm 8 & 141 \pm 2 & 138 \pm 5 & 140 \pm 4 & 127 \pm 3 & 125 \pm 3^{*} \\ \text { Day 23 } & 119 \pm 4 & 129 \pm 4 & 128 \pm 3 & 119 \pm 6 & 120 \pm 5 & 106 \pm 3 \\ \text { Week 14 } & 127 \pm 2 & 123 \pm 2 & 126 \pm 3 & 135 \pm 11 & 128 \pm 6 & 121 \pm 2\end{array}$

Total protein $(\mathrm{g} / \mathrm{dL})$

$\begin{array}{lcccccc}\text { Day 3 } & 6.2 \pm 0.1 & 6.2 \pm 0.0 & 6.2 \pm 0.1 & 6.3 \pm 0.1 & 6.3 \pm 0.1 & 6.5 \pm 0.1^{* *} \\ \text { Day 23 } & 6.5 \pm 0.0 & 6.6 \pm 0.0 & 6.6 \pm 0.1 & 6.5 \pm 0.0 & 6.6 \pm 0.1 & 6.8 \pm 0.0^{* *} \\ \text { Week 14 } & 7.5 \pm 0.1 & 7.5 \pm 0.0 & 7.4 \pm 0.1 & 7.4 \pm 0.1 & 7.6 \pm 0.1 & 7.6 \pm 0.1 \\ \text { Albumin (g/dL) } & & & & & & \\ \text { Day 3 } & 4.5 \pm 0.1 & 4.5 \pm 0.0 & 4.4 \pm 0.0 & 4.4 \pm 0.1 & 4.5 \pm 0.0 & 4.6 \pm 0.1 \\ \text { Day 23 } & 4.6 \pm 0.0 & 4.6 \pm 0.0 & 4.6 \pm 0.0 & 4.6 \pm 0.0 & 4.6 \pm 0.0 & 4.7 \pm 0.0^{*} \\ \text { Week 14 } & 5.0 \pm 0.0 & 4.9 \pm 0.0 & 4.9 \pm 0.0^{*} & 4.9 \pm 0.0 & 5.0 \pm 0.0 & 5.0 \pm 0.0\end{array}$

Globulin (g/dL)

$\begin{array}{lcccccc}\text { Day } 3 & 1.7 \pm 0.0 & 1.7 \pm 0.0 & 1.8 \pm 0.0 & 1.8 \pm 0.0 & 1.9 \pm 0.0^{*} & 1.9 \pm 0.0^{* *} \\ \text { Day 23 } & 1.9 \pm 0.0 & 2.0 \pm 0.0 & 2.0 \pm 0.0 & 1.9 \pm 0.0 & 2.0 \pm 0.0^{*} & 2.1 \pm 0.0^{* *} \\ \text { Week 14 } & 2.5 \pm 0.0 & 2.5 \pm 0.0 & 2.5 \pm 0.0 & 2.4 \pm 0.0 & 2.6 \pm 0.0 & 2.6 \pm 0.0\end{array}$

$\mathrm{A} / \mathrm{G}$ ratio (albumin/globulin ratio)

\begin{tabular}{lcccccc} 
Day 3 & $2.6 \pm 0.0$ & $2.6 \pm 0.0$ & $2.5 \pm 0.0$ & $2.5 \pm 0.0^{*}$ & $2.4 \pm 0.0^{* *}$ & $2.4 \pm 0.0^{* *}$ \\
Day 23 & $2.4 \pm 0.0$ & $2.4 \pm 0.0$ & $2.3 \pm 0.0$ & $2.4 \pm 0.0$ & $2.3 \pm 0.0$ & $2.3 \pm 0.0$ \\
Week 14 & $2.0 \pm 0.0$ & $2.0 \pm 0.0$ & $2.0 \pm 0.0$ & $2.0 \pm 0.0$ & $1.9 \pm 0.0$ & $1.9 \pm 0.0$ \\
\hline
\end{tabular}


Vinylidene Chloride, NTP TR 582

\begin{tabular}{|c|c|c|c|c|c|c|}
\hline & $\begin{array}{c}\text { Chamber } \\
\text { Control }\end{array}$ & $6.25 \mathrm{ppm}$ & $12.5 \mathrm{ppm}$ & 25 ppm & 50 ppm & 100 ppm \\
\hline \multicolumn{7}{|c|}{ Alanine aminotransferase (IU/L) } \\
\hline Day 3 & $54 \pm 1$ & $54 \pm 1$ & $53 \pm 2$ & $53 \pm 1$ & $61 \pm 1 * *$ & $70 \pm 4 * *$ \\
\hline Day 23 & $44 \pm 1$ & $45 \pm 1$ & $42 \pm 1$ & $43 \pm 1$ & $45 \pm 1$ & $63 \pm 4 * *$ \\
\hline Week 14 & $129 \pm 18$ & $113 \pm 5$ & $97 \pm 6$ & $94 \pm 4$ & $96 \pm 5$ & $82 \pm 2 * *$ \\
\hline \multicolumn{7}{|c|}{ Alkaline phosphatase (IU/L) } \\
\hline Day 3 & $578 \pm 11$ & $580 \pm 7$ & $575 \pm 9$ & $587 \pm 8$ & $622 \pm 9 * *$ & $625 \pm 13^{* *}$ \\
\hline Day 23 & $385 \pm 8$ & $404 \pm 9$ & $397 \pm 8$ & $382 \pm 8$ & $415 \pm 9^{*}$ & $434 \pm 11 * *$ \\
\hline Week 14 & $254 \pm 4$ & $238 \pm 3$ & $233 \pm 5^{*}$ & $239 \pm 5$ & $241 \pm 6$ & $263 \pm 5$ \\
\hline \multicolumn{7}{|c|}{ Creatine kinase (IU/L) } \\
\hline Day 3 & $532 \pm 64$ & $424 \pm 30$ & $426 \pm 22^{b}$ & $450 \pm 34$ & $629 \pm 96$ & $563 \pm 35$ \\
\hline Day 23 & $244 \pm 16$ & $327 \pm 58$ & $330 \pm 28 *$ & $335 \pm 15^{* *}$ & $397 \pm 42 * *$ & $378 \pm 50 * *$ \\
\hline Week 14 & $189 \pm 22$ & $208 \pm 32$ & $237 \pm 32$ & $226 \pm 25$ & $283 \pm 59$ & $261 \pm 33$ \\
\hline \multicolumn{7}{|c|}{ Sorbitol dehydrogenase (IU/L) } \\
\hline Day 3 & $13 \pm 1^{\mathrm{b}}$ & $12 \pm 1$ & $13 \pm 1$ & $12 \pm 1$ & $12 \pm 1$ & $16 \pm 1$ \\
\hline Day 23 & $14 \pm 1$ & $14 \pm 1$ & $14 \pm 1$ & $13 \pm 1$ & $13 \pm 1$ & $27 \pm 3 * *$ \\
\hline Week 14 & $26 \pm 3$ & $25 \pm 1$ & $24 \pm 1$ & $23 \pm 1$ & $26 \pm 1$ & $25 \pm 1$ \\
\hline \multicolumn{7}{|c|}{ Bile acids $(\mu \mathrm{mol} / \mathrm{L})$} \\
\hline Day 3 & $5.8 \pm 0.8$ & $4.5 \pm 0.5$ & $4.2 \pm 0.4$ & $6.7 \pm 2.0$ & $6.0 \pm 0.8$ & $6.9 \pm 1.2$ \\
\hline Day 23 & $4.3 \pm 0.5$ & $4.0 \pm 0.2$ & $3.7 \pm 0.2$ & $4.2 \pm 0.4$ & $5.1 \pm 1.0$ & $4.2 \pm 0.3$ \\
\hline Week 14 & $3.2 \pm 0.2$ & $3.0 \pm 0.1$ & $2.7 \pm 0.1$ & $3.3 \pm 0.2$ & $2.7 \pm 0.2$ & $2.7 \pm 0.1$ \\
\hline
\end{tabular}

Female

\section{Hematology}

n

\begin{tabular}{|c|c|c|c|c|c|c|}
\hline Day 3 & 10 & 10 & 10 & 10 & 9 & 10 \\
\hline Day 23 & 10 & 10 & 10 & 10 & 10 & 10 \\
\hline Week 14 & 10 & 10 & 10 & 10 & 10 & 10 \\
\hline
\end{tabular}

Hematocrit (manual) (\%)

\begin{tabular}{|c|c|c|c|c|c|c|}
\hline Day 3 & $49.7 \pm 0.8$ & $49.4 \pm 0.5$ & $48.8 \pm 0.4$ & $49.2 \pm 0.8$ & $49.3 \pm 0.5$ & $50.7 \pm 0.4$ \\
\hline Day 23 & $48.9 \pm 0.5$ & $48.6 \pm 0.3$ & $47.7 \pm 0.2$ & $48.7 \pm 0.5$ & $48.5 \pm 0.2$ & $49.1 \pm 0.4$ \\
\hline Week 14 & $48.4 \pm 0.4$ & $48.0 \pm 0.3$ & $47.3 \pm 0.2$ & $47.5 \pm 0.2$ & $47.8 \pm 0.4$ & $47.6 \pm 0.3$ \\
\hline \multicolumn{7}{|c|}{ Packed cell volume (auto) (\%) } \\
\hline Day 3 & $48.5 \pm 0.8$ & $48.9 \pm 0.4$ & $47.8 \pm 0.5$ & $48.4 \pm 0.8$ & $48.4 \pm 0.6$ & $49.5 \pm 0.3$ \\
\hline Day 23 & $48.2 \pm 0.4$ & $48.3 \pm 0.3$ & $47.2 \pm 0.3$ & $48.2 \pm 0.4$ & $47.7 \pm 0.2$ & $48.5 \pm 0.5$ \\
\hline Week 14 & $48.0 \pm 0.6$ & $47.9 \pm 0.3$ & $47.2 \pm 0.2$ & $47.3 \pm 0.2$ & $47.3 \pm 0.6$ & $47.8 \pm 0.3$ \\
\hline
\end{tabular}

Hemoglobin (g/dL) 
Vinylidene Chloride, NTP TR 582

\begin{tabular}{|c|c|c|c|c|c|c|}
\hline & $\begin{array}{l}\text { Chamber } \\
\text { Control }\end{array}$ & $6.25 \mathrm{ppm}$ & 12.5 ppm & 25 ppm & 50 ppm & 100 ppm \\
\hline Day 3 & $15.0 \pm 0.2$ & $15.3 \pm 0.1$ & $15.1 \pm 0.1$ & $15.3 \pm 0.2$ & $15.4 \pm 0.1$ & $15.7 \pm 0.1 * *$ \\
\hline Day 23 & $15.5 \pm 0.1$ & $15.6 \pm 0.1$ & $15.3 \pm 0.1$ & $15.5 \pm 0.1$ & $15.4 \pm 0.1$ & $15.7 \pm 0.2$ \\
\hline Week 14 & $15.4 \pm 0.1$ & $15.4 \pm 0.1$ & $15.3 \pm 0.1$ & $15.2 \pm 0.1$ & $15.2 \pm 0.2$ & $15.2 \pm 0.1$ \\
\hline \multicolumn{7}{|c|}{ Erythrocytes $\left(10^{6} / \mu \mathrm{L}\right)$} \\
\hline Day 3 & $7.87 \pm 0.12$ & $8.03 \pm 0.08$ & $7.92 \pm 0.08$ & $7.99 \pm 0.12$ & $8.08 \pm 0.09$ & $8.31 \pm 0.07 * *$ \\
\hline Day 23 & $8.27 \pm 0.07$ & $8.26 \pm 0.08$ & $8.17 \pm 0.08$ & $8.30 \pm 0.08$ & $8.16 \pm 0.04$ & $8.40 \pm 0.10$ \\
\hline Week 14 & $8.46 \pm 0.08$ & $8.47 \pm 0.06$ & $8.39 \pm 0.04$ & $8.41 \pm 0.04$ & $8.36 \pm 0.10$ & $8.40 \pm 0.07$ \\
\hline \multicolumn{7}{|c|}{ Reticulocytes $\left(10^{6} / \mu \mathrm{L}\right)$} \\
\hline Day 3 & $0.37 \pm 0.04$ & $0.35 \pm 0.01^{\mathrm{c}}$ & $0.37 \pm 0.03$ & $0.36 \pm 0.03^{b}$ & $0.36 \pm 0.03$ & $0.38 \pm 0.02^{b}$ \\
\hline Day 23 & $0.21 \pm 0.01$ & $0.24 \pm 0.01$ & $0.22 \pm 0.01$ & $0.24 \pm 0.01$ & $0.25 \pm 0.01$ & $0.25 \pm 0.01$ \\
\hline Week 14 & $0.17 \pm 0.01$ & $0.15 \pm 0.01$ & $0.18 \pm 0.01$ & $0.16 \pm 0.01$ & $0.16 \pm 0.01$ & $0.20 \pm 0.01$ \\
\hline \multicolumn{7}{|c|}{ Nucleated erythrocytes/100 leukocytes } \\
\hline Day 3 & $0.4 \pm 0.2$ & $0.1 \pm 0.1$ & $0.2 \pm 0.1$ & $0.1 \pm 0.1$ & $0.1 \pm 0.1$ & $0.1 \pm 0.1$ \\
\hline Day 23 & $0.0 \pm 0.0$ & $0.1 \pm 0.1$ & $0.3 \pm 0.2$ & $0.0 \pm 0.0$ & $0.0 \pm 0.0$ & $0.3 \pm 0.2$ \\
\hline Week 14 & $0.4 \pm 0.2$ & $0.6 \pm 0.2$ & $0.5 \pm 0.2$ & $0.7 \pm 0.3$ & $0.7 \pm 0.3$ & $0.5 \pm 0.2$ \\
\hline \multicolumn{7}{|c|}{ Mean cell volume (fL) } \\
\hline Day 3 & $61.6 \pm 0.3$ & $60.9 \pm 0.4$ & $60.3 \pm 0.4$ & $60.7 \pm 0.4$ & $60.0 \pm 0.5^{*}$ & $59.6 \pm 0.4 * *$ \\
\hline Day 23 & $58.3 \pm 0.3$ & $58.5 \pm 0.4$ & $57.9 \pm 0.3$ & $58.2 \pm 0.3$ & $58.5 \pm 0.1$ & $57.7 \pm 0.2$ \\
\hline Week 14 & $56.7 \pm 0.2$ & $56.5 \pm 0.2$ & $56.2 \pm 0.2$ & $56.2 \pm 0.2$ & $56.6 \pm 0.2$ & $56.9 \pm 0.2$ \\
\hline \multicolumn{7}{|c|}{ Mean cell hemoglobin (pg) } \\
\hline Day 3 & $19.0 \pm 0.0$ & $19.0 \pm 0.1$ & $19.1 \pm 0.1$ & $19.1 \pm 0.1$ & $19.1 \pm 0.1$ & $19.0 \pm 0.1$ \\
\hline Day 23 & $18.8 \pm 0.1$ & $18.8 \pm 0.1$ & $18.7 \pm 0.1$ & $18.7 \pm 0.1$ & $18.9 \pm 0.1$ & $18.7 \pm 0.1$ \\
\hline Week 14 & $18.2 \pm 0.1$ & $18.2 \pm 0.1$ & $18.3 \pm 0.0$ & $18.1 \pm 0.1$ & $18.1 \pm 0.1$ & $18.1 \pm 0.0$ \\
\hline \multicolumn{7}{|c|}{ Mean cell hemoglobin concentration $(\mathrm{g} / \mathrm{dL})$} \\
\hline Day 3 & $30.8 \pm 0.1$ & $31.2 \pm 0.2$ & $31.7 \pm 0.2 * *$ & $31.5 \pm 0.2 * *$ & $31.9 \pm 0.3 * *$ & $31.8 \pm 0.2 * *$ \\
\hline Day 23 & $32.3 \pm 0.2$ & $32.3 \pm 0.1$ & $32.4 \pm 0.1$ & $32.1 \pm 0.1$ & $32.2 \pm 0.1$ & $32.3 \pm 0.2$ \\
\hline Week 14 & $32.1 \pm 0.2$ & $32.1 \pm 0.1$ & $32.5 \pm 0.1$ & $32.2 \pm 0.1$ & $32.0 \pm 0.1$ & $31.8 \pm 0.1$ \\
\hline \multicolumn{7}{|c|}{ Platelets $\left(10^{3} / \mu \mathrm{L}\right)$} \\
\hline Day 3 & $844.0 \pm 22.9$ & $807.7 \pm 31.8$ & $831.1 \pm 27.3$ & $777.3 \pm 14.4$ & $879.0 \pm 20.7$ & $799.8 \pm 23.6$ \\
\hline Day 23 & $719.0 \pm 20.6$ & $709.5 \pm 22.2$ & $692.0 \pm 19.0$ & $701.0 \pm 13.3$ & $706.2 \pm 12.5$ & $725.0 \pm 11.2$ \\
\hline Week 14 & $630.0 \pm 15.5$ & $624.1 \pm 13.2$ & $597.4 \pm 11.8$ & $626.6 \pm 11.9$ & $607.3 \pm 9.9$ & $614.9 \pm 12.3$ \\
\hline \multicolumn{7}{|c|}{ Leukocytes $\left(10^{3} / \mu \mathrm{L}\right)$} \\
\hline Day 3 & $10.27 \pm 0.39$ & $11.19 \pm 0.54$ & $12.73 \pm 0.31 * *$ & $13.41 \pm 0.46^{* *}$ & $13.21 \pm 0.49 * *$ & $12.48 \pm 0.34 * *$ \\
\hline Day 23 & $8.12 \pm 0.29$ & $7.16 \pm 0.36$ & $8.11 \pm 0.61$ & $8.46 \pm 0.43$ & $8.17 \pm 0.74$ & $8.00 \pm 0.59$ \\
\hline Week 14 & $6.69 \pm 0.50$ & $5.34 \pm 0.25$ & $6.52 \pm 0.44$ & $5.90 \pm 0.34$ & $6.19 \pm 0.52$ & $6.02 \pm 0.47$ \\
\hline
\end{tabular}


Vinylidene Chloride, NTP TR 582

\begin{tabular}{|c|c|c|c|c|c|c|}
\hline & $\begin{array}{l}\text { Chamber } \\
\text { Control }\end{array}$ & $6.25 \mathrm{ppm}$ & $12.5 \mathrm{ppm}$ & 25 ppm & 50 ppm & 100 ppm \\
\hline \multicolumn{7}{|c|}{ Segmented neutrophils $\left(10^{3} / \mu \mathrm{L}\right)$} \\
\hline Day 3 & $0.82 \pm 0.06$ & $1.04 \pm 0.13$ & $1.85 \pm 0.10^{* *}$ & $1.20 \pm 0.07 *$ & $0.94 \pm 0.05$ & $0.84 \pm 0.04$ \\
\hline Day 23 & $0.85 \pm 0.07$ & $0.97 \pm 0.11$ & $0.84 \pm 0.04$ & $0.79 \pm 0.03$ & $0.96 \pm 0.14$ & $0.68 \pm 0.03$ \\
\hline Week 14 & $1.06 \pm 0.09$ & $0.90 \pm 0.08$ & $0.95 \pm 0.07$ & $0.79 \pm 0.05$ & $1.08 \pm 0.07$ & $1.09 \pm 0.10$ \\
\hline \multicolumn{7}{|c|}{ Bands $\left(10^{3} / \mu \mathrm{L}\right)$} \\
\hline Day 3 & $0.00 \pm 0.00$ & $0.00 \pm 0.00$ & $0.00 \pm 0.00$ & $0.00 \pm 0.00$ & $0.00 \pm 0.00$ & $0.00 \pm 0.00$ \\
\hline Day 23 & $0.00 \pm 0.00$ & $0.00 \pm 0.00$ & $0.00 \pm 0.00$ & $0.00 \pm 0.00$ & $0.00 \pm 0.00$ & $0.00 \pm 0.00$ \\
\hline Week 14 & $0.00 \pm 0.00$ & $0.00 \pm 0.00$ & $0.00 \pm 0.00$ & $0.00 \pm 0.00$ & $0.00 \pm 0.00$ & $0.00 \pm 0.00$ \\
\hline \multicolumn{7}{|c|}{ Lymphocytes $\left(10^{3} / \mu \mathrm{L}\right)$} \\
\hline Day 3 & $9.16 \pm 0.39$ & $9.83 \pm 0.43$ & $10.62 \pm 0.31^{*}$ & $11.76 \pm 0.40^{* *}$ & $11.80 \pm 0.37 * *$ & $11.34 \pm 0.35^{* *}$ \\
\hline Day 23 & $7.04 \pm 0.25$ & $5.87 \pm 0.27$ & $7.03 \pm 0.60$ & $7.40 \pm 0.45$ & $6.87 \pm 0.63$ & $7.04 \pm 0.56$ \\
\hline Week 14 & $5.29 \pm 0.45$ & $4.21 \pm 0.23$ & $5.23 \pm 0.48$ & $4.85 \pm 0.32$ & $4.77 \pm 0.47$ & $4.53 \pm 0.37$ \\
\hline \multicolumn{7}{|c|}{ Monocytes $\left(10^{3} / \mu \mathrm{L}\right)$} \\
\hline Day 3 & $0.18 \pm 0.05$ & $0.19 \pm 0.04$ & $0.13 \pm 0.05$ & $0.31 \pm 0.10$ & $0.33 \pm 0.10$ & $0.17 \pm 0.07$ \\
\hline Day 23 & $0.11 \pm 0.04$ & $0.22 \pm 0.12$ & $0.14 \pm 0.07$ & $0.16 \pm 0.06$ & $0.23 \pm 0.08$ & $0.18 \pm 0.06$ \\
\hline Week 14 & $0.25 \pm 0.07$ & $0.14 \pm 0.05$ & $0.24 \pm 0.07$ & $0.16 \pm 0.04$ & $0.26 \pm 0.06$ & $0.32 \pm 0.06$ \\
\hline \multicolumn{7}{|c|}{ Basophils $\left(10^{3} / \mu \mathrm{L}\right)$} \\
\hline Day 3 & $0.015 \pm 0.002$ & $0.017 \pm 0.002$ & $0.012 \pm 0.003$ & $0.020 \pm 0.004$ & $0.026 \pm 0.006$ & $0.021 \pm 0.005$ \\
\hline Day 23 & $0.009 \pm 0.002$ & $0.006 \pm 0.003$ & $0.009 \pm 0.004$ & $0.010 \pm 0.003$ & $0.007 \pm 0.003$ & $0.006 \pm 0.002$ \\
\hline Week 14 & $0.005 \pm 0.002$ & $0.003 \pm 0.002$ & $0.005 \pm 0.002$ & $0.007 \pm 0.006$ & $0.005 \pm 0.002$ & $0.005 \pm 0.002$ \\
\hline \multicolumn{7}{|c|}{ Eosinophils $\left(10^{3} / \mu \mathrm{L}\right)$} \\
\hline Day 3 & $0.09 \pm 0.01$ & $0.12 \pm 0.02$ & $0.12 \pm 0.01$ & $0.11 \pm 0.01$ & $0.12 \pm 0.01$ & $0.11 \pm 0.01$ \\
\hline Day 23 & $0.10 \pm 0.01$ & $0.10 \pm 0.01$ & $0.10 \pm 0.01$ & $0.10 \pm 0.01$ & $0.10 \pm 0.01$ & $0.09 \pm 0.02$ \\
\hline Week 14 & $0.09 \pm 0.01$ & $0.08 \pm 0.01$ & $0.10 \pm 0.01$ & $0.09 \pm 0.01$ & $0.08 \pm 0.01$ & $0.08 \pm 0.01$ \\
\hline \multicolumn{7}{|c|}{ Clinical Chemistry } \\
\hline n & 10 & 10 & 10 & 10 & 10 & 10 \\
\hline \multicolumn{7}{|c|}{ Urea nitrogen $(\mathrm{mg} / \mathrm{dL})$} \\
\hline Day 3 & $10.5 \pm 0.5$ & $10.6 \pm 0.5$ & $10.4 \pm 0.6$ & $10.7 \pm 0.5$ & $12.7 \pm 0.6^{*}$ & $15.1 \pm 0.6^{* *}$ \\
\hline Day 23 & $10.9 \pm 0.4$ & $12.6 \pm 0.7^{*}$ & $12.2 \pm 0.5^{*}$ & $12.6 \pm 0.5^{* *}$ & $13.2 \pm 0.5 * *$ & $14.7 \pm 0.6^{* *}$ \\
\hline Week 14 & $14.6 \pm 0.4$ & $15.1 \pm 0.6$ & $15.1 \pm 0.5$ & $15.8 \pm 0.4$ & $15.9 \pm 0.4$ & $15.1 \pm 0.4$ \\
\hline \multicolumn{7}{|c|}{ Creatinine $(\mathrm{mg} / \mathrm{dL})$} \\
\hline Day 3 & $0.29 \pm 0.01$ & $0.32 \pm 0.01$ & $0.30 \pm 0.01$ & $0.27 \pm 0.02$ & $0.31 \pm 0.01$ & $0.30 \pm 0.00$ \\
\hline Day 23 & $0.26 \pm 0.02$ & $0.28 \pm 0.01$ & $0.27 \pm 0.02$ & $0.28 \pm 0.01$ & $0.29 \pm 0.01$ & $0.30 \pm 0.00$ \\
\hline Week 14 & $0.39 \pm 0.01$ & $0.39 \pm 0.01$ & $0.40 \pm 0.00$ & $0.43 \pm 0.02$ & $0.42 \pm 0.02$ & $0.45 \pm 0.02 * *$ \\
\hline Glucose (mg & & & & & & \\
\hline
\end{tabular}


Vinylidene Chloride, NTP TR 582

\begin{tabular}{|c|c|c|c|c|c|c|}
\hline & $\begin{array}{c}\text { Chamber } \\
\text { Control }\end{array}$ & $6.25 \mathrm{ppm}$ & $12.5 \mathrm{ppm}$ & 25 ppm & $50 \mathrm{ppm}$ & 100 ppm \\
\hline Day 3 & $133 \pm 6$ & $152 \pm 7$ & $134 \pm 6$ & $135 \pm 5$ & $128 \pm 4$ & $111 \pm 3^{* *}$ \\
\hline Day 23 & $142 \pm 10$ & $107 \pm 5^{* *}$ & $117 \pm 6^{*}$ & $113 \pm 5^{*}$ & $112 \pm 3^{*}$ & $99 \pm 3^{* *}$ \\
\hline Week 14 & $124 \pm 3$ & $134 \pm 8$ & $127 \pm 6$ & $132 \pm 11$ & $125 \pm 4$ & $130 \pm 4$ \\
\hline \multicolumn{7}{|c|}{ Total protein $(\mathrm{g} / \mathrm{dL})$} \\
\hline Day 3 & $6.2 \pm 0.1$ & $6.0 \pm 0.1$ & $6.2 \pm 0.1$ & $6.3 \pm 0.1$ & $6.3 \pm 0.1$ & $6.5 \pm 0.1 * *$ \\
\hline Day 23 & $6.2 \pm 0.0$ & $6.4 \pm 0.1$ & $6.3 \pm 0.0$ & $6.4 \pm 0.1$ & $6.5 \pm 0.1 * *$ & $6.6 \pm 0.1 * *$ \\
\hline Week 14 & $7.2 \pm 0.1$ & $7.3 \pm 0.1$ & $7.5 \pm 0.1$ & $7.3 \pm 0.1$ & $7.4 \pm 0.1$ & $7.4 \pm 0.1$ \\
\hline \multicolumn{7}{|c|}{ Albumin (g/dL) } \\
\hline Day 3 & $4.6 \pm 0.1$ & $4.4 \pm 0.1$ & $4.5 \pm 0.0$ & $4.6 \pm 0.1$ & $4.6 \pm 0.0$ & $4.7 \pm 0.0$ \\
\hline Day 23 & $4.6 \pm 0.0$ & $4.8 \pm 0.0$ & $4.7 \pm 0.0$ & $4.8 \pm 0.1 *$ & $4.9 \pm 0.1 * *$ & $4.9 \pm 0.1 * *$ \\
\hline Week 14 & $5.1 \pm 0.1$ & $5.2 \pm 0.1$ & $5.3 \pm 0.1$ & $5.2 \pm 0.0$ & $5.2 \pm 0.1$ & $5.1 \pm 0.1$ \\
\hline \multicolumn{7}{|c|}{ Globulin (g/dL) } \\
\hline Day 3 & $1.6 \pm 0.0$ & $1.6 \pm 0.0$ & $1.7 \pm 0.0$ & $1.7 \pm 0.0^{*}$ & $1.8 \pm 0.0^{*}$ & $1.8 \pm 0.0 * *$ \\
\hline Day 23 & $1.6 \pm 0.0$ & $1.6 \pm 0.0$ & $1.6 \pm 0.0$ & $1.6 \pm 0.0$ & $1.7 \pm 0.1$ & $1.7 \pm 0.0$ \\
\hline Week 14 & $2.1 \pm 0.0$ & $2.1 \pm 0.1$ & $2.2 \pm 0.0$ & $2.1 \pm 0.0$ & $2.2 \pm 0.0$ & $2.3 \pm 0.1$ \\
\hline \multicolumn{7}{|c|}{ A/G ratio (albumin/globulin ratio) } \\
\hline Day 3 & $2.8 \pm 0.1$ & $2.7 \pm 0.0$ & $2.7 \pm 0.1$ & $2.6 \pm 0.0 * *$ & $2.6 \pm 0.0 * *$ & $2.6 \pm 0.0 * *$ \\
\hline Day 23 & $2.9 \pm 0.0$ & $3.0 \pm 0.1$ & $2.9 \pm 0.0$ & $3.0 \pm 0.0$ & $2.9 \pm 0.1$ & $2.8 \pm 0.0$ \\
\hline Week 14 & $2.4 \pm 0.0$ & $2.5 \pm 0.0$ & $2.4 \pm 0.0$ & $2.5 \pm 0.0$ & $2.4 \pm 0.0$ & $2.3 \pm 0.0$ \\
\hline \multicolumn{7}{|c|}{ Alanine aminotransferase (IU/L) } \\
\hline Day 3 & $48 \pm 1$ & $46 \pm 3$ & $43 \pm 2$ & $47 \pm 1$ & $43 \pm 1$ & $63 \pm 2$ \\
\hline Day 23 & $38 \pm 1$ & $39 \pm 1$ & $38 \pm 1$ & $37 \pm 1$ & $35 \pm 1$ & $49 \pm 2$ \\
\hline Week 14 & $75 \pm 6$ & $65 \pm 5$ & $58 \pm 5^{* *}$ & $51 \pm 2 * *$ & $52 \pm 2 * *$ & $51 \pm 2 * *$ \\
\hline \multicolumn{7}{|c|}{ Alkaline phosphatase (IU/L) } \\
\hline Day 3 & $492 \pm 9$ & $467 \pm 11$ & $478 \pm 5$ & $508 \pm 5$ & $511 \pm 9$ & $512 \pm 10$ \\
\hline Day 23 & $300 \pm 4$ & $288 \pm 5$ & $293 \pm 7$ & $307 \pm 7$ & $320 \pm 5^{*}$ & $326 \pm 6^{* *}$ \\
\hline Week 14 & $204 \pm 6$ & $192 \pm 4$ & $186 \pm 7$ & $189 \pm 4$ & $200 \pm 5$ & $213 \pm 4$ \\
\hline \multicolumn{7}{|c|}{ Creatine kinase (IU/L) } \\
\hline Day 3 & $600 \pm 77$ & $1,147 \pm 334$ & $598 \pm 73$ & $509 \pm 63$ & $444 \pm 42$ & $702 \pm 140$ \\
\hline Day 23 & $289 \pm 34$ & $291 \pm 35$ & $305 \pm 15$ & $288 \pm 32$ & $267 \pm 20$ & $300 \pm 36$ \\
\hline Week 14 & $198 \pm 13$ & $209 \pm 30$ & $212 \pm 27$ & $176 \pm 27$ & $222 \pm 20$ & $254 \pm 34$ \\
\hline \multicolumn{7}{|c|}{ Sorbitol dehydrogenase (IU/L) } \\
\hline Day 3 & $11 \pm 1$ & $8 \pm 1$ & $9 \pm 1$ & $12 \pm 0$ & $11 \pm 1$ & $19 \pm 1 * *$ \\
\hline Day 23 & $12 \pm 1$ & $12 \pm 1$ & $12 \pm 0$ & $12 \pm 1$ & $14 \pm 0 *$ & $20 \pm 1 * *$ \\
\hline Week 14 & $18 \pm 1$ & $16 \pm 1$ & $15 \pm 1$ & $14 \pm 0^{*}$ & $15 \pm 1$ & $18 \pm 1$ \\
\hline
\end{tabular}


Vinylidene Chloride, NTP TR 582

\begin{tabular}{lcccccc}
\hline & $\begin{array}{c}\text { Chamber } \\
\text { Control }\end{array}$ & $\mathbf{6 . 2 5} \mathbf{~ p p m}$ & $\mathbf{1 2 . 5} \mathbf{~ p p m}$ & $\mathbf{2 5} \mathbf{~ p p m}$ & $\mathbf{5 0} \mathbf{~ p p m}$ & $\mathbf{1 0 0} \mathbf{~ p p m}$ \\
\hline \multicolumn{2}{l}{ Bile acids $(\mu \mathrm{mol} / \mathrm{L})$} & & & & & \\
Day 3 & $5.1 \pm 0.6$ & $5.8 \pm 0.5$ & $6.9 \pm 1.8$ & $4.8 \pm 0.3$ & $5.8 \pm 0.7$ & $8.2 \pm 2.1$ \\
Day 23 & $7.9 \pm 1.8$ & $5.7 \pm 0.8$ & $7.2 \pm 2.2$ & $5.2 \pm 0.4$ & $4.2 \pm 0.3^{*}$ & $4.6 \pm 0.4$ \\
Week 14 & $4.7 \pm 0.2$ & $6.2 \pm 1.4$ & $4.6 \pm 0.2$ & $5.4 \pm 1.0$ & $4.3 \pm 0.1$ & $4.6 \pm 0.7^{*}$ \\
\hline
\end{tabular}

*Significantly different $(\mathrm{P} \leq 0.05)$ from the chamber control group by Dunn's or Shirley's test.

$* * \mathrm{P} \leq 0.01$.

a Data are presented as mean \pm standard error. Statistical tests were performed on unrounded data. ${ }^{\mathrm{b}} \mathrm{n}=9$.

$c_{n}=8$. 
Vinylidene Chloride, NTP TR 582

Table F-2. Hematology Data for Mice in the Three-Month Inhalation Study of Vinylidene Chloride ${ }^{\mathrm{a}}$

\begin{tabular}{|c|c|c|c|c|c|c|}
\hline & $\begin{array}{l}\text { Chamber } \\
\text { Control }\end{array}$ & $6.25 \mathrm{ppm}$ & $12.5 \mathrm{ppm}$ & 25 ppm & 50 ppm & 100 ppm \\
\hline \multicolumn{7}{|l|}{ Male } \\
\hline $\mathbf{n}$ & 10 & 10 & 10 & 10 & 8 & - \\
\hline Hematocrit (manual) (\%) & $49.9 \pm 0.5$ & $48.6 \pm 0.3$ & $47.8 \pm 0.4 * *$ & $46.5 \pm 0.4^{* *}$ & $45.9 \pm 0.4^{* *}$ & - \\
\hline Packed cell volume (auto) (\%) & $50.4 \pm 0.4$ & $49.2 \pm 0.4$ & $48.1 \pm 0.3 * *$ & $47.2 \pm 0.3 * *$ & $46.9 \pm 0.4 * *$ & - \\
\hline Hemoglobin (g/dL) & $15.5 \pm 0.1$ & $15.1 \pm 0.1$ & $14.9 \pm 0.1 * *$ & $14.5 \pm 0.1 * *$ & $14.2 \pm 0.1^{* *}$ & - \\
\hline Erythrocytes $\left(10^{6} / \mu \mathrm{L}\right)$ & $10.18 \pm 0.09$ & $9.96 \pm 0.09$ & $9.74 \pm 0.07 * *$ & $9.54 \pm 0.07 * *$ & $9.40 \pm 0.08 * *$ & - \\
\hline Reticulocytes $\left(10^{6} / \mu \mathrm{L}\right)$ & $0.25 \pm 0.02$ & $0.24 \pm 0.01$ & $0.24 \pm 0.02$ & $0.24 \pm 0.01$ & $0.24 \pm 0.02$ & - \\
\hline $\begin{array}{l}\text { Nucleated erythrocytes/100 } \\
\text { leukocytes }\end{array}$ & $0.1 \pm 0.1$ & $0.0 \pm 0.0$ & $0.0 \pm 0.0$ & $0.0 \pm 0.0$ & $0.0 \pm 0.0$ & - \\
\hline $\begin{array}{l}\text { Howell-Jolly bodies } \\
\text { (\% erythrocytes) }\end{array}$ & $0.2 \pm 0.0$ & $0.2 \pm 0.0$ & $0.2 \pm 0.0$ & $0.2 \pm 0.0$ & $0.1 \pm 0.0$ & - \\
\hline Mean cell volume (fL) & $49.5 \pm 0.2$ & $49.4 \pm 0.2$ & $49.4 \pm 0.2$ & $49.5 \pm 0.2$ & $49.9 \pm 0.2$ & - \\
\hline Mean cell hemoglobin (pg) & $15.3 \pm 0.1$ & $15.2 \pm 0.1$ & $15.3 \pm 0.1$ & $15.2 \pm 0.0$ & $15.2 \pm 0.0$ & - \\
\hline $\begin{array}{l}\text { Mean cell hemoglobin } \\
\text { concentration }(\mathrm{g} / \mathrm{dL})\end{array}$ & $30.8 \pm 0.2$ & $30.8 \pm 0.2$ & $30.9 \pm 0.1$ & $30.6 \pm 0.1$ & $30.4 \pm 0.1$ & - \\
\hline Platelets $\left(10^{3} / \mu \mathrm{L}\right)$ & $866.7 \pm 15.6$ & $846.8 \pm 15.9$ & $898.2 \pm 14.8$ & $970.3 \pm 10.7 * *$ & $993.4 \pm 11.8 * *$ & - \\
\hline Leukocytes $\left(10^{3} / \mu \mathrm{L}\right)$ & $2.52 \pm 0.27$ & $2.45 \pm 0.32$ & $2.48 \pm 0.28$ & $2.24 \pm 0.28$ & $2.56 \pm 0.43$ & - \\
\hline Segmented neutrophils $\left(10^{3} / \mu \mathrm{L}\right)$ & $0.31 \pm 0.03$ & $0.26 \pm 0.03$ & $0.31 \pm 0.06$ & $0.28 \pm 0.03$ & $0.28 \pm 0.04$ & - \\
\hline Bands $\left(10^{3} / \mu \mathrm{L}\right)$ & $0.00 \pm 0.00$ & $0.00 \pm 0.00$ & $0.00 \pm 0.00$ & $0.00 \pm 0.00$ & $0.00 \pm 0.00$ & - \\
\hline Lymphocytes $\left(10^{3} / \mu \mathrm{L}\right)$ & $2.13 \pm 0.24$ & $2.07 \pm 0.29$ & $2.06 \pm 0.25$ & $1.87 \pm 0.25$ & $2.18 \pm 0.40$ & - \\
\hline Monocytes $\left(10^{3} / \mu \mathrm{L}\right)$ & $0.02 \pm 0.01$ & $0.05 \pm 0.01$ & $0.06 \pm 0.02$ & $0.04 \pm 0.01$ & $0.04 \pm 0.02$ & - \\
\hline Basophils $\left(10^{3} / \mu \mathrm{L}\right)$ & $0.009 \pm 0.002$ & $0.012 \pm 0.002$ & $0.011 \pm 0.002$ & $0.012 \pm 0.003$ & $0.014 \pm 0.003$ & - \\
\hline Eosinophils $\left(10^{3} / \mu \mathrm{L}\right)$ & $0.04 \pm 0.01$ & $0.05 \pm 0.01$ & $0.03 \pm 0.00$ & $0.04 \pm 0.01$ & $0.04 \pm 0.01$ & - \\
\hline \multicolumn{7}{|l|}{ Female } \\
\hline $\mathbf{n}$ & 10 & 9 & 10 & 10 & 10 & 6 \\
\hline Hematocrit (manual) (\%) & $50.2 \pm 0.4$ & $49.8 \pm 0.4$ & $49.8 \pm 0.3$ & $49.3 \pm 0.4$ & $48.3 \pm 0.5 * *$ & $50.3 \pm 0.4$ \\
\hline Packed cell volume (auto) (\%) & $50.7 \pm 0.4$ & $50.2 \pm 0.3$ & $50.4 \pm 0.4$ & $49.9 \pm 0.4$ & $48.7 \pm 0.5^{*}$ & $50.5 \pm 0.4$ \\
\hline Hemoglobin (g/dL) & $15.9 \pm 0.1$ & $15.7 \pm 0.1$ & $15.7 \pm 0.1$ & $15.6 \pm 0.2$ & $15.3 \pm 0.1^{*}$ & $15.7 \pm 0.1$ \\
\hline Erythrocytes $\left(10^{6} / \mu \mathrm{L}\right)$ & $10.19 \pm 0.09$ & $10.08 \pm 0.06$ & $10.02 \pm 0.07$ & $9.97 \pm 0.11$ & $9.73 \pm 0.09 * *$ & $9.80 \pm 0.08 * *$ \\
\hline Reticulocytes $\left(10^{6} / \mu \mathrm{L}\right)$ & $0.21 \pm 0.01$ & $0.20 \pm 0.02$ & $0.20 \pm 0.01$ & $0.19 \pm 0.01$ & $0.20 \pm 0.02$ & $0.16 \pm 0.02$ \\
\hline $\begin{array}{l}\text { Nucleated erythrocytes/100 } \\
\text { leukocytes }\end{array}$ & $0.0 \pm 0.0$ & $0.0 \pm 0.0$ & $0.0 \pm 0.0$ & $0.0 \pm 0.0$ & $0.0 \pm 0.0$ & $0.0 \pm 0.0$ \\
\hline $\begin{array}{l}\text { Howell-Jolly bodies } \\
\text { (\% erythrocytes) }\end{array}$ & $0.2 \pm 0.0$ & $0.2 \pm 0.0$ & $0.1 \pm 0.0$ & $0.2 \pm 0.0$ & $0.1 \pm 0.0$ & $0.2 \pm 0.0$ \\
\hline Mean cell volume (fL) & $49.8 \pm 0.2$ & $49.8 \pm 0.1$ & $50.3 \pm 0.2$ & $50.1 \pm 0.3$ & $50.0 \pm 0.1$ & $51.5 \pm 0.2 * *$ \\
\hline Mean cell hemoglobin (pg) & $15.6 \pm 0.1$ & $15.6 \pm 0.1$ & $15.7 \pm 0.0$ & $15.7 \pm 0.1$ & $15.7 \pm 0.0$ & $16.0 \pm 0.0^{* *}$ \\
\hline $\begin{array}{l}\text { Mean cell hemoglobin } \\
\text { concentration }(\mathrm{g} / \mathrm{dL})\end{array}$ & $31.3 \pm 0.1$ & $31.3 \pm 0.1$ & $31.2 \pm 0.1$ & $31.3 \pm 0.1$ & $31.4 \pm 0.1$ & $31.2 \pm 0.1$ \\
\hline Platelets $\left(10^{3} / \mu \mathrm{L}\right)$ & $751.2 \pm 11.4$ & $789.1 \pm 17.1$ & $801.8 \pm 13.3^{*}$ & $833.2 \pm 13.4 * *$ & $853.0 \pm 14.9 * *$ & $864.3 \pm 28.3 * *$ \\
\hline
\end{tabular}


Vinylidene Chloride, NTP TR 582

\begin{tabular}{lcccccc}
\hline & $\begin{array}{c}\text { Chamber } \\
\text { Control }\end{array}$ & $\mathbf{6 . 2 5} \mathbf{~ p p m}$ & $\mathbf{1 2 . 5} \mathbf{~ p p m}$ & $\mathbf{2 5} \mathbf{~ p p m}$ & $\mathbf{5 0} \mathbf{~ p p m}$ & $\mathbf{1 0 0} \mathbf{~ p p m}$ \\
\hline Leukocytes $\left(10^{3} / \mu \mathrm{L}\right)$ & $2.90 \pm 0.25$ & $2.67 \pm 0.11$ & $2.48 \pm 0.19$ & $3.22 \pm 0.39$ & $3.19 \pm 0.28$ & $3.61 \pm 0.40$ \\
Segmented neutrophils $\left(10^{3} / \mu \mathrm{L}\right)$ & $0.37 \pm 0.03$ & $0.31 \pm 0.03$ & $0.26 \pm 0.03$ & $0.33 \pm 0.06$ & $0.41 \pm 0.07$ & $0.30 \pm 0.04$ \\
Bands $\left(10^{3} / \mu \mathrm{L}\right)$ & $0.00 \pm 0.00$ & $0.00 \pm 0.00$ & $0.00 \pm 0.00$ & $0.00 \pm 0.00$ & $0.00 \pm 0.00$ & $0.00 \pm 0.00$ \\
Lymphocytes $\left(10^{3} / \mu \mathrm{L}\right)$ & $2.45 \pm 0.22$ & $2.26 \pm 0.09$ & $2.14 \pm 0.16$ & $2.78 \pm 0.33$ & $2.67 \pm 0.27$ & $3.20 \pm 0.38$ \\
Monocytes $\left(10^{3} / \mu \mathrm{L}\right)$ & $0.04 \pm 0.01$ & $0.06 \pm 0.02$ & $0.05 \pm 0.01$ & $0.07 \pm 0.01$ & $0.05 \pm 0.01$ & $0.06 \pm 0.01$ \\
Basophils $\left(10^{3} / \mu \mathrm{L}\right)$ & $0.013 \pm 0.002$ & $0.022 \pm 0.004$ & $0.012 \pm 0.002$ & $0.019 \pm 0.004$ & $0.019 \pm 0.003$ & $0.020 \pm 0.005$ \\
Eosinophils $\left(10^{3} / \mu \mathrm{L}\right)$ & $0.03 \pm 0.01$ & $0.03 \pm 0.01$ & $0.02 \pm 0.01$ & $0.03 \pm 0.01$ & $0.04 \pm 0.01$ & $0.03 \pm 0.01$ \\
\hline
\end{tabular}

*Significantly different $(\mathrm{P} \leq 0.05)$ from the chamber control group by Dunn's or Shirley's test. $* * \mathrm{P} \leq 0.01$.

${ }^{\text {aD }}$ Data are presented as mean \pm standard error. Statistical tests were performed on unrounded data. 


\section{Appendix G. Organ Weights}

\section{Tables}

Table G-1. Organ Weights and Organ-Weight-to-Body-Weight Ratios for Rats in the

Two-week Inhalation Study of Vinylidene Chloride G-2

Table G-2. Organ Weights and Organ-Weight-to-Body-Weight Ratios for Rats in the

Three-month Inhalation Study of Vinylidene Chloride G-4

Table G-3. Organ Weights and Organ-Weight-to-Body-Weight Ratios for Mice in the Two-week Inhalation Study of Vinylidene Chloride G-6

Table G-4. Organ Weights and Organ-Weight-to-Body-Weight Ratios for Mice in the Three-month Inhalation Study of Vinylidene Chloride G-8 
Table G-1. Organ Weights and Organ-Weight-to-Body-Weight Ratios for Rats in the Two-week Inhalation Study of Vinylidene Chloride ${ }^{a}$

\begin{tabular}{|c|c|c|c|c|c|c|}
\hline & Chamber Control & $25 \mathrm{ppm}$ & $50 \mathrm{ppm}$ & 100 ppm & 200 ppm & 400 ppm \\
\hline \multicolumn{7}{|l|}{ Male } \\
\hline $\mathbf{n}$ & 5 & 4 & 5 & 5 & 0 & 0 \\
\hline Necropsy body wt & $158 \pm 2$ & $150 \pm 3$ & $159 \pm 5$ & $154 \pm 2$ & - & - \\
\hline \multicolumn{7}{|l|}{ Heart } \\
\hline Absolute & $0.57 \pm 0.01$ & $0.55 \pm 0.02$ & $0.57 \pm 0.02$ & $0.56 \pm 0.01$ & - & - \\
\hline Relative & $3.590 \pm 0.042$ & $3.640 \pm 0.079$ & $3.559 \pm 0.046$ & $3.655 \pm 0.043$ & - & - \\
\hline \multicolumn{7}{|l|}{ R. Kidney } \\
\hline Absolute & $0.61 \pm 0.01$ & $0.70 \pm 0.01 * *$ & $0.71 \pm 0.02 * *$ & $0.71 \pm 0.02 * *$ & - & - \\
\hline Relative & $3.878 \pm 0.045$ & $4.641 \pm 0.054 * *$ & $4.460 \pm 0.124 * *$ & $4.625 \pm 0.074 * *$ & - & - \\
\hline \multicolumn{7}{|l|}{ Liver } \\
\hline Absolute & $7.06 \pm 0.18$ & $6.50 \pm 0.16$ & $6.84 \pm 0.21$ & $6.79 \pm 0.13$ & - & - \\
\hline Relative & $44.561 \pm 0.628$ & $43.247 \pm 0.147$ & $43.045 \pm 0.419$ & $44.042 \pm 0.578$ & - & - \\
\hline \multicolumn{7}{|l|}{ Lung } \\
\hline Absolute & $1.04 \pm 0.02$ & $1.14 \pm 0.05$ & $1.11 \pm 0.07$ & $1.20 \pm 0.06$ & - & - \\
\hline Relative & $6.557 \pm 0.110$ & $7.548 \pm 0.248$ & $6.991 \pm 0.263$ & $7.776 \pm 0.372 *$ & - & - \\
\hline \multicolumn{7}{|l|}{ R. Testis } \\
\hline Absolute & $0.904 \pm 0.020$ & $0.922 \pm 0.029$ & $0.965 \pm 0.037$ & $0.918 \pm 0.022$ & - & - \\
\hline Relative & $5.712 \pm 0.123$ & $6.128 \pm 0.077$ & $6.065 \pm 0.128$ & $5.954 \pm 0.115$ & - & - \\
\hline \multicolumn{7}{|l|}{ Thymus } \\
\hline Absolute & $0.401 \pm 0.020$ & $0.389 \pm 0.021$ & $0.417 \pm 0.024$ & $0.374 \pm 0.011$ & - & - \\
\hline Relative & $2.533 \pm 0.104$ & $2.584 \pm 0.103$ & $2.622 \pm 0.119$ & $2.428 \pm 0.080$ & - & - \\
\hline
\end{tabular}




\begin{tabular}{|c|c|c|c|c|c|c|}
\hline & Chamber Control & $25 \mathrm{ppm}$ & $50 \mathrm{ppm}$ & 100 ppm & 200 ppm & 400 ppm \\
\hline \multicolumn{7}{|l|}{ Female } \\
\hline $\mathbf{n}$ & 5 & 5 & 5 & 5 & 0 & 0 \\
\hline Necropsy body wt & $124 \pm 2$ & $125 \pm 3$ & $122 \pm 1$ & $117 \pm 3$ & - & - \\
\hline \multicolumn{7}{|l|}{ Heart } \\
\hline Absolute & $0.45 \pm 0.01$ & $0.46 \pm 0.01$ & $0.47 \pm 0.00$ & $0.46 \pm 0.01$ & - & - \\
\hline Relative & $3.633 \pm 0.044$ & $3.680 \pm 0.059$ & $3.874 \pm 0.045^{* *}$ & $3.924 \pm 0.068 * *$ & - & - \\
\hline \multicolumn{7}{|l|}{ R. Kidney } \\
\hline Absolute & $0.53 \pm 0.01$ & $0.61 \pm 0.01 * *$ & $0.59 \pm 0.01 *$ & $0.59 \pm 0.02 * *$ & - & - \\
\hline Relative & $4.299 \pm 0.068$ & $4.904 \pm 0.083^{* *}$ & $4.826 \pm 0.079 * *$ & $5.084 \pm 0.079 * *$ & - & - \\
\hline \multicolumn{7}{|l|}{ Liver } \\
\hline Absolute & $5.07 \pm 0.13$ & $4.96 \pm 0.12$ & $4.86 \pm 0.08$ & $4.87 \pm 0.14$ & - & - \\
\hline Relative & $40.971 \pm 0.433$ & $39.867 \pm 0.386$ & $39.860 \pm 0.846$ & $41.676 \pm 0.349$ & - & - \\
\hline \multicolumn{7}{|l|}{ Lung } \\
\hline Absolute & $0.88 \pm 0.04$ & $0.95 \pm 0.05$ & $0.95 \pm 0.09$ & $0.87 \pm 0.04$ & - & - \\
\hline Relative & $7.066 \pm 0.214$ & $7.643 \pm 0.350$ & $7.844 \pm 0.747$ & $7.414 \pm 0.277$ & - & - \\
\hline \multicolumn{7}{|l|}{ Thymus } \\
\hline Absolute & $0.330 \pm 0.012$ & $0.373 \pm 0.014$ & $0.353 \pm 0.013$ & $0.328 \pm 0.013$ & - & - \\
\hline Relative & $2.667 \pm 0.082$ & $2.988 \pm 0.046^{*}$ & $2.900 \pm 0.120$ & $2.807 \pm 0.052$ & - & - \\
\hline
\end{tabular}

*Significantly different $(\mathrm{P} \leq 0.05)$ from the chamber control group by Williams' or Dunnett's test.

$* * \mathrm{P} \leq 0.01$.

argan weights (absolute weights) and body weights are given in grams; organ-weight-to-body-weight ratios (relative weights) are given as mg organ weight/g body weight

(mean \pm standard error). No data available for $200 \mathrm{ppm}$ and $400 \mathrm{ppm}$ males and females due to $100 \%$ mortality. 
Table G-2. Organ Weights and Organ-Weight-to-Body-Weight Ratios for Rats in the Three-month Inhalation Study of Vinylidene Chloride $^{\mathrm{a}}$

\begin{tabular}{|c|c|c|c|c|c|c|}
\hline & Chamber Control & $6.25 \mathrm{ppm}$ & $12.5 \mathrm{ppm}$ & 25 ppm & $50 \mathrm{ppm}$ & 100 ppm \\
\hline $\mathbf{n}$ & 10 & 10 & 10 & 10 & 10 & 10 \\
\hline \multicolumn{7}{|l|}{ Male } \\
\hline Necropsy body wt & $326 \pm 7$ & $332 \pm 6$ & $337 \pm 5$ & $319 \pm 6$ & $340 \pm 6$ & $322 \pm 5$ \\
\hline \multicolumn{7}{|l|}{ Heart } \\
\hline Absolute & $0.89 \pm 0.02$ & $0.93 \pm 0.02$ & $0.88 \pm 0.02$ & $0.86 \pm 0.02$ & $0.92 \pm 0.02$ & $0.89 \pm 0.03$ \\
\hline Relative & $2.713 \pm 0.022$ & $2.807 \pm 0.068$ & $2.628 \pm 0.031$ & $2.700 \pm 0.023$ & $2.694 \pm 0.033$ & $2.757 \pm 0.055$ \\
\hline \multicolumn{7}{|l|}{ R. Kidney } \\
\hline Absolute & $0.99 \pm 0.02$ & $1.07 \pm 0.04$ & $1.05 \pm 0.03$ & $1.01 \pm 0.03$ & $1.08 \pm 0.02$ & $1.05 \pm 0.02$ \\
\hline Relative & $3.026 \pm 0.028$ & $3.208 \pm 0.091^{*}$ & $3.129 \pm 0.035^{*}$ & $3.171 \pm 0.039$ & $3.167 \pm 0.029$ & $3.245 \pm 0.038 * *$ \\
\hline \multicolumn{7}{|l|}{ Liver } \\
\hline Absolute & $10.63 \pm 0.32$ & $10.61 \pm 0.26$ & $10.46 \pm 0.27$ & $9.77 \pm 0.27$ & $10.59 \pm 0.32$ & $10.23 \pm 0.28$ \\
\hline Relative & $32.562 \pm 0.400$ & $31.951 \pm 0.510$ & $31.034 \pm 0.404$ & $30.596 \pm 0.376^{* *}$ & $31.062 \pm 0.456$ & $31.697 \pm 0.412$ \\
\hline \multicolumn{7}{|l|}{ Lung } \\
\hline Absolute & $1.66 \pm 0.06$ & $1.59 \pm 0.06$ & $1.60 \pm 0.04$ & $1.59 \pm 0.06$ & $1.71 \pm 0.09$ & $1.50 \pm 0.05$ \\
\hline Relative & $5.075 \pm 0.148$ & $4.781 \pm 0.132$ & $4.766 \pm 0.115$ & $4.986 \pm 0.128$ & $5.003 \pm 0.194$ & $4.665 \pm 0.129$ \\
\hline \multicolumn{7}{|l|}{ R. Testis } \\
\hline Absolute & $1.343 \pm 0.026$ & $1.353 \pm 0.019$ & $1.346 \pm 0.022$ & $1.316 \pm 0.020$ & $1.346 \pm 0.017$ & $1.314 \pm 0.021$ \\
\hline Relative & $4.122 \pm 0.056$ & $4.082 \pm 0.073$ & $4.004 \pm 0.061$ & $4.135 \pm 0.083$ & $3.963 \pm 0.068$ & $4.085 \pm 0.077$ \\
\hline \multicolumn{7}{|l|}{ Thymus } \\
\hline Absolute & $0.335 \pm 0.014$ & $0.358 \pm 0.011$ & $0.326 \pm 0.012$ & $0.314 \pm 0.015$ & $0.344 \pm 0.13$ & $0.328 \pm 0.017$ \\
\hline Relative & $1.025 \pm 0.032$ & $1.080 \pm 0.033$ & $0.969 \pm 0.036$ & $0.985 \pm 0.047$ & $1.014 \pm 0.038$ & $1.018 \pm 0.052$ \\
\hline
\end{tabular}




\begin{tabular}{|c|c|c|c|c|c|c|}
\hline & Chamber Control & $6.25 \mathrm{ppm}$ & $12.5 \mathrm{ppm}$ & 25 ppm & 50 ppm & 100 ppm \\
\hline \multicolumn{7}{|l|}{ Female } \\
\hline Necropsy body wt & $203 \pm 3$ & $205 \pm 6$ & $206 \pm 4$ & $201 \pm 4$ & $205 \pm 4$ & $195 \pm 2$ \\
\hline \multicolumn{7}{|l|}{ Heart } \\
\hline Absolute & $0.61 \pm 0.01$ & $0.60 \pm 0.01$ & $0.61 \pm 0.01$ & $0.61 \pm 0.02$ & $0.63 \pm 0.02$ & $0.60 \pm 0.01$ \\
\hline Relative & $2.978 \pm 0.055$ & $2.926 \pm 0.039$ & $2.980 \pm 0.038$ & $3.017 \pm 0.048$ & $3.077 \pm 0.044$ & $3.046 \pm 0.042$ \\
\hline \multicolumn{7}{|l|}{ R. Kidney } \\
\hline Absolute & $0.64 \pm 0.01$ & $0.67 \pm 0.02$ & $0.69 \pm 0.02 *$ & $0.68 \pm 0.01 *$ & $0.72 \pm 0.01 * *$ & $0.71 \pm 0.02 * *$ \\
\hline Relative & $3.155 \pm 0.041$ & $3.280 \pm 0.055$ & $3.356 \pm 0.043^{* *}$ & $3.393 \pm 0.040 * *$ & $3.512 \pm 0.025 * *$ & $3.645 \pm 0.058 * *$ \\
\hline \multicolumn{7}{|l|}{ Liver } \\
\hline Absolute & $5.84 \pm 0.10$ & $5.72 \pm 0.24$ & $5.87 \pm 0.18$ & $5.51 \pm 0.14$ & $5.97 \pm 0.16$ & $5.94 \pm 0.16$ \\
\hline Relative & $28.741 \pm 0.345$ & $27.921 \pm 0.470$ & $28.538 \pm 0.588$ & $27.452 \pm 0.505$ & $29.175 \pm 0.598$ & $30.393 \pm 0.495$ \\
\hline \multicolumn{7}{|l|}{ Lung } \\
\hline Absolute & $1.08 \pm 0.02$ & $1.11 \pm 0.03$ & $1.10 \pm 0.02$ & $1.09 \pm 0.03$ & $1.12 \pm 0.05$ & $1.07 \pm 0.02$ \\
\hline Relative & $5.303 \pm 0.080$ & $5.415 \pm 0.100$ & $5.338 \pm 0.128$ & $5.429 \pm 0.125$ & $5.451 \pm 0.248$ & $5.454 \pm 0.070$ \\
\hline \multicolumn{7}{|l|}{ Thymus } \\
\hline Absolute & $0.279 \pm 0.010$ & $0.265 \pm 0.013$ & $0.268 \pm 0.011$ & $0.255 \pm 0.008$ & $0.274 \pm 0.009$ & $0.266 \pm 0.008$ \\
\hline Relative & $1.372 \pm 0.040$ & $1.303 \pm 0.069$ & $1.301 \pm 0.048$ & $1.270 \pm 0.032$ & $1.342 \pm 0.046$ & $1.359 \pm 0.037$ \\
\hline
\end{tabular}

*Significantly different $(\mathrm{P} \leq 0.05)$ from the chamber control group by Williams' or Dunnett's test.

$* * \mathrm{P} \leq 0.01$.

a Organ weights (absolute weights) and body weights are given in grams; organ-weight-to-body-weight ratios (relative weights) are given as $\mathrm{mg}$ organ weight/g body weight (mean \pm standard error). 
Table G-3. Organ Weights and Organ-Weight-to-Body-Weight Ratios for Mice in the Two-week Inhalation Study of Vinylidene Chloride ${ }^{\text {a }}$

\begin{tabular}{|c|c|c|c|c|c|c|}
\hline & Chamber Control & $25 \mathrm{ppm}$ & $50 \mathrm{ppm}$ & 100 ppm & 200 ppm & $400 \mathrm{ppm}$ \\
\hline \multicolumn{7}{|l|}{ Male } \\
\hline $\mathbf{n}$ & 5 & 4 & 5 & 5 & 0 & 0 \\
\hline Necropsy body wt & $26.6 \pm 0.9$ & $24.4 \pm 0.9$ & $24.9 \pm 0.2$ & - & - & - \\
\hline \multicolumn{7}{|l|}{ Heart } \\
\hline Absolute & $0.13 \pm 0.01$ & $0.12 \pm 0.01$ & $0.12 \pm 0.00$ & - & - & - \\
\hline Relative & $4.952 \pm 0.129$ & $4.826 \pm 0.059$ & $4.728 \pm 0.087$ & - & - & - \\
\hline \multicolumn{7}{|l|}{ R. Kidney } \\
\hline Absolute & $0.22 \pm 0.02$ & $0.23 \pm 0.01$ & $0.22 \pm 0.01$ & - & - & - \\
\hline Relative & $8.309 \pm 0.292$ & $9.495 \pm 0.137 * *$ & $8.851 \pm 0.301$ & - & - & - \\
\hline \multicolumn{7}{|l|}{ Liver } \\
\hline Absolute & $1.42 \pm 0.07$ & $1.48 \pm 0.07$ & $1.56 \pm 0.03$ & - & - & - \\
\hline Relative & $53.190 \pm 0.796$ & $60.483 \pm 1.044^{* *}$ & $62.658 \pm 0.713^{* *}$ & - & - & - \\
\hline \multicolumn{7}{|l|}{ Lung } \\
\hline Absolute & $0.18 \pm 0.01$ & $0.19 \pm 0.01$ & $0.19 \pm 0.01$ & - & - & - \\
\hline Relative & $6.663 \pm 0.215$ & $7.682 \pm 0.279 *$ & $7.751 \pm 0.237^{*}$ & - & - & - \\
\hline \multicolumn{7}{|l|}{ R. Testis } \\
\hline Absolute & $0.100 \pm 0.004$ & $0.102 \pm 0.003$ & $0.095 \pm 0.002$ & - & - & - \\
\hline Relative & $3.749 \pm 0.068$ & $4.188 \pm 0.107 *$ & $3.816 \pm 0.113$ & - & - & - \\
\hline \multicolumn{7}{|l|}{ Thymus } \\
\hline Absolute & $0.049 \pm 0.003$ & $0.055 \pm 0.005$ & $0.053 \pm 0.004$ & - & - & - \\
\hline Relative & $1.845 \pm 0.046$ & $2.222 \pm 0.156$ & $2.113 \pm 0.173$ & - & - & - \\
\hline
\end{tabular}




\begin{tabular}{|c|c|c|c|c|c|c|}
\hline & Chamber Control & $25 \mathrm{ppm}$ & $50 \mathrm{ppm}$ & 100 ppm & 200 ppm & 400 ppm \\
\hline \multicolumn{7}{|l|}{ Female } \\
\hline $\mathbf{n}$ & 5 & 5 & 5 & 4 & 0 & 0 \\
\hline Necropsy body wt & $22.2 \pm 0.4$ & $21.8 \pm 0.5$ & $21.4 \pm 0.3$ & $22.2 \pm 0.7$ & - & - \\
\hline \multicolumn{7}{|l|}{ Heart } \\
\hline Absolute & $0.12 \pm 0.00$ & $0.12 \pm 0.01$ & $0.11 \pm 0.00$ & $0.10 \pm 0.00 *$ & - & - \\
\hline Relative & $5.321 \pm 0.125$ & $5.580 \pm 0.138$ & $5.133 \pm 0.111$ & $4.633 \pm 0.071 * *$ & - & - \\
\hline \multicolumn{7}{|l|}{ R. Kidney } \\
\hline Absolute & $0.16 \pm 0.01$ & $0.18 \pm 0.01 *$ & $0.17 \pm 0.00$ & $0.16 \pm 0.01$ & - & - \\
\hline Relative & $7.026 \pm 0.241$ & $8.340 \pm 0.212^{* *}$ & $8.029 \pm 0.134 * *$ & $7.224 \pm 0.204$ & - & - \\
\hline \multicolumn{7}{|l|}{ Liver } \\
\hline Absolute & $1.14 \pm 0.03$ & $1.23 \pm 0.04$ & $1.30 \pm 0.01 *$ & $1.43 \pm 0.07 * *$ & - & - \\
\hline Relative & $51.248 \pm 0.827$ & $56.253 \pm 0.396 * *$ & $60.528 \pm 0.792 * *$ & $64.395 \pm 1.497 * *$ & - & - \\
\hline \multicolumn{7}{|l|}{ Lung } \\
\hline Absolute & $0.15 \pm 0.01$ & $0.21 \pm 0.01 * *$ & $0.19 \pm 0.01 *$ & $0.21 \pm 0.02 * *$ & - & - \\
\hline Relative & $6.932 \pm 0.514$ & $9.460 \pm 0.297 * *$ & $9.055 \pm 0.315^{* *}$ & $9.567 \pm 0.456^{* *}$ & - & - \\
\hline \multicolumn{7}{|l|}{ Thymus } \\
\hline Absolute & $0.066 \pm 0.003$ & $0.074 \pm 0.005$ & $0.069 \pm 0.002$ & $0.059 \pm 0.006$ & - & - \\
\hline Relative & $2.976 \pm 0.105$ & $3.375 \pm 0.160$ & $3.228 \pm 0.075$ & $2.649 \pm 0.239$ & - & - \\
\hline
\end{tabular}

*Significantly different $(\mathrm{P} \leq 0.05)$ from the chamber control group by Williams' or Dunnett's test.

$* * \mathrm{P} \leq 0.01$.

argan weights (absolute weights) and body weights are given in grams; organ-weight-to-body-weight ratios (relative weights) are given as mg organ weight/g body weight

(mean \pm standard error). No data available for $100 \mathrm{ppm}$ males and $200 \mathrm{ppm}$ and $400 \mathrm{ppm}$ males and females due to $100 \%$ mortality. 
Table G-4. Organ Weights and Organ-Weight-to-Body-Weight Ratios for Mice in the Three-month Inhalation Study of Vinylidene Chloride $^{\mathrm{a}}$

\begin{tabular}{|c|c|c|c|c|c|c|}
\hline & Chamber Control & $6.25 \mathrm{ppm}$ & $12.5 \mathrm{ppm}$ & $25 \mathrm{ppm}$ & $50 \mathrm{ppm}$ & 100 ppm \\
\hline \multicolumn{7}{|l|}{ Male } \\
\hline $\mathbf{n}$ & 10 & 10 & 10 & 10 & 8 & - \\
\hline Necropsy body wt & $39.4 \pm 1.2$ & $37.8 \pm 0.5$ & $35.5 \pm 0.6^{* *}$ & $33.5 \pm 0.8 * *$ & $33.0 \pm 0.5^{* *}$ & - \\
\hline \multicolumn{7}{|l|}{ Heart } \\
\hline Absolute & $0.16 \pm 0.01$ & $0.15 \pm 0.00$ & $0.15 \pm 0.01$ & $0.15 \pm 0.00$ & $0.15 \pm 0.01$ & - \\
\hline Relative & $4.090 \pm 0.083$ & $3.950 \pm 0.061$ & $4.171 \pm 0.104$ & $4.516 \pm 0.084 * *$ & $4.548 \pm 0.121 * *$ & - \\
\hline \multicolumn{7}{|l|}{ R. Kidney } \\
\hline Absolute & $0.32 \pm 0.01$ & $0.28 \pm 0.01 * *$ & $0.26 \pm 0.01 * *$ & $0.25 \pm 0.01 * *$ & $0.25 \pm 0.01 * *$ & - \\
\hline Relative & $8.073 \pm 0.180$ & $7.390 \pm 0.120^{*}$ & $7.217 \pm 0.199 * *$ & $7.607 \pm 0.162$ & $7.421 \pm 0.234$ & - \\
\hline \multicolumn{7}{|l|}{ Liver } \\
\hline Absolute & $1.60 \pm 0.05$ & $1.52 \pm 0.03$ & $1.62 \pm 0.04$ & $1.65 \pm 0.05$ & $1.72 \pm 0.08$ & - \\
\hline Relative & $40.528 \pm 0.231$ & $40.138 \pm 0.502$ & $45.631 \pm 0.986 * *$ & $49.264 \pm 0.948 * *$ & $51.978 \pm 1.596 * *$ & - \\
\hline \multicolumn{7}{|l|}{ Lung } \\
\hline Absolute & $0.21 \pm 0.01$ & $0.20 \pm 0.01$ & $0.21 \pm 0.01$ & $0.21 \pm 0.01$ & $0.21 \pm 0.01$ & - \\
\hline Relative & $5.271 \pm 0.135$ & $5.248 \pm 0.123$ & $5.878 \pm 0.162 *$ & $6.379 \pm 0.194 * *$ & $6.390 \pm 0.262 * *$ & - \\
\hline \multicolumn{7}{|l|}{ R. Testis } \\
\hline Absolute & $0.113 \pm 0.002$ & $0.115 \pm 0.002$ & $0.111 \pm 0.003$ & $0.116 \pm 0.002$ & $0.110 \pm 0.003$ & - \\
\hline Relative & $2.887 \pm 0.072$ & $3.033 \pm 0.041$ & $3.138 \pm 0.067^{*}$ & $3.471 \pm 0.090 * *$ & $3.335 \pm 0.102 * *$ & - \\
\hline \multicolumn{7}{|l|}{ Thymus } \\
\hline Absolute & $0.050 \pm 0.003$ & $0.053 \pm 0.002$ & $0.047 \pm 0.002$ & $0.055 \pm 0.002$ & $0.052 \pm 0.002$ & - \\
\hline Relative & $1.258 \pm 0.073$ & $1.395 \pm 0.060$ & $1.338 \pm 0.045$ & $1.638 \pm 0.052 * *$ & $1.575 \pm 0.050 * *$ & - \\
\hline
\end{tabular}




\begin{tabular}{|c|c|c|c|c|c|c|}
\hline & Chamber Control & $6.25 \mathrm{ppm}$ & $12.5 \mathrm{ppm}$ & 25 ppm & 50 ppm & 100 ppm \\
\hline \multicolumn{7}{|l|}{ Female } \\
\hline $\mathbf{n}$ & 10 & 10 & 10 & 10 & 10 & 6 \\
\hline Necropsy body wt & $35.2 \pm 1.2$ & $30.8 \pm 0.6^{* *}$ & $31.9 \pm 0.9 * *$ & $30.9 \pm 0.8 * *$ & $28.7 \pm 0.6^{* *}$ & $29.9 \pm 0.8^{* *}$ \\
\hline \multicolumn{7}{|l|}{ Heart } \\
\hline Absolute & $0.15 \pm 0.00$ & $0.14 \pm 0.00$ & $0.15 \pm 0.00$ & $0.15 \pm 0.00$ & $0.15 \pm 0.01$ & $0.16 \pm 0.00$ \\
\hline Relative & $4.176 \pm 0.113$ & $4.589 \pm 0.127 * *$ & $4.630 \pm 0.087 * *$ & $4.985 \pm 0.061 * *$ & $5.123 \pm 0.147 * *$ & $5.297 \pm 0.096^{* *}$ \\
\hline \multicolumn{7}{|l|}{ R. Kidney } \\
\hline Absolute & $0.21 \pm 0.01$ & $0.21 \pm 0.00$ & $0.22 \pm 0.01$ & $0.23 \pm 0.00$ & $0.22 \pm 0.00$ & $0.24 \pm 0.01 * *$ \\
\hline Relative & $6.119 \pm 0.175$ & $6.791 \pm 0.125^{* *}$ & $6.990 \pm 0.149 * *$ & $7.308 \pm 0.167 * *$ & $7.680 \pm 0.161 * *$ & $8.114 \pm 0.219 * *$ \\
\hline \multicolumn{7}{|l|}{ Liver } \\
\hline Absolute & $1.43 \pm 0.03$ & $1.41 \pm 0.03$ & $1.55 \pm 0.04 *$ & $1.77 \pm 0.04 * *$ & $1.63 \pm 0.05 * *$ & $1.87 \pm 0.08 * *$ \\
\hline Relative & $40.788 \pm 0.973$ & $45.680 \pm 0.880 * *$ & $48.769 \pm 0.632 * *$ & $57.129 \pm 0.447 * *$ & $56.632 \pm 0.571 * *$ & $62.493 \pm 1.149 * *$ \\
\hline \multicolumn{7}{|l|}{ Lung } \\
\hline Absolute & $0.24 \pm 0.01$ & $0.22 \pm 0.01$ & $0.25 \pm 0.01$ & $0.23 \pm 0.01$ & $0.25 \pm 0.02$ & $0.29 \pm 0.01 * *$ \\
\hline Relative & $6.755 \pm 0.325$ & $7.009 \pm 0.165$ & $7.841 \pm 0.333^{*}$ & $7.602 \pm 0.291 *$ & $8.613 \pm 0.493 * *$ & $9.631 \pm 0.261 * *$ \\
\hline \multicolumn{7}{|l|}{ Thymus } \\
\hline Absolute & $0.058 \pm 0.003$ & $0.057 \pm 0.003$ & $0.057 \pm 0.002$ & $0.067 \pm 0.005$ & $0.063 \pm 0.002$ & $0.060 \pm 0.005$ \\
\hline Relative & $1.653 \pm 0.091$ & $1.835 \pm 0.086$ & $1.795 \pm 0.080$ & $2.162 \pm 0.146^{* *}$ & $2.191 \pm 0.044 * *$ & $2.003 \pm 0.144 * *$ \\
\hline
\end{tabular}




\section{Appendix H. Reproductive Tissue Evaluations}

\section{Tables}

Table H-1. Summary of Reproductive Tissue Evaluations for Male Rats in the Threemonth Inhalation Study of Vinylidene Chloride

Table H-2. Estrous Cycle Characterization for Female Rats in the Three-month Inhalation Study of Vinylidene Chloride.

Table H-3. Summary of Reproductive Tissue Evaluations for Male Mice in the Threemonth Inhalation Study of Vinylidene Chloride

Table H-4. Estrous Cycle Characterization for Female Mice in the Three-month

Inhalation Study of Vinylidene Chloride H-4 
Vinylidene Chloride, NTP TR 582

Table H-1. Summary of Reproductive Tissue Evaluations for Male Rats in the Three-month Inhalation Study of Vinylidene Chloride ${ }^{a}$

\begin{tabular}{lcccc}
\hline & $\begin{array}{c}\text { Chamber } \\
\text { Control }\end{array}$ & $\mathbf{2 5} \mathbf{~ p p m}$ & $\mathbf{5 0 ~} \mathbf{p p m}$ & $\mathbf{1 0 0} \mathbf{~ p p m}$ \\
\hline $\mathbf{n}$ & 10 & 10 & 10 & 10 \\
\hline Weights (g) & & & & \\
$\quad$ Necropsy body wt & $326 \pm 7$ & $319 \pm 6$ & $340 \pm 6$ & $322 \pm 5$ \\
L. Cauda epididymis & $0.1745 \pm 0.0043$ & $0.1724 \pm 0.0059$ & $0.1703 \pm 0.0049$ & $0.1642 \pm 0.0103$ \\
L. Epididymis & $0.5200 \pm 0.0162$ & $0.5138 \pm 0.0158$ & $0.4903 \pm 0.0092$ & $0.4932 \pm 0.0165$ \\
L. Testis & $1.4096 \pm 0.0229$ & $1.3879 \pm 0.0235$ & $1.3749 \pm 0.0301$ & $1.3718 \pm 0.0246$ \\
Spermatid measurements & & & & \\
$\quad$ Spermatid heads (10\%/testis) & $188.4 \pm 8.4$ & $169.3 \pm 8.2$ & $177.8 \pm 7.6$ & $158.5 \pm 5.2^{*}$ \\
$\quad$ Spermatid heads (10\%/g testis) & $150.3 \pm 4.9$ & $136.5 \pm 6.6$ & $148.4 \pm 5.1$ & $128.4 \pm 3.9 *$ \\
Epididymal spermatozoal measurements & & & & \\
$\quad$ Sperm motility (\%) & $87.13 \pm 1.13$ & $84.90 \pm 1.20$ & $84.55 \pm 0.90$ & $82.55 \pm 1.07 * *$ \\
$\quad$ Sperm (10\%/cauda epididymis) & $106.4 \pm 6.6$ & $107.8 \pm 5.8$ & $107.5 \pm 6.8$ & $102.8 \pm 6.4$ \\
$\quad$ Sperm (10\%/g cauda epididymis) & $610 \pm 37$ & $632 \pm 41$ & $629 \pm 33$ & $655 \pm 67$ \\
\hline
\end{tabular}

*Significantly different $(\mathrm{P} \leq 0.05)$ from the chamber control group by Dunn's'test.

**Significantly different $(\mathrm{P} \leq 0.01)$ from the chamber control group by Shirley's test.

aData are presented as mean \pm standard error. Differences from the chamber control group are not significant by Dunnett's test (body and tissue weights) or Dunn's test (sperm per cauda epididymis and per g cauda epididymis).

Table H-2. Estrous Cycle Characterization for Female Rats in the Three-month Inhalation Study of Vinylidene Chloride ${ }^{\mathrm{a}}$

\begin{tabular}{|c|c|c|c|c|}
\hline & $\begin{array}{c}\text { Chamber } \\
\text { Control }\end{array}$ & 25 ppm & 50 ppm & 100 ppm \\
\hline Number weighed at necropsy & 10 & 10 & 10 & 10 \\
\hline Necropsy body wt (g) & $203 \pm 3$ & $201 \pm 4$ & $205 \pm 4$ & $195 \pm 2$ \\
\hline Proportion of regular cycling females ${ }^{b}$ & $10 / 10$ & $10 / 10$ & $10 / 10$ & $10 / 10$ \\
\hline Estrous cycle length (days) & $4.95 \pm 0.05$ & $4.85 \pm 0.11$ & $5.00 \pm 0.00$ & $5.10 \pm 0.10$ \\
\hline \multicolumn{5}{|l|}{ Estrous stages (\% of cycle) } \\
\hline Diestrus & 49.2 & 45.0 & 50.8 & 48.3 \\
\hline Proestrus & 17.5 & 19.2 & 20.8 & 17.5 \\
\hline Estrus & 20.0 & 18.3 & 20.0 & 20.8 \\
\hline Metestrus & 13.3 & 16.7 & 8.3 & 13.3 \\
\hline Uncertain diagnoses & 0.0 & 0.8 & 0.0 & 0.0 \\
\hline
\end{tabular}

${ }^{a}$ Necropsy body weights and estrous cycle length data are presented as mean \pm standard error. Differences from the chamber control group are not significant by Dunnett's test (body weight) or Dunn's test (estrous cycle length). By multivariate analysis of variance, exposed females do not differ significantly from the chamber control females in the relative length of time spent in the estrous stages. Tests for equality of transition probability matrices among all groups and between the chamber control group and each exposed group indicated exposed females did not have significantly more extended estrus or diestrus than the chamber control group.

${ }^{\mathrm{b}}$ Number of females with a regular cycle/number of females cycling. 
Table H-3. Summary of Reproductive Tissue Evaluations for Male Mice in the Three-month Inhalation Study of Vinylidene Chloride ${ }^{a}$

\begin{tabular}{|c|c|c|c|c|}
\hline & $\begin{array}{c}\text { Chamber } \\
\text { Control }\end{array}$ & $12.5 \mathrm{ppm}$ & 25 ppm & 50 ppm \\
\hline $\mathbf{n}$ & 10 & 10 & 10 & 8 \\
\hline \multicolumn{5}{|l|}{ Weights (g) } \\
\hline Necropsy body wt & $39.4 \pm 1.2$ & $35.5 \pm 0.6^{* *}$ & $33.5 \pm 0.8 * *$ & $33.0 \pm 0.5 * *$ \\
\hline L. Cauda epididymis & $0.0221 \pm 0.0011$ & $0.0217 \pm 0.0011$ & $0.0182 \pm 0.0010$ & $0.0200 \pm 0.0019$ \\
\hline L. Epididymis & $0.0604 \pm 0.0020$ & $0.0646 \pm 0.0032$ & $0.0563 \pm 0.0029$ & $0.0567 \pm 0.0020$ \\
\hline L. Testis & $0.1096 \pm 0.0027$ & $0.1119 \pm 0.0020$ & $0.1092 \pm 0.0021$ & $0.1090 \pm 0.0029$ \\
\hline \multicolumn{5}{|l|}{ Spermatid measurements } \\
\hline Spermatid heads $\left(10^{6} /\right.$ testis $)$ & $21.24 \pm 1.45$ & $21.63 \pm 0.95$ & $21.38 \pm 1.08$ & $20.74 \pm 0.68$ \\
\hline Spermatid heads $\left(10^{6} / \mathrm{g}\right.$ testis $)$ & $242.7 \pm 13.9$ & $230.5 \pm 7.5$ & $231.8 \pm 4.2$ & $240.8 \pm 9.0$ \\
\hline \multicolumn{5}{|c|}{ Epididymal spermatozoal measurements } \\
\hline Sperm motility (\%) & $82.7 \pm 1.4$ & $84.6 \pm 0.9$ & $84.8 \pm 1.4$ & $79.8 \pm 2.0$ \\
\hline Sperm (10\%/cauda epididymis) & $21.4 \pm 1.3$ & $17.3 \pm 0.5^{* *}$ & $15.7 \pm 0.4 * *$ & $14.9 \pm 0.6^{* *}$ \\
\hline Sperm ( $10^{6} / g$ cauda epididymis $)$ & $751 \pm 44$ & $631 \pm 35$ & $736 \pm 61$ & $609 \pm 75$ \\
\hline
\end{tabular}


Table H-4. Estrous Cycle Characterization for Female Mice in the Three-month Inhalation Study of Vinylidene Chloride ${ }^{a}$

\begin{tabular}{lcccc}
\hline & $\begin{array}{c}\text { Chamber } \\
\text { Control }\end{array}$ & $\mathbf{1 2 . 5} \mathbf{~ p p m}$ & $\mathbf{2 5} \mathbf{~ p p m}$ & $\mathbf{5 0 ~} \mathbf{~ p m}$ \\
\hline Number weighed at necropsy & 10 & 10 & 10 & 10 \\
$\quad$ Necropsy body wt (g) & $35.2 \pm 1.2$ & $31.9 \pm 0.9^{*}$ & $30.9 \pm 0.8^{* *}$ & $28.7 \pm 0.6^{* *}$ \\
Proportion of regular cycling females ${ }^{\mathrm{b}}$ & $9 / 10$ & $9 / 9$ & $10 / 10$ & $9 / 10$ \\
Estrous cycle length (days) & $4.09 \pm 0.12$ & $3.98 \pm 0.14^{\mathrm{c}}$ & $3.88 \pm 0.05$ & $4.10 \pm 0.10$ \\
Estrous stages (\% of cycle) & & & & \\
Diestrus & 25.8 & 25.8 & 25.0 & 25.0 \\
Proestrus & 1.7 & 0.0 & 0.8 & 0.8 \\
Estrus & 48.3 & 48.3 & 48.3 & 50.0 \\
Metestrus & 24.2 & 25.0 & 25.0 & 24.2 \\
Uncertain diagnoses & 0.0 & 0.8 & 0.8 & 0.0 \\
\hline
\end{tabular}

*Significantly different $(\mathrm{P} \leq 0.05)$ from the chamber control group by Williams' test.

$* * \mathrm{P} \leq 0.01$.

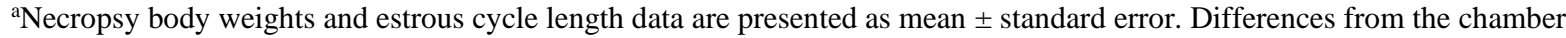
control group are not significant by Dunn's test (estrous cycle length). By multivariate analysis of variance, exposed females do not differ significantly from the chamber control females in the relative length of time spent in the estrous stages. Tests for equality of transition probability matrices among all groups and between the chamber control group and each exposed group indicated exposed females did not have significantly more extended estrus or diestrus than the chamber control group.

${ }^{b}$ Number of females with a regular cycle/number of females cycling.

${ }^{\mathrm{c}}$ Estrous cycle was longer than 12 days or unclear in 1 of 10 animals. 


\section{Appendix I. Chemical Characterization and Generation of Chamber Concentrations}

\section{Table of Contents}

I.1. Procurement and Characterization of Vinylidene Chloride ............................................. I-2

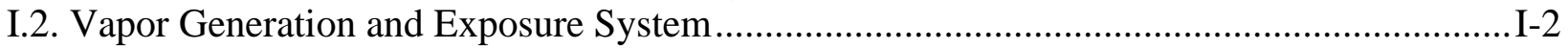

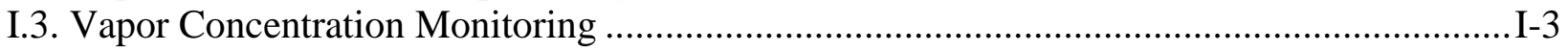

I.4. Chamber Atmosphere Characterization.........................................................................

\section{Tables}

Table I-1. Gas Chromatography Systems Used in the Inhalation Studies of Vinylidene

Chloride.

Table I-2. Summary of Chamber Concentrations in the Two-week Inhalation Studies of Vinylidene Chloride

Table I-3. Summary of Chamber Concentrations in the Three-month Inhalation Studies of Vinylidene Chloride

Table I-4. Summary of Chamber Concentrations in the Two-year Inhalation Studies of Vinylidene Chloride.

\section{Figures}

Figure I-1. Infrared Absorption Spectrum of Vinylidene Chloride I-8

Figure I-2. Proton Nuclear Magnetic Resonance Spectrum of Vinylidene Chloride

Figure I-3. Schematic of the Vapor Generation and Delivery System in the Inhalation Studies of Vinylidene Chloride 


\section{I.1. Procurement and Characterization of Vinylidene Chloride}

Vinylidene chloride, manufactured by Dow Chemical Company (Freeport, TX), was obtained in one lot from Sigma-Aldrich and was used in the 2-week, 3-month, and 2-year studies. The material was identified as lot SB20019301. Identity and purity analyses were conducted by the analytical chemistry laboratory at Chemir Pharma Services (Maryland Heights, MO) and the study laboratory at Battelle Toxicology Northwest (Richland, WA). Reports on analyses performed in support of the vinylidene chloride studies are on file at the National Institute of Environmental Health Sciences.

Lot SB20019301, a colorless, low viscosity liquid with a sweet odor, was identified as vinylidene chloride by the analytical chemistry laboratory using Fourier transform infrared (IR) and proton nuclear magnetic resonance (NMR) spectroscopy. All spectra were consistent with the literature spectra ${ }^{155 ; 156}$ and the structure of vinylidene chloride. Representative IR and proton NMR spectra are presented in Figure I-1 and Figure I-2, respectively.

For lot SB20019301, the analytical chemistry laboratory determined the water content using Karl Fischer titration, conducted elemental analyses to determine the carbon and hydrogen content, and determined residual chloride content after extraction for free chloride using anion exchange chromatography by a system that included a Dionex DX-100 ion chromatograph (Dionex Corporation, Bannockburn, IL). Additional testing was performed on the bulk chemical by the study laboratory that included titration with potassium iodide (KI) to determine the amount of peroxide present; a turbidity assay to determine the polymer content using a Beckman DU-650 spectrophotometer (Beckman Coulter, Inc., Fullerton, CA) with ultraviolet detection at $420 \mathrm{~nm}$; and gas chromatography (GC) with flame ionization detection (FID) by one system to measure the concentration of the stabilizer monomethyl ether hydroquinone (MEHQ) and by a second system to determine area percent purity.

For lot SB20019301, Karl Fischer titration indicated a water content of 74 ppm. Elemental analyses for carbon and hydrogen were consistent with theoretical values. KI titration indicated that peroxide was less than $1 \mathrm{ppm}$ by weight as active oxygen compared to vinylidene chloride. Anion exchange chromatography indicated that residual chloride content was less than 2 ppm. A turbidity assay showed that the concentration of polymer was less than $9 \mathrm{ppm}$. GC/FID by system A (Table I-1) indicated that the test article was stabilized with approximately $300 \mathrm{ppm}$ MEHQ. GC/FID by system B indicated an area percent purity greater than $99.9 \%$. The overall purity of lot SB20019301 was determined to be greater than $99.9 \%$.

To ensure stability, the bulk chemical was stored under a nitrogen headspace in the original shipping containers (400-L steel mini-Bulk ${ }^{\mathrm{TM}}$ containers) at a temperature of approximately $63^{\circ} \mathrm{F}$. Periodic reanalyses of the bulk chemical were performed during the 2-week, 3-month, and 2-year studies by the study laboratory using the same turbidity and GC/FID (system B) assays used in the initial bulk chemical purity assays, and no degradation of the bulk chemical was detected.

\section{I.2. Vapor Generation and Exposure System}

A diagram of the vapor generation and delivery system used in the studies is shown in Figure I-3. Vinylidene chloride was pumped from a disposable 4 liter amber glass generator reservoir into a heated glass flask. Nitrogen entered the flask and assisted in vaporizing the chemical while 
conveying it from the generator into a short vapor distribution manifold. Concentration in the manifold was determined by the chemical pump and nitrogen flow rates. Pressure in the distribution manifold was kept fixed to ensure constant flows through the manifold and into all chambers as the flow of vapor to each chamber was adjusted.

Individual Teflon ${ }^{\circledR}$ delivery lines carried the vapor from the manifold to three-way exposure valves at the chamber inlets. The exposure valves diverted vapor delivery to the exposure chamber exhaust until the generation system stabilized and exposure could proceed. The flow rate to each chamber was controlled by a metering valve at the manifold. To initiate exposure, the chamber exposure valves were rotated to allow the vinylidene chloride vapor to flow to each exposure chamber inlet duct where it was diluted with conditioned chamber air to achieve the desired exposure concentration.

The study laboratory designed the inhalation exposure chamber (Harford Systems Division of Lab Products, Inc., Aberdeen, MD) so that uniform vapor concentrations could be maintained throughout the chamber with the catch pans in place. The total active mixing volume of each chamber was $1.7 \mathrm{~m}^{3}$. A small particle detector (Model 3022A; TSI, Inc., St. Paul, MN) was used with and without animals in the exposure chambers to ensure that vinylidene chloride vapor, and not aerosol, was produced. No particle counts above the minimum resolvable level (approximately 200 particles $/ \mathrm{cm}^{3}$ ) were detected.

\section{I.3. Vapor Concentration Monitoring}

Summaries of the chamber vapor concentrations are given in Table I-2 through Table I-4. Chamber and room concentrations of vinylidene chloride were monitored by an on-line gas chromatograph (system C, Table I-1). Samples were drawn from each exposure chamber approximately three times (2-week and 3-month studies) or twice (2-year studies) per hour during each 6-hour exposure period using Hastelloy ${ }^{\circledR}-\mathrm{C}$ stream-select and gas-sampling valves (VALCO Instruments Company, Houston, TX) in a separate, heated oven. The sample lines composing each sample loop were made from Teflon ${ }^{\circledR}$ tubing and were connected to the exposure chamber relative humidity sampling lines at a location close to the gas chromatograph. A vacuum regulator maintained a constant vacuum in the sample loop to compensate for variations in sample line pressure. An in-line flow meter between the vacuum regulator and the gas chromatograph allowed digital measurement of sample flow.

The on-line gas chromatograph was checked throughout each exposure day for instrument drift against an on-line standard vapor of methylene chloride in nitrogen supplied by a standard generator (Kin-Tek; Precision Calibration Systems, La Marque, TX). The on-line gas chromatograph was recalibrated as required to meet acceptance criteria. Calibration was performed by a comparison of chamber concentration data to data from grab samples collected with activated coconut charcoal gas-sampling tubes $\left(\mathrm{ORBO}^{\mathrm{TM}}-32\right.$; Supelco Inc., Bellefonte, PA), extracted with toluene containing an internal standard of methylene chloride and analyzed using an off-line gas chromatograph equipped with an electron capture detector (system D). Known volumes of chamber atmosphere were sampled at a constant flow rate ensured by a calibrated critical orifice. The off-line gas chromatograph was calibrated with gravimetrically prepared standard solutions of the test chemical containing methylene chloride as an internal standard in toluene. 


\section{I.4. Chamber Atmosphere Characterization}

Buildup and decay rates for chamber vapor concentrations were determined with (all studies) and without (3-month and 2-year studies) animals present in the chambers. At a chamber airflow rate of 15 air changes per hour, the theoretical value for the time to achieve $90 \%$ of the target concentration after the beginning of vapor generation $\left(\mathrm{T}_{90}\right)$ and the time for the chamber concentration to decay to $10 \%$ of the target concentration after vapor generation was terminated $\left(\mathrm{T}_{10}\right)$ was approximately 9.4 minutes. For rats and mice in the 2-week studies, $\mathrm{T}_{90}$ and $\mathrm{T}_{10}$ values ranged from 9 to 10 minutes with animals present. For rats and mice in the 3 -month studies, $\mathrm{T}_{90}$ values ranged from 9 to 11 minutes without animals present and from 10 to 11 minutes with animals; $\mathrm{T}_{10}$ values were 9 to 10 minutes without animals present and 10 minutes with animals. For rats and mice in the 2-year studies, T90 values ranged from 8 to 10 minutes without animals present and from 9 to 12 minutes with animals; $T_{10}$ values ranged from 9 to 10 minutes without animals present and from 9 to 11 minutes with animals. A T90 value of 12 minutes was selected for the 2-week studies and a $\mathrm{T}_{90}$ value of 10 minutes was selected for the 3-month and 2-year studies.

The uniformity of vinylidene chloride vapor concentration in the inhalation exposure chambers without animals present was evaluated before the 3-month and 2-year studies began; in addition, concentration uniformity with animals present in the chambers was measured once during the 2week studies, once during the 3-month studies, and approximately quarterly during the 2-year studies. The vapor concentration was measured using the on-line gas chromatograph (system C, Table I-1) with the stream-selection valve fixed in one position to allow continuous monitoring from a single input line. During the 2-week studies and prior to the 3-month and 2-year studies, concentrations were measured at 12 chamber positions, one in front and one in back for each of the six possible animal cage unit positions per chamber. During the 3-month and 2-year studies, concentrations were measured at the regular monitoring port and from sample ports at levels where animals were present. Chamber concentration uniformity was maintained throughout the studies.

The persistence of vinylidene chloride in the chambers after vapor delivery ended was determined by monitoring the vapor concentration in the $400 \mathrm{ppm}$ chambers in the 2-week studies, the $100 \mathrm{ppm}$ chambers in the 3-month studies, and the $100 \mathrm{ppm}$ rat and $25 \mathrm{ppm}$ mouse chambers in the 2-year studies with (all studies) and without (3-month and 2-year studies) animals present in the chambers. In the 2 -week studies, the concentration decreased to $1 \%$ of the target concentration within 21 minutes with animals present. In the 3-month studies, the concentration decreased to $1 \%$ of the target concentration within 21 minutes without animals present and within 23 minutes with animals present. For the 2-year rat studies, the concentration decreased to $1 \%$ of the target concentration within 22 minutes with and without animals present; for mice, the concentration decreased to $1 \%$ of the target concentration within 18 minutes without animals present and within 21 minutes with animals present.

Samples of the test atmosphere from the distribution lines and the low and high exposure concentration chambers for each species were collected prior to the study without animals present (3-month and 2-year studies) and at the beginning and end of one generation day with animals present during the 2-week, 3-month, and 2-year studies. The atmosphere samples were collected with adsorbent gas-sampling tubes containing activated coconut charcoal $\left(\mathrm{ORBO}^{\mathrm{TM}}-32\right)$ 
followed by a tube containing silica gel $\left(\mathrm{ORBO}^{\mathrm{TM}}-52\right.$; Supelco, Inc.), and extracted with carbon disulfide. Additional samples were collected from the generator reservoir, and all of the samples were analyzed using GC/FID by system B or a system similar to system B to measure the stability and purity of vinylidene chloride in the generation and delivery system. To assess whether impurities or degradation products co-eluted with vinylidene chloride or the solvent, a second GC/FID analysis of the samples was performed using a polar column capable of resolving compounds with similar boiling points and polarities (system E). Separate atmosphere samples were collected in these studies using toluene bubblers; MEHQ inhibitor was assayed in these distribution line samples using GC/FID by system A, and peroxide was assayed in these distribution line and low (except 2-week studies) and high exposure concentration chamber samples by KI titration. HCL, formaldehyde, and phosgene concentrations were measured in atmosphere samples collected during the last 2 hours of a 6-hour generation day. Fourier transform IR spectroscopy was used to measure the presence of HCL in samples collected prior to the 3-month studies and during the 2-week, 3-month, and 2-year studies; spectra were generated using a MIDAC I-1101 spectroscope (MIDAC Corporation, Irvine, CA) equipped with a $9.5 \mathrm{~m}$ pathlength gas cell held at approximately $25^{\circ} \mathrm{C}$ and were compared to those of prepared HCL standards. Formaldehyde and phosgene were measured in atmosphere samples collected on silica adsorbent sampling tubes coated with 2,4-dinitrophenylhydrazine (LpDNPH H10 or S10; Supelco, Inc.) prior to the 3-month and 2-year studies and during the 2-week, 3-month, and 2year studies. These samples were analyzed using a liquid chromatography procedure conducted with a Hewlett-Packard liquid chromatograph (Hewlett-Packard, Palo Alto, CA) equipped with a Phenomenex $\mathrm{C}_{18}(250 \mathrm{~mm} \times 4.6 \mathrm{~mm}, 5 \mu \mathrm{m})$ column (Phenomenex, Torrance, CA). The mobile phase $(1.2 \mathrm{~mL} /$ minute) consisted of acetonitrile:water:tetrahydrofuran:2-propanol [ A) 30:59:10:1; B) 65:35:0:0; and C) 100:0:0:0]; the analysis utilized a solvent program of a linear gradient from $100 \% \mathrm{~A}$ to $60 \% \mathrm{~A}: 40 \% \mathrm{~B}$ in 20 minutes, held for 5 minutes, then a linear gradient to $100 \% \mathrm{~B}$ in 10 minutes followed by linear gradient to $100 \% \mathrm{C}$ in 2 minutes, held for 10 minutes, and then a linear gradient to $100 \% \mathrm{~A}$ in 0.1 minutes. Absorbance was recorded at $355 \mathrm{~nm}$. Samples were collected from the generator reservoir 3 to 14 days after the reservoir was placed in use in studies conducted without animals present prior to the 3-month and 2-year studies and at the same timepoints during the 2-week, 3-month, and 2-year studies. These samples were analyzed for area percent purity, polymer formation, peroxide content, and MEHQ concentration using the same methodologies employed for the initial bulk chemical characterization assays.

No evidence of degradation of vinylidene chloride was noted in any part of the exposure system in any of the samples collected prior to the 3-month and 2-year studies or during the 2-week, 3month, and 2-year studies. No impurity peaks with areas greater than $0.1 \%$ of the total peak area were detected in atmosphere or generator reservoir samples and no additional impurities were found in any of the atmosphere or reservoir samples using the polar column. HCL concentrations in the atmosphere samples were consistently determined to be less than the detection limit. Formaldehyde and phosgene concentrations were less than $0.1 \%$ by weight compared to vinylidene chloride in all distribution line and chamber atmosphere samples. Acceptable, low concentrations of peroxide as active oxygen relative to vinylidene chloride were found in all atmosphere samples. All distribution line samples contained concentrations within the acceptable range for the inhibitor MEHQ relative to vinylidene chloride. No evidence of degradation, peroxide formation, or polymer formation was noted in any of the samples taken from the generator reservoir after multiple days of use. 
Vinylidene Chloride, NTP TR 582

Table I-1. Gas Chromatography Systems Used in the Inhalation Studies of Vinylidene Chloride ${ }^{\text {a }}$

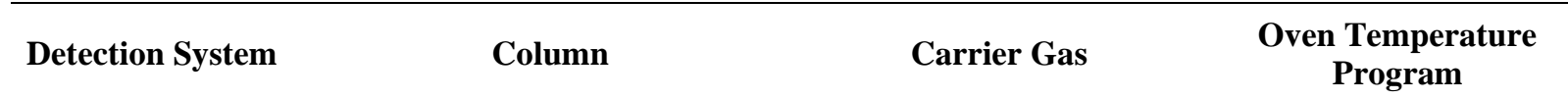

\section{System A}

Flame ionization

DB-5, $30 \mathrm{~m} \times 0.53 \mathrm{~mm}, 1.5 \mu \mathrm{m}$

film (J\&W Scientific, Folsom, CA)

Helium at 12 psi head

pressure

\section{System B}

Flame ionization

DB-624, $30 \mathrm{~m} \times 0.53 \mathrm{~mm}, 3.0 \mu \mathrm{m}$ film (J\&W Scientific)

Helium at 2.5 psi head pressure $90^{\circ} \mathrm{C}$ for 1 minute, then $12^{\circ} \mathrm{C} /$ minute to $200^{\circ} \mathrm{C}$

$35^{\circ} \mathrm{C}$ for 3 minutes, then $4^{\circ} \mathrm{C} /$ minute to $110^{\circ} \mathrm{C}$, then $8^{\circ} \mathrm{C} /$ minute to $260^{\circ} \mathrm{C}$

\section{System C}

Flame ionization

Rtx $^{\circledR}-624,30 \mathrm{~m} \times 0.53 \mathrm{~mm}, 5.0 \mu \mathrm{m} \quad$ Nitrogen at $25 \mathrm{~mL} / \mathrm{minute}$ film (Restek, Bellefonte, PA)

System D

Electron capture

$\operatorname{Rtx}^{\circledR}-624,30 \mathrm{~m} \times 0.53 \mathrm{~mm}, 5.0 \mu \mathrm{m} \quad$ Nitrogen at film (Restek)

\section{$3.5 \mathrm{~mL} / \mathrm{minute}$}

$45^{\circ} \mathrm{C}$ for 1 minute, then $3^{\circ} \mathrm{C} /$ minute to $70^{\circ} \mathrm{C}$, then $15^{\circ} \mathrm{C} /$ minute to $160^{\circ} \mathrm{C}$

\section{System E}

Flame ionization DB WAX, $30 \mathrm{~m} \times 0.53 \mathrm{~mm}, \quad$ Helium at 12 psi head $1.0 \mu \mathrm{m}$ film (J\&W Scientific) pressure

$90^{\circ} \mathrm{C}$ for 1 minute, then $12^{\circ} \mathrm{C} /$ minute to $200^{\circ} \mathrm{C}$ 
Table I-2. Summary of Chamber Concentrations in the Two-week Inhalation Studies of Vinylidene Chloride

\begin{tabular}{lccc}
\hline & $\begin{array}{c}\text { Total Concentration } \\
(\mathbf{p p m})\end{array}$ & $\begin{array}{c}\text { Total Number of } \\
\text { Readings }\end{array}$ & $\begin{array}{c}\text { Average Concentration } \\
(\mathbf{p p m})\end{array}$ \\
\hline Rat Chambers & & 200 & $25.1 \pm 0.5$ \\
& 50 & 201 & $50.1 \pm 1.3$ \\
& 100 & 202 & $99.7 \pm 4.3$ \\
& 200 & 16 & $200 \pm 1$ \\
& 400 & 64 & $398 \pm 34$ \\
\hline Mouse Chambers & 25 & 218 & $25.1 \pm 0.5$ \\
& 50 & 219 & $50.1 \pm 1.3$ \\
& 100 & 220 & $99.7 \pm 4.1$ \\
& 200 & 16 & $200 \pm 1$ \\
& 400 & 19 & $396 \pm 2$ \\
\hline
\end{tabular}

${ }^{\mathrm{a}}$ Mean \pm standard deviation.

Table I-3. Summary of Chamber Concentrations in the Three-month Inhalation Studies of Vinylidene Chloride

\begin{tabular}{lccc}
\hline & $\begin{array}{c}\text { Total Concentration } \\
(\mathbf{p p m})\end{array}$ & $\begin{array}{c}\text { Total Number of } \\
\text { Readings }\end{array}$ & $\begin{array}{c}\text { Average Concentration }^{\mathbf{a}} \\
\text { (ppm) }\end{array}$ \\
\hline Rat Chambers & & & \\
& 6.25 & 1,193 & $6.28 \pm 0.12$ \\
12.5 & 1,183 & $12.6 \pm 0.2$ \\
25 & 1,185 & $25.1 \pm 0.5$ \\
50 & 1,210 & $50.4 \pm 1.0$ \\
& 100 & 1,224 & $100.0 \pm 2.2$ \\
\hline Mouse Chambers & & \\
& 6.25 & 1,232 & $6.28 \pm 0.12$ \\
12.5 & 1,220 & $12.6 \pm 0.2$ \\
25 & 1,223 & $25.1 \pm 0.5$ \\
50 & 1,249 & $50.4 \pm 1.0$ \\
& 100 & 1,263 & $100.0 \pm 2.2$ \\
\hline
\end{tabular}

${ }^{\mathrm{a}}$ Mean \pm standard deviation. 
Table I-4. Summary of Chamber Concentrations in the Two-year Inhalation Studies of Vinylidene Chloride

\begin{tabular}{lccc}
\hline & $\begin{array}{c}\text { Total Concentration } \\
(\mathbf{p p m})\end{array}$ & $\begin{array}{c}\text { Total Number of } \\
\text { Readings }\end{array}$ & $\begin{array}{c}\text { Average } \\
\text { Concentration } \mathbf{( p p m})\end{array}$ \\
\hline Rat Chambers & & & \\
& 25 & 7,938 & $25.0 \pm 0.6$ \\
& 50 & 7,963 & $50.1 \pm 1.1$ \\
& 100 & 7,968 & $100.0 \pm 2.3$ \\
\hline Mouse Chambers & & & \\
& 6.25 & 8,315 & $6.22 \pm 0.16$ \\
& 12.5 & 8,022 & $12.5 \pm 0.3$ \\
& 25 & 7,917 & $25.0 \pm 0.4$ \\
\hline
\end{tabular}

${ }^{\mathrm{a}}$ Mean \pm standard deviation.

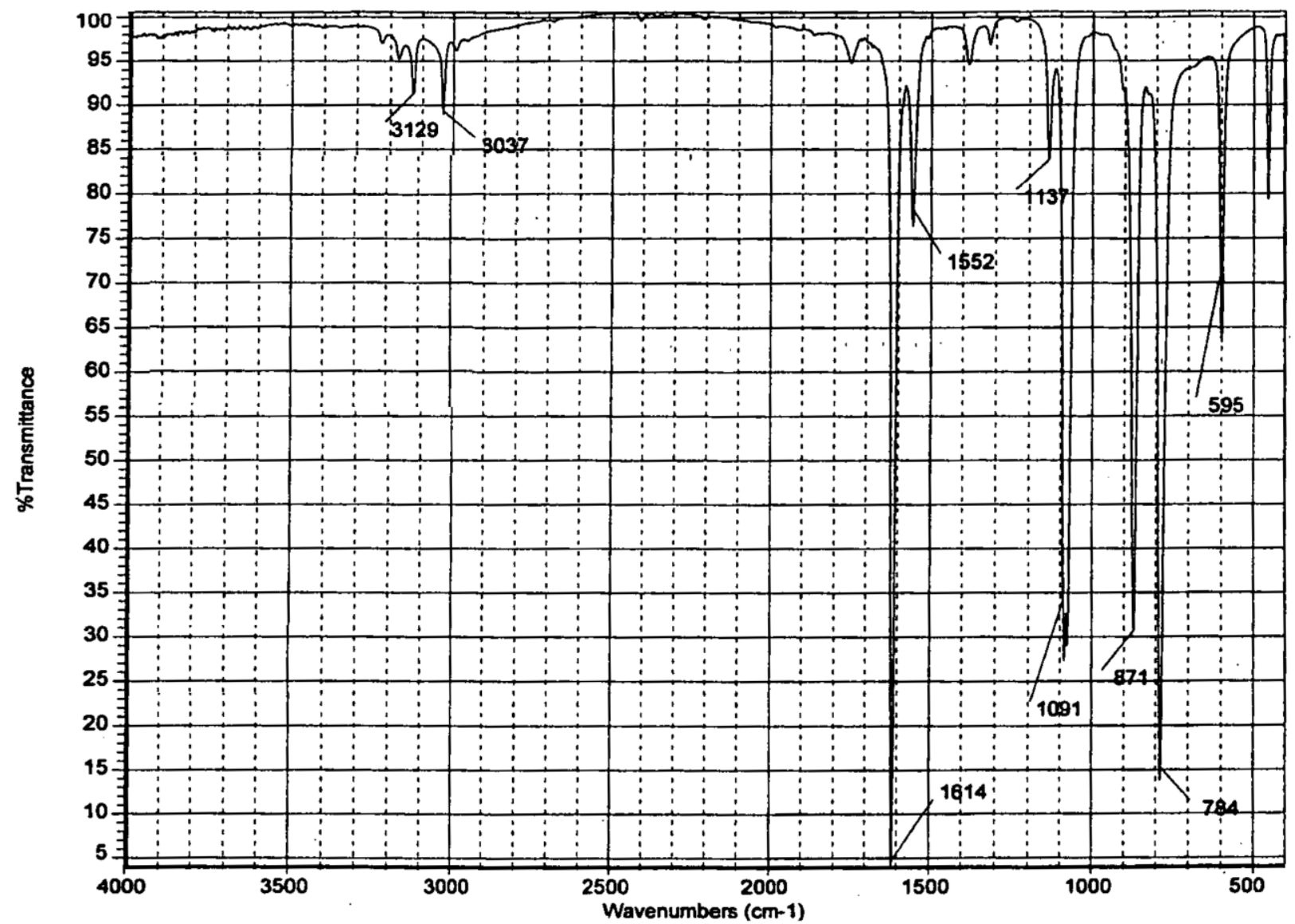

Figure I-1. Infrared Absorption Spectrum of Vinylidene Chloride 
Vinylidene Chloride, NTP TR 582

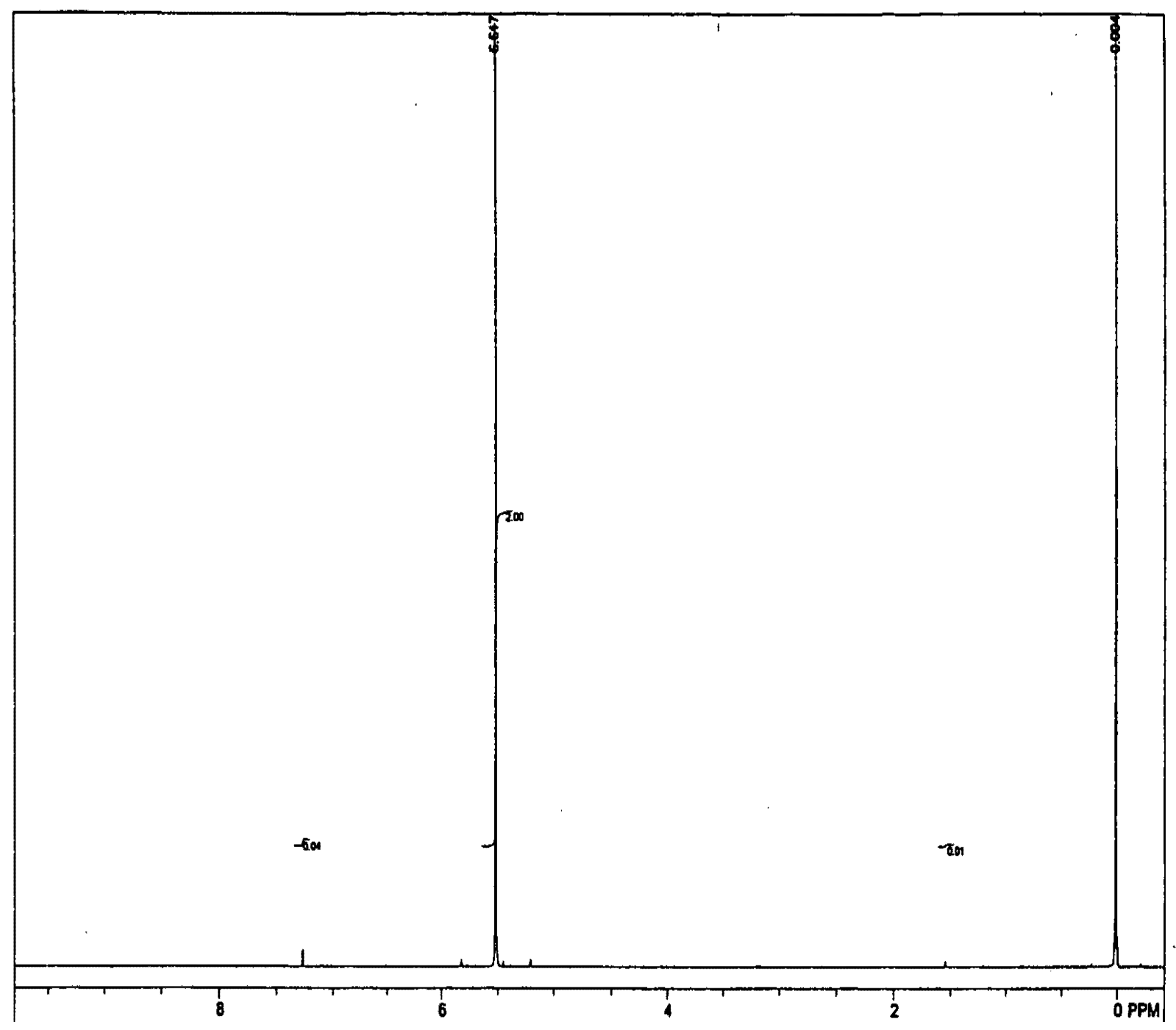

Figure I-2. Proton Nuclear Magnetic Resonance Spectrum of Vinylidene Chloride 


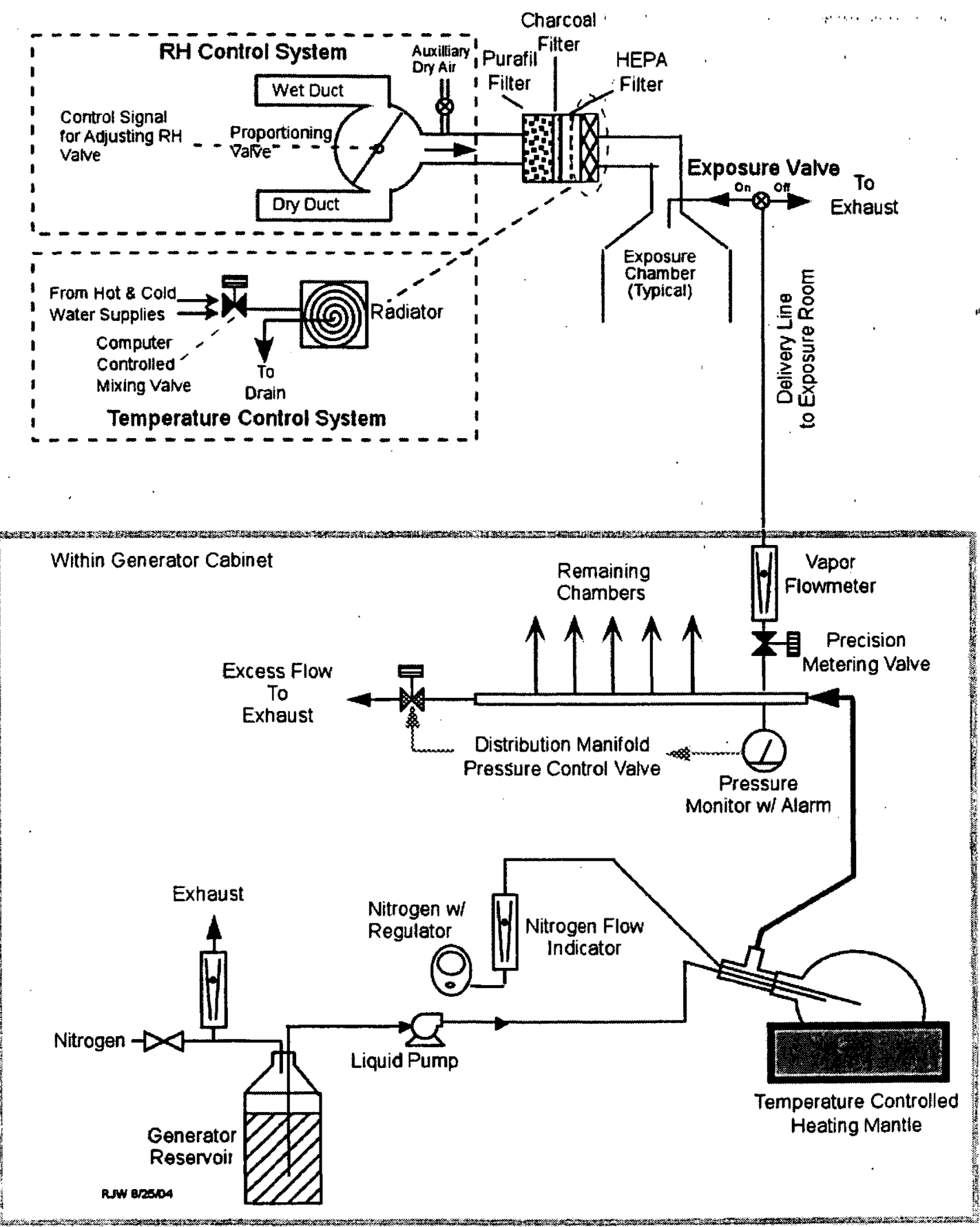

Figure I-3. Schematic of the Vapor Generation and Delivery System in the Inhalation Studies of Vinylidene Chloride 


\section{Appendix J. Ingredients, Nutrient Composition, and Contaminant Levels In NTP-2000 Rat and Mouse Ration}

\section{Tables}

Table J-1. Ingredients of NTP-2000 Rat and Mouse Ration

Table J-2. Vitamins and Minerals in NTP-2000 Rat and Mouse Ration

Table J-3. Nutrient Composition of NTP-2000 Rat and Mouse Ration $\mathrm{J}-3$

Table J-4. Contaminant Levels in NTP-2000 Rat and Mouse Ration 
Table J-1. Ingredients of NTP-2000 Rat and Mouse Ration

\begin{tabular}{|c|c|c|}
\hline Ingredients & & Percent by Weight \\
\hline Ground hard winter wheat & & 22.26 \\
\hline Ground \#2 yellow shelled corn & & 22.18 \\
\hline Wheat middlings & & 15.0 \\
\hline Oat hulls & & 8.5 \\
\hline Alfalfa meal (dehydrated, $17 \%$ protein) & & 7.5 \\
\hline Purified cellulose & & 5.5 \\
\hline Soybean meal (49\% protein) & & 5.0 \\
\hline Fish meal (60\% protein) & & 4.0 \\
\hline Corn oil (without preservatives) & & 3.0 \\
\hline Soy oil (without preservatives) & & 3.0 \\
\hline Dried brewer's yeast & & 1.0 \\
\hline Calcium carbonate (USP) & & 0.9 \\
\hline Vitamin premix ${ }^{a}$ & & 0.5 \\
\hline Mineral premix ${ }^{b}$ & & 0.5 \\
\hline Calcium phosphate, dibasic (USP) & & 0.4 \\
\hline Sodium chloride & & 0.3 \\
\hline Choline chloride ( $70 \%$ choline) & & 0.26 \\
\hline Methionine & & 0.2 \\
\hline \multicolumn{3}{|l|}{$\begin{array}{l}\text { aWheat middlings as carrier. } \\
\text { bCalcium carbonate as carrier. }\end{array}$} \\
\hline Table J-2. Vitamins and Minerals & Amount & id Mouse Ration ${ }^{a}$ \\
\hline \multicolumn{3}{|l|}{ Vitamins } \\
\hline A & $4,000 \mathrm{IU}$ & Stabilized vitamin A palmitate or acetate \\
\hline $\mathrm{D}$ & $1,000 \mathrm{IU}$ & D-activated animal sterol \\
\hline K & $1.0 \mathrm{mg}$ & Menadione sodium bisulfite complex \\
\hline$\alpha$-Tocopheryl acetate & $100 \mathrm{IU}$ & - \\
\hline Niacin & $23 \mathrm{mg}$ & - \\
\hline Folic acid & $1.1 \mathrm{mg}$ & - \\
\hline$d$-Pantothenic acid & $10 \mathrm{mg}$ & $d$-Calcium pantothenate \\
\hline Riboflavin & $3.3 \mathrm{mg}$ & - \\
\hline Thiamine & $4 \mathrm{mg}$ & Thiamine mononitrate \\
\hline $\mathrm{B}_{12}$ & $52 \mu \mathrm{g}$ & - \\
\hline Pyridoxine & $6.3 \mathrm{mg}$ & Pyridoxine hydrochloride \\
\hline Biotin & $0.2 \mathrm{mg}$ & $d$-Biotin \\
\hline
\end{tabular}


Vinylidene Chloride, NTP TR 582

\begin{tabular}{lcl}
\hline & Amount & Source \\
\hline Minerals & & \\
Magnesium & $514 \mathrm{mg}$ & Magnesium oxide \\
Iron & $35 \mathrm{mg}$ & Iron sulfate \\
Zinc & $12 \mathrm{mg}$ & Zinc oxide \\
Manganese & $10 \mathrm{mg}$ & Manganese oxide \\
Copper & $2.0 \mathrm{mg}$ & Copper sulfate \\
Iodine & $0.2 \mathrm{mg}$ & Calcium iodate \\
Chromium & $0.2 \mathrm{mg}$ & Chromium acetate \\
\hline aPer kg of finished product. & &
\end{tabular}

Per kg of finished product.

Table J-3. Nutrient Composition of NTP-2000 Rat and Mouse Ration

\begin{tabular}{|c|c|c|c|}
\hline Nutrient & $\begin{array}{c}\text { Mean } \pm \text { Standard } \\
\text { Deviation }\end{array}$ & Range & Number of Samples \\
\hline Protein (\% by weight) & $14.7 \pm 0.65$ & $13.5-16.3$ & 24 \\
\hline Crude fat ( $\%$ by weight) & $8.3 \pm 0.33$ & $7.8-9.3$ & 24 \\
\hline Crude fiber ( $\%$ by weight) & $9.1 \pm 0.55$ & $8.1-10.0$ & 24 \\
\hline Ash (\% by weight) & $4.9 \pm 0.23$ & $4.4-5.4$ & 24 \\
\hline \multicolumn{4}{|c|}{ Amino Acids (\% of total diet) } \\
\hline Arginine & $0.783 \pm 0.070$ & $0.670-0.970$ & 22 \\
\hline Cystine & $0.220 \pm 0.024$ & $0.150-0.250$ & 22 \\
\hline Glycine & $0.701 \pm 0.041$ & $0.620-0.800$ & 22 \\
\hline Histidine & $0.352 \pm 0.077$ & $0.270-0.680$ & 22 \\
\hline Isoleucine & $0.546 \pm 0.044$ & $0.430-0.660$ & 22 \\
\hline Leucine & $1.095 \pm 0.067$ & $0.960-1.240$ & 22 \\
\hline Lysine & $0.711 \pm 0.114$ & $0.310-0.860$ & 22 \\
\hline Methionine & $0.409 \pm 0.046$ & $0.260-0.490$ & 22 \\
\hline Phenylalanine & $0.628 \pm 0.040$ & $0.540-0.720$ & 22 \\
\hline Threonine & $0.505 \pm 0.043$ & $0.430-0.610$ & 22 \\
\hline Tryptophan & $0.150 \pm 0.028$ & $0.110-0.200$ & 22 \\
\hline Tyrosine & $0.401 \pm 0.061$ & $0.280-0.540$ & 22 \\
\hline Valine & $0.665 \pm 0.043$ & $0.550-0.730$ & 22 \\
\hline \multicolumn{4}{|c|}{ Essential Fatty Acids (\% of total diet) } \\
\hline Linoleic & $3.95 \pm 0.259$ & $3.49-4.55$ & 22 \\
\hline Linolenic & $0.30 \pm 0.032$ & $0.21-0.35$ & 22 \\
\hline \multicolumn{4}{|l|}{ Vitamins } \\
\hline Vitamin A (IU/kg) & $3,755 \pm 64$ & $2,340-5,080$ & 24 \\
\hline Vitamin D (IU/kg) & $1,000^{\mathrm{a}}$ & - & - \\
\hline
\end{tabular}


Vinylidene Chloride, NTP TR 582

\begin{tabular}{|c|c|c|c|}
\hline Nutrient & $\begin{array}{c}\text { Mean } \pm \text { Standard } \\
\text { Deviation }\end{array}$ & Range & Number of Samples \\
\hline$\alpha$-Tocopherol (ppm) & $80.6 \pm 22.03$ & $27.0-124.0$ & 22 \\
\hline Thiamine (ppm) $)^{\mathrm{b}}$ & $7.5 \pm 1.08$ & $5.5-10.0$ & 24 \\
\hline Riboflavin (ppm) & $7.6 \pm 2.89$ & $4.20-17.50$ & 22 \\
\hline Niacin (ppm) & $78.9 \pm 9.08$ & $66.4-98.2$ & 22 \\
\hline Pantothenic acid (ppm) & $26.9 \pm 12.63$ & $17.4-81.0$ & 22 \\
\hline Pyridoxine (ppm) $)^{\mathrm{b}}$ & $9.54 \pm 1.99$ & $6.44-13.7$ & 22 \\
\hline Folic acid (ppm) & $1.62 \pm 0.48$ & $1.15-3.27$ & 22 \\
\hline Biotin (ppm) & $0.32 \pm 0.10$ & $0.20-0.704$ & 22 \\
\hline Vitamin $B_{12}(\mathrm{ppb})$ & $53.6 \pm 39.6$ & $18.3-174.0$ & 22 \\
\hline Choline (ppm) ${ }^{\mathrm{b}}$ & $2,846 \pm 485$ & $1,820-3,790$ & 22 \\
\hline \multicolumn{4}{|l|}{ Minerals } \\
\hline Calcium (\%) & $0.953 \pm 0.055$ & $0.865-1.080$ & 24 \\
\hline Phosphorus (\%) & $0.549 \pm 0.028$ & $0.499-0.607$ & 24 \\
\hline Potassium (\%) & $0.666 \pm 0.030$ & $0.626-0.733$ & 22 \\
\hline Chloride (\%) & $0.386 \pm 0.039$ & $0.300-0.474$ & 22 \\
\hline Sodium $(\%)$ & $0.189 \pm 0.016$ & $0.160-0.222$ & 22 \\
\hline Magnesium (\%) & $0.216 \pm 0.062$ & $0.185-0.490$ & 22 \\
\hline Sulfur $(\%)$ & $0.170 \pm 0.029$ & $0.116-0.209$ & 14 \\
\hline Iron (ppm) & $186 \pm 39.2$ & $135-311$ & 22 \\
\hline Manganese (ppm) & $51.4 \pm 10.28$ & $21.0-73.1$ & 22 \\
\hline Zinc (ppm) & $53.4 \pm 8.46$ & $43.3-78.5$ & 22 \\
\hline Copper (ppm) & $7.01 \pm 2.562$ & $3.21-16.3$ & 22 \\
\hline Iodine (ppm) & $0.503 \pm 0.206$ & $0.158-0.972$ & 22 \\
\hline Chromium (ppm) & $0.694 \pm 0.276$ & $0.330-1.380$ & 22 \\
\hline Cobalt (ppm) & $0.256 \pm 0.164$ & $0.098-0.864$ & 22 \\
\hline
\end{tabular}

${ }^{\text {aFrom formulation. }}$

${ }^{\mathrm{b}}$ As hydrochloride (thiamine and pyridoxine) or chloride (choline). 
Vinylidene Chloride, NTP TR 582

Table J-4. Contaminant Levels in NTP-2000 Rat and Mouse Ration ${ }^{\mathrm{a}}$

\begin{tabular}{|c|c|c|c|}
\hline & $\begin{array}{c}\text { Mean } \pm \text { Standard } \\
\text { Deviation }^{b}\end{array}$ & Range & Number of Samples \\
\hline \multicolumn{4}{|l|}{ Contaminants } \\
\hline Arsenic (ppm) & $0.25 \pm 0.066$ & $0.16-0.40$ & 24 \\
\hline Cadmium (ppm) & $0.05 \pm 0.008$ & $0.04-0.07$ & 24 \\
\hline Lead (ppm) & $0.09 \pm 0.011$ & $0.07-0.15$ & 24 \\
\hline Mercury (ppm) & $<0.02$ & - & 24 \\
\hline Selenium (ppm) & $0.35 \pm 0.195$ & $0.18-0.97$ & 24 \\
\hline Aflatoxins (ppb) & $<5.00$ & - & 24 \\
\hline Nitrate nitrogen $(\mathrm{ppm})^{\mathrm{c}}$ & $13.88 \pm 7.43$ & $4.8-36.8$ & 24 \\
\hline Nitrite nitrogen $(\mathrm{ppm})^{\mathrm{c}}$ & $1.86 \pm 1.64$ & $0.30-4.99$ & 24 \\
\hline BHA $(\mathrm{ppm})^{\mathrm{d}}$ & $1.17 \pm 0.82$ & $1.0-5.0$ & 24 \\
\hline BHT $(\mathrm{ppm})^{\mathrm{d}}$ & $1.17 \pm 0.82$ & $1.0-5.0$ & 24 \\
\hline Aerobic plate count (CFU/g) & $10 \pm 0.0$ & $10-10$ & 24 \\
\hline Coliform (MPN/g) & $3.0 \pm 0.0$ & $3.0-3.0$ & 24 \\
\hline Escherichia coli (MPN/g) & $<10$ & - & 24 \\
\hline Salmonella (MPN/g) & Negative & - & 24 \\
\hline Total nitrosoamines $(\mathrm{ppb})^{\mathrm{e}}$ & $4.7 \pm 1.90$ & $2.0-9.9$ & 24 \\
\hline$N$-Nitrosodimethylamine (ppb) ${ }^{\mathrm{e}}$ & $2.5 \pm 1.25$ & $1.0-6.3$ & 24 \\
\hline$N$-Nitrosopyrrolidine $(\mathrm{ppb})^{\mathrm{e}}$ & $2.2 \pm 1.23$ & $1.0-6.1$ & 24 \\
\hline \multicolumn{4}{|l|}{ Pesticides (ppm) } \\
\hline$\alpha-\mathrm{BHC}$ & $<0.01$ & - & 24 \\
\hline$\beta-\mathrm{BHC}$ & $<0.02$ & - & 24 \\
\hline$\gamma$-BHC & $<0.01$ & - & 24 \\
\hline$\delta$-BHC & $<0.01$ & - & 24 \\
\hline Heptachlor & $<0.01$ & - & 24 \\
\hline Aldrin & $<0.01$ & - & 24 \\
\hline Heptachlor epoxide & $<0.01$ & - & 24 \\
\hline DDE & $<0.01$ & - & 24 \\
\hline DDD & $<0.01$ & - & 24 \\
\hline DDT & $<0.01$ & - & 24 \\
\hline $\mathrm{HCB}$ & $<0.01$ & - & 24 \\
\hline Mirex & $<0.01$ & - & 24 \\
\hline Methoxychlor & $<0.05$ & - & 24 \\
\hline Dieldrin & $<0.01$ & - & 24 \\
\hline Endrin & $<0.01$ & - & 24 \\
\hline
\end{tabular}


Vinylidene Chloride, NTP TR 582

\begin{tabular}{lccc}
\hline & $\begin{array}{c}\text { Mean } \pm \text { Standard } \\
\text { Deviation }\end{array}$ & Range & Number of Samples \\
\hline Telodrin & $<0.01$ & - & 24 \\
Chlordane & $<0.05$ & - & 24 \\
Toxaphene & $<0.10$ & - & 24 \\
Estimated PCBs & $<0.20$ & - & 24 \\
Ronnel & $<0.01$ & - & 24 \\
Ethion & $<0.02$ & - & 24 \\
Trithion & $<0.05$ & - & 24 \\
Diazinon & $<0.10$ & - & 24 \\
Methyl chlorpyrifos & $0.075 \pm 0.048$ & $-010-0.186$ & 24 \\
Methyl parathion & $<0.02$ & - & 24 \\
Ethyl parathion & $<0.02$ & - & 24 \\
Malathion & $0.221 \pm 0.249$ & $-0.020-0.997$ & 24 \\
Endosulfan I & $<0.01$ & - & 24 \\
Endosulfan II & $<0.01$ & - & 24 \\
Endosulfan sulfate & $<0.03$ & 24 \\
\hline
\end{tabular}

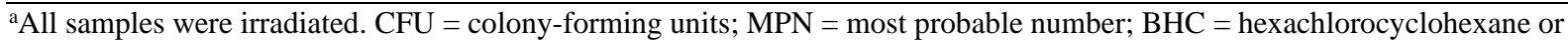
benzene hexachloride.

${ }^{b}$ For values less than the limit of detection, the detection limit is given as the mean.

'Sources of contamination: alfalfa, grains, and fish meal.

${ }^{\mathrm{d}}$ Sources of contamination: soy oil and fish meal.

eAll values were corrected for percent recovery. 


\section{Appendix K. Sentinel Animal Program \\ Table of Contents}

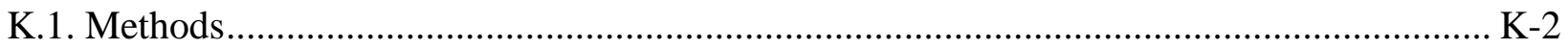

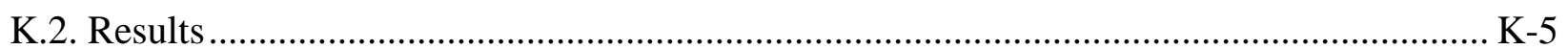

Tables

Table K-1. Laboratory Methods and Agents Tested for in the Sentinel Animal Program ......... K-2 


\section{K.1. Methods}

Rodents used in the National Toxicology Program are produced in optimally clean facilities to eliminate potential pathogens that may affect study results. The Sentinel Animal Program is part of the periodic monitoring of animal health that occurs during the toxicologic evaluation of test compounds. Under this program, the disease state of the rodents is monitored via sera or feces from extra (sentinel) or dosed animals in the study rooms. The sentinel animals and the study animals are subject to identical environmental conditions. Furthermore, the sentinel animals come from the same production source and weanling groups as the animals used for the studies of test compounds.

Blood samples were collected, allowed to clot, and the serum was separated. Additionally, fecal samples were collected and tested for Helicobacter species. All samples were processed appropriately and tested in-house or sent to BioReliance Corporation (Rockville, MD) for determination of the presence of pathogens. The laboratory methods and agents for which testing was performed are tabulated below; the times at which samples were collected during the studies are also listed.

Blood was collected from five animals per sex at each time point except four female mice at 12 months and four male rats at 18 months in the 2-year studies. Fecal samples were collected from five male and five female mice during the 2-year study.

Table K-1. Laboratory Methods and Agents Tested for in the Sentinel Animal Program

\begin{tabular}{ll}
\hline \multicolumn{1}{c}{ Method and Test } & \multicolumn{1}{c}{ Time of Collection } \\
\hline Rats & \\
\hline Two-week Study & \\
In-house Antibody Testing & Study termination \\
Mycoplasma pulmonis & Study termination \\
PVM (pneumonia virus of mice) & Study termination \\
RCV/SDA (rat coronavirus/sialodacryoadenitis virus) & Study termination \\
RPV (rat parvovirus) & Study termination \\
Sendai & \\
\hline Three-month Study & \\
In-house Antibody Testing & 2 weeks \\
M. pulmonis & 2 weeks \\
PVM & 2 weeks \\
RCV/SDA & 2 weeks \\
RPV & 2 weeks \\
Sendai & \\
ELISA & Study termination \\
Mycoplasma arthritidis & Study termination \\
M. pulmonis &
\end{tabular}


Vinylidene Chloride, NTP TR 582

\begin{tabular}{|c|c|}
\hline Method and Test & Time of Collection \\
\hline PVM & Study termination \\
\hline $\mathrm{RCV} / \mathrm{SDA}$ & Study termination \\
\hline Sendai & Study termination \\
\hline \multicolumn{2}{|l|}{ Immunofluorescence Assay } \\
\hline Parvovirus & Study termination \\
\hline \multicolumn{2}{|l|}{ In-house Antibody Testing } \\
\hline M. pulmonis & 2 weeks \\
\hline PVM & 2 weeks \\
\hline $\mathrm{RCV} / \mathrm{SDA}$ & 2 weeks \\
\hline RPV & 2 weeks \\
\hline Sendai & 2 weeks \\
\hline \multicolumn{2}{|l|}{ ELISA } \\
\hline M. arthritidis & Study termination \\
\hline M. pulmonis & Study termination \\
\hline PVM & 6,12 , and 18 months, study termination \\
\hline $\mathrm{RCV} / \mathrm{SDA}$ & 6,12 , and 18 months, study termination \\
\hline Sendai & 6,12 , and 18 months, study termination \\
\hline \multicolumn{2}{|l|}{ Immunofluorescence Assay } \\
\hline Parvovirus & 6,12 , and 18 months, study termination \\
\hline \multicolumn{2}{|l|}{ Mice } \\
\hline \multicolumn{2}{|l|}{ Two-week Study } \\
\hline \multicolumn{2}{|l|}{ In-house Antibody Testing } \\
\hline GDVII (Theiler's murine encephalomyelitis virus) & Study termination \\
\hline MHV (mouse hepatitis virus) & Study termination \\
\hline MPV (mouse parvovirus) & Study termination \\
\hline M. pulmonis & Study termination \\
\hline PVM & Study termination \\
\hline Sendai & Study termination \\
\hline \multicolumn{2}{|l|}{ Three-month Study } \\
\hline \multicolumn{2}{|l|}{ In-house Antibody Testing } \\
\hline GDVII & 2 weeks \\
\hline MHV & 2 weeks \\
\hline MPV & 2 weeks \\
\hline M. pulmonis & 2 weeks \\
\hline PVM & 2 weeks \\
\hline Sendai & 2 weeks \\
\hline
\end{tabular}


Vinylidene Chloride, NTP TR 582

\begin{tabular}{|c|c|}
\hline Method and Test & Time of Collection \\
\hline \multicolumn{2}{|l|}{ ELISA } \\
\hline Ectromelia virus & Study termination \\
\hline EDIM (epizootic diarrhea of infant mice) & Study termination \\
\hline GDVII & Study termination \\
\hline LCM (lymphocytic choriomeningitis virus) & Study termination \\
\hline MAd-FL (mouse adenovirus) & Study termination \\
\hline MHV & Study termination \\
\hline MMV VP2 (mouse minute virus) & Study termination \\
\hline MPV VP2 (mouse parvovirus) & Study termination \\
\hline M. arthritidis & Study termination \\
\hline M. pulmonis & Study termination \\
\hline PVM & Study termination \\
\hline Reovirus & Study termination \\
\hline Sendai & Study termination \\
\hline \multicolumn{2}{|l|}{ Immunofluorescence Assay } \\
\hline MCMV (mouse cytomegalovirus) & Study termination \\
\hline \multicolumn{2}{|l|}{ Two-year Study } \\
\hline \multicolumn{2}{|l|}{ In-house Antibody Testing } \\
\hline GDVII & 2 weeks \\
\hline MHV & 2 weeks \\
\hline MPV & 2 weeks \\
\hline M. pulmonis & 2 weeks \\
\hline PVM & 2 weeks \\
\hline Sendai & 2 weeks \\
\hline \multicolumn{2}{|l|}{ ELISA } \\
\hline Ectromelia virus & 6,12 , and 18 months, study termination \\
\hline EDIM & 6,12 , and 18 months, study termination \\
\hline GDVII & 6,12 , and 18 months, study termination \\
\hline LCM & 6,12 , and 18 months, study termination \\
\hline MAd-1 & 6,12 , and 18 months, study termination \\
\hline MHV & 6,12 , and 18 months, study termination \\
\hline MMV VP2 & 6,12 , and 18 months, study termination \\
\hline MPV VP2 & 6,12 , and 18 months, study termination \\
\hline M. arthritidis & Study termination \\
\hline M. pulmonis & Study termination \\
\hline PVM & 6,12, and 18 months, study termination \\
\hline
\end{tabular}


Vinylidene Chloride, NTP TR 582

\begin{tabular}{ll}
\hline \multicolumn{1}{c}{ Method and Test } & \multicolumn{1}{c}{ Time of Collection } \\
\hline Reovirus & 6,12 , and 18 months, study termination \\
Sendai & 6,12 , and 18 months, study termination \\
Immunofluorescence Assay & 12 and 18 months \\
EDIM & 18 months \\
GDVII & Study termination \\
MCMV & 12 and 18 months \\
MMV & 18 months \\
MPV & 18 months \\
PVM & 12 months \\
Reovirus & \\
Polymerase Chain Reaction & 18 months \\
Helicobacter species &
\end{tabular}

\section{K.2. Results}

All test results were negative. 


\section{Appendix L. Global Gene Profiling of Mesothelioma in Vinylidene Chloride-Exposed F344/N Rats}

Pamela E. Blackshear ${ }^{1,5}$, Arun R. Pandiri ${ }^{1,6}$, Sachin Bhusari ${ }^{1}$, Lily Hong ${ }^{1}$, Thai-Vu T. Ton ${ }^{1}$, Natasha P. Clayton ${ }^{1}$, Michael E. Wyde ${ }^{2}$, Keith R. Shockley ${ }^{3}$, Shyamal D. Peddada ${ }^{3}$, Kevin E. Gerrish $^{4}$, Robert C. Sills ${ }^{1}$, and Mark J. Hoenerhoff ${ }^{1}$

${ }^{1}$ Cellular and Molecular Pathology Branch, and

${ }^{2}$ Experimental Toxicology Group, Division of the National Toxicology Program, Research Triangle Park, North Carolina, USA

${ }^{3}$ Biostatistics Branch, and

${ }^{4}$ Laboratory of Toxicology and Pharmacology, National Institute of Environmental Health Sciences, Research Triangle Park, North Carolina, USA

${ }^{5}$ ILS, Inc., Research Triangle Park, North Carolina, USA

${ }^{6}$ Experimental Pathology Laboratories, Inc., Research Triangle Park, North Carolina, USA

\section{Table of Contents}

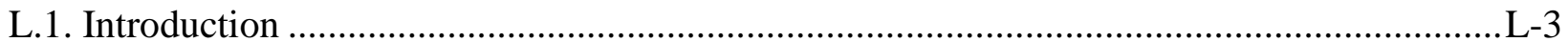

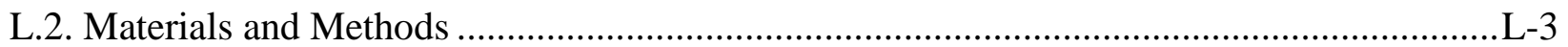

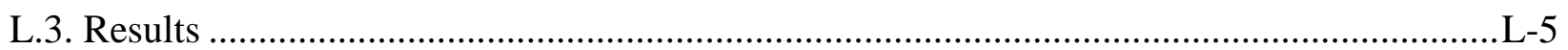

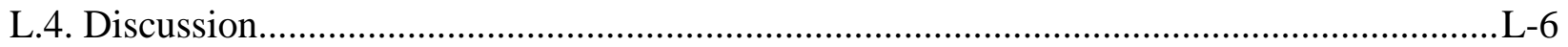

\section{Tables}

Table L-1. Spontaneous and Vinylidene Chloride-Exposed Malignant Mesotheliomas from Male F344/N Rats Used for Genomic Profiling

Table L-2. Selected Significantly Expressed Pathways in Mesotheliomas from Vinylidene Chloride-Exposed and Control F344/N Rats Compared to Fred-PE Cells $(\mathrm{P}<0.001)$

Table L-3. Selected Differentially Expressed Genes Associated with Inflammation and Immune Response in Vinylidene Chloride-Exposed and Spontaneous Mesotheliomas Compared to Fred-PE Cells ( $<$ 0.001).

Table L-4. Quantitative PCR (qPCR) Validation of Gene Expression Changes on Microarray of Spontaneous and Vinylidene Chloride-Exposed Mesotheliomas in F344/N Rats

\section{Figures}

Figure L-1. Principal Component Analysis Comparing Global Gene Profiles of Fred-PE Mesothelial Cells (Red), Spontaneous Mesotheliomas from Control Rats (Blue), and Mesotheliomas from Vinylidene Chloride-Exposed Rats (Green) .....L-15 
Figure L-2. Top Overrepresented Biologic Functions Related to Tumorigenesis in Spontaneous Mesotheliomas and Mesotheliomas from Vinylidene ChlorideExposed Male F344/N Rats $(\mathrm{P}<0.05)$.

Figure L-3. Significantly Overrepresented Canonical Pathways Related to Inflammation and Immune Dysfunction Not Overrepresented in Spontaneous Mesotheliomas $(\mathrm{P}<0.05)$. 


\section{L.1. Introduction}

The 2-year National Toxicology Program (NTP) bioassay indicated that male F344/N rats exposed to vinylidene chloride had statistically significant increases in the incidences of malignant mesotheliomas arising from the tunica vaginalis of the testes. The goal of this study was to investigate global gene expression alterations in mesotheliomas from vinylidene chlorideexposed animals in order to elucidate their chemical-specific gene profiles compared to spontaneous mesotheliomas. We compared global gene expression profiles of mesotheliomas from vinylidene chloride-exposed male F344/N rats, spontaneous mesotheliomas in control male F344/N rats from three other NTP studies (codeine, riddelliine, cobalt metal), ${ }^{157-159}$ and the immortalized, nontransformed, F344/N rat peritoneal mesothelial cell line, Fred-PE, as a control.

\section{L.2. Materials and Methods}

\section{L.2.1. Sample Collection}

For collection of frozen tissues for molecular biology analysis in NTP studies, sections of background and treatment-related tumors or suspect tumors and corresponding tumors from untreated control male and female rats and mice are collected and frozen for animals sacrificed moribund and those sacrificed at study termination. When a tumor is at least $0.5 \mathrm{~cm}$ in diameter, one-half of that tumor is collected for fixation in $10 \%$ neutral buffered formalin (NBF), and the other corresponding half is flash frozen in liquid nitrogen. Sections of frozen tissue are then utilized for isolation of nucleic acids for quantitative PCR (qPCR) or microarray analysis (RNA), mutation analysis or methylation profiling (DNA), or western blotting or other protein measurements or analyses (protein). In this study, mesothelioma samples were collected from vinylidene chloride-exposed male F344/N rats and frozen sections were used for isolation of RNA for global gene expression profiling analysis and qPCR. Spontaneous mesotheliomas from control male F344/N or F344/NTac rats from other NTP studies (codeine, riddelliine, cobalt metal) ${ }^{157-159}$ were available in the NTP frozen tissue repository for analysis (Table L-1). A nontransformed, immortalized mesothelial cell line was used as a nontumor mesothelial control, as described in previous studies ${ }^{160 ; 161}$. Fred-PE cells were originally isolated by Dr. DeAngelo (Environmental Protection Agency) and were prepared from the peritoneal cavities of normal F344 male rats. The identity of these cells was previously confirmed by dual immunostaining with pan-cytokeratin and vimentin. RNA from Fred-PE control mesothelial cells was obtained as a generous gift from Dr. Yongbaek Kim, North Carolina State University. Mesothelioma samples for analysis were chosen based on the criteria of size and tumor viability. Tumor size and viability were chosen as criteria for tumor selection in order to maximize the amount and quality of RNA obtained for microarray analysis. Tumor viability was assessed by histopathology of adjacent NBF-fixed, paraffin-embedded samples matched with the frozen samples, in order to choose samples with minimal to no autolysis, necrosis, or hemorrhage.

\section{L.2.2. Extraction and Quantification of RNA}

Extraction of RNA was performed using the Invitrogen PureLink ${ }^{\circledR}$ Mini Kit (Invitrogen catalog no. 12183018A; Invitrogen Corporation, Carlsbad, CA). Frozen tissue samples were lysed and homogenized in TRIzol ${ }^{\circledR}$ reagent (Invitrogen Corporation) using a rotor-stator homogenizer. Isolation of RNA was performed according to Mini Kit protocol. On-column DNase treatment 
was performed using the PureLink ${ }^{\circledR}$ DNase kit (Invitrogen Corporation) to purify RNA samples. RNA quantification and RNA integrity number were measured on a bioanalyzer (Agilent Technologies, Santa Clara, CA). Samples were aliquoted and stored at $-80^{\circ} \mathrm{C}$ until analyzed.

\section{L.2.3. RNA Labeling, Microarray Hybridization, and Data Processing}

Gene expression analysis was conducted by the National Institute of Environmental Health Sciences, Microarray Core Laboratory using Affymetrix Rat Genome 2302.0 GeneChip $^{\circledR}$ arrays (Affymetrix, Santa Clara, CA). One hundred ng of total RNA were amplified according to the Affymetrix 3' IVT Express kit protocol. Amplified biotin-labeled RNA (12.5 $\mu \mathrm{g})$ was fragmented and $10 \mu \mathrm{g}$ of sample was hybridized to each array according to the Affymetrix Eukaryotic Target Hybridization protocol, using the provided control input RNA. Array slides were double stained with streptavidin and phycoerythrin and washed for antibody amplification according to the GeneChip ${ }^{\circledR}$ Hybridization, Wash, and Stain Kit user manual. Arrays were scanned in an Affymetrix Scanner 3000, and data was obtained using the GeneChip ${ }^{\circledR}$ Command Console Software (AGCC; Version 1.1) using the MAS5 algorithm to generate .CHP files.

Probe intensity data from all arrays were entered into the $\mathrm{R}$ software environment $<$ http://www.R-project.org > directly from .cel files using the R/affy package ${ }^{162}$. Image reconstruction, intensity histograms, and boxplots were used to evaluate data quality. During quality control procedures, image reconstruction indicated that one vinylidene chloride sample had a large smudge (animal 604), so this sample was removed from the analysis. The remaining 19 samples (six Fred-PE cell lines, five spontaneous mesotheliomas, eight vinylidene chlorideexposed mesotheliomas) were normalized using the robust multiarray average (RMA) method to form one expression measure for each gene on each array ${ }^{163}$. The RMA method adjusts the background of perfect match (PM) probes, applies a quantile normalization of the corrected PM values, and calculates final expression measures using the Tukey median polish algorithm. Pairwise comparisons were made for each probeset between Fred-PE cells and each tumor group (spontaneous mesothelioma, vinylidene chloride-exposed mesothelioma) using a bootstrap $t$-test while controlling for the mixed directional false discovery rate (mdFDR) at $0.05(5 \%)$. The mdFDR procedure controls the overall false discovery rate across multiple comparisons and takes into account directional errors corresponding to upregulated or downregulated genes ${ }^{164}$. Statistical calculations were performed in the ORIOGEN software package using 10,000 bootstrap samples ${ }^{165}$.

A core analysis comparing the three experimental groups (Fred-PE mesothelial cells, spontaneous mesotheliomas, and vinylidene chloride-exposed mesotheliomas) was performed to identify differentially expressed genes in vinylidene chloride-exposed and spontaneous mesotheliomas compared to Fred-PE mesothelial cells. A comparison analysis of the significantly differentially expressed genes between spontaneous mesotheliomas and vinylidene chloride-exposed mesotheliomas was then performed to identify relevant biologic functions, canonical pathways, and transcription factor activation. Through testing for the association of gene products with a curated database of biological networks [Ingenuity Pathways Analysis ${ }^{\mathrm{TM}}$ (IPA) version 9.0; Ingenuity Systems, Inc., Redwood City, CA] <http://www.ingenuity.com/>, overrepresented gene categories were identified. Significantly differentially expressed genes $(\mathrm{P}<0.001)$ in the IPA core analysis were then grouped by pathways to account for upstream and downstream effectors as well as overlapping pathways. Upstream activation was based on an IPA Z-score of greater than 2.0 with no bias. All .cel files are available in the Chemical Effects 
in Biological Systems database

<http://www.niehs.nih.gov/research/resources/databases/cebs/index.cfm>.

\section{L.3. Results}

Global gene expression analysis enabled the identification of distinct genomic signatures that differentiated between mesotheliomas in vinylidene chloride-exposed animals and spontaneous mesotheliomas in control animals. Using a principal components analysis, there was distinct clustering of samples within each experimental group, while there was clear separation of samples between each experimental group, based on significantly differentially expressed genes (Figure L-1). Using Fred-PE mesothelial cells as a baseline for gene expression, a comparison analysis between spontaneous mesotheliomas and mesotheliomas in vinylidene chloride-exposed animals showed that of the 31,099 probesets on the array, the two tumor groups shared 10,372 probesets, while 3,764 probesets were unique to vinylidene chloride-exposed mesotheliomas and 3,612 probesets were unique to spontaneous mesotheliomas. Of the 10,372 shared probesets, 9,568 were mapped to known genes in the IPA database and 7,454 were considered analysis ready according to IPA based on a threshold of $\mathrm{P}<0.001$ and filtering for duplicates. IPA core analysis was used to correlate the 7,454 probesets with relevant biological functions. Biological functions representative of the top up and downregulated genes in both tumor groups included cellular development, cell and tissue morphology, organismal injury, embryonic development, organ and tissue development, inflammatory response, cellular growth and proliferation, and cell cycle regulation, with many of the probesets showing overlapping biological functions in multiple categories, while overrepresentation of DNA replication, recombination, and repair was observed as statistically significant in mesotheliomas from vinylidene chloride-exposed animals and not in spontaneous mesotheliomas (Figure L-2).

There was significant differential expression of several oncogenes, growth factors, cell cycle regulators, embryonic genes, cell survival genes, and solute carrier molecules in both spontaneous and vinylidene chloride-exposed mesotheliomas compared to Fred-PE cells ( $\mathrm{P}<0.001$ ) (Table L-2). There was significant overlap of genes associated with cell growth and

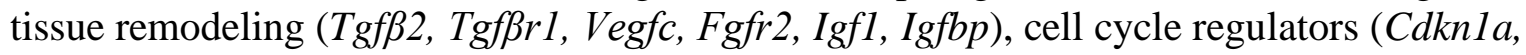
$C d k n 1 b)$, oncogenes and proto-oncogenes (Mafb, Fos, Junb, Lyn), RAS-Mapk pathway mediators (Rasd1, Rnd, Prkcb, Mapk12), tumor suppressor genes (Tp53, Lats2), adhesion molecules (Epcam, Cdh22, Ctnnb1, Itgb2), apoptosis genes (Gadd45b, Bcl2a1), developmental genes (Plac8, Wnt4, Plau, Gata5), transporters and solute carriers (Slc7, Slc28, Abc), mesothelial cell markers (Krt18/19, Des) and genes associated with oxidative stress (Duox, Gpx2), compared to Fred-PE cells. In many cases, the expression of these genes was fairly similar between spontaneous and vinylidene chloride-exposed mesotheliomas, with both tumor types showing overlapping of genes associated with multiple categories. However, there were noticeable differences in the expression of some genes from each tumor group.

Mesotheliomas from control animals and vinylidene chloride-exposed animals shared genes associated with the overrepresented biologic category inflammatory response as involved in tumorigenesis (Figure L-2). Genes associated with inflammatory response included chemokines (Ccl5/6/11/27, Cxcl9/11), cytokines and cytokine receptors (Il1rn, Il6r, Il10/18/24/34, Tnfrsf11b, Cd40, Il1b, Il7r), cell surface receptors (Fcer, Fcgr, S1pr1, Stab1, Cd163, Cd68, Cd53, Clec, Cd36), pattern recognition receptors ( $T l r 2 / 7 / 8, M r c 1)$, interferon pathway mediators (Ifngrl, Irf5, 
Irf9, Ifitml), activated macrophage products (Chi3ll, Sparcll, Clqa, Clqb, S100a9), complement factors (Clqa/b, Cfh, Serping 1), and a variety of inflammatory mediators (Aifl, Ptgds1/2, Lyz2, Mcpt10, Tdo2, Ubd, Cybb, Pla2g2a, Lyvel, Ddx60) compared to Fred-PE cells $(\mathrm{P}<0.001)$ (Table L-3). There was differential expression of several of these shared genes between tumor groups, including upregulation of proinflammatory chemokines $(\mathrm{Ccl} 5, \mathrm{Ccl} 6$, Cxcl9) and decreased expression of anti-inflammatory cytokines $(I l 10, I l 18, I l 24)$. There was higher upregulation of genes associated with tissue damage (Tlr2, Mrcl, Pla2g2a, Dpt) and damage-associated molecular pattern (DAMP) molecules (Mrc1, Lyve1, S100a8, S100a9), in vinylidene chloride-exposed mesotheliomas.

In contrast to the above shared overrepresented pathways, there were several canonical pathways associated with inflammation and immune response that were significantly overrepresented in mesotheliomas from vinylidene chloride-exposed animals compared to Fred-PE cell line control $(\mathrm{P}<0.05$ ), which were not significantly overrepresented in spontaneous tumors (Figure L-3). These included proinflammatory pathways such as PI3K/AKT signaling (Ccl5, Plac8, Gnai3, Nfkb2), the NF-kB signaling pathway (Illr2, Il33, Egf, Ghr, Plcg2, Tlr4), IL-8 (Irak2, Myl2, Hmox1, Prkd3, Mmp2, Mmp9, Gnai3) and IL-12 (Prkd3, Apod, S100a8, Rbp4, Pik3r3, Prkce) interleukin responses, Fc receptor signaling (Vav3, Fcgr2b, Plcg2, Sos1, Cd79b, Pkpd1, Mapk9), and NK and DC signaling (Klrc2, Pak2, Acta1, Actc1, Camk2b, Cd69, Faslg, Tlr4, Pak4), among others (Table L-3 and Figure L-3). While spontaneous mesotheliomas and mesotheliomas from vinylidene chloride-exposed animals shared similar expression of a number of genes in these categories compared to Fred-PE cells, based on canonical pathway involvement, there was significant overrepresentation of pathways associated with a proinflammatory phenotype and immune dysfunction in mesotheliomas from vinylidene chloride-exposed animals. Select genes from these pathways were validated by qPCR (Table L-4).

\section{L.4. Discussion}

Comparison of global gene expression profiling of mesotheliomas arising in male F344/N rats exposed to vinylidene chloride, spontaneous mesotheliomas in F344/N rats, and cultured rat mesothelial cells (Fred-PE cells) was performed in order to characterize the molecular features of these tumors and elucidate their chemical-specific gene expression profiles. Global gene expression profiling enabled the separation of these tumors based on their transcriptomic profiles, despite an indistinguishable morphologic difference between spontaneous and vinylidene chloride-exposed mesotheliomas. The principal component analysis (PCA) plot illustrating statistically significantly differentially expressed genes showed clear clustering of samples within groups, and separation of experimental groups. Furthermore, variations in site, vehicle, and dose did not significantly impact the global gene expression analysis in this study. Spontaneous mesotheliomas were obtained from control animals in three 2-year NTP bioassays that used different routes of administration (gavage, feed, and inhalation), and three of the five spontaneous tumors were collected from different sites within the same animal (cobalt metal study) (Table L-1). Regardless of these variables, the spontaneous tumors showed tight clustering and overlap on the PCA. In addition, the three spontaneous tumor samples obtained from the single animal overlapped and admixed with the tumor samples from the other studies (riddelliine and codeine), indicating that the tumor samples from the single animal did not cluster together. In terms of mesotheliomas from vinylidene chloride-exposed animals, samples did not cluster based on exposure concentration or site of collection. Finally, in terms of the Fred-PE cell 
line control, it is well known that variations in RNA collection, time in culture, cell passage, and other in vitro factors when using these cells may contribute to variation in gene expression. However, the Fred-PE samples clustered very tightly together, and neither passage number nor RNA isolation variables significantly impacted gene expression analysis in this study.

Similarities between spontaneous mesotheliomas and those from vinylidene chloride-exposed animals primarily involved genes associated with tumorigenesis. Commonly affected biologic functions involved a number of similarly expressed oncogenes, tumor suppressor genes, growth factors, embryonic genes, and apoptosis genes in both tumor groups (Table L-2). For example, there was consistent representation of the $T g f \beta$ and $I g f$ pathways in mesotheliomas from vinylidene chloride-exposed and control rats; these pathways are important in tissue remodeling of many organs during disease and tumorigenesis, including mesothelioma ${ }^{166}$. However, differences in common pathways between tumors from control and vinylidene chloride-exposed animals were often noted; for example, overrepresentation of DNA replication, recombination, and repair was observed as a statistically significantly overrepresented biologic function only in mesotheliomas from vinylidene chloride-exposed animals, suggesting an association of these genes with vinylidene chloride exposure that may reflect differences in DNA repair between the two tumor groups. Furthermore, differences in the expression of individual genes from shared overrepresented biologic functions were also noted. For example, dermatopontin $(D p t)$, which is known to interact with $T g f \beta$ to enhance its biologic activity ${ }^{167}$, was markedly upregulated in mesotheliomas from vinylidene chloride-exposed animals compared to controls (Table L-4). Based on significantly overrepresented canonical pathways, vinylidene chloride-exposed mesotheliomas were distinguished from spontaneous mesotheliomas by a proinflammatory phenotype and immune dysfunction. While the exact effects of vinylidene chloride on mesothelial cells are not known, the increased incidence of mesotheliomas in the 2-year study resulting from vinylidene chloride exposure suggests that long-term exposure to vinylidene chloride directly or indirectly affects mesothelial cell function. It has been shown that exposure to vinylidene chloride results in saturation of the glutathione pathway and the generation of reactive vinylidene chloride metabolites (1,1-diethylene oxide, chloroacetyl chloride), which have potential to cause tissue damage ${ }^{142}$. Inflammation is also a well-known contributor to mesotheliomagenesis ${ }^{139-141}$, consistent with the overrepresentation of genes associated with immune dysregulation, inflammation, and tissue damage observed in this study associated with vinylidene chloride-exposed mesotheliomas. Several of the pathways that were significantly overrepresented in mesotheliomas from vinylidene chloride-exposed animals and not observed in spontaneous mesothelioma involved well-known proinflammatory pathways such as the $\mathrm{NF}_{\mathrm{K}} \mathrm{B}$ pathway, and the IL-8/Il-12 proinflammatory pathways. The $\mathrm{NF}_{\mathrm{K}} \mathrm{B}$ pathway is a key orchestrator between pathways mediating cell stress, inflammation, and cancer ${ }^{168}$. IL-8 plays a major role in chemotaxis of inflammatory cells, phagocytosis, and angiogenesis ${ }^{169}$, and IL-12 stimulates production of interferon-gamma (IFN $\gamma$ ) and tumor necrosis factor alpha (TNFa) from cytotoxic T cells and natural killer (NK) cells ${ }^{170}$. Activation of these cytotoxic pathways can play a role in cytotoxicity and apoptosis in the innate and adaptive immune response as well as in response to neoplastic disease. Direct damage to mesothelial cells from inflammation or reactive metabolites can lead to cell proliferation and/or innate immune response activation. Responses such as these have been associated with mesothelial cell proliferation ${ }^{143}$. Chronic inflammation (primarily due to pulmonary asbestosis) is a well-known risk factor in human mesothelioma and is known to play a role in carcinogenic transformation and progression. Histologic evidence of inflammation is generally a component of human mesothelioma; in this study, minimal evidence of 
inflammation was present in mesotheliomas from control and vinylidene chloride-exposed animals, and there was not a significant difference in inflammation between the tumor groups. However, previous gene expression analysis in spontaneous mesothelioma has shown that inflammatory and immune response pathways are overrepresented, despite a relative lack of a significant histologically evident inflammation ${ }^{171}$. This is consistent with what is being reported in the current study, with an increased representation of these proinflammatory pathways and immune dysfunction in mesotheliomas from vinylidene chloride-exposed animals.

Key differences in differential gene expression observed between spontaneous mesotheliomas and mesotheliomas occurring in vinylidene chloride-exposed animals differentiated these tumors from each other based on their global transcriptomic profiles, despite indistinguishable morphology. Furthermore, these data provide important mechanistic information regarding genomic alterations associated with chemical exposure. These genomic studies provide a better understanding of the molecular features of mesotheliomas arising in vinylidene chloride-exposed F344/N rats.

Table L-1. Spontaneous and Vinylidene Chloride-Exposed Malignant Mesotheliomas from Male F344/N Rats Used for Genomic Profiling

\begin{tabular}{llclll}
\hline \multicolumn{1}{c}{ Dose } & \multicolumn{1}{c}{ Study } & Animal Number & Frozen ID & Weight (g) & Location \\
\hline Control & Riddelliine & 5 & SO2130 & 0.5200 & Peritoneum \\
Control & Codeine & 19 & MB 194 & 1.0000 & Peritoneum \\
Control & Cobalt metal & 34 & BW 4719 & 1.1050 & Peritoneum \\
Control & Cobalt metal & 34 & BW 4721 & 0.5179 & Peritoneum \\
Control & Cobalt metal & 34 & BW 4723 & 0.5406 & Testes, capsule \\
$50 \mathrm{ppm}$ & Vinylidene chloride & 401 & BW 2457 & 0.7086 & Peritoneum \\
$50 \mathrm{ppm}$ & Vinylidene chloride & 401 & BW 2447 & 0.3128 & Mesentery \\
$50 \mathrm{ppm}$ & Vinylidene chloride & 402 & BW 2304 & 1.1392 & Mesentery \\
$100 \mathrm{ppm}$ & Vinylidene chloride & 601 & BW 2287 & 1.2258 & Testes, capsule \\
$100 \mathrm{ppm}$ & Vinylidene chloride & 613 & BW 2353 & 0.3700 & Testes, capsule \\
$100 \mathrm{ppm}$ & Vinylidene chloride & 632 & BW 2259 & 0.9484 & Testes, capsule \\
$100 \mathrm{ppm}$ & Vinylidene chloride & 640 & BW 2281 & 0.9158 & Testes, capsule \\
$100 \mathrm{ppm}$ & Vinylidene chloride & 646 & BW 2276 & 0.9109 & Testes, capsule \\
\hline
\end{tabular}

Table L-2. Selected Significantly Expressed Pathways in Mesotheliomas from Vinylidene ChlorideExposed and Control F344/N Rats Compared to Fred-PE Cells $(P<0.001)^{\mathrm{a}}$

Gene Name

\begin{tabular}{|c|c|c|}
\hline $\begin{array}{c}\text { Gene } \\
\text { Symbol }\end{array}$ & Spontaneous & $\begin{array}{l}\text { Vinylidene } \\
\text { Chloride- } \\
\text { Exposed }\end{array}$ \\
\hline
\end{tabular}

Growth Factors

Transforming growth factor, beta 2

$\operatorname{Tg} f \beta 2 \quad-18.77 \quad-18.94$

Transforming growth factor, beta receptor 1

$\operatorname{Tgf\beta r} 1$

2.07

1.80

Transforming growth factor, beta-induced, $68 \mathrm{kDa}$

$T g f \beta i$

39.53

48.79

Vascular endothelial growth factor $\mathrm{C}$

Vegfc

$-7.26$

$-8.00$ 


\begin{tabular}{|c|c|c|c|}
\hline Gene Name & $\begin{array}{c}\text { Gene } \\
\text { Symbol }\end{array}$ & Spontaneous & $\begin{array}{c}\text { Vinylidene } \\
\text { Chloride- } \\
\text { Exposed }\end{array}$ \\
\hline Fibroblast growth factor receptor 2 & $F g f r 2$ & -1.79 & -1.53 \\
\hline Insulin-like growth factor 1 (somatomedin C) & Igfl & 17.04 & 37.54 \\
\hline Insulin-like growth factor 2 binding protein 1 & Igf $2 b p l$ & -2.80 & -2.70 \\
\hline Insulin-like growth factor binding protein 3 & $I g f b p 3$ & 32.46 & 29.23 \\
\hline Insulin-like growth factor binding protein 6 & Igfbp6 & 9.96 & 8.42 \\
\hline \multicolumn{4}{|l|}{ Cell Cycle } \\
\hline Cyclin-dependent kinase inhibitor 1A (p21, Cip1) & Cdknla & -4.60 & -6.67 \\
\hline Cyclin-dependent kinase inhibitor 1B (p27, Kip1) & $C d k n 1 b$ & -5.68 & -4.95 \\
\hline \multicolumn{4}{|l|}{ Oncogenes/Proto-oncogenes } \\
\hline v-Maf musculoaponeurotic fibrosarcoma oncogene homolog B (avian) & $M a f b$ & 23.48 & 26.02 \\
\hline FBJ murine osteosarcoma viral oncogene homolog & Fos & -9.09 & -7.02 \\
\hline Jun B proto-oncogene & Junb & -4.51 & -6.29 \\
\hline v-Yes-1 Yamaguchi sarcoma viral related oncogene homolog & Lyn $(v-y e s)$ & 5.02 & 5.44 \\
\hline \multicolumn{4}{|l|}{ RAS-Mapk Pathway } \\
\hline RAS, dexamethasone-induced 1 & Rasdl & 38.52 & 14.18 \\
\hline Rho family GTPase 1 & Rndl & -13.26 & -8.60 \\
\hline Rho family GTPase 3 & Rnd3 & -11.37 & -28.00 \\
\hline Protein kinase $\mathrm{C}$, beta & Prkcb & 68.52 & 53.86 \\
\hline Mitogen-activated protein kinase 9 & Mapk9 & -1.15 & 1.34 \\
\hline Mitogen-activated protein kinase 12 & Mapk12 & 5.53 & 8.21 \\
\hline Mitogen-activated protein kinase-activated protein kinase 3 & Mapkapk3 & 15.13 & 11.95 \\
\hline \multicolumn{4}{|l|}{ Tumor Suppressor Genes } \\
\hline Tumor protein $\mathrm{p} 53$ & $\operatorname{Tp} 53$ & -2.20 & -2.80 \\
\hline Large tumor suppressor homologue 2 & Lats2 & -1.82 & -1.87 \\
\hline \multicolumn{4}{|l|}{ Adhesion Molecules, Integrins, Catenins } \\
\hline Epithelial cell adhesion molecule & Epcam & 21.48 & 12.63 \\
\hline Cadherin 22, type 2 & Cdh22 & 128.56 & 22.82 \\
\hline Catenin (cadherin-associated protein), beta $1,88 \mathrm{kDa}$ & Ctnnbl & -1.41 & -2.09 \\
\hline Integrin, beta 2 (complement component 3 receptor 3 and 4 subunit) & $\operatorname{Itg} b 2$ & 23.11 & 33.51 \\
\hline \multicolumn{4}{|l|}{ Growth Arrest, Apoptosis } \\
\hline Growth arrest and DNA-damage-inducible, beta & Gadd $45 b$ & -10.34 & -8.88 \\
\hline BCL2-related protein A1 & Bcl2al & 14.42 & 13.86 \\
\hline Fas apoptotic inhibitory molecule 3 & Faim3 & 9.43 & 17.41 \\
\hline
\end{tabular}

Embryonic/Cell Development (Cell Migration, Differentiation) 
Vinylidene Chloride, NTP TR 582

\begin{tabular}{lccc}
\hline \multicolumn{1}{c}{ Gene Name } & $\begin{array}{c}\text { Gene } \\
\text { Symbol }\end{array}$ & Spontaneous & $\begin{array}{c}\text { Vinylidene } \\
\text { Chloride- } \\
\text { Exposed }\end{array}$ \\
\hline Placenta-specific 8 & Plac8 & 44.99 & 214.04 \\
Wingless-type MMTV integration site family, member 4 & Wnt4 & 10.91 & 6.00 \\
Plasminogen activator, urokinase & Plau & 18.08 & 21.11 \\
GATA binding protein 5 & Gata5 & 14.53 & 7.91 \\
\hline Adhesion Molecules and Matrix Remodeling Genes & & & \\
Collagen, type VI, alpha 1 & Col6al & 57.66 & 35.84 \\
Collagen, type VI, alpha 2 & Col6a2 & 65.56 & 26.35 \\
Integrin, beta 2 (complement component 3 receptor 3 and 4 subunit) & Itgb2 & 23.11 & 33.51 \\
\hline Transporters and Solute Carriers & & & \\
Solute carrier family 7, member 7 & Slc7A7 & 14.24 & 11.70 \\
Solute carrier family 7, member 9 & Slc7A9 & 12.44 & 9.67 \\
Solute carrier family 28, member 2 & Slc28A2 & 14.32 & 26.94 \\
ATP-binding cassette, subfamily A (ABC1), member 4 & Abca4 & 33.55 & 26.82 \\
\hline Mesothelial Cell Markers & & & \\
Cytokeratin 18 & Krt18 & 145.17 & 75.19 \\
Cytokeratin 19 & Krt19 & 440.67 & 299.57 \\
Thrombomodulin & Thbd & 27.52 & 49.60 \\
Desmin & Des & 22.17 & 26.26 \\
\hline Reactive Oxygen Species & & & \\
Dual oxidase 2 & Duox2 & 87.37 & 44.62 \\
Glutathione peroxidase 2 (gastrointestinal) & Gpx2 & 88.16 & 68.67 \\
\hline Nomeric values expresed are fold changes in gene expression compar & \\
\hline
\end{tabular}

${ }^{a}$ Numeric values expressed are fold changes in gene expression compared to Fred-PE mesothelial cells. 
Table L-3. Selected Differentially Expressed Genes Associated with Inflammation and Immune Response in Vinylidene Chloride-Exposed and Spontaneous Mesotheliomas Compared to Fred-PE Cells $(\mathbf{P}<0.001)^{\mathrm{a}}$

\section{Gene Name}

Vinylidene

Gene Symbol Spontaneous Chloride-

Exposed

\section{Chemokines}

Chemokine (C-C motif) ligand 5

Ccl5

19.0

35.6

Chemokine (C-C motif) ligand 6

Ccl6

84.5

143.6

Chemokine (C-C motif) ligand 11

Ccll1

742.5

457.6

Chemokine (C-C motif) ligand 27

Ccl27

14.6

7.3

Chemokine (C-X-C motif) ligand 9

Cxcl9

6.6

24.0

Chemokine (C-X-C motif) ligand 11

Cxcll1

6.5

19.1

\section{Interleukin Signaling}

Interleukin 1 receptor, type 2

$\begin{array}{lll}\text { Ill } r 2 & - & 3.2\end{array}$

Interleukin 1 receptor antagonist

Ill rn

10.0

5.5

Interleukin 1 beta

$I l 1 b$

2.04

3.03

Interleukin 6 receptor

Il6r

7.4

6.0

Interleukin 7 receptor

$I l 7 r$

6.687

6.11

Interleukin 10

Il10

17.9

11.5

Interleukin 18 (interferon-gamma-inducing factor)

Ill 18

43.5

28.9

Interleukin 24

Ill24

25.5

10.6

Interleukin 33

Il33

$-$

21.1

Interleukin 34

Ill34

9.0

5.5

Interleukin-1 receptor-associated kinase 2

Irak2

$-$

2.3

Tumor necrosis factor receptor superfamily, member $11 \mathrm{~b}$

CD40 molecule, TNF receptor superfamily member 5

Tnfrsfl1b

42.4

65.7

Myosin, light chain 2, regulatory, cardiac, slow

Cd40

9.1

3.0

Heme oxygenase 1

Myl2

34.2

Epidermal growth factor

Hmoxl

2.7

Growth hormone receptor

Egf

2.4

Ghr

7.4

CD74 molecule, major histocompatibility complex, class II

Cd74

440.5

398.0

\section{Natural Killer Cell and Dendritic Cell Signaling}

$\mathrm{SH} 2$ domain containing $1 \mathrm{~A}$

$\begin{array}{ccc}\text { Sh2dla } & - & 3.8 \\ \text { Vav3 } & - & 2.6 \\ \text { Fcerla } & 37.8 & 35.5 \\ \text { Fcerlg } & 104.6 & 93.9 \\ \text { Fcgr2a } & 46.1 & 70.4\end{array}$




\begin{tabular}{|c|c|c|c|}
\hline Gene Name & Gene Symbol & Spontaneous & $\begin{array}{l}\text { Vinylidene } \\
\text { Chloride- } \\
\text { Exposed }\end{array}$ \\
\hline Fc fragment of IgG, low affinity IIb, receptor (CD32) & Fcgr $2 b$ & 195.4 & 260.5 \\
\hline Fc fragment of IgG, low affinity IIIa, receptor (CD16a) & Fcgr3a & 54.9 & 24.7 \\
\hline Killer cell lectin-like receptor subfamily C, member 2 & Klrc2 & - & 2.1 \\
\hline Killer cell lectin-like receptor subfamily C, member 3 & Klrc3 & - & 2.1 \\
\hline Killer cell lectin-like receptor subfamily D, member 1 & $K l r d 1$ & 6.5 & 9.3 \\
\hline P21-activated kinase 4 & Pak4 & - & -2.16 \\
\hline Phospholipase C, gamma 2 (phosphatidylinositol-specific) & Plcg2 & - & 2.1 \\
\hline Protein kinase D3 & $\operatorname{Prkd} 3$ & - & 1.7 \\
\hline Protein kinase $\mathrm{C}$, theta & Prkcq & 5.2 & 8.7 \\
\hline P21 protein (Cdc42/Rac)-activated kinase 2 & Pak2 & - & 1.7 \\
\hline Actin, alpha 1 , skeletal muscle & Actal & - & 77.6 \\
\hline Actin, alpha, cardiac muscle 1 & Actcl & - & 8.4 \\
\hline Calcium/calmodulin-dependent protein kinase II alpha & Camk2a & -1.3 & 3.0 \\
\hline Calcium/calmodulin-dependent protein kinase II beta & Camk2b & - & 4.8 \\
\hline CD69 molecule & $C d 69$ & - & 4.5 \\
\hline Fas ligand (TNF superfamily, member 6) & Faslg & - & 2.2 \\
\hline Hematopoietic cell signal transducer & Hcst & 21.1 & 23.7 \\
\hline \multicolumn{4}{|l|}{ Pattern Recognition Receptors } \\
\hline Toll-like receptor 2 & $T l r 2$ & 8.3 & 10.1 \\
\hline Toll-like receptor 4 & $T l r 4$ & - & 1.8 \\
\hline Toll-like receptor 7 & $\operatorname{Tlr} 7$ & 10.7 & 14.0 \\
\hline Toll-like receptor 8 & $T l r 8$ & 25.7 & 31.7 \\
\hline Mannose receptor, c-type 1 & Mrcl & 78.6 & 113.0 \\
\hline \multicolumn{4}{|l|}{ Interferon Pathway Mediators } \\
\hline Interferon gamma receptor 1 & Ifngrl & 2.3 & 2.7 \\
\hline Interferon regulatory factor 5 & $\operatorname{Irf5}$ & 2.2 & 2.1 \\
\hline Interferon regulatory factor 9 & $\operatorname{Irf9}$ & 4.0 & 2.9 \\
\hline Interferon induced transmembrane protein 1 & Ifitm 1 & 20.2 & 27.5 \\
\hline \multicolumn{4}{|l|}{ Inflammatory Mediators/Enzymes/Miscellaneous } \\
\hline Allograft inflammatory factor 1 & Aifl & 171.6 & 115.8 \\
\hline Apolipoprotein D & Apod & - & 3.897 \\
\hline Phospholipase C, gamma 2 & Plcg2 & - & 2.1 \\
\hline Matrix metalloproteinase 2 & Mmp2 & - & 16.7 \\
\hline Matrix metalloproteinase 9 & Mmp9 & - & 2.7 \\
\hline
\end{tabular}




\begin{tabular}{|c|c|c|c|}
\hline Gene Name & Gene Symbol & Spontaneous & $\begin{array}{l}\text { Vinylidene } \\
\text { Chloride- } \\
\text { Exposed }\end{array}$ \\
\hline Guanine nucleotide-binding protein, alpha subunit 3 & Gnai3 & - & 2.81 \\
\hline Nuclear factor of kappa light polypeptide gene enhancer in b-cells 2 & $N f k b 2$ & - & -1.52 \\
\hline Prostaglandin D2 synthase $21 \mathrm{kDa}$ & Ptgds & 270.0 & 144.6 \\
\hline Prostaglandin-endoperoxide synthase 1 & Ptgsl & 25.6 & 23.7 \\
\hline Prostaglandin-endoperoxide synthase 2 & Ptgs 2 & -91.0 & -58.1 \\
\hline Placenta-specific 8 & Plac8 & 44.99 & 214.04 \\
\hline Lysozyme 2 & $l y z 2$ & 217.9 & 209.0 \\
\hline Mast cell protease 10 & Mcpt10 & 226.3 & 68.9 \\
\hline Tryptophan 2,3-dioxygenase & Tdo2 & 218.9 & 60.5 \\
\hline Ubiquitin D & $U b d$ & 173.2 & 274.0 \\
\hline Cytochrome b-245, beta polypeptide & $C y b b$ & 21.3 & 30.6 \\
\hline Phospholipase A2, group IIA & Pla2g2a & 86.1 & 110.4 \\
\hline Dermatopontin & $D p t$ & 14.73 & 57.77 \\
\hline Protein kinase $\mathrm{C}$, epsilon & Prkce & -2.18 & - \\
\hline Phosphoinositide-3-kinase, regulatory subunit 3 & Pik3r3 & -1.8 & - \\
\hline Lymphatic vessel endothelial hyaluronan receptor 1 & Lyve1 & 87.0 & 247.7 \\
\hline Chitinase 3-like 1 & Chi3ll & 164.4 & 29.9 \\
\hline SPARC-like 1 (hevin) & Sparcll & 71.0 & 147.8 \\
\hline Complement component $1, \mathrm{q}$ subcomponent, A chain & Clqa & 134.5 & 133.4 \\
\hline Complement component $1, \mathrm{q}$ subcomponent, B chain & $C l q b$ & 110.9 & 102.9 \\
\hline Complement factor $\mathrm{H}$ & $C f h$ & 285.37 & 223.67 \\
\hline S100 calcium binding protein $\mathrm{A} 8$ & $S 100 a 8$ & 2.7 & 18.5 \\
\hline S100 calcium binding protein A9 & S100a9 & 4.0 & 19.2 \\
\hline Serpin peptidase inhibitor, clade $\mathrm{G}$ & Serpingl & 265.08 & 289.04 \\
\hline Protein phosphatase 1 , regulatory subunit $3 \mathrm{~A}$ & Ppp1r3a & - & 38.986 \\
\hline Retinol binding protein 4 , plasma & Rbp4 & - & 15.544 \\
\hline \multicolumn{4}{|l|}{ Cell Surface Markers/Receptors } \\
\hline Sphingosine-1-phosphate receptor 1 & Slprl & 25.6 & 48.5 \\
\hline Son of sevenless homolog 1 & Sosl & - & -1.2 \\
\hline CD79b molecule, immunoglobulin-associated beta & $C d 79 b$ & - & -1.2 \\
\hline Stabilin 1 & Stabl & 55.0 & 36.2 \\
\hline 3-phosphoinositide dependent protein kinase-1 & Pkpdl & - & -1.4 \\
\hline Fc fragment of IgG, high affinity Ia, receptor (CD64) & Fcgrla & 29.3 & 29.3 \\
\hline Fc fragment of IgG, low affinity IIa, receptor (CD32) & Fcgr $2 a$ & 40.8 & 70.4 \\
\hline CD14 molecule & Cd14 & - & 2.7 \\
\hline
\end{tabular}




\begin{tabular}{|c|c|c|c|c|c|}
\hline \multicolumn{3}{|c|}{ Gene Name } & Gene Symbol & I Spontaneous & $\begin{array}{l}\text { Vinylidene } \\
\text { Chloride- } \\
\text { Exposed }\end{array}$ \\
\hline \multicolumn{3}{|l|}{ CD53 molecule } & $C d 53$ & 137.2 & 139.8 \\
\hline \multicolumn{3}{|l|}{ CD68 molecule } & Cd68 & 29.4 & 34.6 \\
\hline \multicolumn{3}{|l|}{ CD163 molecule } & Cd163 & 46.7 & 132.3 \\
\hline \multicolumn{3}{|c|}{ C-type lectin domain family 4 , member a3 } & Clec4a3 & 92.1 & 73.3 \\
\hline \multicolumn{3}{|c|}{ C-type lectin domain family 4 , member A } & Clec4a & 35.3 & 32.6 \\
\hline \multicolumn{3}{|c|}{ C-type lectin domain family 7 , member A } & Clec7a & 29.1 & 22.8 \\
\hline \multicolumn{3}{|c|}{ C-type lectin domain family 10 , member A } & Clec10a & 48.1 & 54.3 \\
\hline \multicolumn{3}{|c|}{ CD36 molecule (thrombospondin receptor) } & $C d 36$ & 139.7 & 236.3 \\
\hline \multicolumn{6}{|c|}{$\begin{array}{l}\text { aNumeric values expressed are fold changes in gene expression compared to Fred-PE mesothelial cells. } \\
\text {-Not differentially expressed on microarray. }\end{array}$} \\
\hline \multicolumn{6}{|c|}{$\begin{array}{l}\text { Table L-4. Quantitative PCR (qPCR) Validation of Gene Expression Changes on Microarray of } \\
\text { Spontaneous and Vinylidene Chloride-Exposed Mesotheliomas in F344/N Rats }{ }^{\mathrm{a}}\end{array}$} \\
\hline \multirow[t]{2}{*}{ Gene Name } & Gene Symbol & \multicolumn{2}{|c|}{ Spontaneous } & \multicolumn{2}{|c|}{ Vinylidene Chloride-Exposed } \\
\hline & & Microarray & qPCR & Microarray & qPCR \\
\hline Cytokeratin 18 & Krt18 & 162.94 & $1,079.19$ & 75.19 & 473.86 \\
\hline $\begin{array}{l}\text { Epithelial cell adhesion } \\
\text { molecule }\end{array}$ & Epcam & 21.48 & 481.96 & 12.63 & 860.43 \\
\hline $\begin{array}{l}\text { Cyclin-dependent kinase } \\
\text { Inhibitor 1A (p21) }\end{array}$ & Cdknla & -4.6 & -2.88 & -6.67 & -3.97 \\
\hline Fatty acid binding protein 4 & Fabp4 & 72.71 & $2,705.77$ & 251.32 & $12,796.5$ \\
\hline Placenta-specific 8 & Plac8 & 44.99 & $16,744.15$ & 214.04 & $25,150.22$ \\
\hline Synuclein, gamma & Sncg & 9.53 & 745.92 & 25.59 & $3,094.01$ \\
\hline Dermatopontin & $D p t$ & 14.73 & $2,397.67$ & 57.77 & $13,203.71$ \\
\hline Tumor protein p53 & Tp53 & -2.2 & -1.11 & -2.8 & -1.67 \\
\hline
\end{tabular}

${ }^{a}$ Numeric values expressed are fold changes in gene expression compared to Fred-PE mesothelial cells. 


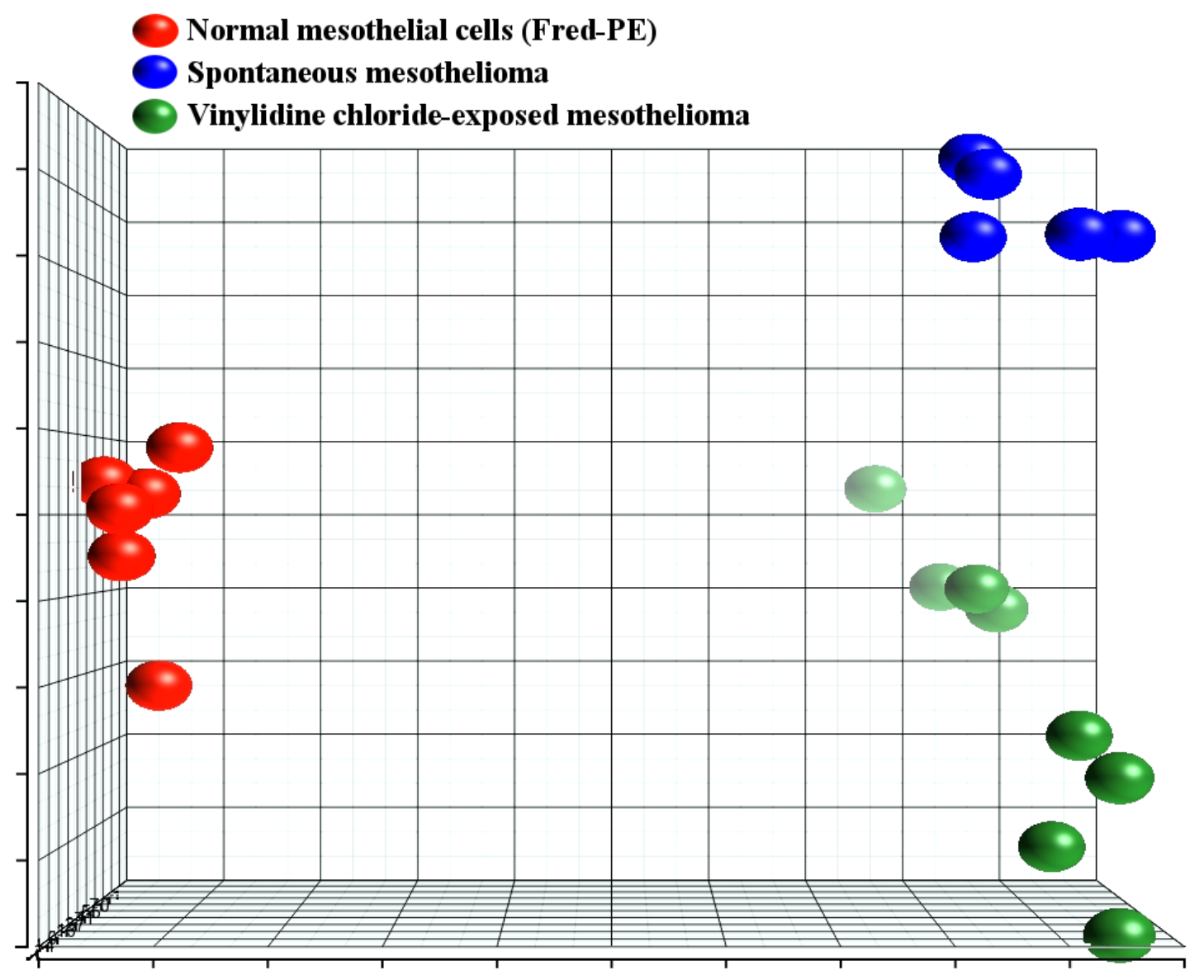

Figure L-1. Principal Component Analysis Comparing Global Gene Profiles of Fred-PE Mesothelial Cells (Red), Spontaneous Mesotheliomas from Control Rats (Blue), and Mesotheliomas from Vinylidene Chloride-Exposed Rats (Green)

Principal component analysis shows significant intergroup similarities in global gene expression and clear separation of experimental groups in space, indicating significant differences between groups in terms of their global gene expression. Principal component analysis is a multivariate data analysis procedure that linearly transforms the original data set $(\mathrm{N}$ genes $\times \mathrm{P}$ samples) so that each principal component $(1 \times \mathrm{P})$ becomes a variable that is a combination of the original variables and is orthogonal to all other principal components. The total variance explained by the principal component analysis is $69.6 \%$. Each axis explains a certain percentage of the variance in the data; the $\mathrm{x}$-axis explains the most variance (52.8\%), the y-axis explains the second most variance (11.4\%), and the $\mathrm{z}$-axis explains the third most variance (5.4\%) between the 19 samples. 


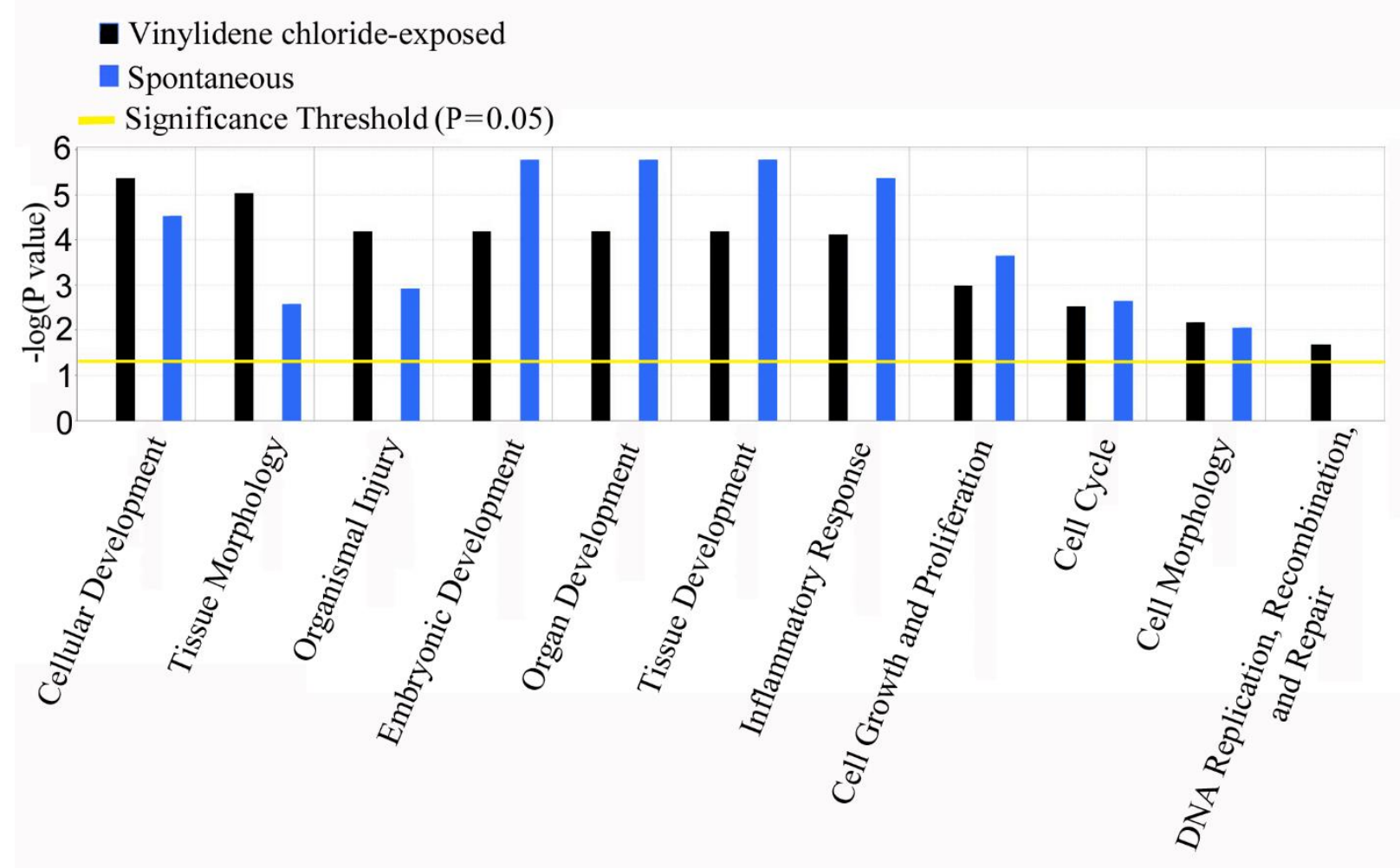

Figure L-2. Top Overrepresented Biologic Functions Related to Tumorigenesis in Spontaneous Mesotheliomas and Mesotheliomas from Vinylidene Chloride-Exposed Male F344/N Rats $(P<0.05)$ 


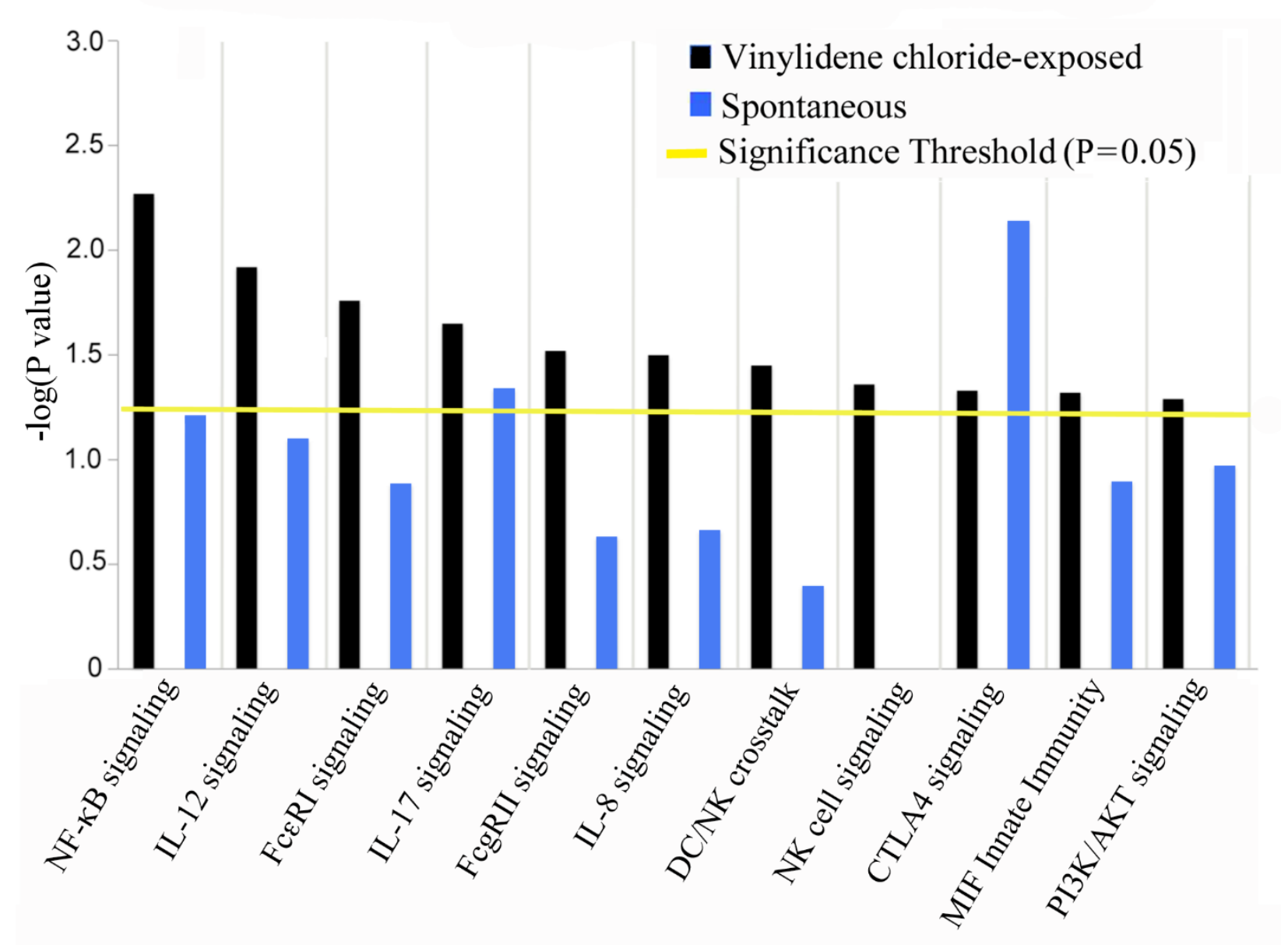

Figure L-3. Significantly Overrepresented Canonical Pathways Related to Inflammation and Immune Dysfunction Not Overrepresented in Spontaneous Mesotheliomas $(P<0.05)$ 


\section{Appendix M. Summary of Peer Review Panel Comments}

On October 29, 2013, the draft Technical Report on the toxicology and carcinogenesis studies of vinylidene chloride received public review by the National Toxicology Program's Technical Reports Peer Review Panel. The review meeting was held at the National Institute of Environmental Health Sciences, Research Triangle Park, NC.

Dr. M.E. Wyde, NIEHS, introduced the studies on vinylidene chloride, a high production volume chemical used to make common household products, artificial turf, pipes, lacquer resins and latex, and flame-resistant carpet backing. Two-week, 3-month, and 2-year inhalation studies were conducted in F344/N rats and B6C3F1/N mice, as well as genetic toxicology studies. The proposed conclusions were clear evidence of carcinogenic activity of vinylidene chloride in male F344/N rats, some evidence of carcinogenic activity of vinylidene chloride in female F344/N rats, and clear evidence of carcinogenic activity of vinylidene chloride in male and female B6C3F1/N mice.

Dr. M.J. Hoenerhoff, NIEHS, described the molecular pathology studies of mesothelioma in vinylidene chloride-exposed $\mathrm{F} 344 / \mathrm{N}$ rats. He provided background information about the use of molecular pathology studies, which generate supplementary and supportive data for NTP on molecular characterization of chemically induced rodent tumors. The gene mutation or expression data help discriminate spontaneous tumors from those of chemical-exposed groups, but are not used for levels-of-evidence conclusions in the NTP Technical Reports.

Mr. W.C. Norman, Patton, Boggs LLP, spoke by telephone on behalf of vinylidene chloride producers. Mr. Norman suggested that the vinylidene chloride bioassays in the draft report did not meet the NTP criteria for clear evidence of carcinogenic activity. He noted that there was a total of 18 cancer bioassays of vinylidene chloride using multiple strains of rats, mice, and hamsters in the literature, and the totality of those data did not show consistent evidence of carcinogenicity. Thus, he noted that the NTP cancer bioassays represent the first that demonstrate an apparent increase in tumors in both sexes of two species.

In addition, he said NTP had used dose levels that exceeded the maximum tolerated dose (MTD) in both rats and mice, noting that NTP and EPA guidance point to the need for caution when viewing cancer bioassays that exceed the MTD and suggested that the observed tumors might have arisen as a consequence of stress placed on the animals by dosing at levels above the MTD. Based on that factor, he said the studies should not be considered adequate for the assessment of carcinogenicity, particularly as the results were so different from the previous studies.

Dr. E. Van Miert, Solvay SA, spoke by telephone and focused on the vinylidene chloride genotoxicity assessment. He proposed that the following statement from the draft technical report is not in line with genotoxicity data in the report and public domain: "The results from a variety of genetic toxicology studies...indicate that vinylidene chloride has mutagenic, clastogenic, and aneugenic properties." He cited several studies referenced in the draft report that indicated negative results with vinylidene chloride as well as the Concise International Chemical Assessment Document 51 from the World Health Organization, a report from the Scientific Committee on Occupational Exposure Limits of the European Commission, and a $2009 \mathrm{REACH}$ [Registration, Evaluation, Authorization and Restriction of Chemicals] dossier of vinylidene 
chloride that suggest no evidence of genotoxicity with vinylidene chloride. He called for more research on the mode of action of vinylidene chloride.

Dr. N. Ball, Dow Chemical Company, spoke on behalf of the vinylidene chloride producers by telephone. He proposed that the experimental design and conduct of the studies do not support the conclusions regarding clear evidence of carcinogenic activity in male rats and male and female mice and some evidence in female rats. He provided two key reasons: (1) both mouse and rat studies exceeded MTD according to NTP and EPA guidance and (2) inadequate dose spacing and lack of a dose providing a no-observed-adverse-effect level (NOAEL). He discussed his concerns in more detail and asked that the Peer Review Panel consider the studies inadequate to assess carcinogenicity to humans.

Dr. Cattley, the first primary reviewer, recommended that the methods and results concerning genetic toxicology testing be revised to account for different methodologies of bacterial mutagenesis assays. He urged NTP to add findings from the molecular pathology appendix to the Results section. He suggested resolution of an apparent discrepancy between the discussion and introduction sections concerning how data from the 1982 NTP Technical Report on vinylidene chloride were referenced. He asked if a statement regarding "increased incidences of systemic neoplasms" referred only to malignant mesotheliomas or to other tumor types and noted that hemangioma is often considered a benign end-stage lesion. He asked that discussion be added concerning the progression between hemangioma and hemangiosarcoma. He recommended that the discussion concerning the mechanism of action of vinylidene chloride account for the lack of in vivo genotoxicity. He said the report should not characterize vinylidene chloride as a "weak initiator of tumorigenesis" without supporting context in the final sentence of the Discussion section.

Regarding the molecular pathology appendix, Dr. Cattley noted that isolated RNA from malignant mesotheliomas induced by vinylidene chloride was compared to the cultured rat mesothelial cell (Fred-PE cell) RNA, and he asked that NTP discuss the potential for bias arising from different RNA isolation parameters for Fred-PE cells. He questioned why the results for the spontaneous mesothelioma in that study were not presented. He recommended adding a figure from Dr. Hoenerhoff's presentation to Appendix L to clarify confusion from Figure L-2. He suggested including discussion and explanation of the relationship between inflammation and risk of mesothelioma as cited in the literature. He suggested that NTP discuss the predicted, if not actual gene expression results, of incubating Fred-PE cells with vinylidene chloride, vinylidene chloride metabolites, or vinylidene chloride plus a metabolic activation system. He found the conclusions in the draft report acceptable and agreed with the levels of evidence.

Dr. Gordon, the second primary reviewer, found the vinylidene chloride study well conducted and the draft report well written. He suggested that the "time to first incidence" data deserved mention in the results section. He noted that the addition of the evaluation of global gene changes for the spontaneous vs. induced mesotheliomas is a major step in the right direction; however, the gene expression and pathway analyses should go beyond stating that a proinflammatory environment was associated with mesotheliomas, given that most cancers are thought to be associated with inflammation. He questioned the conclusion that proinflammatory and immune pathway genes were different for spontaneous vs. induced tumors because the gene expression changes presented in Table L-3 appear similar for those pathways. He suggested that 
Table L-2 needed more definitions. While he would have preferred the study to include some lower doses, he agreed with the conclusions in the draft report.

Dr. Parker, the third primary reviewer, focused his comments on the molecular pathology appendix. He noted that the analysis was done across all genes, so there was strong evidence for the segregation; however, he felt the report should discuss possible factors that could constitute potential sources of bias (e.g., site of the tissue, RNA insolation differences) and include a statement that technical factors were not associated with the gene expression. He noted that there was some segregation in the plot for vinylidene chloride in the principal component analysis (PCA). While that is secondary to the segregation between vinylidene chloride and spontaneous mesothelioma plots, the segregation in the vinylidene chloride plot itself may be important and could potentially be explained by known biological processes. He noted additional methods to illustrate segregation including cross-validation and machine learning techniques. Regarding the oncogenic signatures and inflammatory signatures, he said it was clear that there was significant overlap or enrichment of the genes of interest with these known pathways. However, he asked whether the direction of change supported overexpression or underexpression of those pathways. He suggested that producing a hypothesis or model system about the pathways involved and their direction of change would make the results much stronger. He showed interest for a direct comparison between the vinylidene chloride-exposed and spontaneous mesothelioma microarray datasets; the control dataset may inhibit the detection of other significant pathways. Generally, he agreed with the results of the study.

Dr. Zacharewski, the fourth primary reviewer, also focused on the molecular pathology appendix. He proposed that the global gene profiling study was a valuable, complementary study and could be used to differentiate between spontaneous and treatment-related tumors; however, he suggested the study is not the most appropriate method to use to determine mechanism of action. He did not find the data overly compelling for indicating significant differences between the spontaneous and vinylidene chloride-exposed tumors, and he noted that a PCA is not necessarily a statistical analysis, but more of a classification method. Although the PCA did show some separation, he suggested the separation might have been due to varying treatment of samples (e.g., the RNA was extracted in different ways, tumors were stored for different lengths of time). He suggested there would have been tremendous value in follow-up studies, such as qRT-PCR on individual genes, to demonstrate there were significant differences among the microarrays. He noted that microarrays are "last century's technology" and RNASeq should be employed in the future.

Dr. Cattley added that the discussion regarding the dose-selection rationale for the 2-year study should be expanded to address the reduction in body weights in the male mice and the incidence and severity of nonneoplastic lesions.

Addressing the issue of the decrease in body weight, Dr. Zacharewski asked for clarification about NTP's definition of an "inadequate study." He also asked whether MTD was defined strictly on body weight and survival without looking at any other endpoints. Dr. N.J. Walker, NIEHS, replied that "inadequate" is defined as having major flaws in the design and conduct of a study, and he added that for issues of MTD and dose selection, all available information is considered (e.g., body weight, historic experience); there are no hard and fast guidelines. Dr. Zacharewski asked whether NTP is obliged to follow EPA guidelines, and Dr. Walker stated those guidelines are considered in decision-making, but NTP is not obliged to follow them. 
Dr. Barlow remarked that, based on the results of the 3-month study, a dose between 100 and $200 \mathrm{ppm}$, perhaps $150 \mathrm{ppm}$, should have been used in the 2-year rat study. Upon reviewing the final data, however, he said it was clear that the doses used were appropriate and the study was adequately designed. He had some ambivalence regarding the data for C-cell tumors in female rats to support the call of clear evidence of carcinogenicity, given that there was not a clear dose response, and he suggested a possible change to some evidence. He noted the gene expression information was useful and interesting, but he questioned how the data would be used and whether those studies should be conducted and reported outside of the technical reports. He asked for NTP's response on a public comment regarding genotoxicity statements in the discussion section of the draft report: ".... variety of genetic toxicology studies...indicate that vinylidene chloride has mutagenic, clastogenic, and aneugenic properties." He recommended correction to the statement "fixation quality of the rat testes was poor." He called for more discussion about the additional carcinogenicity studies in the literature that were not considered adequate.

Dr. Cullen mentioned that NTP had not combined the hepatocholangiocellular carcinomas with the primary liver tumors; however, in later draft technical reports, hepatoblastomas were combined with hepatocellular tumors. He asked for NTP's rationale regarding what is grouped together and what is not.

Responding to Dr. Cattley's comments, Dr. Wyde said he would clarify the methodologies for previous studies in the Introduction and Discussion. He would address Dr. Cattley's suggestion to expand the discussion of the dose-selection rationale, and he acknowledged other editorial suggestions. He acknowledged Dr. Cattley's and Dr. Barlow's recommendations to amend the genetic toxicity discussion paragraph.

Dr. Hoenerhoff responded to comments from Dr. Cattley on gene profiling. He acknowledged Dr. Cattley's concern about potential bias from different RNA isolation parameters, but these parameters did not appear to have an impact on altering gene expression profiles. He would address the issue of different methods of isolation between the cell lines and tumors in the Discussion section. Regarding the spontaneous mesotheliomas, he said they were too small to trigger collection during necropsy, as were the female mesotheliomas. He noted that there was not a significant inflammatory component histologically in the study, and there was not a significant difference in inflammation between the spontaneous and exposed group mesotheliomas. However, the gene expression data suggested that there is a proinflammatory component in vinylidene chloride mesotheliomas and those issues would be discussed further in the report. Regarding the potential gene expression results of incubating Fred-PE cells with vinylidene chloride or vinylidene chloride metabolites, he noted it would be valuable for followup in vitro validation experiments or more focused functional experiments.

Dr. Wyde responded to Dr. Gordon's comments, stating that Dr. Hoenerhoff would address the time-to-tumor incidence data in the Results section. He agreed with Dr. Gordon about the global gene expression analysis being the first step in developing more focused, hypothesis-driven experiments to address specific questions. The gene expression experiment results suggest that there is an increased proinflammatory or immune dysfunction signature, and the Discussion would be updated to add more information on how that may influence tumorigenesis in the study. He noted that an additional figure, as seen in his presentation, would be added to Appendix L. He would address expanding Table L-3 to include more of the differentially 
expressed genes and genes that are exclusively expressed in vinylidene chloride mesotheliomas compared to spontaneous mesotheliomas.

Addressing Dr. Parker's comments, Dr. Hoenerhoff said the PCA plot included all of the genes on the array. For the Discussion section, he would address particular factors influencing gene expression that are technical or biologically related to tumor site, dose, or method of RNA extraction. Regarding the variation within the vinylidene chloride treatment group in principal component 3, he said there is some variation in those samples. Additional analysis solely on the vinylidene chloride group could identify how those segregate and if it has any relationship to any other gene expression that might identify a subset of tumors or some kind of biological difference. For future studies, he would consider Dr. Parker's suggestion about additional studies for validation, cross-validation, or machine learning. He said discussion would be added regarding the directionality of the genes associated with the proinflammatory signature. For the comment about a direct comparison of vinylidene chloride mesotheliomas with spontaneous mesotheliomas, he noted that the results from a direct comparison are difficult to interpret without the context of the normal tissue. NTP could consider a direct comparison in future studies to see if additional information can be gained.

Addressing Dr. Zacharewski's comments, Dr. Hoenerhoff said Table L-2 and Table L-3 would be amended to include additional genes from a figure in his presentation. This figure would also be added to demonstrate those overrepresented pathways and the genes within those pathways. He said NTP agrees with the value of RNASeq, and that those assays are being implemented in other studies.

Dr. Zacharewski asked whether the microarray data sets were submitted to public repositories such as GEO (Gene Expression Omnibus, NCBI). Dr. Hoenerhoff said they would be submitted to GEO, and that this particular data set is available in CEBS (Chemical Effects in Biological Systems, NIEHS). He added that once the final report is public, the data sets would be deposited into a public section of CEBS and would be available in GEO.

Dr. Wyde addressed Dr. Barlow's comments regarding the dosing issue, stating that there was $100 \%$ mortality at 200 ppm, so there was hesitation about using any higher doses. There were liver and nasal lesions at the $100 \mathrm{ppm}$ dose, so the dosing was appropriate. He said the call regarding $\mathrm{C}$-cell tumors was primarily driven by the benign adenomas in the thyroid gland, and the significant increase in carcinomas was seen only at the low dose. Thus, this was supportive of some evidence, not clear evidence, of carcinogenicity. He agreed that the report would benefit from an expanded discussion of previous carcinogenicity studies.

Dr. D.E. Malarkey, NIEHS, addressed Dr. Cattley's and Dr. Cullen's comments about combining hemangiomas and hemangiosarcomas, noting that recent data suggest that hemangiomas can progress to hemangiosarcomas, providing evidence to support combining them for analysis. He said each of the tumor types was considered individually, along with which might be appropriate to combine. Anything that is of the same histogenesis was considered appropriate to combine. Dr. Malarkey acknowledged Dr. Cattley's suggestion to include the rationale in the report.

Dr. Foster addressed Dr. Barlow's comment regarding fixation of the testes. He said NTP no longer fixes testes in formalin, which has improved histological profiles. Dr. Barlow noted that 
the necropsies were performed 6 years earlier. He suggested that the information should be released to the public more quickly, and it was important to keep up with current technology.

Dr. Cattley moved to accept the conclusions as written. Dr. Cory-Slechta seconded the motion. The panel voted unanimously ( 7 in favor) to accept the conclusions as written. 


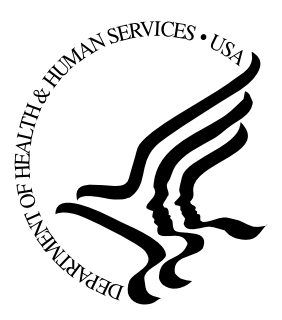

\title{
National Toxicology Program
}

\author{
NTP Central Data Management, MD EC-03
}

National Institute of Environmental Health Sciences

P.O. Box 12233

Research Triangle Park, NC 27709

http://ntp.niehs.nih.gov 